

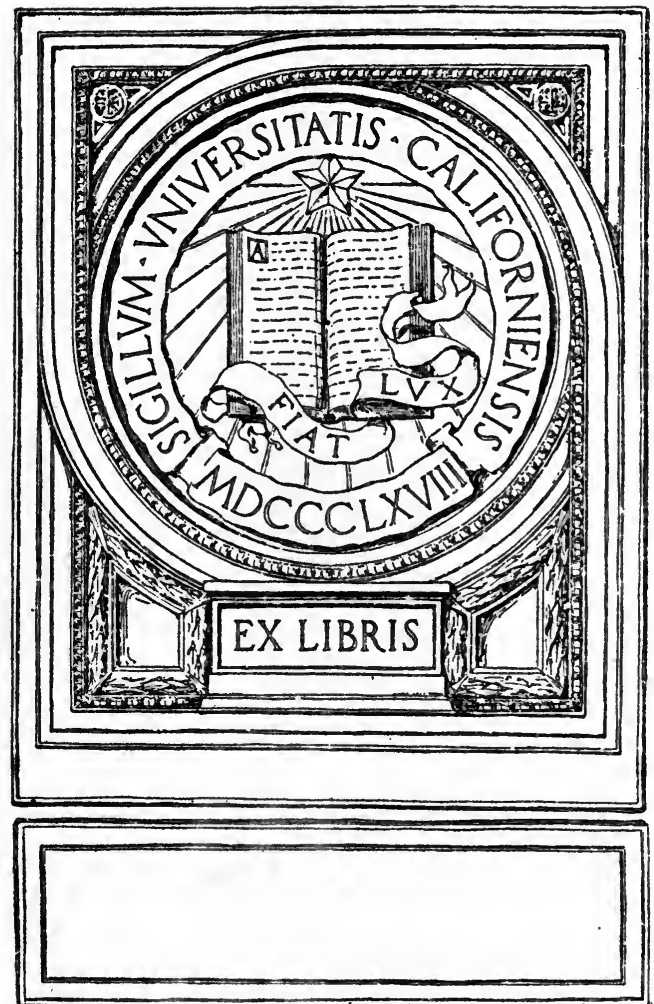


CEMENT, CONCRETE AND BRICKS 


\section{OUTLINES OF INDUSTRIAL}

\section{CHEMISTRY.}

A Series of Text-Books IntroDUCtory to the Chemistry

of the National

INDUSTRIES.

EDITED BY

Guy D. Bengough, M.A., D.Sc. 



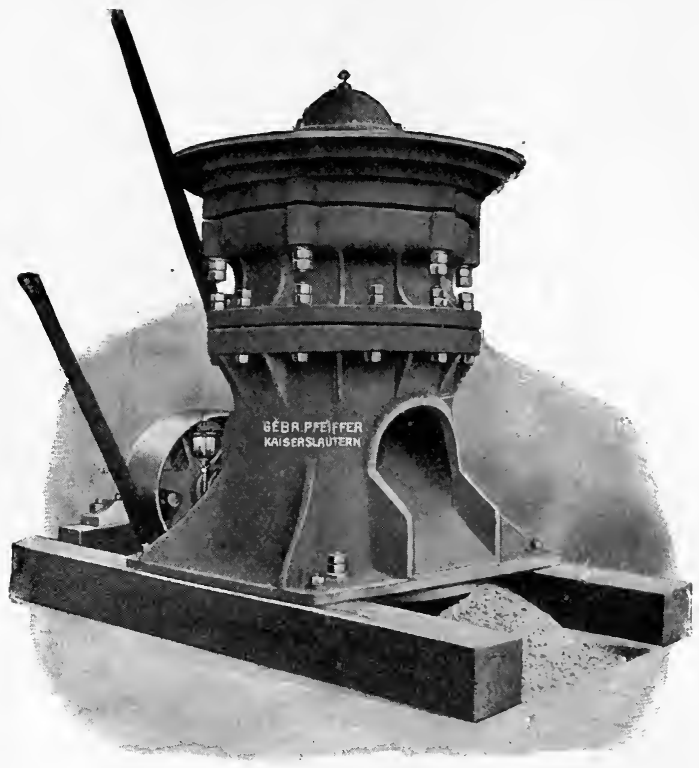

Disintegrator for Coarse Grinding.

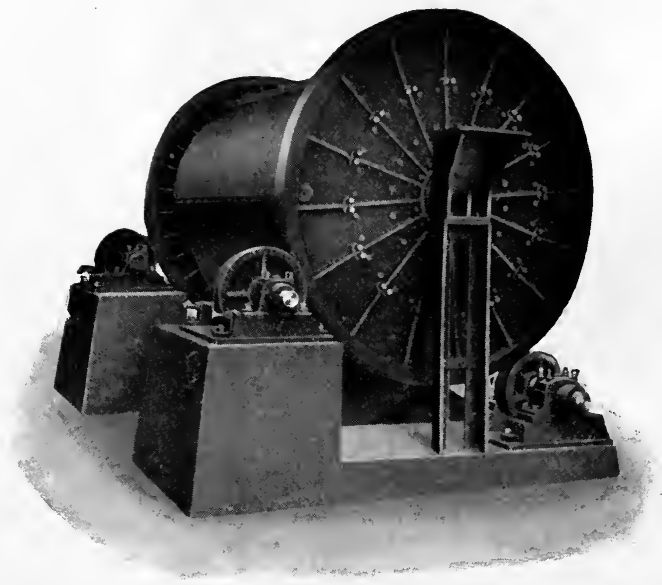

Mill for Fine Grinding. (Gebr. Pfeiffer.) 


\section{OUTLINES OF INDUSTRIAL CHEMISTRY.}

\section{CEMENT, CONCRETE AND BRICKS}

BY

\section{ALFRED B. SEARLE}

LECTURER ON BRICKMAKING UNDER THE CANTOR BEQUEST; CONSULTING EXPERT IN THE CEMENT AND CLAY PRODUCTS INDUSTRIES

AUTHOR OF " BRITISH CLAYS, SHALES AND SANDS," "THE NATURAL HISTORY OF CLAY," "MODERN BRICKMAKING," "THE CLAYWORKER'S HANDDOOK"; JOINT AUTHOR OF "REINFORCED CONCRETE," ETC.

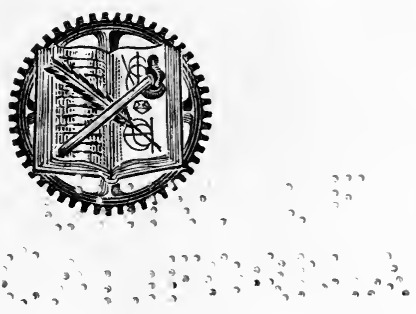

NEW YORK

D. VAN NOSTRAND CO. TWENTY-FIVE PARK PLACE 
$x^{+3} !$
54

$\begin{aligned} \therefore & \ddots \\ \therefore & 0\end{aligned}$ 


\section{PREFACE}

OF all building materials which are not found in a state of nature, the most important are, unquestionably, cement, concrete and bricks. The first of these includes a large variety of materials used to bind together particles of stone, sand, and other naturally occurring materials; the second-used in a broad sense-includes all kinds of artificial stones made by cementing various materials together without the aid of heat, and the last-bricks-includes an even larger number of different articles, distinguished by their general form and by the fact that heat has been used to render their shape permanent. It is a mistake to suppose that all bricks are made of clay; at the present time they are made from a number of other materials, such as destructor refuse, sand, slag, etc. Indeed, the composition of some bricks so closely resembles that of concrete as to render it necessary to include them as one of the forms taken by this material.

It is important, in considering the chemical and other properties of these three typical building materials, to observe the genetic relationships between them. To neglect this is to enter upon a course of study which is exceptionally difficult, and to follow a pathway of thought along which many men have lost their way. So long as cement and concrete are considered as having nothing in common with bricks, and vice versa, it is almost impossible to understand the constitution of any of these materials. Separately, they lead to no important conclusions, but considered together they throw a light on each other's characteristics which is as important as it is unexpected.

Until a few years ago the brick industry of this country had no men of sufficient scientific training to study adequately the constitution of the materials used or the chemical and physical changes which occur during manufacture. Consequently, the 
industry was largely worked by " rule of thumb," and men had often to pay very dearly for their experience, simply because there was no source from which to obtain guidance on the complex technical problems associated with their work.

The manufacturers of cement have been more fortunate, for they realised at an early stage that success or failure depended largely on maintaining a mixture of constant chemical composition; they found that tests were necessary at so many stages in the manufacture that the employment of several chemists became essential. With this scientific assistance the chemical and physical laws affecting the production of cement were studied with very gratifying results, and though much remains to be done, the importance of a knowledge of chemistry in the manufacture of cement has been fully established.

Concrete is in an intermediate stage so far as the application of science to its production is concerned. It does not appear to lend itself to such definite study as cement, on the one hand, or the changes produced by heat in brick materials on the other, yet the physical properties of concrete, and the light it throws on many of the problems met with in the manufacture of bricks, are sufficiently important to render its study invaluable, whilst the increasing use of concrete by engineers and builders renders a thorough knowledge of its characteristics, under various circumstances, quite essential.

With these facts in mind the purpose of the present volume is to show the intimate relationships which exist between cement and bricks (with concrete as a relative of both), and at the same time to indicate some of the directions in which a further study of any of these materials will be likely to prove of value. In carrying out this work it may be necessary, at times, to question statements generally regarded as facts, and to show that some of these are erroneous; at the same time, the position taken by the author is one of progressive conservatism, in which the old ideas are retained as long as is reasonably possible, and are only abandoned where the evidence against them is conclusive.

For the use of illustrations the author is indebted to the various firms whose names are mentioned in connection with the systems of reinforcement described, to Messrs. J. Whitehead 
\& Co., Ltd., of Preston; Whittaker \& Co., Ltd., of Accrington; Sutcliffe, Speakman \& Co., Ltd., of Leigh; Geb. Pfeiffer, of Kaiserslautern; the Associated Portland Cement Manufacturers, Ltd., the British Engineering Standards Committee, and to numerous other writers and firms duly acknowledged in the text. For much assistance in writing, and also in revising the proofs, the author is also indebted to Mr. J. W. Merchant and other members of his staff.

The White Building,

ALFRED B. SEARLE.

- Sheffi Eld.

March, 1913. 



\section{CONTENTS}

CHAP.

PAFE

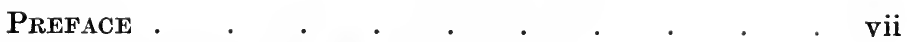

I. The Raw Materials for Cements . . . . 1

II. Methods of Cement Mandfacture . . . . 20

III. The Chemical and Physical Changes in Cements . 39

IV. The Changes which occur in Setting and HARDENING . . . . . . . . 81

V. Testing the Properties of Cements . . . . 96

Vi. The Components of Concrete and their Properties 146

ViI. The Preparation of Concrete • • • . . 162

VIII. ReInfORCEd CONCRETE . . . . . . . 206

IX. Special Properties of Concrete . . . . 254

X. Testing Concrete . . . . . . . . . . 277

XI. The Raw Materials for Bricks. . . . . 296

XII. Methods of Brickmaking . . . . . . . . 319

XiII. The Cinemical and other Changes in Drying and BURNING BRICKS . . . . . . . . 363

XIV. The Properties of Bricks . . . . . . 376

XV. Siliceous Bricks . . . . . . . . 395

XVI. Basic and Neutral Bricks. . . . . . 401 INpex . . . . , , , , , 403 



\title{
CEMENT, CONCRETE AND BRICKS
}

\author{
CHAPTER I
}

\section{THE RAW MATERIALS FOR CEMENTS}

In the present volume, the term cement is used with reference to those materials which are employed to effect adhesion between stones, sand and other aggregates used in the construction of buildings, reservoirs, etc. Cements of organic origin, such as fish glue, seccotine, etc., are purposely excluded, together with those cements (Keene's cement, Parian cement, etc.) which have gypsum as their chief constituent, and the cements composed of oxy-chlorides and oxy-phosphates (Porcelain cements).

In the limited sense in which the term cement is used in the following pages, it refers to a variety of substances composed essentially of clay and lime, and includes Portland cement, Roman cement, trass, hydraulic lime, pozzolana, etc. With the exception of the first-named, all these cements are made from naturally occurring materials without any admixture; and no serious attempt is made to ensure their having any fixed composition or more than roughly uniform properties. Portland cement, on the contrary, is made by carefully mixing clay with limestone or chalk, or materials corresponding to these substances, such as marls and loams, in definite proportions so as to secure a product of perfectly uniform composition and properties, and special care is taken by analysis and other methods of testing to ensure this uniformity in the product. This is one reason why the manufacture of Portland cement now exceeds in importance that of all other hydraulic cements : the product is uniform instead of variable in its properties, it is greatly superior because the defects due to unsuitable

C. 
composition are removed, and, being made from materials which occur in extremely large quantities in several important industrial areas, its use enables an artificial product of known composition and properties to be used in place of an inferior cement made from natural materials, which can never be so reliable.

Cements of the kinds herein considered are conveniently termed hydraulic cements, as their hardness, when set, is not. appreciably affected by immersion in water. Zulkowsky has suggested the term hydraulite (with the corresponding adjective, hydraulic) as convenient for all cements of this class.

There are no naturally occurring cements, though some metamorphosed volcanic lavas may be regarded as feeble cements. Consequently, cements are all prepared by various methods of treatment.

The raw materials used in the manufacture of cements are clays, chalk, limestone, volcanic tuffs and lavas, various muds more or less related to these substances and sundry by-products of other industries, as slags. These raw materials may be classified as follows:-

(a) Those which require to be mixed with one or more substances and then heated and ground before a cement is obtained (clays and limestones).

(b) Those which merely require to be heated and ground in order to form a cement (natural cements and hydraulic limes).

(c) Those which require no heating, but must be mixed with a complementary substance, such as lime, before a cement is produced (pozzolanas).

(d) Those which merely require to be ground (slags).

(a) The Raw Materials of Portland Cements.

The raw materials used in the manufacture of Portland cement are essentially lime and clay - a compound of these two substances, in which the lime plays the part of a base and the clay that of an acid, being formed when they are heated together to a sufficiently high temperature. As combination does not take place until a temperature is reached which is higher than that at which calcium carbonate is converted into quicklime, it is customary to use some naturally 
occurring form of calcium carbonate, such as limestone or chalk, in place of lime itself.

The lime compounds used in the manufacture of hydraulic cements furnish the basic portion of the product. It is essential that they shall produce quicklime at a temperature lower than that at which the cement-clinker is produced, and for this reason only the naturally occurring calcium carbonates are employed.

\section{LIME COMPOUNDS.}

The chief lime compounds used in the manufacture of Portland cement are as follows :-

Chalk is a soft limestone, and is composed mainly of minute sea-shells, but these have been so damaged by earth-movements, etc., that it is only occasionally that their definite structure can be recognised. As found in the south-eastern counties, chalk is a fairly pure form of calcium carbonate, which occurs as white, compact masses which are readily crushed to powder. Flints and other stones and impurities occur in the chalk, and these should be removed by stirring the chalk with water in a wash-mill, the creamy white fluid so obtained being run off and the impurities remaining behind in the mill.

Chalk is largely used in Kent and Sussex, where it occurs, and considerable quantities of it are sent to Northumberland and Yorkshire, where it is used in connection with a local clay.

Axalyses of Chatk (after drying at $110^{\circ} \mathrm{C}$.).

\begin{tabular}{|c|c|c|c|c|c|c|c|c|}
\hline & & & $\begin{array}{l}\text { Nedway } \\
\text { Upper } \\
\text { Chalk. }\end{array}$ & $\begin{array}{c}\text { Gravesend } \\
\text { Upper } \\
\text { Chalk. }\end{array}$ & $\begin{array}{l}\text { Purfleet } \\
\text { Upper } \\
\text { Chalk. }\end{array}$ & $\begin{array}{c}\text { IIarefield } \\
\text { Upper } \\
\text { Chalk. }\end{array}$ & $\begin{array}{l}\text { Hitchen } \\
\text { Middle } \\
\text { Chalk. }\end{array}$ & $\begin{array}{l}\text { Cambridge } \\
\text { Lower } \\
\text { Chalk. }\end{array}$ \\
\hline Silica & & & $2 \cdot 34$ & $1 \cdot 12$ & $1 \cdot 22$ & $1 \cdot 86$ & $0 \cdot 69$ & $3 \cdot 57$ \\
\hline Alumina & - & & $1 \cdot 84$ & $0 \cdot 21$ & 0.58 & $0 \cdot 63$ & 0.57 & $0 \cdot 56$ \\
\hline Iron oxide & . & & $1 \cdot 49$ & $0 \cdot 13$ & $0 \cdot 11$ & $0 \cdot 30$ & $0 \cdot 37$ & $0 \cdot 14$ \\
\hline Calcium carbonate & & & $92 \cdot 18$ & $97 \cdot 88$ & $97 \cdot 82$ & $97 \cdot 01$ & $96 \cdot 81$ & $91 \cdot 94$ \\
\hline Magnesium carbonat & ate & & $1 \cdot 16$ & $0 \cdot 41$ & $0 \cdot 25$ & $0 \cdot 15$ & $1 \cdot 42$ & $1 \cdot 37$ \\
\hline Other substances . & • & ${ }^{\circ}$ & $0 \cdot 99$ & $0 \cdot 25$ & 0.02 & $0 \cdot 05$ & $0 \cdot 14$ & $2 \cdot 42$ \\
\hline
\end{tabular}

Wherever chalk and a suitable clay are found in sufficiently close association, Portland cement may be manufactured. 
Where the two materials do not occur together, the nature of the demand for the cement will largely determine the most suitable site for the works. In the south-eastern counties the works are close to the chalk, and the clay is brought to them from some distance; at Newcastle and Hull, on the contrary, the works are situated on the clay and the chalk is brought from the south-eastern counties.

Limestone, like chalk, consists chiefly of calcium carbonate ; it has been coloured by trifling proportions of organic matter. It is much harder than chalk, and must be crushed before use. This makes its use more costly than that of chalk.

The limestone chiefly used for cement manufacture is of Liassic origin, and occurs in the Midlands and South Wales in association with shale. Limestones which are free from shale or clay are inconvenient because of the cost of bringing the two essential materials together; hence, argillaceous limestones are almost invariably selected.

Some oolitic limestones are used, notably in Northamptonshire.

Liassic limestones are characterised by great regularity in composition when sufficiently large quantities are examined; smaller quantities show considerable variations in the different strata, numerous bands of clay or shale alternating with those of limestone. In some quarries thirty or more different beds. may clearly be recognised.

The following analyses are typical of the Lower Lias limestones used for cement making :-

Analyses of Lias Limestones (after drying at $110^{\circ} \mathrm{C}$.).

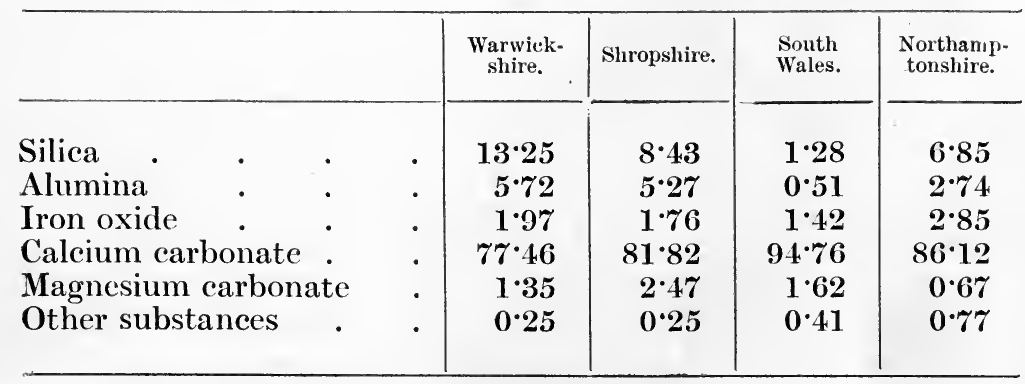


Great care must be taken not to use dolomitic limestone which contains much magnesia, as this substance is deleterious to the resultant cement.

Argillaceous limestones are the raw material from which hydraulic limes are made (p. 13).

If the limestone is sufficiently free from clay or shale it will, when burned, produce quicklime. If the latter is slaked and then ground with sand and water it forms ordinary builders' mortar. The quality of such mortar depends on the purity of the limestone, satisfactory burning, and thorough mixing or tempering with sand. Many builders at the present time do not pay sufficient attention to these details and so obtain a mortar of inferior quality.

\section{CLAYS, SHALES, MARLS AND MUDS.}

The clays and similar materials used in the manufacture of Portland cement furnish the acid constituent which combines with the lime to form the final product. The essential constituent of all clays is aluminosilicic acid, but whether there is one or more varieties of this substance is, at present, uncertain. In the author's opinion there are many aluminosilicic acids which have so similar a chemical composition that some of them cannot readily be distinguished by analysis. Such compounds are known as isomers; they differ greatly in many ways from each other, especially in physical properties. Many clays used in cement manufacture are probably isomeric, their apparent similarity in analysis being merely a coincidence. The study of isomers forms an important branch of organic chemistry; but little attention has, as yet, been paid to complex inorganic isomeric substances. (See Chapter III.).

Even if several distinct aluminosilicic acids should be found to be the essential constituents of various clays, their composition and properties must be very similar, as the product obtained by refining most, if not all clays has a composition corresponding to the formula $x \mathrm{H}_{2} \mathrm{O} \cdot \mathrm{y} \mathrm{Al}_{2} \mathrm{O}_{3} \cdot \mathrm{zSiO}_{2}$. Thus, carefully washed china clay, which is the purest clay known, is composed of :- 
Alumina Silica . or $\mathrm{H}_{4} \mathrm{Si}_{2} \mathrm{Al}_{2} \mathrm{O}_{9}$.
$39 \cdot 45$

$46 \cdot 64$

$13 \cdot 91$

Together with the aluminosilicic acid, clays contain very variable proportions of impurities, the chief of which are free silica, iron oxide and sulphide, lime and magnesia compounds, together with various minerals such as mica, felspar and other siliceous rocks.

The clays chiefly used for the manufacture of Portland cement are those commonly known as surface clays. Their composition is unimportant providing that they do not contain an excessive amount of coarse sand. Lean or slightly plastic clays are better than those of a more sticky character, as they are more easily treated; the highly plastic clays are usually somewhat richer in aluminosilicic acid.

It is only natural that those clays should chiefly be used which are situated, in convenient localities, and at the present time the gault clay of Sussex, a surface clay in Northumberland of apparently glacial origin, and an alluvial clay at Hull are the ones most extensively employed. In other localities more conveniently situated, clays are employed on a small scale. Thus, there is no reason, except lack of demand for cement in the localities where they occur, why the extensive deposits of 'Triassic clays should not be more largely used than is at present the case.

The Gault clay occurs in the lower portion of the chall formation, immediately above the Greensand or between the upper and lower Greensand. It is a very stiff, dark blue or black clay, which often becomes brown on weathering. It extends from Folkestone on the east to Eastbourne on the west, and also occurs in Norfolk, Cambridgeshire, Hertfordshire, Bedfordshire, Buckinghamshire, and to a small extent on the east coast of Yorkshire, near Filey. For cement making it is chiefly used in Sussex and Kent. It contains a considerable amount of calcium carbonate (chalk)-occasionally as much as 33 per cent. and seldom less than 13 per cent.together with nodules of pyrites and calcium phosphate. These nodules should be removed by washing the clay. 
The composition of gault clay varies considerably; the following shows the composition of samples taken from the upper reaches of the Medway :-

$\begin{array}{lllllr}\text { Silica . } & . & . & . & . & 44.23 \\ \text { Alumina . } & . & . & . & . & 14.85 \\ \text { Iron oxide . } & . & . & . & . & 5.93 \\ \text { Calcium carbonate } & . & . & . & 26.54 \\ \text { Magnesium carbonate } & . & . & . & 6.06 \\ \text { Alkalies . } & . & . & . & . & 0.51 \\ \text { Water, etc. . } & . & . & . & . & 1.88\end{array}$

Alluvial clays are found on the sites of former lakes or river beds and near to the banks of existing rivers. They occur in various parts of the country, particularly in East Yorkshire, Lincolnshire, Cambridgeshire, Norfolk, Suffolk, Essex, Kent, Sussex, Somerset and Lancashire, and to an even larger extent in central Ireland. Small areas occur in other low-lying districts. These clays have usually been deposited under such conditions that they are relatively light and somewhat open in texture, though some of them are highly plastic. They are seldom free from appreciable proportions of very finely divided calcium carbonate, which is an advantage to the cement manufacturer, but is objectionable to some brickmakers. As the term "alluvial" implies, these clays have been collected from a variety of sources and their composition varies in each locality in which they occur. The chief alluvial clays used for cement making show the following composition on analysis :-

Alluvial Clays and Muds (after drying at $110^{\circ} \mathrm{C}$.).

\begin{tabular}{|c|c|c|c|c|c|c|c|}
\hline \multirow[b]{2}{*}{ Silica . } & \multirow[b]{2}{*}{$\dot{v}$} & \multirow[b]{2}{*}{ - } & \multirow[b]{2}{*}{. } & \multirow{2}{*}{$\begin{array}{c}\text { Hull. } \\
51 \cdot 32\end{array}$} & \multicolumn{2}{|c|}{$\begin{array}{l}\text { Thames Estuary Mud. } \\
\text { a. }\end{array}$} & \multirow{2}{*}{$\begin{array}{c}\text { Medway Mud } \\
51 \cdot 98\end{array}$} \\
\hline & & & & & $60 \cdot 12$ & $73 \cdot 68$ & \\
\hline Alumina & $\cdot$ & - & - & $20 \cdot 76$ & $10 \cdot 81$ & $7 \cdot 46$ & $15 \cdot 63$ \\
\hline Iron oxide & 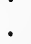 & • & • & $6 \cdot 89$ & $7 \cdot 46$ & $11 \cdot 13$ & $9 \cdot 12$ \\
\hline Calcium carb & na & • & $\dot{*}^{\circ}$ & $10 \cdot 44$ & $8 \cdot 31$ & $2 \cdot 36$ & $4 \cdot 08$ \\
\hline Magnesium c & $\mathrm{rb}$ & te & • & $7 \cdot 81$ & $1 \cdot 86$ & $1 \cdot 61$ & $2 \cdot 76$ \\
\hline Alkalies. & . & . & . & $1 \cdot 86$ & $0 \cdot 62$ & $1 \cdot 84$ & $0 \cdot 92$ \\
\hline Water, etc. & . & . & . & $0 \cdot 92$ & $10 \cdot 82$ & $1 \cdot 92$ & $15 \cdot 51$ \\
\hline
\end{tabular}


Alluvial clays are essentially superficial in character and may be distinguished from the other great class of surface clays (the boulder clays) by the absence of large stones in which the boulder clays abound.

Loams are naturally occurring mixtures of sand and clay. They are of little use for cement manufacture on account of the large proportion of sand they contain, but clayey loams are occasionally used with advantage. Strictly speaking, any clay which contains free silica (sand) is a loam, but the term is only applied to those with a low plasticity and open texture.

Shales are naturally indurated clays which have been compressed to almost stony hardness by the forces of nature, but the term is also applied to any rock which can be split into thin layers, so that some shales contain very little clay.

Slate waste-a variety of shale-has been used in America for the manufacture of cement.

Analyses of Shales (after drying at $110^{\circ} \mathrm{C}$.).

\begin{tabular}{|c|c|c|c|c|c|c|c|}
\hline & & & & $\begin{array}{l}\text { Warwick. } \\
\text { shire. }\end{array}$ & Shropshire. & $\begin{array}{l}\text { South } \\
\text { Wales. }\end{array}$ & $\begin{array}{l}\text { Northamp- } \\
\text { tonshire. }\end{array}$ \\
\hline Silca & . & - & . & $31 \cdot 7+$ & $8 \cdot 07$ & $58 \cdot 17$ & $8 \cdot 41$ \\
\hline Alumina & . & . & . & $9 \cdot 23$ & $5 \cdot 23$ & $14 \div 34$ & $5 \cdot 39$ \\
\hline Iron oxide & . & . & . & $3 \cdot 14$ & $1 \cdot 84$ & $5 \cdot 11$ & $1 \cdot 72$ \\
\hline Calcium carl & na & . & . & $17 \cdot 41$ & $80 \cdot 17$ & $12 \cdot 61$ & $77 \cdot 29$ \\
\hline Magnesium & $\mathrm{rb}$ & te & . & $7 \cdot 35$ & $3 \cdot 73$ & $5 \cdot 98$ & $5 \cdot 86$ \\
\hline Alkalies . & . & . & . & $0 \cdot 37$ & - & $2 \cdot 47$ & $0 \cdot 97$ \\
\hline Water, etc. & . & . & . & $0 \cdot 76$ & $0 \cdot 96$ & $1: 32$ & $0 \div 36$ \\
\hline
\end{tabular}

Clay shales occur in enormous quantities in Great Britain, particularly in Coal Measure, Permian, Jurassic and Wealden regions, and are of very diverse character and composition. Some shales are so closely interstratified with limestone that it is difficult to separate these substances, but this is not important where the material is to be used for cement manufacture, providing that sufficient limestone is available. For cements, the sandy and bituminous shales are of little value. Shales are costly to grind, and so are only used for cement when found in close association with limestone, the Liassic beds 
of the Midlands and especially of Warwickshire and the shales of South Wales being chiefly employed for this purpose.

The chemical composition of shales varies at different depths in the deposit as well as in different areas, but if sufficiently large quantities are obtained at a time and a little care is taken to mix the strata in approximately constant proportions, a sufficiently uniform product may be obtained without difficulty.

For brickmaking, the shales must be free from large percentages of lime and pyrites, but for cement making the lime is an advantage. The pyrites is objectionable in both cases on account of its discolouring power. The organic matter present in shales-sometimes exceeding 5 per cent.-is an advantage in so far as it saves fuel, but it tends to cause an overheating of the material in the kilns.

Muds are essentially impure clays which have not been compacted by pressure. Those found in the estuaries of the Thames and Medway are largely used for cement manufacture on account of the readiness with which they can be mixed with washed chalk. Some muds consist almost exclusively of lime dust, 'and if these are to be used for cement, clay must be added to them (see Alluvial Clays, p. 7).

The composition of the muds used varies greatly, and, like that of the clays previously mentioned, is of little importance providing that the muds contain sufficient real clay. On account of the ease with which they can be converted into a slurry, muds are generally mixed with chalk slurry in the manufacture of cement.

Marls are naturally occurring mixtures of clay and calcium carbonate (chalk), but the term is also used in a misleading manner for friable rocks which are free from lime compounds. The chief marls used in the manufacture of Portland cement are friable limestones of fine texture and lacking the compactness and coherence of ordinary limestones. Cement makers specially favour those found in Cambridgeshire between the Chalk and the Greensand formations, but marls from other districts-such as those in the centre of Ireland-may be used with equal advantage when the demand for cement in their locality is sufficiently great, 
Marls have, apparently, been formed by the "natural admixture of clayey and chalkey slimes ; streams carrying the finely divided clay or chalk in suspension meeting at some locality and depositing their burdens in the form of a mixture. There is, however, some considerable divergence of opinion as to their true origin, more especially as many marls contain more silica than corresponds to a mixture of clay and chalk. This additional silica may be in the free state (as appears most likely), but Le Chatelier's experiments lend support to the view that marls contain an aluminosilicic acid which is richer in silica than is that usually found in "clays." If the mode of formation indicated above is correct it is clear that marls in different localities must vary greatly in composition; some of them being rich in clay and poor in lime, whilst others are so poor in clay as to be regarded as impure lime compounds. For cement manufacture, the most suitable marls are those which have a composition resembling that of raw Portland cement slurry.

For Portland cement manufacture, the composition of the marl must be ascertained frequently, so that the proportions of the other ingredients of the "mix" may be accurately adjusted. For this reason, many cement manufacturers prefer to use a relatively pure chalk on which they can rely, rather than a marl with an irregular composition.

It is very important that the marl should be fine in texture and free from hard lumps, for pieces the size of a pea will seriously increase the cost of manufacture, and if left in the material they are very liable to produce an irregular cement. Marls differ greatly in this respect and great care is, therefore, needed in their selection.

Marls for cement manufacture differ from those used for brickmaking on account of the much larger percentage of lime permissible in the former. For brickmaking, marls with 60 per cent. of calcium carbonate are almost useless, but for cement they are more suitable than those containing at most 12 per cent. of chalk, which is the largest proportion acceptable to a brickmaker. In this way a material useless to one branch of clay-working is of great advantage to another branch.

Pure marls are white in colour, but most marls are grey on 
account of the organic matter they contain. This burns away on heating, and is of no importance to manufacturers.

Marls which burn red are seldom useful for cement manufacture unless they are rich in clay and sufficient limestone or chalk is available in the same locality.

Marls from the Permian formation are usually rich in magnesia, and should be avoided by cement manufacturers. Liassic marls, on the contrary, are valuable.

The "Midland Marls" are not true marls (but Triassic clays), and do not contain enough lime to be so named. They are greatly prized for the manufacture of red bricks and terra cotta, but before they can be used for cement manufacture they must have nearly three times their weight of limestone or chalk added to them. The Cambridge marls; on the contrary, are argillaceous limestones with a composition so similar to that of unburned cement slurry that they are used for natural cements.

Analyses of Marlas used for Cenent

(after drying at $110^{\circ} \mathrm{C}$.).

\begin{tabular}{|c|c|c|}
\hline & Cambridge. & Petersfield. \\
\hline Silica & $18 \cdot 16$ & $26 \cdot 82$ \\
\hline Alumina & $7 \cdot 82$ & $2 \cdot 14$ \\
\hline Iron oxide & $0 \cdot 94$ & $3 \cdot 47$ \\
\hline Caleium carbonate & $68 \cdot 16$ & $52 \cdot 86$ \\
\hline Magnesium carbonate & $2 \cdot 77$ & $1 \cdot 49$ \\
\hline Water, etc. & $2 \cdot 15$ & $13 \cdot 22$ \\
\hline
\end{tabular}

Broadly speaking, the clays used in cement manufacture should be highly siliceous, and should contain 60 to 70 per cent. of silica and 6 to 20 per cent. of alumina. Magnesia should not exceed 3 per cent., and the alumina and iron oxide together should not exceed half the silica. Clays very rich in iron should be avoided as they produce a dark coloured cement; those with less than 10 per cent. of iron oxide are not objectionable in this respect. Also, clays containing stones should be avoided as they unduly increase the cost of grinding. 
All clays on heating to a dark red heat are decompòsed, the aluminosilicic acid splitting up into free silica, alumina and water, or else forming a compound in which the silica and alumina are exceptionally able to combine with lime; if the temperature and proportions of each of these substances are suitable a clinker is formed which, on grinding, produces Portland cement. The reactions which occur during the formation of this clinker are described in Chapter III.

Further particulars of the occurrence of clays, shales and muds suitable for the manufacture of Portland cement will be found in the author's " British Clays," published by Messrs. C. Griffin \& Co., London, W.C.

The proportions in which the clay or its equivalent and the lime compound are mixed to produce Portland cement depends on the precise composition of the actual materials selected. The mixture (before burning) should contain 75 to 77 per cent. of calcium carbonate and 23 to 25 per cent. of real clay, the best proportions being found by trial and adhered to as closely as possible in the course of manufacture. It is clear that if the "clay" contains lime compounds (like the marls), less limestone or chalk will be needed than when a lime-free clày or shale is used. The great value of Portland cement lies in the accuracy with which the materials are mixed so as to obtain a product the composition of which is exceedingly uniform. This uniformity can only be secured by paying the closest attention to the composition of the mixture before it is burned, and, in all cement works of importance, analyses of the mixture are made daily, or even more frequently.

\section{(b) The Raw Materials used in the Manufacture of Natural Cements and Hydraulic Limes.}

The materials used for the production of natural cements, chiefly clayey limestones or highly calcareous marls, are characterised by containing calcium carbonate (chalk) and aluminosilicic acid (clay) in proportions similar to those in Portland cement. Those usually employed in this country are in the form of calcareous nodules or septaria ${ }^{1}$ which are

1 Septaria are nodules of impure limestone which occur in some clays and derive their name from characteristic divisional lines (septæ). These lines appear to be 
dredged from the sea-bottom near Harwich, Sheppey, etc., or are obtained from dry land near the coast, as was formerly the case at Speeton in Yorkshire. Calcareous nodules from beds of Kimeridge, Greensand and Liassic formations, and some of the Cambridgeshire marls (p. 9) are also used for this purpose.

Analyses of Natural Cement Nodules.

\begin{tabular}{|c|c|c|c|c|c|c|c|}
\hline \multicolumn{4}{|l|}{ - } & $\begin{array}{l}\text { Sheppey } \\
\text { Septaria. }\end{array}$ & $\begin{array}{l}\text { Harwich } \\
\text { Septaria. }\end{array}$ & $\begin{array}{l}\text { Speeton } \\
\text { Nodules. }\end{array}$ & $\begin{array}{l}\text { Tuurnai } \\
\text { Earth. } 1\end{array}$ \\
\hline Siliea & . & . & . & $17 \cdot 84$ & $20 \cdot 74$ & $20 \cdot 43$ & $21-28$ \\
\hline Alumina & . & . & . & $6 \cdot 42$ & $4 \cdot 21$ & $8 \cdot 81$ & $3-5$ \\
\hline Iron oxide & . & . & . & $4 \cdot 13$ & $7 \cdot 85$ & $6 \cdot 87$ & $1-2 \frac{1}{2}$ \\
\hline Calcium car & ons & . & . & $63 \cdot 76$ & $58 \cdot 79$ & $56 \cdot 36$ & $60-63$ \\
\hline Magnesium & $\mathrm{arb}$ & ate & . & $4 \cdot 37$ & $5 \cdot 46$ & $3 \cdot 42$ & $\frac{1}{2}-1 \frac{1}{2}$ \\
\hline Water, ete. & . & . & . & $3 \cdot 48$ & $2 \cdot 95$ & $4 \cdot 11$ & - \\
\hline
\end{tabular}

Where a bed of rocky material is of suitable composition (i.e., with a composition similar to that of the mixture of clay and chalk used for Portland cement) to be calcined without any admixture, the product is termed rock cement. Large quantities of this kind of cement are produced annually in America, but the troubles caused by irregularities in composition have made many manufacturers use this material as the basis for. Portland cement, the composition being adjusted from time to time by the addition of clay or limestone as may be required.

As the materials are used without any purification, rock and natural cements usually suffer from the presence of an excess of iron oxide, which colours them dark brown, and of inconvenient proportions of magnesia, etc.

\section{HYDRAULIC LIMES.}

The properties of hydraulic lime were first recognised by John Smeaton in 1760, who, when investigating the properties shrinkage cracks, which have become filled with crystallised calcium carbonate. The use of septaria for cement manufacture was first patented by James Parker in 1796 ; it has since been known as Roman cement.

1 The material of which Belgian cement (p. 31) is made. 
of different limestones for use in the Eddystone lighthouse, found that the Aberthaw limestone and others rich in clay were more resistant to immersion in water than purer limestones. A hydraulic lime is one prepared by calcining an argillaceous limestone, the clay present entering into combination with a portion of the lime and forming what may be regarded as a mixture of Portland cement and quicklime. Its value as a hydraulite must, therefore, depend on the extent to which the lime and clay have combined.

Hydraulic limes differ from ordinary lime in slaking less readily and in setting to a hard stony mass when immersed in water.

The chief raw material in this country for hydraulic limes is the blue Liassic limestone of Warwickshire, South Wales, etc. (p. 4), but other argillaceous limestones may be used. As will be understood from the previous section on the raw materials used for Portland cement, a much superior cement is obtained when the composition of the material is adjusted so as to give a product of approximately the same composition as Portland cement.

The composition of the limestones used for making hydraulic limes must lie between (1) pure limes which are free from clay, and (2) marls or mixtures of clay and chalk which contain no excess of lime. It has been found that argillaceous limestones with 70 to 80 per cent. of calcium carbonate, 10 to 17 per cent. of silica and not more than 3 per cent. of iron and alumina are best, as, in the hydraulic limes made from these, most of the clay is combined with lime, yet there is sufficient free lime present to cause the material to slake satisfactorily. Hydraulic limes may also be produced by under-burning a rock which would, at a higher temperature, produce an excellent natural cement, but these are very inferior and unsatisfactory.

\section{(c) Volcanic Lavas, Tuffs and Trass.}

Both the Greeks and Romans were aware that the addition of certain materials of volcanic origin, in a finely ground condition, to mortar had the effect of making it hydraulic. Such lavas and tuffs have already been heated previous to 
their discharge from the volcano, and when mixed with lime they form pozzolanic cement or pozzolana, from the occurrence near Pozzoli, in the Bay of Naples, of the most typical material of this kind.

Pozzolana is chiefly obtained in Italy, in south-eastern France, and in the Azores. It is usually found near the surface, but some of the Italian workings are several hundred feet in depth.

All the natural pozzolanas are volcanic lavas which have undergone subsequent changes (now attributed to the action of superheated steam and carbon dioxide), whereby they have been reduced to a fine sand and have gained hydraulic properties. Their composition is very variable, but their essential constituents are the same as those of clays which have been heated to dull redness. Their value depends on the amount of silica and alumina (possibly also ferric oxide) present in a form in which it can produce hydraulitic compounds when the pozzolana is mixed with lime and water. Though generally amorphous, pozzolanas not infrequently contain crystals of various igneous rocks.

Artificial pozzolanas have been made since Roman times by heating clays to redness or, more frequently, by crushing burnt clay ballast, broken bricks, or tiles to a fine powder. Broken pottery (potsherds) is occasionally used, but these should be of porous material, not of vitrified stoneware or porcelain.

The completeness with which brick or tile dust can be used to replace natural pozzolana is strongly confirmative of the view, already expressed, that natural pozzolanas and trass have the same composition and general properties as calcined clay.

Tosca is a pozzolana or volcanic ash obtained from Teneriffe, in the Canary Islands, and chiefly used in Spain.

Trass is also a metamorphosed volcanic lava, the most important deposits being found near the Rhine. It resembles pozzolana in many ways, and has a similar composition, but is quite distinct from it.

Santorin earth is another similar material obtained from the Greek island of that name. It is usually slightly more siliceous 
and contains rather less alumina than Rhenish trass or true pozzolana earth.

\section{(d) Slags}

are really glasses and are in the state of an extremely viscous fluid, the rigidity of which is apparently equal to that of a solid, though it is devoid of any crystalline structure. All glasses are in a state of instability and tend to crystallise just as a slowly cooling liquid does, only far more slowly. The conversion into the more stable crystalline form is hindered by the enormous viscosity of the material; if this is reduced (as by heating the substance to below its melting point), crystallisation proceeds more rapidly.

It is extremely difficilt to ascertain what compounds actually exist in granulated slags, as prolonged heating may cause a molecular rearrangement of their coristituents, whereby the crystals so formed would not represent the composition of the slag out of which they grew. In any case, the crystals found in granulated slags lack the characteristic forms of the calcium orthosilicate they most closely resemble (gehlenite and melilite), and their identity has not been satisfactorily established. The commonly accepted view is that granulated basic slags contain $a$-dicalcium orthosilicate, but this is based on evidence which is by no means conclusive.

W. and D. Asch have assigned to such slags formulæ bearing a resemblance to those used by them for clays and cements.

Some slags obtained from blast furnaces as a by-product in the manufacture of pig iron, contain the same constituent oxides as Portland cement, but not necessarily in the same proportions. In a well-managed ironworks the composition of such slags is very constant, and, as they are of small value and require a large amount of storage space, many attempts have been made to convert them into Portland cement or similar hydraulites. As blast-furnace slags are very hard and difficult to grind they are run direct from the furnace into water and so become reduced to a coarse powder or granulated.

Blast furnace slags may be divided into three classes :-

(a) Slags of such a composition that when granulated and 
ground they form a kind of Portland cement, best termed slag cement, as it contains less lime and more alumina than true Portland cement.

(b) Slags which, when granulated and ground, form a pozzolanic material, i.e., a material which must be mixed with lime before it becomes hydraulic.

(c) Slags of an acid character which must be mixed with limestone and calcined. Such slags simply replace the clay ordinarily used in the manufacture of Portland cement.

Although it is conceivable that cements may be produced from basic blast-furnace slags with a composition and properties closely resembling those of true Portland cement, it is difficult to do this at a sufficiently low cost to make the manufacture commercially profitable in countries where suitable clays are available. In the United States this method is largely used as a means of getting rid of the enormous quantities of slag produced in the large ironworks, the charges for tipping and storing on land being thereby avoided. The slag is very cheap though the grinding is costly, and the fact that it is a by-product prevents its composition being materially altered in the furnace. The addition of more limestone to the contents of the furnace will usually result in the production of a mass which is too viscous to be run off, it being seldom possible to produce a fluid slag containing more than 50 per cent. of lime, whilst a good Portland cement contains more than 60 per cent. of this base.

The production of a pozzolanic slag is much easier than that of a Portland cement from the same slag, and large quantities of such are now made. To obtain satisfactory results, the slags must have a composition within somewhat narrow limits, such as the following: silica 30 to 36 per cent., alumina and iron oxide 12 to 17 per cent., lime 48 to 50 per cent., and magnesia under 3 per cent. Like all pozzolanas, such slags only form cements when ground with lime and water.

The utilisation of blast-furnace slag in cement manufacture has attracted much attention for a long time, but the difficulties in handling the material are so great that much remains to be done. At present, only basic slags can be used for the purpose, and the methods of granulation and of reduction to powder c. 
present difficulties almost as great as do the variations in the composition of the slags.

\section{(e) Sundry Raw Materials used in the Manufacture of Cements. \\ IRON ORE.}

Iron ore has been largely used in the manufacture of a kind of Portland cement used in the Panama Canal and for various marine works. The iron ore is used in place of clay, and the process of manufacture is precisely the same as that used for producing Portland cement from shale and limestone. The cement produced has a composition closely resembling that of Portland cement in which the alumina has been replaced by iron oxide. W. Michaelis has published the following analysis of

\section{Iron-ore Cenent :-}

$\begin{array}{lllllr}\text { Silica } & . & . & . & . & 23 \cdot 26 \\ \text { Alumina } & . & . & . & . & 1 \cdot 67 \\ \text { Iron oxide } & . & . & . & . & 8 \cdot 20 \\ \text { Lime } & . & . & . & . & 64 \cdot 84 \\ \text { Magnesia } & . & . & . & . & 0 \cdot 66 \\ \text { Sulphur trioxide }\left(\mathrm{SO}_{3}\right) & . & . & . & 1 \cdot 08 \\ & & & & \\ & & & & 99 \cdot 71\end{array}$

\section{ALKALI-WASTE.}

For many years the waste produced by alkali works was unusable; it consists chiefly of calcium carbonate with a considerable proportion of sulphides. Now that the sulphur can be removed, the purified "waste"-in the form of a fine slurry-is admirably adapted for the manufacture of Portland cement. For this purpose it is "blunged" in a wash-mill with a suitable quantity of clay and water, and the mixed slurry is run off to a dryer. Alkali-waste containing a large percentage of calcium sulphate is unsuitable for cement manufacture.

The Le Blanc process waste is inferior to ammonia process waste for the manufacture of Portland cement. 
The following is an analysis of alkali-waste :-

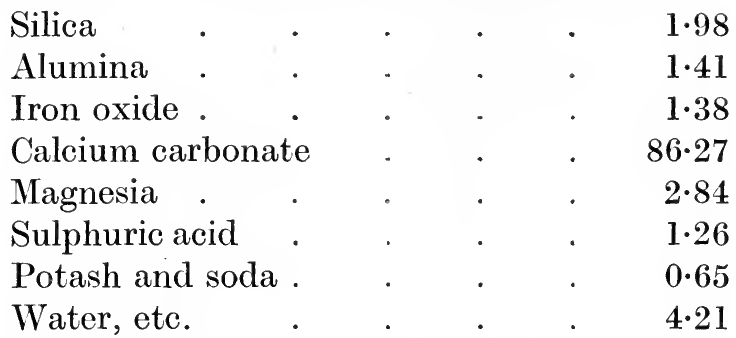

If sufficient care is taken in freeing the waste from sulphur compounds, in adding the correct proportion of clay, and in securing a finely-ground and well-burned clinker, the use of alkali-waste is highly satisfactory. Unfortunately, the waste, after purification, is often more costly than if limestone is used. 


\section{CHAPTER II}

\section{METHODS OF CEMENT MANUFACTURE}

Hydraulic cements are manufactured by a variety of processes in which the underlying principles are practically identical; they consist of $(a)$ the preparation of a suitable and uniform material, $(b)$ heating it to a suitable temperature, and $(c)$ reducing the calcined product (clinker) to the state of a very fine powder. In some cases (as in natural and rock cements) only one material is used, and a large part of the first stage of manufacture may be omitted; in others (as the pozzolanas) the material is obtained after natural calcination by volcanic action and the second stage may be omitted; but in spite of these modifications the general principles apply in all cases.

\section{PORTLAND CEMEN'T.}

Portland cements are chiefly made by mixing some form of limestone, chalk or other lime-compound with some form of aluminosilicic acid (clay), the materials used being chosen for their cheapness, accessibility and general convenience. The most important of these materials have already been described (pp. 3, 5, et seq.).

The development of machinery used in the cement industry has brought about so great an improvement in the preparations of the raw materials that it is no longer difficult to produce a good Portland cement from any suitable materials. The selection of the best method of working is, consequently, much easier now than formerly, though the difficulties experienced in some cases are made far more serious in consequence of the stress of competition. A scheme of general applicability to be employed by all firms can never be given, because in each case local conditions must receive proper consideration.

According as the raw materials are of a soft and open, or 
hard and compact nature, two entirely different methods of manufacture are employed, and are respectively known as the "wet" process and the "dry" process.

In the "wet" process, which is the older of the two, the materials must be sufficiently soft to form a cream or slurry when vigorously stirred with water. Hard, rocky materials cannot, therefore, be treated in this manner, and the wet process is largely confined to the use of chalk with clays, marls or muds. These are thrown, in suitable proportions, into a washmill-a circular brickwork tank about fourteen feet diameter, built below the surface of the ground, which is fitted with rotating arms or harrows so arranged that they completely sweep every part of the mill and thoroughly stir and mix the contents. Sufficient water is added and the harrows rotated by steam or electrical power, whereby the chalk and clay are rapidly churned into a slurry. Some wash-mills are arranged to work continuously, the solid materials and water being added at regular intervals and the slurry flowing away in a continuous stream. Other mills are charged, set in motion so as to convert the whole material into a slurry, and then the harrows are stopped and the slurry is run off through a grating. The intermittent system of working is slower, but wastes less material and is considered to produce a more uniform mixture.

In either case the flints, stones and other coarse impurities in the raw materials sink to the bottom of the mill, and are either removed continuously by means of a bucket elevator, or they are removed from the mill after the slurry has been run off.

In order that the output of the wash-mill may be as large as possible it is customary to break up lumps of chalk more than three inches diameter with small picks or hammers or to pass the chalk over a very coarse screen, the rejected portion being crushed by rollers and again passed on to the screen. To keep the slurry passing out of the mill free from coarse material a fine grid or gauze is placed in the outlet pipe. In some works catch pits for any coarse sand in the slurry are also used, the slurry flowing through these as soon as it has left the mill. Some firms also grind their slurry in a tube mill in order to ensure the complete absence of coarse particles. The 
slurry is next run into settling tanks or "backs" where the solid portion settles and the clear water is run off. As soon as the material in the "backs" is fairly stiff and has attained the consistency of butter, it is taken to the mixer and then to the drying floors.

It is of the greatest importance that the mixture should be quite uniform in composition, as small variations will, in some cases, create serious differences in the product. Its fineness and its chalk-content must therefore be tested several times daily.

As the settling of the material in the "backs" is a slow
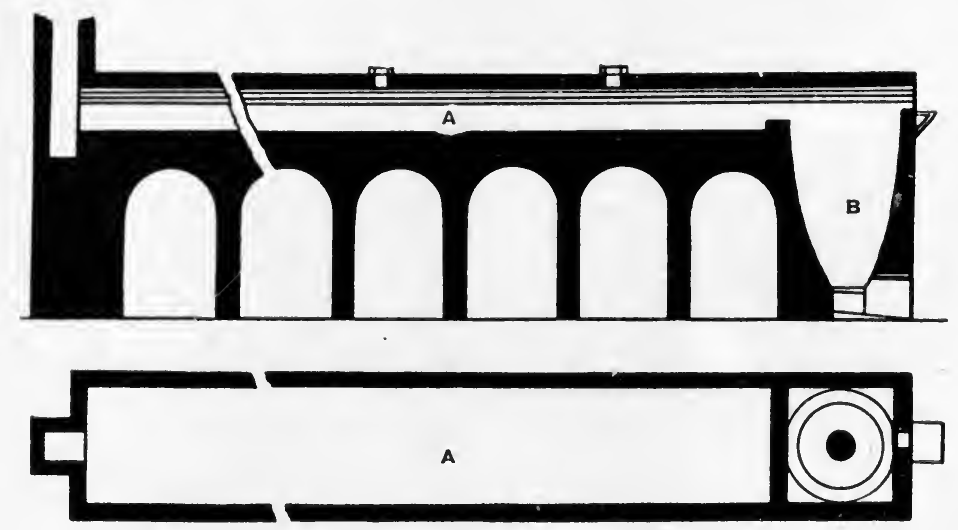

FIG. 1.-Johnson's Kiln.

process and tends to cause a separation of the various ingredients, whilst most of the water remaining in the paste must be all dried out before the material can be sent to the kilns, many attempts have been made to reduce the amount of water used whilst still obtaining a material so fine that only 4 per cent. will remain on a sieve with 180 holes per linear inch. The process which has proved most successful is based on a suggestion of Goreham, who recommended the addiiion of only about 15 per cent. of water to the materials, which are therefore converted into a much thicker slurry. The washmill is the same as that previously described, but a grating with $\frac{3}{8}$-inch openings is used instead of the fine sieve, and the slurry is ground between mill stones or in a tube-mill consisting 
of a cylinder rotating about its longitudinal axis and containing heavy steel balls. To ensure the absence of coarse particles of flint, etc., the slurry is then sieved before being passed to the mixing tanks and thence to the rotary kilns.

Where one material is much harder than the other it is treated separately, and the slurries from each mill are mixed in suitable proportions. This arrangement secures a larger output of a more uniform character, as if the clay is washed separately from the chalk the proportions of each may be more accurately gauged. The grinding of the mixed slurry in a special mill has only been practised in recent years. It increases the cost of manufacture, but gives so superior a product

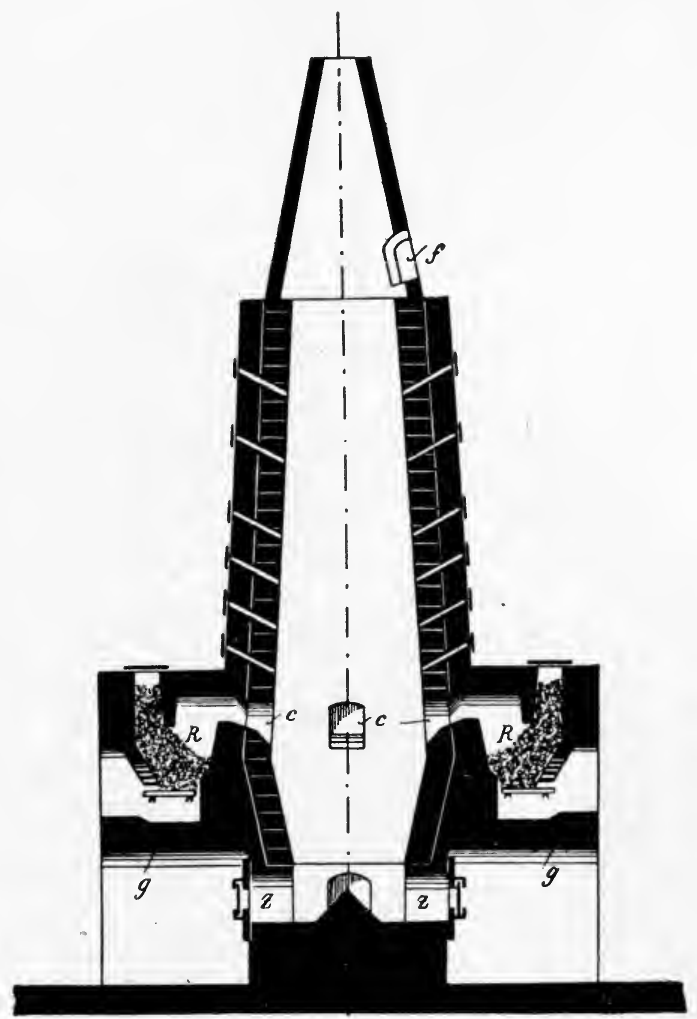

Fig. 2.-Modern Shaft Kiln. that it should seldom, if ever, be omitted.

The paste produced from the slurry must be dried to a solid mass if stationary kilns are used, as the material must be sufficiently firm to resist the crushing action of the material above it. Some firms press the paste into bricks and dry these, but the usual practice has been to spread the paste on a level floor heated by waste gases from the kilns (Fjg. 1). 
Owing to the shrinkage it undergoes on drying, the material cracks into pieces of a convenient size and these are placed in

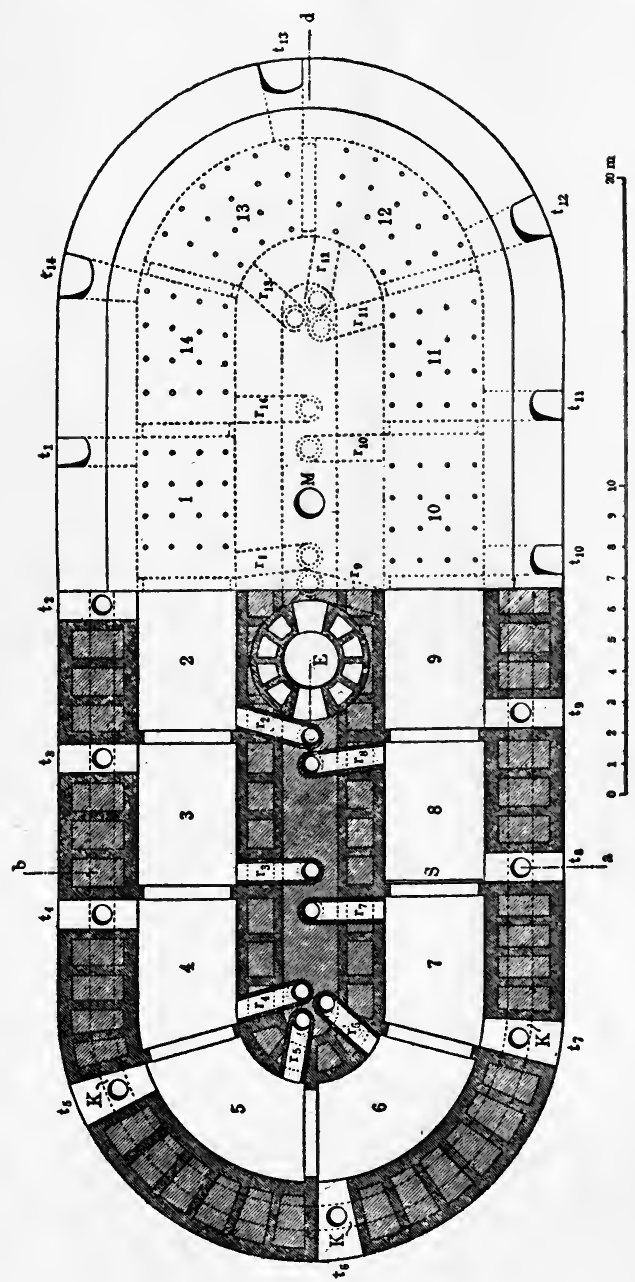

Fig. 3.-Hoffmann Kiln. the kiln. Two forms of stationary kiln are used-the shaft kiln (Fig. 2), of which there are numerous patterns, differing from each other chiefly in the arrangements provided for preventing the waste of heat. A typical example is Johnson's kiln (Fig. 1), in which the slurry is dried in the part $A$ by waste heat from the kiln $B$. Another is the Hoffmann kiln (Fig. 3), in which the material is slaked in a series of chambers, the heat from one being used to warm up the others so that it is used to the best advantage. Both these classes of kiln are now being replaced by rotary kilns (p. 26), so that no detailed description of them is needed.

The dry process is suitable for almost every kind of material, though sticky, highly plastic clays are troublesome unless previously heated to destroy their plasticity. This heating is usually termed "drying," though it does more than merely drive off the moisture in the clays. The material is usually 
passed through a preliminary crusher which reduces it to pieces of a convenient size for "drying." The "dried" materials are then mixed in suitable proportions in a mixing drum and passed into storage bins. From these bins the material passes to the grinding mills, where it is ground so fine that not more than 4 per cent. will remain on a No. 180 sieve, though the actual fineness is a matter for experiment, some comparatively coarse materials making an excellent cement. The mills used for this purpose are edge runners, ball mills, mill stones, centrifugal mills, or disintegrators, the last named being only suitable for coarse grinding. Various screening or sifting devices are employed to separate the fine material and to return the coarser product to the mill to be still further reduced.

The ground material, termed raw meal, is stored in silos or bins, each sufficiently large to hold about six hours' output. To secure a uniform product some means of mixing the material is employed in these silos, a species of bucket elevator, which removes the material from the bottom and returns it to the top of the silo, being generally used. The material in the silos must be tested for fineness, and its composition must be adjusted by the addition of clay or limestone powder if it does not correspond exactly to that required to make good cement.

From the mixer the raw material is passed to a rotary kiln (Fig. 4), which consists of an inclined steel tube lined with firebricks and cement clinker, $100 \mathrm{ft}$. or more in length and $6 \mathrm{ft}$. or more in diameter. The raw meal is fed in at the top whilst the fuel, in the form of dust, is blown in at the other end by a blast of air more than sufficient for its combustion. As the kiln revolves the material travels slowly down the tube, becoming hotter and hotter until it reaches a state of partial fusion or sintering, and is eventually discharged from the lower end of the kiln in a white hot condition. Variations in the shape of the kiln have been made from time to time, the modern tendency being to use kilns which are of larger diameter in the zone of greatest heat than they are at either end. The speed of rotation is quite slow-about thirty revolutions per hour-and is regulated to suit the material being heated. The final temperature reached in the kiln is about $1410^{\circ} \mathrm{C}$. 
The material discharged from the lower end of the kiln is termed clinker, and is received into a eooling device which usually consists of a rotating, inclined steel tube 30 to $50 \mathrm{ft}$. long and $5 \mathrm{ft}$. wide, which is partially lined with firebrick and fitted with baffles. As the cooler rotates, these baffles lift the elinker and allow it to fall in the form of a eascade, so that it is brought into close contact with a current of air which is sent through the cooler by means of a fan. The design and

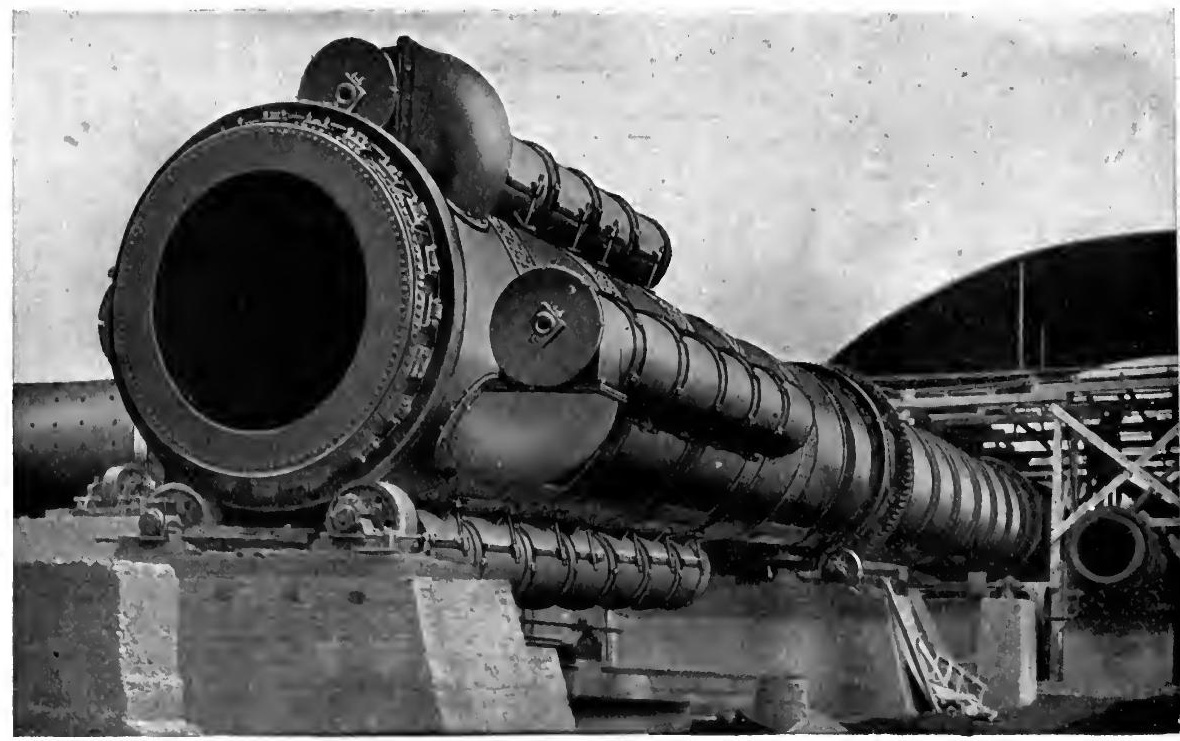

F'r. 4.-Pfeiffer's Rotary Kiln.

construction of a rotary kiln and its accessory coal-grinding plant require a large amount of skill. A number of firms have specialised in their manufacture, have brought them to a high degree of perfection, and have adopted many devices of considerable importance in obtaining a first-class product in the most economical manner. These details are beyond the scope of the present volume.

Cement clinker from stationary kilns is in the form of irregular lumps; that from rotary kilns is in grains rather larger than peas. If eorrectly burned it is a dark grey or blue grey sub- 
stance, extremely hard and full of minute pores. Insufficiently burned clinker is buff coloured; it must be separated and reburned. Over-heated clinker can only be produced when the material has been in contact with a siliceous kiln lining, as clinker alone is not affected by the greatest attainable heat in a cement kiln. In the presence of silica, on the contrary, a more siliceous silicate is formed which is not hydraulic, and is therefore useless for cement.

The cooled clinker is usually passed into a storage bin, from which it is drawn as required by the men in charge of the grinding plant. It is a curious fact, and one which in the early days of rotary kilns caused great inconvenience, that merely to reduce rotary kiln clinker to a fine powder will not produce a satisfactory cement; such a powder sets immediately, and some means must be used, therefore, to delay its setting for a convenient time. This is usually accomplished by the addition of about 2 per cent. of water, preferably in the form of steam, and 1 per cent. of gypsum. The grinding machines are chiefly tube or ball mills consisting of rotary cylinders containing steel balls which fall like a cascade when the mill is in action, and, in falling, crush the material to powder. This powder is then passed into a separator in which it falls on a rapidly rotating plate, the coarse powder being returned to the mill whilst the fine powder is carried along by a current of air and is eventually deposited in sacks or casks or in a silo. Sieves may be used in place of separators, but are understood to give less fine flour in the cement.

Many arguments have been brought forward as to the relative advantages of the dry and wet processes, but the opinion is still held by many people that the wet process is preferable wherever it can be applied. A careful investigation of both processes will fail to show any material differences in the final product, and it may be taken for granted that with equal care and skill either method of working will produce good results. The choice of one method should, therefore, depend on the costs of manufacture and, as these will differ in different localities, it is usually necessary to employ an impartial and independent expert to go fully into the question. Broadly speaking, the wet process is the cheaper for moist, 
soft, raw materials such as chalk and marly clays; its chief drawback being the high cost of burning due to the evaporation of the added water. If the dry process is used, the raw materials contain only 10 to 15 per cent. of moisture, and this is removed by the waste gases of the kiln without any cost. With the wet process, on the contrary, the grinding is much less expensive; but this small saving cannot counterbalance the high cost of fuel for drying out the added water. Moreover, the saving in power will be nullified if the wet mills require more repairs than the dry ones. A well-managed plant working in the wet way averages $5 \mathrm{lbs}$. of medium quality coal to each $100 \mathrm{lbs}$. of cement more than when the dry process is used, as the evaporation of the water in the wet process requires as much heat as will clinker the dry raw material. This is equivalent to almost 20 per cent. of the coal used.

In the earlier days of rotary kilns, when they were bailt too short for materials treated by the dry process, the coal burned was greater in the dry than in the wet process, and the influence of the fuel ashes was so great that many firms were driven to use the wet process. Recently, the dimensions of rotary kilns have increased enormously, and the modern kilns can deal with dry-process material in a perfectly satisfactorymanner. Other important reasons for using the wet process are the absence of drying plant for the raw material and absence of dust, but neither of these are of primary importance.

The idea that the wet process effects a better mixing of hard materials and improves the quality of the cement is no longer tenable, and the belief that less power is required is equally inaccurate. The power required is only less when the output of a wet mill is compared with that of a ball or tube mill of an old pattern; the modern dry-process machines operate very advantageously and satisfy all requirements with regard to uniformity and fineness of product and power consumption, providing the materials are suitable; wet materials being best treated by the wet process. For hard materials, such as limestone and shale, the dry process is preferable. In this country, the softer materials are available in such large quantities that the wet process is more generally used; in America, on the contrary, the harder materials are the 
more frequently employed, and the dry process is preferred there.

\section{SAND CEMENT.}

Sand Cement is a mixture of equal weights of sand and Portland cement, the two materials having been ground together. Sand cement has a tensile strength almost as great as that of neat Portland cement, but its value is greatly exaggerated by tensile and other tests, as will be seen by using sand eement mixed with three times its weight of sand. It will then be found that the strength of the cement-sand mixture is much lower than that of mixtures of Portland cement and sand in the same proportion. The fact is that tests of the tensile strength of neat cements are almost meaningless, and only mixtures of cement and sand in the proportion of $1: 3$ give really satisfactory results. Tests of neat cement are no longer made on the Continent (see p. 139).

\section{NATURAL CEMENTS.}

Long before Portland cement had been invented, many so-called "natural cements" were in use. These were made by heating certain naturally occurring materials (p. 13) and grinding the calcined product. These "natural" or "rock" cements are far less uniform in composition than are Portland cements, because no care is taken to adjust the composition of the raw materials used. They are also inferior because they are generally under-burned-the temperature in the furnace being insufficient to cause complete combination of the clay and lime or their equivalents-as it is under $1200^{\circ} \mathrm{C}$. instead of $1400^{\circ} \mathrm{C}$. or above.

It is essential that the materials from which they are made should contain clay and limestone (or the equivalent aluminosilicic acid and calcium carbonate) in suitable proportions, and the value of the cements produced depends largely on the composition of the raw rock.

The methods employed in the manufacture of natural and rock cements resemble those used for Portland cement, except that there is only one raw material instead of two, and 
that no efforts are made to test and adjust the composition of the material during manufacture. The raw rock or septaria (p. 13) are placed in the kiln without being crushed, stationary kilns (Figs. 2 and 3) being employed. The calcined material is then ground to powder in a similar manner to cement, though the grinding is seldom so complete.

The clinker drawn from the kiln must be sorted, the lightcoloured under-burned pieces being separated from the darker clinker and used only for inferior work or returned to the kiln to be re-heated. Some manufacturers claim that the clinkered material is less satisfactory than a rather more lightly burned product. These differences in behaviour are probably due to differences in the composition of the clinker : the greater the proportion of lime the higher must be the temperature inside the kiln to secure an adequate combination. If, on the contrary, the burning has been properly executed, a cement with a large proportion of lime will be stronger than one containing less lime. If the proportion of lime $(\mathrm{CaO})$ in the raw rock or marl is between 1.8 and 2.4 times that of the silica and alumina, a good natural cement will be obtained at a temperature of about $1150^{\circ} \mathrm{C}$., but if the lime exceeds four times the "silica + alumina," the temperature needed will be as high as that required for Portland cement. The absence of accurate knowledge of the composition of the materials and variations in the temperature of the kilns used, usually results in a considerable proportion of over- and under-burned material being produced, and it is not unusual for one quarter of the contents of a kiln to be rejected.

Natural cements are usually much coarser than Portland cements, but during the last few years finer grinding has been customary so as to be better able to compete with Portland cement.

The great drawback to natural and rock cements is their unreliability. At the present time, their chief purpose appears to be to form a cheap rival to Portland cement. The superiority of the latter is so great, however, that manufacturers are finding it will pay them better to take more pains to secure a uniform product of a composition and properties practically identical with those of Portland cement. Some of them have, 
therefore, installed arrangements for testing and adjusting the composition of the raw material and of treating it in the same manner as in making Portland cement. The.process is certainly more costly, but the better prices obtained fully warrant the additional expense. With natural materials so nearly correct in composition it seems unfortunate that firms should continue to produce so inferior a product as natural cement when they might so advantageously manufacture Portland cement. To do this it is essential that the material should be ground to powder and thoroughly mixed before it enters the kiln, as the direct calcination of relatively large lumps is one of the chief causes of irregular composition. The two chief constituents of the material are not in sufficiently intimate contact to produce a uniform product unless the raw material has first been reduced to powder.

Roman cement (p. 13) is one of the oldest of the natural cements, but its name is quite misleading, as the material bears no resemblance to the mortar used by the ancient Romans. It was first made in England in 1796, the raw material being the septaria (p. 13) or clayey nodules dredged from the sea near Harwich and Sheppey. These nodules are calcined lightly in a shaft kiln (Fig. 2) and are then reduced to a rather coarse powder.

Whilst useful where Portland cement is not available, Roman cements can only be regarded as crude inferior products of a similar type, their disadvantages being due to their irregularity in composition and the coarseness of the product, but their low cost-about half that of Portland cement-causes them to be largely used in some localities.

Belgian cement-sometimes, but erroneously, sold as Belgian Portland cement-is a natural cement manufactured in the district of Tournai, where apparently inexhaustible quarries of clayey limestone occur. This material (see analysis on p. 13) when calcined, very closely resembles Portland cement clinker, and is only distinguished from it with difficulty.

Belgian cement is made with greater care than most natural cements, but it is, nevertheless, very inferior to Portland cement on account of the lower temperature at which it is burned and the coarseness of the final product. Good 
genuine Portland cement is undoubtedly produced in Belgium, but what is known as "Belgian cement" is quite different, and is notoriously inferior, very unreliable, and often even dangerous. The prudent professional man should never allow its use on works under his control. This "Belgian cement" is no better than a hydraulic lime, and is made in the same manner. There is no careful mixing of two separate raw materials, with all the refinements of scientific control at every stage of the process and at every hour of the day in order to remedy the ever-present variations in the chemical composition of the materials employed, and to secure a uniform chemical composition of the resulting product, by which alone a uniform quality can be obtained. The Belgian rock, which varies greatly in its chemical composition and is usually deficient in lime, is taken just as it comes from the quarry, burned and ground exactly as if it were to be sold as "hydraulic lime" ; indeed, much of it is sold under that name in its own country. But some wily vendors, keenly alive to the value of a name, know by experience that many persons who would not touch it under a true description will buy readily enough if it be sold as "Portland cement," or " best Portland cement," and they therefore pack it in casks exactly like that used for genuine Portland cement, are ever ready to attach any label preferred by the purchaser, and more often than not print the label in the English language, call their firm by an English name, and do everything they can to make the guileless consumer imagine he is buying genuine Portland cement produced by English makers, whose reputation throughout the world still stands as a guarantee of high and reliable quality. In short, the sooner the use of the word "Portland" in connection with such Belgian cement is stopped, the better.

\section{QUICK AND HYDRAULIC LIMES.}

Hydraulic limes are prepared by burning limestones containing clay (p. 4) in a manner precisely similar to that used in the manufacture of quick-lime. The material is placed in a shaft kiln with alternate layers of coal, and the burned lime is drawn out at the bottom of the kiln. In order to avoid 
the admixture of ashes from the fuel with the burned lime, gas may be used instead of coal, and where the output is large various methods are used for keeping the kilns continuously at work. With smaller kilns, the usual custom is to fill, burn and empty them, treating each kiln separately from the rest. This arrangement has the advantage of keeping the lime in larger lumps than when it has to travel down a tall shaft as is the case when the kilns are worked continuously. Horizontal draught kilns of the Hoffmann type (Fig. 3) are also used for this purpose. It is important to avoid overheating, whereby the lime becomes partially vitrified or sintered. In burning pure or fat lime this over-heating does not readily occur, but the proportion of clay and free silica in hydraulic limes renders special precautions necessary or the lime will be dead-burnt.

The difficulty in burning hydraulic limes is increased by the fact that they require a higher temperature of calcination than does common (fat) lime.

After burning, the material is carefully slaked by the addition of a suitable quantity of water, and the fine powder thereby produced is then ready for sale. Properly-made hydraulic lime, therefore, needs no grinding and can thus be produced more cheaply than Portland cement. Ordinarily, however, lumps of material remain after slaking and must be separated by screening (see Grappier cement, p. 34).

The chief difference between hydraulic lime and quick-lime is the clay in the former which prevents the hydraulic lime from slaking readily, but enables it to set when immersed in water.

The raw materials used for hydraulic limes have been described on pp. 4 , et seq.

Hydraulic limes consist essentially of mixtures of " Portland cement" with considerable quantities of quick-lime, the proportions of each being dependent on the amount of clay in the original limestone and on the temperature attained during the burning. Some hydraulic limes made from blue Lias limestone have a composition corresponding almost exactly with that of Portland cement, but others correspond more nearly with a mixture of 70 per cent. of Portland cement

c. 
and 30 per cent. of free lime. There is, at present, no limit of composition whereby hydraulic limes can be distinguished from other cements, and they are best defined as made from argillaceous limestones and as containing sufficient cementitious material to give hydraulic properties to the product and sufficient free lime to enable the material to slake on the addition of water. The advantage of the free lime present is that the material can be reduced to powder simply by the addition of water (slaking), and so does not need to be ground as does Portland cement clinker. It is, however, important that no more free lime should be present than is essential for this slaking, as an excess of lime merely weakens the cementing value of the material. Finely-ground grappiers (below) are usually added to increase the hydraulic properties of the lime.

One of the most famous hydraulic limes is exported from Teil, in the south of France, and is considered to be specially suitable for sea walls and marine work. The following is an analysis of Teil hydraulic lime before slaking:-

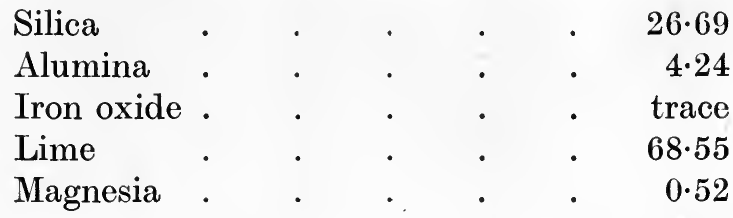

Most English hydraulic limes are only moderately hydraulitic and are much feebler than some of the French and German products, owing to their much larger proportion of free lime. They are improved by the addition of 5 per cent. of finelyground plaster of Paris, and the product is then known as Scott's cement or selenitic cement.

Grappier cement consists of the ground lumps or nodules which remain when hydraulic limes are screened. It is a true cement, though of a composition somewhat different from that of Portland cement, being usually rather low in alumina and lime. Grappier lumps consist chiefly of the hydraulite and of unburned limestone ; if the latter is present in a large proportion the cement will be useless. The following is an analysis of a typical grappier cement :- 


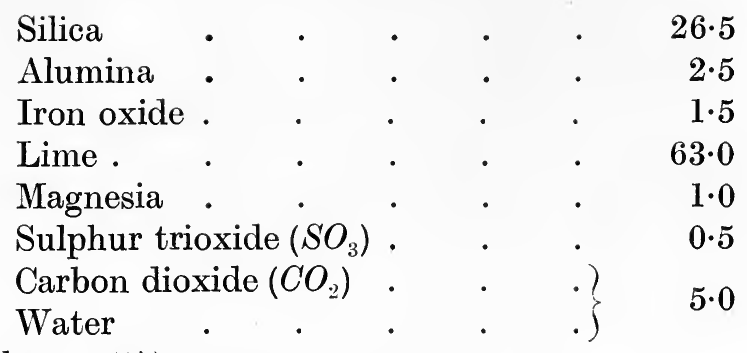

(See also p. 52):

\section{POZZOLANAS.}

Pozzolanas are not true cements, but only become so when mixed with lime and water. The raw materials composing pozzolanas are, essentially, clays which have been heated to redness either by natural forces, such as volcanic action, or artificially in kilns. Pozzolanas are, as regards their origin, of three classes :-

(a) The direct products of volcanic action, usually found on the slopes of volcanoes, such as pozzolana proper, santorin, tosca, tetin and trass (p. 15). These pozzolanas bear a close resemblance to ashes and slags.

(b) Products of the decomposition of certain igneous rocks. These are but feeble hydraulites.

(c) Artificial pozzolanas obtained by crushing lightly-burned clay, ballast, tiles, bricks, etc. Care should be taken to avoid clays which have been heated to partial vitrification. Some blast-furnace slags, when ground, are also pozzolanic.

\section{SLAG CEMENTS.}

Certain basic blast-furnace slags, when granulated by sudden cooling with water and then ground to a fine powder, form valuable cements. The sulphur present in the slags is largely removed in the form of sulphuretted hydrogen gas during the granulation. Small percentages of various other elements are also present, but do not appreciably affect the hydraulicity of the cement.

The use of slag as a raw material for cements which, in many ways, resemble Portland cements, has already been discussed 
(p. 16), and some of the chief differences have been pointed out. All slags are not suitable for cement manufacture, and it is convenient to divide those made from blast-furnace slag into three classes :-

(1) Pozzolanic slag cements which consist of ground slag of a pozzolanic nature, to which sufficient slaked lime is added during the grinding of the material to bring the total content of calcium oxide up to 63 to 66 per cent. Such a cement is but little better than a hydraulic lime.

(2) Plaster-slag cements made by mixing rapidly cooled and granulated slags of innate hydraulicity with a considerable proportion of plaster of Paris. Such cements contain little free lime, and are peculiarly resistant to acids and magnesium salts. There appears to be a future for slags of this neutral type-preferably with a neutral, sulphur-free substitute for the plaster-for maritime work. (See Asch's suggestion in a later section dealing with the effect of sea water on cement.)

(3) Iron Portland cement, which is used in large quantities in Germany and in the Far East. The title is far from being a satisfactory one, as the material is not Portland cement at all, but is produced from basic blast-furnace slag. Basic slag is mixed with a suitable proportion of limestone, the material being then ground and burned in the usual manner. The clinker is mixed with nearly half its weight of granulated slag and then ground to a fine powder.

Iron Portland cement differs from true Portland cement in the materials from which it is made and in some of the properties it possesses, though in many respects the two materials closely resemble each other.

The composition of Iron Portland cement varies considerably in different localities; a fair average is :-

Silica

per cent.

Alumina and iron oxide

20 to 25

Lime

$9,, 15$

Magnesia

$54,, 60$

Sulphur tri-oxide $\left(\mathrm{SO}_{3}\right)$

$0 \cdot 6,5 \cdot 0$

Alkalies .

$0 \cdot 8,2 \cdot 7$

0,2 
The term "iron-Portland cement" is also applied to blastfurnace slag which has been mixed with twice its weight, or more, of true Portland cement. It then resembles "sand cement" (p. 29), but is rather stronger. It is, of course, weaker than pure cement.

The Iron Portland cement above mentioned must not be confused with the Iron Ore cement mentioned on p. 18.

Slag cements are essentially mixtures of slaked lime and slag, and are therefore of the nature of pozzolanic cements, the slags being regarded as a kind of artificial pozzolana. Some firms produce a kind of Portland cement in which slag takes the place of the clay and part of the limestone or chalk, and in this way less fuel is used than in the manufacture of ordinary Portland cement, the temperature at which the slag-lime mixture clinkers being lower than that needed in a Portland cement kiln. The disadvantage of slag used in this manner is that the granulation of the slag introduces a large amount (20 to 40 per cent.) of water which must be driven off by heat before the mixture can be calcined.

The slag is run from the furnace in the form of a white hot molten stream, which is reduced to porous grains of slag-sand by contact with water. Various methods of effecting this granulation are in use, one of the most satisfactory consisting in allowing the stream of slag to flow into a trough containing a rapid stream of water. Sometimes a jet of steam or water is allowed to play on the slag before it reaches the trough.

Granulation plays an important part in the manufacture of slag cement, for it not only reduces the material to a coarse powder in a simple and cheap manner, but the water appears to have a chemical action, as the granulated slag has much stronger hydraulic properties than slag which has been more slowly cooled. In fact, the hydraulic properties of slowlycooled slag are almost negligible.

The porous granulated slag cannot be ground direct on account of the water it contains. It must, therefore, be dried at a temperature below a red heat in an automatic dryer. Such a dryer consists preferably of two concentric pipes slightly inclined from the horizontal. The material is passed through the annular space between the pipes and hot air is passed over 
it, so that the wet material enters the machine at one end and emerges sufficiently dry at the other.

The dried slag is next mixed with a suitable proportion of slaked lime, usually about 35 parts of lime to 100 of slag being used. The mixture is then reduced to a fine powder in a tube-mill. The mixing is usually effected automatically, and without requiring any special attention, by charging the mills used for fine grinding with the various raw materials in the desired proportions. The grinding machinery is the same as is used for Portland cement (p. 25).

Slag-cements set so slowly that they must usually be accelerated by the addition of calcined silica, highly aluminous slag, or caustic alkali.

Slag-cements are much used as adulterants of, or substitutes for, Portland cement, but differ from the latter in the lower proportion of lime and alumina they contain and in the proportion of calcium sulphide present. The chief distinction to be found is in the 4 to 8 per cent. loss which occurs on the ignition of slag cements, due to the water they contain.

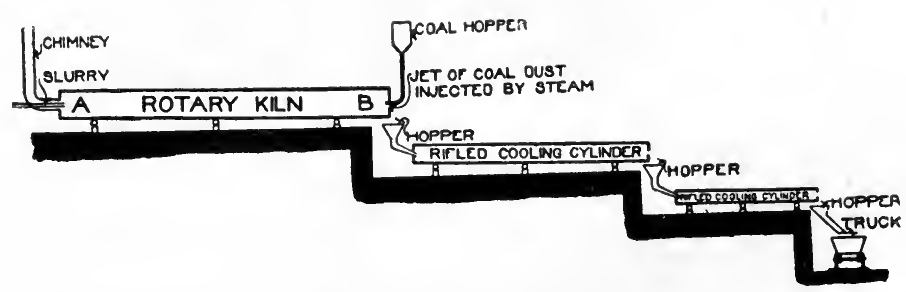

Diagram of Modern Rotary Kiln and Cooling Cylinders. 


\section{CHAPTER III}

THE CHEMICAL AND PHYSICAL CHANGES IN CEMENTS

The chemical and physical changes which occur in the manufacture and use of cements are both complex and difficult to investigate. They may be more easily studied by separating them into groups : $(a)$ the changes which occur in the manufacture of cement from the raw materials, and $(b)$ the changes occurring when the cement is used.

Changes in Manufacture. - From what has been stated in previous chapters, it will be understood that the various cements described are formed essentially from an acid substance corresponding to aluminosilicic acid in combination with a basic substance. The acid and base occur quite separately in the form of clay, pozzolanas, etc., and chalk or limestone respectively, or as a mixture (marl, argillaceous limestone, and the raw materials used for natural cements). Combination only occurs when the mixture is heated to a suitable temperature, and it is during this heating that the most important "changes during manufacture" occur.

No perfectly pure clay occurs in nature, and this still further complicates the problem. Most of the clays used in the manufacture of cement appear to consist of a mixture of what may be termed clay substance (aluminosilicic acid) together with free silica and other (non-plastic) minerals. As naturallyproduced mixtures must vary greatly in composition, no single chemical formula can be assigned to natural clays. The best way is to consider the essential constituent of each of such clays as the chief factor in the acid portion of the cement, the free silica and other minerals being considered separately. In other words it is necessary first to consider the action of the heat on each of the constituents of the raw materials apart from each other, and then to study what reactions occur when the substances produced by the action of heat are brought into 
intimate contact with each other. In the case of cementburning, both these sets of changes occur at the same time in different portions of the material, and their separate consideration is only a convenient means of explaining what actually occurs. It is also convenient to distinguish as far as possible between the chemical changes which take place on heating the raw materials and the purely physical changes which occur simultaneously.

\section{The Chemical Action of Heat on Clay Substance.}

The first effect of heat on clay is to drive out any moisture it may contain, either in the free state or in the form of water absorbed by any colloidal matter present. Some clays contain as much as 30 per cent. of such water without appearing to be really wet. The changes which occur during this drying are purely physical so long as the temperature is not appreciably above $100^{\circ} \mathrm{C}$, and will be described later.

If the temperature is raised, chemical decomposition occurs with appreciable rapidity, and at $500^{\circ}$ to $800^{\circ} \mathrm{C}$. a quick evolution of water occurs. The precise nature of the decomposition, of which this is a sign, is not clearly understood. Rebuffat, Mellor and Holdcroft, and others maintain that theclay molecule is completely decomposed into a mixture of free oxides-silica, alumina and water; but other chemists maintain that an anhydride or similar compound of alumina and silica is formed. Thus, W. and D. Asch believe that clays are aluminosilicic acids, or the corresponding hydrates, in which the various atoms are arranged in a series of hexagons and pentagons resembling the well-known "benzene ring" of organic chemistry and they represent a molecule of the purest clay obtainable (refined china clay) as

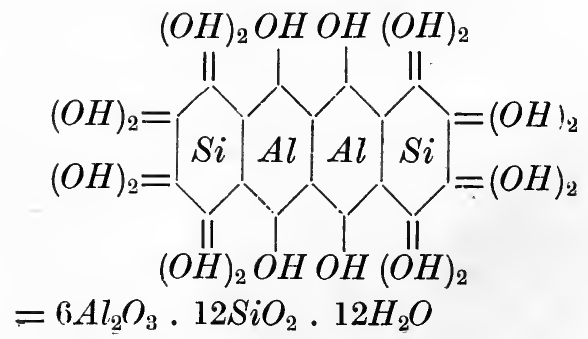


Other and less pure clays have corresponding formulæ, depending on their composition (see p. 5).

A complete statement of Asch's theory is too lengthy and complex to be included in the present volume, ${ }^{1}$ but its general correctness has been confirmed in various ways. It is of great value in explaining the changes which occur whilst the materials are in the kiln. As, according to Asch's theory, clays are merely crude aluminosilicic acids, the reactions which occur on heating a clay with a suitable proportion of lime consists chiefly in displacing some of the hydrogen atoms in the clay by lime or magnesia, just as the corresponding hydrogen in a complex organic acid is replaced by a base when the acid is neutralised. Any study of the reactions is complicated by the fact that the clays and bases (lime or chalk) are far from pure. The precise nature of the compound formed must depend largely on the extent to which the reaction is allowed to occur as well as on the particular aluminosilicic acid originally present. Fortunately for the manufacturer all aluminosilicic acids (clays) act as though they are partially decomposed at high temperatures, and form one of three types of stable compounds, viz. :--

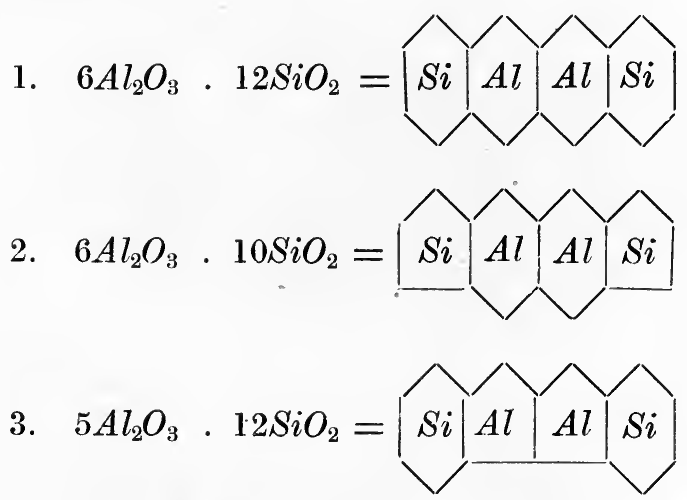

Thus, a clay of the type $6 \mathrm{Al}_{2} \mathrm{O}_{3} 12 \mathrm{SiO}_{2} 12 \mathrm{H}_{2} \mathrm{O}$ will, on heating, lose water and silica, or water, silica and alumina, according to the temperature and duration of heating, and will form one of the types above mentioned.

1 Readers with.a sufficient knowledge of chemistry should consult "The Silicates," by W. \& D. Asch, published by Constable \& Co., Ltd., London. 
The effect of this particular decomposition is to convert all clays into one or more of the above types of compounds, and, consequently, enables commercially useful Portland cements to be made from almost any material containing a sufficient proportion of clay.

Whatever substances are produced by the direct action of heat, it is generally recognised that their nearest natural equivalents are the trasses and pozzolanas already described (p. 14) and corresponding (e.g.) to $3 \mathrm{H}_{2} \mathrm{O}$. $4 \mathrm{RO} .3 \mathrm{Al}_{2} \mathrm{O}_{3}$. $18 \mathrm{SiO}_{2}$.

That a decomposition of the clay molecule, and not a mere evolution of water of crystallisation occurs when clay is heated cannot be doubted, and Sokoloff has shown that the production of a pozzolanic material of maximum hydraulicity occurs precisely at the point where a clay loses the whole of its constitutional water. This production of pozzolanas by heating clays to a temperature of about $500^{\circ} \mathrm{C}$. appears to be characteristic of most, if not all, clays, and is strong evidence of the existence of a definite type of essential constituent or " clay substance" in all clays, even though its composition and the arrangement of the atoms within the molecule may vary considerably.

The action of more intense heat on clays is extremely difficult to study. The only definitely crystalline substance which is produced by heating pure clay to the highest available temperature and allowing it to cool is sillimanite $\left(\mathrm{SiAl}_{2} \mathrm{O}_{5}\right)$. This substance appears to be formed at $1200^{\circ} \mathrm{C}$., but whether it is a decomposition product of a more complex alumino-silica compound or whether it is produced by the recombination of silica and alumina set free at a temperature of $800^{\circ} \mathrm{C}$. has not yet been determined, though the latter appears to be the more probable explanation. Indeed, Mellor and Holdcroft regard the formation of sillimanite at $1200^{\circ} \mathrm{C}$. as strong evidence of the complete dissociation of clay into free silica and alumina at a lower temperature. There is, however, remarkably little evidence as to the true composition of this crystalline substance. It resembles sillimanite in several respects, but is not improbably one of the three compounds whose structural formulæ are given on p. 41. The quantities of crystals available for analysis are far too small for a clear dịstinction to be made 
between $\mathrm{SiAl}_{2} \mathrm{O}_{5}$ and the three types of compounds mentioned, though the formation of the latter is, theoretically, far more probable than the complete dissociation of the clay into free silica and alumina, and its recombination into sillimanite.

In the present volume, the product of the direct action of heat on clay alone is termed calcined clay.

\section{The Chemical Action of Heat on Free Silica.}

The chemical action of heat on free silica is inappreciable at temperatures below $800^{\circ} \mathrm{C}$., but above this temperature a considerable increase in the volume of the silica occurs and tridymite, which is apparently a polymerised form of silica, i.e., $x \mathrm{SiO}_{2}$, is produced. (For the action of heat on a mixture of free silica and lime, see p. 66).

The proportion of free silica in a well-made Portland cement is extremely small; together with all the other insoluble matter it should not exceed 3 per cent. As it is quite inert when the cement is in use the presence of so small a proportion is quite devoid of importance.

In the raw materials used for the manufacture of cements a notable proportion of colloidal silica $\left(\mathrm{SiO}_{2} \mathrm{xH}_{2} \mathrm{O}\right)$ may be present, but is converted into ordinary, amorphous silica on heating. At one time much stress was laid on the distinction between colloidal (soluble) and amorphous (insoluble) silica owing to the greater reactivity of the former, but this distinction is valueless in the case of all cements in the manufacture of which a high temperature has been employed, providing that the material is ground sufficiently fine.

\section{The effect of Heat on Free Alumina.}

The effect of heat on free alumina is to make it insoluble in acids and very resistant to the action of alkalies. It therefore becomes inert. It is doubtful whether free alumina ever exists really in cements to any appreciable extent. When free alumina is added in small quantities (4 per cent.) to some samples of commercial Portland cement it causes expansion on gauging; on other samples it appears to have no action of 


\section{CHEMICAL AND PHYSICAL CHANGES IN CEMENTS}

this kind even when briquettes made of the mixture are kept in boiling water for several hours.

Other minerals in clay will undergo various physical and chemical changes when exposed to the action of heat at temperatures reached in the manufacture of cement. Some of the complex aluminosilicates appear to decompose with the formation of simpler silicates; others lose water, and must, therefore, be regarded as undergoing some decomposition, though the nature of this is far from being well understood. As the temperatures reached-particularly in rotary kilnsare very high (about $1400^{\circ} \mathrm{C}$.), it is not unreasonable to suppose that any calcium aluminosilicates present in a clay produce substances which bear a close resemblance to the essential constituent of cements, and that the sodium, potassium and magnesium aluminosilicates produce analogous substances which may, however, be devoid of hydraulic properties.

As the proportion of "other minerals" in clays and similar substances used for cement making is seldom large, the direct chemical action of heat upon them may be neglected; the total effects of their presence is noted on a later page. The chemical changes induced by the reaction of these substances on one another are described on p. 72.

\section{The Chemical Action of Heat on Limestone.}

The chemical action of heat on limestone is comparatively easy to understand. Chalk and limestone are essentially composed of calcium carbonate which, on heating to $700^{\circ} \mathrm{C}$. or above, dissociates into free lime $(\mathrm{CaO})$ and carbon dioxide $\left(\mathrm{CO}_{2}\right)$; the latter, being a gas, escapes and leaves the free lime behind. The extent to which this decomposition occurs depends on the pressure of the carbon dioxide produced; if this gas is allowed to escape the whole of the carbonate will be converted into oxide, but if some of the carbon dioxide remains in the kiln or other appliance in which the heating occurs, it will, in time, produce such a pressure that no further decomposition of the carbonate will take place. This is commonly expressed by the following equation :-

$$
\mathrm{CaCO}_{3} \longleftrightarrow \mathrm{CaO}+\mathrm{CO}_{2},
$$

which indicates the reversibility of the reaction. 
Lime which has been heated to above $1000^{\circ} \mathrm{C}$. loses part of its power to slake when water is added to it, but this is believed to be due to a reduction in the surface area of the material rather than to any molecular rearrangement.

Free lime does not occur in properly made Portland cement ; many statements to the contrary are based upon erroneous conclusions drawn from experimental observations. This is due to the ease with which Portland cement is hydrolysed when treated with water, whereby lime, originally in combination, is set free. The presence of free lime in cement would be very disadvantageous, as when the cement is in use the lime hydrates, expands, and may easily cause dangerous cracks in the structure. Comparative tests on good Portland cements, with and without the addition of 6 per cent. of lime, showed that the whole of the expansion of the lime occurred when the briquettes were exposed for twenty-four hours to a moist atmosphere. The same results are produced in an insufficiently-burned cement, i.e., one in which all the lime and clay have not entered into combination, so that free lime and free "calcined clay" are present.

It is because of the danger caused by the presence of free lime that a limit to the proportion of lime is usually imposed. The best means of controlling its presence is the "expansion test" described in a later chajter. If a cement can pass this test the proportion of free lime in it will be insignificant.

If a cement mixture containing an excess of chalk or limestone is heated so strongly that the excess of lime produced is converted into the slow-slaking, dense modification, or into the cubic crystalline form produced by prolonged exposure at a temperature exceeding $1400^{\circ} \mathrm{C}$., the cement produced will crack when it is gauged and placed in water. The lime then slakes so slowly that the cement sets before the slaking is complete, and the increased volume of the slaked lime brings about the cracking, or even complete disintegration, of the mass. Very small percentages of this crystalline lime will render a cement unsound, but as its presence is exceedingly difficult to detect, it is customary to omit all search for it and to test the cement directly as to its soundness and expansibility in water. (See p. 124). 
In the rotary and Hoffmann kilns used for cement manufacture there is generally sufficient draught for the complete removal of all the carbon dioxide liberated, but in some of the shaft kilns a small but recognisable proportion of undecomposed (or re-formed) calcium carbonate is usually present.

The impurities present in the chalk or limestone will behave - so far as any chemical changes are concerned-like the similar constituents of the clays or like calcium carbonate. Thus, magnesium carbonate is decomposed, forming free magnesia and carbon dioxide.

\section{Chemical Reactions between Clay and Lime.}

The most important chemical changes which occur in the manufacture of cements are not the direct chemical action of heat on the various substances used, each being considered separately, but are due to the various reactions of the various substances upon each other. Thus, either a pure clay or lime, when heated separately, is quite infusible at all industrial temperatures, but when a mixture of clay and lime in suitable proportions is heated, it melts at a temperature of $1400^{\circ} \mathrm{C}$. or lower, and the product is entirely different in chemical and physical properties from the original mixture. Owing to the variety of substances present in natural clays and chalk or limestone, the various reactions of these upon each other are extremely difficult to study. Some of the reactions at present regarded as of minor importance may be proved, later, to be of greater significance; at the moment of writing, however, the following are considered to be the chief reactions which occur :

Those portions of the contents of a kiln which have attained a temperature of $1000^{\circ} \mathrm{C}$. or above will not consist of the original clay and chalk or limestone fed into the kiln, but of a mixture of "calcined clay" 1 and free lime, together with such free silica (including tridymite) and other "calcined minerals" as may be present adventitiously. At the temperature mentioned some amount of fusion will have taken place, particularly among the "calcined minerals," and the glassy

\footnotetext{
1 It is clear that with the present divergence of opinion as to the nature of this "calcined clay" (p. 43) it is inadvisable to regard it definitely as either a mixture of free silica and alumina or as an aluminosilicic complex.
} 
substances so produced will bring the particles of lime and "calcined clay" into such intimate contact with each other that various reactions will commence. Indeed, one object of the fine grinding and thorough mixing of the raw materials is to secure the most intimate contact possible between the various materials.

That no fusion is necessary is clearly observable if a mixture of pure china clay and pure lime is heated in a Doelter's microscope, when it will be found that no appreciable fusion occurs until a temperature of $1300^{\circ} \mathrm{C}$. is reached, though the complete solubility of the product heated to a lower temperature will show that combination of the two substances has occurred. Moreover, as shown later, J. W. Cobb has conclusively proved that reactions between lime, silica and alumina can occur with the production of a mass completely soluble in hydrochloric acid at temperatures far below that at which even partial fusion takes place. The partial fusion which occurs, with some clays, at a temperature of $1000^{\circ} \mathrm{C}$. is due to the impurities present, and has no essential connection with the progress of the main reaction whereby cement clinker is formed, though it may have a physical effect in increasing the rapidity of the reaction by bringing the particles into more intimate contact with each other.

If the "calcined clay" is regarded as a simple mixture of silica and alumina, both in the free state, the chief action of the lime will be to form :-

(a) calcium silicates $\left(x \mathrm{CaO}, y \mathrm{SiO}_{2}\right)$

(b) calcium alumirnates $\left(x \mathrm{CaO}, y \mathrm{Al}_{2} \mathrm{O}_{3}\right)$

(c) calcium aluminosilicates $\left(x \mathrm{CaO}, y \mathrm{Al}_{2} \mathrm{O}_{3}, z \mathrm{SiO}_{2}\right)$.

These substances will be mixed together in proportions depending on the relative amounts of lime and "clay," on the duration of the heating, and on other conditions required for the formation of each of these classes of substances.

From a simple mixture of lime, silica and alumina, it is most natural to suppose that the product would consist largely of a mixture of one or more calcium silicates with one or more calcium aluminates, and that the proportion of calcium aluminosilicates would be very small. The apparent simplicity 
of this arrangement has made many investigators content to regard cements as mixtures of simple binary compounds, and especially as solid solutions of a calcium aluminate in a calcium silicate. This theory of solution is, indeed, so popular that very few writers realise the peculiarly slender foundations on which it is based and the enormous lacunce between the assumptions made as to the theoretically possible existence of certain substances and the complete failure to produce these substances under the conditions existing in the manufacture of cements.

If, on the contrary, the "calcined clay" is considered to be an aluminosilicic complex or anhydride, it is more probable that the greater part of the product would consist of ternary compounds, i.e., calcium aluminosilicates, and that the proportion of binary calcium silicates and calcium aluminates would be small. The presence of all three classes of substance ${ }^{1}$ is, of course, quite probable, whichever theory as to the chemical constitution of "calcined clay" is adopted; it is only the relative proportions of each which is important. Again, it is quite possible that the action of the lime on any aluminosilicic anhydrides present may result in a decomposition of the complex and the consequent formation of simple binary silicates and aluminates, though there are serious objections to the view that this decomposition occurs to any great extent.

Three entirely different series of methods of investigation have been adopted in studying the constitution of cements. The first of these comprises analytical methods applied to the cements themselves and including the study of the physical properties as well as their behaviour towards chemical reagents. The second method of investigation comprises synthetic methods of research which consist essentially in endeavouring to prepare the apparent or presupposed constituents of cements, and in comparing the properties of these synthetic products with cements prepared for purposes of commerce. The third method consists in observing the reactions which occur when the raw materials are heated or when the clinker is cooled. In this connexion it is important to observe that great care must be taken to avoid overheating, with the 
resultant fusion of the clinker, for this produces substances which do not necessarily exist in ordinary cement clinker. Dittler and Herold go so far as to state that observations of what occurs when well-made and carefully-burned cement clinkers are allowed to cool, can never show the constitution of the clinker satisfactorily as the formation of crystals does not take place like that in most other systems of two or more components, for instead of the substances in excess separating first, it is the substance which has the greatest rate of crystallisation which first becomes crystalline. The formation of the various compounds does not occur during the cooling, but during the heating, the fusion and crystallisation occurring simultaneously. For these reasons the results of observations made on cooling clinker should be accepted with great reserve.

In studying what occurs when the raw materials are heated under conditions where the reactions can be observed, the changes in the electrical conductivity of the mixture are of great value. It is well known that the extent to which a substance will conduct electricity is a measure of its dissociation into ions, and it is an important fact that when clays and cements are heated above $700^{\circ} \mathrm{C}$. their electrical conductivity increases rapidly with increasing temperature to $900^{\circ} \mathrm{C}$., after which it is rather slower; at temperatures of $1400^{\circ} \mathrm{C}$. to $1600^{\circ} \mathrm{C}$. it is as high as that of aqueous solutions of corresponding salts. This behaviour implies that at the highest temperature reached in rotary kilns, cement clinker is completely dissociated into its separate ions, though the constitution of these ions has not yet been ascertained.

If Asch's theory (p. 55) is correct, these ions would be $\mathrm{Ca}$ and $6 \mathrm{Al}_{2} \mathrm{O}_{3} 12 \mathrm{SiO}_{2}$. No other published theory explains in a simple manner what ions are produced by this dissociation.

Each of the lines of investigation mentioned above is important and neither is reliable without the others, yet so difficult is the study of cements and so great is the influence of the theories of the earlier investigators that, in spite of the enormous amount of evidence available, it is difficult to reach conclusions which will be accepted by all chemists interested in cements.

Thus, a microscopic examination of a thin section of clinker, c, 
or preferably a similar study of a piece of first-class clinker which has been polished and then etched with very dilute acid or water, shows that such clinker is chiefly composed of a single crystalline constituent, the particles of which are separated by a much smaller quantity of other material. Clinker from a rotary kiln usually contains less intercrystalline matter than that obtained from stationary kilns, as the burning is more efficient in the former. As the crystals of the principal constituent form so large a proportion of the whole material

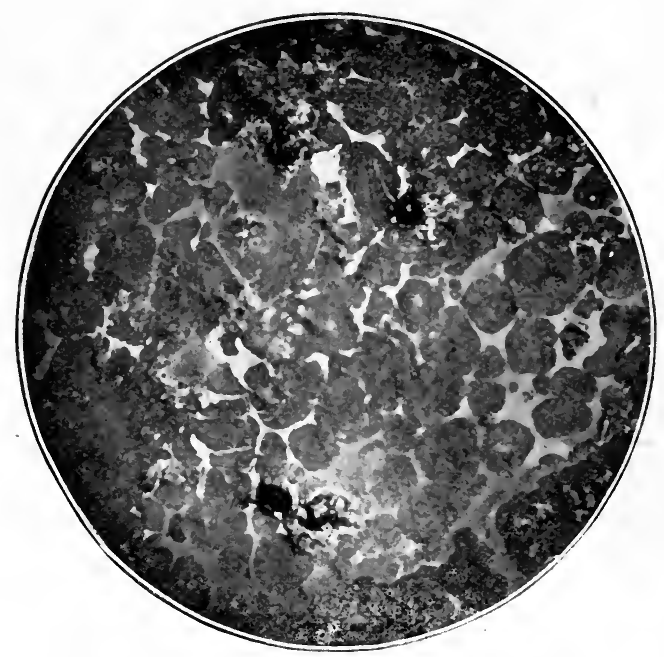

FIG. 5.-Cement Clinker $\times 180$ diams. ${ }^{1}$

(Lightly etched with very dilute hydrochloric acid.)

in really well-made clinker, it is not unreasonable to suppose that these crystals represent the really essential constituent, and that the remaining materials are of an entirely adventitious character and are due to impurities in the raw materials or to imperfections in the processes of manufacture.

Le Chatelier and Törnebohm were among the first investigators to use the microscope in investigating the nature of cement clinker in the manner described above. They observed four different kinds of crystals, for which Törnebohm proposed the names alite, belite, celite and felite, respectively. By far the most important of these are alite and celite, particularly the former, which constitutes the principal portion of the material, the celite (with occasionally a little belite and felite) forming a filling material or matrix between the grains of alite. 
Belite resembles alite in some respects, but is a dirty green colour, is characteristically striated, and gives brilliant interference colours. It has never been isolated in a crystalline form nor in a state sufficiently pure for analysis, but is generally understood to be calcium ortho-silicate, $2 \mathrm{CaOSiO}_{2}$.

Calcium ortho-silicate, prepared synthetically by heating a mixture of lime and silica in equivalent proportions to $1150^{\circ} \mathrm{C}$., melts at $2074^{\circ} \mathrm{C}$. It is almost devoid of hydraulicity and rapidly falls to powder on exposure to air. According to Day and Shepherd, there are three calcium ortho-silicates, depending on the temperature of the material, the $\alpha$-form, which crystallises in monoclinic prisms with a hardness of 5 to 6 on Moh's scale and is only stable above $1410^{\circ} \mathrm{C}$.; the $\beta$-form, which is produced when the $\alpha$-form is cooled from $1410^{\circ} \mathrm{C}$. to about $675^{\circ} \mathrm{C}$., and is ortho-rhombic with a specific gravity of $3 \cdot 27$; and the $\gamma$-form, which is produced by cooling to temperatures below $675^{\circ} \mathrm{C}$. The $\gamma$-form has a specific gravity of $2 \cdot 97$, so that its formation is accompanied by an increase in volume which accounts for the material disintegrating as the rapidlycooled $\alpha$-form is slowly converted into the $\beta$-ortho-silicate.

Various attempts have been made to explain the difference between the slowly cooled, or $\gamma$-ortho-silicate, and the hydraulic, or $a$-ortho-silicate, obtained by suddenly quenching the molten mass, by representing them as of different molecular arrangements. Such attempts are, however, founded on data which are far too slight to justify the use of different structural formulæ.

It should be observed that the calcium ortho-silicates obtained by Day and Shepherd were produced by heating mixtures of lime and silica to complete fusion and then allowing the molten mass to cool to various temperatures. Slags are subjected to this treatment, so that the work of these investigators is valuable when applied to slags; but in the manufacture of other cements complete fusion is never reached, and the conditions are so entirely different as not to warrant the application of these investigations to Portland cement (p. 49).

Celite is recognised by its deep brownish-orange colour. It is of lower fusing point than alite and gives brilliant colours when examined between crossed nicol prisms. Richardson 
claims to have identified celite with dicalcium aluminate $\left(2 \mathrm{CaOAl}_{2} \mathrm{O}_{3}\right)$ in solution in dicalcium silicate $\left.(2 \mathrm{CaOSiO})_{2}\right)$.

Celite has never been isolated and examined apart from the other constituents of cement. Its composition is, therefore, entirely problematical, and definite statements with regard to it should be accepted with reserve.

Felite forms colourless rhombic crystals in some partially decomposed blast-furnace slags, but is by no means common. Its composition is not accurately known, though Kappen and others believe it to be a non-hydraulic form of calcium orthosilicate. Some chemists maintain that it is a magnesium orthosilicate, or a double silicate of magnesium and calcium.

Alite crystals belong to the rhombic system, and tend to assume hexagonal forms, but their properties are by no means clearly established. C. Richardson claims to have identified alite as a solid solution of tricalcium aluminate $\left(3 \mathrm{CaOAl} \mathrm{O}_{3}\right)$ in tricalcium silicate $(3 \mathrm{CaOSiO})_{2}$. Such a solid solution cannot exist in the form of such definite crystals as those generally recognised as alite. Le Chatelier has found that certain grappiers (p. 34) consist almost entirely of alite, and contain :-

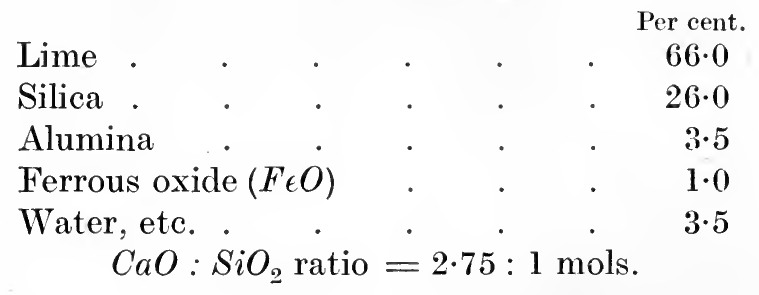

This is, however, far too low in alumina to be comparable to the best Portland cement.

Le Chatelier regarded the alumina and water in cement as impurities, and concentrated his attention exclusively on the lime and silica present. He therefore endeavoured to prepare a synthetic cement in which the ratio of $\mathrm{CaO}: \mathrm{SiO}_{2}=3: 1$, on the assumption that the lower ratio, $2 \cdot 75: 1$, in grappiers and in some of the best Portland cement is due to impurities. He found that a calcined mixture containing lime and silica in the proportion of 3 molecules to $1(3 \mathrm{CaOSiO})$ remained 
constant in volume on setting, but hardened remarkably slowly. The brothers Newberry confirmed this, and showed that with even a slight excess of lime $\left(3 \frac{1}{2} \mathrm{CaO}\right.$. $\left.\mathrm{SiO}_{2}\right)$ the product did not form a sound cement, but cracked when kept under water. Le Chatelier also found that commercial cements with only sufficient lime to correspond to a ratio of $2.5 \mathrm{CaOSiO}_{2}$ were inferior in strength, liable to disintegrate and deficient in alite.

Nevertheless, the evidence is almost conclusive against the existence of $3 \mathrm{CaOSiO}_{2}$ in notable quantity in cements, or even of the possibility of its formation by heating pure lime and silica in suitable proportions. Day, Shepherd and Wright.have found that specimens which were thought to be the synthetic trisilicate were really composed of an intimate mixture of lime and calcium ortho-silicate crystals, which may easily be mistaken for a homogeneous substance.

Some chemists have suggested that the microscopical appearance of alite crystals implies that profound modifications have been induced in consequence of the presence of adventitious substances in the cement, as a result of which the $3 \mathrm{CaOSiO}_{2}$ has been rendered stable. Such a supposition is purely speculative and unnecessary. The repeated unsuccessful attempts by such competent authorities as Le Chatelier and others to produce a really satisfactory cement from pure lime and silica indicate that some constituent other than lime and silica is essential. The clearly recognisable differences between cements made from basic slag and limestone and those made from clay and limestone also indicate that the particular state of combination, or the existence in the free state, of the alumina and silica present is of great importance as regards the structure of the resultant cement. The constancy of the ratio $\mathrm{CaO}: \mathrm{SiO}_{2}=3: 1$ appears to be merely a coincidence and not to indicate the whole of the facts, for this ratio would be the same in a compound with the formula $3 x \mathrm{CaO} \cdot y \mathrm{Al}_{2} \mathrm{O}_{3}$. $x \mathrm{SiO}_{2}$, but the properties of such a compound would be entirely different from those of $3 x \mathrm{CaO} . x \mathrm{SiO}_{2}$ on account of the alumina present. It is precisely because investigators have been obsessed with the idea of the existence of $3 \mathrm{CaO} . \mathrm{SiO}_{2}$ in cements that most of them have overlooked the possible existence of 
calcium alumino-silicates, whilst most of those who have recognised the possibility of such triple compounds have not pursued their researches far enough to prove their case. It is one of the curiosities of modern chemistry that so many investigators have so willingly accepted statements as to the existence of certain silicates and aluminates in spite of the fact that these substances cannot be prepared under conditions met with in the manufacture of cements. Yet these considerations have been almost entirely overlooked by those engaged in investigations of the chemical constituents of cements.

Thus, to account for the presence of alumina in all satisfactory cements, various investigators have prepared calcium aluminates corresponding to the ratio $2 \mathrm{CaO} . \mathrm{Al}_{2} \mathrm{O}_{3}$, and finding that these set very rapidiy, producing cements of constant volume when set and of good hardening properties, they at once assumed that such binary aluminates are present in Portland cement in simple admixture with the alite already mentioned. Unfortunately, no one has yet been able to isolate such calcium aluminates in appreciable quantities from commercially valuable cements, and as calcium aluminates, when pure, turn an alcoholic solution of phenolphthalein red, their presence in Portland cement would be readily detected by this indicator. Well made and freshly burned Portland cements do not, however, produce any colour with this solution, so that it is improbable that free calcium aluminates occur in these cements. Thus, although the theory that cements are composed of simple mixtures of substances, such as $3 \mathrm{CaO} . \mathrm{SiO}_{2}$ and $2 \mathrm{CaO} . \mathrm{Al}_{2} \mathrm{O}_{3}$, is in some respects simple and convenient, its disadvantages are very great.

Some of the largest alite crystals yet obtained were produced by Schmidt and Unger by heating Portland cement to complete fusion in an electric arc. The whole mass became crystalline on cooling, and consisted of a largely preponderating proportion of crystals all of one kind, together with a microcrystalline aggregate of a different substance, possibly celite, but more probably a heterogeneous mixture of crystals containing all the "impurities" in the cement. The largest and most perfect crystals proved to be identical in physical characters with alite. On analysis they were found to contain :- 
Lime .

Silica

Alumina

Ferrous oxide

Magnesia

Water, etc.
$67 \cdot 43$ per cent.

$23 \cdot 43$

$3 \cdot 78$

$2 \cdot 32$

$2 \cdot 44$

$0 \cdot 60$

These results agree sufficiently closely with those found by Le Chatelier (p. 52), but are lower in alumina than are the best Portland cements.

W. and D. Asch have shown that, in all probability, there is no single substance-alite-which is the essential constituent of all Portland cements, but that these materials contain one or more calcium alumino-silicates of a highly complex structural composition. They consider that Portland cements are basic salts of these aluminosilicic acids, and that they consist of a series of hexagonally or pentagonally arranged groups of silicon and aluminium atoms to which are attached a number of side chains, the latter containing the greater part of the base.

In Great Britain, the clays and shales generally used for cement-making are highly siliceous, and probably have a constitution corresponding to $(a) \mathrm{H}_{18} \mathrm{Al}_{6} \mathrm{Si}_{12} \mathrm{O}_{42}$, or $(b) \mathrm{H}_{18} \mathrm{Al}_{6} \mathrm{Si}_{15} \mathrm{O}_{48}$, though other types are possible. In accordance with Asch's theory these typical clays have the following constitutional formulæ ${ }^{1}:-$

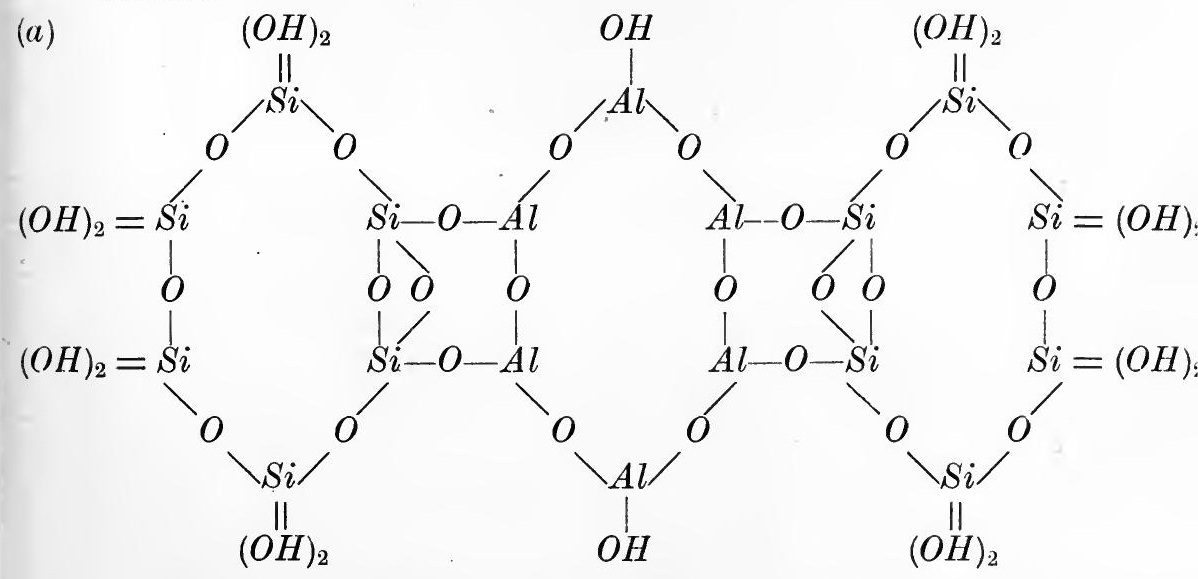

1 The lime, magnesia and alkalies present in the clays replace equivalent hydroxyl $(O H)$ groups and the iron compounds as described on p. 74, kut for clearness the formulæ shown are those for pure clays of the same type. 
56 CHEMICAL AND PHYSICAL CHANGES IN CEMENTS

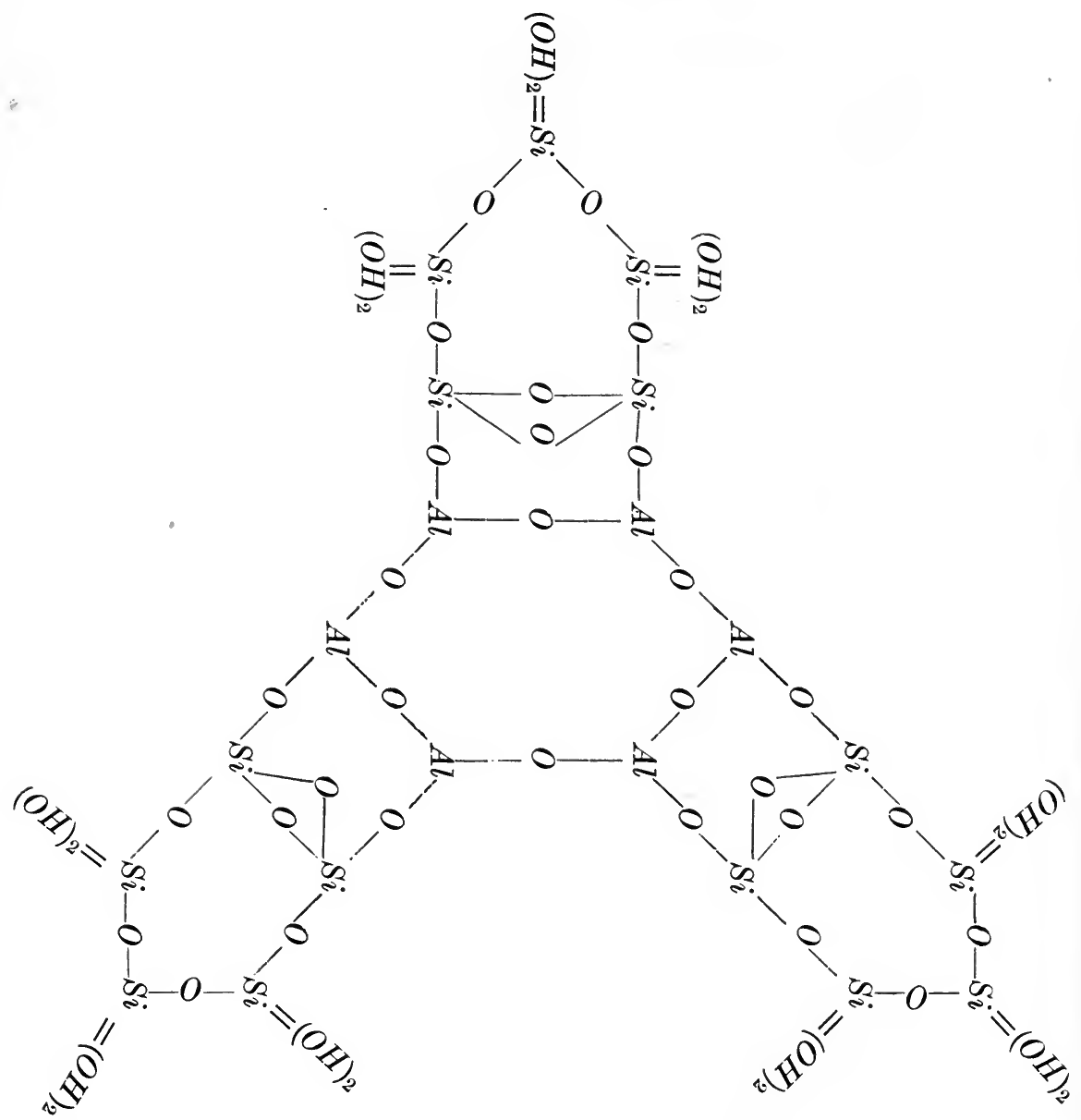

These may be represented more simply, as

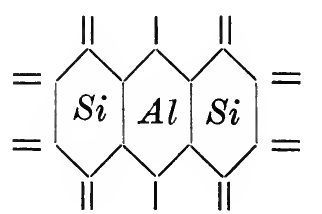

(a)

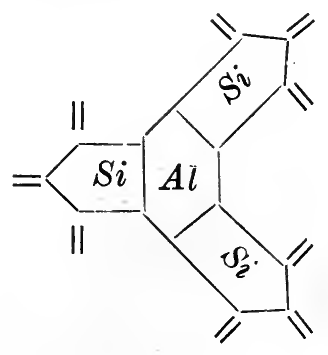

(b) 
On heating with lime, combination occurs which, in the case of formula $(a)$, may be represented by the following equation :-

$$
\mathrm{H}_{18} \mathrm{Al}_{6} \mathrm{Si}_{12} \mathrm{O}_{42}+38 \mathrm{CaO}=\mathrm{H}_{2} \mathrm{Ca}_{38} \mathrm{Al}_{6} \mathrm{Si}_{12} \mathrm{O}_{72}+8 \mathrm{H}_{2} \mathrm{O}
$$

water being liberated owing to the hydroxyl $(\mathrm{OH})$ groups which give the clay its acid character being replaced by basic groups and forming a cement with the structural formula on p. 58, which may be represented in an abbreviated form by :-

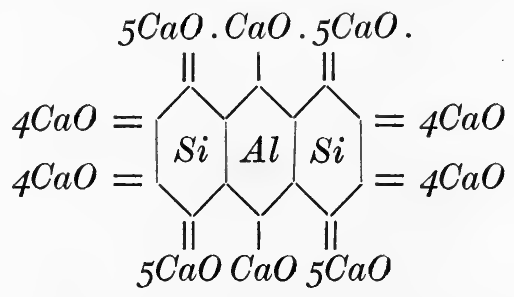

Clays of type $(b)$ form cements with formulæ similar to the second one on p. 59.

According to this theory, there is an extremely large number of calcium alumino-silicates of very similar percentage composition, yet having noticeably different chemical structures. This number is indefinitely increased by the presence of magnesia, potash, soda and iron oxide in the raw materials from which cements are made, these oxides forming still more complex groupirgs around the central hexagon or pentagon rings. Any potash or soda present may replace part or all of the $\mathrm{CaO}$ attached to the $A l$-ring; any magnesia will usually replace one or more of the $\mathrm{CaO}$ molecules at the sides of the formula. These complications have, however, been omitted for the sake of clearness.

The following are typical examples of Portland cements :-

(2) (2) $O K(2)(2)$

$$
\begin{aligned}
& =2 \mathrm{H}_{2} \mathrm{O} .31 \mathrm{CaO} \cdot \mathrm{MgO} \cdot \frac{1}{2}\left(\mathrm{~K}_{2} \mathrm{O} \cdot \mathrm{Na}_{2} \mathrm{O}\right) .3 \mathrm{Al}_{2} \mathrm{O}_{3} .12 \mathrm{SiO}_{2} .
\end{aligned}
$$


58 CHEMICAL AND PHYSICAL CHANGES IN CEMENTS

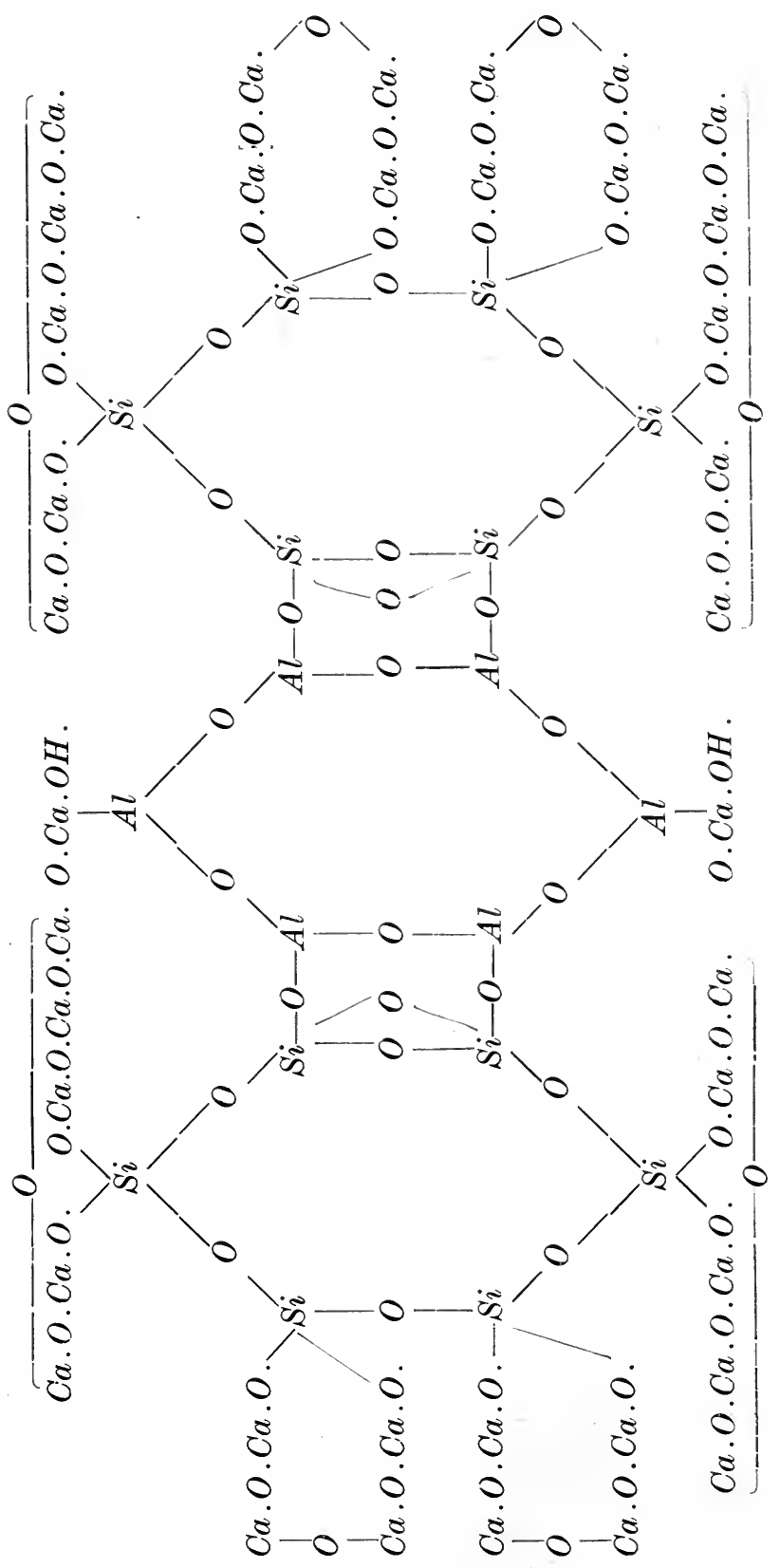




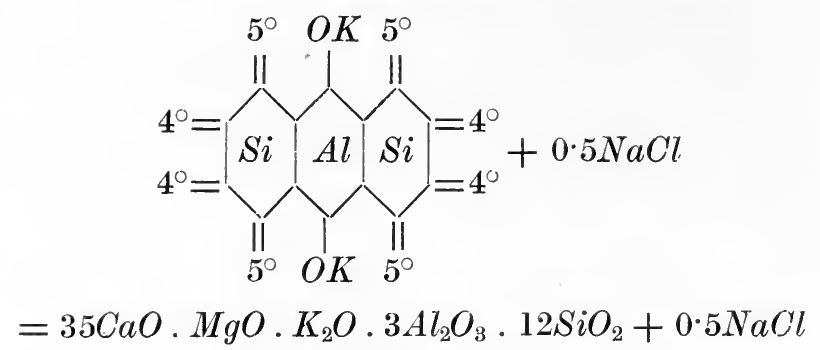

where each hexagonal ring represents $6 \mathrm{SiO}_{2}$ or $3 \mathrm{Al}_{2} \mathrm{O}_{3}$, and the numbers indicate the corresponding number of molecules of $\mathrm{CaO}$ or $\mathrm{MgO}$ which have replaced $\mathrm{OH}$ groups in the clay. A somewhat different type of cement is

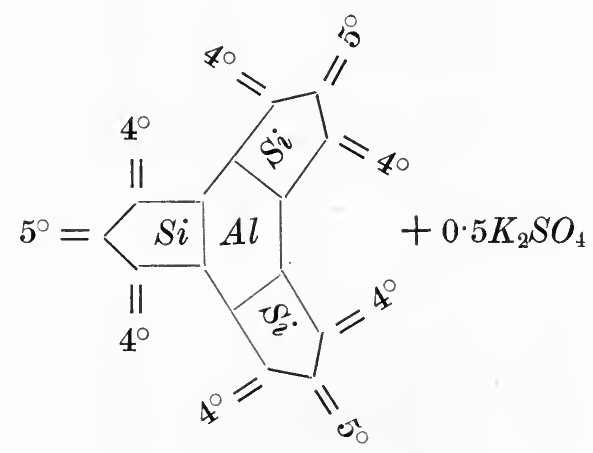

$$
39 \mathrm{CaO} \cdot 3 \mathrm{Al}_{2} \mathrm{O}_{3} \cdot 15 \mathrm{SiO}_{2}+0 \cdot 5 \mathrm{~K}_{2} \mathrm{SO}_{4}
$$

in which the hexagonal ring represents $3 \mathrm{Al}_{2} \mathrm{O}_{3}$ and each pentagon represents $5 \mathrm{SiO}_{2}$, the numbers having the same meaning as before.

If this theory is correct, what occurs when a mixture of clay and calcium carbonate is heated under the conditions usual in the manufacture of Portland cement is that the hydroxyl groups attached to the silicon atoms in the clay are replaced by anhydrobasic groups derived from the lime. This implies that on heating clays the molecule is not broken up into its constituent oxides, but that a single compound is formed (p. 4l), or the material is dissociated into its respective 
ions. These ions may, at a later stage in the use of the cement, re-act as though a single compound was present. The loss of resistance to, or conversely the increase of conductivity of, electricity suffered by the raw materials in the manufacture of Portland cements is shown in Fig. 6, which represents the results obtained by E. Dittler and K. Herold on (1) a dry marl, (2) another dry marl, (3) a cement mix of chalk and marl made by the dry method, (4) a cement mix of limestone and clay

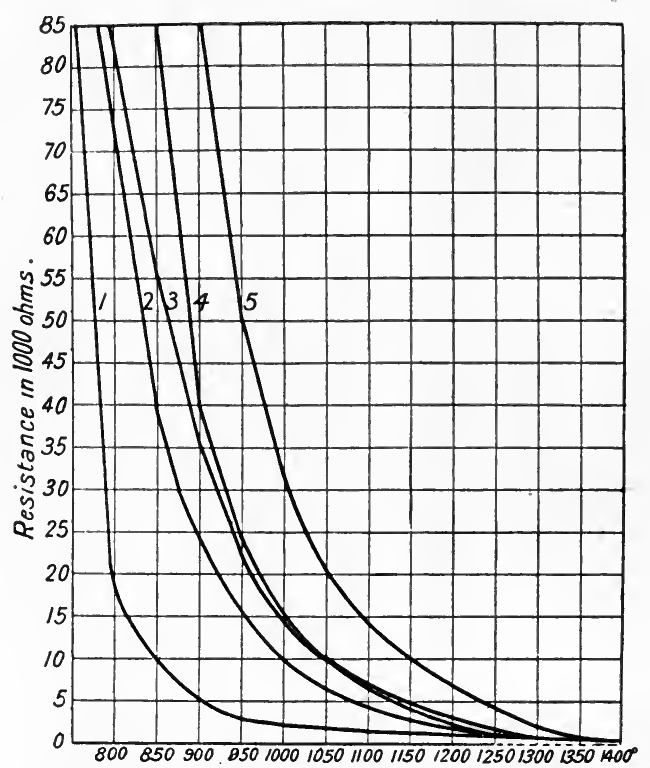

F'IG. 6.-Electrical Conductivity of Raw Cement Mixes. made by the wet method, and (5) a mixture of pure calcium carbonate and kaolin (china clay). The general similarity of the curves is very striking, and it appears highly probable that the differences observable - which are greatest at the lower temperatures - are chiefly due to the variations in the composition of the materials rather than to any differences in the reactions which occur.

E. Dittler and L. Jesser (Zentr. Chem. Anal. Hydraul. Zemente, 1910, pp. 71-78) have found that the electrical conductivity increases gradually until a temperature of about $1375^{\circ} \mathrm{C}$. is reached, when there is a break in the graph representing it accompanied by an endothermic reaction and slight fusion, and when the temperature reaches 1425 to $1450^{\circ} \mathrm{C}$. an exothermic reaction occurs suddenly with the immediate formation of crystals of alite (?) with a little celite. The change in conductivity and formation of the alite (?) is shown in Fig. 7, which is the resistance graph of a clay-limestone 
cement maintained for three hours at a temperature of $1430^{\circ} \mathrm{C}$.

Such a break in the conductivity curve of many minerals is well known to coincide with their melting points, and clearly points to the formation of a crystalline compound of definite composition and with a sharply marked melting point of $1425^{\circ} \mathrm{C}$. This result is in complete opposition to the view that cements are composed of a mixture of tricalcium silicate and dicalcium aluminate, and shows that a cement clinker is a definite chemical individual and not a solid solution of two or more substances. In this respect it confirms Asch's theory that the chief constituent of cements is a definite calcium alumino-silicate.

If alite has the definite composition such as those assigned to the $\mathrm{ch}$ i e f con-

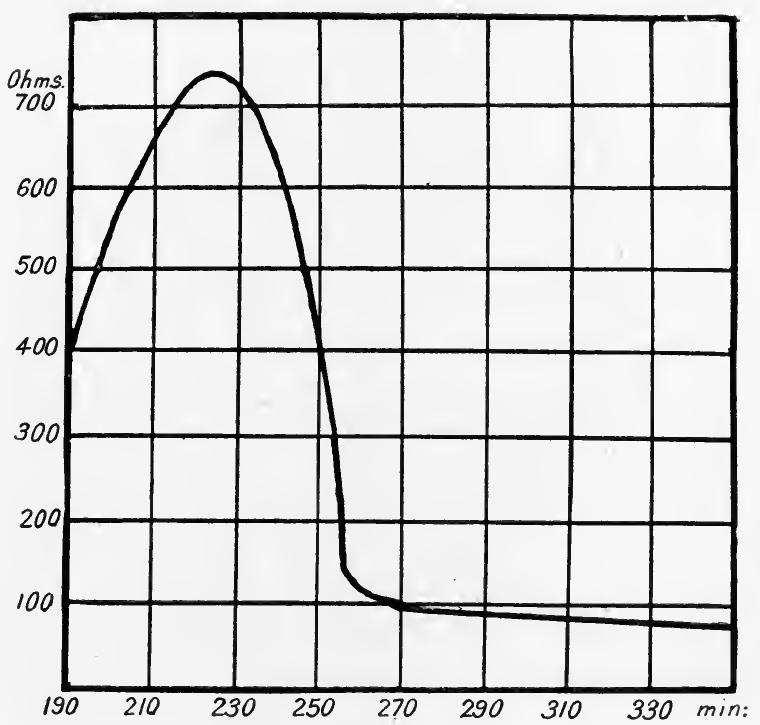

FIG. 7.-Electrical Conductivity of Clay-lime Mixture.

stituent in cements by W. and D. Asch-and there seems little reason to doubt that its composition is quite definite for any given cement, whatever may be the arrangement of the atoms within the molecule-it is clear that the best qualities of cement will be those in which the composition most closely resembles that of the particular alumino-silicate (alite ?) present in the largest proportion. It has long been recognised that very small variations in the percentage of lime cause serious differences in the strength and properties of the cement, and that the limits of composition of the mixture of 
raw materials are very narrow. In endeavouring to obtain some simple guide of the limits of composition of cements, it has been customary to follow Le Chatelier's assumption that Portland cements are composed of $3 \mathrm{CaOSiO}_{2}$ and $3 \mathrm{CaOAl}_{2} \mathrm{O}_{3}$ and Newberry's assumption that they are composed of $3 \mathrm{CaOSiO}_{2}$ and $2 \mathrm{CaOAl}_{2} \mathrm{O}_{3}$. On these assumptions a cement will consist of $a$ molecules of $3 \mathrm{CaOSiO}_{2}$, and $b$ molecules of either $3 \mathrm{CaOAl}_{2} \mathrm{O}_{3}$ or $2 \mathrm{CaOAl}_{2} \mathrm{O}_{3}$. From this it follows that the ratio between the lime and (silica + alumina) in cements should remain constant, and the ideal proportion of these oxides would then be-

(1) according to Le Chatelier :

$$
\frac{\text { molecules } \mathrm{CaO}}{\text { molecules } \mathrm{SiO}_{2}^{-}+\text {molecules } \mathrm{Al}_{2} \mathrm{O}_{3}}=3
$$

(2) according to Newberry :

$$
\frac{3 a+2 b \text { molecules } \mathrm{CaO}}{a \text { molecules } \mathrm{SiO}_{2}+b \text { molecules } \mathrm{Al}_{2} \mathrm{O}_{3}}=3
$$

In spite of the fact that $3 \mathrm{CaOAl} l_{2} \mathrm{O}_{3}$ has not been proved to exist in cements and that the constant 3 is too high, the equation suggested by Newberry has not been adopted, and Le Chatelier's is still regarded in many quarters as indicating the maximum proportion of lime which can exist in a sound cement. In the British standard specification for Portland cement a somewhat lower constant is given, viz. :-

$$
\frac{\text { molecules } \mathrm{CaO}}{\text { molecules } \mathrm{SiO}_{2}+\text { molecules } \mathrm{Al}_{2} \mathrm{O}_{3}}=2 \cdot 85
$$

This demands a somewhat lower lime content than that suggested by Le Chatelier.

Where the use of molecular equivalents is inconvenient, the limit is expressed as

$$
\% \text { lime }=2.8 \times \% \text { silica }+1 \cdot 1 \times \% \text { alumina }
$$

The exact proportion of lime which can be used will depend on the care and skill used in the manufacture of the cement. If the raw materials are extremely finely ground, thoroughly mixed and properly burned, a higher proportion of lime may be 
present than in a less skilfully prepared cement. The larger the proportion of lime present, combined as alumino-silicate,

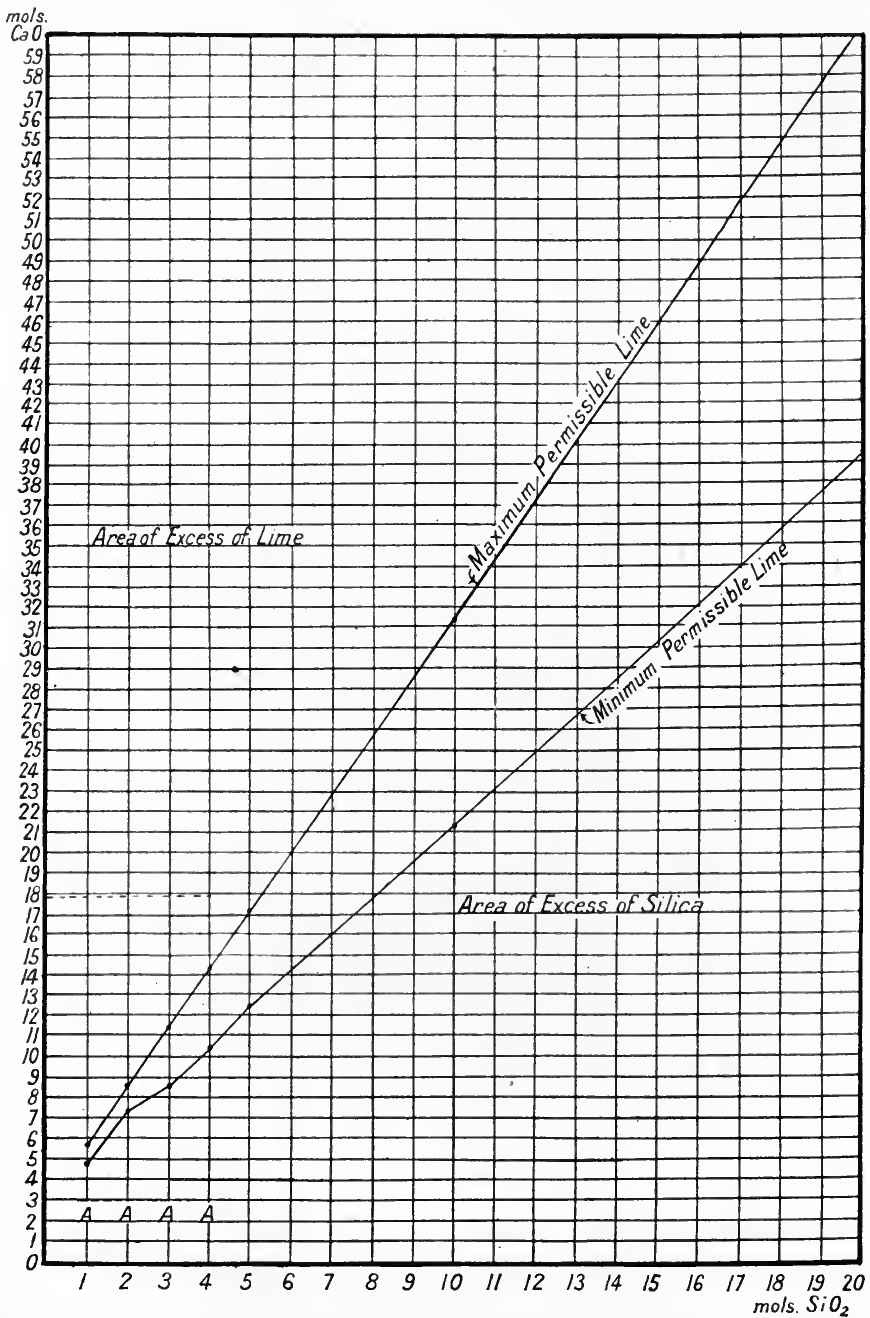

FIg. 8.-Empirical Limits of Composition of Portland Cements. the stronger will be the cement. Lime in other forms is less valuable, and uncombined or free lime is dangerous.

As the proportions of lime, silica and alumina all vary in different samples of commercial cement, it is convenient, 
in classifying samples, to express the proportions in molecular equivalents, the number of molecules of alumina being taken as unity, thus-

$$
14 \mathrm{CaO} \cdot \mathrm{Al}_{2} \mathrm{O}_{3} \cdot 4 \mathrm{SiO}_{2} \text {. }
$$

In this way. one of the three variables is removed and the remaining two may be plotted on a chart as ordinates and abscissæ, respectively. Thus, accepting the limits in the British standard specification given above, the molecular ratio of each of the oxides is-

$$
\begin{array}{r}
2.85(a+b) \text { molecules } \mathrm{CaO} \\
a \text { molecules } \mathrm{SiO}_{2} \\
b \text { molecules } \mathrm{Al}_{2} \mathrm{O}_{3}
\end{array}
$$

and by taking $b=1$, the maximum permissible limit of lime $=$ $2 \cdot 85(a+1)$ molecules to each $a$ molecules of silica and 1 molecule of alumina. The disadvantages of assuming the existence of $3 \mathrm{CaOSiO}_{2}$ and $2 \mathrm{CaOAl}_{2} \mathrm{O}_{3}$ in cements are, in this way, avoided, and the influence of each of the constituent oxides is most easily perceived. Fig. 8 is a chart of this kind, based on the ratios

$$
x \mathrm{CaO} y \mathrm{SiO}_{2} \mathrm{1} \cdot 00 \mathrm{Al}_{2} \mathrm{O}_{3}
$$

in which the various values of $x$ are plotted on the ordinate and those of $y$ on the abscissæ. The value for alumina being made constant it does not require to be plotted. In order to show the limits within which commercially useful cements lie, the curve giving the maximum limits for lime recognised by the British standard specification based on the ratios

$$
2 \cdot 85(a+1) \mathrm{CaO}, \mathrm{aSiO}_{2}, 1 \cdot 00 \mathrm{Al}_{2} \mathrm{O}_{3}
$$

is shown. The lowest proportions of lime generally recognised as permissible is that given in the hydraulic modulus, a term introduced by W. Michaelis, and adopted in the German standard specification.

Hydraulic Modulus $=\frac{\% \text { lime }}{\% \text { silica }+\% \text { alumina }+\% \text { ferric oxide }}$

German experience has shown that the hydraulic modulus should never be less than 1.7. In any case, the hydraulic 
modulus is not alone sufficient for determining the proportions of each of the ingredients used in making Portland cement.

The foregoing limits are too wide in some respects, for it is well known that a variation of 2 per cent. in the proportion of calcium carbonate in the slurry or mixture before it enters the kiln will make all the difference between a sound and an unsound cement. The limits mentioned, and shown in Fig. 8, must, therefore, be regarded as purely approximate, and as of academic rather than empiric value.

In connection with this diagram it is interesting to note that according to Asch's theory all cements should lie on one of the four vertical lines marked $A$. The height above the base line at which they should be placed depends on the lime-content, which-according to the same theory - may vary within limits similar to those indicated by the dotted lines on the chart, i.e., between three and eighteen molecules of lime.

The commercial limits of composition usually recognised are somewhat larger than those corresponding to Asch's theory. This is due to the impurities in the materials used commercially.

In the limiting formulæ mentioned on pp. 62-64, no definite ratio between the silica and alumina is stated, yet this is of great importance, as cement rich in silica is deemed superior to that deficient in it. Moreover, cement mixtures low in silica when burned in rotary kilns cause the formation of adherent rings of clinker which choke the kiln. O. Dormann has found that the best cements are obtained commercially when the limits are $\mathrm{R}_{2} \mathrm{O}_{3}: \mathrm{SiO}_{2}=1: 2.5$ to 3.0 expressed in absolute weight, or 1 molecule $\mathrm{Al}_{2} \mathrm{O}_{3}$ to each $4 \cdot 25$ to $5 \cdot 1$ molecules $\mathrm{SiO}_{2}$, and a study of numerous published analyses of German, American and British cements confirms this ratio, very few high-class cements with an $\mathrm{Al}_{2} \mathrm{O}_{3}: \mathrm{SiO}_{2}$ ratio lower than 3.66 (molecules) having been found. According to the theory of the constitution of cements given on pp. $55-59$ the $\mathrm{Al}_{2} \mathrm{O}_{3}: \mathrm{SiO}_{2}$ ratio should be definitely 4 or 5 (molecules).

In the chart shown on p. 63, the minimum values of lime are made to include an allowance for the iron oxide by assuming that it is equivalent to that of the alumina present.

The lines on the chart show the relatively narrow range of composition permissible in cements, but it must not be for-

c. 
gotten that they are not defined with absolute accuracy, and future investigations into the constitution of cements may result in an even narrower limit of composition being imposed. The assumptions on which they are based are by no means free from objection; thus, it is not by any means correct to add together the percentages of alumina, ferric oxide and silica as is done in the formula for the hydraulic modulus, though, in the ordinary manufacture of cement, variations in the proportion of alumina and iron are sufficiently small to permit such formulæ to be conveniently used in spite of their theoretical inaccuracies. For the same reasons the lines on the chart cannot rightly be extended very far beyond the positions shown, as it has been found that cements containing a ratio of only 2.5 molecules of lime to 1 molecule of silica are unsound.

\section{Chemical Reactions between Silica and Lime.}

Owing to the proportion of free silica in the raw materials and the possible decomposition of the clay into a mixture of free silica and alumina, there is always some free silica present in the contents of the cement kiln during an early stage of the heating.

As well-made Portland cements leave only an insignificant proportion of insoluble matter when treated with hydrochloric acid, the study of the silicates present is simplified by the exclusion of all possible silicates which are insoluble in this acid. For this reason, synthetic experiments in which the substances actually present in the raw materials used (or supposed to be produced by the direct action of heat on these materials) are heated in groups of twos and threes, are of the utmost importance. The products obtained from pure materials can be examined with accuracy and without the disturbing factors present when less pure materials are used. Experimenting in this manner, J. W. Cobb has found that on heating a mixture of limestone or chalk and finely powdered quartz, a reaction occurs at $800^{\circ} \mathrm{C}$. (i.e., at or below the temperature at which free lime is formed), and the combination of the lime and silica takes place with increasing rapidity as the temperature is raised, a soluble silicate being formed. At 
temperatures below $1250^{\circ} \mathrm{C}$. no fusion is observable, though the formation of the soluble silicate $\mathrm{CaOSiO}_{2}$ is quite definite. At $1400^{\circ} \mathrm{C}$. (or just below the highest temperature in a rotary kiln) the formation of calcium mono-silicate is practically complete. Any calcium sulphate present is also decomposed by the silica, calcium mono-silicate being formed at temperatures above $1005^{\circ} \mathrm{C}$.

Cobb also found that if sufficient silica is present, the proportion of silica and lime has no influence on the result, and that the compound $\mathrm{CaOSiO}_{2}$ is invariably formed. When the original mixture contained the materials in the ratio $3 \mathrm{CaO}+$ $\mathrm{SiO}_{2}$ he observed the formation of a more basic silicate $\left(2 \mathrm{CaO} . \mathrm{SiO}_{2}\right)$ at first, and that this persists in the presence of sufficient lime; otherwise $\mathrm{CaO} . \mathrm{SiO}_{2}$ is formed. Under no circumstances could Cobb produce a calcium silicate containing more lime than $2 \mathrm{CaOSiO}_{2}$.

The apparent impossibility of producing a compound corresponding to $3 \mathrm{CaOSiO}$ makes it very difficult to accept the largely-held view that Portland cements contain a large proportion of this substance. As already indicated, in such a view the alumina present in cements is overlooked, or is, at least, regarded as forming entirely different compounds.

So far as cements are concerned, it appears improbable that more than an insignificant proportion of any calcium silicate as basic as, or more basic than, $2 \mathrm{CaOSiO}_{2}$ can be present, and that such reactions as may occur between free lime and free silica in the cement must finally result in the formation of calcium mono-silicate $\left(\mathrm{CaOSiO}_{2}\right)$ : The fact discovered by Boudouard, that $\mathrm{CaOSiO}_{2}$ corresponds to the most fusible mixture producible from lime and silica alone, implies that this substance, if present; forms part of the inter-crystalline material observable in all Portland cements, and as it is devoid of hydraulic properties it is of no value in cements.

Calcium ortho-silicate $2 \mathrm{CaOSiO}_{2}$ is present in cements and slags not containing sufficient silica, or which have not been heated sufficiently long to form the meta-silicate $\mathrm{CaOSiO}_{2}$. The ortho-silicate is described under the term belite (p. 51).

Many chemists interested in cements have attached great importance to the investigations of Shepherd, Day, Rankine. 
Wright and others on the products formed by fusing binary mixtures of lime and silica, or lime and alumina, and ternary mixtures of lime, alumina and silica, and allowing the fused mass to cool slowly. Under such conditions various crystalline substances are found in the mass produced, the most important being -in the case of lime-silica mixtures- $\alpha, \beta$ and $\gamma$ $\mathrm{Ca}_{2} \mathrm{SiO}_{4}, \alpha$ and $\beta \mathrm{CaSiO}_{3}$, tridymite, quartz and free lime. In burning cements, however, complete fusion of the mass is never reached, and the products formed in a mixture which has only been partially fused are not the same as those produced in a completely fused mass of the same original composition. For this reason the application of the work of the abovementioned investigators to the constitution of sement clinker is somewhat misplaced. Indeed, no less an authority than C. Doelter (Zeitsch. f. Elektro Chem., Bd. 17 (1911), p. 795) has reached the conclusion that "the application of the phase rule to fused mixtures of silicate components is erroneous," and that such substances " must not be treated as metallic alloys, as this leads to erroneous conclusions which only increase the difficulties experienced in the application of physical chemistry to mineralogical problems." Doelter has also shown, experimentally, that silicate mixtures when heated above their melting point produce quite different substances from those which are formed when no over-heating has occurred. The study of such completely fused mixtures is, therefore, of little value in studying the constitution of cements, and is most likely, as Doelter suggests, to lead to false conclusions.

The size of the grains of free silica has an important influence on the reaction. O. Dormann has found that unless the free silica is fine enough not to leave a residue of more than 20 per cent. on a No. 180 sieve, a considerable part of it will remain uncombined.

Experience shows that, within certain limits, cements with a high proportion of silica are stronger than others, the ultimate strength increasing approximately with the percentage of silica. This is usually attributed to the larger proportion of tri-calcium silicate in such cements, but, in view of the doubts as to the existence of tri-calcium silicate in cements, a more probable explanation is that, within the limits indicated, the 
ultimate strength really depends on the nature as well as on the amount of alumino-silicate formed.

An increase in the percentage of silica in a cement will usually be accompanied by a decrease in the alumina and a reduction in the speed of setting of the cement. This is apparently due to the smaller proportion of the aluminosilicate, which is the essential constituent of the cement, and to the correspondingly larger proportion of inert matter present.

\section{Chemical Reactions between Lime and Alumina.}

It is by no means certain that the contents of a cement kiln ever contain an appreciable amount of free alumina, though it may possibly be produced by the direct action of heat on clay. Such free alumina as does occur may enter into combination with both lime and silica, forming an alumino-silicate, or it may combine solely with lime to form one of two calcium aluminates, $\mathrm{CaOAl}_{2} \mathrm{O}_{3}$ or $\mathrm{CaO} 2 \mathrm{Al}_{2} \mathrm{O}_{3}$, both of which are soluble (with decomposition) in hydrochloric acid.

The reaction between lime and alumina commences (according to $\mathrm{J} . \mathrm{W}$. Cobb) at $850^{\circ} \mathrm{C}$, occurs rapidly at $1100^{\circ} \mathrm{C}$., and is practically complete at $1300^{\circ} \mathrm{C}$. According to the proportion of lime and alumina either $\mathrm{CaOAl}_{2} \mathrm{O}_{3}$ (which is soluble in acid), $2 \mathrm{CaOAl}_{2} \mathrm{O}_{3}$ (which is very slowly soluble) or an insoluble calcium aluminate of unknown composition is produced. Cobb has been unable to produce a calcium aluminate corresponding to $3 \mathrm{CaOAl}_{2} \mathrm{O}_{3}$ and soluble in hydrochloric acid. The $3 \mathrm{CaOAl} \mathrm{O}_{3}$ obtained from molten mixtures at $1531^{\circ} \mathrm{C}$. by Shepherd and others is not produced under conditions existing in cement kilns, and, as already explained (p. 68), it is erroneous to suppose that a substance produced when a completely fused and usually overheated mixture is allowed to cool is necessarily formed when the same raw materials are heated to only partial fusion. Many binary silicates and aluminates possessing hydraulic properties appear to exist, but in all probability a large number of these are incapable of production by the methods at present employed in the manufacture of cements. The tri-calcium aluminate and tri-calcium silicate, so generally 
considered to be essential constituents of cements, both appear to be of this nature. The compound $5 \mathrm{CaO} 3 \mathrm{Al}_{2} \mathrm{O}_{3}$, which melts at $1386^{\circ} \mathrm{C}$., may be present in cements, but has not yet been identified therein.

The importance of such calcium aluminates as may be present depends upon the proportions in which they occur in cements. Those who maintain that cements consist chiefly of a mixture of tri-calcium silicate and tri-calcium aluminate, naturally consider that a large proportion of the latter aluminate must be present, notwithstanding the fact that it has not yet been definitely isolated from commercial cements.

The di-calcium compound $2 \mathrm{CaOAl}_{2} \mathrm{O}_{3}$ prepared by Newberry is a quick-setting hydraulite with constant volume and good hardening properties. If present in a commercial cement it would not affect the quality of the material, though it might increase the rate of setting. Hence, it is generally considered desirable to have the proportion of alumina as low as possible, so as to secure greater ultimate strength and slowness of setting, but it must not be in too small a proportion, or the material will not be properly burned at the temperature ordinarily used.

In other words, if too little alumina is present the amount of alumino-silicate produced will be insufficient to produce a valuable cement, and a mixture of various feeble hydraulites with only a little true cement will be formed. If the composition of cement is represented as $x$ molecules $\mathrm{CaO}$, $\mathrm{SiO}_{2}+y$ molecules $2 \mathrm{CaO}, \mathrm{Al}_{3} \mathrm{O}_{3}$ it is difficult to conceive how the presence of alumina can reduce the temperature at which the cement clinker is formed, because a mixture of di-calcium aluminate and tri-calcium silicate, when heated, does not form a clinker at the temperature reached in cement kilns. The behaviour of a completely fused mixture which has been heated to a much higher temperature and then allowed to cool does not have any bearing on this question, and the almost inevitable conclusion is that the alumina enters into combination with both the lime and silica and produces a definite alumino-silicate, and not a solid solution. It is precisely because this aluminosilicate is an essential constituent of the cement that the percentage of alumina in the raw mixture must not fall below 
a certain limit, the exact value of which has not been definitely ascertained, though it appears to be approximately onetwentieth of the weight of the lime in the cement. If, on the contrary, too large a proportion of alumina is present, the excess above that needed for the alumino-silicate will induce the formation of calcium aluminates, which produce a sticky and adherent clinker of less strength than that formed from alumino-silicate alone. If the $2 \mathrm{CaOAl}_{2} \mathrm{O}_{3}$ theory is held, it is difficult to understand why an increase in the proportion of alumina above one-third of the weight of the silica present should produce a weaker cement than is formed when the normal proportion of alumina is present, as pure di-calcium aluminate forms a stronger cement than pure tri-calcium silicate. The chief evidence against the existence of calcium aluminates in appreciable quantities in commercial cements is (a) the appearance of the latter under the microscope, (b) the fact that the "alite" crystals contain practically all the alumina in the cement, apparently in the form of a compound of lime alumina and silica, and $(c)$ the absence of any colouration when Portland cements, are heated with an alcoholic solution of phenolphthalein, whereas both the synthetical calcium aluminates produce a strong colouration with this indicator.

\section{Chemical Reactions between Lime, Alumina and Silica.}

J. W. Cobb has found that when a ternary mixture of lime, alumina and silica, corresponding to $\mathrm{CaO}+\mathrm{Al}_{2} \mathrm{O}_{3}+10 \mathrm{SiO}_{2}$, is heated to temperatures ordinarily reached in cement manufacture, the reaction begins at $800^{\circ} \mathrm{C}$. and proceeds slowly up to $1300^{\circ} \mathrm{C}$, at which temperature a siliceous mass is produced which is unaffected by hydrochloric acid. A similar mixture, but containing a much larger proportion of lime, corresponding to $9 \mathrm{CaO}+\mathrm{Al}_{2} \mathrm{O}_{3}+3 \mathrm{SiO}_{2}$, and intended to represent Portland cement (though it has at least 3 per cent. more alumina and 3 per cent. less silica than the average cement), forms, at $1250^{\circ} \mathrm{C}$., a product which is soluble in hydrochloric acid, but is not a useful cement and contains much free lime. If it is really a compound it has a 
composition corresponding to $2 \cdot 1 \mathrm{CaO}, 0 \cdot 4 \mathrm{Al}_{2} \mathrm{O}_{3}, \mathrm{SiO}_{2}$. J. W. Cobb inclines to the view that the insoluble products are true ternary compounds, whilst the soluble ones are mixtures of binary silicates and aluminates, though the evidence afforded by his experiments is by no means conclusive on this point.

A further idea of the great complexity of a study of these compounds may be gained from the fact that in the product formed by heating $\mathrm{CaO}+\mathrm{Al}_{2} \mathrm{O}_{3}+10 \mathrm{SiO}_{2}$ the alumina acts as a base and is replaced by $\mathrm{Na}_{2} \mathrm{O}$, but in the analogous product from $\mathrm{Na}_{2} \mathrm{O}+\mathrm{CaO}+10 \mathrm{Al}_{2} \mathrm{O}_{3}$, the alumina acts precisely like silica, i.e., as an acid, the last named compound bearing the most striking resemblance in many of its properties to that from $\mathrm{CaO}+\mathrm{Al}_{2} \mathrm{O}_{3}+10 \mathrm{SiO}_{2}$.

The inter-reactions of other substances in cements are extremely difficult to ascertain. To a large extent the felspathic, micaceous and other complex minerals which may be present, form, either alone or in combination with the lime present, a considerable portion of the amorphous inter-crystalline matter always observable when a polished piece of cement clinker is etched with water and examined under the microscope.

The influence of the small proportions of these various silicates cannot be ascertained with accuracy, as the apparently complex products partake of the nature of viscous glass or slags, and do not readily crystallise in the form of definite compounds. Moreover, attempts to cause the amorphous, glassy matter to crystallise invariably effect changes in its composition, so that an examination of the crystals so formed is of little real value. Cements made some years ago, for which stationary kilns were used, show a considerably higher proportion of insoluble matter and of imperfectly burned material, most of which is inert and useless in the cement. The use of rotary kilns, working at higher temperatures, enables a superior cement with a much smaller proportion of undesirable and inert matter to be produced, facilitates the formation of those compounds which have a hydraulic value, correspondingly reduces the proportion of uncombined oxides and useless products, and increases the rate at which the cement sets.

Some of the oxides stated in analyses as being present in 
cement are of sufficient interest for their reactions to be described briefly.

Magnesia is only present in small quantities in the better class commercial cements, as the use of magnesic materials is prohibited in all official specifications for Portland cement, but larger proportions are present in many natural cements. It combines with alumina and silica in a manner analogous to lime, but there is a great difference of opinion as to the value of magnesic cements. Magnesia needs a much higher kiln temperature than lime in order that it may combine with silica and alumina; hence an excess of it in a cement mixture is undesirable, as it will largely exist in an uncombined state unless an unusually high kiln temperature is employed.

Newberry has found that magnesia up to 20 per cent. produces a satisfactory cement if due care be taken in mixing and burning, and the relatively high proportion of magnesia in many satisfactory natural cements shows that magnesia is not in itself a disadvantage, providing that the cement is properly burned. Therein lies the difficulty.

Tests on cement to which magnesia has been added just previous to gauging, show that magnesia causes expansion, but much less rapidly than in the case of free lime, and the damage effected is correspondingly-less.

Since the failure of a French bridge and a portion of the Aberdeen harbour works, it has been customary to limit the percentage of magnesia compounds to a maximum of 3 per cent. $M g O$.

The lime-magnesia cements differ in several important respects from Portland cements, but are not, at present, of sufficient commercial importance to warrant further description here.

"Alkalies"-chiefly potash and soda silicates and aluminosilicates-are only present to a small extent, as a large proportion of the alkaline oxides are volatilised during the burning when rotary kilns are used, so that when present only in small quantity in the raw mixture they are unimportant. According to Hillebrand the alkalies begin to volatilise before all the sulphur tri-oxide has been expelled, i.e., at a temperature of about $1150^{\circ} \mathrm{C}$. Being very fusible, particularly when mixed 
with lime, alumina and silica, they form a part of the amorphous glassy material of an inert nature observable in all cements.

Iron compounds, analogous to those of alumina, appear to be formed in the manufacture of cements, but their nature is by no means well known. The reducing atmosphere inside most cement kilns causes the formation of ferrous compounds, in which the iron oxide behaves precisely like a base, though calcium ferrites $\left(x \mathrm{CaO}, y \mathrm{Fe}_{2} \mathrm{O}_{3}\right)$ appear to exist in small quantities in some cements, these proportions being much smaller than is generally supposed. Under ordinary conditions, the ferrites are devoid of hydraulic properties, but a mixture corresponding to $2 \mathrm{CaO}, \mathrm{Fe}_{2} \mathrm{O}_{3}$ was prepared by Newberry and produced a black slag on heating; the ground slag did not set when mixed with water in the cold, but on exposure to a temperature of $100^{\circ} \mathrm{C}$. it rapidly formed a very hard mass of constant volume.

Newberry also found that a cement in which iron oxide entirely replaced the alumina usually present sets slowly to a sound mass. This points to the existence of ferro-silicates, rather than ferrites in cements. These calcium ferro-silicates are apparently of the type $x \mathrm{CaO}, y \mathrm{Fe}_{2} \mathrm{O}_{3}, z \mathrm{SiO}_{2}$, but very little investigation has been made of their properties. They appear to have a close resemblance to the corresponding aluminosilicates and to be formed in a similar manner, but are much less hydraulitic. "The fusibility of ferrous alumino-silicates, their strong tendency to form glasses or slags, and the ease with which they are formed at the temperatures employed in cement burning, make it highly probable that these compounds contain the greater part of the iron present in the cement. Their nature is such, however, that it is almost impossible to isolate them. Ferrous alumino-silicates prepared synthetically have a close resemblance to cements, but are, on account of their dark colour and the rapidity with which they set, almost useless for commercial cements.

A variety of Portland cement, in which iron ore replaces the clay ordinarily used, is employed in considerable quantities on the Continent and in the Panama Canal on account of its resistance to sea water. In this case the iron appears to replace the alumina in ordinary Portland cement and to form a completely analogous compound. It has not yet been 
conclusively shown whether such iron ore cement contains a calcium ferro-silicate of the hexite-pentite type or whether it is a mixture of calcium silicates and ferrites, but the existence of a ferro-silicate is the more probable.

There is a custom among writers on cement to associate together the alumina and iron expressed in the form of ferric oxide $\left(\mathrm{Fe}_{2} \mathrm{O}_{3}\right)$ as though they were mutually replaceable. Although ferric oxide is, to some extent, capable of replacing alumina in a hydraulite, it very seldom does so in commercial cements, because the reducing action of the kiln gases cause the formation of ferrous oxide, which is instantaneously converted into ferrous silicate or ferrous alumino-silicate, and then takes little or no part in the chemical changes which occur in the kiln. Very few Portland cements contain an appreciable proportion of ferric oxide $\left(\mathrm{Fe}_{2} \mathrm{O}_{3}\right)$ (notwithstanding the fact that this substance is reported in most analyses); the greater part of the iron is in the ferrous state, and exists in combination with silica and alumina as a glassy mass or slag. It would be more correct, in most cements, to regard the iron as allied to the lime and magnesia - as a fairly powerful base-and not, as is so often the custom, to associate it with the alumina and silica as though it were an acid. That a small proportion of the iron in a cement is present in the form of an acid radical is not improbable, but the greater part of it is certainly not in this form. Hence, in empirical formulæ designed to express the limits of composition of a cement mixture, the iron oxide (unless more than 10 per cent. is present) is preferably omitted, the "constant" in the formula being altered accordingly, if necessary.

The chief objections to a large proportion of iron compounds in a cement are the very dark colour of the cement, the reduced hydraulicity, and the lower fusing point of the materials as a whole, with a consequent change in the conditions under which the cement is burned, and an increased tendency to the decomposition of the cementitious compounds desired and the formation of solid solutions of simpler silicates.

Sulphates and sulphides-chiefly calcium sulphide CaS, ferrous sulphide $\mathrm{FeS}$, and calcium sulphate $\mathrm{CaSO}_{4}$-are often present in small proportions in cements and in larger propor- 
tions in slags. They are removed from the latter by quenching the molten slag in water; the sulphur is then evolved as sulphuretted hydrogen, $\mathrm{H}_{2} \mathrm{~S}$. Sulphides occur in the raw materials used for cement-making, but the greater part found in cement is due to the action of the sulphur in the fuel used for heating the kiln. J. W. Cobb has found that a mixture of pure chalk, alumina and quartz, in proportions corresponding to Portland cement, absorbed 17 per cent. of sulphur tri-oxide during a twenty-four hours' heating in a works furnace, the greater part of this being absorbed below a temperature of $800^{\circ} \mathrm{C}$. The reducing atmosphere present in most cement kilns prevents the absorption of so high a proportion of sulphur tri-oxide by the cement, and any calcium sulphate produced during the earlier stages of the burning would be again dissociated at a temperature above $1100^{\circ} \mathrm{C}$. Nevertheless, it is important to avoid the use of materials and fuel containing sulphur as far as it is possible to do so. The chief danger arising from the presence of sulphides is their liability to become oxidised, forming sulphates and, at the same time, expanding and tending to disintegrate the cement. For this reason, a higher proportion than $2 \frac{3}{4}$ per cent. of sulphur as tri-oxide $\left(\mathrm{SO}_{3}\right)$ is usually prohibited in specifications. The addition of slag to Portland cement usually raises the proportion of sulphur trioxide beyond the limit just mentioned as permitted by the British Standard Specification.

In order to regulate the setting of cement, the addition of 2 per cent. of water and 2 per cent. of anhydrous gypsum $\left(\mathrm{CaSO}_{4}\right)$ is permitted in the British Standard Specification. The water is applied in the form of steam and the gypsum in the form of plaster of Paris. Hence, an examination of most Portland cements will show a somewhat higher proportion of calcium sulphate than is derivable from the raw materials. This additional calcium sulphate is not included in the limit of $23^{\circ}$ per cent. previously mentioned. The addition of anhydrous gypsum has a greater retarding effect on the setting than the equivalent amount of plaster of Paris. If, however, the cement is aerated, the gypsum becomes hydrated, and its retarding effect is correspondingly diminished.

The addition of gypsum or plaster of Paris, or the presence 
of free calcium sulphate in a cement, may be shown by adding 5 per cent. of barium carbonate to the cement, gauging the mixture and testing its expansion after it has been boiled in water (Le Chatelier's test). The barium carbonate decomposes the calcium sulphate and a notable increase in the expansion of the cement is observable.

\section{Chemical Changes in Manufacturing Natural Cements and Hydraulic Lime.}

In the so-called Roman and natural cements made from naturally occurring substances (p. 13), in which the proportions of lime and aluminosilicic acid are such as enable useful cements to be made, the chemical changes which occur are precisely the same as those described in the foregoing pages. The final product is very inferior on account of $(a)$ the lower temperature in the kilns-whereby the reactions between the various substances do not proceed so completely-and $(b)$ the absence of any adjustment of the composition of the mixture, which is seldom exactly correct.

Although the sintering point is seldom reached in burning natural cements, this does not prove that certain silicates and aluminates have not been formed, for, as already noted, J. W. Cobb has ascertained that calcium silicates and aluminates (and also alumino-silicates) are formed at temperatures far below their melting points.

Unfortunately, natural cements do not usually form a clinker of sufficient rigidity to enable them to be polished, etched and examined microscopically, so that their true composition must largely be argued from analogy. The better qualities, which yield a stronger clinker, bear a close resemblance to Portland cement, and the same changes may, therefore, be assumed to occur as take place in the manufacture of the latter cement.

For the same reason, the nature of the changes which occur in the burning of hydraulic limes eannot be stated with accuracy. These limes are clearly mixtures of free lime with some form of pozzolana, or of free lime and a kind of Portland cement. 
Such natural cements, therefore, contain free chalk as well as free pozzolanic material, and are equivalent to a mixture of Portland cement containing an indefinite quantity of raw materials, and of the products, such as lime, obtainable from these by heating at a relatively low temperature.

\section{Chemical Changes in Manufacturing Pozzolanas and Slag Cements.}

As already explained (p. 16), granulated slags differ from other raw materials used in the manufacture of cement in that they have been heated to fusion and then cooled rapidly by quenching with water.

Like the natural pozzolanas, the granulated slags are usually mixed with lime, and the changes which occur have not been studied to the extent as those occurring in the burning of Portland cements. That any form of combination occurs between the lime and the pozzolana or slag when the materials are in the dry state is scarcely to be expected. In all probability the reaction which occurs takes place as soon as water is added to the cement. The nature of this reaction is described more fully later under the heading "Setting and Hardening."

Some basic slags, when quenched and granulated, contain sufficient lime to produce useful cements, though much less than is found in Portland cement. The fact that the production of a slag involves the complete fusion of the material, accounts for the reaction being more complete, so that a smaller proportion of lime is sufficient. Such cements are, however, quite different in constitution from Portland cements, and partake largely of the nature of unstable glasses, which are readily decomposed by water. The absence of all crystallisation in such cements makes it impossible to state what compounds are contained in them ; they may be solid solutions of various calcium silicates and aluminates or may consist chiefly of a calcium alumino-silicate, which is so viscous that it retains small quantities of other substances in solution. The partial crystallisation which occurs when such slag cements are maintained for a long time at a temperature just below the melting point is generally considered to imply the existence 
of several binary compounds rather than one impure ternary one, but Doelter's and Dittler's researches point to the opposite conclusion.

\section{The Physical Changes during Manufacture.}

The physical changes which occur during the conversion of the raw materials into cement are less interesting than the chemical changes with which they are so closely associated. The most obvious is the gradual conversion of irregular lumps of clay or shale and chalk or limestone into a slurry in the wash mills, or a powder in the grinding mills. The slurry is then dried and passed to the kilns, whilst the powdered mixture is either made into briquettes and passed into a stationary kiln, or it is taken direct to a rotary kiln as described in Chapter II.

It is in the kiln that the chief physical as well as the chief chemical changes occurring during manufacture take place, the material being converted from a friable material, or loosely adherent powder, into a hard, dark grey clinker with lighter, softer portions when the burning has been less complete. A microscopical investigation of this clinker will show, as already explained (p. 50), that it consists largely of a preponderating crystalline constituent (alite?) and of a much smaller proportion of a glassy or slag-like material, the nature of which is not easily ascertained. The composition and texture of this glassy material vary in different cements, and it is probably not unreasonable to suppose that it constitutes the residium of all the ingredients left in the raw materials after the formation of the alite or cement proper.

On observing a sample of raw mix heated gradually to $1450^{\circ} \mathrm{C}$. by means of a Doelter's microscope, no visible change occurs until a temperature of about $1375^{\circ} \mathrm{C}$. is reached, slight fusion then occurs, but is barely appreciable until the temperature rises to $1410^{\circ} \mathrm{C}$. or thereabouts, when a sudden formation of (alite?) crystals takes place simultaneously with the fusion of the remaining constituents of the material. The purer the raw materials, i.e., the nearer they approach to aluminosilicic acid and calcium carbonate, the smaller will be the amount of fusion observable, and when the purest possible materials are 
used it is difficult to see any fusion at all until just at the moment when the crystals are formed. With very impure materials, on the contrary, or where the proportion of lime is too large and the clay is highly siliceous, the production of a fused material in relatively large quantities may be observed at a temperature of about $1300^{\circ} \mathrm{C}$.

Contrary to the statements of some writers who have argued from analogy rather than from direct observation, the cement materials do not fuse gradually, the fused portion attacking the remainder and bringing more and more of the material into the molten state. On the contrary, the combination between the lime and the aluminosilicic acid occurs without fusion, and as soon as the temperature is reached at which fusion does occur the compound formed (alite?) begins to crystallise with great rapidity. It is only with very impure materials or in very abnormal mixtures that a large amount of glassy material is produced.

The clinker itself, in spite of its hard and vitrified appearance, is an extremely porous material with a true specific gravity of 3 to 3.4 as compared with 2.5 in the case of the raw mix before burning.

The slag cements are usually harder and less porous, whilst the natural cements, pozzolanic cements and hydraulic limes are quite soft and more free from noticeable pores.

Whilst the raw materials are not chemically changed in contact with water, the clinker is decomposed in a manner presently to be described, and whilst dilute acids only dissolve the calcareous portion of the raw mix and leave the clayey portion as an insoluble residue, the same acids will dissolve clinker completely.

The changes in the optical character of the materials are those which naturally result from the conversion of a mixture of amorphous materials into a vitrified mass composed of crystals with glassy inter-crystalline matter.

The physical properties of clinker are of small importance so long as the clinker is maintained in the form of irregular lumps, or is ground to the fine powder -in which commercial cements are sold ready for use. When mixed with water, however, the changes which occur are so striking and so important that they must be described in a separate chapter. 


\section{CHAP'TER IV}

THE CHANGES WHICH OCCUR IN SETTING AND HARDENING

THE chemical and physical changes which occur when a cement is mixed with water are both numerous and important, but are so complex that the physics and chemistry of some of them cannot readily be considered separately. They are comprised in the various phenomena which are known collectively as setting and hardening.

When a cement is mixed with a suitable proportion of water, ${ }^{1}$ it is converted into a plastic paste which may readily be moulded into any simple shape. After a time, the mass loses its plasticity and becomes more rigid and the water disappears from its surface ; it is then said to have "set." After a much longer period it becomes intensely hard and mechanically resistant. The period between the first addition of water and this loss of mobility is termed the initial set. With a quicksetting cement the change is very noticeable, but with others it is so indistinct as to be almost unrecognisable. In some stages this division into two separate stages is strongly marked, but in the plasters only one stage is observable. It is important not to continue the gauging after the initial set has commenced or the interlocking network of the particles will be destroyed, and the final strength of the cement correspondingly reduced. For this reason, cements should be gauged in small quantities at a time and placed in position, or moulded, before an appreciable amount of setting occurs.

The proportion of water affects the time of setting, an excess of water retarding and a very dry gauging accelerating the setting. An increase of temperature also increases the speed of setting and hardening; hence, cements set more rapidly in hot climates than in cooler ones, and some difficulty is

1 The process of mixing water and cement to form a paste is known technically as gauging.

C. 
experienced in hot weather on account of the cement setting much more quickly than usual.

The conversion of the mixture of cement and water into a mass of a hard, stony nature may be due to one or more of the following changes, which may proceed simultaneously :-

(a) The formation of a crystalline magma from a supersaturated solution.

(b) The desiccation of a colloidal substance or gel.

(c) The reaction of various substances upon each other, or with water, giving rise to a product which is either crystalline, as in $(a)$, or colloidal, and is later desiccated as in $(b)$.

Crystallisation from a super-saturated solution is characteristic of the setting of plaster of Paris and allied substances, including some of the simpler meta-silicates, such as $\mathrm{BaOSiO}_{2}$, $\mathrm{CaOSiO}_{2}$, etc. The first stage, or "setting," of a Portland cement appears to be of this nature, crystallised calcium hydrate being formed. In such cases the substance dissolves in the water present, more material entering into solution than can long remain in that state. A hydrate is then formed by combination of the basic portion of the substance with the water, and as this hydrate crystallises out, more of the anhydrous material is dissolved, the process being continued, though at a rapidly diminishing rate, until all the water is combined or all the material is hydrated. If sufficient water is present to separate the crystals from each other, they will not form a cement, though the chemical changes which take place are identical ; the setting of the mass under the conditions described being merely a question of the spacial relationship of the crystals.

The rate at which such setting occurs depends on the purity of the solution ; the presence of comparatively small quantities of lime and other colloidal substances in solution will retard the setting, or may even prevent its taking place.

Colloidal substances form hard, stone-like products in an entirely different manner, no chemical reaction taking place. When a substance is composed of extremely minute particles of an amorphous character it possesses a number of peculiar properties which distinguish it from the same substances when in a crystalline state. Gelatin or glue is a typical colloid, and 
its colloidal properties are easily recognised, but calcium hydrate $\left(\mathrm{CaO}_{2} \mathrm{H}_{2}\right)$, clay, silica, alumina, and many other substances are, under certain conditions, of the same nature.

All colloids may exist in three forms, $(a)$ one in which extremely fine particles are suspended in a liquid; this mixture bears a close resemblance to a true solution, as it can be filtered without removing the colloidal substances from it (such a pseudo-solution being termed a sol); and (b) a coagulated form obtained by heating the sol or by adding acids and certain salts whereby the substance becomes thick and slimy, and a plastic, gelatinous solid or gel is then removable from it by filtration or deposition. Some of these gels and sols are convertible into each other an indefinite number of times, but other gels (or coagulated form) cannot be converted into the sol form, and are then said to be "fixed" or "irreversible." (c) A third form consists of an amorphous one corresponding to the dried gel ; it may be of a horny or a granular nature or in the form of a fine powder. Unless "fixed" it may be converted into a sol on treatment with water, though some colloids in this form are readily hydrolysed by such treatment.

The behaviour of a colloid is most readily understood by observing that of gelatin or glue. If this substance is placed in water it gradually swells and softens, the increase in volume being very large. If sufficient water is present the gelatin will appear to pass into solution ( $s o l$ form), otherwise it will form an exceedingly soft jelly (gel form). If this jelly is removed from the water and allowed to dry, it will gradually shrink and harden until a strong, horn-like mass is produced. If the drying is carried still further by the aid of heat, the dried material may be rendered irreversible, and will not soften again when placed in water. Instead of drying the sol, the colloid may be coagulated by the addition of various chemicals, chiefly of an acid nature.

Lime, silica, and possibly some alumino- or other silicates are the chief colloids found in cements and mortars previous to the addition of water. The existence of free lime is natural to hydraulic lime and mortar, but it should not occur in cement which has been carefully made and well burned. Free lime retards the setting of a cement or mortar containing 
it, as on treating the material with water some of this lime enters into solution and thereby furnishes one of the products of the hydrolysis. The presence of such a reaction-product always reduces the rate of a chemical reaction, as it tends to establish an equilibrium earlier than would occur if such a product were entirely produced by the reaction itself. The free lime (if any) in cement and mortar must not be confused with that produced by the action of water on cement.

The colloidal silica present in some cements and mortars before they are mixed with water is never large in amount, and is due to the decomposition of adventitious silicates or aluminosilicic acids in the kiln. The behaviour of colloidal silica obtained in this manner may be observed under the microscope, as described later, though it cannot, with this instrument, be distinguished from any colloidal aluminosilicic acid which may be produced by the hydrolysis of an alumino-silicate by the water added to the material.

The chief changes in the setting and hardening of cements, mortar, or other hydraulites, may be most conveniently observed in connection with Portland cement, those in other cements and hydraulites being analogous, but less easily studied on account of the greater irregularities in the composition of the materials.

As already explanied, Portland cement consists of a crystalline constituent, which is a calcium alumino-silicate, together with a much smaller proportion of a slag-like or glassy mass, which is an aggregate of the various "impurities" contained in the raw materials used.

When the cement is mixed with water, allowed to harden, and then polished and examined under the microscope, it will be found that about half of it consists of the unaltered grains of cement and the remainder of colloidal or gelatinous material. The latter may be readily distinguished by soaking the specimen in an aniline dye, such as methyline blue or eosin (red ink), and washing out the unabsorbed dye. The colloidal matter retains the dye so persistently that it cannot be removed by simple washing, and in this way the particles of colloid may be readily distinguished under the microscope by their colour. The proportion of unaltered cement depends on the fineness 
to which the cement has been ground, the finest particles being the most readily affected by the water, but in commercial cements it is found that there is always 30 to 50 per cent. of unaltered cement in the fully hardened neat cement. By the addition of sand or other suitable inert material the particles of cement are distributed more widely, so that in mixtures of this kind a more complete use of the cement is made than when it is the sole constituent of the material. The finer the grains of cement, the greater the proportion of inert material which may be used, and the more complete the hydrolysis. It is important to observe that this unaltered cement takes no part in the hardening (unless it forms a nucleus to the colloid, for which sand is equally efficient). Failure to remember this has led to several fanciful attempts to explain what occurs during the hardening of cements, and has especially led to unnecessary complex theories as to the reason that a hardened cement will set a second time if re-ground and then again gauged with water. Careful experiments with the aid of the microscope have shown that so long as unaltered cement is present the hardened mass may be re-ground and re-gauged an indefinite number of times, the limit being fixed by the amount of cement which is hydrolysed each time the mass is mixed with water. Even with the most finely ground cements and the most carefully made mixtures of these with sand, the whole of the cement is never hydrolysed the first time the mixture is gauged with water.

Those portions of the cement which have been altered by contact with water are found, on examination, to have undergone a chemical decomposition, free calcium hydrate $\left(\mathrm{CaO}_{2} \mathrm{H}_{2}\right)$ and a new series of compounds (hydro-silicates and hydroalumino-silicates) being formed. Water acts both as a base and an acid and decomposes the cement, liberating lime and colloidal silica, colloidal aluminosilicic acid and, possibly, colloidal calcium silicates. The lime crystallises as hydrate from the solution, and the remaining substances rapidly assume a gelatinous form. Careful examination under a microscope will show that the crystallisation of the lime occurs somewhat rapidly, especially with quick-setting cements. At the same time, though much more slowly, the other minute particles 
of decomposed cement material show their characteristically colloidal nature inasmuch as they gradually swell and lose their well-defined shape (just as gelatin does in water) and produce a gelatinous transparent substance. This colloidal material gradually increases in density and hardness as the lime set free by the hydrolysis is absorbed by the gel, and this desiccation of the colloid continues even though the cement is immersed in water. That the effect of water on cement is chemical and not entirely physical is shown by the rise in temperature being roughly inversely proportional to the time of setting of the cement. Slow-setting cements have only a trifling rise in temperature. For a long time no satisfactory explanation could be given for this rise in temperature, but it is now recognised that it occurs at the moment of hydration of the lime liberated from the silicate molecule in cements which contain no free lime. In hydraulic limes (in which free lime as well as "cement" is present) a development of heat occurs at first; this is due to the hydration of the lime. Then, after an interval, a second development of heat is observable corresponding to the chief one occurring in Portland and other lime-free cements, and produced at the moment when the lime is first separated from the alumino-silicate (alite?) molecule, and forms free calcium hydrate $\left(\mathrm{CaO}_{2} \mathrm{H}_{2}\right)$. It is not improbable that the water first attacks the glassy constituents of the cement and that the rise in temperature associated with the initial set is due to this chemical reaction on the amorphous material. The action of water on the crystalline alite is probably slower, and this may account for the second rise in temperature during setting. It should be observed, however, that the hardening of cements, as distinct from the setting, does not admit of very accurate and precise study, especially as both it and the setting occur, to some extent, simultaneously.

The conflicting views as to the constitution of Portland cements have their counterpart in the variety of substances which are supposed to occur in a cement which has been mixed with water and then allowed to harden completely. Those chemists who maintain that cements are solid solutions of calcium aluminate and silicate aver that the action of water 
on cement is to produce a mixture of colloidal and crystalline tri-calcium aluminate $\left(3 \mathrm{CaOAl}_{2} \mathrm{O}_{3}\right)$, colloidal and crystalline calcium hydroxide $\left(\mathrm{CaO}_{2} \mathrm{H}_{2}\right)$, and colloidal calcium silicate. The existence in hardened cements of free calcium hydroxide $\left(\mathrm{CaO}_{2} \mathrm{H}_{2}\right)$ in crystalline form was discovered by Le Chatelier, but his explanation of the reaction of cement with water cannot be accepted, as it refers exclusively to the behaviour of tricalcium silicate (which has never been definitely isolated from cement), and omits all reference to the alumina present. Moreover, the analogous barium silicates are hydrolysed and form a hard mass which differs from Portland cement in being crystalline and not colloidal, and in being useless as a hydraulite on account of the product being soluble in water. In view of the fact that the chief constituent of cements is a calcium alumino-silicate, it appears to be far more probable that the result of the action of water will be to form such compounds as are shown on p. 88 , in which a portion of the lime has become hydrolysed and has been liberated as $\mathrm{Ca}(\mathrm{OH})_{2}$. The total proportion of lime thus set free need not be large, and there are reasons for supposing that only a proportion of the lime attached to the silicon rings, together with the whole of. that attached to the alumina ring $(p .55)$ is removed from the molecule.

The simplest and most obvious theory explaining the setting and hardening of cements is that which regards these phenomena as hydration processes of the cement molecule. In fact, it follows directly. from Asch's theory of the chemical constitution of cements ( $p .55$ ) that the addition or substitution of a large number of hydroxyl groups is.possible, and W. and D. Asch, Feichtinger, and others have also found experimentally that substances which can add hydroxyl $(O H)$ groups at a definite rate to their molecule are hydraulites. The addition of water must be progressive and must not occur too rapidly. The experimental evidence suggests that any substance in which the addition of the $O H$-groups occurs slowly at first and progresses at a suitable rate until, finally, a very large number of $O H$-groups have been added, will form a harder and denser cement than if a smaller quantity of water 
had entered into the reaction or if the reaction had occurred more rapidly. ${ }^{1}$

If the constitutional formula of a typical cement is represented in accordance with Asch's theory as

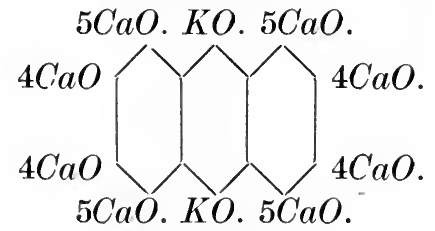

Formula A.

it can, on treatment with water, form numerous hydrated compounds, ${ }^{2}$ such as

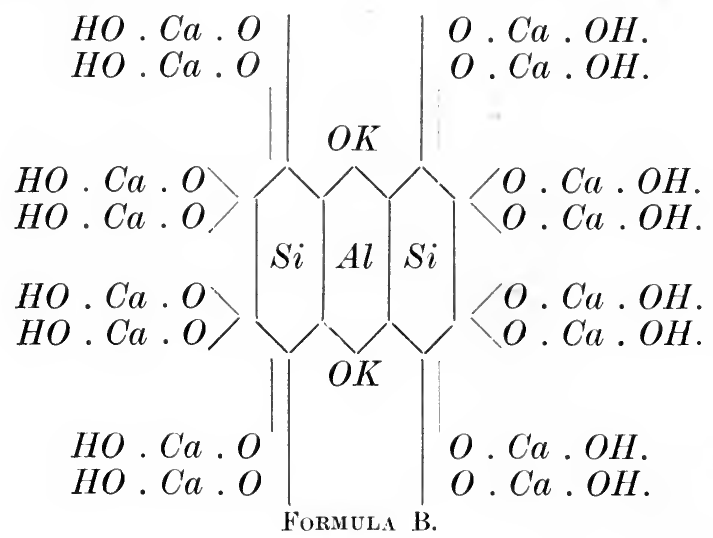

and will require twenty-eight molecules, or 13.8 per cent. of water-a figure which agrees remarkably closely with that found experimentally by Zulkowski in a " perfect" cement when set.

The dissociation of the alumino-silicate molecule marks the commencement of the conversion of the mixture of cement and water from a plastic paste to a solid mass. This is known as the "initial set," the time required for it to occur being termed the "time of setting." Cements differ greatly in this

1 The hardening of trasses and pozzolanas with lime and water may be explained in an analogous manner. These "calcined clays" (p. 43) first react with lime and then add hydroxyl groups to the calcium salt first formed.

2 For other typical hydrated compounds, sce Asch's Silicates (Constable \& Co., Ltd., London. 1913), 
respect, some being very much quicker than others. The earlier cements (which were under-burned in parts and so contained free lime) and the hydraulic limes set slowly, as the free lime in them dissolves in the water and hinders the hydrolysis of the crystals, because lime is one of the products of this hydrolysis. In more modern Portland cements the burning is more efficiently carried out, no free lime occurs in them, and the clinker is much more finely ground, with the result that they set much more rapidly, and a small percentage of plaster or gypsum must usually be.added to retard the setting or it would take place before the mixing of the cement and water is complete.

In a carefully made cement, which has been well-burned in a rotary kiln, the effect of water is tri-fold:-

(a) The alumino-silicate molecule is hydrolysed and is decomposed, free calcium hydroxide $\left(\mathrm{CaO}_{2} \mathrm{H}_{2}\right)$, and such substances as those described on a previous page being produced. The products are in each case colloidal, but may, later, become crystalline. The colloidal matter gradually absorbs the free calcium hydroxide and hardens, and the network of crystalline matter formed as either a primary or secondary product of the hydrolysis adds to the strength of the material.

(b) Any calcium ortho-silicate present in the cement is hydrolysed, calcium hydroxide and a hydrated silicate being produced-

$2 \mathrm{CaO} . \mathrm{SiO}_{2}+(x+1) \mathrm{H}_{2} \mathrm{O}=\mathrm{CaO} . \mathrm{SiO}_{2} \cdot x \mathrm{H}_{2} \mathrm{O}+\mathrm{Ca}(\mathrm{OH})_{2}$

(c) With alumino-silicates the corresponding equation is expressed by one of the following types:-

(1) $\mathrm{Ca}_{36} \mathrm{~K}_{2} \mathrm{Al}_{6} \mathrm{Si}_{12} \mathrm{O}_{70}+28 \mathrm{H}_{2} \mathrm{O}=\mathrm{Ca}_{16} \mathrm{H}_{16} \mathrm{~K}_{2} \mathrm{Al}_{6} \mathrm{Si}_{12} \mathrm{O}_{58}$
$+20 \mathrm{Ca}(\mathrm{OH})_{2}$
(2) $\mathrm{Ca}_{45} \mathrm{Al}_{6} \mathrm{Si}_{15} \mathrm{O}_{84}+36 \mathrm{H}_{2} \mathrm{O}=\mathrm{Ca}_{18} \mathrm{H}_{18} \mathrm{Al}_{6} \mathrm{Si}_{15} \mathrm{O}_{66}+27 \mathrm{Ca}(\mathrm{OH})_{2}$ It will, however, differ slightly according to the particular calcium alumino-silicate present and to the extent of the hydration. ${ }^{1}$

1 That the proportion of lime may vary within wider limits than is generally recognised is implied by some experiments of Fremy (Compt. rend : 67, 1205), and Zulkowsky (Sonderabd. 1908), in which as much as 14 per cent. of lime was removed from some Portland cements without destroying their power to harden when mixed with water. 
Any ferrates, aluminates and ferro-silicates will be hydrolysed in a similar manner, and will form either colloidal products or will add to the complexity of the interlocking silicate crystals. It was at one time thought that quicksetting cements owed their property to the aluminates they contained. This is only indirectly the case. Cements which are rich in alumina are those which contain most aluminosilicate, and they set more rapidly because of this and of the relative absence of retarding substances. Some of the Roman cements set rapidly because of the large proportion of aluminosilicate present. Hence, it is not unreasonable to assume that the greater part of the strength of hardened cements is due to the colloidal matter produced by the action of the water (including the absorbed calcium hydrate) rather than to the formation of any network of crystals which may occur. A microscopical examination of hardened cements which have been polished confirms this view, the total proportion of crystalline matter being small compared with that of the colloid or amorphous matter present.

The opinion held by some chemists that the constituents of hardened cements are free lime, free silica and free alumina, and that the "initial set" marks the hydration of the aluminates, and the "final set" that of the silicates, does not coincide with many of the facts. It is quite true that these substances all occur in hardened cements and mortars, but they are in proportions which are far too small to correspond to the strength of the material as a whole. To a very large extent the existence of free alumina and free silica in large proportions is merely academic deduction from the supposed existence of correspondingly large quantities of tri-calcium silicate and di- or tri-calcium aluminate in cement clinker, and the general supposition that only binary compounds of lime, silica and alumina exist in cements. The proved existence - of large quantities of alumino-silicate, and especially the recognition of the chief constituent of cement as a definite alumino-silicate, deprives the explanation of the process of setting and hardening usually found in text-books of much of its assumed value. The products of the action of water on cements are not free silica and alumina, but complex 
aluminosilicic acids, some of which contain much combined lime.

It was, at one time, thought that the hardening of cements and mortars was due to the direct combination of free lime with silica and the formation of calcium silicate. No combination can occur between sand and lime at ordinary temperatures, but active aluminosilicic acid (such as occurs in pozzolanic materials) will absorb free lime and form a hard colloidal mass which increases in hardness as the water in it is removed. The great hardness of many ancient mortars is due to the use of ground tiles and other pozzolanic material (capable of providing active colloidal silica, alumina and aluminosilicic complexes) in addition to the sand ordinarily used.

The action of carbon dioxide (in the atmosphere) on cements and mortars is always of a secondary character so far as hardening is concerned. The primary action of carbon dioxide is on the free calcium hydroxide present-

$$
\mathrm{Ca}(\mathrm{OH})_{2}+\mathrm{CO}_{2}=\mathrm{CaCO}_{3}+\mathrm{H}_{2} \mathrm{O} .
$$

The lime thus carbonated is rendered insoluble and useless as far as any further reaction is concerned, but the calcium carbonate rapidly assumes a crystalline form, and the interlaced network of crystals slightly increases the strength of the whole mass. The greater part of the hardness and strength is, however, due to the colloidal matter present, as already explained, the action of carbon dioxide being almost entirely confined to the surface of the material and rarely penetrating into the interior even after 2,000 years, as may be seen by examining the walls of ancient buildings.

Some carbon dioxide (about 5 per cent. under favourable conditions) is absorbed by most cements when they are stored or " matured." The amount absorbed was, at one time, thought to correspond to the free lime present in the cement, but more recent investigations have shown that well-made Portland cements contain no free lime, and indicate that the action of carbon dioxide-which requires the simultaneous presence of water-is due to a slight decomposition of the cement.

As the finest particles will react the most rapidly, a definite 
degree of fineness is necessary to the production of a satisfactory hydrated product, but too fine a material will react so rapidly as to form a feeble cement, unless its action is retarded by the addition of a suitable agent.

\section{RETARDATION OF SETTING.}

The retardation of setting becomes increasingly important as the manufacture of cements is improved. Portland cements burned in stationary kilns are comparatively slow-setting, but those burned in rotary kilns set too rapidly for convenient and satisfactory working. The rate of setting of a cement may be decreased in two ways : $(a)$ the cement may be exposed to the air (i.e., aerated), or $(b)$ a small proportion of a retarding agent may be added, some form of calcium sulphate being usually employed. Other salts may be used instead; thus, P. Rohland found the time of setting of cement was shortened by adding calcium chloride, aluminium chloride, potassium sulphide, sodium carbonate, potassium carbonate, aluminium sulphate and alum. The time is lengthened by potassium dichromate, boric acid, borax, sodium sulphate, potassium sulphate and calcium sulphate. Exposure to air is really equivalent to exposure to moisture, and steam is, therefore, used as a retarding agent with good effect. This is due to the hydration of a small portion of the cement and the consequent liberation of a little free calcium hydrate. When the clinker is treated with steam so that about 1 per cent. water is absorbed, the proportion of calcium sulphate required is reduced to about one-half that otherwise needed.

The precise nature of the action of calcium sulphate on cement is not fully understood. As only 2 to 3 per cent. is required, its action may be largely catalytic. Various other salts produce a retardation when used in small quantities and an acceleration when larger proportions are used, though the results of investigations on this subject are far from conclusive and are, in some instances, mutually incompatible.

E. Candlot has also stated that a double salt corresponding to the formula $3 \mathrm{CaOAl}_{2} \mathrm{O}_{3} 3 \mathrm{CaSO}_{4} 30 \mathrm{H}_{2} \mathrm{O}$ is formed by the interaction of calcium sulphate and cement, and that this compound is insoluble in water, and so converts any aluminate into a form 
in which it takes no part in the setting. This explanation is widely accepted, but can hardly be said to meet the facts. Candlot has endeavoured to remove some of the objections to this theory by postulating that a certain quantity of free lime is necessary in order that the gypsum may have its effect. It is true that a partially hydrated cement is retarded by a much smaller quantity of calcium sulphate than a cement which has not been treated with steam or moisture, but this does not necessarily prove Candlot's theory. A more probable explanation is that the calcium sulphate dissolves at such a rate that its saturated solution prevents the hydrolysis of the cement by enabling only a very small proportion of lime to be liberated and dissolved at a time. Whichever theory be adopted, it is a curious fact that the highly soluble calcium chloride has an even stronger retarding action than calcium sulphate, but magnesium chloride accelerates the setting. This implies that it is the acid portion of the material $\left(\mathrm{SO}_{4}\right.$, $\mathrm{Cl}$, etc.) which is the active agent, and that some combination of these ions and the cement molecule occurs. The destructive action of sulphate solutions, and particularly of sea-water on cement immersed in them, confirms the opinion that some reaction occurs between the $\mathrm{SO}_{4}$-ion and the cement.

In a hydrated or hardened Portland cement such as is represented by Formula B (p. 88), the two OK groups are readily replaceable by monovalent acid radicals such as $\mathrm{SO}_{2} \cdot \mathrm{OH}$, so that when such a cement comes in contact with a solution of calcium sulphate there is a great probability that an alumino-silicate will be formed in which this replacement has occurred. Such alumino-silicates are well known, and include many sodalites and ultramarines. As the replacement is accompanied by a change of volume, it will, if at all extensive, tend to cause the cracking and ultimate disintegration of the cement. Arguing in this manner, W. \& D. Asch have suggested that the only way to prevent adventitious sulphates (including those in sea water) from affecting concrete structures is to avoid all cements of the type $a, \mathrm{p} .56$, in which these readily replaceable groups attached to the aluminium hexite are present, and to use exclusively cements in which they do not exist, e.g., cements of the type $b$, p. 56 . 
The retarding action of calcium sulphate is diminished by storing the cement. This has been explained as being due to the gradual carbonation of the lime set free by the sulphate and moisture, but it is equally probable that a combination between the sulphate and the cement occurs on long storage or on exposure to the atmosphere.

Calcium sulphate is usually added to cement clinker in the form of gypsum, the materials being ground together. Finely powdered gypsum may also be added to the ground cement, but it is preferable to use plaster of Paris, which is obtainable in a much finer state of powder than is gypsum. The amount of either gypsum or plaster needed depends on the proportion of $\mathrm{CaSO}_{4}$ present and on the fineness of its particles; not on any imaginary difference in the chemical activity of these two substances.

Experiments as to the effect of the addition of 2 to 3 per cent. of calcium sulphate to various quick-setting cements show curiously irregular results, and indicate that the action of this substance is by no means so simple as is sometimes supposed. Some of the discrepancies may be due to lack of uniformity in the cement itself or to irregular admixture of the retarding agent. Whatever the cause, the disadvantages of adding such retarders should not be overlooked, and the amount used should be kept as small as possible.

The whole subject of the action of retarding agents and the changes which take place when the cements are stored is worthy of further investigation. The inherent difficulties of the subject are, however, very serious.

Aeration, or exposure of cement to the atmosphere, reduces the rate of setting and so acts as a retarder. It also hydrates any finely divided particles of free lime which may be present, and so reduces their tendency to expand or "blow" at a later stage in the use of the cement. The changes which occur in aeration are similar to those effected by water, but the small proportion of water present in the atmosphere makes the changes much slower. The carbon dioxide in the air converts any hydrated lime into microscopic crystals of calcium carbonate and so renders them inert. Excessive exposure to air reduces the value of the cement by effecting 
the hydrolysis and carbonation of the finest and therefore most valuable particles.

The earlier cements were improved by aeration, which hydrated any quicklime present and so reduced it to a fine powder, but well-made modern cements are not improved by this treatment. Nevertheless, it is a wise precaution, when testing cements which yield unsatisfactory results, to expose them to the air for three or four days and then test again ; they will then, in many cases, yield satisfactory results.

NORMAL RATES OF SETTING.

For information on the rates at which setting and hardening occur, the reader should refer to p. 109, et seq. 


\section{CHAPTER V.}

\section{TESTING THE PROPERTIES OF CEMENTS.}

The primary object of all cement-testing is to determine whether the material is satisfactory in two important particulars-strength and soundness. Other tests-for fineness, specific gravity, the time of setting and chemical analysisare only of value as additional information on the general suitability of the material.

Of all materials which are regularly tested in chemical and physical laboratories there are none in which the tests are more dependent on the judgment and skill of the operator than cements, and even in the best equipped testing stations it is impossible to avoid a large personal equation. For this reason tests carried out by amateurs are usually of little value until the necessary manipulative skill has been attained.

It is of the greatest importance in studying results obtained in testing cements that the precise manner in which the tests have been performed should be known. Thus, differences in the proportion of water used in the gauging will cause great discrepancies, and may lead to erroneous conclusions. Where the tests are supposed to have been made in accordance with a standard specification, care should be taken to see that the instructions have been fully carried out. Even then, there is still room for widely differing results, because two testers, working quite independently on the same cement, may have different ideas as to the precise meaning of "normal consistency" as applied to gauged cements.

Users of cement are frequently, though quite unconsciously, very unfair in their manner of judging the value of different cements. Some of them prefer to make what they eall a "practical test," that is to say, they observe the behaviour of cements from different sources when in use for actual constructional work. This, at first sight, appears to be the best of all 
tests, but it overlooks the enormous influence of the " personal equation." A little carclessness or lack of skill on the part of the workmen employed will result in the production of inferior work, and may lead to the condemnation of a cement of exceptionally good quality. There are many ways in which good cements may be spoiled by faulty manipulation and by the use of unsuitable aggregates, and to obtain uniformly satisfactory results needs the unceasing exercise of vigilance, care and skill on the part of everyone concerned.

Other users base their judgment on unimportant matters and conclude that a cement which hardens more slowly than another must be inferior, or they condemn a cement which, after twenty-eight days, does not show a large increase in strength when its original strength is greatly above the normal. Only as users are prepared to study cements scientifically will the true value be appreciated and the best results obtained.

The improvements effected in the manufacture of cements, and particularly of Portland cement, are due, in large measure, to the imposition of standard specifications for cements in all the more important countries. These standards differ somewhat from each other, partly on account of the differences in the climatic conditions, and partly because of minor variations in the manner in which some of the tests are carried out. These variations are rapidly disappearing in consequence of the work of the International Association for Testing Materials. In the following pages only brief notes are given as to the various properties with the limits set in the specifications, and as these limits are varied from time to time and the details of the official tests are occasionally altered, it is desirable that the specification in force at any particular time should be consulted. The British Standard Specification may be obtained from the Engineering Standards Committee, 28, Victoria Street, Westminster, London, S.W., price 5s. 3d., post free. This relates exclusively to Portland cement, no official standard for other cements having yet been prepared.

In drawing up this specification for use by engineers, the chief aim has been to select properties which will indicate a lack of soundness in the cement when in use, together with such

c. 
other properties as will ensure the closest similarity between various batches of cement or cements made by different firms. It is recognised that great variations exist in the composition of the raw materials used, and the specification is therefore arranged so as to secure a maximum of uniformity with a minimum of disturbance to existing manufacturers.

Not only is care and skill needed in carrying out the tests themselves, but the manner in which the samples are taken from the bulk must be such as will yield "fair" samples.

The procedure recommended in the British Standard Specification is generally adopted in Great Britain, viz. :-

"Each sample for testing shall consist of approximately equal proportions selected from twelve different positions in the heap or heaps when the cement is loose, or from twelve different bags, barrels, or other packages, when the cement is not loose, or where there is a less number than twelve different bags, barrels, or other packages, then from each bag, barrel, or other package. Every care shall be taken in the selection, so that a fair average sample may be taken.

"When more than 250 tons of cement is to be sampled at one time separate samples shall be taken from each 250 tons or part thereof."

\section{CHEMICAL COMPOSITION.}

The chemical composition of Portland cements has been limited by the definition of Portland cement as " the product resulting from the burning of an intimate admixture of calcareous and argillaceous materials as principal ingredients, which burning is carried to the point of incipient fusion, the clinker produced being ground to a fine powder.". In the most recent British Standard Specification the composition is still further regulated by the ratio $\frac{\mathrm{CaO}}{\mathrm{SiO}_{2}+\mathrm{Al}_{2} \mathrm{O}_{3}}$ (expressed in molecular equivalents), being limited between $2 \cdot 85$ as a maximum and $2 \cdot 0$ as a minimum. This limited range of composition is intended to exclude cements containing granulated blast-furnace slag. (See p. 62.) 
The maximum amount of the following constituents is also fixed at the figures stated below :-

Per cent.

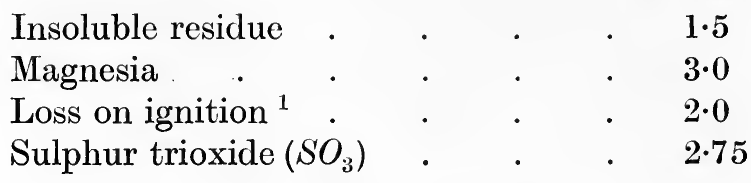

\section{APPARENT DENSITY.}

The apparent density of a cement is the ratio of the weight of a given volume of cement to its volume, but the expression is of small value unless the method of filling the measuring vessel with cement is known. If, for example, the powder is introduced into a glass flask, the latter being tapped gently from time to time, a very different figure will be obtained for the apparent density than if no tapping or shaking is permitted. The usual practice is to employ a funnel provided with a stopper at its lower end. A sufficient quantity of cement is placed in this funnel and is allowed to run into a cylindrical measure placed beneath until the latter is filled to overflowing. The excess of cement is removed from the receiver by drawing a straight-edge across the top of the latter so as to leave it exactly full. The receiver with its contents is then weighed.

The receiver may be of any convenient capacity. In former days it held exactly one bushel (=8 gallons), but at the present time it is more frequently 1 litre. From the larger measure the "weight per bushel " is easily ascertained; from the latter the "litre-weight" is equally easy. It is desirable to check the capacity of the receiver by weighing or measuring the water it holds when filled exactly to the brim.

The object of ascertaining the apparent density is to gain some idea as to whether the cement has been under-burned, as the more complete the burning the greater will be the weight per bushel or litre-weight. This test is complicated by the fact that the fineness and age of the cement both reduce the apparent density, so that it is of little use in comparing cements

1 Unless it can be shown that the cement has been ground for more than four weeks. 
from different sources, but is of value to the manufacturer who, by its means, is able to check the correctness or otherwise of the calcination of the cement. With the increasing use of rotary kilns and the consequent reduction in the proportion of under-fired clinker, the necessity for determining the apparent density is gradually disappearing.

The usefulness of this ratio is also limited by the fact that the weight of ten bushels, or litres, or any other volume, does not correspond to that of a smaller number. The size and shape of the measuring vessel have a great influence on the relative positions of the particles. For the same reason cement cannot be measured instead of weighed by dividing the weight required by the apparent density. The volume thus calculated differs sufficiently from the true volume to cause an appreciable difference in the strength of the mortar for which the cement is used. Where the cement all comes from the same works, however, and the true relation between weights and measures on a large scale has been found, the apparent density may be used with more accuracy.

The weight per bushel of a good Portland cement will vary between 95 and $115 \mathrm{lbs}$., and the litre-weight from 1,010 to 1,400 grammes, but, as already mentioned, these figures are reduced by grinding the cement more finely, and by storing it for some time, when the particles become partially hydrated and carbonated.

The specific gravity test has for several years replaced the weight-per-bushel and litre-weight tests in this country, as the latter are unreliable with very finely ground cements.

\section{SPECIFIC GRAVITY.}

The specific gravity of any substance is the ratio of the weight of that substance to the weight of an equal volume of water. In the case of fine powders, such as cements, the specific gravity differs from the apparent density because the former relates to the volume-weight of the individual particles, whilst the latter relates to the volume-weight of the mass, and includes the space between the particles which is occupied by air. Hence, to determine the specific gravity it is necessary 
to measure the total volume of all the particles, each one being considered separately. To do this, there is introduced into a flask or bottle with a very narrow neck ${ }^{1}$ sufficient paraffin, turpentine, or other convenient fluid, which is without action on the cement, until it reaches the prearranged mark on the neck of the vessel. The vessel with its contents is then weighed accurately, and the weight noted. The vessel is then partly emptied and a definite weight of cement introduced through a funnel. The vessel is then refilled to the mark with the fluid, tapped gently to loosen air-bubbles, and its weight again noted. If

$F=$ the weight (in grammes) of the empty vessel,

$T=$ the weight of the vessel when filled with fluid,

$W=$ the weight of the vessel when containing cement and also fluid,

$C=$ the weight of cement introduced into the vessel,

$S=$ the specific gravity of the fluid used,

then the specific gravity of cement $=\frac{C S}{T-W+C}$.

It is by no means easy to determine the specific gravity of cement, as the air adheres very closely to the particles, and some of the latter are liable to be carried to the top of the fluid, and even to rise above it. Only by very careful tapping in a horizontal direction can the cement be kept in its place below the surface of the liquid. On no account must the vessel be shaken vertically, or an accurate determination will be rendered impossible on account of the cement which will lodge on the upper part of the neck of the vessel. Several patterns are in use, but one of the most convenient is that devised by W. H. Stanger and B. Blount, which is a modification of one used by Le Chatelier. It consists of a flattened flask with a narrow neck graduated in one-tenths of a c.c. The capacity of the flask to the lowest graduation is 64 c.c., and this is marked 14, the remainder of the larger graduations being marked successively $15,16,17$ and 18 , so that the capacity of the flask to the top graduation is exactly 68 c.c. This flask is carefully

1 The use of an ordinary stoppered specific gravity bottle is inadvisable on account of the floating of the finest cement particles. 
dried and exactly 50 c.c. of paraffin is introduced into it by means of a pipette, great care being taken not to wet the graduated portion of the neck of the flask. Then exactly 50 grammes of cement is added through a funnel, and the flask is gently tapped to remove air-bubbles. The level of the liquid is then read on the graduations. This number divided into 50 will give the specific gravity of the cement. Thus if the liquid reached to $\mathbf{1 5 \cdot 8}$ the specific gravity of the cement is $50 \div 15 \cdot 8=3 \cdot 16$. The cumbersome calculation which is necessary when a specially designed vessel is not used may, by this means, be avoided. The cement should be introduced after the paraffin, as otherwise it is difficult to get a sharp reading.

Unlike the apparent density (p. 99), the specific gravity is not affected by the fineness of the cement, but the specific gravity diminishes as the age of the cement increases, in consequence of the absorption and chemical combination of moisture and carbon dioxide from the atmosphere, whereby partial hydration and carbonation of the cement are effected.

The chief uses of the specific gravity are: (a) To distinguish Portland cement from natural cement and particularly from that form of the latter known as Belgian cement (p. 31). Genuine Portland cement has a specific gravity between 3.0 and $3 \cdot 4$, whilst natural cement has a specific gravity below $3 \cdot 0$.

(b) The specific gravity is also used as a test of the value of a cement in relation to the extent to which the clinker has been burned, but the difference between the specific gravity of under-burned and normal clinker is too slight to be relied upon. It not infrequently happens that a cement of low specific gravity is of greater strength than one of high specific gravity, so that no important conclusions should be based on this test.

(c) In testing for adulterants in cement the specific gravity is of little value unless the added material is present in a very large proportion. The specific gravity of Kentish rag - a sandy limestone at one time much used as an adulterant -is 2.9 ; that of basic slag is still closer to that of cement, so that the differences are, for most purposes, insignificant. 
In short, although Portland cement has a specific gravity of 3.00 to $3 \cdot 40$, which is higher than that of other cements, and this enables a somewhat denser mortar to be produced, a low specific gravity does not necessarily indicate an inferior cement, as the absorption of water and carbonic acid from the atmosphere will cause a considerable reduction of the specific gravity and yet may not lower the value of the cement.

The British Standard Specification imposes a minimum specific gravity of $3 \cdot 15$ for fresh Portland cement and 3.10 for cement which has been ground more than four weeks previous to testing. The lower limit for older cement is to allow for the change in specific gravity which occurs when cement is hydrated and part of the lime present is converted into calcium carbonate on exposure or storage. The effect of the age of the cement on the specific gravity may largely be eliminated by heating the cement to a temperature of $1,000^{\circ} \mathrm{C}$. (bright red heat) for a short time. This treatment drives off the water and carbonic acid which have been absorbed, but the cement is not really re-converted into a properly burned cement, as the hydration effected by the moisture in the atmosphere to which the cement was originally exposed causes a decomposition of the cement which reheating at the temperature mentioned does not restore. For most purposes, however, the error introduced into the specific gravity figure is so small that it may be neglected.

\section{FINENESS.}

The size of the particles of cement is a matter of the greatest importance, as the reactions between the cement and waterwhich give the material its chief value-depend upon it. The test for fineness is also highly important, because fine cement has a much greater binding power, and much larger proportions of aggregate may therefore be used than with a coarser cement, or, conversely, the strength of the material will be much greater for the usual proportions of aggregate if a finely ground cement is used.

It is sometimes stated that the "flour" or finest particles contain the whole of the cementitious material. This is not strictly correct, though sufficiently so for many purposes. 
Careful tests of the coarser particles will show that they are cementitious, but that they are less rapidly attacked by the water used in gauging. On grinding the coarser particles to flour they have the same cementitious value as the fine particles from which they have been separated. The difference in their behaviour is entirely due to the relative amount of surface exposed and not to any other chemical or physical difference. With coarse particles the relative surface area is much less than with finer ones, so that the water can only react to a much smaller extent, and the final product is much weaker than would be the case if finer cement were used. In addition to this, the finer particles can be distributed over a much larger quantity of aggregate when the cement is made into mortar or concrete, so that the finer a cement is ground the less will be the proportion of cement needed to produce a mortar of given strength. Commercially this is very important, as the cement is by far the most costly ingredient.

There is, however, another reason why cement should be finely ground, namely, its much greater freedom from "blowing" and cracking, particularly if it be underburned or overlimed. This has clearly been shown by D. B. Butler, who found that a number of cements, in the state in which they were received from the manufacturer, formed pats which were badly blown under trying conditions, yet the same cements when re-ground, so as to pass completely through a No. 180 sieve, gave perfectly sound pats.

According to W. Michaelis, only those particles are of value which pass through a $305 \times 305$ sieve. Hence the old methods of grinding gave only 50 per cent., but the best modern ones yield not less than 70 to 75 per cent. of the only valuable constituent of cement.

In the face of these results, it is not surprising that the compressive strength of mixtures of fine cement with three parts of normal sand exceeds that of normal cement and normal sand by over 1,400 lbs. per square inch. A still finer raw material will increase the strength still more.

Better quality, higher commercial value, with moderate increase in the cost of production, are the chief advantages resulting from fine grinding. 
The only drawback to fine grinding is the increased rate at which the cement sets; this is usually overcome by treating the hot clinker with steam and adding about 2 per cent. of calcium sulphate or other retarder (p. 92).

To produce a cement of very great fineness is necessarily costly, and there is, therefore, a tendency not to grind more finely than the user considers necessary. Some years ago a residue of 10 per cent. on a No. 50 sieve and 20 per cent. on a No. 76 sieve was considered to be good grinding and is now customary for some of the cheaper cements. For Portland cement of good quality, however, the lcading makers now grind so that there is less than 3 per cent. on a No. 76 sieve, and the tendency is to demand increasingly fine grinding.

In order to obtain so fine a product r a pidly - driven grinding machines must be excluded, as they are not suitable for very fine grinding.

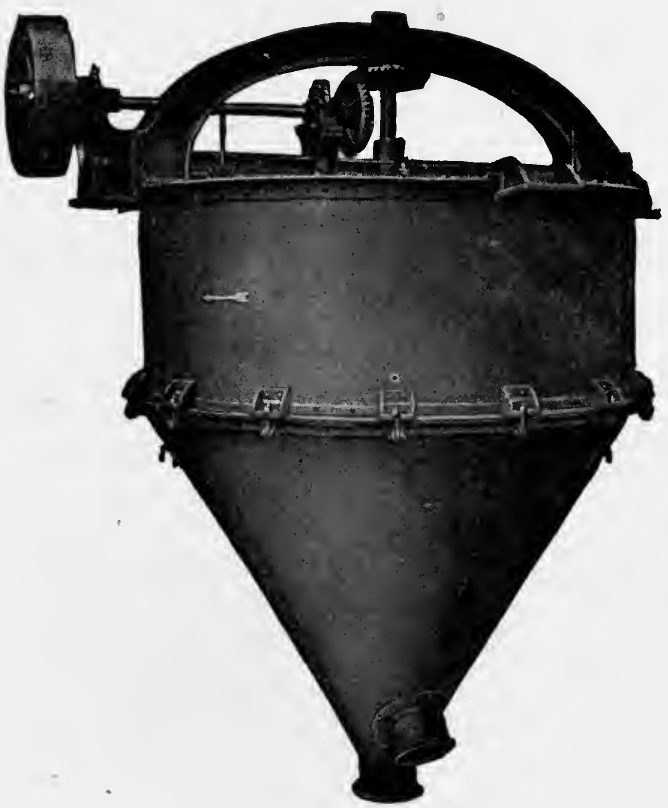

Fig. 9.-Air Separator (Gebr. Pfeiffer).

Tube-mills and millstones can grind very fine, but for a residue of, say, 10 per cent. on a $175 \times 175$ sieve their output is so small that they cannot be used commercially; if a still finer product is required, e.g., 2 per cent. on a $175 \times 175$ sieve, the output is insignificant. There can, on the contrary, be no question as to the ability of ball-mills to grind to any desired degree of fineness, whenever a suitable separating or sifting device is available. Such an arrangement must not operate in the rough and ready manner of a sieve, but must 
only remove the very finest particles and must return the remainder to the mill so that it may be crushed still finer. Such an apparatus appears to exist in the "Selector"-a form of air-separator (Fig. 9)-which can easily produce a cement with as little as 2 per cent. residue on a $175 \times 175$ sieve with an output of 80 per cent. of that obtained when cement of normal fineness is ground. The product of such a device, when tested, gave Michaelis the following results :-

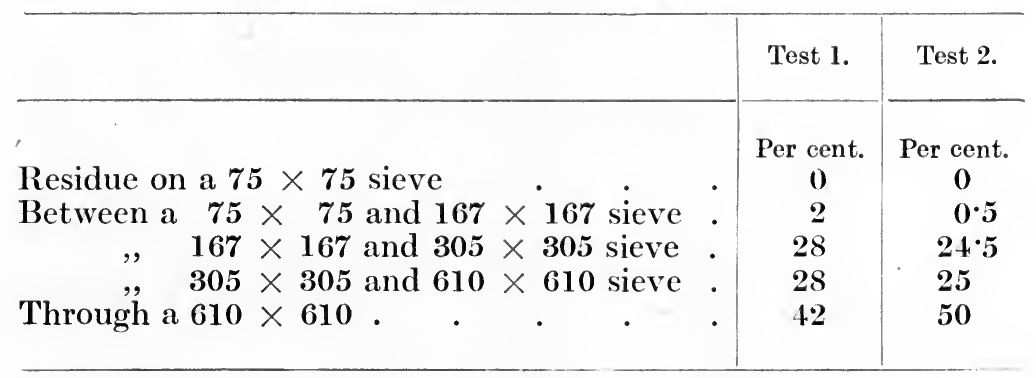

Modern Portland cements contain about 55 per cent. of flour separable by a current of air, the remainder being in the form of a very fine grit. In cement plants using air-separators there is a somewhat larger proportion of flour than when screens are used.

The fineness of a cement is ascertained by sifting the material through carefully standardised sieves. In all the chief countries of the world two kinds of standard sieves are used; the coarser has seventy-six holes per linear inch or 900 per sq. cm., and the finer has 180 holes per linear inch or 4,900 per sq. $\mathrm{cm}$. Finer sieves are also used in testing laboratories for special investigations, though it is almost impossible to use sieves with more than 250 holes per linear inch on account of the clogging which ensues.

In selecting a sieve it is of the greatest importance that all the holes should be exactly the same size, as otherwise the particles which pass through the sieve will be so irregular as to make the results useless. The recognised standard is to make the holes twice as wide as the diameter of the wire. For the No. 76 sieve the British standard size of wire is 0.0044 inch diameter, and for the No. 180 sieve it is 0.0022 inch. 
The sieves and gauze ordinarily sold by wire merchants are quite useless, the wires being too irregularly spaced, and some of the gauze is twilled instead of being evenly woven. Messrs. Greening \& Sons, Limited, of Warrington, are regarded as the semi-official makers of suitable gauze. The manner in which the gauze is attached to the frame is important. It must not be stretched or strained over a circular frame, as this alters the shape of the holes and destroys the value of the gauze. The proper method is to use a square frame of wood or metal about three inches deep, and to attach the gauze to this by means of a thin supplementary frame or slips of wood screwed to the former one. It is very convenient to make the sieves fit into each other, the upper, coarser one being provided with a closefitting lid, and the lowest with a box to receive the finest material. This arrangement enables the sifting to be carried out without creating any dust, and is more rapid than when each sieve is used separately.

To drive the fine particles through the sieve it is necessary to shake it continuously, an operation which requires a certain amount of skill. In the British Standard Specification it is directed that 100 grammes or 4 ounces of cement is to be continuously sifted for a period of fifteen minutes on each sieve. The area of the sieves is not stated, but the mesh is Nos. 76 and 180, respectively. The residue on the coarser sieve must not exceed 3 per cent., and that on the finer sieve 1.8 per cent. Mechanical contrivances for shaking the sieves are frequently used, but do not produce such satisfactory results as hand shaking, the vibration being much sharper when the sieve is mechanically shaken. The use of a fine sieve is so tedious that several attempts have been made to separate the finest particles by other methods. The use of a washing or elutriating apparatus with paraffin as the levigating fluid is seldom practical, as it involves the use of enormous volumes of paraffin which cannot be readily purified for repeated use. Attempts to separate the finer particles by a process of sedimentation in paraffin have also proved unsatisfactory. Results of reasonable reliability have been obtained by Gary and Lindner, and independently by Cushmann and Hubbard, who passed a current of air through a series of three vessels of different sizes. 
The diameter of each vessel is arranged to correspond to a convenient speed of air and to give a product of which the particles are within very narrow limits of size. The air is admitted at a pressure of $100 \mathrm{~mm}$. water column to the bottom of the first vessel, and passing through it is then carried to the bottom of the second vessel, and so on throughout the whole apparatus. A convenient quantity of cement (usually 20 grammes) is introduced into the first vessel and is separated by the air-current, the particles being carried along in proportion to their fineness. The largest particles remain in the first vessel, the smallest pass through the apparatus into a collecting vessel, and particles of intermediate fineness are left in the second and third vessels respectively. When carefully used, this apparatus, which is known as a "flourometer," gives fairly concordant results, though these are always subject to a loss of about 5 per cent. of the original material. The flourometer is of insignificant value in distinguishing cements and adulterants; its chief value lies in showing the thoroughness or otherwise of the grinding.

The author has obtained highly satisfactory results with a modification of a form of centrifugal apparatus patented by W. J. Gee. In this appliance paraffin of a definite density is mixed with the cement to form a thin slip or cream which is then run into the top of a rapidly rotating cylinder. Clear paraffin passes out at the bottom of the apparatus and on opening the latter the cement is found to be graded accurately, the finest particles being at the lower end. The separation is remarkably sharp and repeated tests have confirmed its reliability and superiority to the "flourometer" described above.

No complete standard of fineness has yet been formulated, those in use merely limiting the proportion of useless, coarser particles and paying no attention to the size of particle which is actually the most efficient. D. B. Butler has made experiments which appear to indicate that cement particles which pass a No. 120 sieve, but are retained on a No. 180 sieve, are sufficiently small, but the demands of users since those experiments were made have resulted in the best commercial brands of cements being so fine that only about 5 per cent. is left on a No. 180 sieve. 
For the British Standard Specification, Portland cement shall be ground so fine that the residue left on a No. 76 sieve must not exceed 3 per cent., and that on a No. 180 sieve shall not exceed 18 per cent. All the better brands of Portland cement conform to these limits, and a number of them leave only a trace on the No. 76 sieve and 2 per cent. or less on the No. 180 sieve.

\section{RATE OF SETTING.}

When Portland cement is mixed with water ${ }^{1}$ a plastic paste is formed, which soon loses its plasticity, stiffens and "sets," and, later, hardens to a stonelike mass, which was supposed by the inventor to resemble Portland stone. (See Chapter IV.)

Setting and hardening are two entirely different properties, and seem to have little, if any, connection with each other. It is, however, generally true that quick-setting cements harden more slowly than slow-setting ones.

The speed at which a cement sets when gauged with water is no criterion of its ultimate strength, except in so far as quick-setting cements are very difficult to work and so may produce a weak material. If the workman should continue the mixing of the cement and water after the initial set has commenced, the ultimate strength of the material will be seriously reduced on account of the destruction of the crystalline network formed in the first stage of the setting. With modern quick-setting cements, excessive gauging resulting in working through the initial set is responsible for much faulty work in concrete construction. This is a defect which is extremely difficult to avoid, and is one of the soundest reasons for using a slow-setting cement whenever possible.

As previously mentioned (p. 81), two distinct stages are recognised in the setting of cements : the first, or initial set, is when the pasty mass becomes just " solid," and the second, or final set, when the cement mass is sufficiently hardened to resist scratching by the thumb-nail or by some more accurate method of applying a light but definite pressure, such as a Vicat's needle. 
The point at which the initial set occurs is often difficult to recognise with quick-setting cements unless some definite method is adopted for ascertaining it. The one in general use consists in placing a pat of the cement paste on a glass plate. The Vicat needle is then applied; if it penetrates the pat completely no setting has occurred, but if the needle sinks into the pat, but fails to penetrate it, the initial set has begun.

In stationary kilns the proportion of fuel ash which becomes mixed with the cement is sufficient to make the latter slowsetting. Cement which has been burned in rotary kilns contains much less fuel ash and sets almost instantaneously, unless a suitable amount of a retarding agent is present.

Cement manufacturers supply quick, medium and slowsetting cements, and occasionally a lot may be delivered of a different rate of setting to that to which the user is accustomed.

Owing to the serious consequences which may follow the use of a quick-setting cement without its rate of setting being observed, it is important that each bag of cement should be tested before use.

The three rates of setting are defined in the British Standard Specification as follows :-

Quick.-Initial setting time not less than two minutes.

Final setting time not less than ten minutes, nor more than thirty minutes.

Medium.-Initial setting time not less than ten minutes.

Final setting time not less than half an hour, nor more than two hours.

Slow.-Initial setting time not less than twenty minutes.

Final setting time not less than two hours, nor more than seven hours.

It should be observed that quick-setting cements have a lower tensile strength and a lower compressive strength than those which set more slowly, but this is not invariably the case.

The final set is said to occur when the Vicat needle, having been gently lowered on to the pat, fails to make an impression on it. The needle should be applied at sufficiently frequent intervals-usually every ten minutes-to a different part of 
the pat. Skilled workers usually invert the pat before testing for the final set, as the side uppermost when moulded is usually covered with a misleading scum which is much softer than the cement.

The Vicat needle (Figs. 10 and 11$)^{1}$ ordinarily used consists of a round steel bar which, with its flat head, weighs exactly 300 grammes. At the lower end of this rod a needle or wire exactly $1 \mathrm{sq} . \mathrm{mm}$. in cross section is clamped. The rod carries an indicator which moves over a graduated scale attached to the frame. The cement is held by a split ring $8 \mathrm{~cm}$. in diameter, $4 \mathrm{~cm}$. high $(E)$, resting on a glass plate.

The cement confined in the ring resting on the plate is placed under the rod bearing the needle, which is then gently brought into contact with the surface of the cement and quickly released and allowed to sink into the cement. ${ }^{2}$ This process is repeated until the needle, when brought into contact with the cement, does not pierce it completely, and the period between the time when the cement is filled into the mould and the time at which the needle ceases to pierce the cement completely is the initial setting time above referred to.

Various auxiliary devices, the object of which is to make the Vicat needle automatic and self-registering, have been devised, but none of them are so satisfactory as the simpler form described. ${ }^{3}$

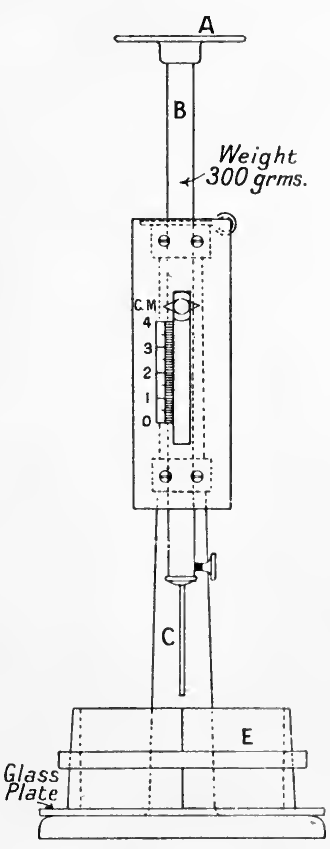

FIG. 10.-Vicat's Needle (front view).

A test which would be better than the use of a Vicat needle would consist in measuring the pressure needed to drill a standard distance into the block of hardened cement. Such

1 The illustrations are of the British Standard Specification pattern.

2 Care must be taken that the needle $C$ rests with its full weight on the pat.

${ }^{3}$ The Vicat needle may, if desired, be fitted with a mechanical attachment, such as a "dash-pot," so as to ensure the steady and gentle application of the point of the needle to the surface of the pat and thereby render the test independent of the hand of the operator. 


\section{TESTING THE PROPERTIES OF CEMENTS}

a test would be particularly useful in distinguishing defective cements which harden only on the surface and leave a soft interior.

A disadvantage applying to all mechanical methods of ascertaining the time of setting and hardening is the fact that the processes which occur in the cement are chemical, and it might be supposed that they would be more accurately measured by thermal than by mechanical methods. For this

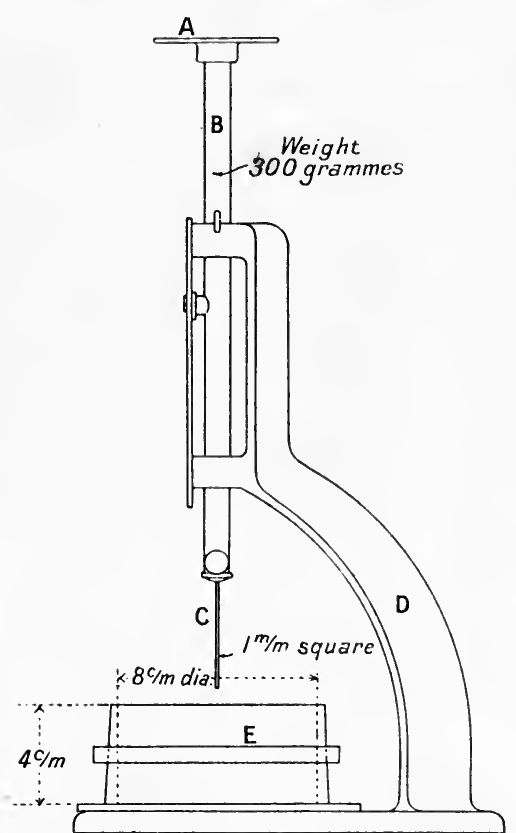

FIG. 11.-Vicat's Needle (side view). reason it is interesting to note that a method originally used by Faija, but abandoned by him in 1884, was revived in a modified form by Gary in 1906. H. Faija observed that when the greased bulb of a thermometer was placed in a pat of cement immediately after gauging, the temperature rose until a maximum was reached, after which it slowly sank to the original temperature. Gary, however, observed that at the moment corresponding to the final set the temperature again rises appreciably. ${ }^{1}$ This method, whilst apparently of great promise, is affected by so many minor considerations, material used and the rate of setting, that much further investigation is necessary before it can be brought into general use. Moreover, its indications do not always agree with the generally accepted Vicat needle test, the second rise in temperature in some cements occurring over an hour after the "final set" shown by the needle. H. Fäija, who investigated

1 W. Ostwald, in 1883, drew attention to the rise in temperature 5-7 days after the first set. W. and D. Assch consider that it is due to the separation and hydration of calcium oxide from the alumino-silieate molecule. 
the thermal method very thoroughly, found its indications were so irregular that he abandoned it in favour of the needle, as constant results can be obtained with the latter. The following table will show the discrepancies between the two methods :-

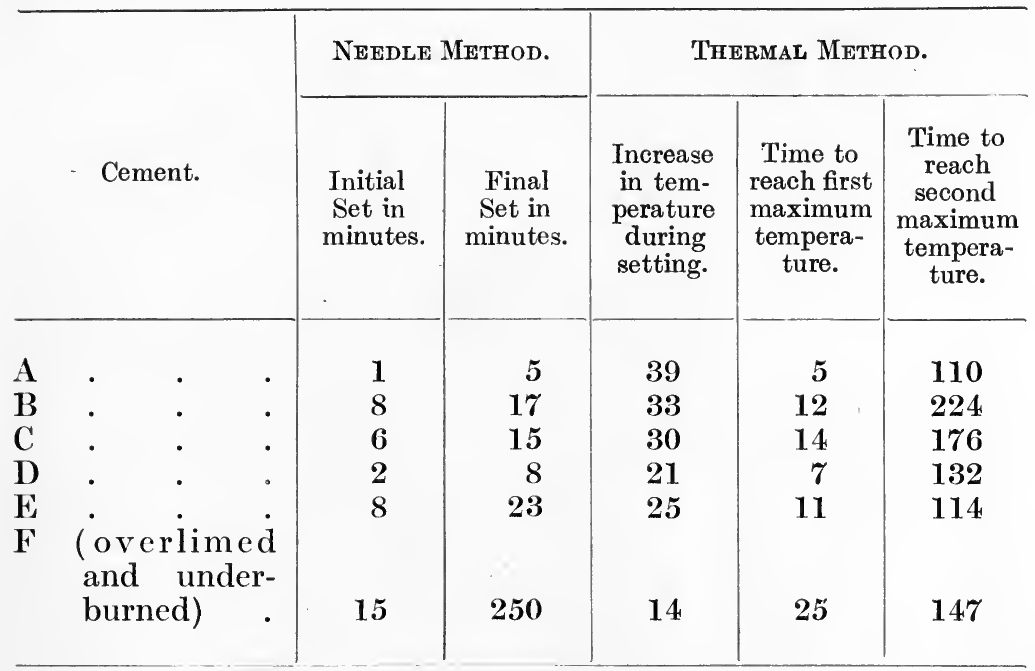

It is very important, in gauging cements which are afterwards to be tested, that the water used should be free from salts, as these would alter the rate of setting.

The use of well water of exceptionally low temperature will cause test pieces to show a low tensile and compressive strength, a difference of only 3 or 4 degrees below the normal being quite sufficient for this purpose (p. 131); hence, the necessity for testing the temperature of all water used for gauging. The mixture of cement and water, or of cement, sand and water, should be of the proper consistency. Unfortunately, it is very difficult to define the limits of consistency, and the amateur should, therefore, make a number of tests on wellknown brands of cement and compare his results with those published by the manufacturer. In this way he will soon learn to judge what is the correct consistency far better than by attempting to use prescribed limits. For the same reason, 


\section{TESTING THE PROPERTIES OF CEMENTS}

the committee responsible for the British Standard Specification express themselves in exceedingly cautious terms, merely providing that "the cement shall be mixed with such a proportion of water that the mixture shall be plastic

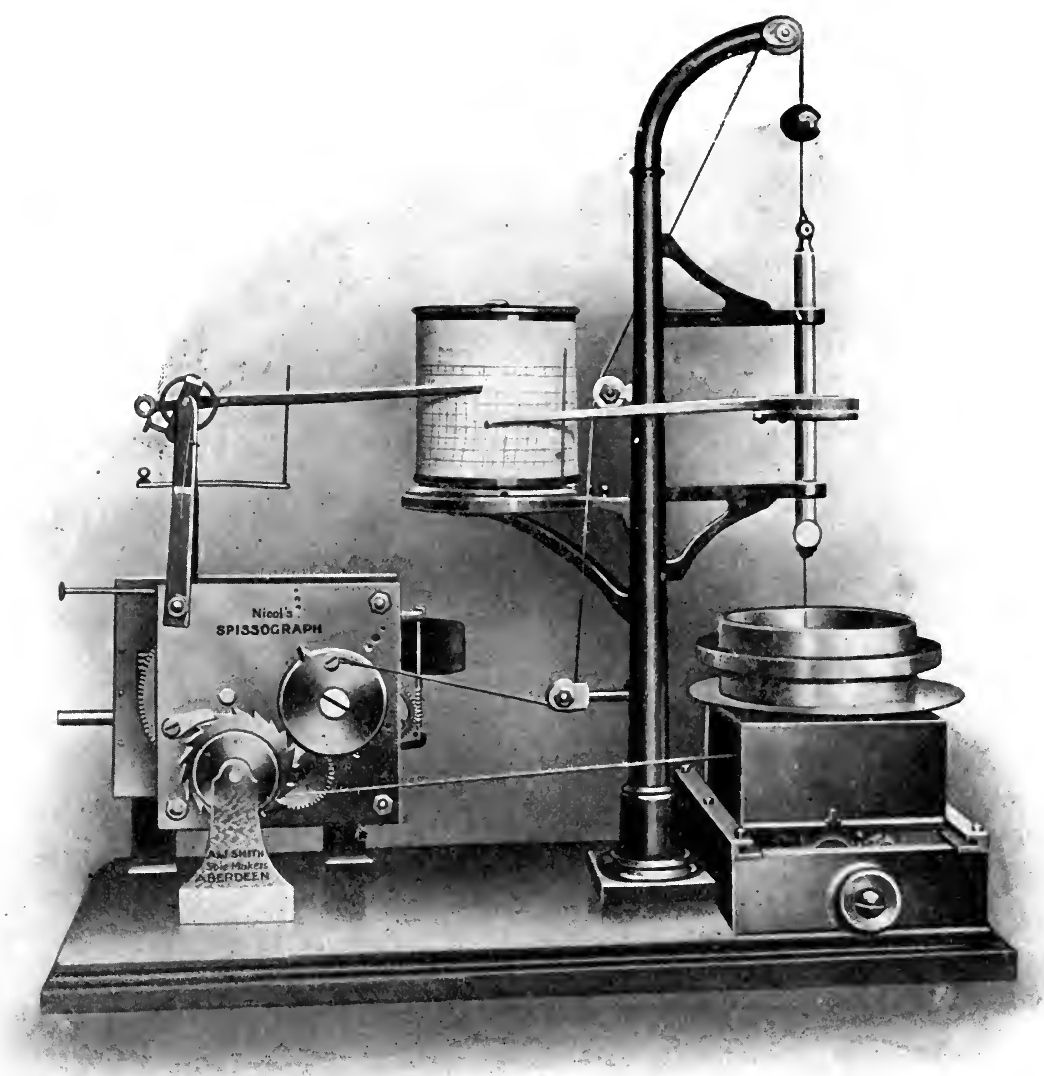

Fig. 12.-Nicol's Spissograph.

when filled into the mould," and adding the proviso that "the gauging shall be completed before signs of setting occur."

In Germany an excess of water is used, a syrup being first 
formed which runs off the trowel in long threads. To this more cement is added in small quantities with vigorous trowelling until the mixture slimes and ceases to adhere to the mixing board.

Where a more accurate guide to the consistency of the paste is required than that offered by noticing its behaviour during the gauging, the makers of one form of Vicat needle (Messrs. Adie, of London) provide a short cylinder $1 \mathrm{~cm}$. in diameter which replaces the ordinary needle. The cement paste is gauged until it has reached what is considered to be the desired consistency, the time taken being carefully observed. It is then placed in the mould supplied with the instrument and tested. The cylinder should sink to a depth of $6 \mathrm{~mm}$. above the level of the glass plate - a scale being provided on the instrument to show the depth it has sunk. If the cylinder sinks further in the paste the latter is too thin; if it does not sink so far the paste is too thick, and fresh proportions of water and cement, or cement and sand, must be tried until the correct consistency is obtained.

An ingenious device for automatically recording the initial and final setting points is Nicol's Spissograph obtainable from A. \& J. Smith, Maxwell House, Aberdeen (Fig. 12). This consists of a Vicat needle suspended from a cord and lowered on to the cement at regular intervals by clockwork. A supplementary mechanism ensures that the needle is applied to a different part of the cement each time it is lowered. The depth to which the needle sinks and the time of each test are marked on a revolving chart.

The gauging ought not to occupy more than three minutes with slow-setting cements, or more than one minute with quick-setting ones. It is essential that the temperature of the cement, water and room in which the gauging is performed should be between $15^{\circ}$ and $16^{\circ} \mathrm{C}$., as variations in the temperature have a marked effect on the rate of setting. Yet comparatively little attention is paid to this matter. If the room is too warm the cements will be found to be quicker setting than they should be, whilst in a cold testing room a quick-setting cement which might cause serious trouble in use may be overlooked. The following 
table by D. B. Butler shows the variations in five typical cements :-

\begin{tabular}{|c|c|c|c|c|c|c|c|c|}
\hline \multirow{3}{*}{$\begin{array}{c}\text { Sample } \\
\text { No. }\end{array}$} & \multicolumn{8}{|c|}{ 'Temperature Centigrade. } \\
\hline & $38^{\circ}$ & $27^{\circ}$ & $16^{\circ}$ & $5^{\circ}$ & $38^{\circ}$ & $27^{\circ}$ & $16^{\circ}$ & $5^{\circ}$ \\
\hline & \multicolumn{4}{|c|}{ Initial set in minutes. } & \multicolumn{4}{|c|}{ Set hard in hours. } \\
\hline 1 & $1 \frac{1}{2}$ & 4 & 6 & 13 & $1 \frac{1}{4}$ & $1 \frac{1}{2}$ & 2 & $2 \frac{1}{2}$ \\
\hline 2 & $3^{2}$ & 5 & 6 & 8 & 1 & $1 \frac{1}{4}$ & $1 \frac{3}{4}$ & $2 \frac{1}{2}$ \\
\hline 3 & 4 & 10 & 15 & 20 & $\frac{1}{2}$ & $\frac{3}{4}$ & $1 \frac{1}{2}$ & $6 \frac{1}{2}$ \\
\hline 8 & 10 & 15 & 35 & 40 & $\frac{3}{4}$ & 1 & $1 \frac{1}{4}$ & $1 \frac{3}{4}$ \\
\hline 12 & 15 & 35 & 70 & 360 & $3 \frac{4}{2}$ & 6 & $7^{4}$ & $22^{4}$ \\
\hline
\end{tabular}

The increased rate at which cements set at slightly higher temperatures than the normal makes it necessary in the tropics to employ cements which would here be very slow in setting.

\section{SOUNDNESS.}

In order that a cement may be useful and satisfactory, it must not undergo any changes in volume when in use under any probable conditions of exposure. If the cement shrinks unduly during setting it will produce cracks, whilst if it expands after setting a different kind of cracking is produced, which is known technically as "blowing." Excessive contraction is seldom observed in Portland cements, the minute cracks produced by the small contraction which occurs in most cements being almost entirely superficial, and have no appreciable effect on the strength of the cement. Expansion after setting (" blowing ") is, on the contrary, one of the commonest defects of badly made or inferior cements, and as the results of such expansion are serious, and may even result in the destruction of a building with loss of life, it is of the greatest importance to ascertain by appropriate tests whether such expansion is likely to occur. A cement which cracks or twists after setting is said to be unsound.

Unsoundness is usually attributed to the too tardy hydration 
of some of the constituents of a cement. It may, to some extent, be a result of imperfect mixing or gauging of the cement with water, or to the occurrence in the cement of undesirable substances. Thus, it is well known that quicklime has a powerfully expansive force when moistened, and some other calcareous compounds possess the same property. Quite recently, however, Hans Kühl has found, experimentally, that normal Portland cements (with and without gypsum), dead burned lime and quick-lime have a smaller volume when mixed with water than the sum of the volumes of the solid substance and the water, the contraction being greater with cements than with quick-lime. Cements which "blow" badly after setting were found by Kühl to have a much smaller contraction (in some cases they expanded), from which he concludes that the true cause of "blowing" and expansion in cement is to be found in the formation of crystals from a supersaturated solution and in the pressure due to this crystallisation.

In former years much of the unsoundness of cements was due to the use of too much lime in the raw materials; this is now a far less frequent cause.

A cement in which there is an appreciable proportion of free lime or an excessive proportion of magnesia or of sulphates is usually unsound, and though each of these substances undergoes a different chemical reaction with water, the final physical effect-expansion and possible destruction of the materialis the same.

The action of magnesia in unsound cement is not clearly understood. The strict limitation as to the proportion of magnesia permissible is due to the collapse of certain bridges and other structures, including the Cassel Town Hall, in which magnesian limestone was used in the manufacture of the cement. In these cases the defects were attributed to the magnesia present, though it is by no means improbable that this is erroneous, as excellent samples of cement have been prepared from magnesian limestone. It is, however, necessary to burn cements containing magnesia at a higher temperature than when no magnesia is present (see p. 73).

Magnesia requires a much higher temperature before it 


\section{8}

combines with clay to form a cement; if strongly heated, yet insufficiently so to effect combination, it will prove dangerous on account of the great expansion of highly calcined magnesia in the presence of water. Lightly calcined magnesia has no influence on cement. The increasing use of cements containing a large proportion of magnesia indicates that the danger of this oxide is far less than is commonly supposed, if only the conditions of manufacture, and particularly of burning, are correct. Improperly burned cements-whether made of purely calcareous or magnesian limestones-will be defective, the latter being particularly so. Hence the limit of 3 per cent. imposed in the British specification is a wise one.

The action of sulphates on cement is discussed iater, in the section on concrete, as it is of great importance in connection with maritime work.

The presence of free lime or of lime in an unsuitable state of combination is usually regarded as the chief and commonest cause of unsoundness in cements. Properly prepared Portland cement contains no free lime, but although the original proportion of lime in the cement-mix may have been correct, it is not unusual, particularly when some of the earlier methods of settling, drying and burning are used, for the final clinker to be far from uniform in composition. With rotary kilns fed with slurry there is less likelihood of the various materials becoming unmixed, but in the intermittent, stationary kilns fed with broken lumps of deposited material, the extent of the irregularity is considerable, and, in some cases, is serious. This irregularity in composition is partly due to defective mixing appliances and partly to the natural tendency of materials mixed in the "wet process" to "settle out" in the wash-backs or settling tanks. No amount of grinding and mixing of the clinker will entirely remove the lack of homogeneity, for the well-mixed clinker will be composed partly of true cement and partly of calcined but uncombined materials, and can thus destroy the value of the whole material. Underburning may also account for the presence of free lime in the cement, and almost always occurs when stationary kilns are used, owing to irregularities in the draught; the injurious action of this is avoided by carefully sorting out the clinker 
before sending it to the mills. Under-burning occurs to only an insignificant extent in well-managed rotary kilns. Free lime in Portland cement is seldom due to wrong proportions of the raw ingredients, special care being taken to avoid this. It may be avoided by carefully checking the proportions of the raw mix and by securing as uniform a mixing and burning as possible, but as there is always a chance of free lime being present it is advisable to test all batches of cement as to their soundness.

The general opinion that free lime is the cause of unsoundness in Portland cements is disputed by H. E. Kiefer, who found that, with sufficiently fine grinding, a mixture of cement and quick-lime containing 25 per cent. of lime will pass the ordinary tests for soundness. To avoid blowing, all that is necessary is that the lime shall be so finely ground that it becomes hydrated immediately. Kiefer's investigations seem to show that the phenomenon of "seasoning" is not so much one of hydrating the free lime as a decrepitation process in which the glassy particles of the cement are broken up. This is shown by the increased percentage of fine particles in a cement which has been stored in vacuo for some weeks. If Kiefer's views are correct the widely-held theory that unsoundness is due to free lime is not well founded.

The soundness of a cement is difficult to ascertain with great accuracy, as the majority of the Portland cements now on the market are of such a character that they all pass any ordinary test for unsoundness. A very large number of different tests have been proposed as indicating the soundness or otherwise of a cement, and some of these are so severe as to make it questionable whether they really measure the soundness at all. In nearly all soundness tests the cement is subjected to very trying conditions, and any changes in it (such as an increase in volume, cracking, etc.) are noted. A cement in which no change can be found is regarded as sound under the conditions of the test.

A test which is remarkably accurate, considering its simplicity, consists in gauging some of the cement to be tested with sufficient water to form a slurry or cream. This is then poured into a test-tube until the latter is full. The test-tube 
with its contents is hung in a tank of cold water for one or more days. If the cement expands, due to imperfect burning or over-liming, it will crack the test-tube ; if it contracts, because the raw materials do not contain sufficient lime, the cement will shrink and become loose in the tube. Unfortunately the test-tube with its contents cannot be immersed in hot water, as the glass and cement expand unequally, and the former is cracked even with sound cements.

The contraction of cements after setting is tested by means of a tapered metal mould which is filled with cement paste. If the cement shrinks or contracts it will gradually become loose, whilst a cement of constant volume will remain so tight in the mould as to be difficult to remove. There is no official test for contraction, but the mould used for determining the rate of hardening is generally made tapered and is commonly used for ascertaining whether a cement shrinks.

Owing to the naturally slow hydration and other changes which occur during the hardening of cement it is almost hopeless to expect that any tests for soundness can be made with much rapidity. Moreover, it does not necessarily follow that because a cement can withstand the action of boiling water for several hours it will therefore resist exposure for several years; in other words, an accelerated test does not necessarily give the same results as actual use, during which the cement hardens slowly in air. The present tests must, therefore, be regarded as tentative in character. The value of such accelerated tests is disputed by many cement manufacturers and chemists, and to such a height did controversy rise at one time with regard to Le Chatelier's test (p. 125) that an International Congress Committee was appointed to investigate it thoroughly, and found it quite trustworthy and capable of detecting unsound cements which were passed as good by a number of other tests. Even at the present time the German manufacturers object to this test, on the ground that it gives different results with the same cement when tested in different places, and that it has failed to condemn some cements which swell when tested by the usual German method, viz., keeping pats in cold water for a month.

Although all hot-water tests do undoubtedly reject some 
sound cements, from the user's point of view there are so many firms manufacturing cement which will stand the action of boiling water that these naturally have the preference. Some injustice is done to those manufacturers of sound cements which will not stand these tests, but under present commercial conditions this appears to be unavoidable. The student should, however, always bear in mind that a cement is not necessarily unsound because it cannot stand the Le Chatelier test; at the same time, all cements which do pass this test can be relied on as being sound in use so far as the existence in them of expansive ingredients is concerned.

The whole attitude of those responsible for the officially recognised tests is somewhat inconsistent so far as accelerated tests are concerned, and in different countries widely differing opinions are held. Thus, in the German Standard Rules recently issued, accelerated tests are entirely ignored, and in the American Standard Specification the following significant paragraph is included : "In the present state of our knowledge it cannot be said that cement should necessarily be condemned simply for failure to pass the accelerated tests; nor can a cement be considered entirely satisfactory simply because it has passed these tests."

Whatever excellent reasons there may be for or against accelerated tests, it is clearly unwise for engineers and others engaged in the use of cement to be too dogmatic on the subject. It is a well-known fact that fifteen years ago not 10 per cent. of Portland cement manufactured in England or elsewhere would withstand boiling-water tests, and the obvious inference is that if these are a true test for soundness, 90 per cent. of the cement used fifteen years ago was unsound. This, in view of the hundreds of thousands of tons then used for important engineering work throughout the world, is rather startling and, having regard to the excellent condition of such work at the present time, is a view that cannot be seriously maintained. The risk of using unsound cement is so great, however, that it is questionable whether any test can be really too severe, providing that it is a true test for soundness and not for some unimportant property.

The earliest method of testing the soundness of a cement 


\section{2}

consisted in making the cement paste into a thin pat with tapering edges and in placing it in water as soon as it is set. If at the end of a week it developed no cracks or twists it was considered to be sound. This is known as the "plunge test," but is now seldom used; it has been found in practice to be too lenient, as exposure for a longer period frequently developed cracks, and it is unfair to cements which set very slowly. It has, therefore, been modified to avoid this objection. 'Thus, in what is known as the "cold water test," the cement pat is kept for twenty-four hours in moist air and is then placed in water for twenty-eight days. This modification requires an inconveniently long time, and is considered to be too lenient ; its severity has therefore been increased in various ways. At the other extreme is Erdmenger's test, in which the test pieces are heated in an autoclave under a pressure of $560 \mathrm{lbs}$. per square inch; this test has been regarded as unnecessarily severe.

Of the accelerated tests, that devised by $\mathrm{H}$. Faija was exceedingly popular for some years. It consists in maintaining a freshly gauged pat in water vapour at a temperature of $38^{\circ}$ to $40^{\circ} \mathrm{C}$. for about seven hours, or until thoroughly set, and then immersing it in water of a temperature of $46^{\circ}$ to $49^{\circ} \mathrm{C}$. for the remainder of the twenty-four hours. A sketch of the apparatus used is shown in Fig. 13. It consists of a double-walled vessel in which the space between the walls is filled with water to act as a temperature equaliser. The inner vessel is only partially filled with water so that pats of cement placed on the shelf shown are immersed in vapour. According to D. B. Butler, who has an exceptionally thorough acquaintance with this test, a cement can be relied upon with perfect confidence if, after being treated in the manner described, it shows no signs of cracking or blowing at the end of twenty-four hours and adheres firmly to the glass plate on which it was made. Butler insists that the narrow limits of temperature prescribed are essential ; if a lower temperature than $46^{\circ} \mathrm{C}$. is permitted a faulty cement will go undetected, whilst if exposed to too high a temperature some cements will be condemned which would prove satisfactory in use. The great advantage of the Faija test is that it requires only 
twenty-four hours to sort out almost all the defective cementssubmitted to it, and where testing machines and plant are not available it is generally quite satisfactory. During the past few years, however, the demand for more severe tests, in which the cement is exposed to the action of boiling instead of merely warm water, has resulted in the Faija test falling into disuse, the Le Chatelier test being included in the British Standard Specification.

The most characteristic feature of Faija's test, viz., exposure of the freshly-made pat to warm moist air in order to accelerate the setting and hardening, has been abandoned in more recent tests in favour of a longer exposure to cold moist air. This is regarded by many of those interested in cement as unfortunate, for extensive experiments have shown that the higher temperature has a very important effect on the cement.

Deval's Hot Water Test has also been the subject of much controversy. It consisted originally in allowing a pat of cement to remain in moist air for twenty-four hours and then immersing it

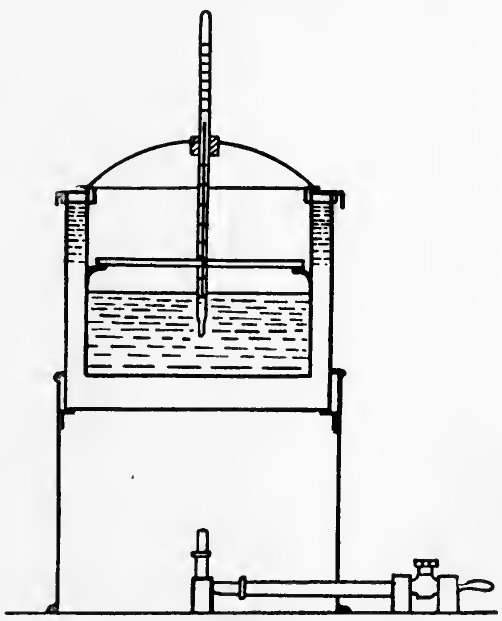

FIG. 13.-H. Faija's Test for Soundness. in hot water at a temperature of $80^{\circ} \mathrm{C}$. for six days or more, after which treatment sound cements are to show no signs of twisting, cracking or blowing. The tensile strength of test pieces subject to Deval's test is equal to that gained after twenty-seven days' immersion in cold water. More recently, the temperature of the water used in the test has been raised to boiling point, and the time has been shortened to three hours, both of which modifications will greatly simplify the test. In this modified form the test is much used in Germany under the somewhat inappropriate term, "Darrprobe," which really signifies a drying test. Twelve or fourteen 
years ago Deval's test was considered to be unduly severe, but so greatly has the manufacture of cement improved within the last decade that in 1909 the International Association for Testing Materials found that all good cements stood it easily, but that it was uncertain in indicating some doubtful ones. On the recommendation of this association it was therefore abandoned in Great Britain in favour of the Le Chatelier test.

Bauschinger's Method.-One of the most accurate methods of measuring the expansion or contraction of cement is that devised by Bauschinger, who uses a special micrometer calliper, in which the test pieces consist of prisms or square bars $100 \mathrm{~mm}$. long and $22 \mathrm{~mm}$. by $22 \mathrm{~mm}$. cross section; the delicacy of the instrument is such that variations in the length of the bar to within $\frac{1}{2} \frac{1}{0} \mathrm{~mm}$., or 0.0005 per cent., can be determined with certainty. It requires, however, such very careful expert handling, and is somewhat expensive (the equipment, including moulds, costing about $£ 12$ ), that it is only used for research purposes when an unusually high degree of exactitude is required.

Le Chatelier's Test is based on a somewhat different principle to those previously mentioned. Instead of the treated samples being examined for cracks they are measured before and after heating in water and the amount of expansion is noted. Le Chatelier's test is therefore much more sensitive than the earlier ones, and is correspondingly more severe. The total increase in volume is exceedingly small, and is almost impossible of direct measurement except with the use of exceedingly delicate appliances, which are more suited to the purposes of scientific research than to the needs of the cement manufacturer and user. This difficulty has, however, been overcome in a very ingenious manner by the invention by Le Chatelier of a special calliper (Fig. 14) which greatly magnifies the expansion. Le Chatelier's calliper ${ }^{1}$ consists of a brass cylinder 0.5 $\mathrm{mm} .(\cdot 02 \mathrm{inch})$ in thickness forming a mould $30 \mathrm{~mm} .\left(1 \frac{3}{16}\right.$ inch $)$ internal diameter, and $30 \mathrm{~mm}$. ( $1 \frac{3}{16}$ inch) high. This ring is split, and on each side of the split an indicator $165 \mathrm{~mm}$. ( $6 \frac{1}{2}$ inches) long is attached. The free ends of these indicators are pointed so as to facilitate accurate and rapid reading.

1 This description of the instrument and test is taken from the British Standard Specification. 
In carrying out the test the calliper is placed on a small sheet of glass and is filled with freshly-gauged cement, the edges of the cylinder being kept together during this operation by means of a clip or piece of fine string. The cylinder is then covered with another piece of glass on which a small weight is placed, and the whole appliance is then placed in cold water $\left(15^{\circ} \mathrm{C}\right.$.) for twenty-four hours. The calliper is then taken out of the water, the clip or string fastening removed, and the distance apart of the points of the indicators is accurately measured, and the calliper with its contents is then placed in cold water which is heated at such a rate that it boils in about half an hour and is kept boiling for six hours. The calliper is
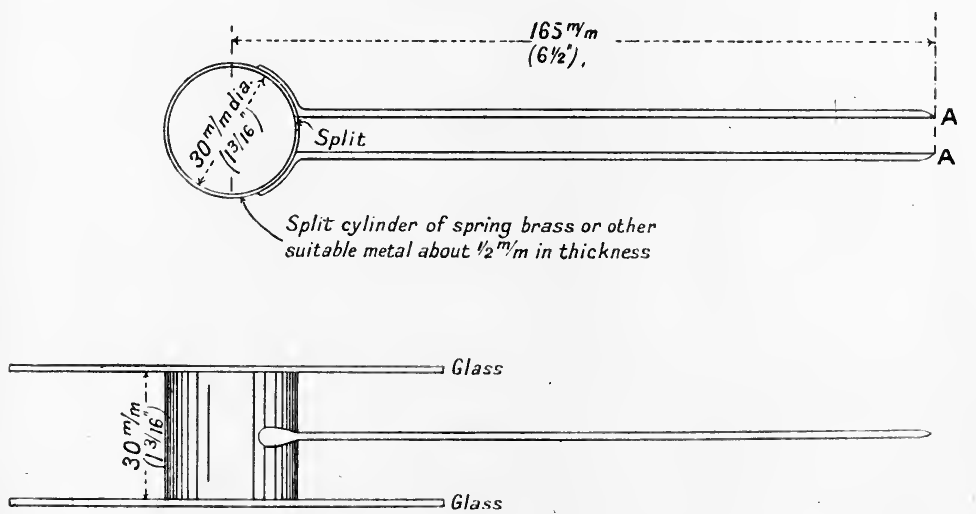

Fig. 14.-Le Chatelier's Test.

again removed from the water, allowed to cool, and the distance apart of the pointed ends of the indicators is again measured. The increase in their distance is proportionate to the expansion of the cement. The British Standard Specification imposes the following limits of expansion under the foregoing conditions: The difference between the two measurements must not exceed the following limits, namely, $10 \mathrm{~mm}$. when the cement has been spread in a layer three inches thick and exposed to the air for twenty-four hours, or, if this fails, $5 \mathrm{~mm}$. after the cement has been exposed to the air for seven days in the same manner.

In cold water, iron cements expand rather more than Portland 
cements, a mixture of hydraulic lime and sand (1:3) shows the same expansion as Portland cement, whilst a mixture composed of four parts of trass, three of lime and two of sand only expands half as much as Portland cement. Roman cements usually show an expansion of $20 \mathrm{~mm}$., and hydraulic limes an expansion of $4 \mathrm{~mm}$. in the Le Chatelier test. None of these substitutes for Portland cement can withstand long exposure to boiling water; they crack and disintegrate.

As previously mentioned (p. 120), Le Chatelier's test is by no means generally accepted, notwithstanding its inclusion in several standard specifications. It yields some curiously anomalous results at times, such as greater expansion in cold water than after boiling for six hours. Some of the difficulties experienced in its use are undoubtedly due to the delicacy of the measurements to be made ; others are due to an insufficient allowance for certain characteristics in the cements themselves. Thus, cements which set very slowly will yield bad results if tested in the ordinary manner by Le Chatelier's method, but if the same cements are allowed to harden properly before being tested the results will be normal, i.e., there will be only a trifling increase in volume. This test is, therefore, unsuitable for cements which do not set hard in twenty-four hours. The results of the Le Chatelier test should not, for these reasons, be interpreted too rigidly.

The soundness of cement is increased by fine grinding, but in many cases users do not avail themselves of the extra fineness (which should enable them to use less cement), but continue to use the same proportion as in years gone by when only coarse cements were available.

\section{COMPRESSIVE STRENGTH.}

The value of a cement depends chiefly on its power to bind particles of inert material together so as to form a compact mass of great strength. The chief mechanical resistance required by structural materials in which cement is used is that to compression, and, accordingly, the compressive strength of cement, and more particularly of concrete or cement-sand mortar, is of the greatest importance. 
The compressive strength of a cement, concrete or mortar is ascertained by crushing cubes of the material in a hydraulic press (Fig. 93), the pressure applied being measured by means of a sensitive gauge. The cubes usually measure three inches, or $70.7 \mathrm{~mm}$., each side for cement, and 6 -inch cubes for concrete.

The Tests Committee of the Concrete Institute specify a crushing test in addition to the tests in the British Standard Specification. This test is carried out as follows: 3-inch cubes consisting of three parts by weight of standard sand to one part of cement shall be made in the manner described for cement-sand mixtures used in the tensile test. The crushing strength shall not be less than ten times the tensile strength after twenty-eight days required by the British Standard Specification.

It is difficult to obtain uniform results in tests of the compressive strength of cement, as apparently trifling differences in the arrangement of the cubes or in the distribution of the pressure produce marked variations in the result. To equalise the pressure as far as possible, thin boards of soft wood are placed above and below the cube to be tested. If the crushing strain has been properly distributed the cube will, when crushed, leave two fairly perfect pyramids.

Tests of compressive strength form part of the official tests on the Continent, but in Great Britain they are seldom made, the difficulties in the way of obtaining concordant results being considered to be too great for the test to be brought into general use. The unsatisfactoriness of the results of tensile tests and the obvious advantages of compressive tests are, however, becoming more generally recognised, and it is probable that before many years a minimum compressive strength (probably $250 \mathrm{lbs}$. per square inch) will be included in the British Standard Specification. However, it has been found that the tensile strength is so closely proportionate to the compressive strength in well-made cements, being usually onetenth $^{1}$ of the latter, and tests of tensile strength are so much easier to make, that they are generally substituted for compressive tests.

1 The ratio of tensile to compressive strength increases with time, so that in very old mortars it may be as high as $1 \cdot 18$. 


\section{TENSILE STRENGTH.}

At the present time, the test which is regarded as of the chief importance is that of tensile strength. Although it is very convenient, the test itself is so illogical (cement structures seldom, if ever, being subjected to tensile stresses) and the results are so erratic that it cannot be regarded as really satisfactory. It is commonly supposed that the tensile strength is directly proportionate to the compressive strength of the material, but this ratio is only approximate and varies considerably with different cements. This has been fully established by results obtained by Tetmajor. Hence, the test

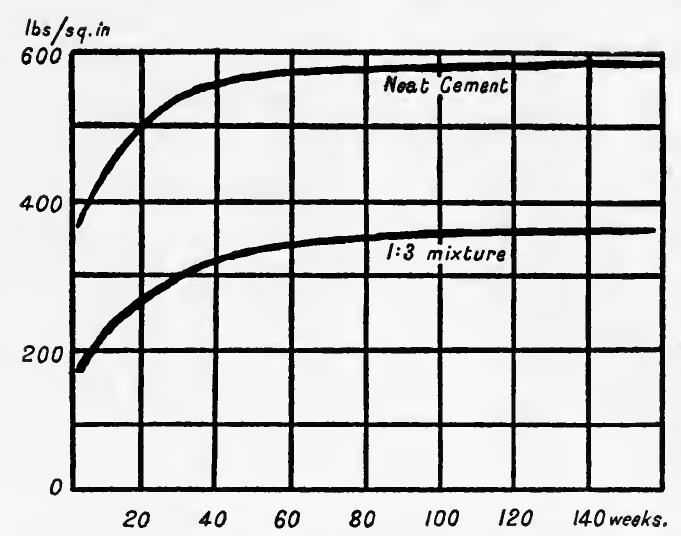

Fig. 15.-Increase of Tensile Strength with Time (Unwin). of tensile strength is only used because of its general convenience and should be replaced by compressive tests whenever possible.

As will be understood from the statements made in respect of setting and hardening in a previous chapter, cements gradually increase in strength as they increase in hardness. The increase is very rapid at first, but becomes increasingly slow with the age of the gauged material, and though it does not reach a complete maximum, even after several years, the strength reached after two years is so near to the final maximum that it may be regarded as identical for most purposes. The chemical and physical changes which occur during hardening are extremely complex, and it is therefore necessary to determine the strength of a cement on at least two different dates, which should be as widely separated as possible. From a number of such tests a graph may then be drawn and the probable maximum strength of the cement ascertained by extrapolation. Two such graphs obtained by 
W. C. Unwin, in 1886, are shown in Fig. 15. The increase in strength is so rapid during the first week that it cannot be used for estimating the maximum strength likely to be developed; after the expiration of a year the rate of increase is very slow, and the total strength then approaches the maximum.

It will be thus understood that the total strength is likely to be greatest when the rate of increase does not diminish very rapidly during the weeks following the first. Hence, the custom has arisen of ascertaining the tensile strength at the end of three, seven and twenty-eight days, respectively, from the time of gauging. Much longer intervals are desirable, but are impracticable under most circumstances, and, so far, the three periods just mentioned appear to give a sufficient clue as to the probable maximum strength. It is not desirable to calculate the maximum strength likely to be developed, but to see that the strength at certain periods after gauging is above certain minimum limits. The most suitable limits recognised at the present time are prescribed in the standard specifications of the chief civilised countries where Portland cement is used. Thus, the British Standard Specification demands that test pieces (erroneously termed "briquettes"), made as directed (see p. 132) and tested in a suitable machine, in which the load is applied steadily at the rate of $100 \mathrm{lbs}$. in twelve seconds, shall give the following results :-

For Neat ${ }^{1}$ Cement :

25 per cent. when the seven-day test is above $400 \mathrm{lbs}$. and not above $450 \mathrm{lbs}$.

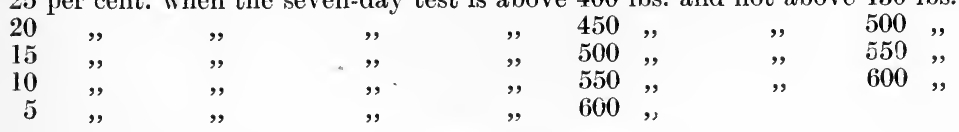

For $1: 3$ Cement-Sand Mortar :

25 per cent. when the seven-day test is above $200 \mathrm{lbs}$. and not above $250 \mathrm{lbs}$.

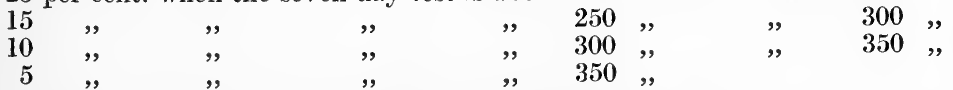

Measurements of the tensile strength of test piøces which have been "aged" artificially by immersion in hot water : ave

1 By neat cement is meant a mixture of cement and water alone, no sand or other aggregate being added. The objections to tests of the tensile strength of neat cements are stated later under sand-cement tests.

c. 
not given satisfactory results, the strength of the " accelerated" test pieces never showing any definite relation to those of the same cements kept under normal conditions for more lengthy periods. Attempts to measure the strength of " accelerated" test pieces have now been abandoned. Accelerated tests, omitting the determination of the tensile strength, are, however, valuable for indicating the presence of expanding constituents (p. 120).

The complexity of the reaction which occurs during the hardening of cement is so great that the utmost care must be taken in gauging the cement (or cement-sand mixture) with water if uniform results are to be obtained. For the same reason at least six test pieces must be used for each test, as single tests are often far from correct. The following precautions are essential :-

(a) The proportion of water used must be correct within somewhat narrow limits. This has already been mentioned with regard to the setting and hardening (soundness) of cements (p. 113), but it is particularly important in connection with the tensile tests. No definite proportions of water can be specified, as cements differ greatly in the amounts they require. It may, however, be taken that the best-known brands of Portland cement require about 18 to 25 per cent. of water for neat cement, and about 12 per cent. for the usual $3: 1$ mixture of sand and cement. The smaller the proportion of water the better will be the results. Some amount of experience and skill is needed to know whether sufficient or too much water has been added. If the former, the cement will crumble under the trowel used for mixing it and cannot be made to take a smooth surface ; with too much water, on the contrary, the paste will be so fluid that it can be poured from one vessel to another. It will usually be found that if the water just rises to the surface of the cement when the mixture has been well smoothed with a trowel, the mixture has the right consistency - It will then be plastic without being unduly dry c. iruid. This plastic mass can be mixed and moulded to the greatest advantage and is therefore preferred to a drier mixture possibly containing only 10 per cent. of water, though the latter may give a stronger product. Such dry mixtures give 
such irregular results, however, that they cannot be relied upon.

The British Standard Specification gives no precise directions as to the proportion of water, but merely states that it must be such that " after filling into the mould the mixture shall be plastic."

(b) The temperature of both water and cement must be normal, i.e., between $14 \frac{1}{2}^{\circ}$ and $18^{\circ} \mathrm{C}$. $\left(58^{\circ}\right.$ to $64^{\circ} \mathrm{F}$.). If the temperature of the water is only $10^{\circ} \mathrm{C}$. above normal the strength of the cement may be reduced 20 per cent.

Lack of increase in strength on storage is also frequently traceable to the cement being tested in too hot a room, wherein the test pieces harden so rapidly that they really form accelerated tests. This trouble is particularly noticeable in summer in buildings with iron or glass roofs.

(c) The duration of the gauging must be controlled. Steinbrück has found that the strength of cement increases with the thoroughness and duration of the gauging so long as the commencement of the initial set is not reached. This merely

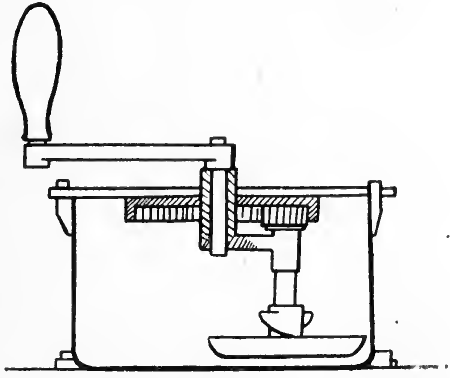

FIG. 16.-Faija's Mechanical Gauger. means that the better the mixing the stronger will be the cement, and for this reason, and because the gauging of many cements becomes extremely fatiguing, the author has made extensive use of a simple mechanical gauger devised by H. Faija (Fig. 16). This consists of a circular pan about one foot in diameter, within which revolve the arms of a stirrer. These arms revolve round their own axis in one direction and round the pan in the reverse, this motion being given them by an internally toothed wheel, which actuates the pinion of the stirring spindle. The modus operandi is as follows: After having ascertained, by means of a preliminary hand-gauged pat, how much water the cement under treatment requires, sufficient cement to fill a nest of moulds is put into the gauger, and the correct amount of water added all at once. The 
handle of the machine is then turned fairly quickly for a half or three-quarters of a minute, by which time it will be found that the cement is thoroughly incorporated with the water, and the mass is in a proper condition to be turned out on the gauging plate or bench and filled into the moulds. In gauging cement and sand in this machine, for making sand briquettes, it is necessary, of course, first thoroughly to mix the sand and

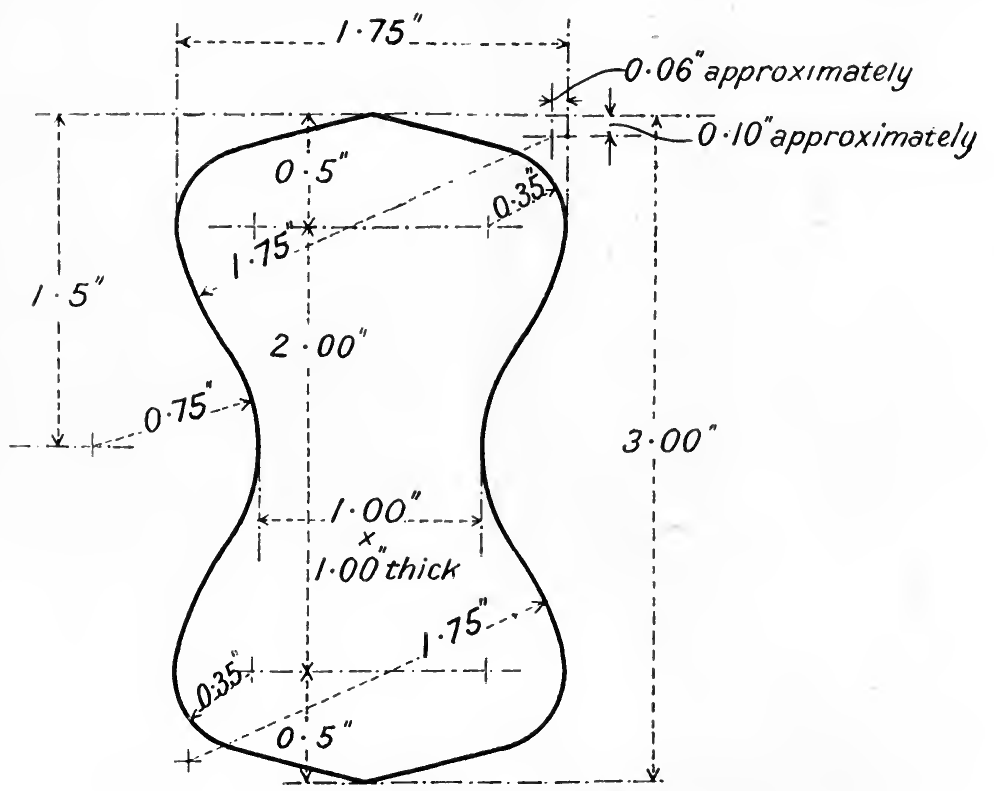

Fig. 17.-Dimensions of British Standard Test Piece.

cement in the dry state, after which the same routine may be followed. By the use of this machine two or three pounds of cement at a time can be efficiently gauged in a few minutes, and personal experience has proved it to be of the greatest value in avoiding the labour and wrist work necessary to bring the cement to a proper consistency with a trowel.

The whole operation of filling a nest of moulds, from the time of adding the water, should not exceed five or six minutes, and after being smoothed off with a trowel, the moulds should be placed on one side until the briquettes are sufficiently set to be removed. 
During recent years the Steinbrück-Schmelzer machine has been brought into extensive use for gauging cement for testing purposes. This machine consists chiefly of a single edgerunner moving in a rotating annular trough. Both roller and trough move in the same direction but at different speeds, the paste being turned over by two curved scrapers. The action of this machine is very satisfactory, about twenty rotations of the pan being ample to mix the cement. The roller and scrapers are then moved out of the way, giving ready access to the paste, and permitting of a rapid cleaning of the machine.

If a cement is very quick setting it may be necessary to gauge it by hand in very small quantities at a time, or it may be spread out in a thin layer and exposure to the air to aerate for two or three days ; this exposure will make it slower setting. The addition of any retarding agent to a cement for the purpose of facilitating the testing is expressly forbidden in the British Standard Specifica-

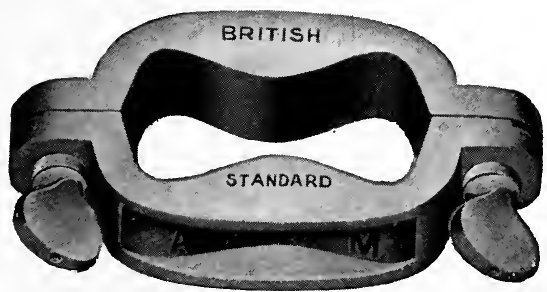
tion. On no account must Fig. 18.-Mould for Testing Cement. the gauging be continued after the initial set has commenced, or the strength of the material will be irretrievably reduced. In gauging cements of which the rate of setting is unknown it is, therefore, desirable to test the rate of setting as described on p. 109.

(d) The mould must be of standard size and shape. That now universally adopted was devised by Grant, but the shape of the ends has been modified. Fig. 17 shows the standard dimensions, and Fig. 18 the mould. The mould and plate on which it stands should be slightly oiled before use.

(e) The moulds must all be filled in a uniform manner. "The usual method consists in placing the mould on a glass or smooth metal plate, taking up on a trowel more paste than will fill the mould, throwing the paste into the latter, and then tamping it with the trowel until the mould is filled evenly, and the water rises to the surface, giving it a shiny appearance. The 


\section{TES'TING THE PROPERTIES OF CEMENTS}

superfluous paste is then cut off by drawing the edge of the trowel across the top of the mould.

(f) The test piece must be stored under standard conditions. It is important that the moulds and their contents should be
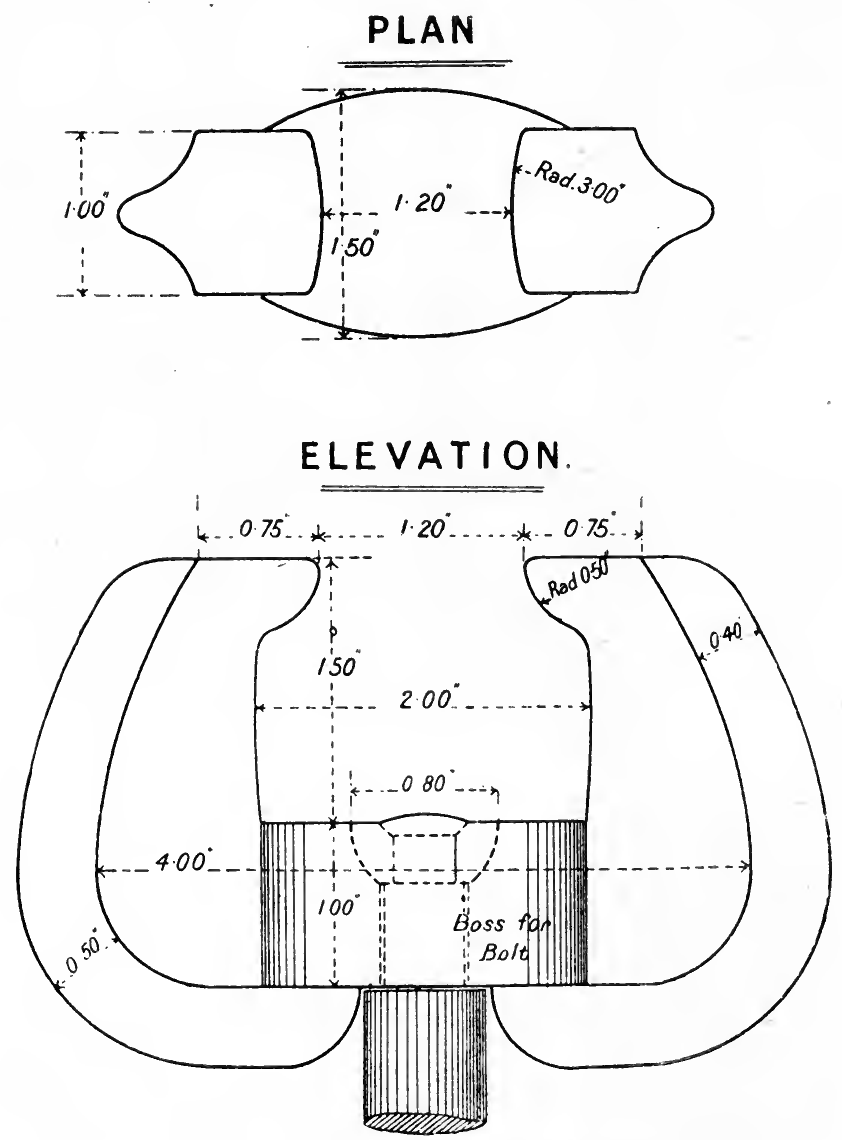

FIG. 19.-Jaws of Tensile Machine.

placed on a bench which is free from vibration, or the strength of the test pieces will be impaired. If kept on the same bench or table as that used for filling other moulds, low results will be obtained, and too much care cannot be taken in this respect, particularly when tests are made of mixtures of cement and 
sand. It should also be noted that all test pieces used for strength tests should be kept immersed in water until ready for testing. This keeps them at a uniform temperature and also makes the test rather more severe than when the test pieces are kept in air.

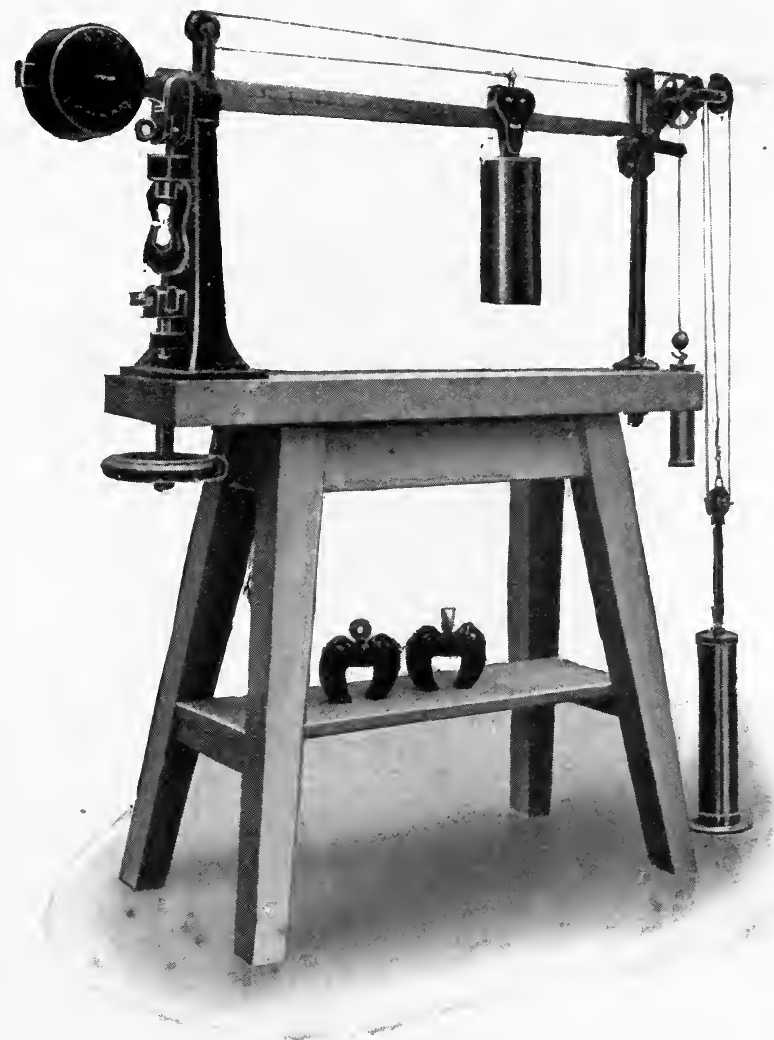

Fiç. 20.-Tensile Test Machine. (Adit.)

The British Standard Specification demands that when the cement has set sufficiently to enable the test piece to be removed from the mould without injury, it is so removed and kept in a damp atmosphere for the remainder of the twentyfour hours after gauging. It is then to be placed in clean fresh water and allowed to remain there until required for breaking. 
The water used for this purpose is to be changed every seven days, and is to be maintained throughout at a temperature of $14 \frac{1}{2}^{\circ}$ to $18^{\circ} \mathrm{C}$. $\left(58^{\circ}\right.$ to $64^{\circ} \mathrm{F}$. $)$.

The test pieces are to be tested for tensile strength at seven and twenty-eight days after gauging, six pieces being used for each period.

(g) The jaws of the testing machine must be of standard size and shape. Those most generally used are the ones recognised by the British Standard Specification, and shown in Fig. 19. The test pieces are greased slightly where they come in contact with the jaws.

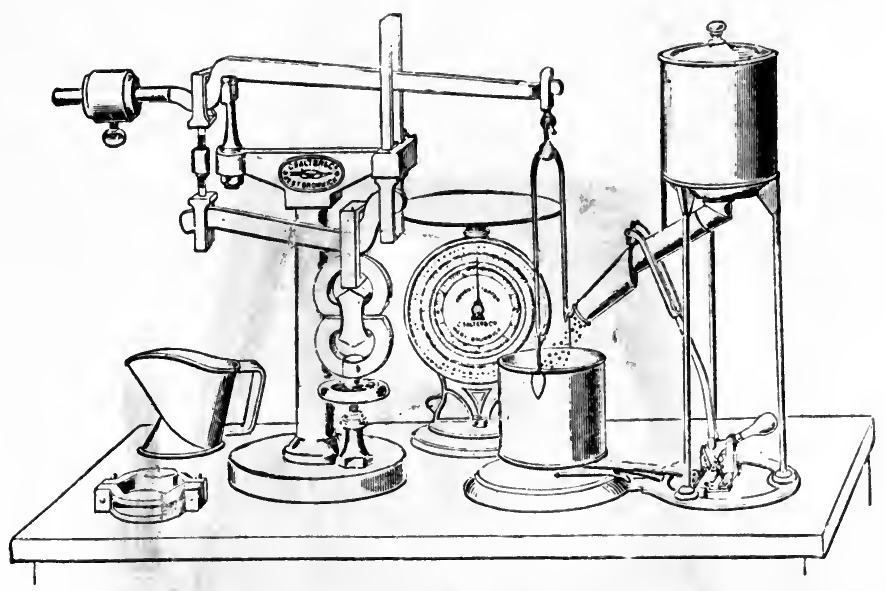

FIg. 21.-Tensile Test Machine. (Salter \& Co.)

The testing machine may be of any convenient pattern; one of the most compact is the compound lever originally devised by Adie (Fig. 20), but several other patterns are in use. So long as the load is applied "steadily and uniformly, starting from zero and increasing at the rate of $100 \mathrm{lbs}$. in twelve seconds" the particular type of machine is unimportant.

Some means of arresting the indicator or of enabling the machine to work automatically is desirable. In the machine shown in Fig. 21, the weight corresponding to the breaking strain is applied in the form of shot, which runs from a reservoir 
into a vessel attached to the beam of the machine. When the test piece breaks, this vessel falls, strikes a lever below it and instantly cuts off the supply of shot. The shot in the receiving vessel is then weighed and multiplied by the necessary factor to express the breaking strain in pounds per square inch. In some testing machines, water is used instead of shot, and in others a weight (Fig. 20) slides along the beam of the machine, its position at the moment of breaking indicating the tensile strength of the test piece.

Great care should be taken to place the test piece properly in the jaws of the machine, with the contact between the two evenly distributed. After each piece has been broken it should be examined to ensure that no side strain or irregular pressure has been applied. Unless very great care is taken when placing the test piece in the machine one or more results will be much below the average; this is frequently due to a defectively shaped test piece, or to its not having been placed truly in the machine.

(h) The rate at which the load is applied must be the same in all tests. D. B. Butler tested over 800 samples at different rates of applying the load, and found that a rapid application greatly increased the apparent strength. He and Faija therefore adopted as a standard a uniform increase in load of $100 \mathrm{lbs}$. in fifteen seconds, which was largely adopted, but was afterwards altered to $100 \mathrm{lbs}$. in twelve seconds when the British Standard Specification was drawn up.

The minimum permissible tensile strength of test pieces made of neat cement is defined by the British Standard Specification as follows :-

"The average breaking strength of the briquettes seven days after gauging must not be less than 400 lbs. per square inch of section.

" The average breaking stress of the briquettes twenty-eight days after gauging must show an increase on the breaking stress at seven days after gauging of not less than-

25 per cent. when the seven-day test is above $400 \mathrm{lbs}$. and not above $450 \mathrm{lbs}$.

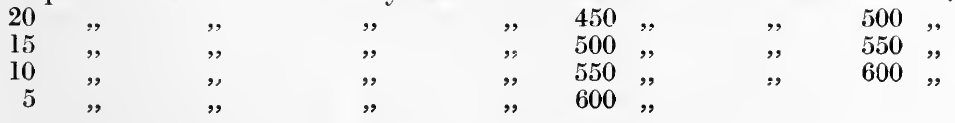


(i) The age of the cement and the amount of aeration it has undergone will affect the tensile strength. Modern cements are not, as a rule, improved by aerating, but rather the contrary. No really satisfactory explanation for this has been offered.

(j) The conclusions drawn from different tests may be inaccurate. Thus, it is customary to average the results of a number of tests of the strength of cements and mortars, but the accuracy of such an average is seldom great. Cement manufacturers consider that the highest result of a series represents the value of a cement most accurately, and attribute the lower results to discrepancies in the gauging, moulding or fitting into the testing machine.

\section{CEMENT-SAND TESTS.}

The tensile strength of neat cement is a purely arbitrary factor, as cement alone is never used to withstand heavy structural strains, but for this purpose is always mixed with several times its weight of inert materials. Indeed, tests of the tensile strength of neat cement will frequently lead to erroneous conclusions in the absence of corresponding tests on mixtures of cement and sand. Thus, a very finely-ground cement if tested neat will appear to be inferior to a coarser sample, because, in the latter, the coarser particles will behave more like an inert material. Mixtures of cement and sand, on the contrary, show the great advantage to be derived from fine grinding.

The futility of tensile tests on neat cement is shown by the fact that, if a mixture of cement with an equal weight of sand is finely ground, the product, when tested neat, has the same tensile strength as pure Portland cement. With the modern demand for a very finely-ground cement, therefore, in place of neat tests an admixture of sand should be employed in estimating the value of a cement.

In the "neat" tensile test the full value of the cement as a concreting material, i.e. its cementing power, never comes into play ; and though it is generally recognised that a finer cement is a more valuable product, yet a coarse sample in a neat test will give results as to tensile strength equal to those obtained by a fine cement. On the other hand, the difference between 
the constructive values of a coarse and of a fine cement will be most noticeable in a test for tensile strength if carried out with a mixture of sand and cement in the proportion of $3: 1$.

The value of sand tests in the place of neat tests is becoming more appreciated day by day, and tensile tests on neat cement are not recognised in the German, Austrian and Swiss Standard Specifications.

In order to obtain concordant and comparable results it is necessary to employ a " standard sand "; that recognised in the British Standard Specification being obtained from Leighton Buzzard. This sand is " thoroughly washed, dried and passed through a sieve of $20 \times 20$ meshes per square inch, and must be retained on a sieve of $30 \times 30$ meshes per square inch, the wires of the sieves being $\cdot 0164$ inch and $\cdot 0108$ inch in diameter, respectively." The German standard sand is rather coarser, as it passes through a plate perforated with circular holes $\cdot 054$ inch diameter, but not through holes 031 inch diameter. The French, Austrian, Swiss and American standard sands are of the same fineness as the British. The Russian sand is rather finer. There is an objection to the use of a different material in the tests to that which will be employed in the actual structure, namely, the differences between the two materials will prevent a true comparison of the results. It is, indeed, possible that a cement will be condemned when tested in admixture with standard sand, but will prove highly satisfactory.when tested as a portion of an actual structure. This discrepancy cannot, at present, be avoided without great difficulty; substituting the sand and aggregate to be used in the actual structure does not solve the problem, as low tests on a given cement might then be attributed to unsuitable aggregates rather than to defective cement. At the same time the discrepancy between cement-sand mixtures and concrete made from the same cement is, in some cases, so serious as to make tests on the actual concrete imperative in all important structures where failure of the material might involve loss of life.

The tensile strength of mixtures of cement and sand is very valuable in detecting adulteration in the form of inert material, such as Kentish rag (limestone) added to cement to cheapen 
it. So far as the test on neat cement is concerned, the addition of an inert material will frequently increase the tensile strength, but the admixture will readily be detected by the low results obtained when the sand-cement mixture is tested.

The great drawbacks to testing mixtures of sand and cement are $(a)$ the irregularities in the results unless skilled men are employed, and $(b)$ the length of time required for the test. The latter difficulty is not appreciable when the tests described in the British Standard Specification are used, as the time required for the tensile test of the neat cement is made the same as that for the cement-sand mixture, viz., twenty-eight days.

The variations in the results obtained by different testers, or even by the same man on different occasions, are much greater than in the case of neat cement unless great manipulative skill is used in the gauging and filling of the moulds. With skilled operators the differences are not important. They are due almost entirely to the greater difficulty in gauging a cement-sand mixture and in handling it afterwards.

The following extract from the British Standard Specification represents the best modern practice :-

"The cement shall be tested by submitting to a tensile stress briquettes prepared from one part by weight of cement to three parts by weight of dry standard sand, the said briquettes being of the shape described for the neat cement tests.

"The mixture of cement and sand shall be gauged with so much water as to be moist throughout, but no surplus of water shall appear when the mixture is gently beaten with a trowel into the mould. Clean appliances shall be used for gauging, and the temperature of the water and that of the test room at the time the said operations are performed shall be from $58^{\circ}$ to $64^{\circ} \mathrm{F}$., and no ingredient other than cement, sand, and elean, fresh water shall be introduced in making the test. The mixture gauged as above, shall be filled, without mechanical ramming, into moulds of the form shown in Fig. 18 (p. 133), each mould resting upon a non-porous plate until the mixture has set. When the mixture has set sufficiently to enable the mould to be removed without injury to the briquettes, such 
removal is to be effected. Each said briquette shall be kept in a damp atmosphere for twenty-four hours after gauging, when it shall be placed in clean, fresh water and allowed to remain there until required for breaking, the water in which the test briquettes are submerged being renewed every seven days, and the temperature thereof maintained between $58^{\circ}$ and $64^{\circ} \mathrm{F}$.

"The briquettes shall be tested for breaking at seven and twenty-eight days after gauging, six briquettes for each period. The average tensile stress of the six briquettes shall be taken as the tensile stress for each period. For breaking, the briquette shall be held in strong metal jaws, of the shape shown in Fig. 19 (p. 134), the briquettes being slightly greased where gripped by the jaws. The load must be steadily and uniformly applied, starting from zero, increasing at the rate of $100 \mathrm{lbs}$. in twelve seconds.

"The average breaking stress of the cement and sand briquettes seven days after gauging must be not less than $150 \mathrm{lbs}$. per square inch of section.

"The average breaking stress of the briquettes twentyeight days after gauging must not be less than $250 \mathrm{lbs}$. per square inch of section, and the increase in breaking stress from seven to twenty-eight days must not be less than :-

\begin{tabular}{|c|c|c|c|c|c|c|c|c|}
\hline 15 & „, & , & ,, & , & 250 & , & , & 300 \\
\hline 10 & ," & , & ," & , & 300 & ", & ", & 350 \\
\hline 5 & , & ", & ," & , & 350 & ", & & \\
\hline
\end{tabular}

All the best British Portland cements give much higher results than those just mentioned, and a large number tested under the author's supervision yielded results with an average of :

After seven days.

Neat cement, 660 lbs. per square inch.

$\left.\begin{array}{c}\text { Cement-Sand } \\ 1: 3\end{array}\right\} 250$,
After twenty-eight days. 800 lbs. per square inch

350 ,

The German standard is confined to $1: 3$ cement-sand mixtures, which must have a tensile strength exceeding $228 \mathrm{lbs}$. per square inch after twenty-eight days, and a compressive strength of $2,280 \mathrm{lbs}$. per square inch.

The French specification requires the gauging to be done 
with sea-water, and gives the minimum tensile strength as $114 \mathrm{lbs}$. per square inch after seven days, and $214 \mathrm{lbs}$. per square inch after twenty-eight days, with a further proviso that the increase in strength between seven and twenty-eight days must be at least $24 \frac{1}{2} \mathrm{lbs}$. per square inch. A further clause in the French specification, which is not always insisted upon, requires the strength of the cement-sand test pieces to be at least $256 \mathrm{lbs}$. per square inch at the end of eighty-four days, and in any case greater than at the end of twenty-eight days.

Although mechanical ramming is not allowed in the above specification, it is employed on the Continent and (for their own satisfaction) by a few firms in Great Britain. Massive iron moulds must then be used in which a piston is fitted, and a considerable number of blows-usually 150-are then delivered to the top of this piston at the rate of one blow per second, either by means of a small tilt-hammer devised by Boehme, or by a miniature pile-driving rammer designed by Klebe. The latter is prescribed in the Austrian and Swiss specifications. Presses-of either the "screw " or " hydraulic" type-have been used to consolidate the cement-sand mixture in the moulds, but they give lower results than do mechanical hammers, and have not been adopted in any official specifications.

The tensile strength of slag cements, mortars, hydraulic lime, pozzolanas, etc., is tested in a manner similar to that just described, though slight modifications are necessary on account of the different nature of the materials. Slag cement should give tensile strength results almost identical with those of Portland cement. Feeble hydraulic limes have a tensile strength of 70 to $100 \mathrm{lbs}$. per square inch, but the stronger limes show results up to 140 lbs. per square inch. Roman cements, rock cements and natural cements vary greatly, but should not have a tensile strength below $130 \mathrm{lbs}$. per square inch; very few of them reach as high as $200 \mathrm{lbs}$. per square inch, which may be regarded as the minimum for a $1: 3$ Portland cement-sand mixture. Pozzolanas (including trass) must be mixed with lime as well as sand before being tested. According to M. Gary, a mixture of equal volumes of trass, 
standard lime paste and standard sand should have a tensile strength of at least $200 \mathrm{lbs}$. per square inch. The standard lime paste used is made by mixing slaked or hydrated lime with an equal weight of water.

\section{TRANSVERSE BENDING S'TRENGTH.}

In most cements the bending strength is fairly proportionate to the compressive and tensile strengths, and, as it is not difficult to measure, its determination is becoming increasingly popular, especially as the variations between different tests are less than in those of tensile and compressive strengths.

Though not yet recognised in any official specifications, the resistance of cements and cement - sand mixtures to bending stresses have been extensively studied. Instead of the test pieces previously described, prisms (usually

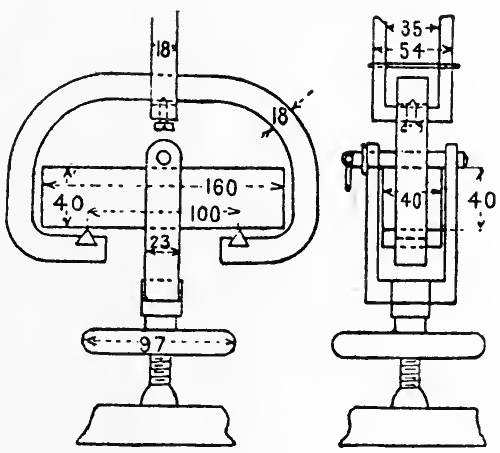
$16 \times 4 \times 4 \mathrm{~cm}$.) are employed, the cement and sand mixture being gauged with one-tenth of its weight of water. The prisms are tested by three knife edges-two below and one above the prism-which

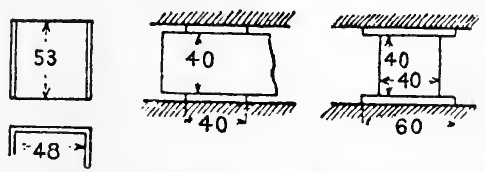

FIG. 22.-Schüle's Machine for Transverse Bending Tests.

are fitted to the jaws in a tensile strength testing machine (Fig. 22), the load being applied in the same manner as when testing tensile strength.

O. Frey has found that the bending strength of a number of German standard cement-sand mixtures tested by him is about one-fifth of the compressive strength or double the tensile strength, but the British cements examined by the author show lower figures. The conclusions which may be drawn as to the value of a bending test may be summarised in the following manner :- 
1. The testing of cements by means of prisms made from plastic mortar is distinguished by its extreme simplicity, and by the great advantage that both bending and compression tests can be obtained from the same block-samples. This testing process is the solution of the question as to equal capacity of the tensile and compression test samples.

2. The individual differences compared with the mean are smaller by this method than by the use of tensile test samples of 8 shape. For compression tests there is no considerable difference between the individual deviations and the mean values given by the results with cubes or with prisms.

3 . The lower figures given by the prism method correspond better with the strengths obtained in practice than do the high figures obtained with material of earth-moist consisteney subjected to hard ramming.

4. The difficulty of exactly determining the mixing-water and the work of ramming is solved in a satisfactory manner by using the same weights of the cement, sand and water in every test.

5. The use of prisms gives the compression tests the importance which they deserve, which far exeeeds that of the tensile and bending strengths, both in regularity and praetieal importance.

\section{SHEARING STRENGTH.}

The resistance of blocks made of cement and sand to a shearing stress would furnish valuable information if only it could be measured easily and accurately. At present, however, this is not the case, but as this subject is receiving a considerable amount of attention, a satisfactory method may shortly be discovered. Meanwhile, bending tests (p. 143) are the nearest approximation.

\section{O'THER TESTS.}

A number of other properties of cements and cement-sand mixtures have been proposed as the basis of valuations, but have never been extensively used.

The adhesion of cement to metal is an important property as, in reinforced concrete, it tends to counteract the sliding of the 
metallic bars embedded in the material. This adhesion or resistance to gliding is a resultant of several forces, including the resistance of the cement to shearing, the pressure exercised between the metal and the cement, the alterations in volume accompanying the hardening of the cement and the action of external loads. Unfortunately, it is, at present, impossible to measure this adhesion accurately.

Adhesiveness is tested by placing a mould on the surface to which it is desired the cement shall adhere (stone, brick, etc.), and then filling the cement, cement-sand mixture or mortar as usual. When the material is sufficiently hard the mould is removed and the test piece is subjected to tensile strain in the ordinary testing machine. The most satisfactory results are obtained when the test piece has the shape and dimensions shown in Fig. 17. Tests of adhesion are, usually, tests of the "other" material rather than of the cement, and are not required except in very unusual circumstances.

The compactness or apparent density of a test piece is determined by means of a volumenometer, ${ }^{1}$ in which the volume of the test piece is measured. The volume in c.c., divided by the weight of the test piece in grammes, is the apparent density, and may be regarded as a measure of the compactness.

The porosity of a test piece is determined by weighing it, then immersing it in a vessel from which all the air can be exhausted. Enough water must then be admitted to completely cover the test piece. The air is exhausted so as to cause the water to enter all the open pores in the test piece; the latter is then wiped dry and then re-weighed. The increase in weight will be the water absorbed by the pores in the test piece.

The porosity of test pieces made of neat cement is extremely low; that of concrete aggregates is much higher and is preferably determined, as described in the section on concrete.

1 For a description of this apparatus, see the author's "British Clays, Shales and Sands," C. Griffin \& Co., London, 1911. 


\section{CHAPTER VI}

THE COMPONENTS OF CONCRETE AND THEIR PROPERTIES

CoNCRETE may be defined as an inert material, the particles of which are united by cement to form a hard, stony mass useful for all the ordinary purposes of natural building stones.

The use of concrete has been extended enormously during the past few years, and now covers a wide sphere of usefulness in the construction of bridges, breakwaters, docks, canals, dams, reservoirs, paving stones, partitions, roofing tiles, building blocks, boats, rafts, conduits, water mains, sewers, telegraph poles, fences, caissons, pipes, etc., etc. Each year new uses are made of this remarkable material, and our knowledge of its properties is increased.

The inert material is usually composed of sand of different degrees of fineness and a coarser material termed an aggregaie. Other materials are, however, introduced in special cases to confer additional properties on the concrete. Thus, pozzolanas (p. 161) are sometimes added to increase the hardness of the mass, whilst very finely ground rock, dust or clay is sometimes used to secure a denser concrete. Clay is inadvisable for this purpose on account of its plasticity and water-repelling power.

The components of concrete are usually four in number: $(a)$ cement, $(b)$ sand, $(c)$ aggregate, and $(d)$ water. To these must be added metal (usually steel) in the case of reinforced concrete.

The apparent simplicity of concrete has led to its abuse in many ways, and there is widespread belief that any inert material and almost any kind of lime or cement may be used with satisfactory results. This is altogether wrong, for in reality the production of a satisfactory concrete is by no means simple, and involves considerable knowledge, continual supervision and conscientious work. 


\section{CEMENT.}

Many kinds of cementitious material may be employed for concrete, the strength of the structure depending on that of the cement and of the aggregate. Lime and hydraulic lime concretes are largely used for foundation work on account of the low cost; natural cements (p. 29) are used for somewhat stronger work, and Portland cement (p. 20) where the best and strongest concrete is required, and for all reinforced concrete.

The strength and reliability of Portland cement are such that it is rapidly replacing other kinds in all the most important work. Care should, however, be taken that only Portland cement of good quality, and preferably that complying with the requirements of the British Standard Specification (p. 97) should be used. For greater accuracy of working as well as convenience, the cement should be delivered in bags or barrels containing a definite weight of cement. This weight and the maker's name should be marked legibly on the bags or barrels.

\section{WATER.}

The water ordinarily available is suitable, unless it contains a notable quantity of humic acid or other organic matter which retards the setting of the cement. The water used should always be clean; that from ponds and streams is liable to contain clay and other detrimental matter in suspension. In case of doubt it should be run into a settling tank or filtered through sand. The water should therefore be tested to ascertain the effect (if any) of its constituents on the rate at which the cement sets. Hard water should be avoided wherever possible as the action of the salts dissolved in it is always uncertain and often detrimental. Carefully collected rain water is the most generally suitable kind of water; that from wells sunk in the chalk is the most unsatisfactory of all kinds of fresh water. Sewage and other effluents should never be used.

\section{AGGREGATES.}

Many varieties of stone, broken bricks, coke, clinker, ashes and other substances of a stony character may be used as 
aggregates in concrete, the selection of any particular piece of work depending on the purpose for which the concrete is to be used, the strength it is desired the concrete should possess, the accessibility and cost of each aggregate-material andin many instances-the whim of the architect or engineer in charge of the work. Strictly speaking, the whole of the solid non-cementitious material used in concrete constitutes the aggregate, but this term is usually applied solely to the coarser portion, the finer being termed "sand."

Aggregates used in concrete may be divided into four groups: (a) natural stones, such as granite, limestone, etc.; (b) artificial stones, such as burned clay, broken bricks, etc.; (c) by-products of various kinds, such as coke, blast-furnace slag, clinker or ashes; and $(d)$ pozzolanas or trass (p. 159).

Natural stones must usually be broken into pieces of convenient size, but those which occur in the form of gravel have the advantage that, if free from sand and clay, they are ready for use without any further preparation. The most suitable are angular fragments of moderate density ; rounded pebbles from the sea-shore or river beds (ballast) are less satisfactory, but are used in large quantities on account of their convenience. Fortunately, the difference between the useful strength of concrete made with pebbles and that made with angular pieces is not sufficient to be of importance in most instances.

What are known to geologists as igneous rocks furnish many excellent aggregates, though the basalts, traps, felsites and denser lavas have too high a specific gravity $(2 \cdot 9$ to $3 \cdot 2)$ to be desirable. The lighter lavas, such as pumice stone, on the contrary, have so low a crushing strength that they can only be used for partitions and other work where lightness rather than strength is required. Where pumice stone is not available, a good, light concrete of a similar nature may be made from hard coke. ${ }^{1} \quad$ Some of the basalts have the further disadvantage of a glossy surface, to which the cement does not adhere satisfactorily.

Granite, if washed free from adventitious substances and powder, is a very suitable aggregate for almost any class of

1 The risk of fire must not be overlooked. This danger is often exaggerated (see p. 150). 
structure. Granite-concrete is dense and rather heavy (i.e., of rather high specific gravity), but is particularly useful for large structures and for maritime work. It is costly, except in those localities where granite occurs, but is universally recognised as the best aggregate.

As the presence of fine adherent granite dust is detrimental, the granite chippings should be thoroughly washed before use. In quarries when fans or dust extractors are used the granite is more free from dust, and is to that extent superior-in the absence of facilities for washing the material.

Limestones are amongst the most valuable sedimentary rocks which may be used as aggregates, and are so widely distributed as to be generally available. The harder varieties with a specific gravity of $2 \cdot 7$ are the most suitable for the purpose. The most artistic results are obtained with the particular variety of limestone known as Portland stone, on account of the close resemblance it bears to Portland cement, thereby enabling the concrete to be carved and dressed in a manner impossible when an aggregate of a different colour is used.

The chief disadvantage of limestone as an aggregate is the decomposition it undergoes when subjected to the action of fire, resulting in the shrinkage and rapid collapse of the structure.

Sandstones, quartzites and other siliceous stones are generally very suitable as aggregates, but shales, slates and micaceous sandstones should be avoided, as the flat fragments they produce do not form a strong concrete.

In some districts-particularly in the eastern countiesflint pebbles are the only stones available. They make an excellent concrete for use at ordinary temperatures, but one which is apt to "fly" and split when heated. This tendency is reduced by crushing the flints in a stonebreaker, but their great hardness makes this costly.

The artificial stones used as aggregates consist chiefly of broken bricks, terra-cotta or burnt clay ballast. Inferior material should be avoided, as it has a low crushing strength and is very liable to crumble. The materials selected should be hard and preferably should show signs of vitrification. 
Soft and crumbly material should be avoided. In addition to their primary nature as hard and inert materials, all products composed of burnt clay have cementitious properties when mixed with lime (see pozzolanas, p. 35), and so tend to increase the strength of the concrete. This is particularly the case where the material is ground to the state of sand (p. 159).

If broken bricks are used they should be carefully cleaned from any adherent mortar and dust. Broken pottery, tiles and pipes are unsuitable, as the pieces "bridge over" each other and form excessively large voids.

Bricks from some localities are occasionally found to cause "blowing" or cracking in the concrete, but the reason for this has never been satisfactorily explained. The statement sometimes made that Fletton bricks contain an excessive amount of sulphur does not apply to most of the bricks from the Fletton district, though it is an unquestionable fact that, in several instances, concrete made of bricks alleged to have been made near Fletton has proved unstable. Whether its failure be due to the method employed in making the concrete or to the broken bricks used is, at present, impossible to say.

Coke-breeze, when sufficiently resistant to crushing, forms a good aggregate, but the softer coke which is sometimes substituted is dangerous. Coke has been chiefly used as an aggregate in concrete floors and walls, as it makes a light construction into which nails may be easily and securely driven. It has somewhat undeservedly fallen into disrepute because of its prohibition in Germany where its quality is distinctly inferior to that of good English coke.

It has also been suggested that coke forms an inflammable aggregate, but the tests made by the Fire Prevention Committee with various kinds of floors exposed for three hours to a rapidly increasing and ultimate temperature of $1,900^{\circ} \mathrm{F}$. followed by a spray of cold water, placed coke breeze and burnt clay ballast as first, and showed them to be (after the tests) quite free from cracks and deflection, and much superior to granite so far as these particular tests were concerned.

The fear of expansion and disintegration of coke-concrete in ordinary use also appears to be largely imaginary. The chief disadvantage of coke is the presence of oxidisable sulphur 
compounds in it; these expand and rupture the concrete, sometimes to an alarming extent. What is known as "steel coke " is usually very free from sulphur compounds, and may be highly recommended where a light aggregate is desired, but coke rich in sulphur is undesirable, and ashes are a particularly unsuitable material to mix with the coke. Coke breeze should not be used for reinforced concrete.

Ashes are similar to coke, but usually contain a large proportion of sulphur and so are undesirable, though much used on account of the low cost. Ashes from locomotive boilers are considered to be superior to domestic ashes, the steam in the forced draught being supposed to effect a volatilisation of the sulphur present in the coal. Care should be taken that the ashes are free from admixture with hydraulic lime, as lias limestone is mixed with some of the coal used by engine drivers.

Clinker and furnace slag are stronger aggregates than coke or ashes, but suffer from the presence of sulphur compounds which, when oxidised, expand and may cause the destruction of the concrete. Provided that the proportion of sulphur is sufficiently small to be practically harmless, and that the clinker is hard and free from dust, shale, lime, ash, metal scrap or scale and basic slag, slags form valuable aggregate material, their general availability and low cost rendering them very attractive to builders and contractors. The fact should not be overlooked, however, that many slag heaps vary very greatly in composition, and that tests do not necessarily represent the percentage of sulphur in any and every part of the heap. Hence, there is always some risk in using slag unless its composition is exceptionally uniform. The commercial attractiveness of slags as aggregates must not be allowed to obscure the danger of collapse which accompanies their use, except when the construction of a building has been under the most strict supervision.

Clinker and slags should not be used for reinforced concrete, except under protest.

If the particles composing the aggregate are of various sizes the mass will be more compact than if all the particles are large and uniform in size. Thus a mixture of broken stone. 
cement and sand will occupy a smaller volume than when each of the materials are kept separately. This is clearly shown in Figs. 23-26. In Fig. 24 is shown a plan of a cubical box containing twenty-seven spheres of equal size; there is a considerable amount of space between each of these spheres, even though the box is apparently "full." In Fig. 25 the same box is shown with a number of smaller spheres packed

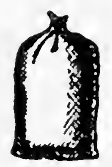

Cement

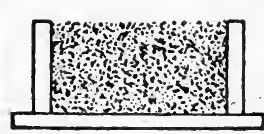

Sand

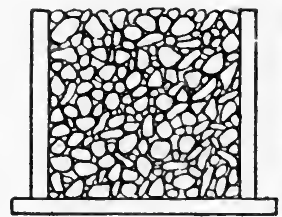

Stone

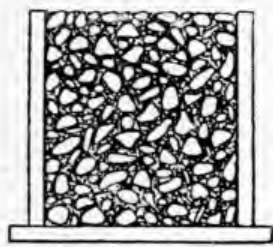

Concrete

FIG. 23.-Space occupied by Concrete and its components.

in between the larger ones, so that the box now contains considerably more material than it did before. At the same time it is clear that there is still space enough to contain a comparatively large quantity of sand and fine powder before all the spaces or voids between the particles would be completely filled. If instead of truly spherical particles, irregularly shaped ones are used, the same facts will be observed, and this

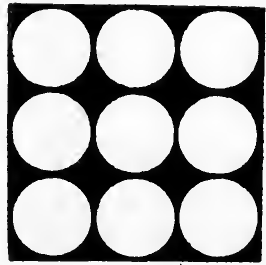

FIG. 24.

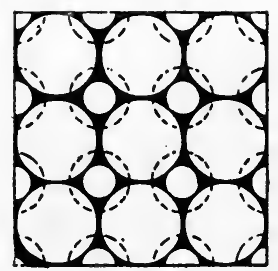

FIG. 25.

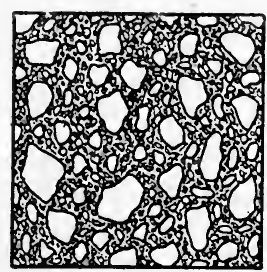

Fig. 26.

is what actually occurs in the-preparation of concrete (Fig. 26). From this it is clear that most aggregates must be graded or separated into fragments of suitable sizes, as if this is not done either a weak concrete will be obtained or a very large amount of cement will be wasted. As the cost of the additional cement is far greater than the expense of grading the aggregate, a careful grading of the material effects a considerable saving 
in cost. It is possible to make a difference of nearly 100 per cent. in the strength of a concrete by careful attention to the grading. If the aggregate is composed of particles all of one size, the amount of voids will be about 50 per cent.; if it is composed of two sizes of particles, the proportion of voids will shrink to between 30 and 40 per cent.; by still more variation in the size of the particles, it is possible to get the amount of voids down to 20 to 25 . per cent., and in a very weak proportion, such as $1: 15$, there is no reason why one should not include an amount of fine sand so as to reduce the percentage of voids still lower. To use a lot of sand will not always so reduce the percentage of voids, because sand, which is composed of a fairly regular form of grain, will likewise contain 50 per cent. of voids. A gradation of size is necessary in either large or small material in order to reduce the amount of voids, it being the gradation in size which enables the particles to arrange themselves more closely together and leave a smaller proportion of interstices. It is easy to see that in a properly graded material wherein the voids are a minimum, the cement will go much further and the concrete will be denser and stronger. The principle applies equally to a poor concrete, such as $1: 5: 1$, or a rich mixture, such as $1: 1: 2$ (see p. 167).

Many gravels require no grading, as the particles they contain are all of sizes and in proportion suitable for use as aggregates; this is one of the advantages of such gravels. Other gravels and most of the larger materials must first be crushed to fragments of a suitable size, the crushed product being then divided by sieves into particles of certain prearranged sizes.

The size of the largest particles permissible in an aggregate depends to some extent on the size of the mass of concrete to be produced. For most purposes the aggregate should pass completely through a hole one inch diameter, though for very large blocks some of it may be large enough to just pass through a 3-inch hole. The Second Report of the Committee of the Royal Institute of British Architects states that $\frac{3}{4}$ inch is the usual maximum size allowable. In very large masses of concrete, such as are used in maritime work, large 
blocks of stone are embedded at intervals. The usual practice is to screen through sieves of the meshes as under :-

For Artificial paving blocks . $\frac{1}{4}$ inch to $\frac{3}{8}$ inch. Floors . Walls : Foundations $\frac{1}{2},, \quad, \frac{3}{4}, "$
$1 \quad, \quad, 2$ inches.
$2 \frac{1}{2}$ inches.

"Plums" or large stones used in ordinary foundation work should be carefully deposited well away from one another, and from the sides and angles of the mass ; they are never allowable in reinforced work.

All material which will pass through a hole $\frac{1}{4}$-inch diameter should be removed by sifting or washing or a combination of these processes, as the presence of loam and clay is highly detrimental, and sand of unusual fineness has been known to cause a failure in the concrete. An aggregate which contains more than 3 per cent. of clay should, generally speaking, be rejected.

It is sometimes urged that the removal of sand from aggregates is undesirable, especially as some sand must be added to the concrete mixture in order to fill the voids in the coarser aggregate. For this reason, some engineers wash the aggregate so as to remove earth, dust, clay and other very fine particles, but endeavour not to remove the coarser sand. If the aggregate is of a very uniform character this method may be adopted with success, but in most instances it will be found that the distribution of the sand in the aggregate is so irregular that it is almost impossible to ascertain accurately the proportion present. The removal of all particles which will pass through a hole $\frac{1}{4}$-inch diameter secures an aggregate of much greater uniformity as regards the voids and greatly assists in the production of a concrete of maximum strength.

Whether a particular aggregate requires. washing may be ascertained in a rough, but usually sufficient manner by a method recommended by the Associated Portland Cement Manufacturers, Limited. A tall glass cylinder, graduated in c.c. and of at least 50 c.c. capacity, is half filled with aggregate and water is then added to fill the cylinder about three-quarters full. The cylinder is then closed with a cork or rubber stopper, 
and it is then shaken violently so as to wash out all clay and sand. The cylinder is then placed on a bench and its contents are allowed to settle. After a few minutes the sand and most of the clay will have settled on top of the aggregate, and its proportion to the latter can be roughly gauged by comparing the respective volumes of each. The apparatus required is shown in Fig. 27.

It should be observed that the foregoing method does not show the presence of sulphurous slag, coke breeze and certain other deleterious ingredients of a coarse nature. If these are suspected, the aggregate must be subjected to a more searching investigation.

The removal of the fine material is best effected by washing in a shallow trough, the bottom of which is perforated. The output is increased if the trough is vibrated in a manner similar to the jiggers used for washing coal and

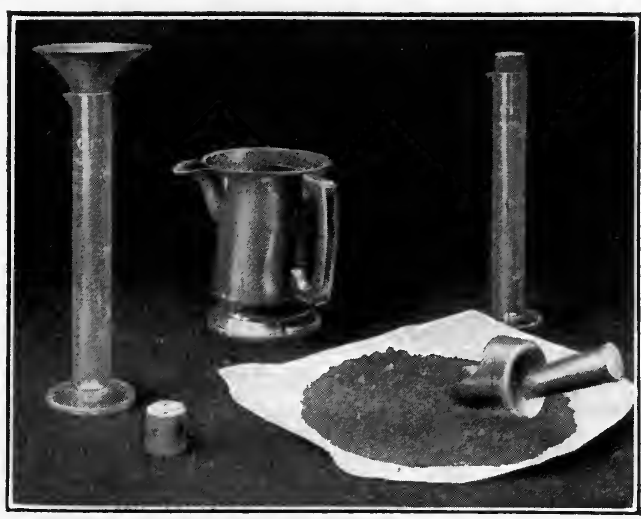

FIG. 27.-Apparatus for determining whether aggregates require washing before use.

(By courtesy of the Associated Portland Cement Manufacturers, Ltd.)

ores. The method-frequently adopted-of throwing the material against a steeply inclined riddle is not satisfactory, and fails to remove a large proportion of the finer material. Where no jigger is available, metal wheelbarrows, the sides and bottom of which are perforated with $\frac{1}{4}$-inch holes, may be substituted. The concrete aggregate is delivered in piles near the work, and carried from them to the mixer in wheelbarrows. Between the mixer and the storage piles a water-pipe is connected up, with a large perforated nozzle at its discharge end. Each wheelbarrow load of gravel on its way to the mixer is rolled under the nozzle and streams of water discharged upon it, the material being churned about with a spade to expose the 
lower part of the load to the cleansing action of the water. The water and the loam pass out through the perforations in the wheelbarrow, and the clean gravel is then carried to the mixer and used.

Aggregates should always be wetted thoroughly before being used, and the additional labour of screening is so insignificant in relation to the advantages gained that it should never be omitted. This is particularly the case where the aggregate is composed of crushed limestone, the-fine dust of which is peculiarly detrimental and may reduce the ultimate strength of the concrete by as much as 40 per cent.

It is a curious fact that the larger the proportion of fine aggregate the weaker will be the concrete. Thus, a concrete made of small pieces of sandstone and cement will be much stronger than one made of the same materials, but with the stone reduced to powder. Consequently, it is desirable to use an aggregate of a coarse nature and also with as few voids as possible. In order to ensure this, the aggregate should all be passed through a screen with holes of a prearranged size (say $1 \frac{1}{2}$ inch diameter), then washed and passed over another screen with holes $\frac{1}{4}$ inch diameter.

As suitably graded aggregates yield stronger concretes than those in which the fragments of aggregate are all the same size, the Testing Committee of the Concrete Institute have suggested that the aggregate should " be sifted to the following degrees and the percentage of voids ascertained of (1) the whole, and (2) of each separate grading :-

To pass an aperture of-

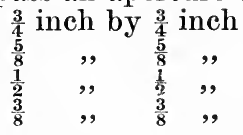

To be retained on an aperture of-

$\begin{array}{llll}\frac{5}{8} \text { inch by } & \frac{5}{8} & \text { inch } \\ \frac{1}{2} & , & \frac{1}{2} & =, \\ \frac{3}{8} & , & \frac{3}{3} & , \\ \frac{1}{4} & , & \frac{1}{4} & ,\end{array}$

No definite proportions of either size of particle or of voids have yet been specified. It is, however, recognised that the more varied the sizes the denser and stronger will be the concrete, and the smaller the proportions of cement and sand needed.

The proportion of each grading to the whole and the specific gravity of the aggregate should also be ascertained. The aggregate thus obtained should then be tested to ascertain the 
proportion of voids present. This should not exceed 45 per cent. and will seldom be less than 25 per cent.

The percentage of voids in an aggregate or sand is determined in a manner .similar to the following, various small refinements being possible where a more accurate determination is required: The aggregate to be tested is well wetted and allowed to drain on a sloping sheet of glass so as to remove all surplus water from the surface without withdrawing any from the pores. Two precisely similar graduated glass cylinders, each of about 1,000 c.c. capacity, are then placed ready for use. In the first cylinder is placed a convenient. quantity of the aggregate. This is shaken and tamped down so as to make it as compact as possible without breaking the fragments. The volume of the aggregate in the cylinder is then carefully noted; it should be about 600 c.c., but must be measured as exactly as possible. In the second cylinder is placed 400 c.c. of water. The measured quantity of aggregate is then completely transferred to the second cylinder, and any air bubbles in the latter are removed by probing carefully with a wire. The contents of the second cylinder are then shaken so that no air spaces exist in the aggregate, and after a few moments settling the height of the water level in this cylinder is noted by means of the graduations on the glass. The difference between the volume of aggregate and water before mixing and after mixing will be the volume of the voids in the quantity of aggregate tested, and from this the percentage of voids may be easily calculated. Thus, supposing that the volume of aggregate used was 640 c.c., the volume of water 400 c.c. (making a total volume before mixing of 1,040 c.c.), and that the volume in the second cylinder (after mixing) was 787 c.c., then the difference in volume on mixing (due to the voids) would be 253 c.c., and the percentage of voids will be-

$$
\frac{253 \times 100}{640}=39.5 \text { per cent. }
$$

The apparatus used is shown in Fig. 28 by courtesy of the Associated Portland Cement Manufacturers, Ltd.

If the aggregate is porous (like coke) it must be well-soaked 
in water before being put into the measuring vessel, as it is the space between the particles and not the porosity of the particles themselves which it is desired to measure. Materials of a highly porous nature, yet with somewhat large pores, are troublesome, as each piece must be immersed in paraffin wax before being tested, for unless the pores are sealed in this way the water will run out of them in transferring the aggregate to the measuring vessel and an erroneous result will be obtained. Fortunately, in the majority of materials used as aggregates, the porosity is so small that its influence may be neglected in making the test, provided the aggregate is well wetted.

The proportion of voids is important in two ways : first, it serves as an index

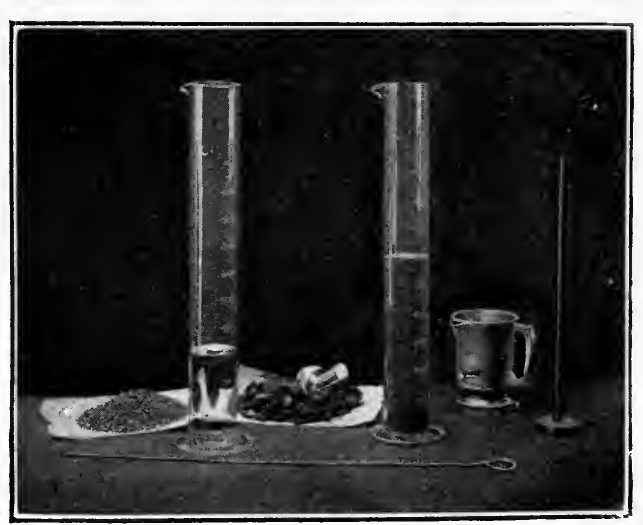

FIa. 28.-A pparatus for determining proportion of voids in aggregates. of the suitability of the aggregate as regards the size of the particles, and secondly, it serves as a measure of the amount of sand which must be added to the concrete, as will be described later.

The sand used in concrete consists essentially of an inert material, the particles of which are sufficiently small to occupy the spaces or voids between the larger fragments of aggregate: The composition of the sand is relatively unimportant providing that it is free from clay. The latter is usually removed by washing the sand in a stream of water either in large tanks or, preferably, in a rotating drum; the clay, roots, grass, seeds, etc., are carried away by the water and the clean sand remains behind. Washing sand does not always improve it, however, as in some cases the finest particles thus removed are of value.

Most contractors are willing to pay a good price for cement, 
but are anxious to use the cheapest sand available. This is a mistake, as the final strength of the concrete will be seriously reduced if an unsuitable sand is employed.

Sands may be divided into three groups: $(a)$ siliceous, (b) calcareous, and (c) pozzolanic.

The siliceous sands are by far the most widely used, and consist of the material abraded by the action of wind, weather and water from the siliceous rocks. The purest siliceous sands consist almost exclusively of fragments of quartz and, under the microscope, may be seen to be composed of small, clear glassy particles with either sharp or rounded edges according to the conditions to which they have been subjected. River sand, the particles of which are sharper and more angular than those of sea sand, is preferable for use in concrete.

The general properties of siliceous sands are well known. Those chiefly used in concrete are :-

(a) Pit sand (other than that of glacial origin).

(b) River sand.

(c) Sea sand.

(d) Grit or sand from crushed coarse material. This may be of a mixed nature and contain calcareous matter.

Calcareous sands do not occur naturally in a sufficiently pure state to be used in concrete. They are prepared by crushing limestone rocks to powder and screening out the coarser particles. It has been found that calcareous sands yield stronger yet lighter concretes than do purely siliceous ones, but the much lower cost of the latter makes it only natural that siliceous sands should chiefly be employed.

Pozzolanic sands are made by crushing burnt clay products, such as broken bricks, terra-cotta, or clay which has been calcined specially or by grinding natural pozzolanas or trass (p. 35) to a fine powder. These sands have the advantage of forming cements in the presence of the free lime produced by the hydrolysis of the cement, and thereby forming a stronger concrete than when entirely inert sand is used. This fact was well known to the ancient Romans, who mixed ground potsherds with their mortar to increase its strength.

The great disadvantage of Portland cement is the formation of free lime when the cement sets. This free lime is gradually 
washed out of the structure-especially in maritime worksand leaves a porous mass which is liable to corrosion and decay in proportion to its porosity. Indeed, there are few works of importance, in which Portland cement has been used, which do not show the serious results of this loss of lime.

In order to prevent these defects, some material must be added which will combine with the lime set free by the hydration of the cement. The ideal substance for this purpose is a trass or pozzolana, as these unite with lime to form a new cement. The proportion of trass to be added should be slightly in excess of that required to neutralise the lime set free in the cement. This is, theoretically, rather more than one-quarter of the Portland cement. Hence, the best proportion of trass is half that of the Portland cement in the concrete mixture. This trass may legitimately take the place of part of the sand used in making the concrete.

Concrete composed of 1 measure of cement, $\frac{1}{2}$ measure of trass, and 5 measures of (sand + aggregate) has proved particularly durable and resistant to sea water. It is not improbable, in fact, that the simultaneous use of both Portland cement and trass may go far towards solving the problems raised by the action of sea water on concrete.

The use of pozzolanic sands in concrete has not been extensive in this country, notwithstanding their obvious advantages. ${ }^{1}$

The shape and hardness of the sand grains is often more important than their composition. Flat grains, derived from micaceous stones or shales, are liable to form a weak concrete on account of their shape. More spherical grains with sharp angular projections are the most suitable.

The size of the sand particles should not be too small. The British specification for Standard Sand limits the size of the grains to those which will pass through a No. 20 sieve, but will be retained on a No. 30 sieve (p. 139). The Standing Committee of the Concrete Institute fix the upper limit of sand as that which passes through a $\frac{1}{4}$-inch by $\frac{1}{4}$-inch aperture, and the lower limit as that which is retained on a $\frac{1}{50}$-inch by $\frac{1}{50}$-inch aperture. The Second Report of the Committee of the Royal

1 Further information on this important subject will be found in "A Manual for Masons," by J.A. van der Kloes and A. B. Searle. (London: J. \& A. Churchill.) 
Institute of British Architects specify a " sand composed of hard grains of various sizes up to particles which will pass a $\frac{1}{4}$-inch square mesh, but of which at least 75 per cent. should pass a $\frac{1}{8}$-inch square mesh. Fine sand alone is not suitable." The Report also states that " the value of a sand cannot always be judged from its fineness, and tests of the mortar prepared with the cement and the proposed sand should always be made."

As coarse sand has fewer voids than fine sand, it is always preferable, and, in addition to yielding a stronger material, it requires less cement.

Graded sands give better results than those in which all the grains are of approximately the same size, as in well-graded sands there are fewer voids. For this reason the Tests Committee of the Concrete Institute have suggested that the "sand" shall be sifted to the following degrees, and the percentage of voids ascertained of (1) the whole, and (2) of each separate grading :-

To pass an aperture of-

$\begin{array}{ccc}\frac{1}{4} \text { inch by } & \frac{1}{4} \text { inch } \\ \frac{1}{8}, & \frac{1}{8}, \\ \frac{1}{16} \quad, & \frac{1}{16} & , \\ \frac{1}{32} \quad, & \frac{1}{32} & ,\end{array}$

To be retained on an aperture of$\frac{1}{8}$ inch by $\frac{1}{8}$ inch

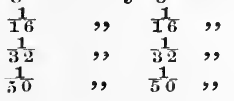

The proportion of each grading to the whole and the specific gravity of the sand should also be ascertained. No definite proportions have been fixed.

The proportion of voids in sand varies with the size of the grains. In sand suitable for concrete it varies from 23 to 40 per cent. The voids are determined in precisely the same manner as those in the aggregate (p. 157).

The tensile strength of test pieces made of standard cement and the proposed sand should be ascertained, so as to ensure that the concrete is not weakened by the use of unsuitable sand. The best method of determining the tensile strength is that described on p. 138 , but substituting the sand to be tested for the Leighton Buzzard sand there mentioned. 


\section{CHAPTER VII}

\section{THE PREPARATION OF CONCRETE}

THE manufacture of a concrete article and the erection of a structure of concrete is similar to the making of a casting in a foundry. Forms or patterns are built to correspond exactly with the shape of the finished work, the reinforcing steel (if any) is set in place, and the concrete is poured into the forms. The whole structure is thus built or moulded into the finished form as a single piece or monolith. ${ }^{1}$ The concrete is allowed to set a requisite length of time, the forms are removed, and the building or article stands complete-a structure carved, as it were, out of solid rock.

Hence, the work of construction or erection consists primarily of four distinct operations: (1) the erection of the forms, centering or false work; (2) the placing of the reinforcing steel (in reinforced concrete); (3) the mixing and pouring or placing of the concrete within the forms ; and (4) the removal of the forms or centering.

As the forms represent the mould from which the finished structure is made, great care is used to make these exact and true to line. They must be built rigid and thoroughly braced so as to bear the weight of the plastic concrete without deflection. In order to give a smooth finish, surface-planed boards are used, and the corners of all columns and beam boxes must be chamfered. All joints should be set closely together so as to make the forms fairly water-tight.

The steel is set accurately in place in accordance with detailed drawings prepared for the purpose by the architect, engineer or firm of concrete specialists, and these drawings should be followed explicitly.

In the production of concrete from its various componentsaggregates, sand, cement and water-it is of the greatest

1 From monos $=$ one, or a single, lithos $=$ a stone or rock. 
importance that every available means should be adopted to secure a product of the highest quality. To this end the greatest care and skill should be used in the selection of the materials, in mixing them thoroughly in the most suitable proportions and in applying the concrete thus produced with all necessary speed. It is equally important that the climatic and other conditions should be suitable, for the production of concrete in times of frost is always detrimental to its quality and strength, though if certain precautions, such as those described on pp. 187, et seq., are taken, the loss of strength may be unimportant.

The results of carelessness, ignorance or lack of skill in the production and shaping of concrete are so serious and are occasionally attended with so great a loss of life that no condemnation of them can be too strong, and no precautions to prevent their occurrence can be too severe.

\section{PROPORTIONS.}

The proportions in which the various components of concrete should be mixed together must be ascertained separately for the aggregate used in each case. The strength and cost of the concrete will depend largely on the correctness or otherwise of these proportions, yet it is surprising how little attention is paid to this matter by many users. Just because some builders have found that for certain aggregates used by them a given proportion of sand and cement gave the best results, numerous others have concluded that for other aggregates the same proportions are the most suitable.

It is generally agreed that the strongest concrete is that which contains the smallest proportion of voids, and the primary object of grading the sand and aggregate is to secure this. At the same time, the proportion of cement present must be sufficient to coat every particle of material in the concrete, and in this way to secure the firm adhesion of all the particles to each other. The builder or engineer who uses concrete has to avoid, on the one hand, the production of too weak a material by the use of too little cement and, on the other, the useless employment of cement (which is expensive) 
merely to fill the voids or spaces between the particles. It is sometimes stated that only those particles of the cement which are left over when the voids have all been filled can be used as cementitious material, but this is not necessarily the case, as a strong concrete may sometimes be obtained notwithstanding the presence in it of a large percentage of voids.

That the percentage of voids cannot in any way be judged by inspection is clearly shown in Figs. 29 and 30 . The limestone shown in Fig. 29 had 37.5 per cent. of voids, and consisted of grains of the following sizes :-

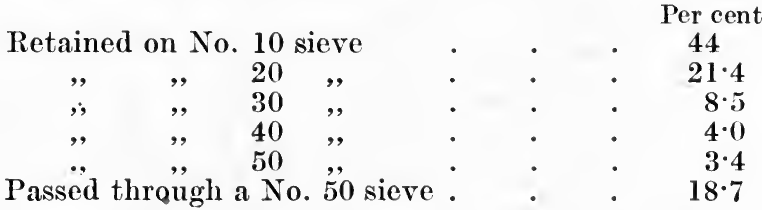

whilst 8 per cent. of that shown in Fig. 30 is passed through a No. 50 sieve. Yet the fine stone contained 40.5 per cent. of voids, required 9 per cent. more cement than the coarser stone, and the resultant concrete had only one-third the tensile strength of that made from the coarser, but better graded stone.

The minimum proportion of cement is that which will cover the whole surface of each particle of aggregate and of each grain of sand with a coating of sufficient thickness to cause the particles of aggregate and sand to adhere so firmly to each other as to form a hard, stone-like mass. This minimum is unattainable in practice, as it would involve coating each grain and particle separately with cement, and making no allowance for cement filling up any voids in the material. In practice these voids are seldom, if ever, filled completely with cement, and it has been found, as the result of innumerable tests, that the strongest concrete is prepared as follows :-

The aggregate-carefully selected, and with particles within the limits of size mentioned on pp. 154, 156-is tested to ascertain the percentage of voids in it (p. 157). The proportion of voids in the sand must also be ascertained. The quantity of sand (consisting of suitably sized grains, as described on 
p. 160) to be added to this aggregate is equal in volume to the total volume of voids in the aggregate used. ${ }^{1}$

The quantity of the cement to be added is then equal to the volume of the voids in the sand used plus an additional quantity to effect the cementation of the various particles. The "allowance" is usually 10 per cent. of the cement required to fill the voids. (Some engineers prefer 15 per cent.) In no case should the amount of cement used be less than will fill the voids in the volume of sand used in the concrete. It is generally advisable to use a larger proportion, as the strength of the concrete is thereby greatly increased.

Thus, if a given aggregate has 40 per cent. of voids and the sand to be used with it has 33 per cent. of voids, to each 100 measures of aggregate there will be required 40 measures of

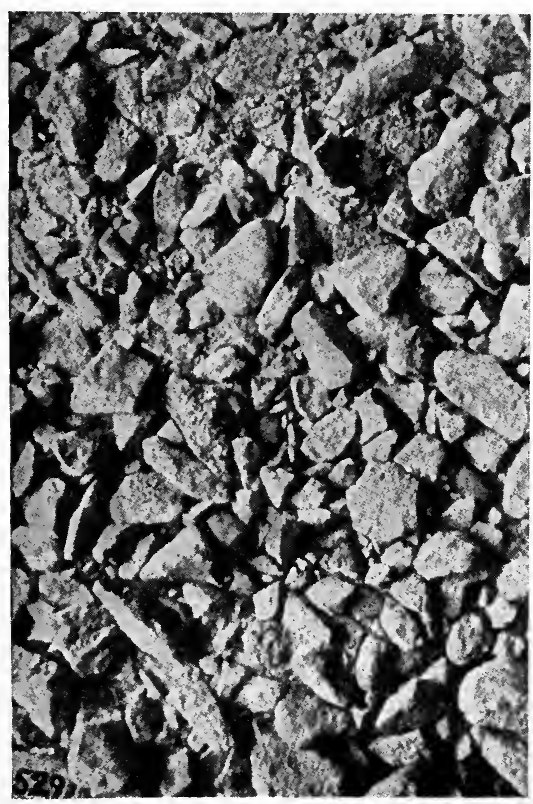

Fig. 29.-Limestone. sand and $\frac{33}{100} \times 40=13 \cdot 2+\frac{13 \cdot 2}{10}=14 \cdot 5$ measures of cement. In other words, the proportions of aggregate, sand and cement will be $100: 40: 14 \cdot 5$, or $7: 2 \frac{3}{4}: 1$.

It must be observed that the volume of cement required is not that of the dry material as received from the manufacturers, but that of the cement after it has set and hardened. This must be determined by making a test piece of neat cement and water, using an accurately weighed quantity of cement, and measuring the volume of the piece after a sufficient length of

1 It is sometimes preferable to replace part of the sand by finely ground trass or pozzolana, as described on p. 159 . 
time (say after twenty-eight days ${ }^{3}$ ). It will then be possible to calculate the volume which will be occupied by any given weight of cement under the conditions in which it exists in concrete. It is usual to reckon 1 cubic foot of dry cement powder as equivalent to 0.85 cubic foot of cement in actual use.

Where large quantities of concrete are used it is better to reverse the calculations and to start with a bag of cement as the unit. The weight of Portland cement is usually marked

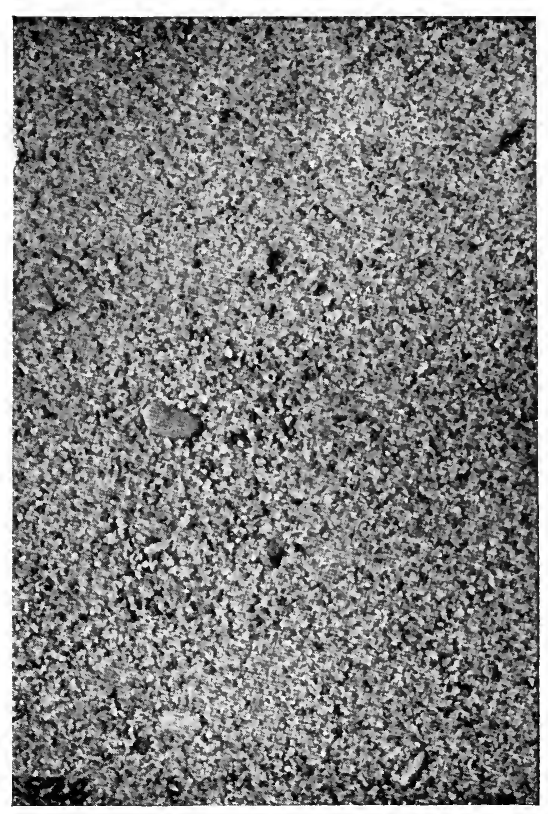

FIG. 30.-Fine Limestone. clearly on the bags in which it is sold, so that no weighing is necessary. For the purposes of proportioning the amount of cement to be added, one cubic foot of Portland cement may be said to weigh 90 lbs. Thus, if an aggregate has 50 per cent. of voids and a sand has 45 per cent. of voids, the proportions of aggregate and sand and cement will be $100: 50: 24 \cdot 75$, or for a bag containing $100 \mathrm{lbs}$. of cement $(=1 \cdot 111$ cubic feet) there will be required 4.5 cubic feet of aggregate and $2 \cdot 25$ cubic feet of sand.

The advantage of specifying the cement by weight and not by measurement is that the makers are prepared to guarantee the weight of material contained in each bag, whereas a contractor can easily make a difference of 5 to 10 per cent. in the weight of cement contained in a given volume.

\footnotetext{
1 In neat cement some of the cement acts as an inert material, so that the volume found in this manner is less than that which would be occupied by cement in concrete. This error may be neglected, as it is on the safe side.
} 
The joint committee formed under the auspices of the Royal Institute of British Architects in 1907 recommended that the proportions of cement and sand should be settled with reference to the strength of concrete required, and the volume of mortar produced by the admixture of the sand and cement proposed to be used should be determined in each case. On small works, it suggests, the following figures may be taken as a guide, and are probably approximately correct for medium siliceous sand :-

\begin{tabular}{|c|c|c|c|c|c|c|c|}
\hline Parts & Parts & & Parts & Parts & Parts & & Parts. \\
\hline Cement. & Sand. & & Mortar. & Cement. & Sand. & & Mortar \\
\hline 1 & $\frac{1}{2}$ & $=$ & $1 \cdot 20$ & 1 & + & $=$ & $2 \cdot 35$ \\
\hline 1 & 1 & $=$ & $1 \cdot 50$ & 1 & $2 \frac{1}{2}$ & $=$ & $2 \cdot 70$ \\
\hline 1 & $1 \frac{1}{2}$ & $=$ & $1: 90$ & 1 & + & $=$ & $3 \cdot 00$ \\
\hline
\end{tabular}

These proportions are only correct for Portland cement; when lime-concretes are required the volume of sand plus aggregate must never be greater than six times that of the cement. The much greater cementing power of Portland cement enables strong concretes to be made which contain only $6 \frac{1}{2}$ per cent. of cement.

The proportions of the components of concrete are usually expressed in the form of a double ratio without any words. Thus, a $1: 2: 4$ mixture is understood to be composed of one measure of cement, two measures of sand, and four measures of aggregate. The following mixtures are in common use :-

(a) In a rich mixture for columns and other structural parts subjected to high stresses or requiring exceptional watertightness, $1: 1 \frac{1}{2}: 3$.

(b) In a standard mixture for reinforced floors, beams, and columns, for arches, for reinforced engine or machine foundations subject to vibrations, for tanks, sewers, conduits, and other water-tight work, the proportions should be $1: 2: 4$.

(c) A medium mixture for ordinary machine foundations, retaining walls, abutments, piers, thin foundation walls, building walls, ordinary floors, side walks, and sewers with heavy walls: proportions, $1: 2 \frac{1}{2}: 5$.

(d) A lean mixture for unimportant work in masses, for heavy walls, for large foundations supporting a stationary load, and for backing for stone masonry : proportions, $1: 3: 6$. 
In order to obtain the best results with the least wastage of cement, however, the proportions of aggregate, sand and eement should be caleulated in the manner deseribed on p. 164 .

To measure the aggregate and sand, boxes of suitable sizes are used. Sometimes a barrel with both ends removed is used as a measure. It is placed on the platform or mixing board and is filled with the material. The barrel is then lifted off and the correct measure of material remains on the board. It is incorrect to place a second, smaller barrel, on top of the first one and to fill the smaller barrel with sand, as some of the sand trickles down into the voids of the coarser aggregate and wrong proportions are obtained.

It is convenient to make the measuring boxes of such a capacity that they correspond exactly to the sand and aggregate needed for two bags of eement, or, if much larger quantities are needed, to four bags of eement. Larger quantities than this are inadvisable except under special eireumstances. The following table shows proportions of materials and the sizes of the measuring boxes :-

Table showing the Quantities of Materials and the Resulting Amount of Concrete for Two-bag Batch (EQUAL TO 168 ${ }_{4}^{3}$ LBS. CEMENT) (WILSON AND GAYLORD).

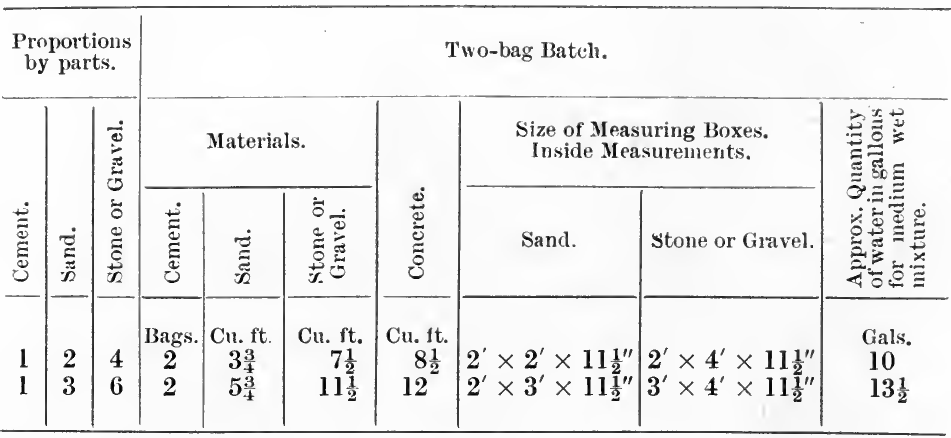

For measuring water a tall, narrow bucket or eylinder is the most suitable. This bucket should be checked as to capacity and should be marked to distinguish it from all others. No other bucket should be used for measuring. 
It is casy to make a mistake in proportioning concrete mixtures and it is, therefore, necessary to use some experimental method in order to ascertain if the proportions of each ingredient in the concrete is correct. To do this a rough, but usually sufficiently accurate method recommended by the Associated Portland Cement Manufacturers, Ltd., may be used. The apparatus required is shown in Fig. 31 to consist of a large and small measure of metal, a combined funnel and strainer fitted with gauze of $\frac{1}{4}$-inch mesh, two 500 c.c.graduated glasses and a vessel capable of delivering a fine stream of water. This last is used for washing the material.

To check a mixing of concrete a sample is drawn from the heap in one of the measures (the large one being used if concrete is poor in cement, or contains large aggregate). The strainer is held over one of the graduated glasses and the sample placed therein (the measure being washed out to ensure inclusion of all cement and sand). The large stones are caught on the mesh of the strainer, and the cement and sand pass through into the glass, this separation being assisted by stirring and washing down with

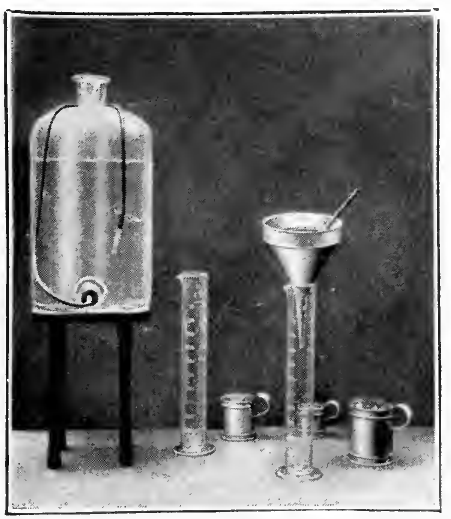

Fig. 31. - Apparatus for checking the composition of Concrete Mixtures.

water from the aspirator. The large aggregate left in the strainer is measured in the second glass to determine whether it is approximately correct. The agitation of the cement and sand by the water in the first graduated glass will cause them to separate; the sand settling more rapidly than the cement. After standing for about 15 minutes, the approximate proportions can be readily seen by means of the graduations. Slight allowance must be made for the fact that the cement will not settle quite so compactly as the sand.

The testing of two samples of equal quantity from different parts of the heap will show whether the mixing is uniform.

This test will not show minor and unimportant variations 
from the specified proportions, but its use will prevent such serious trouble as occurred recently, when after a new sea-wall had been demolished by a storm, it was found by analysis that the concrete, instead of being $4: 1$ as specified, was approximately $9: 1$.

This test cannot be applied to concrete which has set, but only to freshly made mixtures.

\section{CONSISTENCY.}

The amount of water required depends on the consistency desired, on the temperature at the time of mixing and also on the materials composing the aggregate. Four different consistencies are recognised by users of concrete :-

(1) Grout consisting of cement, sand and water in the form of a thick cream or slurry. Very little aggregate can be present unless its particles are small.

(2) Very wet mixture, consisting of concrete wet enough to flow off a shovel yet not so fluid as grout. This mixture is largely used for those portions of reinforced concrete where the metal work is close together.

(3) Dry mixture having a consistency resembling damp earth. It is used for foundations and wherever the concrete is required to set rapidly. This mixture must be thoroughly rammed or tamped so as to secure a uniform distribution of the water in it. It should be observed that the dry mixture is not really dry, but may have had 6 to 12 per cent. of water added to it. It sets with inconvenient rapidity, and owing to the tamping needed it is liable to contain an excessive proportion of voids unless worked by skilled men.

(4) Medium, or ordinary mixture, in which the material is plastic or jelly-like. To remove air bubbles and fill the voids it is necessary to ram or tamp this mixture lightly. It is used for all the ordinary purposes of concrete. It has the consistency which is the safest for men of average skill. 25 to 30 per cent. of water is usually necessary, but the proportions vary greatly. One large firm of concrete users employ one gallon of water to each cubic foot of dry material $(=16$ per cent.), but in warm weather this is increased to $1 \frac{1}{2}$ gallons 
(= 25 per cent.). Another equally important firm generally uses 20 per cent. of the volume of cement plus sand, or about 10 per cent. of the whole mixture.

Notwithstanding these variations in the consistency of the mixture, it is generally agreed that no more water should be added than is necessary to effect the desired chemical changes in the cement, plus an added amount just sufficient to enable the particles to slide over each other and to form a plastic mass. As some aggregates are very porous they should be thoroughly soaked, and the surplus water drained off before adding the water necessary to act on the cement.

The quantity of water to be used must be found by tests, ${ }^{1}$ but it is generally agreed that the mass should be sufficiently plastic to be packed easily into the required position, and yet should not be so wet as to allow any dripping of the cement, water or sand. This point is shown when, after ramming the mass, the water just shows on the surface.

A standing committee of the Concrete Institute has suggested the following specification for the consistency of concrete:-

For mass concrete the quantity of water added to the other constituents shall be sufficient to make a plastic mixture which, after thorough ramming, will quiver like a jelly.

For reinforced concrete the quantity of water added to the other constituents shall be such that the plastic mixture is capable of being rammed into all parts of the moulds and between the bars of the reinforcement. In dry weather the quantity of water shall be increased in order to allow for evaporation.

Some architects and engineers, on the contrary, stipulate that the mixture shall not "quake" or quiver like a jelly when rammed. This is to avoid the production of a "mushy" mass, such as is generally employed in the United States. In Great Britain a mass of so sloppy a consistency that it is difficult to keep on a shovel is considered unsuitable and liable to cause an undue segregation of the cement near the bottom of the material. A slight excess of water is better than too small a quantity, though under normal conditions the best results are obtained when there is neither an excess or a deficiency of water in the mixture. A concrete which has been worked in

${ }^{1}$ See "A Manual for Masons," by J. A. van der Kloes and A. B Searle (J. \& A. Churchill, London). 
too dry a condition does not pack properly, and so is weaker than one in which more water has been used.

The difference between the strength of dry and wet mixtures in the early stages of hardening is strongly in favour of the former, but after several months the strength of both mixtures is approximately equal.

There are a few rough-and-ready methods of telling whether the consistency of concrete is right. If the concrete is placed in a barrow, by the time it is wheeled into its place it should not have taken a horizontal surface. A shovelful of concrete from the bank held at a slight angle, should show no signs of the cement dropping away. Also a hole made in the concrete in the barrow should never be filled in by any ordinary amount of vibration.

The proportion of water which is used in laboratory tests is usually too low for mixing on a larger scale. In the tests, the concrete is mixed on impervious glass plates and is moulded in non-porous metal moulds, whilst in the works the mixing board and the moulds or centering both absorb a large amount of water, the exact amount of which it is almost impossible to ascertain, as it varies with the dryness of the timber.

The nature of the structure has some importance on the proportion of water which is most suitable. Thus, in beamsparticularly near the points of support-the concrete needs to be very fluid to pass between the closely-set reinforcing bars. In plain masses of concrete, on the contrary, a much dirier mixture is preferable, and where the thickness of the concrete is very great (as in foundations) the last portions must be almost dry to counteract the effect of excess of water in the other portion which is brought to the surface in ramming or tamping.

When used for submarine work, as in docks, harbours, etc., the mixture must appear to be dry, though in reality it contains a considerable proportion $(6-12 \%)$ of water. Perfectly dry mixtures of aggregate, sand and cement should never be employed.

In moulded concrete, such as is used for building blocks, the mixture is kept as dry as possible in order that it may be rapidly turned out of the moulds. Even in such work, however, it is 
undesirable to have too little water, as a somewhat larger proportion produces a stronger article with a better surface.

The best consistency of a concrete mixture, like that of a clay used by the potter, is easily recognised by men accustomed to working the material, but it is almost impossible to describe it with accuracy or to express the proportions of solid material and water in terms of definite figures (see p. 171).

Most of the water added to a concrete mixture is purely mechanical in its action; the proportion required to effect the hydrolysis of the cement being small. ${ }^{1}$ Nevertheless, this additional water performs several very important duties, and to limit its amount unduly is to reduce the strength of the concrete. Thus, whilst it is usually necessary to add about 10 per cent. of water to the concrete in order to obtain a workable mass, a considerable proportion of this water is removed on tamping. Some experiments made to ascertain this proportion showed that it is usually about one-quarter of the water originally added, but with very wet mixtures it may amount to half. Most of the water remaining immediately after tamping is removed by evaporation as the structure dries, and only about 1 per cent. is left in combination in the dry concrete.

\section{MIXING.}

The various components of concrete must be thoroughly and rapidly mixed in order to form a uniform mass before the cement has begun to set. To prolong the mixing is seriously detrimental to the concrete, just as cement which has been "worked" too much in making tests (p. 133) is greatly reduced in strength. Two main methods of mixing are employed, viz., by hand and by means of mechanical mixers. The latter have the advantage of ensuring a fairly thorough mixture and avoid any possibility of " scamping" the labour, such as not infrequently occurs in hand mixing. When skilled and conscientious men are employed, however, the concrete they produce is better than that produced by any machine, but the labour of mixing large quantities by hand is so great

1 It has been shown experimentally that the water required for complete hydration is about 14 per cent. of the weight of the cement used (see p. 89). 
and it is so difficult to rely on the men usually employed for this purpose, that machine-mixing is now employed on all large work. Whichever method is used, it is of the greatest importance that the proportions of the various ingredients are as accurate as possible, and that the measures used are correct in size and are properly employed. The mixing must be so thorough that the product is uniform in colour and in texture.

Hand mixing is the most effective if properly carried out, but this can only be done when relatively small quantities of concrete are required. The materials should be turned over three or four times and well mixed in the dry state, these operations being repeated to an equal extent after the addition of the water. The mixing should be made on a water-tight and non-porous platform about nine feet by ten feet, constructed of one-inch boards cleated together and provided with a frame to keep any surplus water from running off the platform. The surface of this platform should be planed smooth. This mixing board should be placed as near as possible to the spot where the cement is to be used, and in such a position that the men, in mixing, move their shovels along, and not across, the joints between the boards. The board must be packed so that it is solid and level before use. Any tendency to sag in the centre must be overcome by packing with sand or ballast.

A suitable quantity of sand should be measured by means of the measuring box (p. 168). The sand is shovelled in without any beating or packing until the box is more than full. The excess of sand is then removed by laying a stout lath or iron bar on top of the box and drawing it along. By repeating this action two or three times, the box will be filled just level with its upper edges. The measured sand is then turned out on to the measuring board and spread into a 3-inch or 4-inch layer. On top of the sand the requisite number of cement bags is emptied as evenly as possible. Two men, standing at opposite sides of the board, then mix the sand and cement together, turning the material over and over so as to mix it thoroughly. The sand and cement should be turned over thrice, a shovelful at a time, after which it should be sufficiently mixed for the aggregate and water to be added. It is next spread as evenly as possible on the board, and the larger 
measuring box (p. 168) is then filled with aggregate in the same manner as the sand, care being taken that the box is filled "just level" and not "heaped up." The measured quantity of aggregate is then turned onto the sand and cement mixture as evenly as possible. About three-quarters of the water likely to be needed is next thrown on to the aggregate, and the whole mass is then turned over and over, one shovelful at a time, water being added to the drier portions until the whole of the water has been added. With skilled men the mixing will be complete after three turnings, but if it shows streaks or dry portions it must be turned again. It is then shovelled into a compact pile and is ready for use. It must not be kept long, nor must much time have been occupied in the mixing, or the cement will have commenced to set and the concrete will be spoiled.

Re-mixed concrete must never be used.

Where the aggregate consists of a naturally occurring mixture of sandy gravel, this should be measured out and spread on the board, wetted thoroughly, and then covered with the proper quantity of cement. The mixture is then turned over three separate times, as before, the additional water not used for the sand being added during the turning. It requires a considerable amount of skill to mix cement with sandy gravel, and it is usually better to screen the materials and mix the sand and cement and add the gravel and water later.

It is never satisfactory to mix the sand and aggregate and to add the cement later; the sand and cement should first be mixed, as this secures a more homogeneous product and yields a stronger concrete.

Too much care cannot be taken in securing the adequate supervision of the men employed in mixing concrete, and in all cases the men themselves should be exceptionally reliable and trustworthy. The mixing of concrete is hard and laborious work, and is severely straining to the wrists. Moreover, the greater part of the labour can be avoided by moving the material without turning it over. This is a dodge to which careless and unscrupulous men resort, yet it is fatal to the successful mixing of the materials, and is one of the strongest arguments in favour of the use of mechanical mixers. 
Each day, at the conclusion of the mixing, the board should be carefully cleaned and freed from all cement, aggregate and sand. This is best accomplished by first sweeping and then scrubbing it. If the board is not properly cleaned the shovelling will be made much harder on later days.

Mechanical mixers may be divided roughly into two main divisions: (1) continuous mixers, in which the material is continuously fed and issued from the machine; and (2) batch mixers, in which a certain quantity of concrete is fed and mixed and then discharged as a batch. There are advocates for both types of machine, and certainly, if operated correctly, both can do excellent work.

Batch mixers are filled with measured quantities of the materials, are then set in operation for a given time and finally discharge a batch of concrete ready for use.

The designing of a concrete mixer which will give the requisite number and kind of movements required for the making of good concrete, is by no means a simple matter, as the long trail of failures has taught the manufacturer and contractor to their cost. A concrete mixer must be designed to operate under the severest conditions, and the mechanical construction should therefore be of the best, while the great rapidity of output required for modern building operations calls for a machine which will mix and discharge a batch in the shortest possible time.

In the Smith mixer (the T. L. Smith Co., Ltd.) and the roll mixer (Builders and Contractors' Plant, Ltd.) the box consists of a double cone which can be revolved on its own axis to discharge the material at one side; in the Ransome mixer the rotating box is a short cylinder with blades to mix the materials. The Express mixer (U. K. Winget Concrete Machine Co.) consists of the open circular pan with blades to mix the materials, the discharge being effected by opening doors in the bottom. A small mixer consisting of an open box or trough with paddles is also made by the Ransome Van Mehr Machinery Co. The objection to paddles is the liability of stones to jam them, but this may be avoided by the provision of safety springs.

It is important that the discharge from machines should be 
rapid or the tendency of the materials to become un-mixed will reduce the strength of the cement.

In the construction of the Panama Canal a machine known as the "Chicago improved cube mixer" is used. This is a simple adaptation of the first form of machine used extensively in the concrete industry-namely, the cubical box, journalled at diagonally opposite corners, and having a door on one side through which the charge of cement, sand, stone, and water were filled; the machine was rotated for several

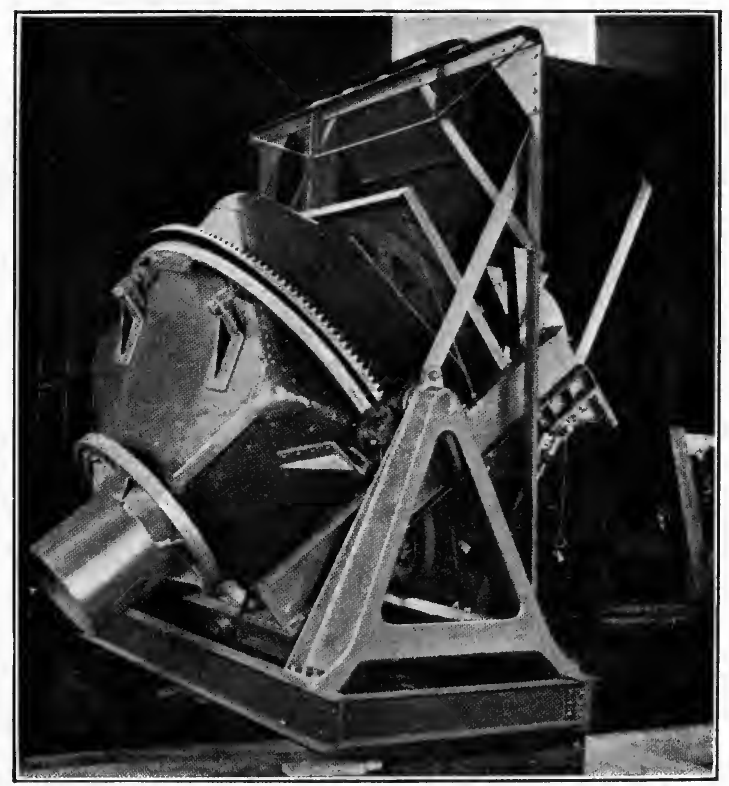

Fig. 32.-Chicago Cube Mixer, used in Panama Canal.

minutes, and the batch of mixed concrete then emptied out. Though mechanically crude, these machines produced an excellent concrete, the main objections to them being that, to discharge, the cube had to be stopped with the door at the bottom and, to be recharged, had to be turned until the side containing the door came to the top-further time, of course, being lost in unclamping and reclamping the door.

In the improved forms of this machine (Figs. 32-37), which preserves the principle of treating the batch as a unit,

c. 
and include both longitudinal and rotary movements, and mix by kneading and not by stirring, many interesting modifications have been introduced. For example, the shaft of the older machines is replaced by hollow trunnions riding on rollers, and made sufficiently large to serve as openings for charging and discharging. To rotate the cube, a strong circumferential rack is fastened around it at right angles to and midway between the trunnions; and this rack, geared with a pinion shaft, is so operated by the engine shaft that all gearing is removed as far as possible from the material which

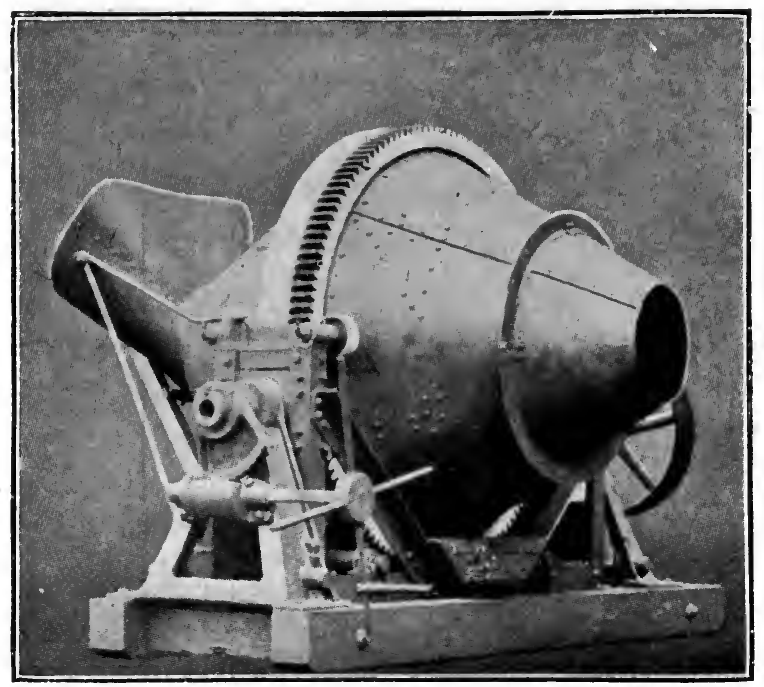

Fig. 33.-T. L. Smith Co., Ltd., Power Mixer.

flies about during the charging and discharging operations. An automatic dumping device has been provided, and, to ensure the construction of a larger cube in the same space, and eliminate any opportunity for pocketing the fine mortar, the former sharp corners and edges are rounded.

The cube in Fig. 32 is provided with breaker rods, from $\frac{5}{8}$ inch to 1 inch in diameter, so placed across each of the six central corners of the cube that as the machine revolves they slice through the mass of concrete, each following a different 
line, and effectually breaking any hard lumps or cakes foundin the materials. Otherwise, the interior of the cube is free from paddles, deflectors, or other obstructions.

In the mixer made by the T. L. Smith Co., Ltd. (Figs. 33 and 34), the drum consists of two cones and contains blades arranged spirally. In the Victoria mixer supplied by the same firm (Figs. 35 and 36) the drum is cylindrical, with four deflecting blades which subject the concrete to twelve distinct mixing actions for each revolution of the machine. A discharging spout (Fig. 36) can be swung partly into the cylinder when required. The use of the skip (Fig. 35) enables the mixer to be loaded from the ground level. Above the machine is a tank (Fig. 35) for the automatic supply of water to the concrete.

The Ransome-ver Mehr Machinery Co., Ltd., make a large number of different types of concrete mixers, and their machines are extensively used in all parts of the United Kingdom. Fig. 37 shows one of them

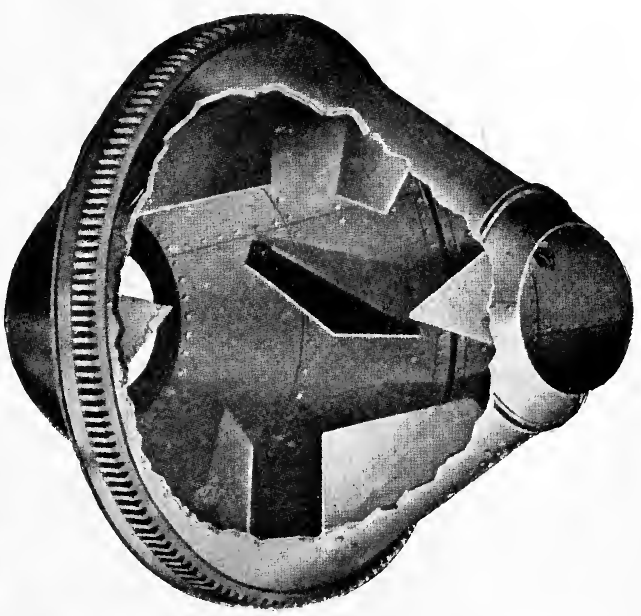

FIG. 34.-Cut-away View showing interior of Fig. 33 . with an engine and boiler directly coupled to the mixer.

Where batches of only two cubic feet each are required, or where a power-driven mixer is not available, a hand mixer may be used.

In the type of hand mixer (Fig. 38) supplied by the Ransomever Mehr Machinery Co., Ltd., the aggregate is fed into an elevating skip by the operator, the skipitself having a capacity of two cubic feet of material. The mouth of the skip is extended in the shape of a chute, in order to ensure no spilling of material when the skip discharges into the mixing drum, the necessary 
water being added simultaneously. Materials entering the drum immediately get into contact with the mixing blades, which are of a special

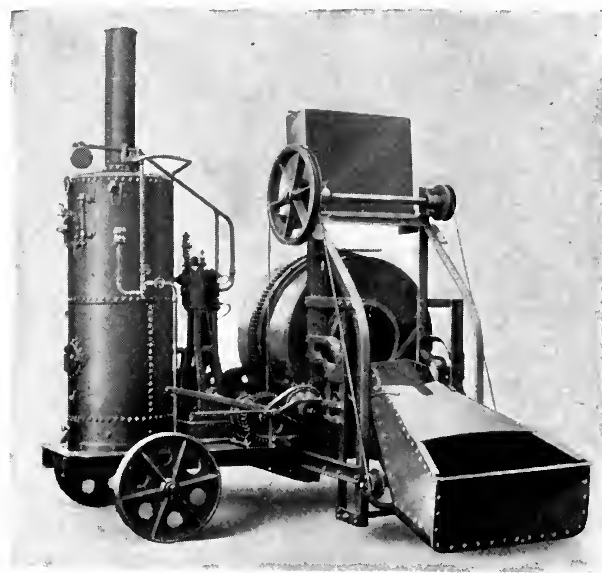

Fıg. 35.-Victoria Mixer, with Skip for filling. form, designed to ensure the whole of the batch being thoroughly mixed.

The mixing operation being complete (this usually occupies about 30 seconds), the drum itself is inverted by means of an auxiliary handle, pinion wheel, and rack. As the drum is inverted it rischarges its contents, being assisted during the whole period by the action of the paddles themselves. The paddles, in addition to faeilitating discharge, at the same time automatically clean the drum. The mixer is of such dimensions that a standard navvy barrow can be readily placed beneath the drum, in order to receive the batch when discharged. This eliminates all necessity for lifting material into the barrows after it is mixed, as is the case with ordinary hand mixing.

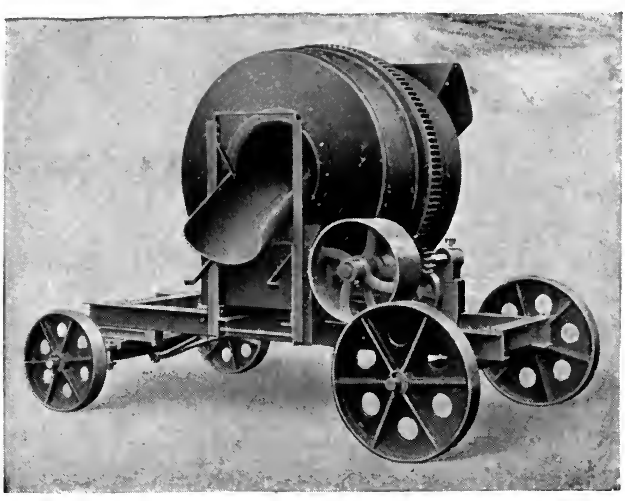

Fig. 36.-Victoria Mixer (in use).

A bateh mixer of a different type is known as the "Express" mixer, and is sold by the U. K. Winget Conerete Machine Co., 
Ltd., of Newcastle-on-Tyne. In designing this machine, the idea kept in view was that of mixing the material by mechanical means in a manner precisely similar to hand-mixing properly conducted. The machine (Figs. 39, 40) will mix concrete in which the aggregate is not larger than one and a half inch gauge; it is therefore particularly suitable for eoncrete block and reinforced work. The maximum charge is five cubic feet; this quantity is mixed dry, then water is added and mixed with

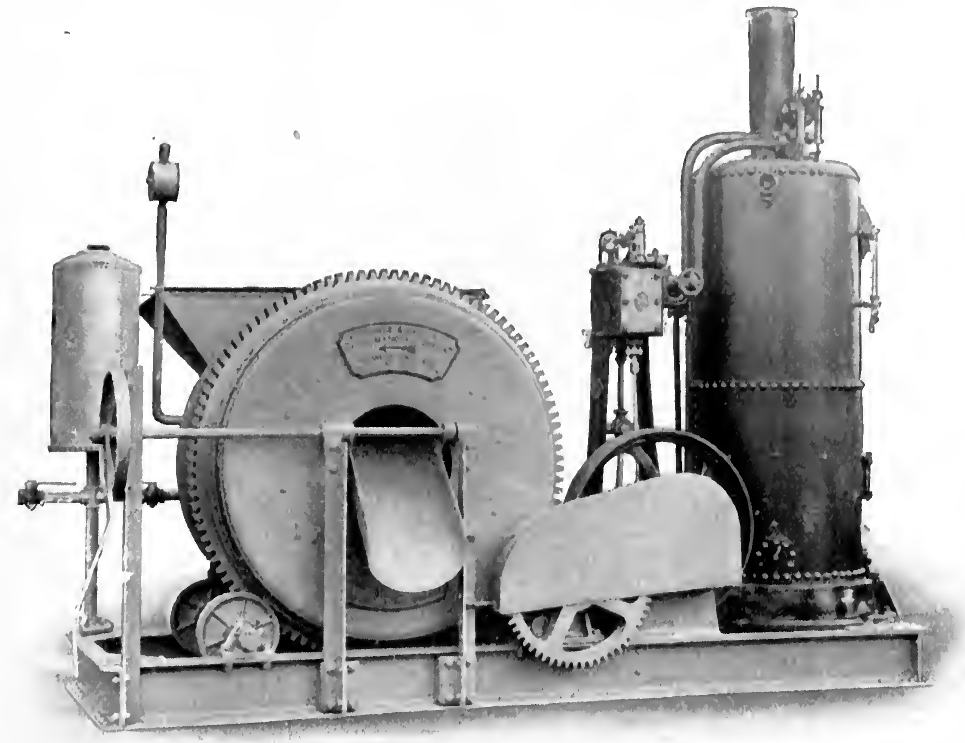

Fic. 37.-Ransome-ver Mehr Power Mixer.

the conerete, the finished product being delivered from the machine on to the ground in sixty seconds. The "Express", mixer will mix either dry, semi-dry, or wet, and as it is a batch mixer the proportions of the different materials may be altered at will to suit requirements. The power required to drive is about 6 b.h.p., so that the "Express" mixer is cheap to drive ; it has nothing to get out of order, and if the ploughs get worn out they can be replaced at a small expense. Each part of the machine is accessible for cleaning, and it does not clog up. 
Fig. 39 gives a general view of the machine, which consists of a stationary pan 6 feet 6 inches diameter and 1 foot 9 inches deep. The capstan is keyed on to a vertical shaft, driven from below by mitre gearing, and carries revolving arms, to which are attached adjustable plough-shaped beaters; each plough carries in its rear an iron rake. The action of the machine is to imitate hand-mixing, but the number of times the materials

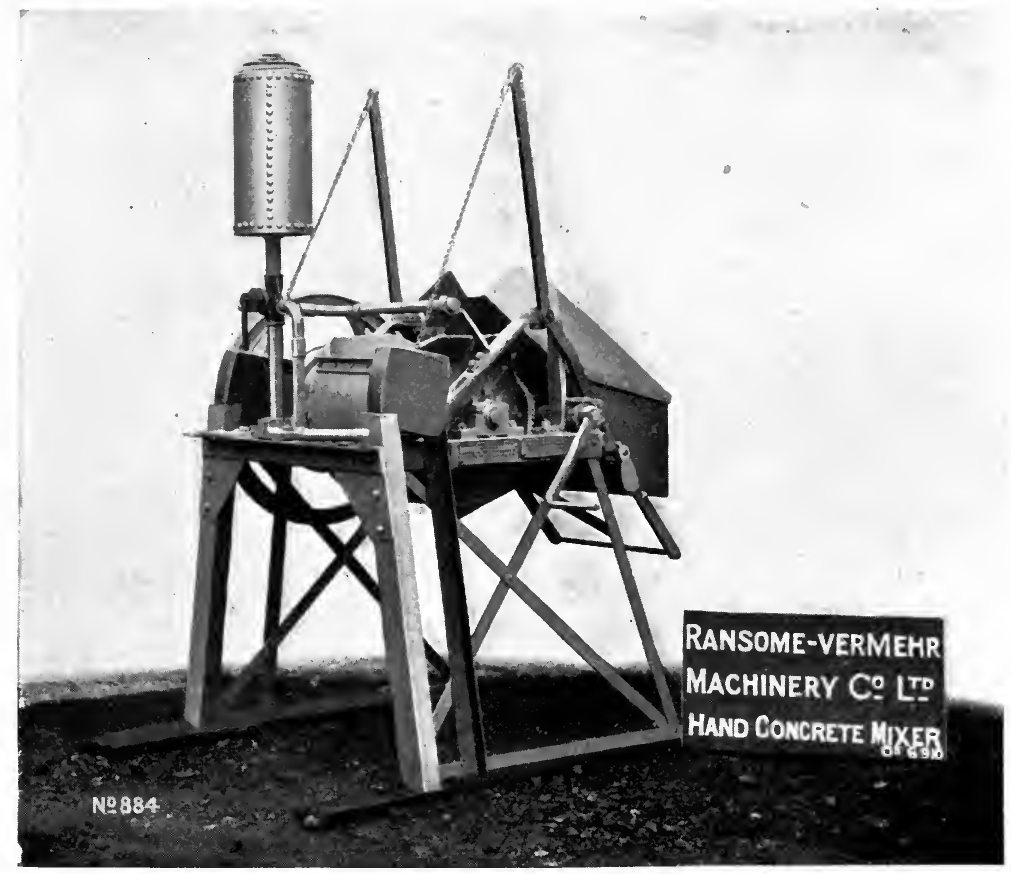

FIG. 38.--Hand Mixer for Concrete.

are turned over in the pan is enormously greater than in the most patient hand-mixing. This is caused by the combined action of the ploughs turning over the material, and the rake immediately following raking it out ready for the next succeeding plough to turn over. In some mixers of this type the materials are piled up in great furrows where the large material falls from the top of the furrow to the bottom, exactly as happens in badly conducted hand mixing, but in the "Express" 
mixer the material is kept level in the pan. This machine mixes without balling the material-a most objectionable thing in concrete block work.

If a continuous mixer is used it must be so constructed that it cannot be tampered with. Some patented mixers of the continuous type do not mix the material sufficiently, and so produce a poor and irregular concrete. For this reason batch mixers are often preferred. With the latter, the same precaution is necessary, as some of them permit the material to be fed in at the same time as other material is being discharged, thereby introducing some imperfectly mixed material into the waggon or

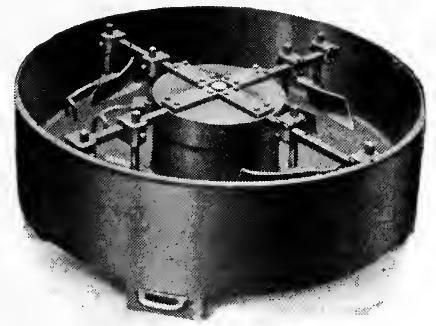

Frg. 39.-Top view of Express Mixer. wheelbarrow intended to receive the mixed concrete. In Barker and Hunter's mixer, the simultaneous filling and discharging of the machine is made impossible by the necessity of rotating the machine in one direction when filling and mixing, and in the opposite one when discharging.

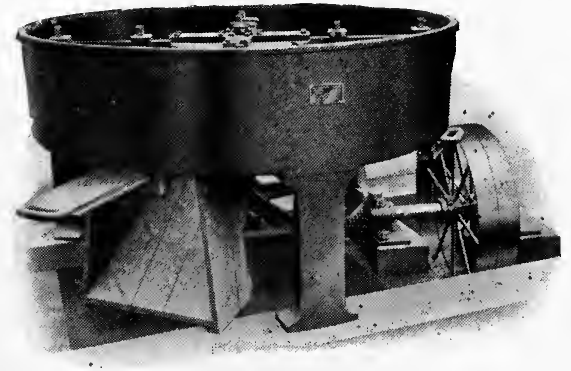

Fig. 40.-Side view of Express Mixer.

A discussion of the relative merits of the various types of mixers is beyond the scope of the present volume, but care should be taken in selecting a machine to choose one in which there is no likelihood of the particles being separated instead of being mixed more completely. There is some danger of this in machines fitted with internal blades. It is also necessary to keep the machine in good working order. As it is essential that the output of the mixer should approximate that at which it is rated by the makers, these machines should always be purchased under guarantee from a reliable 
firm. The effect of the work of mixing is very severe on the machines, and it is often aggravated by neglect. The best way is to put a competent man in charge of the mixer and to make him responsible for it. He should be allowed at least half an hour a day for cleaning the machines, tightening nuts and keys, and attending to the bearings, etc.

Whatever method or machine is used it is wise always to mix the cement and aggregate well before adding the water, then to mix thoroughly after the water has been added, great care being taken not to work through the initial set.

It is desirable not to mix concrete during frost, but if this is unavoidable the use of warm water for gauging and of warm cement and aggregate will reduce the risks of working at undesirably low temperatures. Some suggestions with regard to this will be found later under the caption, "Placing the Concrete."

\section{MOULDS AND CENTERING.}

Freshly mixed concrete is a plastic material which can be moulded into any shapes consistent with the size of its particles. To obtain any given shape, however, some kind of mould or form ${ }^{1}$ is necessary, and the concrete paste is poured into this and allowed to set. The hard mass is then removed from the mould, or, more commonly, the mould is taken away piecemeal, leaving the moulded mass standing and increasing in strength and hardness with the lapse of time.

For most structural purposes, the forms used in concrete construction are built of timber, the boards being used separately or in groups (termed shutters) where a number of forms of the same size are required for consecutive use. Great ingenuity is sometimes exercised in providing forms for structures of special shapes, but for most purposes temporary walls of wood are built on the spot where the concrete wall or other structure is desired. These wooden "walls" or shutters

1 It is interesting to note that the word form was introduced into this country from the United States. It owes its origin to the German emigrants, the word Form being the German equivalent of the English word mould. In modern concrete construction the use of the word mould is limited to the moulds used for comparatively small articles, and indicates a permanent piece of apparatus. Where a "mould" is built up and taken clown after use it is termed a form. Sometimes the terms shuttering or centering are used instead of mould and form. 
are placed the same distance apart as the desired thickness of the concrete, and they are supported by props and angle pieces so as to remain secure against the thrust of the concrete.

The construction of the form for a square column and floor is shown in Fig. 41.

Three important precautions must be taken : the forms must be removable without jarring the concrete, there must be no leakage between the boards constituting the form, and the whole structure must be stiff enough not to bulge or alter in shape during use. To aid this, perforated wooden plugs or separators, with bolts through them, may be used, the bolts and wood being removable, and the holes in the concrete filled up. Much concrete work which would otherwise be excellent is spoiled by insecure and insufficiently rigid forms and

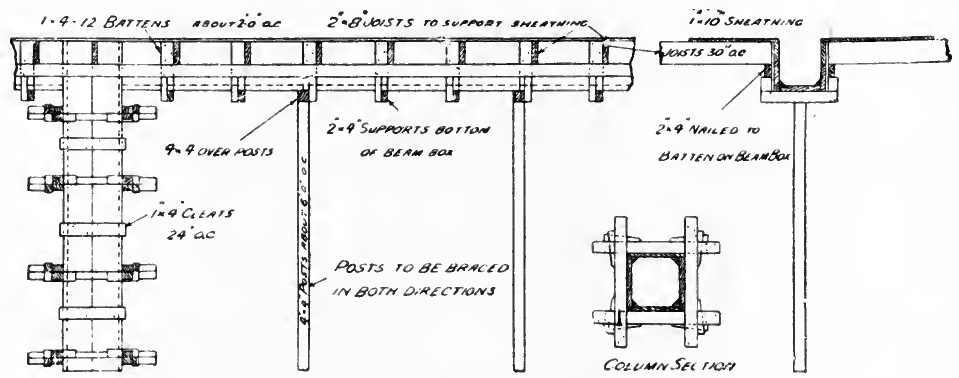

Fig. 41.-Arrangement of Forms.

centering, and it is therefore of great importance that special attention should be paid to this part of the work.

Boards one inch in thickness are usually strong enough, but they must be supported by a sufficient number of shores or buttresses, the latter being also of wood and placed about two feet apart. Thick boards last longer and are cheaper in the end.

The cost of forms is very great, and unless care is taken in constructing them much waste may result. By careful planning beforehand, most of the boards may be used repeatedly, and for small work they need cost practically nothing, being made of odds and ends of timber, which is as valuable afterwards as before it was used.

The construction of the form requires great care, as mistakes cannot be remedied. The space inside should also be kept 
clean, any chips, etc. being removed at once. Where possible the shape should be such that the angles of the concrete are rounded.

The essential characteristics of good forms are rapidity and ease of construction, great stability in use and rapidity and ease of removal without tearing or jarring the concrete.

The wood should be wetted before pouring in the concrete, so as to prevent the adhesion of the latter. Unless this is done, some of the concrete will be torn away when the forms are taken down. For special work the forms may be limewashed, oiled or coated with soft soap. Creosote and kerosene oil are useless, but linseed and black or cylinder oils are excellent. Even when oil is used, it is desirable, just before pouring in the concrete to flush the form with water.

The designing and construction of forms is in itself a large subject, and to enter upon it in further detail is beyond the scope of the present volume. It should be observed, however, that the use of forms would be greatly facilitated and the cost greatly reduced if greater standardisation were possible, though the awkwardly-shaped and restricted sites upon which it is so often necessary to work appear to prohibit this in the majority of cases. Even under good conditions the centering costs one-third of the total price for the concrete, and may easily be more than this, so that any saving which may be effected is of considerable influence. At present the chief economy is realised by avoiding all unnecessary cutting of the boards and by planning out the work in such a manner that the long lengths of timber can be used repeatedly. By making beams, floor panels and columns of certain standard sizes, and adhering to these as far as ever possible, the cost of forms may be reduced to 5 per cent. for firms in regular work. The timber is not damaged by the concrete, but in most instances it is cut up into short, useless pieces which cannot be used again, and have to be replaced by new ones. Architects and engineers may often effect a great saving by using pillars of standard size and placing them standard distances apart. The question of the use of standard forms is one to which the student of concrete construction may well devote a large amount of thought and care. 
The operation which, in the metal industries, is known as casting, and in the plastic industries, as moulding, is, in concrete construction, termed placing. In each case it is the operation which gives the material the shape which it is desired it shall possess.

\section{PLACING CONCRETE.}

Immediately after the concrete has been properly mixed it should be placed in the forms or moulds or on the spot in which it is to be used. There should be no delay in placing the concrete or the consequences may be serious. It is, therefore, wise to mix the material in only small amounts, and on no account to use concrete which has begun to set. A slow-setting cement should be used when the concrete has to be taken a considerable distance from the place of mixing to where it can be poured into the forms. The concrete paste may be handled and "placed" in any convenient manner, providing that it does not begin to set before it is in position and that no un-mixing of the material occurs. Wherever possible, the concrete should be shovelled direct from the mixing board or machine into the forms, but where large quantities are required it is usually necessary to transport it in barrows to that part of the structure where it is required.

A wheelbarrow holding two cubic feet of concrete is an exceedingly heavy load, and where the concrete is very wet, a load of one cubic foot is not uncommon, since the ordinary steel or wooden barrow has a body or bowl too shallow to prevent the wet concrete from overflowing. To reduce the cost of transporting concrete, the Ransome-ver Mehr Machinery Co., Ltd., have designed an all-steel cart (Fig. 42) that holds six cubic feet (water measure). One man can push or pull this cart over a plank runway, even when the cart is level full of concrete. In other words, one man transports from three to six times as much concrete as he could transport in a wheelbarrow. This remarkable result is due to the wheels of the cart being much larger than those of a wheelbarrow, and, therefore, more easy running is secured; no weight is thrown on to the man's hands as in the case of a wheelbarrow, but he is free to use all his strength in pushing or pulling the cart, and as no concrete 
is slopped on to the run-planks where these carts are used, only half the effort is needed to push a cart over clean planks that is necessary when going over dirty ones. In addition to the larger loads moved per man, there is an important economic advantage in being able to discharge the batch from a concrete mixer in much less time where these carts are used instead of wheelbarrows, as a mixer can be discharged into these carts in one-third the time required with wheelbarrows.

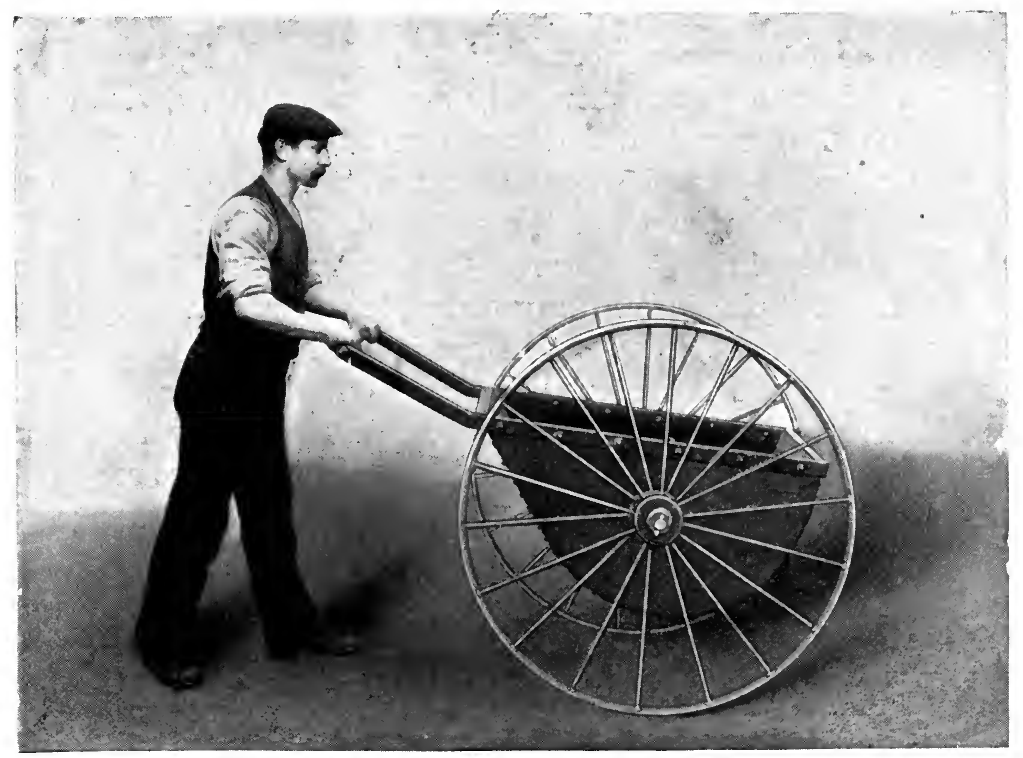

FIG. 42.-Cart for Concrete.

The amount of concrete added at a time should not be more than will produce a layer about six inches in thickness, or three inches in the neighbourhood of reinforcement. Other things being equal, the strength of concrete depends on its compactness or density. Hence it is desirable to use some means of increasing this. A vertical spade is then inserted into this layer close to the inner face of the form, and is worked up and down so as to push the aggregate away from the form, release any air bubbles and produce an even face. The size 
of the spade will depend on the space into which it is introduced; a long board four inches by one inch, sharpened to a chisel edge, is exceedingly uscful for this purpose, though for broader work an ordinary spade may be used. Spading in this manner needs considerable skill if a dry concrete mixture is used; with a very sloppy mixture, on the contrary, no such treatment is needed, though it is, in all cases, a wise precaution. A ram or tamping tool (Fig. 43) is then held just above the top of the concrete layer and is brought down into it in a succession of blows until all the material is compact and the surplus water has risen to the surface. Hard ramming is seldom necessary with a wellmade concrete, though the drier the mixture the harder must be the blows. Indeed, very heavy blows tend to do more harm than good, what is required being a series of tamps or taps of just sufficient force to secure the various particles all fitting into their places without leaving any voids. Many light taps are far more useful than a few heavy ones in consolidating the concrete. Some firms prefer to use a wet mixture and not to tamp at all, but to rely on the natural fluidity of the concrete aided by the use of a special spade (Fig. 44). Vibrators -

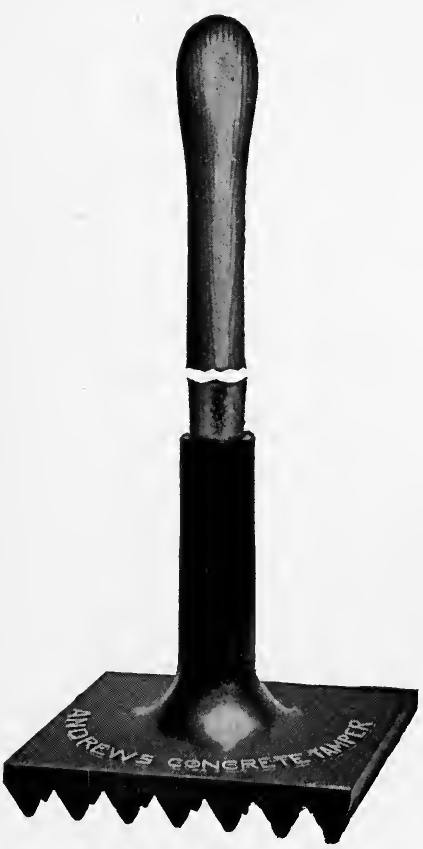

FIG. 43.--Tamping Tool. operated in a similar manner to pneumatic hammers-are applied to each side of the form or shuttering by the Vibrocel Co., Ltd. This special mode of tamping is claimed by the patentees to give a more impervious concrete than is obtainable by any other method. The resumption of placing (after an interval) and the attachment of new concrete to old is also greatly facilitated by vibrating instead of the more usual tamping. 
If the work of placing the concrete is suspended, all necessary grooves for joining future work must be made before the concrete is set. When the placing is resumed, the previous concrete must be wetted, roughened, cleaned of all foreign

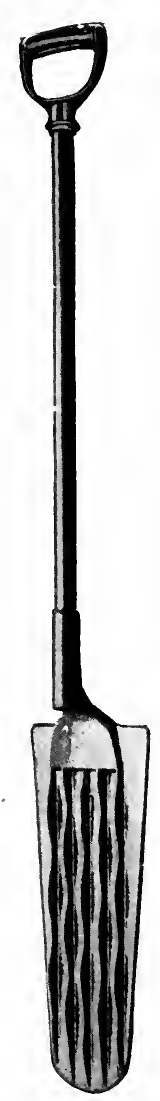
material and covered with mortar, consisting of one part of Portland cement with not more than two parts of sand so as to form a layer of mortar half an inch thick. Care should be taken that joints of this kind are made in positions where they will have the least possible effect on the strength of the structure. Thus, footings and floors should be placed the full thickness at one operation; columns should only be stopped (if at all) at the underside of the lowest projection of the capital ; constructional joints in beams and girders should be vertical and within the middle third of the span, and similar joints in slabs should be near the centre of the span. If "plums" or large masses of stone, or packing is used, the pieces should be placed in position before the concrete is added. These large masses should be at least two inches apart, and should not be within two inches of the face or back of the form. The concrete should be rubbed around them with a spade, and that immediately above and around them should be well tamped.

As the strength of the structure depends largely on the care and skill exercised in the placing of the concrete, this should have all Fig. 44.- Spade for Concrete. (Ross.) the attention it needs. Frost has a very serious effect on plastic concrete, and no placing should be done in frosty weather. Under some circumstances, however, working at a temperature below $32^{\circ} \mathrm{F}$. is unavoidable, and the concrete must therefore be protected against the action of frost until it has set and hardened. Where the concrete will not be seen the addition of common salt or calcium chloride to the water used for mixing will 
reduce the freezing point of the water, and so permit the placing to go on as usual. Where a scummed surface on the concrete must be avoided, it is necessary to heat the materials of which the concrete is made and to shelter the concrete until it has set and become fairly hard. The temperature of the materials should not be higher than that of boiling water, and the water itself should generally be only lukewarm, and certainly not above $100^{\circ} \mathrm{F}$. Immediately the warm materials have been mixed and the concrete placed in position, it must be protected by canvas tents and fires or hot pipes.

In Canada, good results are obtained by spreading the whole of the materials on a steam-heated floor and by using hot water for mixing. The mixing drum is also heated by a steam jacket.

The forms are made of sheet iron and are double, steam being led between the walls so as to heat the core or space to be occupied later by the concrete. During this preliminary warming the forms are covered with tarpaulin, which is removed a little at a time during the placing of the concrete.

Concrete made of warm materials during frost is never considered to be quite as satisfactory as that made at the normal temperature. Hence, the wisest course is to follow the recommendations of the joint committee under the auspices of the Royal Institute of British Architects, viz., to suspend all work during frosty weather, to protect new work at night when frost is expected, to leave the centering in position for a fortnight longer than ordinary, and not to remove it until all signs of frost have departed.

Placing in water.-Concrete should not, as a rule, be allowed to set under water. Where this is unavoidable, special precautions must be adopted, one of the most important being to prevent the cement from floating away. The use of a drop-bottom bucket facilitates rather than prevents this loss of concrete. In no case should soft concrete be allowed to drop through water.

One of the most usual methods is to fill the concrete into bags, sewing up the mouths of these and depositing the whole under water. This method involves the services of divers and is cumbersome, slow and expensive; it is rapidly becoming 
obsolete except for repair work and for work under moving water.

The use of a tremie or pipe with its upper end projecting out of the water appears to have many advantages. The concrete is poured in at the top of the tube as fast as it escapes from the lower end. In practice, this method presents several serious difficulties, as it is by no means easy to prevent the water from rising inside the tube and floating the cement away from the concrete. The motion of the water near the bottom of the tube has a similar action. What is required is to have the lower end of the tube buried in concrete for two to five feet, so as to form an effective seal against the outside water; when this can be secured the use of tremies is highly advantageous. The tremie is raised a few inches at a time as the work progresses.

An ingenious device, used by the Vibrocel Co., Ltd., consists of polygonal cells of concrete which are made on land and then floated to the place where they are to be used. These floating cells are then kept vertical in the water and the bottom is blown out by means of a gelignite charge previously placed therein. The cells then sink to the bottom of the water and form a permanent tremie which is later filled with concrete.

The concrete should be wetter than that employed on dry land, in order that it may flow properly. Care should be taken not to disturb the freshly-set concrete, and the deposition of the concrete should be continuous so as to avoid the necessity for cleaning the surface of the different lots.

Where coffer-dams are used they should be sufficiently water-tight to prevent a current of water through the pit, and to keep any water in the pit quite still.

\section{SETTING AND HARDENING.}

The chemical and physical changes which take place during the setting and hardening of concrete are practically the same as those occurring in cement. If the concrete has been correctly proportioned and prepared, however, there will be far fewer unhydrolysed particles of cement in the concrete than when neat cement is used. In other words the cemen- 
titious power of the cement is more fully utilised than when no sand or aggregate is present. Apart from this, as the reactions which occur take place exclusively between the cement and water, there is no need to describe them further; the reader who desires to refresh his memory concerning them should see pp. 81 et seq.

If the "sand" used in the concrete is made by crushing bricks and burnt clay ballast to powder, it will be, of itself, cementitious, and will unite with the free lime formed by hydrolysis of the Portland cement, and will form a pozzolanic cement whieh will, in its turn, be hydrolysed in a similar manner, and will set and finally harden into a stony mass. Properly burned clay when reduced to powder, therefore, increases the strength of all concrete in which it takes the place of silicious sand (see p. 159).

Concrete which is placed under water sometimes takes much longer to set. This is due to the wetness of the mixture rather than to the influence of the water in which it is immersed.

\section{STRIKING CENTERING.}

The removal of the forms, leaving the concrete mass in situ, is known technically as "striking the centering." This operation usually takes place as soon as the concrete has hardened sufficiently for the support of the forms to be no longer necessary, that is about eight to ten days after "placing." The length of time which elapses must, however, be left to the discretion of the man in charge of the work, and in frosty weather the forms may remain for three weeks or more. The longer the forms remain in place the safer will be the concrete. Some of the simpler forms may, in summer, be removed as early as three days after placing, but this is somewhat risky.

The side casing of beams, the casing of columns, and for the soffits of floor-slabs of less than five feet span, may usually be removed after eight days; the casing of soffits of beams and floors of greater span should not be removed for at least fourteen days, whilst for arches of large span the forms should not be touched for at least a month. 
The striking of centering is a most important and responsible duty, as if done too soon or unskilfully it may result in the collapse of the structure and in serious loss of life. Many of the fatal accidents in connection with concrete-particularly in America-have been caused by too early removal of the centering and by loading the structure before the concrete was properly hardened. Concrete is often used for bridges, floors, and in other positions where the weight of material with no support immediately beneath it is very great, so that the dead weight of the structure alone may be more than half that of the live load it is designed to carry. Consequently, the premature removal of the forms is always risky, and too much care and skill cannot be exercised in preventing accidents due to this cause.

The greatest care should also be taken in removing the forms not to jar, shake or tear the concrete, as it will not be fully hardened and may easily be damaged. After the removal of the forms, the concrete should be protected from the sun's rays, rain, dust and wind by canvas, burlap or sheeting, and its surface should be kept wet by sprinkling water on it twice daily for five or six days. This treatment is necessary to prevent the outside of the mass drying more rapidly than the inside, and so causing strains. In summer weather and tropical climates this watering of the surfaces should be done with care and intelligence. If sheeting or burlap is used, this should be wetted as well as the surface of the concrete.

The forms, after removal from the structure, should be at once cleaned by means of a short-handled hoe, care being taken not to gouge the wood.

\section{SURFACE TREATMENT.}

Concrete is subject to many conditions which make it difficult to obtain a satisfactory finish. Every irregularity and almost every joint in the forms leaves an imprint. Patches of exposed aggregate show here and there, and variations of colour occur in streaks and layers. Thus, a discoloration of the material may be due to $(a)$ partial bleaching of the lime compounds, (b) the formation of efflorescence or "scum," 
(c) the inclusion of organic matter in the water used, and $(d)$ a "laitence" face, caused by an excess of water in some portion of the concrete mixture which has floated some of the lighter cement particles to the surface and produced a thin impermeable coating. Roughness or irregularity of the surface may be due to careless work, too long a time between watering the form and placing the concrete, insufficient "spading" or rough removal of the forms and shuttering, the accidental inclusion of sawdust, chippings, etc.

Untouched concrete work may normally have one of three distinctive surfaces :-

(1) Dense surfaces produced by careful proportioning of the materials. These are the best of all surfaces on concrete, and are obtained by using a medium wet mixture and carefully spading (p. 189) so as to get a rich mixture in contact with the form. Then, if the forms are removed with sufficient care, the surface of the material will be such that it cannot be much improved by later treatment, particularly if the concrete has been properly proportioned in the first place.

(2) Porous surfaces caused by the leanness or dryness of the mixture, by bad mixing or insufficient tamping, by adulteration or careless working. The chief cause is attempting to reduce the cost of working.

(3) Crocodile surfaces due to the cement "floating" to the surface, then shrinking and cracking, or " alligating" on account of the difference in the contraction of the cement and concrete. In bad cases the surface spalls or peels away, but usually it is covered with minute hair-lines, which bear a fancied resemblance to a crocodile skin. This surface is usually due to working with too wet a mixture. Surfaces coated with neat cement often produce these hair-lines. Such surfaces and lines are always due to excessive shrinkage.

The treatment of the surface of concrete is conveniently divided into four main groups :-

(1) Cleanining the surface so as to remove dirt, irregularities, etc. This may be effected by brushing, chipping, rubbing (with carborundum bricks), sand-blasting, etc., or by washing with soap and water, acetic or hydrochloric acid and water, or plain water. Efflorescence or scum is usually removed by 
washing with weak hydrochloric acid, followed by plenty of water applied by means of a hose. If the surface is to be cleaned by brushing it is usually necessary to do so whilst the concrete is still green ${ }^{1}$, as otherwise the process would be too laborious. Hence, the forms must be removed within twenty-four hours of placing the concrete. This limits the applicability of simple brushing.

Hard concrete may be cleaned with acid or with a bushhammer or a pneumatic hammer, but the last-named removes the cement surface and so reduces the water-proofness of the concrete-an objection which applies to all methods of cleaning concrete surfaces.

(2) Filling in the surface voids, without discoloration, in order to produce a more pleasing surface. Plaster is unsuitable for this purpose as it falls away when the concrete becomes damp, and grout is unstable though largely used. A $1: 3: 5$ mixture with fine aggregate is generally considered to be one of the most suitable ; it is made very thin and is applied with a whitewash brush. The chief disadvantage of most fillings applied to concrete lies in their great liability to scale and peel off. This does not always commence at once, but may begin after two or three years.

The only surface fillings which are likely to be permanent must contain a pigment which is resistant to the action of the sun as well as to damp, which is sufficiently heavy to fill the voids and prevent absorption, and of such a nature that the texture of the finished surface bears a sufficiently close resemblance to that of the original concrete.

Ordinary concrete cannot be given a polished surface because the particles of cement crystals are too soft in proportion to the aggregate, and are easily reduced to powder without securing a smooth, hard surface capable of reflecting light. Rich concrete, in which the aggregate is in the state of a very fine powder, placed in a glass-lined mould gives the nearest approach to a polish at present attainable.

(3) Treatment of the surface with a coloured material. Specially prepared paints are sold for this purpose, but black or white marble and other substances may be introduced in

\footnotetext{
1 Concrete which has not reached its greatest hardness is said to be green.
} 
the material nearest to the forms. The face is "cleaned up" as soon as possible after the centering has been removed. If necessary, distance pieces may be used in the forms and the surface concrete may in this way be cast quite independently of the backing.

Specially made cement mixtures-sometimes known as granolithic facings-are sometimes poured in a narrow space arranged between the concrete and the form. There is, however, considerable difficulty in getting the face to adhere to the concrete without alligating or spalling, owing to the difference in contraction between the two mixtures. The facing mixtures may contain red granite or marble chippings in order to give a surface of a colour different from the natural grey of concrete. Other colouring materials are used for the same purpose ; they are added in suitable proportions to the cement-sand mixture used for facing. Those most usually employed are : raw iron oxide for bright red, roasted iron oxide for brown, ultramarine for bright blue, yellow. ochre for buff to yellow, carbon black or lampblack for grey to dark slate, manganese dioxide for black (11 lbs. per bag of cement). A mixture of equal parts of carbon black and red iron ore for dull reds.

Facings of terra cotta-either plain or glazed-are also extensively employed, as they give a particularly pleasing appearance and add a warmth of tone not otherwise obtainable.

Most facings only make concrete damp-proof, and not always that, as dampness may rise through the foundations by capillary attraction in the case of very porous concrete. For this reason it is generally better to adopt some means of rendering the whole mass waterproof, and not to rely too much upon a surface-finish. (See footnote on p. 171.)

(4) Treatment with a view to preserving the concrete from the action of the weather, viz. :-

(a) Damp-proofing with only partial obliteration of the surface and preservation of decorative feature.

(b) Waterproofing with complete obliteration of the surface.

The term damp-proofing should be confined to methods and appliances used for keeping water and dampness out of the superstructures of buildings, the term "waterproofing" being 
used for treating work subject to hydrostatic pressure and for vessels intended to contain or retain water. Three distinct classes of damp-proofing materials are used :-

(1) Transparent coatings.

(2) Opaque cement coatings.

(3) Special bituminous coatings.

Transparent coatings include those which do not change the appearance of the surface treated.

The most frequently used materials are: soaps, oils and various waxes together with fluates, water-glass, casein paints and bitumens.

The old Sylvester process, although now practically obsolete, was one of the earliest efforts in this kind of damp-proofing. This process involves alternate treatments of the surface with solutions of soap and alum, and depends for its efficiency upon the formation of aluminium salts of the fatty acid contained in the soap, which are insoluble and possess a very distinct but temporary water-repellent action. This process is not economical, as it is necessary to repeat the operations a number of times to produce sufficient insoluble soap.

In the treatment of the porous surface with hot paraffin, the exposed surfaces are carefully heated and coated with melted paraffin wax applied with a brush. By this means the paraffin penetrates to a considerable depth before it chills and is thereby deposited in the pores. Fairly successful results can be obtained by this method, but the expense makes its use quite prohibitive in most cases.

Water-glass has also been applied with some success, but it is difficult to get it into the pores of the concrete. Oxalate of soda and various zinc compounds are also used.

Most of the transparent liquid coatings which are applied to the surface with a brush, like paint, and offered as infallible remedies for dampness and porosity, consist of a paraffin or wax of low melting point, dissolved in a light volatile oil. They depend for their efficiency upon the deposition of the wax or paraffin in the pores of the concrete. Some of these waterproofings contain over 95 per cent. of volatile constituents and a very small amount of solid base, only the latter forming the waterproofing agent. 
Quite recently, some progressive manufacturers have been able to produce synthetic water-repellent bases which form far stronger solutions in volatile vehicles, and these are more satisfactory.

Under the term fluates, various soluble silico-fluorides are largely in use for rendering concrete water-proof and for increasing the hardness of its surface. Aluminium, magnesium and zinc silico-fluorides are the ones chiefly used for this purpose, the concrete being either soaked in a solution of fluate or painted with the latter. These fluates act in a manner similar to water-glass, but form a harder product.

There is a very distinct field for all such coatings, as they are the only means available for treating the exterior surfaces of porous stone and concrete in existing structures without altering their appearance.

Opaque Coatings for Cement include paints and coatings of plain cement grout, with the attendant difficulty of obtaining a perfect bond and the tendency of the coating to absorb water. Several manufacturers have produced coatings made with a Portland cement base, which show a perfect bond on the surface coated and are perfectly repellent and dampproof. These products contain no oil and possess none of the characteristic qualities of oil paints. It is well known that an oil paint must not be applied directly to a concrete surface, as the vegetable oils used react with the alkali in the cement, forming a soap, and cause the disintegration of the coating. This may be avoided by the employment of a fluate or of a coating of casein paint previous to the use of the oil paint. Oil paints also dry with a distinct gloss, which is very objectionable on a concrete surface, where the coating should retain the characteristic texture of the surface coated. Casein paints followed by treatment with formaldehyde are becoming increasingly popular.

Where colour is of no importance, as in some underground work, there is no better paint than ordinary tar, applied hot.

Cement coatings have a very general application for making cement surfaces, such as stucco, cement blocks, etc., uniform in colour and are also used to replace the somewhat cheerless 
and unattractive surfaces of untreated concrete with a softtoned surface which is thoroughly damp-proof.

Special Bitumens are not applied to the exposed surface, but to the interior of concrete walls. They are black in appearance and are made of various waterproof gums. They are applied with a brush, and, besides forming a damp-proof surface, they provide a good bond for a coat of plaster applied directly to them.

These products eliminate the necessity of furring and lathing, and so increase the available space and remove all the disagreeable features of the air space. Although the film is a fairly good non-conductor, it has not the same insulating efficiency as an air space, and is not recommended where there is serious condensation on the inner surface.

The term waterproofing should be confined to treating structures subject to water pressure and those designed to retain water, but not to prevent mere dampness. One of the two following methods is generally employed :-

(1) "Integral," or rigid method in which a waterproofing compound is incorporated in the concrete mass, rendering the same waterproof within itself.

(2) "Membrane," or bituminous shield method, in which the concrete work is insulated from contact with the water by interposing a continuous, waterproof, bituminous shield.

The "Integral" method involves the addition of a compound to the composition of the concrete during the mixing or placing, and this compound thus becomes an integral part of the mass of substances. Two classes, characterised by the physical condition in which they are added to the concrete, are used :-

(1) Finely powdered dry compounds added to the dry cement in the proportion of about 2 per cent.

(2) Liquids or pastes added to the water used to temper the dry mixture of cement and aggregate.

The compounds in the first class are usually hydrated lime with a greater or less amount of the lime salts of fatty acids.

The first essential for success lies in obtaining an even, homogeneous distribution of the waterproofing compound. This is very difficult on account of these dry compounds. 
No matter how great an effort is made to mix a repellent compound with dry cement and then with dampened sand, as soon as the water is added the repellent property of the compound will manifest itself, and as the fluidity of the concrete increases, and there will be a tendency for the repellent compound to be concentrated in other sections, thereby making an even, homogeneous distribution impossible. Although the repellent feature is an excellent property for a compound to possess when in place in the mass of concrete, its very nature makes even distribution difficult, and thereby defeats its intended purpose (see p. 205).

In the case of compounds that are added directly to the water, on the contrary, there is no difficulty in obtaining an even distribution, as the water acts as a vehicle or carrier and evenly distributes them. Hence, as far as the homogeneous disposition of the waterproofing agent is concerned, compounds that are originally miscible with water have a decided advantage over dry compounds of a repellent nature. A suitable compound for this class of work should not contain any organic constituents or other materials capable of interfering with the strength of the concrete, as it should not be necessary to sacrifice strength to obtain waterproofing efficiency. Yet results have been obtained which indicate a loss of over 50 per cent. in the strength of concrete when emulsified oils were contained in the compound used for waterproofing.

The "Integral" method of waterproofing has a very general application to waterproofing conditions, though it cannot be used in cases when there is a liability for the continual development of cracks in the work, as these would, of course, destroy the waterproofing efficiency. The "Integral" method is very largely employed for substructural work, cisternș, reservoirs, etc., which are designed for containing water. The waterproofing compounds can be used throughout the mass of concrete, or in cases where this precedure would be impracticable, on account of the cost, it can be concentrated in a plaster coat on the surface of the structure (see p. 205).

The Coating of waterproofed cement mortar should be prepared by thoroughly tempering to required consistency a dry mixture of one part of cement to two parts of sand 
with water, to which the waterproofing compound has been added in the proportion directed by the manufacturer. The sand must be clean and spherical and well graded. Before plastering such cement mortar on to old concrete, the surface of the latter should be treated as follows :-

(a) The old surface must be cleaned very thoroughly with a heavy wire broom so as to remove all dust and dirt. A jet of steam should, if available, be employed to clean the wall.

(b) To the mechanically-cleaned surface a liberal coat of $1: 10$ solution of hydrochloric acid is applied with a large brush. The acid remains until it has exhausted itself, which will require at least ten minutes. A second liberal coating of acid solution should then be applied before removing the first, and a third coat if the two applications have not satisfactorily exposed the aggregate and cntirely removed the skin of hardened cement.

(c) With a hose, under good pressure, the surface should be washed in one direction so as to remove the salts resulting from the action of the acid. This washing is continued until the salts and all loose particles are removed and the old concrete is thoroughly soaked to its full hydrometric capacity.

(d) To the cleaned and saturated surface a coating of pure cement is applied, mixed to the constituency of thick cream with water, and to which the waterproofing agent has been added in the proportion directed by the manufacturer, the coating being rubbed in vigorously with a strong fibre brush so as to fill all the crevices and cavities produced by the action of the acid.

Immediately after applying the above slush coat, the first coating of waterproof cement mortar should be applied (thickness, three-eighths of an inch) directly upon the slush coating and well trowelled into every void or crevice of the surface. Before this first coat has reached its final set, a second and final coat should be applied to an equal thickness, so as to make the full average thickness three-quarters of an inch. The finishing coat should be floated to an even surface, and subsequently trowelled free from any porous imperfections. If the conditions of the work make it impracticable to apply 
a finishing coat before the scratch coat has set, the latter must be dampened and slush coated before the finishing coat is applied.

Floors should be treated and prepared exactly as indicated above for walls, and finished with the waterproofed mortar to a thickness of two inches. Special care should be exercised to bond the wall coating to the floor coating, so as to make the waterproof coat absolutely continuous.

The "Membrane" method of waterproofing differs distinctly from the "Integral," in that it does not attempt to treat the concrete, but rather to insulate it from contact with water by enveloping the structure in a continuous bituminous shield. The fact that the "Membrane" is not a unit or rigid part of the structure permits a certain freedom of movement and action in the structure, without impairing the efficiency of the waterproofing. This feature of the "Membrane" system makes it specially suitable for waterproofing work not fully reinforced and liable to settlement or subject to vibration or shock, such as railway bridges, culverts, etc.

Coatings of burlap and coal-tar felts have been extensively used for this purpose, and there are now on the market specially manufactured felts which are both saturated and coated with bitumen, and possess great pliability and strength.

The bitumens most generally used for cementing the felt together in constructing the membranes are coal-tar pitch, commercial asphalts and special asphalt compositions. Although coal-tar pitch, on account of its eheapness, has been, and still is, being very extensively employed for waterproofing, many engineers regard the coal-tar pitch produced to-day by modern methods of gas production as inferior to that produced by the older process in vogue when pitch was first used-for waterproofing.

The asphalts are more suitable for waterproofing as they possess greater elasticity and permanence, but care should be taken to obtain a material of as low a melting point as the nature of the work will permit.

This not only ensures greater elasticity when subjected to cold temperatures, but it is much more freely and easily applied. Special asphalts are manufactured from a hard 
hydrocarbon, such as gilsonite, tempered with petroleum residuums to impart the necessary elasticity.

Oils.-Animal and vegetable oils which are liable to turn rancid have a corrosive action on cement and should not be kept in concrete tanks. Care should also be taken not to spill such oils on foundations or floors made of concrete, as the acid produced when the oil turns rancid will decompose the cement. Mineral oils are free from this objection.

The waterproofing materials used for concrete are of two kinds: $(a)$ those which are merely pore-fillers, and $(b)$ those which fill the pores and also have a repellent action towards water. Amongst the best pore-fillers are rock dust, slaked lime, and ehina elay; their particles are so fine that they penetrate almost all the pores, and as they are not greasy they become uniformly distributed throughout the material.

Oils and soaps, on the contrary, tend to accumulate in small pasty masses which do not readily break up, and render it almost impossible to obtain homogeneous concrete. To this extent they are a distinct disadvantage, and many of the claims made for them are more in the nature of "selling arguments" than facts of technical importance. Moreover, the addition of oil or soap to a concrete mixture greatly delays its setting, and does not confer any advantage adequate to the risk thereby involved. Soluble soaps, and particularly soft soap (potash soap), are better waterproofing agents than oils, because the soap may be dissolved in the water used and so becomes more evenly distributed throughout the concrete. Useful proportions are 6 to $9 \mathrm{lbs}$. of soap per cubic yard of concrete. The lime set free by the hydrolysis of the cement forms the insoluble lime soap, and this is the compound which fills the pores and repels water.

Waterproofing conerete is best effected by rendering the whole mass as impermeable as possible, and not merely confining the treatment to the surface. The power of water to penetrate eonerete depends on the number and size of the pores in the latter; hence a conerete in which all these pores or voids are completely filled with inert material or are partially filled with a water-resisting substance will be waterproof.

If the necessary care and skill have been taken in preparing 
it from properly graded materials, the ordinary concrete will be sufficiently waterproof for most purposes. The object of water-repellents is simply to occupy voids in the concrete which are produced by imperfect grading or mixing of the concrete.

Most of the substances sold for waterproofing concrete are of a soapy or oleaginous nature, and water-glass (a soluble sodium silicate) is also used, though it is costly.

It should never be forgotten that the addition of oil or soap or any non-cementitious material to concrete reduces the strength of the structure, and is to this extent disadvantageous. Some oils reduce the strength much more than is commonly supposeā.

One of the most effective methods of preparing a waterproof concrete consists in carefully grading and proportioning the materials so as to have as few voids as possible, and to mix them together in a dry state. Then, instead of some sand there is used a mixture of trass or burned clay in such proportions that the amount added will be approximately half that of the cement used. The trass or burned clay powder acts as a pozzolana, fixes the lime set free by the cement and, if the grading and proportioning have been properly effected, renders the concrete quite waterproof. The substitution of a mixture of equal parts of china clay and lime, though sometimes recommended, is far less effective.

Cloyd M. Chapman has found that in many concretes the permeability to water is due to the use of a mixture of aggregate, sand, cement and water, which is either too dry or too wetone extreme being as bad as the other so far as water-proofness is concerned. His investigations showed that the most waterproof concretes he was able to produce were those in which the water represents 13 to 17 per cent. of the weight of the mixture, but these figures may differ with different cements and aggregates. 


\section{CHAPTER VIII}

\section{REINFORCED CONCRETE}

THE term "Reinforced Concrete" or "Ferro-Concrete" 1 is applied to structures consisting of a combination of concrete and metal (usually steel, and termed the "reinforcement") of such a nature that the two materials act as one, which is stronger and more durable than either alone. Concrete is not very suitable for withstanding tensional stresses; steel, on the contrary, is not sufficiently cheap to be used alone. Steel alone is not very resistant to weather, and its surface must be protected. Concrete preserves the steel from deterioration and, in case of fire, from expansion. A combination of steel and concrete is therefore capable of meeting the demands for structures which will resist both these stresses. In short, reinforced concrete combines the structural qualities of steel and timber with the durability of good masonry. It is subject to no form of deterioration which cannot be avoided by reasonable precautions, and is free from many of the limitations of masonry in mass. Because of the greater latitude it affords in the design and execution of structures, it often yields the best and most economical solution, and in some cases the only practicable solution, of the most difficult problems of building construction.

The great advantage of reinforced concrete lies in the fact that it is capable of withstanding stresses due to transverse strains, tension, and shearing. All the forms that could be executed in steel or timber can be closely imitated in reinforced concrete, which is immune from corrosion and decay. This

\footnotetext{
1 The student should remember that the terms "Ferrocrete" and "Steelcrete" have been registered for a Portland cement and do not refer to any form of reinforced concrete.
} 
makes it possible to adopt designs wherein the structure acts by its structural resistance and not by dead weight, and even the material to be retained and held back may be made by this means to add to the stability of the work as a whole. Dead weights on foundations are diminished, difficult excavation is often avoided or lessened, and total costs often greatly decreased, as compared with structures formed of masonry in mass; in many cases reinforced concrete affords a variety of desirable solutions not practicable in any other material.

The saving in the thickness of inverts of locks and dams, or in retaining walls of all kinds, the use of caissons filled with dead materials in lieu of solid masonry walls, the use of reinforced concrete piles to anchor a light structure to the dead mass below, and the many other useful devices and applications, all open up the possibility of practically limitless applications of reinforced concrete to hydraulic structures so as to attain both greater efficiency and a diminished cost.

Unlike timber, iron, and steel, which rapidly perish by natural decay or corrosion, and unlike many stones, which, more slowly, but none the less surely, disintegrate and crumble away as the result of atmospheric influences, good concrete increases in durability and strength by continued exposure. The same property is still more highly developed in reinforced concrete, owing to the superior quality and the scientific proportions of the constituent materials, and in consequence of the close attention devoted to the thorough mixing of the ingredients, and the methods of depositing and tamping the resulting concrete, which are ensured when the execution of works is confined to recognised contractors whose experience and standing give assurance of their perfect reliability.

When properly designed and executed it is, therefore, among the most valuable materials available for use in structural and hydraulic works.

The chief objection to reinforced concrete is an rsthetic one; the appearance of the finished work is dull and colourless, without any of the distinctive tones and colour 
associated with brick and stone; yet, when colour is of minor importance, as in piers, jetties, foundations, etc., reinforced concrete has claims far in advance of any other material.

Steel, when under compression, is about thirty times as strong as concrete, and when under tension is about 300 times as strong as concrete. As steel costs about fifty times as much as an equal volume of concrete, it is possible to use a combination of the two which is cheaper (considering the stresses to be resisted) than either material alone.

Hence, if the members of the structures are arranged in such a way that the compressive stresses are all borne by the

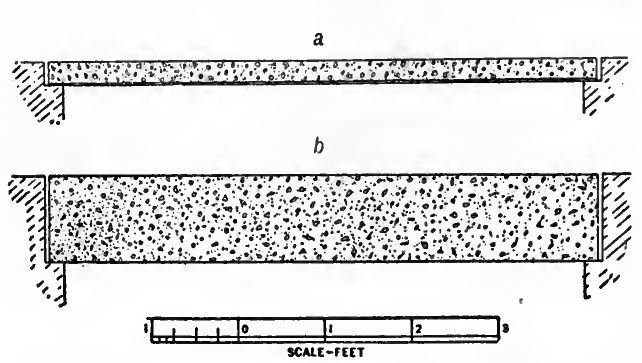

concrete and the tensile stresses by the steel, each material will be used for the purpose for which it is the cheapest and the best fitted. The shearing resistance of concrete is also very inadequate, and hence, in the most

FIG. 45.-Beams, of equal strength, of (a) Reinforced and (b) Ordinary Concrete.

approved designs, the shearing stresses are borne by small steel rods and stirrups embedded in the concrete.

The remarkable effect of steel in increasing the strength of concrete is strikingly illustrated in Fig. 45, which shows two beams designed to carry ordinary floor loads, the one made entirely of concrete and the other of concrete with a sheet of expanded metal embedded in the tensile portion of the beam. The saving in mere weight of concrete alone is obvious; and when it is remembered that the adoption of floor beams entirely of concrete means an increase in thickness of nine inches, or supposing five to eight floors, an increase in the total height of the building (with extra cost of higher and heavier walls, together with heavier foundations to carry them) of from four to six feet, it is clear that even as regards initial outlay for materials, the introduction of steel reinforcement into 
concrete construction is of very great importance. Another most remarkable fact is that the weight of steel, if properly disposed, is so small as almost to be insignificant. Comparing areas of steel and concrete exposed in cross-section, the steel is sometimes only $\frac{1}{2}$ per cent., and rarely rises above 1 or $1 \frac{1}{2}$ per cent. of the area of the concrete.

The concrete must be of first-class quality, and the aggregate must be smaller than that used for mass concrete. No pieces of aggregate which will not pass through a hole $1 \frac{1}{4}$ inches diameter should be used.

Both the aggregate and sand must be carefully selected, especially when a combination of strength and fire resistance is desired. A hard aggregate, such as river ballast, pit gravel, blue bricks, granite, etc., is preferable, as a soft one, such as clinker, red brick, sandstone, etc., means a weaker concrete. The stones should be angular and of an irregular nature, both in shape and size. Flaky aggregates should be avoided as they lie too close together.

For encasing steelwork, flooring and similar work, brick or well-burned furnace clinker, or a mixture of the two, affords an excellent fire-resisting aggregate, but must be hard and free from combustible materials, old mortar, ashes and dust.

The natural aggregates, while they have greater compressional strength, are liable to splinter and " fly" under intense heat; limestone will shrink when exposed to fierce fire, and sandstone is so variable when heated that it should be avoided where fire resistance is required.

Cinders and coke breeze are not recommended for reinforced concrete work, and their use should be restricted to filling purposes, such as bedding to which to nail floor boards.

The sand used should be hard and gritty, with grains of various shapes and sizes. Sharp, angular sand is preferable for reinforced concrete work. Crushed limestone should be avoided, and clayey sand should be entirely prohibited unless the clay is first removed by very thorough washing. Sea sand sometimes causes an efflorescence or scum to appear on the finished work. Very fine or "blown" sand should not be used.

Both the aggregate and the sand should be clean, sharp and c. 
free from all foreign substances, and, if necessary, should be washed before use.

Materials containing more than, say, 1 per cent. of sulphates or other corrosive substances, should be strictly avoided, and when any doubt exists on this point it is wise to have a chemical analysis of them made to ensure the absence of such ingredients. Some bricks-notably some made at Fletton, near Peterborough-have proved unsatisfactory as aggregates on account of the sulphur compounds they contain.

The cement employed must be Portland cement which conforms to the Standard Specification (p. 97), as no other is of sufficiently good quality. The risks in defective reinforced concrete are so enormous that no pains should be spared to prevent them.

The following mixtures, all parts by measure, are typical of those used by the most reliable firms :-

For floors, walls, etc. :-

$\left(\frac{1}{2}\right.$ to $3 \frac{1}{2}$ inches thick)

3 parts of aggregate.

$1 \frac{1}{2}$ parts of sand.

(thicker than $3 \frac{1}{2}$ inches)

1 part of Portland cement. 4 parts of aggregate.

2 parts of sand.

1 part of Portland cement.

For general and heavy concrete work :-

3 parts of aggregate.

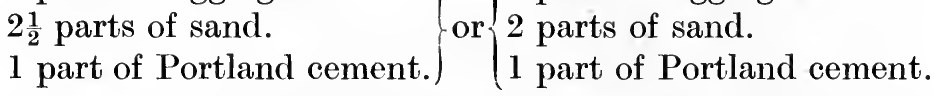

For tanks, etc., where the concrete is required to resist liquid pressures :-

3 parts of aggregate.

2 parts of sand.

1 part of Portland cement.

The practice of using fixed proportions of aggregates, sand and cement is particularly unsatisfactory and dangerous ; in every case the proportions should be selected after ascertaining the percentage of voids in the materials as described on p. 157 .

The mild steel used does not vary in quality so much as the concrete. In tension the strains are proportional to the stress below the elastic limit, beyond which it is unsafe to stretch it. 
The mild steel used for reinforcement usually has an elastic limit corresponding to a stress of 32,000 to $50,000 \mathrm{lbs}$. per square inch. The working stress specified in reinforced concrete is usually about half this, namely, 16,000 to 25,000 lbs. per square inch. The working stress in steel beams under compression may be taken at 16,000 lbs. per square inch, and for columns at 12,000 lbs. per square inch, or still lower if there is any probability of buckling.

The coefficient of expansion of steel and concrete are almost identical at ordinary temperatures, otherwise serious internal strains would be produced. The actual coefficients of expansion vary with different specimens, but on an average steel expands $\cdot 00065$ per cent., and the concrete $\cdot 00060$ per cent. for a rise in temperature of each degree Fahrenheit.

Steel with a high percentage of carbon is unsuitable for use in reinforced concrete, as it is brittle (particularly after hammering), is more costly and more difficult to work than mild steel. Steel containing less than $0 \cdot 3$ per cent. of carbon is not open to this objection, and consequently mild steel is almost invariably employed.

The Committee of the Concrete Institute recommended that the steel used shall have the following properties :-

(a) It shall attain an ultimate tensile strength of not less than $60,000 \mathrm{lbs}$. per square inch.

(b) It shall withstand a stress of at least $34,000 \mathrm{lbs}$. per square inch before showing any appreciable permanent set.

(c) The contraction of area at fracture shall be not less than 45 per cent., or the elongation in the case of bars of one inch diameter and under shall be not less than 25 per cent., measured on a length equal to eight times the diameter of the bar tested.

The elongation shall be measured in the case of bars over one inch diameter on a length equal to four diameters of the bar, and shall be not less than 30 per cent.

(d) All steel shall stand bending cold to an angle of 180 degrees around a diameter equal to that of the piece tested, without fracturing the skin of the bent portion.

(e) The steel shall be free from scabs and flaws, and must be clean and free from rust. It must not be painted or oiled, but a wash of Portland cement grout is desirable.

The Joint Committee under the auspices of the Royal Institute of British Architects has made very similar recommendations, but in $(b)$ this committee places the elastic limit at not less than 10 per cent. nor more thisn 60 per cent. of the 
ultimate strength, and the minimum elongation $(c)$ at 22 per cent., and requires the steel to stand the other tests specified in the British Standard Specification for Structural Steel.

Welding is to be avoided wherever possible; if necessary, it should be at the points of minimum stress.

Some of the firms specialising in concrete construction have even stricter conditions in their specifications. The following extracts from specifications issued by several leading firms give some idea of these additional requirements:-

British Reinforced Concrete Engineering Co., Ltd.

All rods, plates, bars or braces to be of mild steel, manufactured on open-hearth basic or acid Siemen's process, uniform in quality, and entirely free from defects.

Ultimate tensile strength not less than 28 nor more than 32 tons per square inch.

All steel on delivery to be cleaned and stored in a dry place.

All stirrups and hoops to accurately fit rods and bars to be bent to proper shape.

\section{Trussed Concrete Steel Co., Ltd. (Kahn System).}

No reinforcing steel shall be considered that does not provide for shearing stresses as well as direct tension.

These shear-resisting members must be inclined at an angle of 45 degrees, pointing up and towards the supports of the structure.

Shear members shall be rigidly attached to main tension members.

Sufficient steel to be placed that concrete shall be obliged to resist only direct compression and shearing stresses up to $50 \mathrm{lbs}$. per square inch.

No steel shall have at any point less than one inch concrete covering.

In no case will steel of a higher elastic limit than $45,000 \mathrm{lbs}$. be considered. Same shall have a tensile strength of from 60,000 to 70,000 lbs. per square inch, with elongation not less than 20 per cent. in eight inches.

\section{British Concrete-Steel Co.}

The indented steel bars to be of best quality: tensile strength 38 to 42 tons per square inch. Elastic limit not less than 50,000 lbs. (22 tons) per square inch.

Ample supply of soft iron wire is to be provided for lapping steel bars at joints and at points where they cross each other.

\section{G. Mouchel and Partners (Hennebique System).}

Steel to be in the form of round bars and strip, obtained from makers of good repute, and to be mild steel produced by the open hearth, basic or acid process. Neither Bessemer steel nor high carbon-steel to be employed.

\section{Considère Construction Co., Ltd.}

Steel must be of British manufacture and have tensile strength not less than 28 tons or more than 32 tons per square inch, and show 
contraction of area at fracture of 50 per cent. and 40 per cent. respectively, and appearance of fracture not to show more than 5 per cent. and 10 per cent. granular surface respectively.

\section{Expanded Metal Co., Ltd.}

Mixture of concrete not less than $1: 2: 4$ by volume. Working stress not exceeding $16,000 \mathrm{lbs}$. per square inch in tension in the expanded steel, and $500 \mathrm{lbs}$. per square inch extreme surface compression in the concrete. Ratio of the moduli of elasticity of steel and concrete taken as 15 .

\section{Edmond Coignet, Ltd.}

Annealed wire used for binding together various bars of framework at intersection should be about $\frac{1}{16}$-inch diameter.

Binding to be done as tightly as possible and cutting pliers used.

It is of the greatest importance that concrete structures should not be overloaded, especially when their design is such that a rigid economy in material has been anticipated.

Loads in buildings and other structures are of two kinds : dead loads which are constant, and live loads which are moved from time to time, or may even be of a purely momentary character, such as a train passing at a high speed over a bridge. Live loads usually tend to cause vibrations in the structure, and consequently their effect is greater than their actual weight. This effect is most conveniently expressed in the form of a ratio of which the equivalent dead load forms one term. Thus a floor intended to carry a crowd of people would have an equivalent dead weight of $120 \mathrm{lbs}$. per square foot, whilst that of a train travelling over a bridge would correspond to a dead load of $500 \mathrm{lbs}$. per square foot.

When calculating loads, the weight of the structure and all fixed loads and the equivalent of any thrusts and other forces must be included in the dead load, the weight of reinforced concrete being usually taken at $150 \mathrm{lbs}$. per cubic foot.

The following working stresses represent those commonly employed :-

Steel in tension

Steel in compression

Steel in shear

Concrete in compression (bending)

Concrete in compression (columns, etc.)

Concrete in shear

Adhesion of concrete to steel lbs. per square inch.

$\begin{array}{rr}\text {. } & 16,000 \\ . & 12,000 \\ . & 8,000 \\ . & 600 \\ . & 500 \\ . & 60 \\ . & 100\end{array}$


If the concrete has a crushing strength above 2,400 lbs. per square inch after twenty-eight days, the working stress in compression for beams may be taken as one-fourth, and for columns, etc. as one-fifth, of its crushing strength. It is only fair to point out, however, that it is the elastic limit of the steel and not its ultimate strength which forms the critical factor, as at the yielding point of the steel the whole member will fail on account of the concrete being unable to stretch as much as the steel has done.

The following figures represent the value ordinarily assumed for equivalent dead loads on floors :-

Crowd of people

Dwelling-houses, hotels, etc.

Theatres, churches, etc.

Drill halls and ballrooms .

Stores, warehouses, and light factories

Heavy factories and workshops

Roofs lbs. per square foot.

80 to 120

$100,, 150$

$140,, 160$

$100,, 200$

200,400

$30,, 50$

Factors of Safety.-Before the design of a concrete structure is prepared, the following particulars should be definitely settled: $(a)$ the live or maximum load per unit, which should not exceed one-half the elastic limit of the steel used for reinforcement; $(b)$ the factor of safety for the live load, which is usually taken as 4 , but sometimes as 5 or 6 ; (c) the ratio of live to dead load, usually taken as $2: 1 ;(d)$ the factor of safety for the dead load, usually assumed as three-quarters of that of the live load; $(e)$ the test load, which is usually one and a half times the live load.

Where the factor of safety is stated in relation to the tensile strength of the material the elastic limit of the steel should be doubled. For example, with a steel whose elastic limit is one-half its tensile strength, the maximum live load would be one-quarter of the load representing its tensile strength, and if 4 is taken as the factor of safety, the greatest live load permissible would be one-quarter of the factor of safety multiplied by the figure obtained for the live load.

The safe load for Portland cement concrete made in the usual proportions is from 6 to 8 tons per foot super.

For grey stone lime concrete, it is 1 to 2 tons.

For blue lias lime concrete, it is 2 to 3 tons. 
To obtain satisfactory results without using an unnecessary quantity of material, the bending moments, shearing forces, and other stresses to which the structure will be subjected must be calculated. These calculations must be studied from a text-book on "The Theory of Structures," or "Strength of Materials," as they are entirely a matter for structural engineers and are beyond the scope of the present work. For the convenience of the reader the following rules and recommendations of the Joint Committee formed under the auspices of the Royal Institute of British Architects are printed here; the student should study them carefully.

\section{METHODS OF CALCULATION.}

1. Loads.-In designing any structure there must be taken into account:-

(a) The weight of the structure.

(b) Any other permanent load, such as flooring, plaster, etc.

(c) The accidental load.

(d) In some cases also an allowance for vibration and shock.

Of all probable distributions of the load, that is to be assumed in calculation, which will cause the greatest straining action.

(i.) The weight of the concrete and steel structure may be taken at 150 lbs. per cubic foot.

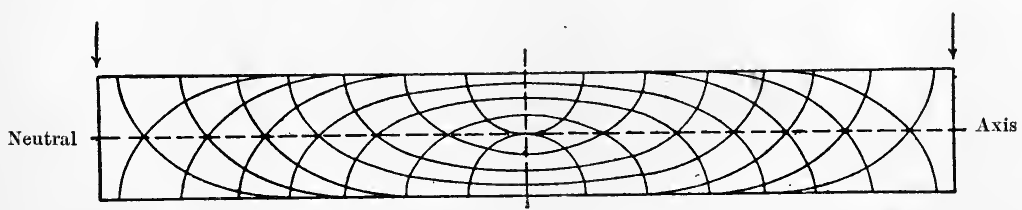

FIg. 46.-Diagram showing Principal Lines of Stress in Loaded Beam.

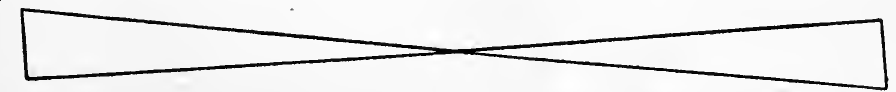

FIG. 47.--Shear Diagram for Beam under gradually increasing Load.

(ii.) In structures subjected to very varying loads and more or less vibration and shock, as, for instance, the floors of public halls, factories, or workshops, the allowance for shock may be taken equal to half the accidental load. In structures subjected to considerable vibration and shock, such as floors carrying machinery, the roofs of vaults under passageways and courtyards, the allowance for shock may be taken equal to the accidental load.

(iii.). In the case of columns or piers in buildings, which support 
three or more floors, the load at different levels may be estimated in this way :-

For the part of the roof or top floor supported, the full accidental load assumed for the floor and roof is to be taken.

For the next floor below the top floor 10 per cent. less than the accidental load assumed for that floor.

For the next floor 20 per cent. less, and so on to the floor at which the reduction amounts to 50 per cent. of the assumed load on the floor.

For all lower floors the accidental load on the columns may be taken at 50 per cent. of the loads assumed in calculating those floors.

2. Spans.-These may be taken as follows: For beams the distance from centre to centre of bearings. For slabs supported at the ends, the clear span + the thickness of slab. For slabs continuous over more than one span, the distance from centre to centre of beams.

3. Bending Moments. - In the most ordinary case of a uniformly distributed load of $w$ lbs. per inch run of span, the bending moments will be as follows:-

(a) Beam or Slab simply supported at the ends.-Greatest bending moment at centre of span of $l$ inches is equal to $w l^{2} \div 8$ inch lbs.

(b) Beam continuous over several Spans, or Encastré or fixed in direction at each end.-The greatest bending moments are at the end of the span, and the beam should be reinforced at its upper side near the ends. If continuity can be perfectly relied on, the bending moment at the centre of the span is $w l^{2} \div 24$, and that over the supports $w l^{2} \div 12$. If the continuity is in any way imperfect, the bending moment at the centre will, in general, be greater, and that at the supports less, but the case is a very indefinite one. It appears desirable that in building construction generally the centre bending moment should not be taken less than $w l^{2} \div 12$. The bending moment at the ends depends greatly on the fixedness of the ends in level and direction. When continuity and fixing of the ends, whether perfect or imperfect, is allowed for in determining the bending moment near the middle of the span, the beam or slab must be designed and reinforced to resist the corresponding bending moments at the ends. When the load is not uniformly distributed, the bending moments must be calculated on the ordinary statical principles.

4. Stresses. - The internal stresses are determined, as in the case of a homogeneous beam, on these approximate assumptions :-

(a) The coefficient of elasticity in compression of stone or gravel concrete, not weaker than $1: 2: 4$, is treated as constant, and taken at one-fifteenth of the coefficient of elasticity of steel.

lbs. per sq. in.

$$
\begin{gathered}
\text { Coefficient for concrete }=E_{c}=\begin{array}{r}
2,000,000 \\
, \quad, \quad \text { steel }
\end{array}=E_{s}=30,000,000 \\
\frac{E_{s}}{E_{c}}=15 .
\end{gathered}
$$

It follows that at any given distance from the neutral axis the stress per square inch on steel will be fifteen times as great as on concrete.

(b) The resistance of concrete to tension is neglected, and the steel reinforcement is assumed to carry all the tension.

(c) The stress on the steel reinforcement is taken as uniform on a cross-section, and that on the concrete as uniformly varying.

5. Working Stresses. - If the concrete is of such a quality that its crushing strength is 2,400 to $3,000 \mathrm{lbs}$. per square inch after twenty- 
eight days, and the steel has a tenacity of not less than $60,000 \mathrm{lbs}$. per square inch, the following stresses may be allowed :Concrete in columns under simple compression ․ $\quad$. 500 Concrete in shear in beams $. \quad \cdot \quad . \quad . \quad .60$ Adhesion $^{1}$ of concrete to metal . . . . . . 100 Steel in tension $\quad . \quad$. $\quad . \quad$. $\quad$. 15,000 to 17,000

When the proportions of the concrete differ from those stated above, the stress in compression allowed in beams may be taken at one-fourth, and that in columns at one-fifth of the crushing stress of cubes of the concrete of sufficient size at twenty-eight days after gauging. If stronger steel is used than that stated above, the allowable tensile stress may be taken at half the stress at the yield point of the steel.

When the foregoing rules are familiar, the formulæ used by specialists in concrete construction ${ }^{2}$ may then be studied with advantage, though many of these simplified formulæ contain constants and other somewhat empirical matter which, in the hands of a man of experience, are useful, but, if used by a beginner, may lead to a considerable risk of error.

Specialists in concrete construction have, by the aid of such calculations, devised various ingenious arrangements of the steel within the concrete so as to produce structures of enormous strength at a relatively low cost. These "systems" of reinforcement usually bear the name of their inventor, or give some indication of the shape of the reinforcement in their titles. Whilst each system usually has some advantage over others, no definite means has yet been formed whereby all points, including economy, may be considered and balanced against each other. Corsequently, it is very difficult for an engineer or architect who has not specialised in reinforced concrete to determine the relative merits of various systems. To attempt to decide on a question of cost-leaving the responsibility of selecting the proper factors of safety to the firms

1 It is desirable that the reinforcing rods should be so designed that the adhesion is sufficient to resist the shear between the metal and concrete. Precautions should in every case be taken by splitting or bending the rod ends, or otherwise, to provide additional security against the sliding of the rods in the concrete. [It should, however, be noted that this treatment has no effect on the greater part of the length of smooth bars, but only near the ends where the adhesjon is least liable to be destroyed.-A. B. S.]

2 The excellent theoretical analysis in the handbook supplied by the manufacturers of the Kahn trussed bar is well worth special study, as it is a particularly clear enposition of the "Straight Line Formula," which is rapidly becoming of general acceptance. 
making the tenders-is, of all ways, the most unsatisfactory, and is sure, at some time, to lead to trouble.

The generally accepted method of reinforcement consists in the insertion of thin horizontal bars or rods and strips of steel in just those places, and in those places alone, where the resistance of the concrete requires to be supplemented in order that it may withstand tensile stresses. These bars may be bent at each end so as to provide an increased resistance to the shearing force supplied by the load, or they may be fitted with "shearing members" in the shape of attached bars, loops, stirrups, etc. The shape of these attachments and of the bars themselves is the subject of various proprietory rights, and forms the chief distinction between the different "systems" of reinforced concrete.

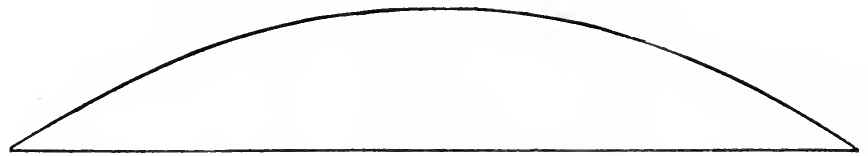

FIG. 48.-Bending Moment of Beam under gradually increasing Load.

These shear members are necessarily of short length, since they are limited by the depth of the beam itself, which, as a rule, does not exceed one or two feet.

It is, therefore, essential that these "shear members" should be rigidly attached to the main tensional members, and it is also of great importance that a good mechanical bond should exist between the steel and the concrete along the shear bars. For this reason the R.I.B.A. Committee Rules (p. 215) stipulate that: "As the resistance of the shear members to the pull depends on the adhesion and the anchorage at the ends, it is desirable to use bars of a small diameter, and to anchor the stirrups at both their ends." If a smooth bar is bent up as a shear bar the adhesion of the concrete to the short length of steel available is insufficient to develop the full strength of the metal before the latter will pull out of the concrete. A large proportion of the metal in the shear bars is thus wasted, and to obtain the requisite strength far more steel has to be provided than is actually necessary. If, how- 
ever, indented bars (p. 235) are used, the full strength of the steel is brought into action. Some of the main tensional members can themselves be bent up towards the ends of the beam into the correct position for taking the shearing stresses. These "shear members" are not merely connected rigidly to the main bars, but are actual portions of the same bars, the anchorage extending throughout their length (Fig. 49).

The L.C.C. rules refer to this property of indented bars when they demand that all shear bars shall have a " mechanical anchorage at both ends, or they shall have a mechanical bond with the concrete throughout their length."

In ordinary commercial round or square bars, small sections are generally favoured, as they give a larger proportionate

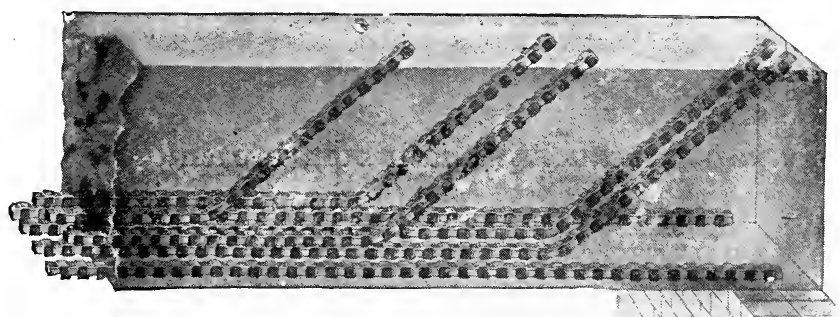

Fig. 49.-Indented Bars bent to form shear Niembers.

surface for adhesion, and are more easily manipulated. Hoops, bands, and flats of small section are used, but rounds and squares are the sections generally employed in reinforced concrete work. Other sections, more particularly $\mathrm{T}$-bars, are specially fitted for reinforcing arches and tall chimneys, while the old type of steel and concrete floor, of which there is a considerable amount still constructed, has small I joists.

Some patent bars for reinforcement are moulded in various shapes and sizes with the idea of providing the mechanical bond, though numerous authoritative investigations have shown these to be unnecessary in many cases, owing to the natural adhesion of the concrete to the steel.

The arrangement of these bars as well as their shapes, 
constitute the foundations of the various " systems" now in use. Each fundamentally different structure requires a different arrangement; thus, independent spread foundations are now reinforced with bars, although the older form of steel joists, crossing each other, is still much used. Where raft foundations are used, a reinforced concrete raft, thoroughly framed together with beams forming ribs, can be constructed very much thinner than one which is not reinforced, and gives security against unequal loading and unequal support from the subsoil, and against shocks and vibrations of great magnitude, so that such rafts are particularly applicable in districts subject to earthquakes.

In reinforced concrete work, most buildings are carried out on the frame principle, the loads being carried from the beams on to columns, and the walls are mere partitions between them.

In ordinary cases, there is very little lateral pressure on walls, and an ordinary square mesh-work embedded is sufficient.

Many retaining walls have been built in reinforced concrete. Steel reduces the thickness and the amount of material to be excavated, because buttresses, with thin intermediate slabs and a projecting foot, can be designed to be thoroughly stable against overturning and shear. There are no special systems with regard to reinforcing retaining walls that call for notice.

A cantilever retaining wall is a striking example of the enormous economy of reinforced concrete as compared with mass concrete, brickwork or masonry, the precise type of wall being selected according to the requirements of the case. For instance, in the retaining walls of the Royal Insurance Offices, in Piccadilly, the thrust of the earth is taken by a vertical wall, and a horizontal slab occurs on the opposite face to the earth pressure. The horizontal beams at the top do not afford any horizontal support to the wall. This wall, constructed in 1908 of concrete reinforced with indented bars, was the first of its type to be built, but several have since been constructed. Counterforts could, of course, be used, but the cantilever type adopted in this instance affords a clear run immediately behind the wall, and affects an enormous saving in space as compared with a counterfort wall, or still more in comparison with a mass concrete or masonry wall, 
which would have been approximately ten feet wide at the base instead of two feet six inches as built. Another excellent example of the use of reinforced concrete (with indented bars) in place of mass concrete is the retaining wall for Selfridges, which is probably the deepest in London, being sixty feet deep and twelve feet thick at the base. The load on the piers which support the building is carried by a heavy reinforced concrete slab. This wall provides three basement floors below street level; it is of cantilever type, similar to that in the Royal Insurance Offices just described.

Columns, piers, posts, or stanchions are constructed of reinforced concrete, the reinforcement being used to reduce the section of the concrete, to bind it together, and to prevent

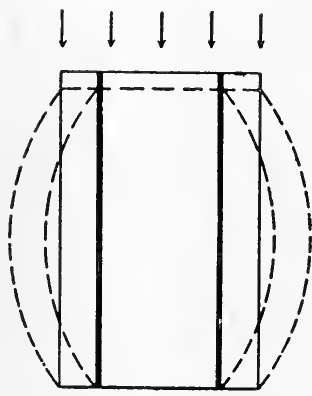

Frg. 50.-No Lateral Ties.

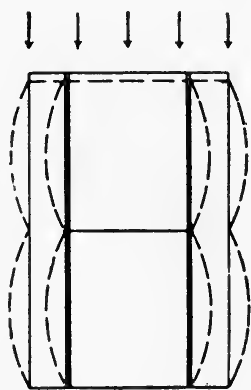

Fig. 51.-One Lateral Tie.

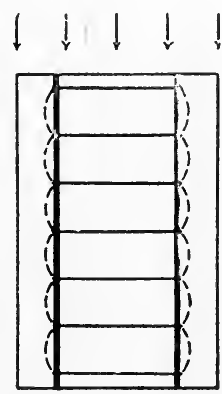

Fig. 52.-Several Lateral Ties.

bulging. For these articles the concrete usually consists of a $1: 2: 4$ mixture. A column provided with longitudinal reinforcement only would bulge or swell when overloaded (Fig. 50). Hence, these longitudinal bars must be tied together by a series of transverse bonds. Four types of these are used : $(a)$ circular hoops or rings placed at a convenient distance apart, $(b)$ rectilinear ties made of wire, similarly placed (Fig. 51), (c) a spiral wire (Fig. 52), and (d) a network surrounding the vertical bars.

The use of these ties was originated by F. Hennebique, and has been applied extensively with satisfactory results. For difficult cases it is well to bear in mind that there is evidence to show that the greatest strength is obtained with longitudinal 
bars surrounded by spiral reinforcement, the distance between the coils being small enough to resist the lateral or radial expansion of the concrete (this is the basis of the Considère System). Jointed circular hoops and horizontal wire ties are slightly inferior, though for ordinary cases they are of more than ample strength.

Tests of concrete columns with short lengths of longitudinal reinforcement in combination with continuous transverse reinforcement show that this is the weakest form. The reinforcements consist of longitudinal bars and horizontal ligatures, the latter being formed

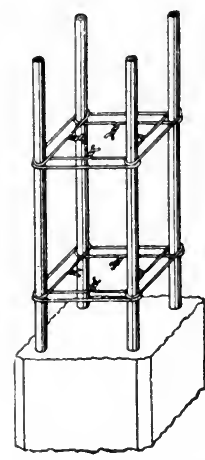

Fig. 53.

Hemmebique

Column.

either of links or spirally-wound rods of smaller section than the longitudinal bars.

The use of hoops, network, or of a spiral wire without longitudinal bars has proved unsatisfactory when tested, the metal in this form

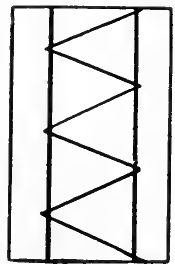

FIG. 54. of reinforcement being able to develop only a small fraction (about 2 per cent.) of its full strength, and is therefore wastefully applied. The use of longitudinal bars of ample size running the whole length of the column and surrounded by suitable ties affords an ample reserve of strength.

The use of longitudinal bars fitted with wings or inclined members, but without ties, is not satisfactory for column construction. If ties are used the inclined members are unnecessary, and without the ties the column is weak.

The objection to a mesh or network for reinforcing columns is the difficulty of making a secure joint along the edges of the material and of tamping the concrete into the meshes of the network. This difficulty is often exaggerated by the representatives of other systems of reinforcement, though it does undoubtedly exist. Attempts to overcome it by using a more fluid concrete should be resisted strenuously (see p. 234).

To overcome the inherent weaknesses of the foregoing systems-especially the strains created in the metal by longitudinal compression on account of the setting of the concrete, 
and the consequent tensional stress in the concrete-the reinforced metal type of column (Fig. 55) has been devised (British Patent 27529, 1910).

It consists of a single axially-disposed steel cylinder, either hollow or solid, or a star-shaped rolled steel section, which furnishes the longitudinal reinforcement, and serves as anchorage for four steel spirals which are disposed eccentrically around it. These spirals embrace the core and on their inner side bear hard against it; they intermesh with one another,

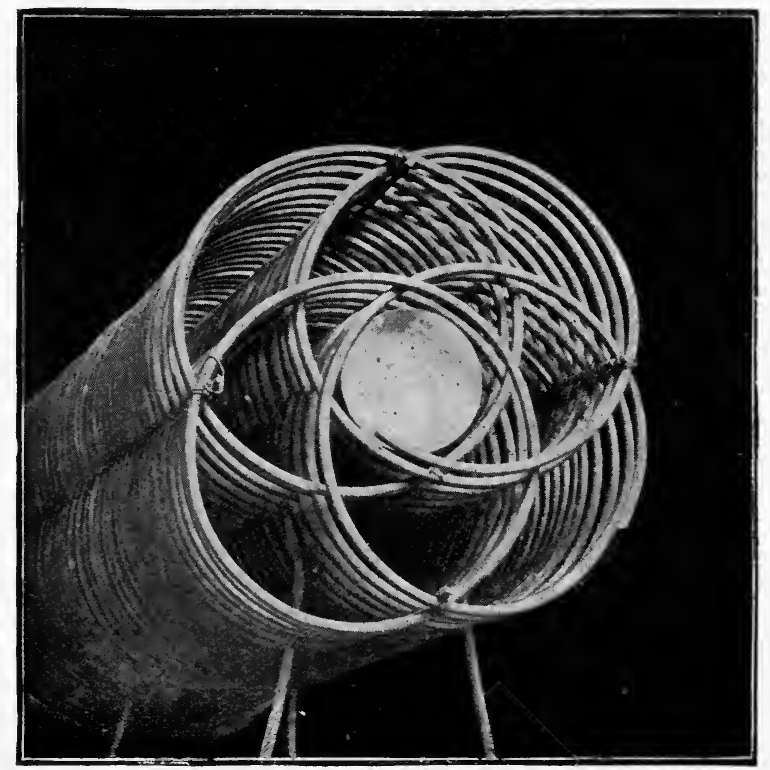

Fig. 55.-Core with Anchored Spirals. End View. ('ourtesy of Reinforced Metal, Ltd.)

giving lateral reinforcement at every point throughout the column and constitute shear-resisting members of a most effective character. The area of steel when a solid core is used is 12.56 per cent., that when a hollow core is used 2.4 per cent. of the area of the column within the reinforcement, but the percentage of steel reinforcing each compartment relatively to the area of its contents is about five times as great as would be the case with the ordinary spirally-hooped column were the 
same total weight of spiralling employed in both. The peculiar characteristic of this arrangement is that, as shown by Professor A. Gray's test, its modulus of elasticity under
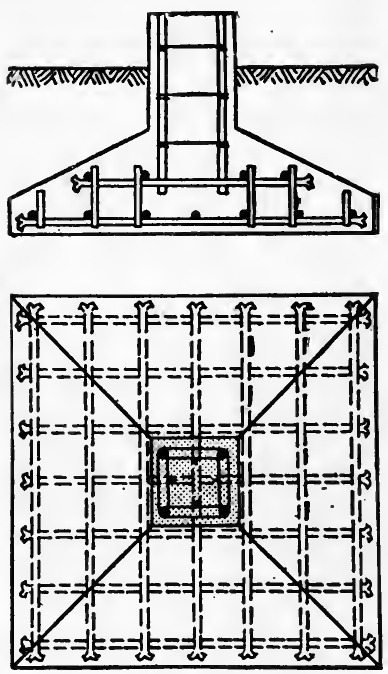

Fig. 56.-Column Base (Hennebique). progressive loading increases with increase of compressive stress-a property possessed by no other combination of materials yet investigated.

The compressive strength of a reinforced metal column is stated by the owners of the patents to be twice that of spirally-hooped concrete column and three times that of a steel stanchion encased in concrete in which the same weight of longitudinal steel and concrete is used.

It is claimed that, as the materials do not cost more to buy nor the column more to make than others, the cost of the Reinforced Metal Column per ton of load capacity per foot of length is only about one-half that of reinforced concrete columns.

Column bases may advantageously be reinforced in two horizontal directions, each at right angles to the other (Figs. 56 and 57) so as to take up all tensional strain which would otherwise result in a spreading of the base.

Beams, girders and stanchions are usually

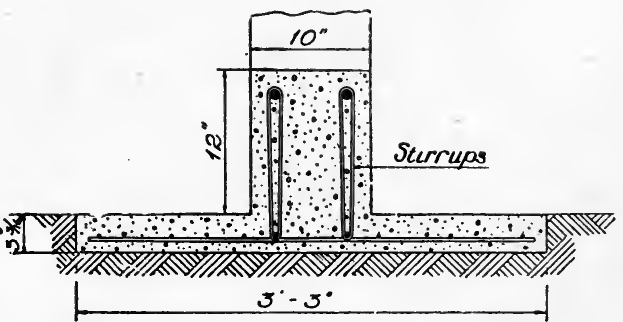

Fig. 57.-Column Base (coignet). made of a $1: 2: 4$ mixture reinforced with one-inch rods of mild steel, with a network reinforcement or with patent bars. The reinforcement of beams-one of the most important branches of concrete structural work-is usually placed near 
to the lower side of the beam, except above the supports where it is bent upwards so as to lie near the top of the beam.

The reason for this is that the parts of a beam which lie in the centre of the span between the columns have the lower part in tension and the upper part in compression. For a short distance over each column, however, the nature of the stresses is reversed, and the upper part of the beam is in tension and the lower part in compression.

A further provision of steel is necessary by way of web reinforcement to resist shear. The function of web reinforcement is to connect together the compression and tension areas in a rigid manner in precisely the same way as the bars of a lattice girder or the members of a truss girder.

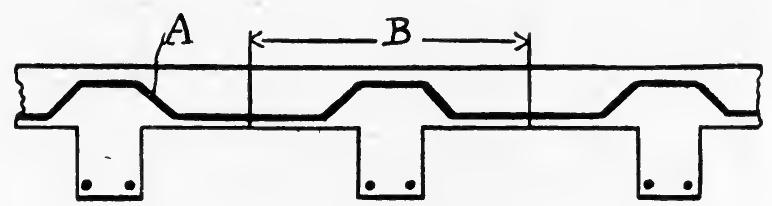

FIG. 58.

The shear which these members resist is the greatest at the ends of a uniformly loaded beam and diminishes towards the centre. It is therefore necessary that shear reinforcement should be heavier at the ends than at the centre, or if the shear bars are of the same section throughout, they should be placed at gradually decreasing distances from the centre to the ends of the beam. The three principal points of reinforcement in beams are, therefore:-

(a) The main tension bars at the bottom of the beam.

(b) The tension bars at the top of the beam at points of contraflexure over columns.

(c) The web or shear reinforcement connecting the tension and compression areas together.

Where the beam is large and $T$-shaped, supplementary reinforcing bars are also placed in the head of the $T$ and at right angles to the others. The same arrangement, is used in reinforced floors carried on beams (Fig. 58),

c. 
As the actual amount of diagonal tension at any point in a beam cannot be determined with accuracy, it is customary to ealculate the vertical shearing stress, and to use that as a convenient measure of the diagonal tensile stress. Hence the survival of the terms " shearing failure" and "shear reinforcement," though in reality the form of failure in beam tests, commonly described as a "shearing failure," is almost invariably a " diagonal tension failure."

The investigations of M. Feret, Professor Spofforth, Professor Talbot and others, have shown that the shearing strength of concrete may be taken as two-thirds of its compressive strength, so that there is little risk of failure by vertical shear, even in a plain concrete beam, but failure will occur by, diagonal
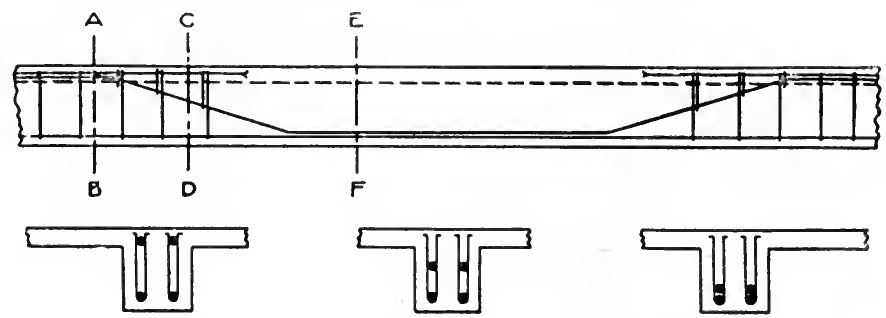

Section on $A \cdot B$.

Scction on C.D

Section on E.F.

Fig. 59.-Reinforced Beam (Hennebique System).

tension when the vertical shearing stress reaches a very moderate intensity, which Professor Talbot has found to vary from $70 \mathrm{lbs}$. to $140 \mathrm{lbs}$. per square inch, according to the quality of the concrete used. Thus, although the shearing stress may not in itself be sufficient to affect the concrete, a comparatively small stress of this kind generally indicates the presence of a dangerous amount of diagonal tension. Hence, it is evident that the shearing stress of concrete-regarded as the measure of diagonal tension-must be kept within limits which are so small as to be practically negligible. Thus, the practice of making no allowance for the shearing resistance of concrete is fully justified, and the recommendation, made by some other engineers, that concrete in shear may be subject to a stress of $50 \mathrm{lbs}$. or $60 \mathrm{lbs}$. per square inch, would leave too small a margin of safety against failure by diagonal tension. 
Whilst failure by diagonal tension may be expected to occur in a beam having no web reinforcement if the shearing stress intensity were to attain about $100 \mathrm{lbs}$. per square inch, recent well-authenticated tests have shown that beams when properly reinforced are capable of withstanding shearing stresses of more than $600 \mathrm{lbs}$. per square inch without giving the slightest indication of failure by diagonal tension.

One of the earliest, and still one of the most prominent, systems of reinforcing beams is that invented in 1892 by $F$. Hennebique (Fig. 59), and used in the General Post Office, London, and numerous other large buildings. Round bars are used, arranged as shown. The bars are hung from

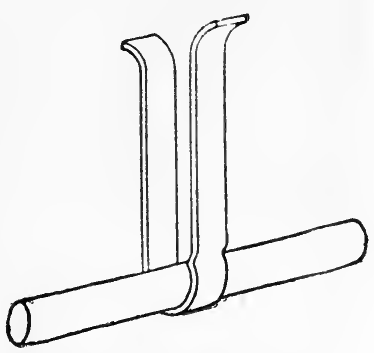

FIG. 60.-Hennebique Stirrup and Bar. strips bent in the form of stirrups, the latter taking the shear, and the inclined bars the diagonal tension. These stirrups are placed uniformly, except at the ends of the span where the shear stress is greater; there they are placed closer together (Figs. 60 and 61).

The bent up ends of the bars lie fairly across the lines of rupture near the supports of the beam, and afford in themselves very secure anchorage. The vertical stirrups are formed

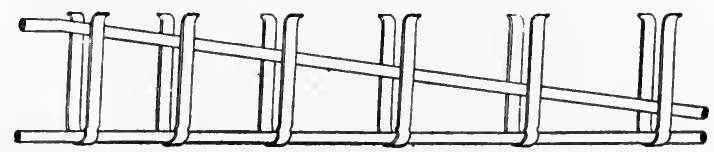

FIG. 61.-Bars and Stirrups (Hennebique System).

so that they can be spaced at proper intervals along the beam to provide for variations of stress from point to point. They cross numerous lines of maximum tension (Fig. 68), are, therefore, of great efficiency, and being vertical they facilitate the operation of ramming the concrete without causing the risk of displacement.' Being made with a simple spring clip at the lower end, the stirrups are automatically held in position on the main bars, thereby obviating the necessity for temporary wedges (Fig. 63) or ties. Finally, the upper ends of each 
stirrup are bent over at right angles so as to ensure perfect anchorage in the concrete, and to make each stirrup an efficient connection between the tension and compression areas of the beam in which they are embedded.

In discussing the relative efficiency of inclined and vertical stirrups, Professor Turneaure has pointed out that while an inclined stirrup, or the bent end of a horizontal bar, is in a position to take stress immediately, a vertical stirrup is more effective in resisting vertical distortion of the concrete. In his opinion, the stirrups should be looped around the horizontal bars so as to be firmly anchored at their lower end where the stress is a maximum, but that attachment to the bars is not necessary, as the object of the stirrup is to prevent vertical or nearly vertical distortion.

The Hennebique vertical stirrups also form an effective web-connection between the tension and compression portions

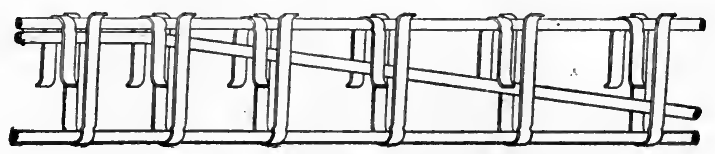

Fig. 62.-Reinforcement for Beam with Compression Bar and Double Stirrups (Hennebique).

in reinforced beams. It has been shown (Fig. 68) that the lines of maximum tension assume diagonal directions towards the ends of a beam, and these can be resolved into two components, one vertical and the other horizontal, the former being taken entirely by the stirrups and the latter by the horizontal bars. This fact is made use of in advocating the adoption of vertical stirrups, as in the Hennebique system, in preference to inclined ones.

The mechanical bond in the Hennebique system is secured by flattening and opening out the ends of all bars so as to form a secure anchorage, and even in the most simple beams at least half the bars are bent up towards the supports, thus giving further security.

Where unusually heavy loads have to be carried by beams, whose dimensions must be kept within comparatively small limits in order to comply with structural or architectural 
requirements, and in some structures where the spans of continuous beams are liable to variable and unequal loadings, such as the main beams in bridges, viaducts, wharves, piers and jetties subject to heavy rolling loads, as of railway rollingstock or other vehicles carrying considerable weights, it is desirable to use compressional reinforcement. In the Hennebique system the beams are provided with stirrups, as before described, for withstanding tension on diagonal planes, and in addition with a series of inverted stirrups passing over the upper bars and anchored in the lower part of the beam. Both the compression and tension bars are carried across the supports or through columns, and so perfect connection is provided between adjoining spans.

The complete arrangement, illustrated in Fig. 62, shows that the system of main bars and double stirrups ensures ample

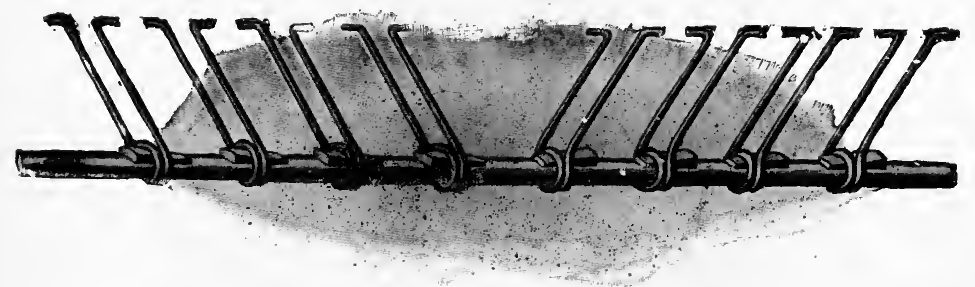

Fig. 63.-Keedon Bar for Beams.

resistance to horizontal tension and compression, and to tension and compression in diagonal directions, while at the same time it constitutes, after incorporation in the surrounding concrete, a truss of great rigidity and extraordinary capacity for withstanding deflection.

Although one of the earliest forms of reinforcement, the general arrangement of the bars, stirrups and ties originated by $F$. Hennebique still form the basis of the most important "systems" now in use. The variations made by other engineers and patentees occur chiefly in the shape and mode of attachment of the shear members, in the use of bars of special surface intended to secure greater adhesion between the concrete and steel, and in the elimination of certain members or the reduction in size of others, with a view to reducing the 
amount of steel used. Some of these "improvements" are of great value, e.g., the rigid attachment of the shear members, and the indentation of the surface of the main bars-but they are usually accompanied by other disadvantages, so that the engineer or architect must study the whole matter with full regard to local requirements before selecting any "system" or arrangement to suit a particular case.

If workmen could be relied upon to follow instructions implicitly, and if the time occupied were of secondary importance, there can be no question that the arrangement of the shear members to suit each case as it may arise would be best, and the Hennebique system would then be the best basis on which to work. As the risk of inserting the shear members in the wrong places, and of displacing them during tamping, to say nothing of other carelessness, must be reckoned with in actual practice, the use of one of the following systems

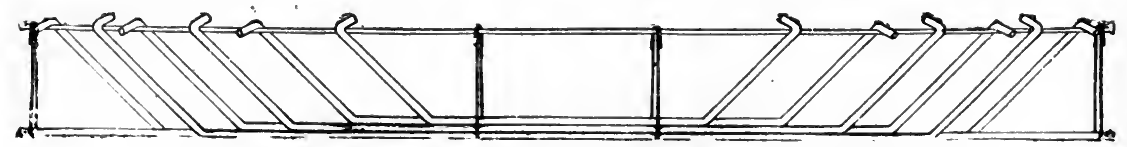

FIG. 64.-Coignet Reinforcement for Beams (latest type).

is often convenient and may, on occasion, prove even more satisfactory. This is not so much due to any defect in the Hennebique system, but to the workmen using it, and the aim of the engineer and architect using concrete should always be to secure the best results whilst leaving as little as possible to the intelligence or integrity of the workmen employed.

For all ordinary structures, the designs of reinforcement suggested by different firms of " concrete specialists " approach so nearly to a common standard that there is little to choose between them. Each of these firms can offer an abundance of evidence of such good work that on this alone no decisive choice can be made.

For special purposes, on the contrary, each of the leading designs has some characteristics of value not possessed by the others, and the architect or engineer must, therefore, study these variations in detail, and choose the system which is best adapted to the special needs of the case. 
In the system invented by $E$. Coignet (Figs. 64 and 65), round bars are also used together with transverse rods of smaller diameter on the upper or compression side. This enables the main beams to be made first, then hoisted into position and the floor slabs fitted afterwards. The stirrups in this system consist of round bars three-sixteenths to one-quarter inch in diameter, the ends of which are twisted to form a loop. These loops are placed over both top and bottom bars, and are tied in place with wire.

The Kahn Trussed Bar (Fig. 66) is of special shape, the section of the main portion being that of a diamond. This bar is provided at frequent intervals with supplementary bars bent

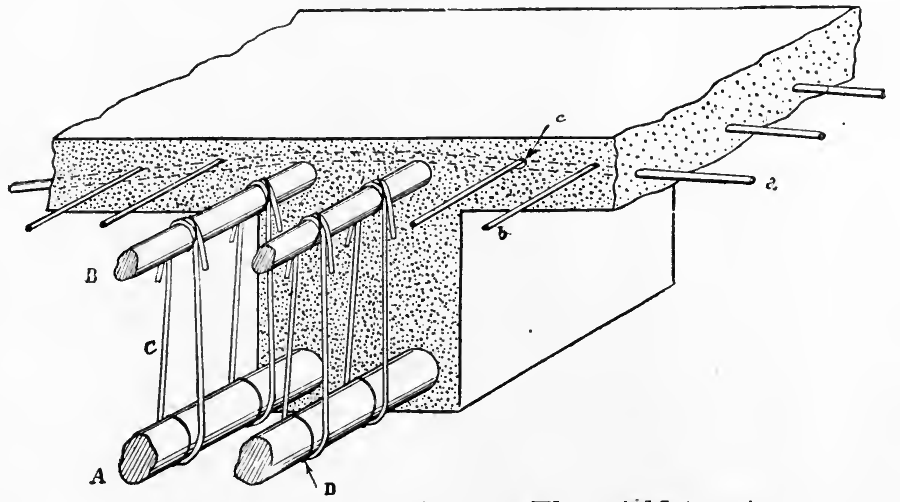

Fig. 65.-Section of Coignet Floor (old type).

at an angle of 45 degrees so as to lie along the principal lines of stress (Fig. 67), and at right angles to the main lines of rupture.

The objection to this arrangement is that the lines of maximum tension only assume the angle of $\mathbf{4 5}$ degrees at the neutral axis and thereby reduce the value of the bent bars, and in practice they are almost certain to be bent during the ramming or tamping of the concrete unless an undesirably fluid mass is used.

When the supplementary bars or stirrups are inclined and rigidly connected to the bar, thus delivering their strain into it, the tensile stress then existing in the horizontal reinforcement is not only that caused by the adhesion of the concrete 
to it, but also the summation of the horizontal components of the strain in each of the diagonals. We then notice that the principles of truss action begin to appear (see Fig. 68). By embedding the bars above described in concrete, a composite truss is formed in which the tension members are steel, and the missing compression members are furnished by the concrete.

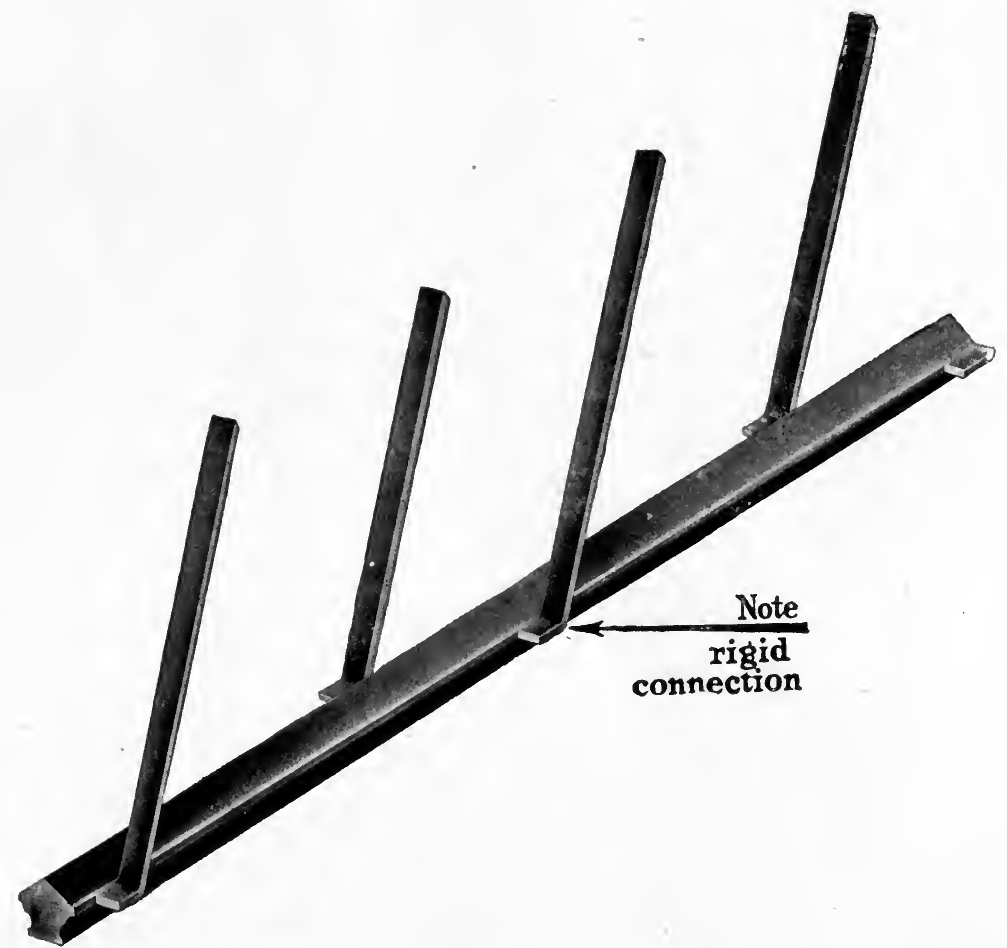

Fig. 66.-Kahn Trussed Bar.

The rigid connection of the bent bars with the large horizontal bar is claimed as a special advantage by the makers, who rightly state that the transfer of the stress from the shear members to the main member can only be accomplished by some definite connection between them which can only be obtained by a rigid attachment.

It is claimed by some engineers that the concrete surrounding 
the bars will prevent the slipping of the loose stirrups or tiedon bars, but aetual tests have proved that slight slipping does sometimes occur. The objection to all bars in which the auxiliary reinforeement is placed at fixed points is that the position of every bar, rod, or strip of steel, if of uniform section, ought to be settled by the designers of such bars conformably with the stress diagram for each structural member, or, if

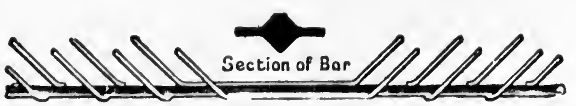

FIG. 67. the auxiliary or web reinforeement is in the form of bars placed at equal distances apart, then the cross-scetional area of the bars should be progressively varied from point to point. Neither of these methods of variation is, however, possible in the case of patent bars where the web reinforeement is formed by shearing and bending up part of a projecting flange rolled with the main bar.

A practical disadvantage of bars with web members attached at the sides is the excessive width of the bars in proportion
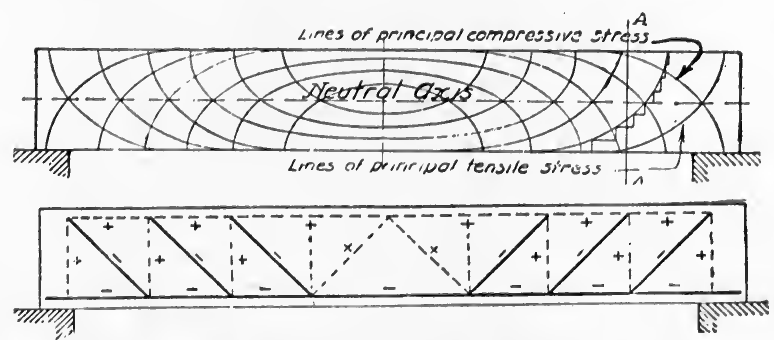

FIG. 68.-Showing position of Shear Members in Kahn Bar and Lines of Stress in Beam.

to their tensile resistance. In eonsequence, bars of this type cannot be used with economy in beams having to earry heavy loads, as the width of the beams must be very great to enable the requisite number of bars to be applied, the excessive width naturally representing waste of material and labour. Moreover, the width of the bars is apt to constitute an obstacle to the flow of eoncrete, making it difficult, if not impossible, to fill every part of the moulds, and to obviate the presence of 
voids between and under the reinforcement. The use of a very fluid concrete only introduces more serious difficulties, as it fills the moulds with concrete of irregular composition, because the aggregate and heavier particles of sand must necessarily settle to the bottom.

The most rational method in the design of reinforcement, whether in beams, columns, piles, or other structural details, is to employ forms of steel which permit the engineer to vary the spacing of the main and auxiliary bars at pleasure, and to determine by calculation the number and sectional area of the stirrups as demanded by the intensity and distribution of the stresses in every part of the construction.

That is the method adopted in the Hennebique System ; it

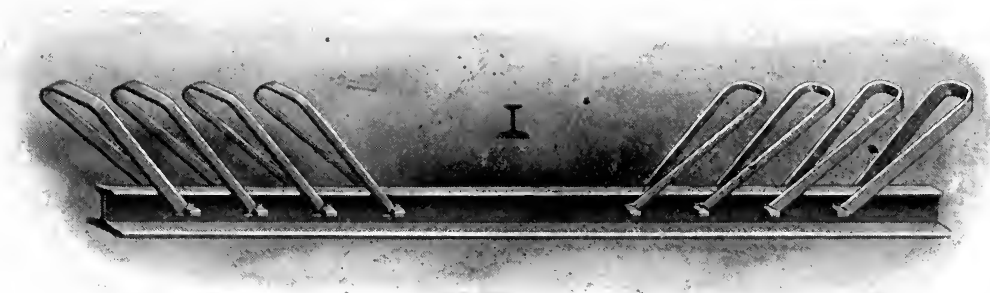

Fig. 69.-Moss Bar.

is generally approved by some of the most eminent authorities and confirmed by the many perfectly satisfactory structures in which it has been used, which occur in every part of the world. Yet there are many engineers and architects who feel that they cannot trust the workmen engaged in placing the concrete to take sufficient care in putting the stirrups in the corrrct positions and in ensuring their non-disturbance during tamping. Such engineers-and they are very numerous-are naturally willing to forego some of the minor advantages of the loose stirrups in order to secure the shear members from slipping out of place and so rendering possible a serious collapse of the whole structure. Consequently, they prefer fixed bars of the Kahn, Moss or similar type.

When used for columns, Kahn bars are placed vertically, one near each corner of a square a little smaller than the 
average area of the column, with the trusses or stirrups projecting towards the interior of the column (p. 222).

In the Moss system (Figs. 69 and 70) the bar is of I section with a large bottom flange; inverted stirrups are fastened along the bar, and at an angle to it so as to form trusses with some resemblance to the Kahn bars. The arrangement of the stirrups depends upon the loading of the bar.

The Indented Bar system uses bars of square or round section with projections or indents on each side (Fig. 49 and 71), these indents being sufficiently deep to prevent the concrete slipping along the bar. These bars are made of steel with a somewhat higher proportion of carbon than is usual in reinforcement, as such steel can be stressed more severely. The ends of the bars are bent where required to take additional shear stresses.

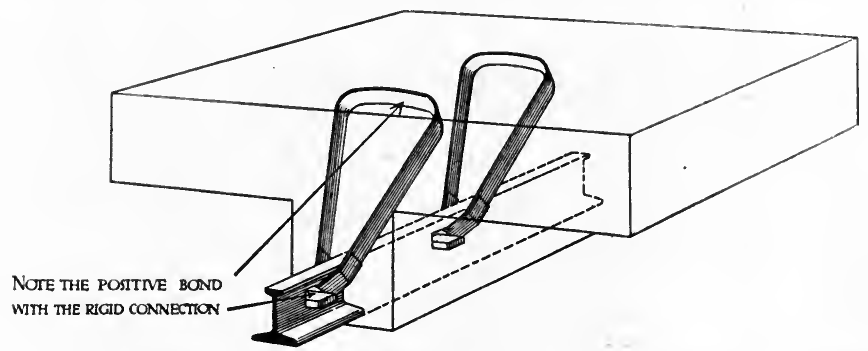

FIG. 70.-Isometric View of Moss's Patent Girder Reinforcement.

In addition to the advantages mentioned on p. 219 , the makers of the indented bars claim that with their bars "there is so close a bond between the concrete and the steel that it prevents undue extension of the concrete towards the beam ends, and the concrete is thus bound together where it is exposed to the greatest shearing stress and diagonal tension, so that it is able to resist shear of itself to a far greater extent than is the case when diagonal tension cracks can take place in the concrete and thus reduce its resistance. There is no doubt that the concrete itself plays a very important part in resisting shear when it is absolutely prevented from cracking by the use of a mechanical bond bar.'"

A further advantage claimed in favour of the use of indented bars is that, with them, " tests and actual practice conclusively 
prove that no cracks of sufficient size to admit moisture to the steel can occur in the concrete until the yield point of the steel has been reached. At this point, however, the whole member will be practically disintegrated owing to the complete inability of the concrete to stretch to the same extent as the steel. In other words, the yield point of steel reinforcement is the critical point at which the structure will fail, and it is utterly fallacious to consider the ultimate or breaking strength of the steel as the critical point."

The objection is sometimes raised that the ridges and sharp angles on indented bars injure the concrete when the structural
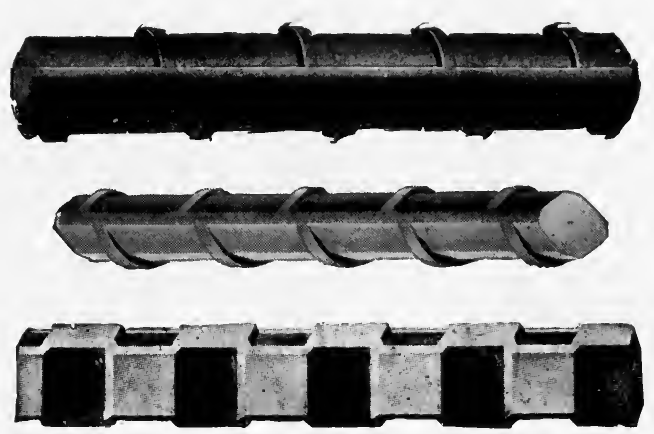

FIG. 71.--Indented Bars. members are in a state of strain. The effect is, however, too small to be appreciated in practical construction, and no failures have yet occurred through it.

Spiral Bars have spiral grooves running along their outer surface and have the advantage over smooth, round bars of rendering crooking or fishtailing the ends of tension bars unnecessary. The spiral grooves secure a strong mechanical bond and enable the bars to be used for working stresses up to $30,000 \mathrm{lbs}$. per square inch or 50 per cent. more than is the case with smooth bars; consequently, a large reduction may be made in the quantity of metal used. The lateral bending resistance is also much greater than that of smooth bars.

In the Expanded Metal system the reinforcement consists of mesh work (Fig. 72) made by cutting slots in a sheet of metal and then pulling it transversely until a network is formed.

The usual types of expanded steel used in reinforced concrete construction are the 3 -inch diamond mesh, and the rib mesh, a few $1 \frac{1}{2}$-inch and 6 -inch diamond meshes being also occasionally used for such work. The lighter weights of the $\frac{3}{4}$-inch and 
$1 \frac{1}{2}$-inch diamond meshes are frequently used in concrete for encasing steelwork.

The "3-inch diamond mesh" measures three inches by eight inches from centre to centre of its intersections or junctions. The size of the mesh is constant, but according to the thickness of the sheet from which it is made the strands vary in sectional area, and thus several weights are produced. Each intersection is twice the sectional area of its strand, and there are eight strands per foot run shortway of mesh.

It is a curious fact that tests prove that the process of expanding raises the elastic limit and increases the ultimate strength, thereby greatly improving it.

In the rib mesh the ribs are constant in cross-section, but are spaced at varying centres. The total area is available for reinforcement in both the " diamond mesh" and "rib mesh."

The rib mesh (Fig. 73) expanded steel consists of a series of straight ribs, or main

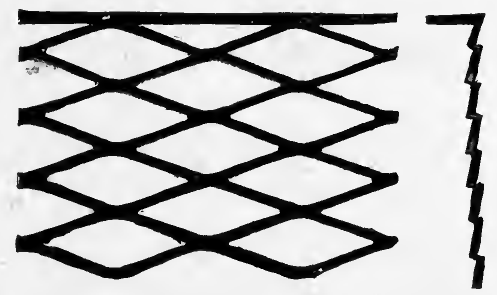

FIG. 72.-Expanded Metal. Diamond Mesh. tension members, which in the process of expansion are left rigidly connected by light cross ties which act as spacers. It is essentially a bar reinforcement without some of the disadvantages of the latter, for it is obviously an improvement on ordinary bars for slab reinforcement to have them attached together as in a sheet of rib mesh expanded steel. It is cut in various meshes, in sheets up to twenty-four feet six inches long, which are made from one original section of steel by cutting the light cross ties shorter or longer, so as to allow of the ribs being opened out less or more widely. While rib mesh expanded steel differs from diamond mesh expanded steel, in that the meshes are square instead of diamond shape, calculations of safe working loads for the two materials are based on the same tensile strength, so that the one mesh may be substituted for the other so long as the same sectional area is used.

The advantages of expanded steel as reinforcement for 
concrete make it specially useful for plain and curved areas. It is supplied in flat sheets ready for use; it packs closely, and is easily transported, and quickly handled; it is simple, economical and effective. The expanded sheets are machine-

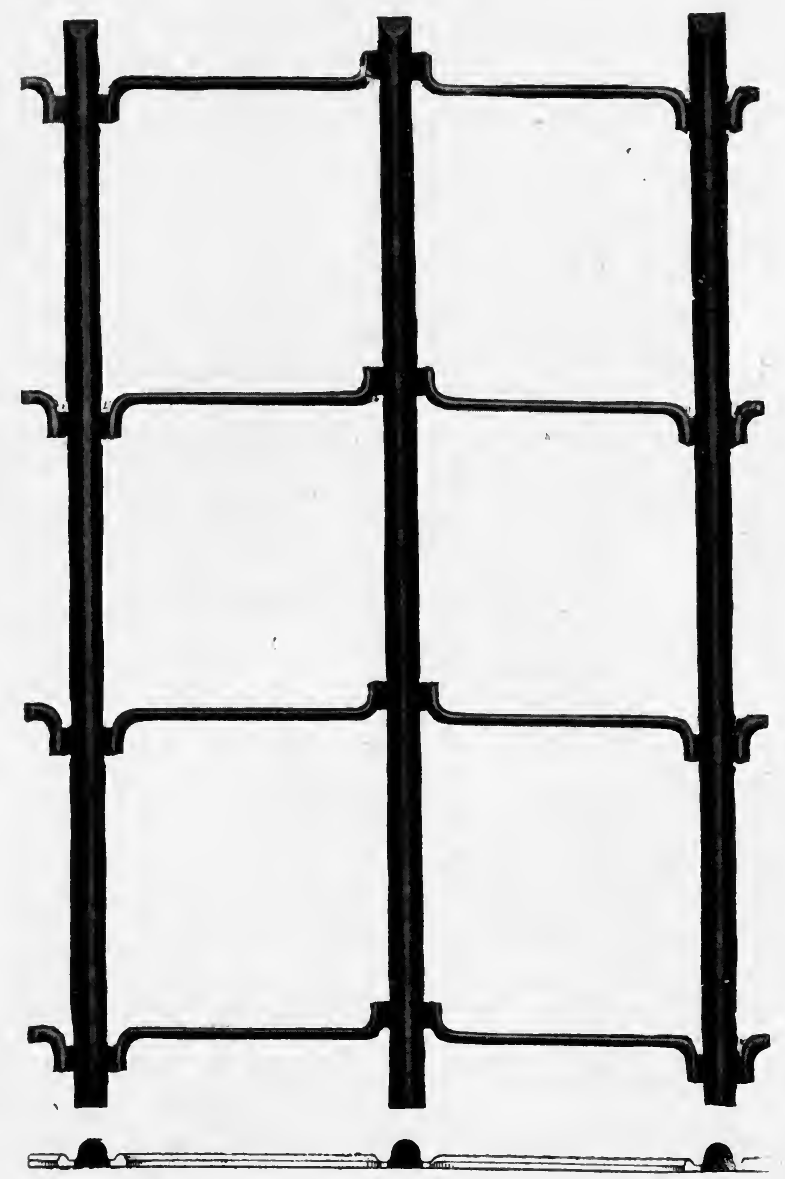

Fig. 73.-Expanded Metal, Rib Mesh.

made, and although of network formation there are no loose strands, as the junctions between the meshes remain uncut during the process of manufacture, and thus the strands or members are all rigidly connected, and have continuous fibres. 
The meshes key into each other and consequently interlock where the sheets overlap at joints, thus the reinforcement may be made continuous no matter how large the area be treated. Excellent mechanical, as well as cross bond, and anchorage are obtained with expanded steel, and owing to its peculiarity it cannot slip within the concrete, for this is most efficiently locked within the meshes.

The special feature of expanded steel is that it is a solid sheet of network formation wherein all the strands or members are all rigidly connected, and when in position cannot be displaced by the laying and tamping of concrete. It is therefore quite reliable as a reinforcement as the steel goes where it is planned to go without requiring skilful setting out on the part of the workmen.

In this respect it is superior to loose bars placed by measurement and tied at intersections with wire, for if one bar is lower than another it is evident that the former will be more highly stressed than the latter, and the full value of the total reinforcement will not be obtained.

The distribution of stress by expanded steel is such that wherever a load may come there is steel to transmit it in all directions, so that a load does not affect merely the portion of slab directly under it. When a concentrated load comes on a slab reinforced with separate bars, only the bar under the load is affected; with the expanded steel the mesh distributes the stress in all directions. Expanded metal sheets are manufactured in various sizes up to sixteen feet the long way of the meshes, and there are some seventy-six varieties with meshes one and three sixths inches to six inches wide. The manufacturers claim that expanded metal saves about 75 per cent. of the bulk of the concrete when used as a tension bond. It is specially used as lathing for partitions and in floors, but is equally available for beams, stanchions and columns, bridge work, reservoirs, conduits, sewer pipes and retaining walls. For beams, a square bar is rolled with a lateral rib; the latter expands upwards so as to form a mesh which takes the place of the stirrups in other systems.

Richard Johnson, Clapham and Morris, Ltd., use a form of wire netting (Fig. 74) as reinforcement. For many purposes 
this is quite satisfactory, but for heavy work drawn wire network is best avoided.

Another form of reinforcement recently introduced into this country is the "triangle mesh" supplied by the United States Products Co. It is made of hard drawn cold steel wire with an elastic limit of 22 tons per square inch. There are no welds in this reinforcement, which, being of the hinged joint type, is flexible without producing initial stresses when bent (Fig. 75).

A large number of other shapes of reinforcing bars and meshes have been devised, but the foregoing are sufficient for the student to gain some idea of the arrangements most commonly used.

The reinforcement in arches and arched bridges constructed of reinforced concrete serves three purposes, namely, to take

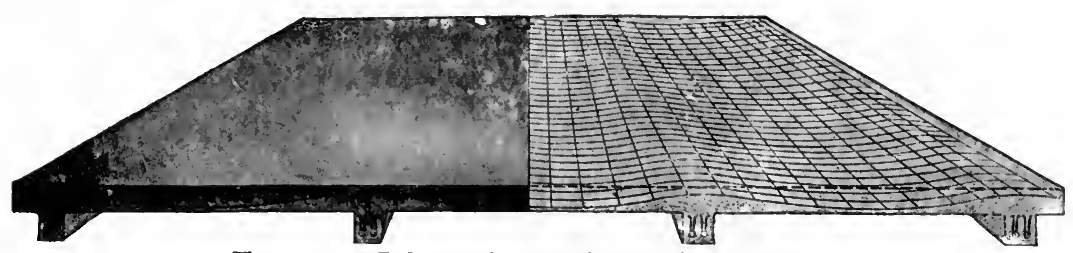

Fig. 74.-Johnson's Netting Reinforcement.

compression, to resist tension, and prevent shearing and temperature cracks. The reinforcement is designed in conformity with the modern theory of the elastic arch, and hinges are often introduced so as to ensure the line of stress passing through given points. The design should prevent tension in the arch ring, and the reinforcement chiefly serve to assist in the resistance of the compressive stresses ; consequently, large $\mathrm{T}$-shaped steel members are frequently adopted.

Trussed bridges of various forms are constructed in reinforced concrete, but no special principles are introduced in their design, the members consisting of posts, perpendicular or inclined, and beams of cantilevers.

For bridges, etc., reinforced concrete has nne marked advantage over most other materials, in that it may indicate conditions of maximum allowable tension in its embedded 
steel before actual danger exists. This advantage rests in the fact that the coefficient of elasticity of the concrete and of the embedded steel do not bear the same ratio as their allowable stresses. When the embedded steel is stressed to 5,000 lbs. per square inch, invisible cracks occur in the surrounding concrete. At 10,000 to $15,000 \mathrm{lbs}$. per square inch these cracks become visible. At 20,000 lbs. per square inch they frequently become objectionable.

In arch design, where the stresses in the arch are magnified by the behaviour of the spandrel walls, cracking of the concrete

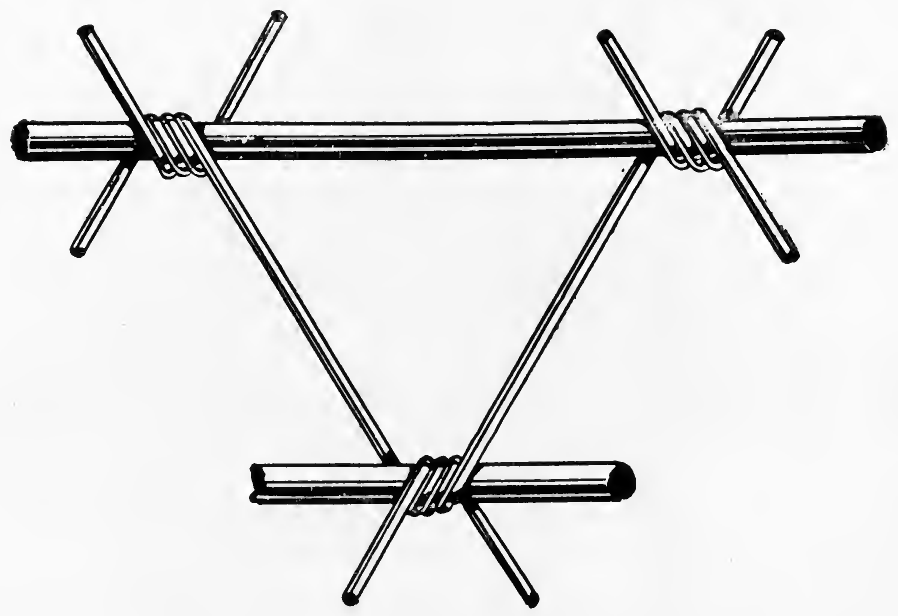

FIG. 75.-Triangle Mesh Reinforcement.

serves the purpose of an extensometer to detect excessive stresses. If an arch is designed too flat at the crown, cracks will appear in the spandrel near the ends of the span. If too flat at the haunches, cracks will appear in the coping over the crown or through the arch ring at the haunches directly under the spandrel only, and not extending far into the soffit of the arch. The tensile stress in the arch itself is rarely sufficient to show cracks actually penetrating the arch ring. Small cracks, particularly in the spandrels, are no indications of failure, being merely the magnified effects of movements in the arch ring, but a properly designed and erected arch will

c. 
be free from such cracks, if provided with expansion joints in the spandrels above each springing.

Reinforced concrete is now extensively used in the construction of conduits, water mains, and sewers. The latter are usually constructed in situ-that is, the concrete is mixed and placed to set in the position it will finally occupy, although a great number of concrete sewer pipes of large diameter are manufactured and sold as an ordinary market commodity. Water and drain pipes are occasionally constructed in situ, but are usually made in moulds. The reinforcement is generally of meshwork, preferably with the warp of spiral form, the strands perfectly crossing the pipe at an angle (Fig. 76), and not running longitudinally and at right angles to the length. The spiral reinforcement serves to resist the bursting pressure. Expanded

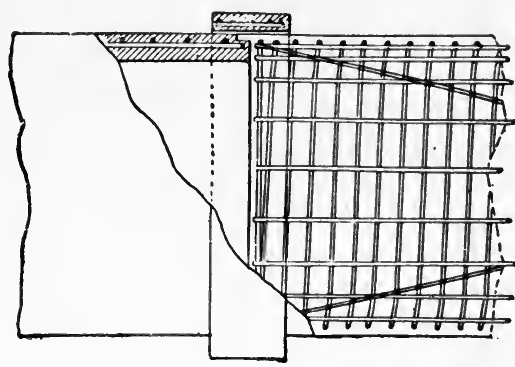

Fig. 76.-Coignet Pipe.

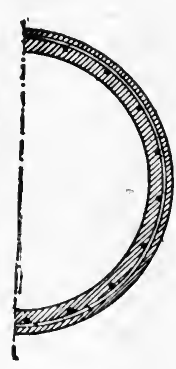

metal and wire meshwork have been largely used for this purpose. In the Bonna system, special cruciform bars are wound spirally inside and outside a thin sheet of steel, the steel

serving to prevent contamination by penetration of external moisture in the soil or percolation under great pressure.

After being made, concrete pipes must usually be kept at a temperature of $50^{\circ} \mathrm{F}$. or above, protected from direct sunlight and air currents, for at least seven days, during which period they must be kept moist by sprinkling with water. They should not be removed to the open air until they are at least a month old. If the pipes are to be "steam cured" they are placed in an autoclave and subjected to the action of moist steam for about forty-eight hours, if the steam is at or below $212^{\circ} \mathrm{F}$., or for a much shorter period if the steam is under considerable pressure, as described later under "Lime Sand Bricks."

For docks, reservoirs, aqueducts and water tanks of all sizes, 
reinforced concrete has proved about 15 per cent. cheaper than mass concrets or bricks, and about 20 per cent. cheaper than stones, and in addition there are practically no charges for maintenance or repair. Silos, magazines for explosives, coal bunkers, as well as tanks for oil, brine, and many other fluids, are proving perfectly satisfactory providing that they are well designed and the concrete is properly made and placed.

Piles are constructed of concrete in a manner similar to columns when they are cast in place, but piles cast in a mould are not usually reinforced so strongly. Concrete piles are superior to wood both as regards strength and durability, and are much cheaper than piles constructed exclusively of steel.

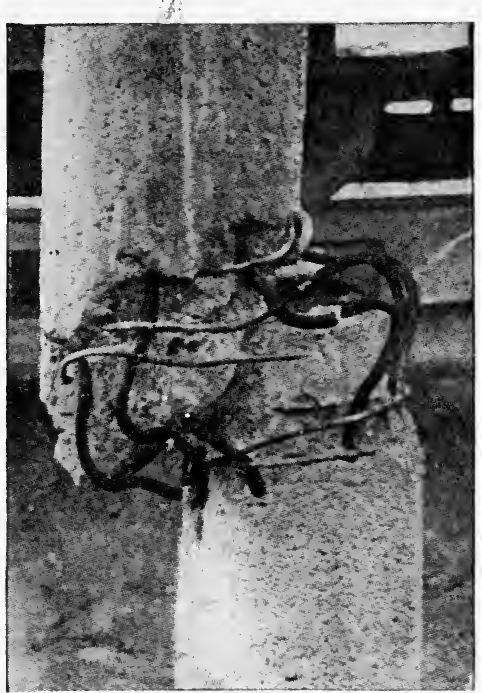

Fig. 77.--Overloaded Column, with Insufficient Longitudinal Reinforcement.

The essentials of a good pile are the following :-

(a) That it shall be capable of being driven into the ground (either soft or hard, wet or

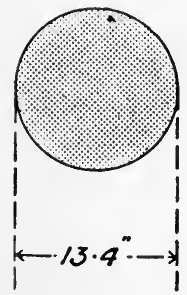

FIG. 78.

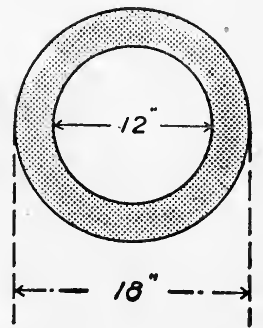

1 dry) to such a depth as will enable the buried portion to support the weight of some superstructure, or to withstand force applied against it in a horizontal direction, or to resist forces applied in any other desired direction.

(b) That the projecting portion of the pile shall be capable of supporting axial vertical loads with perfect safety, and of supporting eccentric vertical loads without appreciable flexure. 
(c) That, if the pile is to be moulded before use and not "cast in place," it shall possess rigidity and elastic strength sufficient to permit it to be transported, slung, and driven without injury.

Piles may be circular, square, or any other cross-section, the usual shape for foundation being that of a square with chamfered edges, whilst rectangular piles are used for sheeting.

The reinforcement usually consists of stout longitudinal bars with suitable wire ties, the construction being very similar to that of columns, and similar considerations apply to them (see p. 221). The metal exposed in cross-section varies from 2 to 5 per cent., and is almost invariably of round rods, clamped and tied as in the columns.

The following table gives particulars of Hennebique piles made and used at Southampton :-

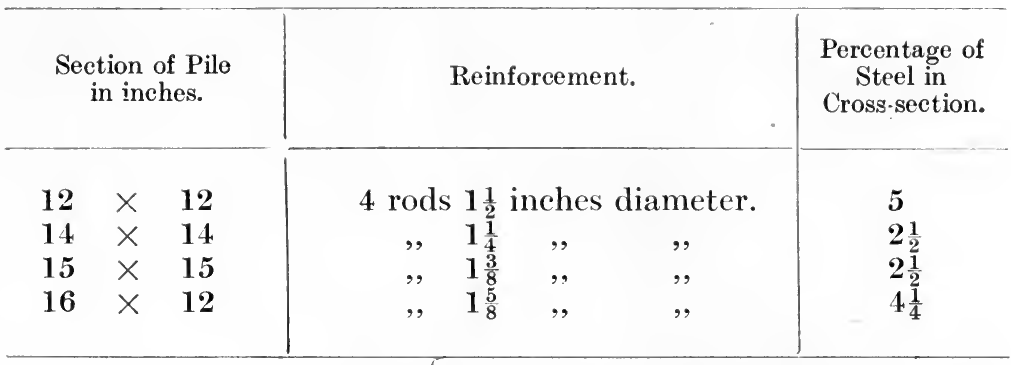

It is important that the longitudinal rods should be of ample diameter, as thin rods may prove disastrous (Fig. 77).

As the power required to drive a pile is largely, if not entirely, due to friction between its surface and that of the surrounding earth, a given volume of concrete in the form of a hollow cylinder should be more effective than if applied as a solid cylinder, or conversely, concrete may be saved by using a hollow pile of the same external dimensions as a solid one.

This point is illustrated in Fig. 78, where the left-hand diagram represents the cross-section of a 13.4 inch diameter solid cylinder with the area of 141 square inches and the circumference of 42 inches; and the right-hand diagram represents the cross-section of an 18-inch diameter hollow cylinder with the net area of 141 square inches and the circum- 
ference of 56.5 inches. Thus, for the same area of material, the circumference of the hollow cylinder is over $33 \frac{1}{3}$ per cent. more than the circumference of the solid cylinder, and the bearing power of a hollow pile can readily be made one-third greater than that of a solid pile without increasing the cost in the slightest degree.

L. J. Mouchel has therefore effected a notable improvement by the construction of hollow piles with a reinforcement based on the Hennebique system.

For practical reasons it is generally desirable to employ piles of rectangular form, and for this reason the Mouchel patent hollow piles are usually made with the cross-section shown in Fig. 79, thereby sacrificing a small proportion of the saving that could be effected by the adoption of the circular form in order to gain advantages which appeal to the engineer using piles as structural members.

The head and point of the pile are usually protected by steel caps.

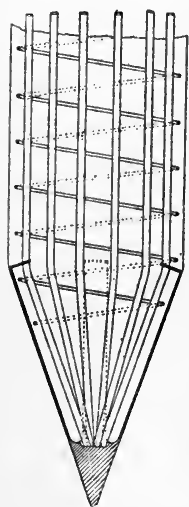

FIG. 80.Coignet Pile.
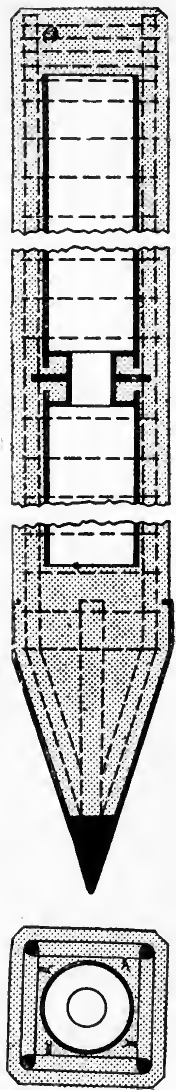

Fig. 79.Mouchel Hollow Pile. After three days the forms are removed and the pile is left for several weeks in order that it may harden properly. After this it is ready for driving. The piles must be made of exactly the required length as it is costly to cut them. Piles which have been treated in steam for three days are ready for driving at the end of this period; the steam or high temperature greatly increase the rate of hardening. 
Chimneys constructed of reinforced concrete can be erected by well-organised firms in about half the time and for about half the cost of brick chimneys of the same size. The larger the chimney the greater is the saving, as a large brick shaft
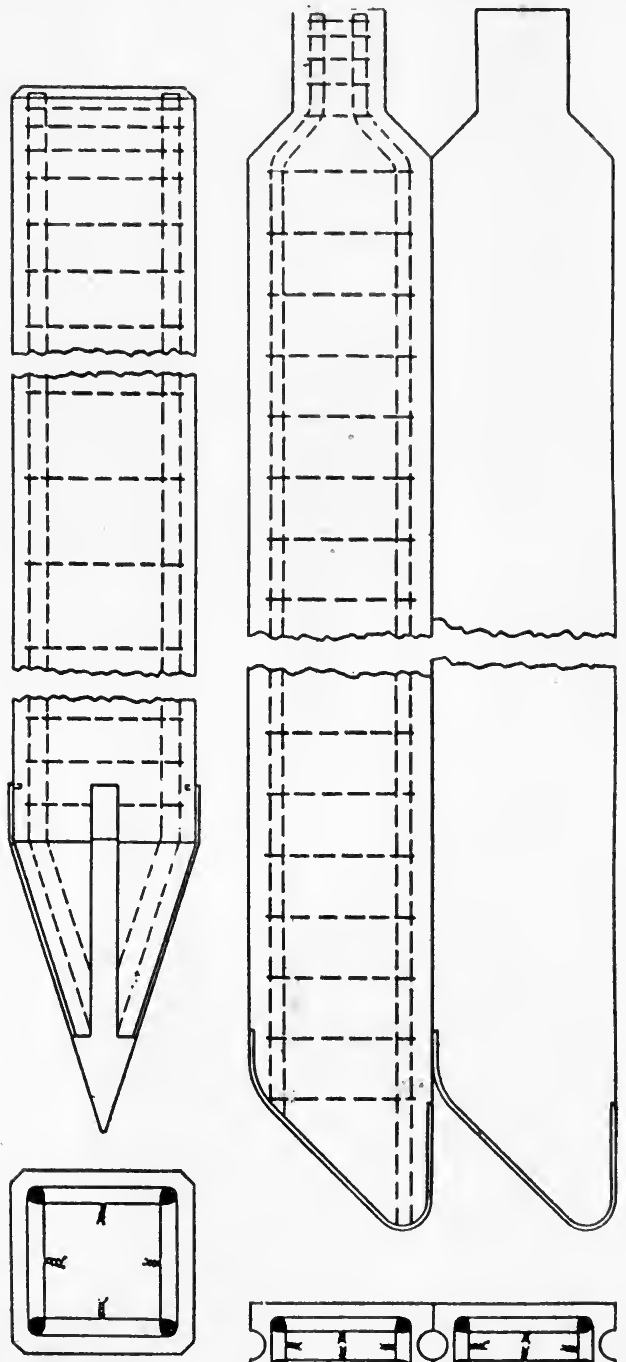

Fig. 81.-

Hennebique Pile.

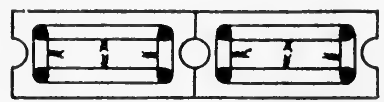

Fig. 82.- Hennebique Sheet Pile.
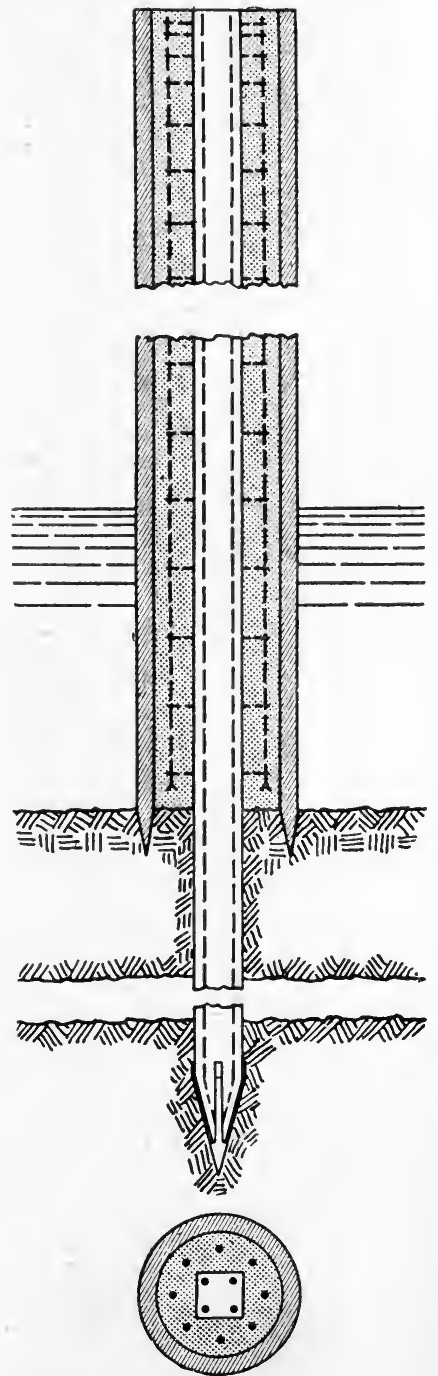

Fig. 83.-Pile with Solid Core. 
must have a very thick base in order to provide the necessary support. The weight and space occupied by a concrete chimney are also less than a brick shaft, this being important where the foundation is treacherous, and it is also claimed that a reinforced concrete chimney, if properly designed, has a greater stability than one of brick or stone on account of its monolithic character. The resistance of concrete to the heat and abrasive action of flue gases appears to meet all requirements, and experimental blocks of concrete placed in brick chimneys were found to have a greater strength than similar blocks stored for an equal time under water. It is, however, necessary that the concrete should be well set before being heated; two months or more should be allowed to lapse before the chimney is used.

A temperature of $520^{\circ} \mathrm{C}$. is considered to be the highest safe temperature for large concrete chimneys, though most concrete can be heated on one side only to $900^{\circ} \mathrm{C}$. for several hours without ill effects. It is, however, essential that only sand be used as aggregate, as stone "flies" under the action of heat.

There have been several serious failures of concrete chimneys, especially in the United States. In almost every case these have been traced to faulty workmanship in construction and not to errors in design. This is due to the use of a safety factor of five for transverse resistance and to allowing for stresses set up by a wind travelling at the rate of 100 miles per hour-a velocity greater than that of a cyclone. A maximum wind pressure of $50 \mathrm{lbs}$. per square foot on a square Fig shaft, and two-thirds of this on a round one is ample allowance.
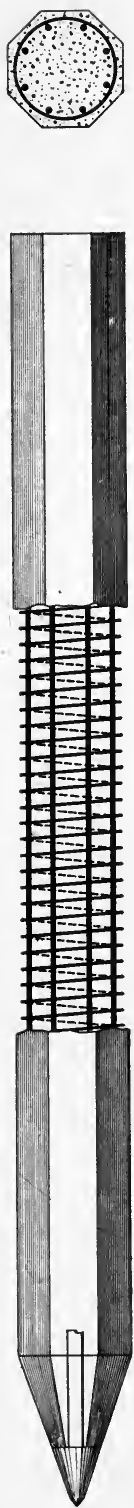

84. - Considère Pile with S piral Reinforcement. 
Engine and dynamo beds and foundations for machinery are more free from vibration when made of concrete than of brickwork or stone. The bed can also be constructed to any shape at a cheaper rate than when other materials are used.

Foundation rafts in boggy or "quick" ground are made of reinforced concrete, and thus enable large buildings to be erected on what would otherwise be too treacherous a foundation.

Floors made of concrete are usually constructed of iron girders or concrete beams (Fig. 85) placed fairly close together, the intervening space being occupied by slabs $3 \frac{1}{2}$ inches to 6 inches thick, formed of a $1: 2: 5$ or other suitable mixture, and reinforced with $\frac{7}{16}$-inch rods placed 4 inches apart, or with
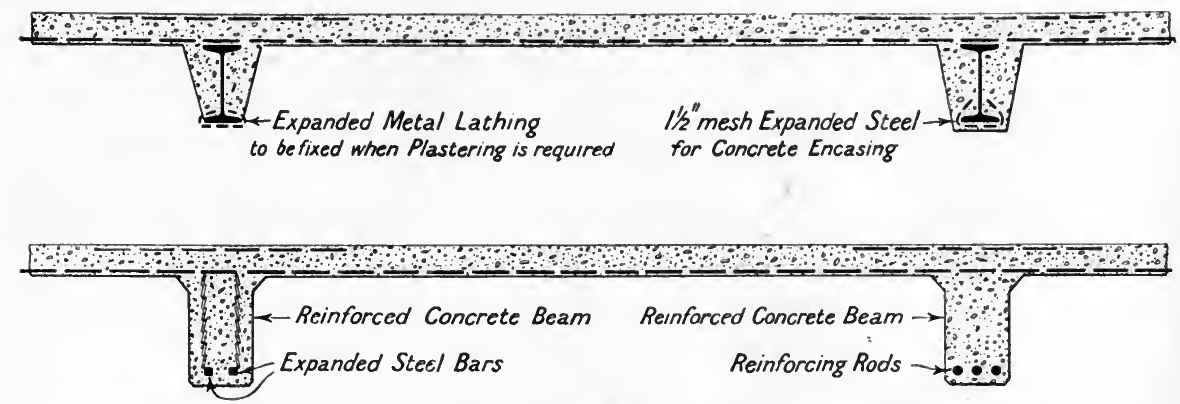

FIg. 85.-Use of Expanded Metal for Beams and Floors.

network reinforcement so that the whole structure can carry a load of $3 \mathrm{cwt}$. per square foot in addition to the weight of the floor itself for factories, or $1 \frac{1}{2} \mathrm{cwt}$. per square foot for houses and public buildings. Many designs of floors are in use, some of them for very large spans.

Paving blocks and floor slabs made of concrete are used increasingly in districts where natural stone is costly. Curbs for pavements are cheaper when made of concrete than of sandstone, and are equally durable.

Building blocks of concrete are also made in large quantities, the claim being made that as a builder can lay fifty blocks 2 feet $\times 1$ foot $\times 9$ inches per day, the use of such blocks is cheaper than ordinary mass concrete. The plastic concrete is 
placed in moulds (Figs. 87, 88) of cast iron or mild steel, and is gently tamped until the surplus water rises to the surface. After being left for a short time until the cement has set, the sides of the mould are allowed to fall and the block or slab is removed and stored in a cool shed until it is hard enough for use. The square slabs used for paving are frequently made in a strong wooden or metal frame, which is laid on a piece of matting or canvas on a smooth level

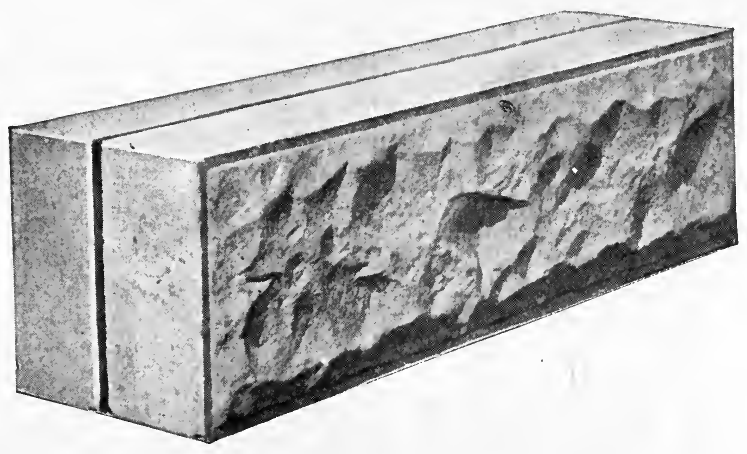
floor. The concrete is placed in this frame, tamped carefully, and the surplus material removed with a long - bladed knife. After the cement has

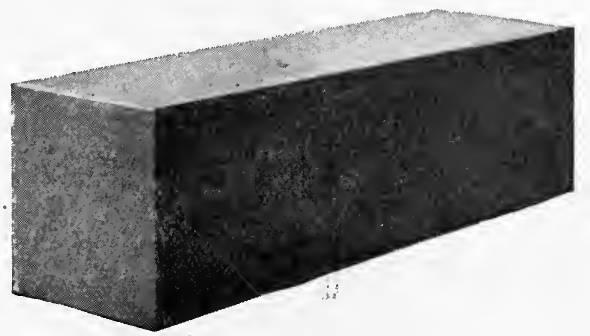

FIG. 86.-Concrete Building Blocks. set, the frame

is removed leaving the paving block on the canvas. If a sufficiently fine aggregate and a fairly rich mixture is used the frame may usually be lifted off as soon as the tamping is finished. The canvas gives a pleasing texture to the surface of the slab and renders it non-slipping. Such slabs are not reinforced in the ordinary sense of the term, the metal (if any) embedded in them being intended to prevent them spalling, and not to increase their tensile strength.

When the number of blocks or slabs is sufficiently large a machine is desirable. Care should be taken in selecting one for this purpose, as some of those on the market are far from 
satisfactory. Among the best is the "Winget" concrete block machine, which consists of a mould box with hinged sides and ends carried in the frame hung in trunnions, as shown, with core blocks set inside. When the lever at the right-hand side of the illustration is pulled down the bottom of the mould box (which is formed with a loose pallet inserted for each block) is lifted up, and at the same time the sides of the box fall outward, leaving the finished block on the pallet ready to be carried off.

When it is required to use the machine in the face-down

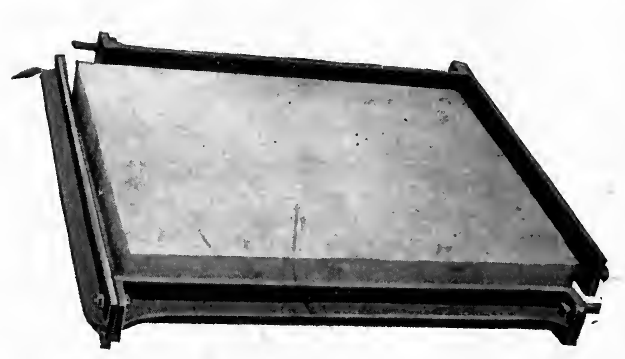

position the frame carrying the mould box is swung over in the trunnions into a horizontal position with the same lever on releasing the stop controlled by the small horizontal lever at the right-hand end of the machine.

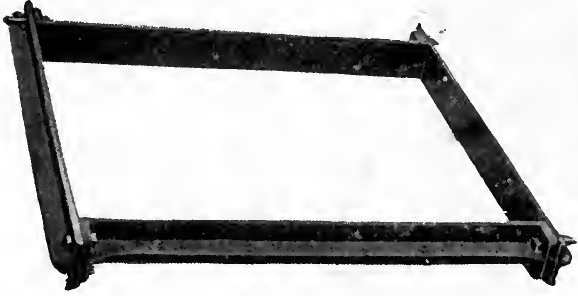
The cores are carried on a fixed bed plate under the pallet forming the bottom of the mould box.

The movements necesFig. 87.-Mould for Slabs. sary to make a block are the fewest and simplest possible, so that the maximum output is secured with a minimum cost for labour. If the instructions given with the machine are followed, two men can make about 400 blocks or 800 slabs per day.

Concrete roads are usually made of mass concrete without reinforcement, except for the paving curbs, but there is a movement in favour of making the whole road of reinforced concrete, and using the hollow space beneath it for sewers, gas pipes, etc.

Lintels have steel joist bars or rods embedded in them, but the distribution of these varies greatly in different cases. A $1: 2: 4$ mixture is generally employed. 
Tiles made of cement are used for both roofing and flooring. They are made in metal moulds consisting of a lower box or container into which an upper plate or plunger fits closely. The plunger is lifted, its lower surface and the inside of the box are oiled or wetted, the box is filled with concrete paste, and

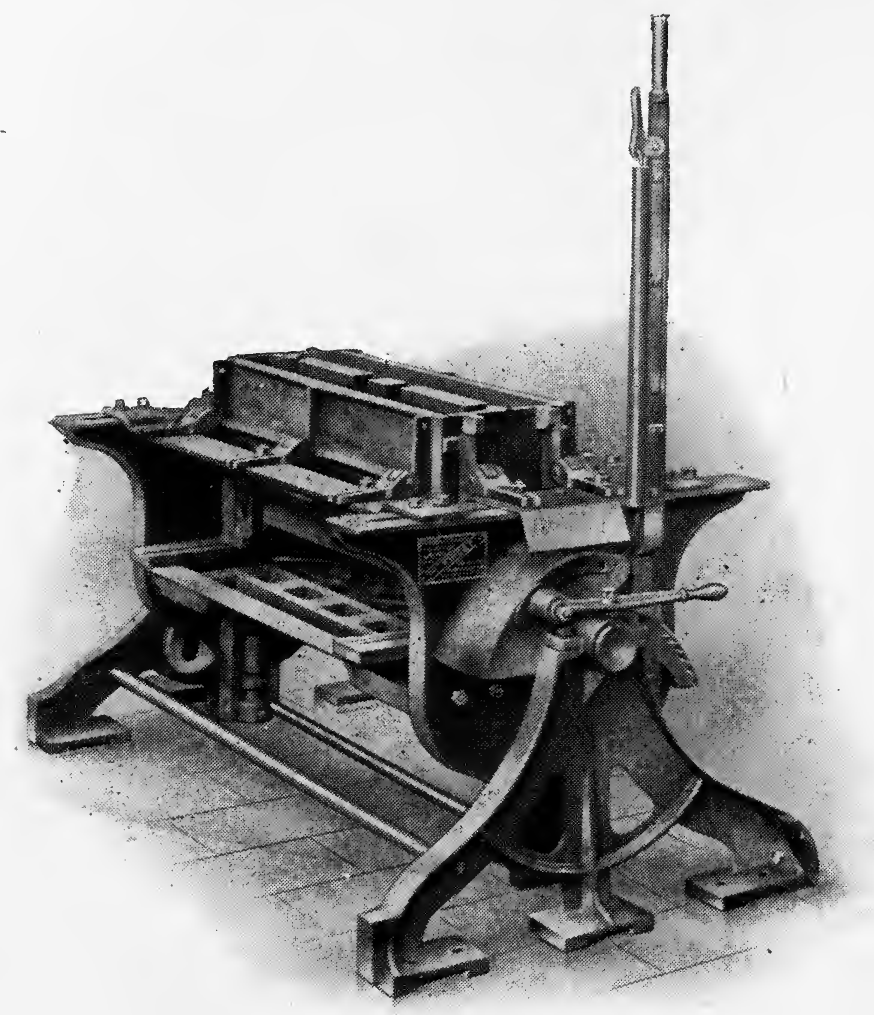

FIG. 88.-"Winget" Block-making Machine.

the plunger is brought down so as to compress the mixture, the tile is turned out on to a bench, and in a few hours is ready for use. About 500 tiles can be made in a day by one man.

Stairways and steps made on the site are reinforced longitudinally in a manner similar to beams and transversely near the front of the tread, with vertically placed studs in order to 
reduce the tendency of this portion of the steps to spall or break away under traffic. The treads and risers are also cast solid, and sold ready to be fixed as stone stairs.

Railway sleepers are used in large numbers in the United States. Though slightly more costly than wood in the first instance, they are reported to be more durable, and so become more economical.

Telegraph poles and tramway standards are cheaper in concrete than in steel. They are of tubular form, and must be carefully made in such a manner that the reinforcement does not slip during the tamping.

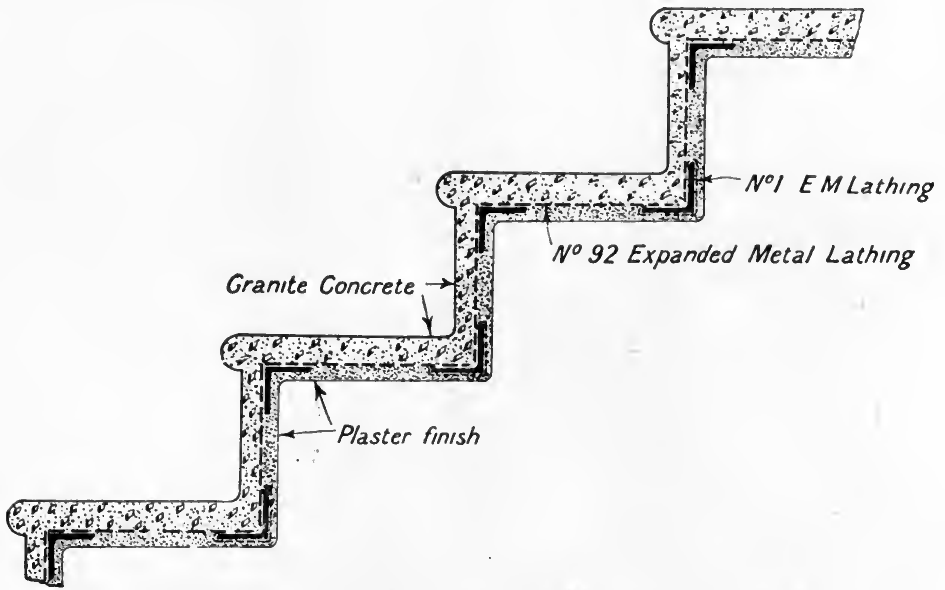

FIG. 89.--Use of Expanded Metal in Stairs.

Pit props, gate posts, boats, pontoons, garden ornaments, and many other useful and ornamental articles are also made of concrete. In fact, new uses of this remarkable substance are constantly being found. Some of these uses are fantastic, in others the naturally suitable materials are discarded in favour of concrete, merely because of a desire to use the latter material, but in the majority of cases concrete may rightly be used in situations where other materials are less readily available, and in circumstances where concrete is particularly suitable.

In all concrete work it is essential that ample precautions shall be taken to secure the concrete being properly made and placed, to prevent the forms being taken away too hurriedly, 
and to ensure that no pains are spared to keep the surface of the material properly wetted when such treatment is necessary. The repeated failures of concrete construction have, in almost every case, been due to the use of concrete under unsuitable conditions, or to the improper manipulation of the materials and forms rather than to inherent disability in the design of the structures. Fortunately, concrete structural work tends increasingly to become a separate occupation, and this will reduce the risks of its use, and men will work more and more skilfully as they become accustomed to the material. The simplicity of many forms of concrete construction makes it specially attractive to farmers and others in isolated situations, but the risks of imperfect mixing, etc., then become more serious. Concrete is an invaluable material, yet those who see its advantages, but not its drawbacks, may easily find themselves and others seriously inconvenienced, especially in the case of buildings erected by men unskilled in this branch of work.

At the same time, even among the most skilled workers there is still room for much improvement in the preparation of concrete, particularly with regard to its strength and permeability. Grading the aggregate more carefully and into a larger number of portions than is at present customary, will probably prove to be the most efficacious, but the cost of this increased grading is so frequently found to be greater than that of an additional quantity of cement that it is difficult to increase the number of grades above that now in use. The study of the proportion of voids in the concrete and of the materials composing it will naturally give the clue to obtaining stronger and more impermeable concretes, and will not improbably result in a decrease in the use of waterproofing materials. That the concrete of the future will be superior to that of the past cannot be doubted by those who are closely in touch with the many attempts now being made to increase the stringency of the present standard specifications. 


\section{CHAPTER IX}

SPECIAL PROPERTIES OF CONCRETE

THE properties of concrete vary with its age and composition as well as with the quality of the cement used.

The crushing strength of concrete is roughly proportional to the amount of cement in the material, the maximum strength being reached when all the voids are filled and each particle of material is coated with cement. As explained in a previous chapter, this usually corresponds to a weight of cement equal to $\frac{11}{10}$ times the amount of voids in the quantity of sand used in a batch of concrete. It is not usually wise to employ a concrete with a compressive strength after twenty-eight days which is below 2,400 lbs. per square inch. (For further particulars see p. 126.)

The tensile strength of concrete may be tested in the same way as that of cement (p. 128), but is usually assumed to be onetenth that of the crushing strength.

The shear strength of concrete is not known with accuracy, and appears to depend largely on the nature of the aggregate. Professor A. W. Talbot finds it to be about half the compressive strength, but one-tenth of the latter is the figure usually assumed.

The effect of testing concrete in shear and also in lines of fracture, are shown in Fig. 90. The blocks tested were 9 inches $\times 12$ inches $\times 12$ inches. The result obtained in the first case is very low and possibly due to some latent imperfection.

The transverse strength of concrete has also been tested in certain instances. The results obtained, after reduction to their equivalent values, for a beam twelve inches square in cross-section, and twelve inches long between supports, are exhibited in Fig. 91. The weight given is the breaking load applied centrally.

Shear tests are peculiarly difficult on account of the material bending instead of simply shearing, and it is not impossible that future experiments will give even higher results. 
The adhesion between concrete and steel is remarkably great, so that there need be no fear of any slipping occurring so long as the reinforcement is properly designed. It is upon this adhesion that much of the value of reinforcement depends.
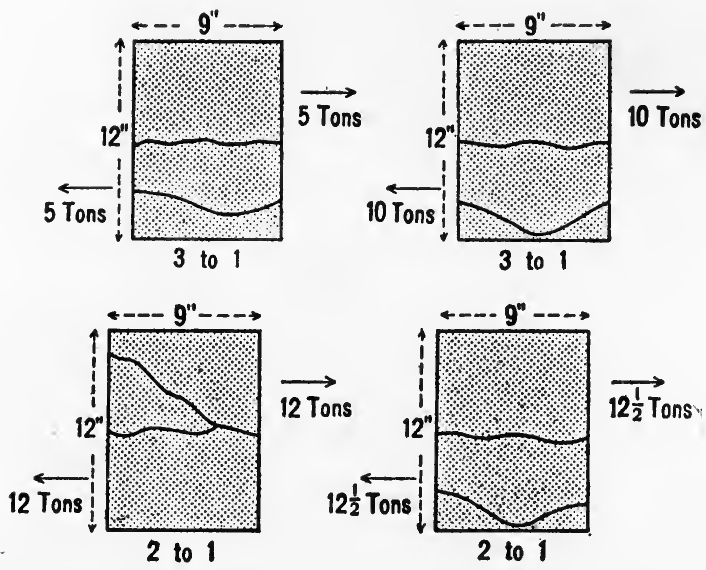

FIG. 99.- Shearing Strength of Concrete and Nature of Fracture under Shearing Stress. (H.R. Jones.)

The adhesion of concrete to steel cannot alone be depended upon to transmit the stresses from the reinforcement to the surrounding concrete.

When the surface of the steel is smooth and free from obvious indentations or projections, all adhesion must be due to the cement particles entering the microscopical irregularities on the surface of the metal, so that whilst the adhesion, under such circumstances, is often remarkable it may be greatly increased by the use of a more irregular surface.

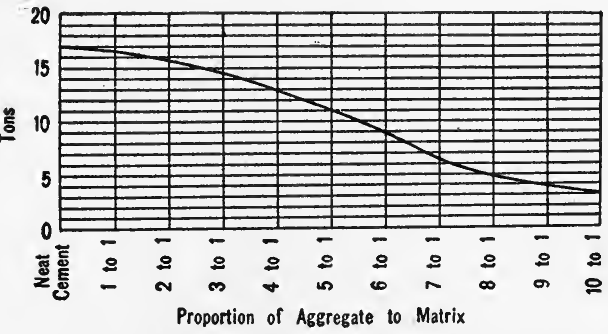

Fig. 91.- Transverse Strength of Concrete. (H.R. Jones.) Moreover, Professor Popplewell has shown that when steel bars are under stress the reduction in area which they 
suffer destroys the adhesion if the bars of the steel are smooth, whilst the bar with ridges, indentations or other irregularities of surface retains its grip on the concrete until the latter is actually broken. Vibration of the concrete mass, as a whole, also reduces adhesion, and may be serious if completely smooth bars with no shear members are used. It is now well known that the shocks and vibration inseparable from the average building are sufficient to reduce appreciably and sometimes to destroy the adhesion when plain rods or bars are used. To guard against this risk many devices are employed by engineers who use plain bars, such as splitting and bending the bars at their ends to obtain anchorage. Such methods are not wholly satisfactory, and are often inadequate, and many types of deformed bars have been devised to overcome these objections. For some purposes there can be no doubt that the best form of reinforcement is a rigid network giving a dependable mechanical and cross bond; for others, indented or ridged bars are preferable.

Adhesion is measured by embedding a steel rod in a rectangular block of concrete and, after a suitable time, measuring the force required to pull it out. The area of the surface of the embedded bar must also be ascertained. The Joint Committee under the auspices of the Royal Institute of British Architects recommends a working adhesive stress of $100 \mathrm{lbs}$. per square inch, though the actual force required to separate a rod from the concrete in which it is embedded varies from 550 to $650 \mathrm{lbs}$. per square inch.

The adhesion is increased by coating the steel reinforcement before use with a thin slurry made of cement and water, and by employing ribbed or corrugated reinforcement bars instead of smooth ones.

For information concerning the loads which can be carried by reinforced concrete see p. 213 .

In addition to its strength, many of the advantages of concrete as a structural material depend on certain of its properties, such as resistance to fire, sea water, shocks, etc., and it is therefore desirable to mention these special properties in somewhat greater detail.

Fire Resistance.-The behaviour of concrete buildings when 
subject to fire has been the subject of numerous investigations and tests. Small changes in temperature, such as occur daily in tropical climates, cause a superficial cracking of the concrete, which is of no structural importance except as regards the appearance of the building. Much greater heat, as when a structure is "on fire," effects several changes, the chief of which are (1) the expansion of the material, which may endanger the stability of the structure ; (2) chemical dehydration; and (3) destruction of the cement and aggregates. All steel structures tend to expand when heated, and this has, in the past, resulted in much loss of property as the girders have pushed out walls in consequence of the expansion of the metal. In reinforced concrete the steel is so covered with concretewhich has a low heat conductivity-that its expansion is reduced to a minimum, but the durability of the material during a conflagration is entirely dependent on there being a sufficient thickness of concrete around the metallic reinforcement. The opinion expressed by the R.I.B.A. Committee that "Usually a cover of $\frac{1}{2}$ inch on slabs, or 1 inch on beams, is sufficient," is much too low where the fire is likely to be of long duration. The tests of the British Fire Prevention Committee have shown that 2 inches of concrete is much more likely to prove a safe minimum, with $2 \frac{1}{2}$ inches for columns, and 3 inches for beams. If the steel is thinly covered or is exposed at any part of the heated structure, its temperature will rise so rapidly that the concrete itself may be strained sufficiently to cause it to rupture. This caused the destruction of several concrete buildings in the San Francisco and Messina disasters.

The action of heat on neat Portland cement is such that at temperatures of $300^{\circ}$ or above, the cement is dehydrated and rapidly crumbles to powder. In well-made concrete structures, however, the heat-conductivity is so low that this integration is confined to the surface unless an unsuitable aggregate has been used. Hence the disintegration of concrete by fire is of academic rather than practical importance, few conflagrations lasting sufficiently long for serious destruction of the concrete to occur by the direct action of the heat.

Unsuitable aggregates greatly reduce the resistance of concrete to fire. The igneous rocks form the most resistant 
aggregates, then broken bricks, sandstones, gravel, limestone, and furnace slag. Ballast-especially if containing flint pebbles-cracks badly on being heated. Coke and cinders are the least satisfactory so far as resistance to fire is concerned.

Measurements of the heat conductivities of various aggregates made by Professor Woolson have shown that gravel has a high conductivity, limestone comes next, then igneous rocks and coke breeze come last with the lowest power of heat transmission. Care must, however, be taken that the breeze is almost free from sulphur. If pan breeze or cinders be substituted, destruction of the concrete through oxidation of the sulphur compounds is likely to occur (p. 151). The coke must not contain more than 5 per cent. of bituminous matter or it may, when thoroughly heated, continue to burn of its own accord.

The heat conductivity of concrete made with sandstone as aggregate has been found by Professor C. L. Norton to be .0021 to .0029 calories per square centimetre per centimetre per second per degree C.: or 150 to 200 B.T.U. per degree F. per square foot per inch thick per twenty-four hours. Untamped and coke breeze concrete give about half the above results on account of their lower density.

Investigations of concrete structures after severe conflagrations show that whilst limestone, sandstone and gravel aggregates suffer under the action of severe fires and must be renewed, yet coke breeze is frequently only injured superficially and does not lose strength. Unexpected results of this kind make it difficult to decide which is the most suitable aggregate to resist fire.

The stability of the structure during conflagration is also increased by connecting the reinforcement on the lower side of beams or floor slabs to that on the upper sides, as the latter are seldom injured by fire.

In buildings more than usually liable to conflagration, the walls, ceilings and floors should be covered with a fire-resisting plaster, as this, if injured, can be cheaply renewed; terra-cotta facings may be used with equal success though they are more costly. The terra-cotta must be suitable for the purpose, as if it is dense in texture it will fly to pieces when heated and will 
prove quite unreliable. Only porous terra-cotta should be employed, and the pieces should be of moderate thickness. Much of the " hollow tile" used in the United States has failed under fire because of its excessively thin web. The most serious disadvantage of terra-cotta for protecting steel work is the difference in expansibility of the two materials, whereby the steel not infrequently becomes exposed, particularly if, under the combined action of fire and a high wind, the terracotta cracks or falls away.

In considering the action of fire on concrete, that of the water applied to quench the fire must not be overlooked. This is frequently more severe than that of the fire itself, as the hot concrete, when suddenly quenched, is extremely liable to crack and spall.

The British Fire Prevention Committee has proposed the following standard requirement for floors intended to resist fire, and grants three groups of certificate according as the protection afforded by the material is " temporary," "partial," or " full."

Standard Classification for Floors.

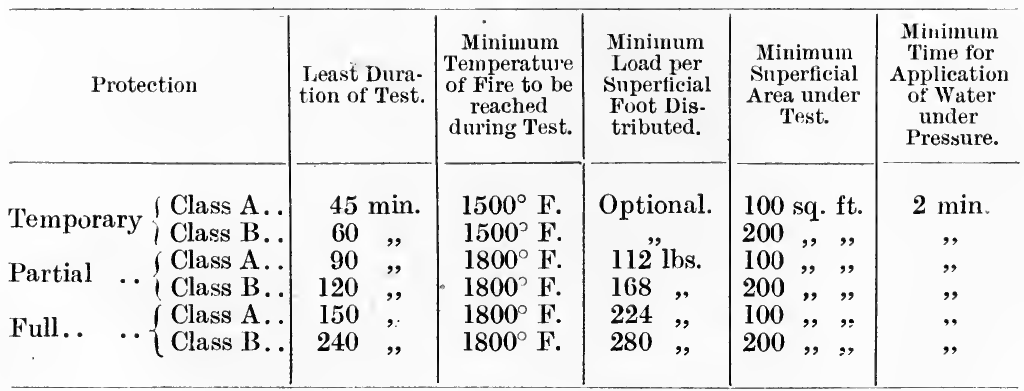

Closeness of surface texture is often an important factor in determining the heat-resistance of a concrete structure. Hence, eoncretes containing a larger proportion of cement will usually prove better than leaner ones, a concrete made from a wet mixture will prove more resistant than one made with less water, and a fine aggregate will prove better than a coarser one. In this connection it is important to note that concrete surfaces which have been treated with fluid water-glass mixed 
with three times its weight of water, the treatment being repeated after twenty-four hours, appear to have a much greater resistance to fire than the same concrete which has not been so treated, as the siliceous coating greatly reduces the rate of dehydration.

Sharp corners in concrete tend to be more seriously affected by fire than those which are rounded, as the sharp angles break or spall off more readily.

Resistance to fire is of minor importance in some buildings, whilst it is highly essential in others, so that different forms of concrete must be used to meet different requirements. This is the more necessary as a floor which affords full protection against fire may not be strong enough to meet the requirements of a warehouse in which the risk of damage by fire is trifling.

Professor C. L. Norton has found that a reinforced concrete beam $6 \times 6 \times 48$ inches, when heated for an hour in a fire which was hot enough to fuse the surface, broke under a compression load of 2,750 lbs. A similar beam, similarly heated for two hours, broke under a load of 1,950 lbs., and a third beam which was not heated at all broke under a load of $5,700 \mathrm{lbs}$. He also found that larger beams are weakened in a lesser proportion. Other experiments confirm the above, and show that concrete still possesses a notable degree of strength even after four hours continuous exposure to a temperature of about $1,600^{\circ} \mathrm{C}$.

The fact should never be overlooked that no building is absolutely fire-proof, and the use of such a term is liable to lead to unnecessary carelessness. The best that can be done is to make a structure as fire-resisting as possible, and to arrange a system of alarms so that the fire brigade can be on the spot before a serious conflagration is produced.

Resistance to Shocks.-Next in importance to resistance to fire comes the ability of a concrete structure to withstand repeated shocks. Such shocks need not necessarily be severe, for comparatively small ones of great frequency will destroy some structures. Earthquake tremors of moderate dimensions are usually resisted by large monolithic buildings, and in countries liable to this form of disturbance reifnorced concrete is particularly valuable. Most of the shock-resisting structures 
are, however, erected to withstand the vibration of traffic over a bridge or of machinery in a factory.

The ability of reinforced concrete to resist repeated and powerful shocks is shown in the thousands of concrete piles which have been successfully driven into moderately hard strata. In such cases the weight of the pile driven is usually between two and three tons, and the blows are repeated so frequently as to keep the pile always moving.

The ability of concrete structures to resist such shocks depends primarily on the adhesion between the concrete and the steel reinforcement, and on the suitability of the design of the reinforcing members. Apart from these no special precautions are necessary. The extensive use of piles made of reinforced concrete is conclusive evidence of the ability of this material to resist shocks.

Permeability-frequently, but quite erroneously spoken of as "porosity" - is the power possessed by a substance to allow water or other fluid to penetrate through it. Porosity consists in the possession of pores or voids, and on immersing a porous substance in water the pores will become more or less filled and a corresponding quantity of water absorbed. This is, however, an entirely different property from the permeability of a material, such as a roofing tile or slab of concrete in which water dropped on one side will gradually percolate through the material and appear in the form of drops on the other side. Permeability appears to have no definite relationship to porosity, and some concretes of low porosity are far more permeable than others. The amount of permeability depends, in fact, on the number and area of the passages through the material, and not on the total volume of pores.

Most concrete is slightly porous, but if its constituents have been well graded and proportioned, concrete should be practically impermeable.

Permeability is a serious defect in concrete intended for water tanks, reservoir and marine embankments, etc. Hence, for such purposes it is necessary to take special care in grading and proportioning the aggregate, sand, cement and water, and for some purposes other materials are added to make the material waterproof. The methods for doing this 
and the principles which underlie them are described on pp. $197-205$.

Resistance to Corrosion.-It is one of the curious properties of steel that when embedded in concrete it does not rust. Indeed, a thin coating of rust which may exist when the steel is embedded will be found, after a time, to have disappeared completely. This is generally explained as being due to the iron oxide comprising the rust combining with the lime set free during the setting of the cement and forming a hydrated calcium ferrite which acts as a protecting agent.

The following instances investigated by R. G. Clark show in a striking manner the highly protective action of concrete.

On the river Thames a reinforced concrete pile had to be withdrawn as the result of a very severe collision. The pile had been driven about three years to a very hard set, as it carried a heavy load. After being pulled up, the pile was laid on the bank for inspection. At various places along the length of the pile the concrete was cut away and the steel exposed. In each case the steel had not the slightest signs of rust. On a pier further down the same river a reinforced concrete tiebeam, that had been in position about eighteen months, had to be cut away to make provision for a diagonal brace. The tie-beam was midway between high and low water mark, so that it had a severe test, being alternately wet and dry. On examination the steelwork was found as good as when put in, and the original rust had disappeared. It might easily be imagined in what condition the steel would have been if it had not been protected by the concrete. Again, at Southampton in 1898, several pile heads were cut off and thrown on the foreshore, so that they were alternately exposed to the air and covered by the tide. They were examined some seven years after by several well-known engineers, who found that the exposed steelwork had greatly rusted and deteriorated, whereas by chipping away the concrete the bars which were embedded in the concrete were found to be as free from rust as on the day when they were first used.

The resistance of concrete itself to the corrosive action of acids is quite a different matter. Most acids-both mineral 
and organic-decompose Portland cement and therefore bring about the destruction of any concrete to which they may be exposed. Such corrosion is particularly noticeable in drain and sewerage pipes, especially where the sewage is obtained from chemical and other factories. Sometimes the acid does not occur in the original fluid, but is produced by the oxidation of sulphur compounds, etc.

Coating the concrete with tar or other acid-proof material is the only method of preventing corrosion by acid, though the impregnation of the concrete with some fatty or oleaginous substance is sometimes of assistance. The only really satisfactory "remedy" consists in facing the concrete with an entirely acid-proof material, or in replacing it by acid-proof ware as salt-glazed pipes.

The occasional absorption of trifling quantities of very dilute acids is less serious, and is frequently neglected.

Fresh sewage is, ordinarily, alkaline and without action on concrete ; it is only when the waste acid liquors from factories and trade effluents are admitted that sewage becomes corrosive. Only two courses are then open : $(a)$ to neutralise the sewage before admitting it to the sewers, or $(b)$ to construct the sewers of a different material. Acid-proof paints, such as coal tar, are only of slight value, as they are soon worn away by the abrasive action of the flowing fluids.

Sewage which has been treated in bacteria beds, on the contrary, is very liable to develop acid sulphur compounds, which corrode the concrete, particularly at the mean waterlevel. This corrosion may usually be prevented by coating the pipes with a coal-tar preparation, but this must be frequently inspected and renewed as occasion requires.

The admission of hot water to sewerage appears to increase the production of sulphuretted hydrogen and sulphur dioxide, both of which have a marked deleterious effect on concrete.

Wine musts and some other liquids of an acid character appear to be without action on concrete, but Rohland has shown that beer attacks concrete to a serious extent.

Even fresh water containing an appreciable amount of carbon dioxide in solution will, in time, bring about the destruction of concrete. The carbon dioxide removes the lime from the 
concrete and so reduces its strength and increases its porosity at the same time.

Quite pure water will also, in time, remove an appreciable quantity of lime from concrete, but if the conerete is made fairly compact, and especially if its surface is water-proofed, the amount of lime removed may usually be neglected. In many cases the removal of the lime may be prevented by adding trass in place of part of the sand (pp. 159, 205).

Sea water appears to have a peculiarly destructive action on some kinds of concrete, and its behaviour is, therefore, of great importance to those engaged in the construction of harbours, docks, breakwaters and other maritime work.

The action of sea water is partly physical, and the impact force of the waves and the grinding action of sand, shingle and pebbles, are not infrequently of greater importance than the purely chemical corrosion. Against much of this purely physical action man is powerless; he can only reduce it by the use of hard aggregates and of dense, well-compacted concrete sufficiently rich in cement to resist for a reasonable number of years. That such remarkably resistant marine works can be constructed is, in fact, one of the wonders of modern engineering. Strength and density are the two chief properties on which modern engineers rely in constructing concrete which will withstand the physical action of the waves.

Experiments on a large scale in Germany and Copenhagen have shown that the succession of saturation, drying, freezing, etc., to which marine work is subjected by the changes in the water level due to the tides, also has a most important effect in causing the destruction of the masonry. The action of frost is particularly powerful, and the utter impossibility of protecting embankments and other marine works from its action makes this all the more serious. The general action of frost on concrete structures is described on p. 271.

A further factor which has not received the attention it deserves is the percolation of salt water into the interior of the concrete, and the crystallisation of the salt as the water evaporates. The effect of this crystallising in cement blocks, which are only immersed at long intervals, is similar to that of frost. 
The chemical action of sea water is due to that of a variety of substances, of which carbon, sulphur and magnesia compounds are usually considered to be the most important.

Sea water in the neighbourhood of land usually contains a notable amount of carbon dioxide, and this dissolves out a portion of the lime in the concrete, leaving the mass more open and accessible. Generally speaking, however, the corrosive action of sea water is confined to the material quite close to the surface of the concrete, as a re-deposition of some of the dissolved matter not infrequently occurs in the pores of the concrete. Excessive action in a compact concrete is also prevented by the slowness with which the water can enter the material.

The constituent of sea water, which is generally regarded as being the most detrimental to concrete, is magnesia in the form of magnesium sulphate, or chloride, as these salts decompose cement, forming calcium sulphate and chloride. The calcium sulphate may then form crystalline calcium aluminium sulphate with considerable increase in volume, and thereby tend to destroy the concrete. Hence, the effect of sea water is greatest when the concrete is porous, and is at a minimum when the concrete is impervious.

C. von Blaese has found that half the lime in a cement is removed as calcium chloride when the cement is treated with an excess of a 6 per cent. solution of magnesium chloride. So intense a reaction is disputed by Kallauner, though the latter agrees that all magnesium salts decompose cement, the chief reaction occurring between them and the calcium hydrate formed during the setting, colloidal magnesium hydroxide and a calcium salt being produced. In contradiction to von Blaese, Kallauner also observed that where the calcium salt is almost insoluble in water the volume of the cement was. altered and cracks formed; when soluble calcium salts are produced the volume of the cement is not affected, but its strength is greatly reduced.

In other words, it is not the small proportion of sulphate in the original cement which is important in submarine work, but the permeability of the concrete which permits the magnesium sulphate in the sea water to react with the cement. 
If this is the true explanation of the destructive action of sea water, the latter may be overcome by the use of an impervious concrete, prepared from a more finely-ground cement and a more carefully graded and proportioned concrete.

The precise reactions produced by magnesia compounds have not, however, been studied with great accuracy, and there is ample room for a further investigation of the subject. Moreover, the calcium sulphate in sea water appears to have a direct chemical action on cement, according to E. Candlot a calcium sulpho-aluminate being formed. Cements which contain little or no alumina (such as Teil hydraulic lime or grappier cement) appear to be less affected by calcium and magnesium sulphates, and the conclusion has been drawn that the action of these sulphates must be largely confined to the alumina in the cement. For this reason iron cements, which are free from alumina, are sometimes used for maritime work. W. and D. Asch, on the contrary, maintain that the action of sea water depends, to a larger extent than is generally supposed, on the constitution of the cement, and that highly aluminous cements are quite resistant to magnesium and calcium sulphates, providing that such cements possess the correct constitution. In accordance with the theory of these investigators ( $p$. 55) most Portland cements contain hydroxyl groups attached to the aluminum rings, these being combined with lime or other base, thus :-

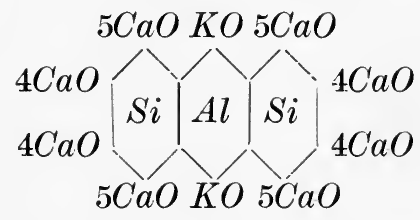

In such a compound the lime attached to the aluminium ring behaves differently from that attached to the silicon rings. Thus, on treating such a cement with water, part of the lime is hydrolysed and separated as calcium hydrate, thus $\mathrm{Ca}_{36} \mathrm{~K}_{2} \mathrm{Al}_{6} \mathrm{Si}_{12} \mathrm{O}_{70}+28 \mathrm{H}_{2} \mathrm{O}=\mathrm{Ca}_{16} \mathrm{H}_{1 \epsilon} \mathrm{K}_{2} \mathrm{Al}_{6} \mathrm{Si}_{12} \mathrm{O}_{58}+20 \mathrm{Ca}(\mathrm{OH})_{2}$. 
The compound formed is, according to Asch's theory, of the type

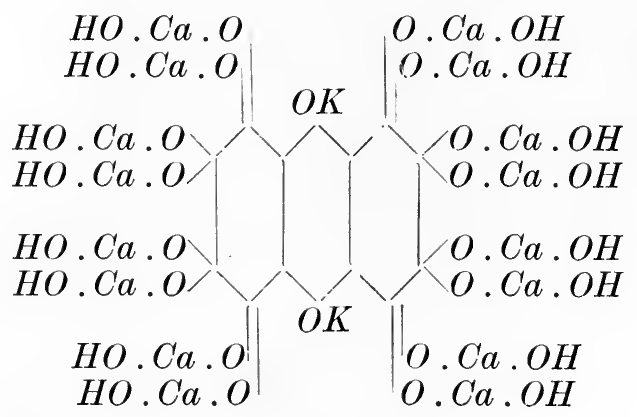

The two $O K$-groups attached to the aluminium ring have a strong tendency to react with groups of acid radicals, such as $-\mathrm{SO}_{2} \mathrm{OH},-\mathrm{SO} \cdot \mathrm{OH}$, etc., so that the destructive action of the sulphates in sea water is a necessary consequence of Asch's theory. From this it follows that if hydraulic cements can be prepared which cannot contain these two hydroxyl groups, they would be resistant to sulphates. Such cements would probably be of the following types:-

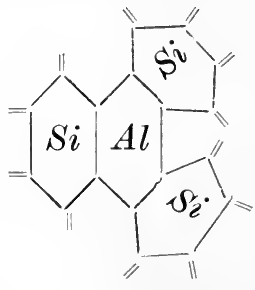

TYPE A.

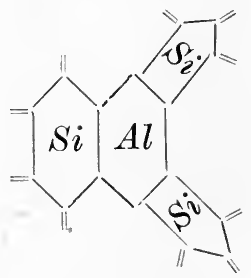

TYPE B.

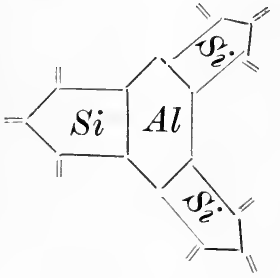

TyPe C.

(See p. 56) W. and D. Asch's conclusions are too new, as yet to be generally accepted. In this connection it is interesting to note that Schuljatschenko, J. A. van der Kloes and the author have each independently found that the replacement of some of the sand in the cement by trass improves concrete for maritime work.

The difficulty of ascertaining accurately the action of acid radicals (including sulphates, etc., in sea water) on cement is greatly increased by the relative impermeability of the concrete. 
This has the effect of reducing the apparent action of the solution, and has led to the conclusion that sea water per se has no action on concrete. Thus, the results of the large scale tests carried out by the Scandinavian Portland cement manufacturers are regarded as showing that, provided a good quality of Portland cement is used and that the mortar is rich ( 1 of cement to 2 of sand) and compact, the chemical action of sea water will be inappreciable in ten years. A loose mortar or one made with hydraulic lime, on the contrary, is soon disintegrated, except in unusually mild climates, such as the Mediterranean.

In order to withstand the severe physical conditions, concrete blocks for marine work should be allowed to harden in air for as long as possible before being immersed in the sea. The results of some important German tests show that a hardening period of a year is desirable. A still more recent report of experiments by R. L. Humphrey states that " while opinions differ as to its durability in fresh and sea water, concrete mixed and placed so that the resulting mass is of maximum density affords ample resistance to the action of both fresh and sea water, especially if allowed to harden before exposure."

The consensus of opinion on this point seems to be as follows :

(a) "Little, if any, damage is done to even the poorest concrete structure below water.

(b) "The principal destructive actions occur between tides, generally at the mean-tide line.

(c) "Where the concrete has disintegrated in sca water this is undoubtedly caused by freezing, for the reason that in tropical waters, where there is no freezing, the structures do not show this deterioration, excepting in cases where sea water has been used in the mixing and the concrete has been placed through sea water, thereby producing an inferior structure unsuited to resist sea water action.

(d) "While there may be some chemical action after the concrete is weakened through freezing, it is a fact that there is little or no chemical action on a properly proportioned, mixed, and placed concrete.

(e) "It seems to be a fact that it is desirable that the cement used in making concrete to be exposed to sea water shall 
contain sufficient hydraulic materials as will satisfy whatever excess lime there may be in the hardened cement. This is accomplished in many parts of Europe through the addition of trass or pozzolana to hydraulic cement. The trass combines with the lime set free from the cement, and so increases its strength and renders it stable in sea water.

"It is generally understood that the concrete must be rich in slow-setting cement and must not contain less cement than the proportions :-
(a) 2 cement, 1 trass, 6 (sand and aggregate) ;
(b) 2 cement, 3 (sand and aggregate).

$(f)$ " It is quite apparent that one of the prime essentials for a concrete structure that will be immune against sea water action is that the surface shall be dense and impervious. An attempt has been made to secure this condition by applying mortar under an air pressure of upwards of $30 \mathrm{lbs}$., and while this undoubtedly increases the density as compared to hand methods, nevertheless it remains to be seen whether it achieves the object desired.

(g) "Good practice demands that the concrete shall be mixed a sufficient length of time, without too much water, so that there results a mass of viscous consistency which will flow readily and yet the ingredients not separate. If such a concrete is deposited under conditions which will prevent the sea water permeating it before it has set, such concrete affords excellent resistance to sea water. Another method proposed has been to deposit the concrete in tremie, as with this form of construction only the upper surface comes in contact with the water, and there results a concrete which is not affected by sea water action. (See p. 192.)

(h) "When reinforced concrete is used in sea water it is essential that the aggregate shall be a hard, dense material of low absorption, and that the reinforcement be protected by a coating of at least one inch of trass-like mortar."

The corrosion of reinforced concrete is much more serious than that of plain mass concrete, as once the corrosive agent attacks the steel reinforcement the process of rusting will continue at an increased rate. As previously explained, 
steel and iron are ordinarily protected from rusting by a coating of concrete, but this does not apply to an exceptionally open and porous material such as is produced by corrosion on the concrete itself. It is also a fact that if concrete is mixed with sea water, or with sea sand, or if it has salt mixed with it, and it is subsequently exposed to dampness, the reinforcement will corrode. This was shown by examples on a rather extended scale some years ago when J. S. Sewell had two experimental slabs of reinforced concrete made of identical composition, except that one was mixed with sea water and one with fresh water. They were exposed to the weather on a roof in Washington, D.C., for some months. At the end of that time the reinforcement in the sea water slab was badly corroded, while that in the other was entirely untouched. It is of importance, therefore, that the ingredients used in mixing concrete for hydraulic works should contain no corrosive material in themselves if the concrete is to be reinforced.

The electrolytic corrosion of the steel reinforcement in concrete is a matter requiring serious attention. The external symptoms usually take the form of deep cracks in the concrete, usually on the under side of beams or vertically in columns and extending to the reinforcement. Wherever the steel is visible it will be found to be rusty. Sometimes the damage is so great that larger flakes of concrete fall away, exposing the reinforcement. Leakage from electric lighting or tramway circuits is the usual cause. H. P. Brown has found that rubber covered wires in japanned steel conduits are not satisfactory in preventing leakage. He also recommends that the intermediate wire in three-wire systems and the secondary circuit of a transformer should not be earthed within a concrete building. All the reinforcing steel in a structure should be in electrical connection by means of binding wire. Gas, water and steam pipes should be electrically insulated where they pass through concrete walls, etc. In new buildings of steel or reinforced concrete the foundation steel should rest on good concrete.

Providing, however, that the concrete is sufficiently compact and that acids and other corrosive agents are kept away from it, there is no likelihood of ordinary, well-made concrete 
being sufficiently porous to permit the steel reinforcement to become rusty.

Frost.-The resistance of hardened concrete to frost depends largely on the density or compactness of the concrete. If the material is so impervious that no appreciable amount of water can penetrate it, the action of frost will be infinitesimal. If, on the contrary, the permeability of the concrete is great, water will penetrate easily and, on freezing, will expand and so break up the bond between the particles forming the concrete. Each repetition of the frost increases the effect until finally, if the frosts are sufficiently numerous and severe, the concrete will be completely disintegrated.

As well-made concrete is : not particularly permeable, the action of frost is unimportant except where the concrete is used in harbours, piers, etc., and in other exceptionally exposed positions. What is required is a well-proportioned mixture to which a liberal, though not excessive, amount of. water has been added, the concrete being carefully tamped and protected from anything which will wash out any ingredients before the cement is properly hardened. Such a mixture, especially if it contains trass, has been found in innumerable instances to fulfil all requirements respecting resistance to frost.

The durability of concrete has long been established beyond all doubt, for in spite of the fact that early Roman and other buildings were made from materials obviously inferior to modern Portland cement, they still exist after 2,000 or more years of exposure. With the elaborate precautions now taken and the superior cement now available, it should not be difficult to ensure modern and equally durable structures being erected whenever they are considered necessary.

The fact that the strength of concrete is increased by age is a further proof of its durability. The rapid increase in strength is indicated by. the steepness of the curve in Fig. 92. In this diagram the area enclosed by the dotted lines includes the results of a large number of tests by Johnson, whilst the continuous curve indicates the average of these results. It will be observed that the strength is expressed as a ratio of tensile strength : compressive strength.

In the case of reinforced concrete, the durability is conditioned 
by the completeness with which the reinforcements is covered. If it is exposed it will soon effect the destruction of the whole edifice, but if properly embedded in sound concrete it will last indefinitely. The only danger that threatens it thereafter is the danger of cracks, which will destroy the integrity of the concrete and open up a way for atmospheric moisture or water to gain direct access to the reinforcement. Such cracks might be due to shrinkage in setting, to expansion and contraction under changes of temperature, or to deformation under stress. If the components of the concrete are well

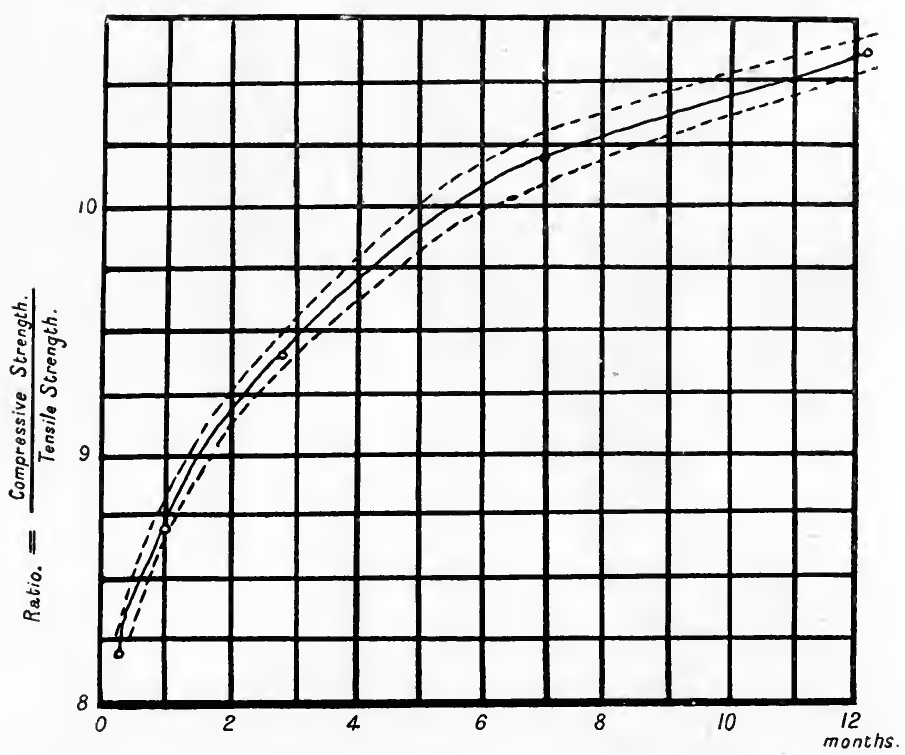

Fig. 92.-Ratio of Strength to Age. (Johnson.)

mixed in the right proportions and kept wet while setting there is small danger of shrinkage cracks, and they are rarely seen in practice. Light reinforcement is sometimes used with a view to preventing them, but it is not easy to see how it would be effective, for the shrinkage of the concrete would set up compressive stresses in the reinforcement, and it is not usually heavy enough to resist them effectively. The danger of such cracks is more imaginary than real, and an abundant supply of water during the mixing, and whilst the concrete 
is hardening together, with protection from evaporation during setting, will ensure a successful result. The reinforcement will generally be heavy enough to prevent shrinkage cracks, even in exceptional cases.

Cracks due to expansion and contraction after setting are brought about probably by a slight slipping of the mass on its bed during expansion, and by the excess of frictional resistance over the tensile strength of the conerete during the subsequent contraction. This trouble can be overcome by proper reinforcement, but it is better to divide a long wall or other structure into sections, so that each can act as a unit.

Cracks due to deformation under stress only oceur when the reinforcement is stressed so that the strain exceeds the limit of extensibility of the concrete. This can be avoided by proper design and workmanship. This danger makes it inadvisable to utilise the high working stresses, otherwise permissible in high carbon steel, since the modulus of elasticity is no greater than with low carbon or medium steel. If working stresses are kept well within the limits allowable for mild steel there. is no danger of cracks in the concrete.

With regard to the tendency to crack, on account of irregular settlement in the foundations, concrete has a great advantage over other materials, as the whole structure may be made monolithic, and so could take tension as well as compression. Any tendeney to cant sets up tension in some member, which in ordinary construction makes itself evident by cracks and fissures.

Efflorescence or "scum" on concrete is due to the presence of soluble salts in the aggregate: sand or water, and, much less frequently, in the cement. These soluble salts are carried to the surface of the concrete during the drying and are deposited there as the water evaporates. Occasionally, efflorescence in concrete is caused by water containing soluble salts, being drawn up from the foundations by capillary attraction.

The only means of preventing efflorescence consists in using materials as free as possible from soluble salts.

The discoloration of concrete is usually due to oil or to dirt on the forms, but in some cases it is caused by impurities in the aggregate, which rise to the surface and form stains. 
Failures in concrete structures have been both numerous and serious, so that a few words with reference to them may be included here. The causes of failures may be divided into two groups-unpreventable and preventable.

Failures from unavoidable causes include earthquakes, inundation, lightning, tempest, fire, explosions and exceptional shocks. As they are, by their nature, unavoidable nothing further need be said about them beyond the remark that concrete structures, if designed for the purpose, will withstand most of these forces as well as or better than any other building material.

Failures from preventable causes are almost invariably due to mistakes or carelessness in construction. If, for instance, the shuttering or forms are too weak, they may collapse and bring about the partial destruction of the building. Badly arranged pillars have been a frequent cause of collapse, and mistakes in the erection of the building have been even more serious. What, for instance, can be thought of the contractor who built a bridge of reinforced concrete and omitted to put the stirrups on the reinforcement? Other mistakes not infrequently observed-particularly when the work is under the charge of men who are not skilled in concrete construction - or the use of dirty water, unsuitable aggregate, unwashed or badly washed sand or low grade cement. If the concrete is placed improperly, and particularly when the adhesion between two successive layers is imperfect (p. 190), failures are almost sure to result.

Some of the common causes of failure in the making of concrete are as follows:-

(a) Too much water during mixing, or water carelessly applied, or an insufficient quantity of water.

(b) An insufficiently graded aggregate, particularly one containing only very coarse material, or one with too much sand or loam.

(c) Incomplete incorporation of the aggregate with the cement.

(d) Allowing the concrete to stand until the setting action has commenced and then regauging before use, or using up old concrete. 
(e) Bad cement. A branded British cement is usually reliable, but it must not be too quick setting or lumpy or caked.

(f) Unsuitable aggregates. It is particularly necessary to avoid using any aggregate that may be handy. The best for the purpose should be chosen. It is also unwise to accept aggregates on the basis of small samples. Natural aggregates are risky on account of the variations in the proportion of sand they contain, and should be screened before use (p. 156).

(g) Rendering cement work on dry foundations and without thoroughly saturating the surface with water.

(h) Dirty aggregate or water containing earthy matter, clay, loam, or strongly coloured water.

(i) Carelessness in proportioning mixtures.

(j) Excessive ramming or tamping.

(k) Weak centering, sparse timbering and badly arranged forms.

(l) Premature removal of forms.

$(m)$ Excessive trowelling or floating of cement surfaces.

(n) Erroneous design or arrangement of the reinforcement.

Failures due to overlooking springs or subsoil water, to errors in calculating the strength and arrangement of the various portions of the structure, or to making insufficient allowance for the face of the sea or wind, are by no means unknown, and the danger of failure by electric currents has already been mentioned (p. 270).

Ignorance and hurry are, in fact, the two great causes of concrete failures. There is frequently an undue stress put upon the contractors or on the workman to use as little shuttering timber as possible, and to remove the forms too soon. It must be remembered that concrete does not gain its total strength immediately, but requires several days before it is strong enough to enable the supports to be removed with safety. Shortage of timber and undue haste in construction are therefore extremely serious, especially if the responsible persons are not too well informed as to the properties of concrete.

It is a noteworthy fact that practically no "mysterious" failures have ever occurred in concrete structures long after they have been completed, so that it may be assumed that in 
almost every case the failure has been due to some error in construction. The carelessness and ignorance of some contractors who undertake eoncrete work, and the indifference they show with regard to inspection during construction, make it essential that all concrete work should be placed in the hands of skilled and trustworthy men. This is confirmed by the fact that all localities in which a good code of regulations is enforced have proved free from great disasters of a preventable nature.

The conclusion seems justified that the objections which have been urged against the use of concrete as a structural material are either imaginary or can be overcome by practicable methods, especially as many of them arose when the subject was not so well understood as at present. That this conclusion is justified is abundantly proved by the increasing and successful use of the material in permanent structures of the most varied kinds in all parts of the world. That concrete is not suitable for every kind of imaginable purpose is not surprising, but its uses are so multifarious that there is no need to attempt to employ it for purposes or in situations for which it is not eminently suitable. 


\section{CHAPTER X}

\section{TESTING CONCRETE}

The greater part of the testing applied to concrete is in relation to the raw materials of which it is made.

Cement.-The tests generally used for Portland cement have been described in Chapter $\mathrm{V}$.

Aggregates.-These are seldom subjected to special tests, though it is very desirable that they should be tested in a manner similar to cement. The proportion of aggregate of various grades or sizes is usually specified by the engineer or architect in charge of the work, and precautions should be taken to ensure these proportions being maintained.

The limits of size of particles in the various grades of aggregate should also be checked, as otherwise very inferior concrete may be produced. It is particularly desirable that all sand should be removed from the coarser grades of aggregate.

The specification of a minimum crushing strength for the aggregate is seldom made, it being generally assumed that if the finished concrete stands the necessary tests, the materials of which it is composed must be ipse facto satisfactory. The usual limitations are stated on p. 154, but far too little attention is paid to the correct grading of the aggregates.

Sand.-The sand must be tested to ensure its freedom from clay and dust, it being now recognised that all material which will pass through an aperture $\frac{1}{50}$ inch by $\frac{1}{50}$ inch should be rejected as harmful. Dust and extremely fine sand greatly reduce the strength of any concrete in which they may be present.

Steel.-The tests imposed on the steel used for reinforced concrete have been mentioned on p. 211 . It is necessary to check the sizes carefully, as any reduction in the cross-section 
may be very serious. Every piece of steel used should also be carefully examined for flaws and irregularities. Steel which shows a granular fracture should be avoided.

The crushing strength of concrete is the chief test imposed. The test pieces are cubes with either 3-inch, 4-inch or 6-inch sides, smaller ones being unreliable. The test pieces are made on the works at the same time as the various batches of concrete are made. The test-cubes should be kept slightly damped

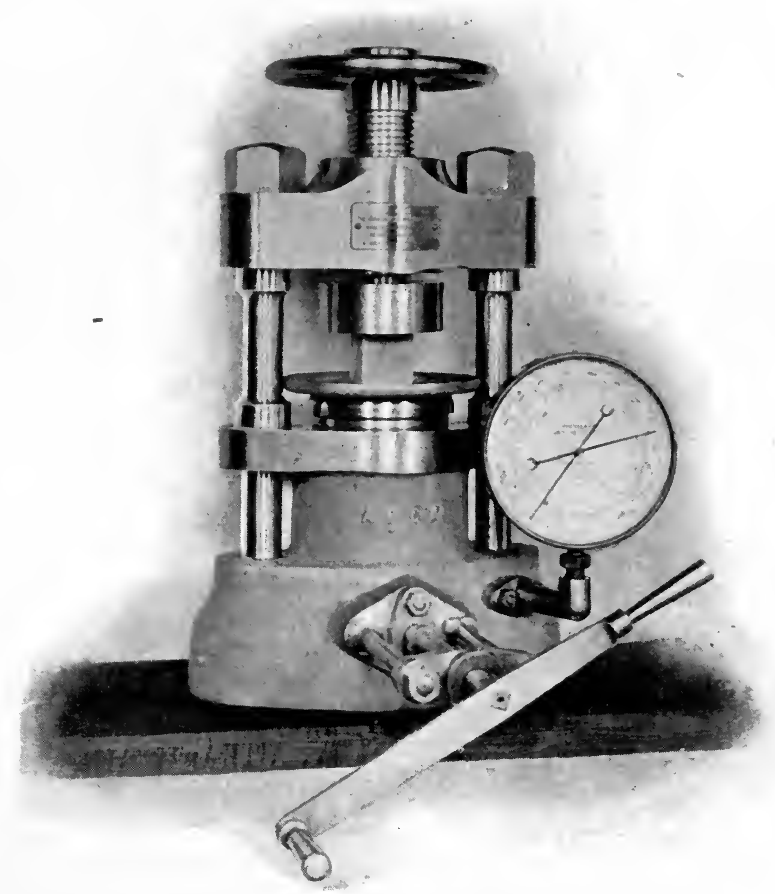

Fig. 93.-Machine for Crushing Tests.

for seven days. For tests to be made after longer periods, the cubes should be kept under cover so as to protect them from dust, rain and direct sunlight.

Care is needed to keep the amount of tamping as similar as possible to that employed on the larger masses of concrete.

Sometimes blocks of concrete are cut from work actually 
under construction, but this very greatly increases the cost of the test on account of the difficulty of cutting the sample.

The Joint Committee under the auspices of the Royal Institute of British Architects has recommended that the cubes should be made "before the detailed designs for an important piece of work are prepared," and that the tests should be made twenty-eight days after moulding. At least six cubes should be used in each test. "In the case of concrete made in proportions of 1 cement, 2 sand, 4 hard stone, the strength should not be less than 1,800 lbs. per square inch." Such a concrete should develop a strength of at least $2,400 \mathrm{lbs}$. per square inch after ninety days.

Other authorities recommend tests to be made at the end of seven, twenty-eight, fifty-six, ninety and 365 days, and some at the end of two, three, four, or five years. Owing to the speed with which large concrete buildings are erected a sevendays' test is desirable, and though it is claimed that its results are unreliable, and that at least twenty-eight days should elapse before testing, there seems much probability of a short-time test being brought into regular use.

Tests on cubes or other small samples are seldom very reliable; tests on full-sized columns, beams or blocks are much more accurate and preferable, but they require such special and powerful machinery, as to necessitate the samples being sent to a testing station fitted for the purpose.

In testing columns of reinforced concrete for crushing strength it will usually be found that they break at the end which was uppermost during manufacture, thus showing that the solidity of a concrete column diminishes towards the upper end. This is confirmed by tests of the specific gravity of the various parts of the columns, the upper end having a much lower density than the lower one.

In testing floors and slabs care must be taken to distribute the load uniformly. Bars of pig iron and building bricks both tend to form arches and cause an irregular distribution of the load.

Loading Tests.-In view of the general unsatisfactoriness of testing cubes of concrete, F. von Emperger proposed, in 1903, that they should be replaced by loading tests on specially 
prepared reinforced concrete beams. The Emperger test is intended to be carried out on the spot, the test beams being prepared from the materials there in use, and the testing apparatus being fitted up close at hand from parts which are packed in portable cases, which also contain bent steel rods as models to be copied by the workmen preparing the test beams. It is best to prepare four such beams for each test, two of which are reinforced with a single longitudinal rod (Type I.), and two with two parallel rods (Type II.). The

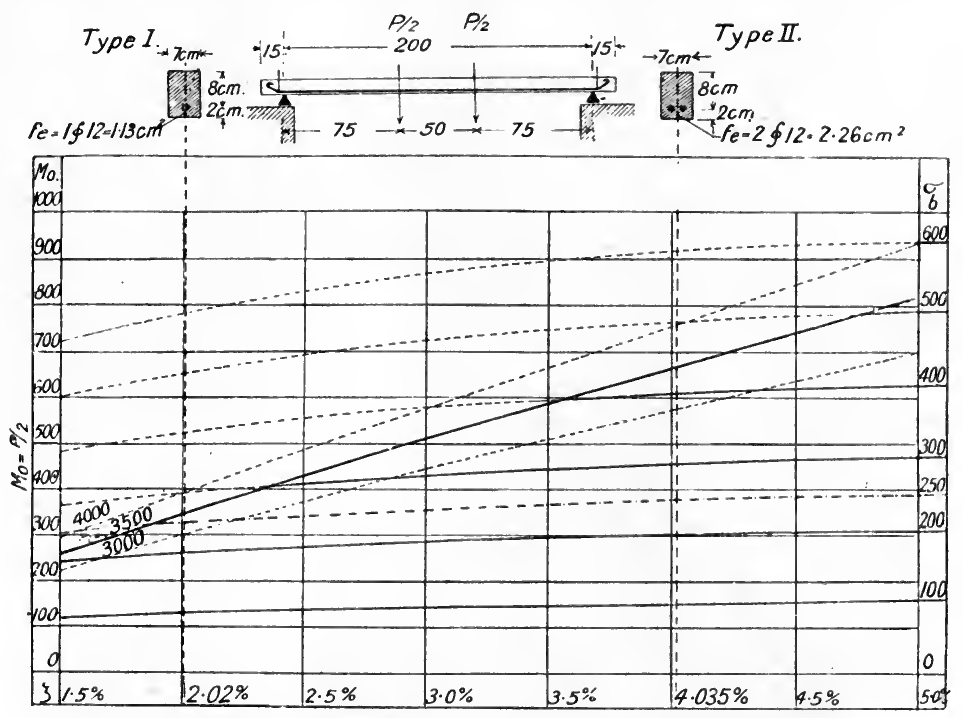

FIG. 94.-Chart for use with Fmperger's Test.

beams are $2 \cdot 30$ metres ( 6 feet 8 inches) long, $7 \mathrm{~cm}$. ( $22_{4}^{3}$ inches) broad, and $10 \mathrm{~cm}$. (4 inches) deep. The reinforcing rods are $12 \mathrm{~mm}$. ( $\left.\frac{1}{2} \mathrm{inch}\right)$ in diameter, and are bent up and turned over at the ends, as shown at the top of Fig. 94. The maximum stress obta nable in concrete by the use of this type of beam is considerably in excess of that ever attained in actual practice. The error due to accidental shifting of the reinforcing rods during the preparation of the beams does not exceed 2 per cent. of the stress. The beams are so chosen that the breaking moment $\left(M_{o}\right)$ is equal to half the breaking load, i.e., $M_{o}=\frac{P}{2}$. 
The moulds are double, made of wood, lined with sheet iron. They are oiled and fitted together by means of distance pieces; two loops to serve as handles are placed in position, and the sides are accurately adjusted by means of a gauge until the middle third has exactly the correct width. The reinforcing rods are then laid in position on the distance irons and handles. The conerete is introduced, and tamped in the same way as in the construction of a floor. The moulds may be removed in two or three days, after which eare is taken that the beams are exposed to the same conditions of temperature and weather
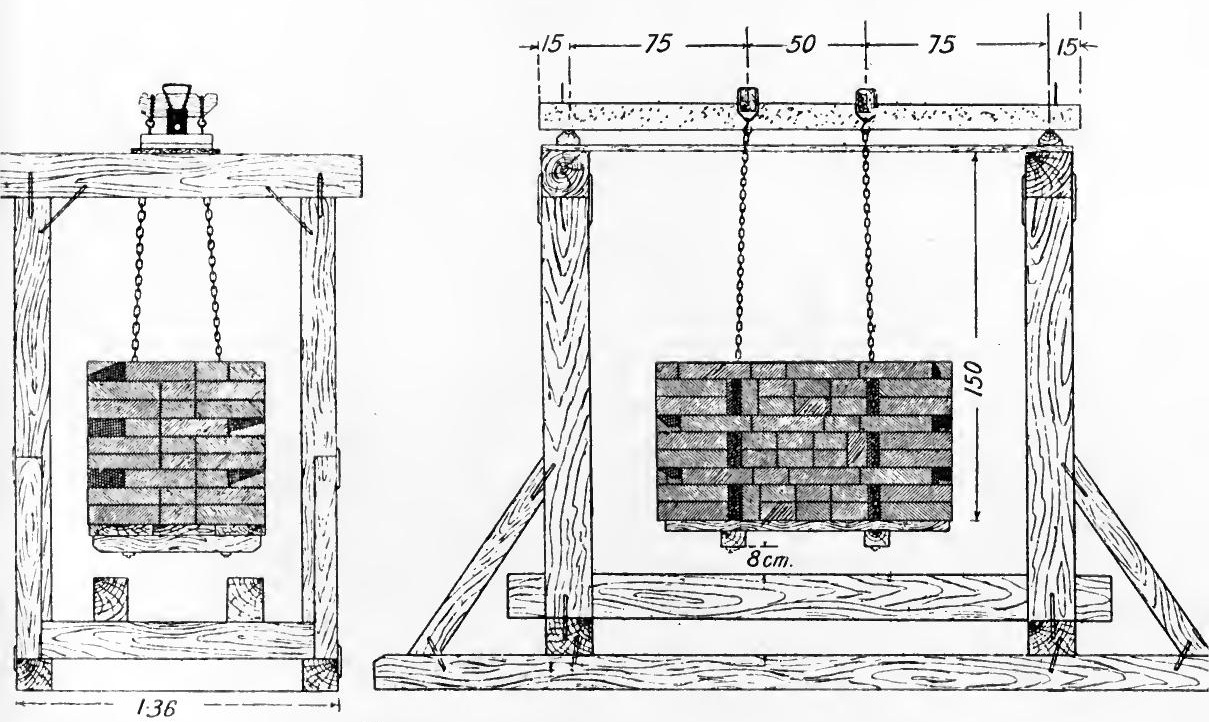

FIG. 95.-Emperger's Loading Test.

as the work to be controlled. If four beams are used, two are tested after three weeks, and two after six weeks, but for rapid tests intended to determine whether centering may be removed, a single beam is sufficient.

The framework used in making the loading test is shown in Fig. 95. The two hardwood knife edges, with iron edges, are placed exactly 2 metres apart, and the load is then hung from two wooden riders, placed as shown at a distance apart of $50 \mathrm{~cm}$. ( 1 foot 8 inches). The chains must allow the loading 
platform to swing freely, without allowing too great a fall when destruction occurs. It is advisable to place a board (not a thick plank) immediately under the beam to receive the broken halves and prevent complete collapse. A vertical scale may be attached to this board at the middle point to measure the deflection before fracture. The load is applied by means of bricks, which are added symmetrically, according to a definite scheme, by two workmen, and are counted until fracture occurs. The breaking load is then made up of the weights of the bricks and the loading apparatus, and twothirds of the weight of the beam. (When loading is applied at four points, corresponding with a test under distributed load, the whole weight of the beam must be included.)

Calling the breaking load $P$, the compressive stress $\left(\sigma_{B}\right)$ reached in the concrete is, for Type I. of reinforcement, $\sigma_{l}$, $0.384 P$, and for Type II., $\sigma_{B}=0.3285 P$. It remains to be determined, however, whether this stress was the cause of fracture-that is, whether the maximum compressive strength was utilised. This is most readily determined by inserting $M_{o}=\frac{P}{2}$ in the graphical diagram here shown. It will be seen from this that for the best qualities of concrete it is advisable to use Type II., with 4 per cent. of reinforcement.

In the diagram (Fig. 94), the percentage of reinforcement is plotted as abscissæ, and the values of the breaking moment, $M_{o}$, as ordinates. The strength of the steel is taken as its elastic limit (which is generally $3,500 \mathrm{kgs}$. per square centimetre or $49,700 \mathrm{lbs}$. per square inch); it is shown as a thick line on the diagram. If the value of $M_{o}=\frac{P}{2}$ falls below the steel curve, fracture is due to failure of the concrete, and the strength of this may be determined by the aid of the second group of curves ; if above, fracture is due to the steel, and it cannot be known whether the maximum strength of the concrete has been reached or not. Actually, failure of the steel is very rarely observed. In the neighbourhood of its elastic limit, the steel unloads itself at the expense of the concrete, and the resulting shifting of the neutral axis upwards, 
and increase of the compressive stress in the concrete, causes fracture of the concrete, really from a secondary cause.

A comparison of Dr. von Emperger's results with those obtained by Professor Mörseh and by Professor von Bach, shows that greater uniformity is found in the bending tests than in the compression tests with cubes.

The average variation in the results of the bending tests is about 7 per cent. to 8 per cent. of the mean value, these variations being attributable to differences of temperature, moistness of air, etc., and in some cases also to the fracture of the beam taking place at different parts. The corresponding compression tests with cubes exhibit far greater irregularities and may easily reach 25 per cent. It is important that the reinforcement should be accurately placed, as quite small errors in this respect cause a serious loss of strength. Excluding the most irregular values, the ratio of the breaking stress in bending tests to that in compression tests is from $1 \cdot 3$ to $1 \cdot 6: 1$.

The cheapness and simplicity of the test, as well as its trustworthiness, are sufficient reasons for its introduction as a means of systematic control of building operations and for the regular courses of instruction in several important colleges. It has been appreciated wherever used, by engineers, contractors and workmen alike.

Concrete structures, particularly floors, are frequently tested by the direct application of a load one-and-a-half times that which they have been designed to carry, the deflection being noted. The great disadvantage of this method of testing is that the structure may be strained and permanently injured. Hence, it is generally desirable only to apply the designed load. If no undue deflection then occurs, further loading can serve no useful purpose, and may prove a serious disadvantage.

The Joint Committee under the auspices of the Royal Institute of British Architects emphatically declare that no load tests on the structure itself should be made until at least two months after the laying of the concrete, and that even then the test load must not exceed one-and-a-half times the accidental load, nor two-thirds of the elastic limit of the steel reinforcement. 
Deflection.-The maximum amount of deflection permissible can be calculated from the bending moment, the elastic modulus, and the equivalent moment of inertia, but this calculation is beyond the scope of the present work.

Permanent deflection-which continues after the load has been removed-is usually a sign that the material has been overloaded, though in some instances it is caused by a "settling" of the material on the bedding or supports, and is then of minor significance. An extremely slight permanent deflection (not exceeding $\frac{1}{8}$ inch) is in most cases unavoidable.

Experiments made by Van Ornum in 1907 show that repeated applications of a load increase the permanent defiection, but do not alter the elastic deflection. The greater part of the permanent set occurs on the first application of the load, but each subsequent application increases it slightly. H. C. Berry and A. T. Goldbeck have confirmed this, and find that the ultimate strength, the maximum deflection, and the adhesion of the steel and concrete are not matcrially affected by one-and-three-quarter million repetitions of high, but safe loads.

Arguments and recommendations based on deflections are often erroneous unless made by thoroughly competent engineers, as the deflection varies according to the distribution of the load, the manner of supporting the test piece, and the relation of the size of the load to that of the test piece.

Tests of the permeability of concrete are made by measuring the amount of water which passes through a slab or disc of the concrete in a given time, under a predetermined pressure. The slab or disc is clamped on to the end of a pipe into which water is pumped under pressure. The water passing through the concrete is collected in a measuring glass. Unfortunately, such a method of testing is far from satisfactory, as it necessitates the use of thin slabs and cannot be applied to blocks of the same thickness as the concrete structure. It is also difficult to use aggregate of the same coarseness as that used on the larger scale.

More reliable results are obtained by mixing the concrete and placing it in a large iron tank made strong enough to resist the testing pressure, and tamping and finishing the surface 
exactly as though the iron tank were a "form." Water is supplied under pressure, and the water which passes through the concrete is collected. Testing with an excessive pressure is useless, as, if the pressure is sufficiently great, solution of the hydrated cement will occur, and all concretes will be found to be permeable. A pressure of $20 \mathrm{lbs}$. per square inch is the maximum ordinarily used.

The permeability of new concrete is not necessarily an indication of bad workmanship. Many tanks will exude a small quantity of water when first filled, but this "weeping" ceases after two or three months, on account of the re-deposition of some of the constituents previously dissolved by the water.

Where permeability is to be tested, apart from pressure, a method suggested by Le Chatelier may be used. The test piece is immersed in a solution of calcium sulphide, and after a suitable length of time it is taken out, wiped dry and broken. The iron compounds in the concrete will be converted into iron sulphide, recognisable as a black or dark green stain, wherever the solution has penetrated. Well-made concrete is quite impermeable when tested in this manner.

Tests for concrete to be used under sea water are peculiarly difficult and costly. It has been shown repeatedly that test pieces immersed in still sea water are useless. Moreover, the test pieces must be immersed for several years, as the changes occurring during the first twelve months are irregular, and conclusions drawn from them are illusory.

An exceedingly valuable record of numerous tests will be found in "Concrete and Constructional Engineering," Vols. IV., V., VI., VII. and VIII. (1909 to 1913). 


\section{BRICKS}

\section{CHAPTER XI \\ THE RAW MATERIALS FOR BRICKS}

BRICKs are ordinarily made of clay or shale, or of a mixture of these with sand. Hence, the raw materials used in brickmaking include all the clays possessing such a degree of plasticity as will enable them to be formed into bricks, which are, at the same time, sufficiently cheap to make the manufacture of bricks reasonably profitable. Bricks are also made of sand, as described in a later chapter, and these are known as "sand lime bricks."

Brick Clays.-No rigid scientific definition of brick clays can be formulated, as almost all clays can (technically) be made into bricks. Whether a particular clay can be commercially used for this purpose depends on a variety of other considerations, the chief of which is the saleable value of the clay for more remunerative purposes. Thus, a fireclay-valuable for its ability to resist high temperatures-may be used for the manufacture of building bricks in a district where the demand for the latter is proportionately greater than that for furnace bricks. Again, some clays-as London claymake excellent bricks when mixed with a suitable proportion of sand, but large quantities are rendered quite useless for this purpose by the absence of sand from the localities in which they occur, and by the selling price of bricks being too low to admit of the transportation of sand from other districts.

For the manufacture of bricks it is essential that the clay shall not contract unduly during drying, so that clays with a high degree of shrinkage are excluded from use as brickmaking materials unless a sufficient quantity of sand is available at a cost not exceeding that of the clay, so that from the two materials a mixture with the desired degree of shrinkage may be obtained. 
For brickmaking purposes, clays are classified according to certain of their physical characteristics, and not according to their chemical composition. Indeed, the latter is of very small significance, except in so far as it enables the physical properties of the clays to be predicted. The difficulties attending the interpretation of a chemical analysis of clay are, moreover, so extraordinarily great that it is often best for the brickmaker to discard it altogether and to rely upon physical tests.

The chemical composition of the clays used for brickmaking is, in fact, so complex that it is doubtful whether it is even approximately understood by some of the most eminent mineralogists and chemists at the present time. Some indication of the present state of knowledge on this subject is given on pp. 5, 40, et seq, but the large proportions of sand and other substances found in most brickmaking earths make it almost impossible to investigate, with accuracy, the real nature of the true clays they contain. Fortunately, for the building and allied trades, this lack of knowledge of the constitution of the clay molecule does not seriously affect the brickmaker, as he deals with the physical rather than the chemical properties of clays.

For the production of good bricks, a clay must, when burned, possess a suitable colour, hardness and porosity; it must be accurate in shape, free from warping, and of sufficient strength to carry any loads likely to be placed upon it. In addition to this it must be sufficiently refractory to withstand the action of any heat to which it may be subjected. In order to produce good bricks, clays must, therefore, be of such a nature when raw that they can possess these properties when burned.

The colour of a raw clay is of little or no importance to the brickmaker and need not be described further. The colour of the burned clay, on the contrary, is often of the greatest importance, especially where réd bricks are required for use on residential property or blue bricks are needed for engineering works. Not a few clays are excellent so far as the technical manufacture of bricks is concerned, but the bricks produced from them have so unpleasant a colour that the clays themselves 
are practically valueless. In some instanees such elays may be purified or otherwise treated so as to remove the discolouring materials, but in other cases this treatment may prove so expensive as to be impractical.

So important is the colour of the burned clays, i.e., of the bricks and other goods produced from them, that it is convenient to elassify clays according to the colour of the finished goods.

Red-burning clays are those from which most of the building bricks used in the Midlands and the North of England and the facing bricks of the South are produced. When free from discolouring substances, the bricks made from these elays are of a uniform "terra-cotta" colour, but unless made from carefully selected materials and prepared and burned with the greatest care, some irregularity in colour is sure to occur.

The red colour is usually attributed to ferric oxide (red oxide of iron) distributed throughout the material in the form of so fine a powder that no artificially prepared ferric oxide can be used to replace it or to convert another class of clay into a really satisfactory red-burning one. The amount of ferric oxide which must be present in a clay in order to produce a good, red brick depends more on the fineness of the oxide than on the actual proportion present-a very small quantity of an extremely fine powder exereising a far greater colouring effect than a much larger proportion of a coarser powder. Clays which show less than 5 to 6 per cent. of ferric oxide on analysis seldom produce bricks of a pleasing red colour, though as little as 3 per cent. will sometimes produce a good red brick.

There is good reason to suppose that no ferric oxide oceurs as such in the raw elay, but that the iron is present in the form of an almost colourless hydro-ferrosilicate or ferrosilicic acid, such as nontronite $\left(\mathrm{Fe}_{2} \mathrm{O}_{3} 2 \mathrm{SiO}_{2} 2 \mathrm{H}_{2} \mathrm{O}\right)$ which, on heating to dull redness, decomposes into free ferric oxide, silica and water. Limonite-a yellow hydrated oxide of iron-also occurs in many elays, and on heating to redness it also forms red ferric oxide.

C. F. Binns and others consider that the colour of red bricks and terra-cotta is due to colloidal iron oxide having been 
precipitated in the raw clay. They attribute the formation of this colloidal matter to the oxidation of pyrites with ferrous sulphate, the latter, being soluble, permeating the clay and, on further oxidation, precipitating oxide of iron. Alternatively, any ferrous carbonate present in the clay may be dissolved by water containing free carbonic acid, and afterwards oxidised to ferric hydrate or oxide. Ferrous carbonate (siderite) when mixed with clay does not produce a good red brick.

It must be clearly understood that the red colour is due to the action of heat on the clays, as some clays which are red, when first dug, do not make good red bricks, but usually produce unpleasantly discoloured ones.

Purple bricks are produced by the reducing action of some substance on the iron compound, whereby a bluish ferrous silicate is produced. The most usual reagent for this purpose is carbon, which may occur naturally in the clay or may be introduced in the form of coal dust, cinder dust ("soil "), or sawdust. The addition to the clay of one-fiftieth of its weight of manganese dioxide, or a rather larger proportion of "Weldon mud," will also produce a purple colour in bricks made of red-burning clay.

Blue bricks are more grey than blue in colour. Like the purple bricks just mentioned, the colour is produced by the reduction of the iron in a red-burning clay to ferrous silicate, on account of the presence of some form of carbon in the clay or of a strongly reducing atmosphere in the kiln. The clays used for blue bricks must be specially suitable for the purpose, and must contain a sufficiently large proportion of iron (corresponding to at least 5 per cent. of ferric oxide) together with sufficient lime and alkalies to form a brick which vitrifies easily without losing its shape in the kiln. The so-called marls of Staffordshire are specially useful for the production of blue, bricks, and with them the blue colour is produced wholly in the firing of the kiln. Some other clays of an entirely different composition and origin may be converted into blue bricks by special methods, such as injecting heavy oil into the kiln just before finishing the firing, or by adopting other means of producing a strongly reducing atmosphere.

c. 
Yellow bricks are produced by the action of heat on clays containing only a small proportion of iron. The intensity of the colour is sometimes increased by mixing the clay with cinder dust or other combustible material containing sulphur. Some yellow bricks are made from clays containing a sufficient proportion of iron to burn red were it not for the simultaneous presence of chalk in the clay (see "White Bricks"). The malm bricks, which are considered in the London district to be the best building bricks, owe this yellow colour to their production from a mixture of red-burning clay, chalk and cinder dust (" soil "), the bricks being burned in contact with the fuel in a clamp. "London stocks" are prepared in the same manner, but are regarded as slightly inferior in quality to malm bricks ; it is, however, not unusual to include both malms and stocks under the term "stocks."

Buff bricks are made by heating clays, containing only a small proportion of iron, in kilns and out of direct contact with fuel. The proportion of iron (expressed as ferric oxide) must usually be less than 3 per cent., though a somewhat larger quantity may be present if it is in the form of iron pyrites $\left(\mathrm{FeS}_{2}\right)$ which forms black spots and not a red colouration. The lower grade fire-clays and certain vitrifiable clays found in the neighbourhood of Little Bytham are the best known buff-burning clays.

The cause of the buff colour has not been ascertained. That it is not due merely to the presence of a small quantity of iron compounds may be proved by mixing a red-burning and a white-burning clay together. The bricks made of such a mixture are not buff-coloured, but pale red. There is reason to suppose that alumina plays an important part in the formation of the buff colour, but the nature of its action is still unknown. The observation of Seger, that all buff clays contain a large proportion of alumina and a small proportion of iron, has been confirmed repeatedly, and quite recently Binns and Makeley have produced good buff-burning test pieces by the addition of alumina to red-burning clays.

White-burning clays are of two classes: (a) those which are so free from iron compounds that they are naturally white when drawn from the kilns, and $(b)$ clays containing iron 
compounds together with a-sufficient proportion of chalk to prevent the development of the red colour. The first class are typified by the clays used for domestic pottery and china ware, which are too valuable to be used for brickmaking, and the second class by the white Suffolk bricks and the bricks made from the alluvial clays in the centre of Ireland and elsewhere.

Clays in which the correct proportions of chalk and iron occur naturally are found in various parts of the country, but many white bricks are made by adding a sufficient quantity of chalk to a red-burning clay. If such an artificial mixture is examined during the burning it will be found to develop a pale red colour at a very low temperature, this colour disappearing at about $850^{\circ} \mathrm{C}$. heat on account of the interaction between the iron compound and the chalk.

The amount of chalk required depends upon the colouring power of the iron compounds in the clay. Usually 10 per cent. of the weight of the clay is ample, and for bricks intended to withstand the action of the weather more than 12 per cent. of chalk can seldom be used ; for inside work, on the contrary, as much as 25 per cent. of chalk may be present in a clay.

White bricks are usually made in localities where the clays naturally contain chalk, so that the proportion of added chalk is usually small. The proportion required must usually be ascertained by making bricks with different proportions of clay and chalk, and observing which are the best when drawn from the kiln. An excess of chalk will weaken the brick and will prevent its being durable, whilst if too little chalk is added the clay will burn to a pale red or " salmon." colour, according to the proportion of free iron oxide present.

Grey bricks are popular in some parts of Lancashire, where they are considered superior to red bricks. As a matter of fact, these grey bricks are merely red bricks which have been badly scummed by improper treatment during the earlier stages of heating in the kiln. This scum is purely superficial and has nothing whatever to do with the strength or other engineering qualities of the bricks, nor does it indicate that the bricks have been well burned. Indeed, the preference of some architects and engineers for these scummed bricks is all the 
more curious in that it is based on an entirely false conception of the cause of the scum.

In other parts of the country grey bricks are produced by firing red-burning clays under reducing conditions (see "Blue Bricks").

The texture of a clay is frequently an important indication of its nature, though this cannot be relied upon entirely.

In respect of texture, clays are classified as $(a)$ shales, (b) marls, (c) loams, $(d)$ boulder clays, and (e) plastic clays, whilst a number of clays which are not comprised in this classification, but are not used in brickmaking, bear special names.

Clay shales are clays which have been subjected to enormous pressure since their deposition, with the result that they have become hard or indurated until they resemble a soft stone. Some shales owe their hardness to the interpenetration of a cementitious solution of a siliceous nature.

It is important to remember that the term "shale" relates solely to the texture and not to the composition of the material. There are, in fact, many shales which are almost devoid of clay, and consist entirely of siliceous matter.

Shales are characterised by the manner in which they are split up into layers when tapped at right angles to the line of their deposition.

The clay shales are extensively used for the manufacture of bricks by mechanical methods, particularly in the North, the Midlands and in South Wales. When observed in situ, or when first dug, these shales do not appear to possess the characteristic properties of clay, but when ground and mixed with water their indurated texture is destroyed and their original argillaceous characters are restored. When properly selected and suitably treated, clay shales make first-class bricks and terra-cotta, and, like most marine-deposited clays, their colour when burned is particularly rich and uniform.

Marls or malms are natural mixtures of clay and chalk, and may usually be recognised by their friable nature, their texture being quite different from that of other clays.

The term "marl" is sometimes used for any material of a friable nature, with a texture resembling the true marls, 
but such an extension of the term is very confusing and should be avoided. All the true marls contain a considerable proportion of chalk, and therefore effervesce violently when a few drops of hydrochloric acid are allowed to fall on them. The so-called marls of the Midlands and some parts of Wales, on the contrary, are almost free from chalk and are harder than the true marls. They are used for blue bricks.

True marls are largely used for white and yellow (stock) bricks, their composition and colour when burned being modified, where necessary, by the addition of a further proportion of chalk. Clays to which an addition of chalk has been made are frequently termed artificial malms.

As it is necessary that no coarse grains of chalk should be mixed with the clay, the material must be treated in a washmill in order to remove all the larger particles. Unless this is done, the larger particles of chalk are liable to split the bricks (see "Boulder Clays").

The true marls chiefly occur in the neighbourhood of the chalk deposits in the south eastern counties, but the red marls -which, as already explained, do not contain chalk-occur chiefly in the Midlands, in North-east Yorkshire and in Wales. The Midland marls belong to the Triassic clays, and are famous for the excellent terra-cotta colour of the wares produced from them. Ruabon terra-cotta and Leicester red bricks and tiles are typical products of the Midland red marls.

Further particulars respecting marls will be found in the author's "British Clays, Shales and Sands" (Charles Griffin and Co., Ltd., London).

Loams are essentially mixtures of sand and clay, and if stirred up with water and allowed to settle for a few minutes leave a residue readily recognised as sand. The term loam is, however, applied in a larger sense to any earth which is not distinctly a sand or clay, but appears to partake of the character of both. Thus, the red marls of the Midlands (supra) are loamy in character, whilst not possessing the peculiar texture of a true loam, and consequently loams and marls are frequently confused. The distinction is clear when the composition of each is considered, and confusion is only the result of regarding the terms marl and loam as having reference 
exclusively to texture. Even then, there is a distinct difference in texture between a loam and a marl, though this is often overlooked.

Loams or sandy clays are of great value for brickmaking, as they do not shrink unduly and yet have sufficient plasticity to be made into bricks and other simple shapes. Where the proportion of clay in a loam is less than one-quarter of the total material the loam is seldom suitable for brickmaking, unless it is mixed with a plastic clay. Consequently, sandy loams are of minor value to brickmakers except as a diluent, though the addition of washed chalk will sometimes enable excellent bricks to be produced, the chalk acting as a binding agent.

Loams are frequently found in association with gravel; the latter must be removed before the loams can be satisfactorily used for brickmaking. Merely to crush the gravel to powder is not sufficient, unless the loam is rich in clay.

Boulder clays form a considerable part of the glacial drift deposited over the whole of the North and Midlands, and are a product of the Great Ice Age. The term "boulder clays" is sometimes erroneously used for the whole deposit; it ought really to be confined to the argillaceous portions, the term applied to the whole being drift, or more correctly, glacial drift. Boulder clays are characterised (as their name implies) by their association with boulders and smaller stones, many of these consisting of limestone brought by the ice over very great distances, and the occurrence of characteristic stones in or close to the clay affords ons of the readiest means of identifying it. It would be too sweeping an assertion to state that all stony clay is of glacial origin, but the statement is sufficiently truthful to cover the majority of cases where a plastic clay in Great Britain contains stones.

Boulder clays are usually lightly plastic and tough, if care be taken to select portions free from stone. Some of them shrink greatly in drying, and require to be mixed with sand in order to produce sound bricks. The presence in them of stones too small to be removed readily by hand picking is a serious disadvantage to the brickmaker desirous of using this material. He must either remove the stones and gravel completely, by 
washing the clay, or he must have the larger stones removed by hand or some simple mechanical means, and must then crush the gravel and smaller stones to so fine a powder that they can do no further harm. Unfortunately, both these methods add largely to the cost of brickmaking, and many firms using boulder clay and other stony clays endeavour to economise by crushing and mixing the whole of the material without subjecting it to any preliminary cleaning or freeing from stones. Where the proportion of stones is small and they are of a siliceous character, the number of bricks spoiled by a simple crushing of the raw material may be insignificant, but if limestone is present, so large a percentage of the bricks produced will be cracked, "blown " and spoiled, that the matter becomes exceedingly serious.

When a particle of limestone is subjected to the ordinary heat of a brick kiln it loses carbon dioxide and is converted into quicklime. If this particle of quicklime is situated at or near the surface of a brick it gradually absorbs water from the atmosphere, becomes hydrated and swells, thereby exerting so great a pressure that the surface of the brick may be cracked. If the lime is on the surface of the brick the hydrated product forms a loose white powder, and the brick is then said to be "blown." If the particles of lime are so far from the surface that they cannot crack or weaken the brick, little or no harm is done and, generally speaking, the action of all particles of lime at a greater depth than one inch from the surface may be ignored.

The only true remedy for these defects is the prevention of their occurrence by the removal of the limestone previous to the clay being made into bricks. Unfortunately, this is, in most cases, impossible, though much may be done by passing the material through a clay cleaner, which consists of a perforated drum through which the soft clay is forced, whilst the stones and gravel larger than the perforations remain behind. As the perforations cannot be made less than $\frac{1}{25}$ inch in diameter if a reasonable output is to be obtained, such an appliance does not remove the smallest particles of limestone ; but the proportion of those left in the clay which are able to destroy the bricks is so small as to make the use of such a clay-cleaner invaluable, 
An alternative means for preventing the effect of limestone on clay consists in grinding the material so fine that the particles will be distributed and so cannot cause the disintegration of the bricks. Such bricks are quite sound, but have an unpleasantly spotted appearance, due to the white particles of lime. If it is possible to burn the bricks at a temperature at which the lime will combine with the clay and form a slag, the spottiness will be removed and an even stronger brick will be produced. Unfortunately, most of the British boulder clays cannot be heated to a sufficiently high temperature without losing their shape.

Notwithstanding the defects caused by the stones and gravel associated with them, the boulder clays are very largely used for the manufacture of common bricks, whilst facing bricks are made in considerable quantities from selected portions of these clays. If care is taken in excavating a boulder clay, it will usually be found that the stones and gravel occur in seams and pockets, and that by careful oversight a clay may be obtained which is sufficiently free from stones and gravel to make excellent bricks.

Plastic clays are the most readily identified on account of their peculiar texture. They are usually composed of much finer particles than are marls and loams, and most of them leave an insignificant residue when mixed with water and rubbed on a No. 200 sieve. This is not due to any difference in the clay itself, but rather to the coarser nature of the chalk, sand and other ingredients of less plastic clays.

Plastic clays occur in almost every part of the United Kingdom, and most of them may be used for brickmaking, providing that the shrinkage is not too great. In some localities this may be reduced by the addition of crushed rock or sand or even of clay burned specially for the purpose, but where none of these materials can be used, highly plastic clays are of small value for brick and pottery manufacture.

The term "plastic" is somewhat indefinite, and no means has yet been found whereby plasticity can be adequately and satisfactorily represented numerically. Indeed, the term plasticity appears to be almost incapable of exact definition, its use by potters and other clayworkers being different from 
the meaning attached to it by artists, engineers, and others working with different materials. The study of plasticity is highly complex and technical, and as it has been dealt with exhaustively in the author's " British Clays, Shales and Sands," its discussion need not be detailed here.

Suffice it to say that a plastic clay is one which can be formed into any desired shape by means of the fingers or light tools, this shape being retained indefinitely and rendered permanent by heating the clay to a suitable temperature in a kiln. The plasticity is thus seen to be closely related to the complexity of shape of articles which can be made from a given clay. A highly plastic clay can be formed into the most complex curves and patterns, whilst a slightly plastic clay can only be made into simple forms, such as bricks and bars. Hence, clays are grouped according to their plasticity, the highly plastic clays being termed tough, strong or foul, and less plastic clays as lean, mild or weak. These terms are by no means exactly definable, but they serve to distinguish between many different clays, and to indicate their apparent nature.

The apparent plasticity of a clay depends largely on the condition in which the clay is found, and may vary from day to day, or even from hour to hour. Thus, a clay when found may appear to be lean and almost devoid of plasticity, yet if suitably moistened or mixed with a little water it will become as plastic as a highly plastic clay. It is therefore necessary, in describing the plasticity of a clay, to state the conditions under which the description is applicable, as otherwise the same clay, on one occasion, may be described as highly plastic and on another as of a mild nature-the state of the atmosphere making a great difference in the appearance of the material.

Many methods have been proposed for comparing the plasticity of clays, but none of them are entirely satisfactory, as this property is not of an elementary nature, but is closely associated with the binding power, viscosity, adhesion, cohesion, absorption, impermeability, and other properties of the particles. Attempts to measure plasticity will usually be found, on investigation, to consist, in reality, in the measurement of one of these other properties, and not in that of the plasticity itself. The result is that numbers supposed to 
represent plasticity obtained by different investigators differ widely from each other and, which is more important, lead to conclusions inconsistent with what is ordinarily understood as plasticity by practical clayworkers. Thus, the plasticity numbers of a certain chemist in London represent china clay as less plastic than ball clay, whereas all potters hold precisely the reverse opinion.

If, as appears probable, the plasticity of clay is due to a variety of minor properties, it can only be adequately measured by some means in which all these minor properties are included. Such a method would appear to be very complex, and almost impossible in its entirety. The plasticity of a clay may, however, be measured with an accuracy sufficient for most practical purposes, as follows :-

(a) A sample of clay is mixed with sufficient water to form a paste of good modelling consistency; that is to say, a paste which is sufficiently moist to be formed into any desired shape and yet not so moist as to adhere to the fingers. A weighed portion of this paste is then dried at $105^{\circ} \mathrm{C}$. and the proportion of water to dry clay is ascertained. A less accurate method consists in weighing the clay and measuring the water required to mike a paste of the desired consistency, but allowance must then be made for the proportion of moisture in the original clay. Clay which has been dried artificially must not be used for this test, unless the plasticity of such dried clay is to be determined instead of that of the raw clay.

(b) Some of the clay paste produced as just described, is placed in a small expression machine (a sausage mincer of the old-fashioned type being suitable), and in this way a cylinder of clay paste about three inches long and one inch diameter is formed. This cylinder is fitted with clamps at each end, and two marks exactly two inches apart are then made on it. Its tensile strength is determined by attaching one clamp to a support and applying a suitable weight to the other. The weight, which is exactly sufficient to rupture the cylinder, is noted, the two broken pieces of clay are then fitted together, and the percentage of extension in length is then measured.

The product of the percentage of water required in $(a)$, the percentage extension and the tensile strength expressed in 
kilogrammes per square centimetre is a figure which has been shown by Zschokke, Rasenow and others to agree with the relative plasticity of clays as far as this can be judged by practical potters.

This method is imperfect, inasmuch as it does not give sufficient prominence to the power of certain clays to retain their plasticity when mixed with sand or rock-dust, but it has proved in the author's experience to be the least objectionable of any method yet published, and its value may readily be increased by applying it to mixtures of any clay to be tested with sand or other non-plastic material.

In the production of bricks and tiles the plasticity of a clay is seldom developed to its fullest extent. Indeed, to do this would usually render the clay useless for these particular purposes, as the paste would shrink so much in drying and burning as to warp or crack. Where pottery or terra-cotta is being manufactured a higher degree of plasticity is usually necessary, and is obtained by a more thorough mixing with water and by storing the clay paste under conditions likely to increase its plasticity. This "souring" or "maturing" is a slow process, and some porcelain clay-mixtures require to be stored for several years before they are fit for use.

The causes of plasticity being imperfectly understood, it is clear that the best method of increasing the plasticity of lean clays is still not known with certainty. If, as appears probable, the plasticity of clays is due to the hydrolytic action of water on the clays themselves, it is probable that any increase in plasticity must be effected by increasing this action of water. If, as suggested by Rohland and others, plasticity is a characteristic of colloidal substances mixed with inert particles, it will be increased by any treatment which will increase the proportion of colloids, e.g., by storing in a moist condition in a cool place. An artificial or pseudo-plasticity may be conferred on clay by the addition of various vegetable colloids, such as starch paste, or of other colloids, such as glue, but the use of such materials is seldom practicable in brickmaking, as it is too costly.

The reduction of the plasticity of clays may be effected in several ways, of which the most important are : $(a)$ drying, 
(b) heating to redness, (c) mixing with sand or other inert material, and $(d)$ by the addition of a minute quantity of a suitable chemical. Of these methods, drying is only temporary, the clay again becoming plastic on further treatment with water. Heating to a temperature short of redness will reduce the plasticity of clay in proportion to the amount of water removed. If only the free water is driven off, the clay will again become plastic when moistened, but not if the clay molecule has been partially destroyed as only the complete molecules can become plastic. When a clay has been heated to redness it cannot again become plastic; its chemical constitution has been destroyed and it is no longer a "clay" (p. 40).

Clays which have had their plasticity reduced by mixing with sand may have it restored by any simple process of elutriation or washing which will remove the added material, but those which have been treated with chemicals behave differently. Thus, the addition of a few drops of baryta solution, or of a solution of caustic soda or potash, will convert a stiff plastic paste into a fluid slip or cream, but the addition of a quantity of acid just sufficient to neutralise the alkali previously added will re-convert the fluid slip into a stiff paste.

The effect of merely a few drops of acid and alkali may be shown in a striking manner in the following experiment, which is well worth making by everyone interested in clays :-

Solutions of hydrochloric acid and of caustic soda are prepared of such a strength that a given volume of one of them exactly neutralises an equal volume of the other. (The "normal" solutions sold by manufacturing chemists are suitable.) A stiff clay paste is made by mixing a little dry clay with water in a shallow cup or basin, and its stiffness noted. A few drops (accurately measured) of the alkaline solution are then added, and the mixing is continued until the mass becomes sufficiently fluid to pour into another vessel. When its fluidity has been clearly demonstrated, the same volume of the acid solution (a few drops) is added and the mixing still further continued, when it will be found that the clay again becomes stiff and pasty and cannot be poured from one vessel to another. Strictly speaking, the addition of acid or alkaline solutions only 
alters the viscosity of the clay, but this property is so closely allied to plasticity that anything which affects the one must have some influence-though not necessarily a proportionate one-on the other.

It has also been suggested that the power possessed by clays of adsorbing dyes from solution might be made a measure of plasticity, but experience has shown that adsorption and plasticity are not related closely enough for this purpose, though in many clays the relationship is remarkable.

At the present time there is no entirely satisfactory method of determining the plasticity of clays, the methods now in use being merely approximations, some of which are far from accurate, except when used to compare several clays of the same type.

The shrinkage of clay pastes is an important factor when classifying clays with regard to their suitability for brickmaking. If the volume of a piece of clay paste is accurately measured before and after drying, it will be found to have diminished roughly in proportion to the plasticity of the clay and to the amount of water present in the paste. If the test piece is then burned in a kiln and is re-measured when cold, a further reduction in volume will have occurred; this is known as kiln shrinkage.

The shrinkage on drying which clay pastes undergo is due to the removal of the water surrounding (and possibly penetrating) each particle, with the result that, as this water evaporates, the particles are brought nearer together, until finally they are as close as their shapes permit. As the particles are irregular in shape, complete contact over the whole of their surfaces is impossible; and some pore spaces or voids are bound to occur.

- Any colloidal material present in the clay will absorb water with which it comes into contact-just as dry glue swells when immersed in water and forms a bulky gelatinous mass. Hence, the volume of the individual particles of colloidal matter in the clay is increased when it is mixed with water and made into a paste. When the clay paste is dried, this water is removed and the colloidal particles shrink to their original (dry) volume. If it be true that the plasticity of clays is due 
to the proportion of active colloidal matter present, then the shrinkage they undergo on drying must bear some relation both to the colloidal matter and to their plasticity. Other causes of shrinkage-such as the surrounding of clay particles into a film or covering of water-are also present, and render it impossible to measure the influence of the colloidal matter, so that the plasticity and shrinkage are not directly proportional, yet, broadly, the more plastic the clay the greater will be the shrinkage of the clay paste and vice versa.

Excessive shrinkage of a clay paste involves so great a movement of the particles that it is almost impossible to dry some clays without cracking them. Even when no heat is used, the irregular rate at which various parts of the material dry is a prolific cause of cracks, and one of the most difficult and worrying problems of the clayworker consists in drying bricks and other articles at a reasonable speed without introducing internal strains and stresses which result in the fracture of the articles. The problem is still further complicated by the fact that it is often impossible to distinguish the cracked articles before they are fixed, so that it is only after the completion of the manufacture-when they are drawn out of the kilns-that the defective articles can be separated from the rest.

The shrinkage which would occur if the clay were taken direct from the pit and dried, is of small importance to the brick manufacturer, and though it is frequently reported in tests of clays it does not give the information required, except in those cases where the material is worked without the addition of any water. The clay or other material must first be made into a paste of the consistency it will have when moulded or otherwise shaped (see p. 332), and it should then be moulded into the form of a small brick or bar. The internal measurements of the mould will then give the size of the test-piece. After drying, until the whole of the free water is removed, the test-piece is again measured and the shrinkage calculated as (a) percentage of the original volume, $(b)$ percentage of the original length, or $(c)$ in inches per linear foot. All three units of shrinkage are in use, but the one most commonly employed in practice is the last, viz., the reduction in length 
which would be observed if a bar or block exactly one foot in length were made of the clay paste and then dried.

The volume shrinkage $(a)$ may be roughly calculated by multiplying the lineal shrinkage $(b$ or $c)$ by three, but this is not exact enough for accurate work.

It is generally found that clays with a shrinkage exceeding one-and-a-half inches per linear foot are unsuitable for brickmaking, unless their shrinkage can be reduced by the addition of a non-plastic material. The majority of brick manufacturers prefer a clay with a shrinkage of one inch per linear foot. Smaller shrinkage usually indicates that the plasticity of the clay is insufficiently developed or that too much sand or other inert material is present, with the result that the bricks will probably be soft and too easily crushed to be used to more than a very limited extent. At the same time, the fact must not be overlooked that some clays with an exceedingly low shrinkage are made into exceptionally strong bricks, some special reactions occurring in the kiln which overcome the weakness due to lack of plasticity in the clay.

In the manufacture of architectural terra-cotta, in which a large number of pieces of different shapes must fit accurately together, it is highly important that accurate allowances shall be made for shrinkage. Where this is not the case the pieces fit so badly that the strength of the structure is seriously reduced, and its rsthetic value is largely destroyed. As the calculations for shrinkage are tedious when large quantities of work are to be executed, manufacturers of architectural terra-cotta usually provide their modellers with specially constructed measuring scales by means of which all calculations for shrinkage are avoided.

The shrinkage of clays is an interesting study, inasmuch as it occurs at some stages with great regularity, and at others in a curiously irregular manner. Carefully recorded measurements of clays at various stages during drying and burning seem to show that the shrinkage proceeds proportionately to the loss of water during the early stages of drying, but as soon as the particles have come as closely into contact with each other as their shape permits, shrinkage ceases, though the loss of water continues. This indicates the close of the first and most 
difficult stage of drying, for it is in the removal of the greater part of the absorbed or colloidal water, and the accompanying shrinkage, that the greater part of the cracking and warping of the goods occurs. Some clays are so delicate at this stage that the only way to dry them is to cover them closely with tarpaulin and to heat them with wet steam. The moisture in the steam prevents them drying, whilst being heated, and when they are at a sufficiently high temperature for the water in them to be converted into vapour, the steam supply is cut off and the bricks are uncovered and heated indirectly. This "sweating" is tedious and costly, but it is the only means available with certain clays. "Most clays are less troublesome and provided they are protected from draughts or irregular heating, they may be dried in sheds of which the floors are heated with steam or fuel, and in summer large numbers of bricks are dried in the open air-a slow process requiring several weeks.

In the second stage of the drying, when no shrinkage accompanies the removal of the water, the goods may be heated more strongly so as to dry them with fair rapidity without incurring any serious risk of warping or cracking. At the end of this second stage the bricks or other articles are placed in the kiln, and there undergo a further contraction ("kiln shrinkage ") due to the decomposition of the clay molecule and the evolution of water. If the goods are damp when placed in the kiln, a further drying first occurs, and this necessitates a very gentle warming of the kiln during the first two or more days; otherwise the evolution of steam will be so rapid that the goods. will be cracked and broken by the expansive force of the imprisoned steam. When the heating is sufficiently slow, the steam escapes steadily, and without doing any damage, leaving a porous material devoid of all plasticity and resembling an extremely soft stone.

The action of heat on clays to be used for bricks is also important. Some clays contain so large a proportion of metallic salts and oxides other than alumina and silica, that they cannot be burned on a large scale without serious loss of shape. The precise changes which occur when clay is heated must be left to a later chapter; it is sufficient for the moment to state 
that a satisfactory clay for brickmaking, etc., must be able to withstand the heat of a kiln sufficiently long for a hard, compact material of the desired characteristics to be produced. To some extent the temperatures reached in the kilns may be adjusted to suit the clays being heated, but this can only be done to a limited extent, and where the composition of the material made into bricks is very irregular, it will be difficult, or, in some cases, impossible, to secure a large proportion of saleable goods.

When overheated, bricks become vitrified, slag-like and very irregular in shape. They are deficient in porosity and, consequently, are very difficult for the bricklayer to use. Such bricks are known by a variety of names-many of them of purely local use-such as crozzles, burrs and clinkers.

Firebricks are distinguished from others by their exceptional resistance to high temperatures. Most red-burning bricks will run to a shapeless mass if maintained for several hours at a temperature of $1,200^{\circ}$ C., but firebrick will not lose its shape at $1,600^{\circ} \mathrm{C}$, and the better qualities are in regular use at much higher temperatures. It is almost impossible to overheat firebricks during manufacture, but the clays from which they are made are too valuable to be used for ordinary building bricks.

Impurities in Clays.-Having realised that there are a number of ways of classifying clays according to one or more of their important properties, the reader will readily understand that an exact and complete classification is at present unattainable. All that can be stated is that most clays appear to consist of mixtures of stones, gravel, sand, silt, rock-flour and other inert materials - all of which are obviously not of the nature of clay-with a substance of a more or less plastic nature, the composition of which resembles that of an aluminosilicic acid (p. 40).

According to the impurities present, a clay will be useful or worthless for certain purposes, and no single clay can be equally valuable for all the purposes for which clays are used. Thus, an almost pure clay would produce white bricks, the production of red bricks and terra-cotta necessitating the presence of certain impurities, notably iron compounds. Again,

c. 
a pure clay, if plastic, would shrink too much for ordinary use and would have to be diluted with sand or other non-plastic material. Hence, pure clay-which does not occur in Natureis of less value to the brickmaker than the impure clays which serve his purposes so admirably. "Pure clay" is, in fact, little more than an abstract idea, for the most carefully refined plastic clays are invariably so different in properties from the refined china clays of apparently the same composition as to leave it a matter of conjecture whether they are two forms of identically the same substance or not. What appears to be most probable is that they are different aluminosilicic acids of highly complex structure.

Whatever may be the real nature of the essential substance of all " clays" and brick earths, it is important, in some cases, to ascertain, at least roughly, the amount of clay substance present. This is a matter for the expert in clays and cannot be ascertained by the ordinary clayworker, nor is it shown by the analysis made by public analysts and other chemists with no special knowledge of clays. A method of so-called "rational analysis" sometimes used for this purpose is particularly misleading and erroneous when applied to brickmaking materials.

It is convenient, and for most purposes sufficiently accurate, to consider clays and brick earths as being composed of a certain amount of real clay ${ }^{1}$ together with silt, sand, chalk, gravel and stones. According to the nature and proportions of these adventitious ingredients the clays will prove satisfactory or otherwise for the manufacture of any given articles.

In addition to the occurrence of impurities in these recognised forms, however, clays also contain impurities which are more conveniently considered under their separate names rather than as constituents of sand, etc. The most important of these impurities are :-

Free silica present as sand, or in a colloidal form readily

1 The author has suggested the word pelinite-derived from a Greek word meaning "of the nature of clay"-for the clayey substance found in all plastic clays. The identity or otherwise of pelinite and kaolinite - the latter being the essential constituent of kaolins and china clays-remains to be proved, though the relationship between the two appears to be very close. Kaolinite is, however, almost devoid of plasticity. (See the author's "Natural History of Clay," Cambridge University Press.) 
soluble in a solution of caustic soda. This colloidal silica absorbs water readily and shrinks greatly on drying, and so is liable to cause trouble in manufacture. The free silica present as grains of quartz or sand, merely serves as a diluent of the clay, reducing its plasticity and shrinkage. If these silica grains are impure they will affect the clay according to the impurities they contain (see later).

If a clay is very impure and readily fusible, the addition of sand may increase its power of heat-resistance as free silica is, in itself, highly refractory.

Free alumina is, in many respects, like free silica so far as its behaviour in brick clays is concerned. It increases the heat-resistance of clays containing it, and appears to aid in the formation of buff-coloured bricks. Free alumina occurs in British clays to so small an extent that it is of little importance, but in some tropical countries its presence is highly significant.

Lime compounds occur chiefly in the form of calcium carbonate (limestone and chalk) and calcium sulphate (gypsum). Both these substances are converted into quicklime on prolonged heating in a brick kiln, but the conversion is not always complete. Lime may also occur in the form of a calcium alumino-silicate as a species of felspar. It then acts as a flux, binding the surrounding particles together as described under $(a)$ below.

Lime compounds have three important characteristics when they occur in clays:-

(a) On heating the clay, the lime unites with the clay substance and with any free silica or free alumina present, and forms a viscous glassy mass, which cements the less fusible particles together into a hard vitrified and very strong mass. Where sufficient lime is present the mass may become so viscous as to lose its shape and form burrs, or clinkers (p. 377) instead of well shaped and sound bricks.

(b) Soluble lime compounds (chiefly the sulphate) dissolve in the water used in making the clay paste, and are brought to the surface of the goods during the drying. As the water evaporates it leaves the salts on the surface in the form of a thin white deposit or scum, which is much more noticeable 
on the burned than on the green bricks. The only means of preventing this scum consists in converting the soluble salts into insoluble ones by the addition of barium carbonate or some other suitable chemical to the clay previous to mixing with water. The scum does no harm to the bricks except that it is unsightly and detracts from their selling value.

(c) Small nodules of limestone, situated near the surface of a brick which is not heated sufficiently in the kiln to cause a combination of the lime with the other constituents, will become hydrated on exposure to moist air, and will then swell and crack the bricks, or they will "blow" and form ugly hollow places. This defect is peculiarly characteristic of some boulder clays (p. 294) and many thousands of bricks are damaged annually in this manner. Two remedies are employed : (1) grinding the material so fine that the particles of lime will be too small to harm the bricks, together with an increased finishing temperature in the kiln which will cause them to combine with the silica, etc., in the bricks and to become harmless ; (2) the bricks may be immersed in water as soon as they are drawn from the kiln. This sudden slaking of the lime prevents the bricks from cracking, but has the disadvantage that they are made heavy with the water they contain, and are not so readily purchased by builders.

Magnesium compounds so closely resemble those of lime that there is no need, in brickmaking, to distinguish them. In the form of mica (a magnesium silicate) magnesium compounds occur in a large variety of clays and may usually be recognised by a silvery sheen, which is characteristic of mica particles. There are several kinds of mica, all of which are in the form of very thin plates, which do little or no damage when present in small quantities, but in larger ones they tend to weaken a structure of articles made from the clay in which they occur.

The influence of mica in the kiln is of small importance in ordinary brickmaking; it tends to make the clay-mass fusible, but at the ordinary temperatures at which bricks are burned its action is scarcely noticeable.

Sodium and potassium compounds are generally regarded together under the term alkalies, though, in reality, the forms 
in which they occur are salts, such as felspar, muscovite, mica, and other minerals. Some clays also contain sea salt (sodium chloride), sodium sulphate, potassium chloride and sulphate, and other soluble salts. These form a scum, as described in (b), p. 307.

Usually, sodium and potassium compounds are among the most fusible constituents of a brickmaking material, and they therefore bind the more refractory particles together. When present in very small proportions; they increase the strength of the bricks, but in large proportions they bring about so rapid a vitrification and fluidity of the clay that an excessive number of shapeless goods is produced.

Iron compounds in brick clays appear to have been derived from a number of minerals, of which the most important are : (a) certain ill-defined ferrosilicates which form free ferric oxide when the clay is heated, $(b)$ pyrites and other forms of ferric sulphide, (c) limonite and other forms of ferric hydrate, and $(d)$ other iron compounds occurring in very small quantities, and of such a nature that they may be regarded by the brick manufacturer as though replaced by compounds in one of the three previous groups.

Silicates containing iron are not easily identified in clays, but are of two classes-those in which the iron remains in the form of a silicate after being heated to redness, and those which are decomposed on heating, red ferric oxide being one of the products. In the first class of compounds, the iron is in the form of a base and may be regarded as having partially displaced one or more of the other metallic bases as in the micas. In the second group the iron forms part of a complex acid group, as in nontronite and other ferrosilicates which are analogous to clays, and on heating form free silica and iron oxide.

Sulphide of iron $\left(\mathrm{FeS}_{2}\right)$ occurs in four well-known forms in clays :-

Pyrite as nodular or kidney-shaped masses, which, on fracture, are seen to consist of minute brassy cubes, or as the minute cubes separately. The brass-like lustre is very characteristic, and pyrite is occasionally mistaken for metallic gold. 
Marcasite, as fibrous masses and twin-rhombic crystals, and occasionally as nodules.

Mundic, as root or twig-like masses of great relative weight, which, on fracture, are found to consist of either pyrite or marcasite.

Chalcopyrite, as nodules resembling pyrite, but differing in containing copper sulphide as well as iron sulphide.

All forms of iron sulphide are objectionable in brick clays, as they form black spots or "splashes" of black slag on the surface of the fired goods. They occur less frequently in the red-burning clays than in the fire clay and buff-burning ones, the pyrites originally present in the first-named having, it is believed, been oxidised previous to, or shortly after, its introduction into the clay.

Hydrates of iron - of which limonite is the best exampleyield red-ferric oxide on heating, and evolve water. The proportion of water in chemical combination with the iron appears to vary greatly, and the formula $2 \mathrm{Fe}_{2} \mathrm{O}_{3} 3 \mathrm{H}_{2} \mathrm{O}$, usually attributed to limonite, cannot be relied upon. These hydrates usually occur in nodules which may be picked out of the clayespecially when it has been exposed to the weather-but they also occur distributed throughout the clay mass in so fine a state of division as to give the raw clay a yellow, brown, or even red colour. The proportion of combined water in limonite and allied compounds appears to influence the colour ; this water may not be in strict chemical combination, however, but rather as a colloidal material.

Ferrous compounds are not readily noticeable in raw clays: but in those which have been heated they form bluish-grey or black slags, to which the well-known "blue Staffordshire bricks " owe their characteristic colour, the ferrous compounds being formed in the kiln by the action of the reducing gases from the fuel.

Carbonaceous matter, derived from plants and animal remains, occurs in many clays, and usually gives them a greyish or brown colour. If this impurity has become carbonised the clay may be quite black, though the total proportion of carbon may not exceed 5 or 6 per cent.

All carbonaceous matter burns away when clays are slowly 
heated in contact with air, so that it has no direct influence on the colour of the finished goods. Indirectly, it tends to produce a reducing atmosphere in the kiln, and so may effect the reduction of some ferric oxide and the formation of the bluish ferrous silicate.

When carbonaceous matter is burned out of a clay, the latter becomes porous; hence, sawdust, etc. is sometimes added to a clay when specially porous bricks are desired.

Other impurities are occasionally important in clays to be used for special purposes. They usually reduce the heat resistance of a clay (as titanium oxide), or affect its colour when burned (as tourmaline), but are not ordinarily of importance in brickmaking, and, therefore, need no further mention in the present volume. Further information concerning them will be found in the author's "British Clays, Shales and Sands."

The following clays are of sufficient importance in brickmaking to be described here in addition to those previously mentioned :

Agglomerate clay is a mixture of angular stones and fragments of rock cemented together with a plastic clay. It is of little or no value.

Alluvial clay collects in valleys in various parts of the country, and is usually of very fine texture. In composition and general character it is liable to vary very greatly within small areas, and is, therefore, less trustworthy than marine deposited clays. Alluvial clay is often rich in chalk and limestone dust, and is then of insignificant value.

The term "alluvial clay" is often used to distinguish light fine clays of low plasticity from the compact, strongly plastic clays, and from the loams and shales.

Ball clays are not intentionally made into bricks unless the clays are of exceptionally low quality. The better qualities are too valuable, and are used for pottery manufacture.

Brick earth is a term used to denote any material containing clay which can be made into good bricks. Some natural products contain so little clay that they cannot suitably be. termed "clays," and yet they can be made into good bricks. Many loams and true marls are of this class, but the term may 
be applied with accuracy to any clay or clay mixture which can be made into good, merchantable bricks.

Clunches are clays which are mined and not quarried, and may be used for a common brick shale or clay or for a highclass firebrick. The term has nothing to do with their composition.

Conglomerate clays are similar to agglomerate clays (q.v.), but the rock particles are rounded instead of angular. They are of little or no value for brickmaking.

Drift clays are commonly termed "Boulder clays," and form the chief brickmaking material in the north of England, where they occur in enormous quantities as the residue. As explained on p. 296, these clays make good building bricks when sufficiently free from stones, but they are liable to be spoiled by fragments of limestone in the gravels with which they are associated. With care this difficulty may be overcome, and good, hard bricks produced.

Fat clays are those which are oleaginous in consistency and usually possess a high degree of plasticity. When used alone they are seldom satisfactory for brickmaking, but on the addition of grog, sand, or very lean clay, they form excellent bricks.

Fireclays are those which can withstand exposure to a temperature rather higher than that of molten steel without showing signs of fusion, and are, consequently, valuable for furnaces, kilns, and other structures where a refractory material is required.

Fireclays are mined from pits sunk in the Coal Measures, and are closely associated with all the best known seams of coal. The manufacture of firebricks, retorts, etc., is, therefore, largely undertaken by colliery proprietors, or by firms working in connection with them. The best fireclays occur in the Stourbridge, Yorkshire, Northumberland and Scotch coalfields, but others of almost equal quality are found in other districts, particularly in Wales.

The chief characteristics required in a fireclay are resistance to heat and to sudden changes of temperature, but other requisite properties are resistance to the corrosive action of slags, dross and metallic compounds, and to the abrasive 
action of lumps of lime, stone or ore and of flue-gases. As it is impossible to obtain a fireclay which can be used for all the purposes for which firebricks, etc. are used, it is necessary to select certain clays for certain purposes. For this reason the fireclays from different localities are specially adapted for different purposes. The colour of raw fireclays is a dirty grey, which becomes buff or stone colour on heating, the fired product being usually spotted with grains of ferrous silicate due to the pyrites in the clay (p. 309).

Fireclays are largely used in the manufacture of crucibles, for which purpose they are frequently mixed with plumbago, which renders them less sensitive to sudden changes in temperature and tends to maintain a reducing atmosphere in contact with the contents of the crucibles. This is important in some metallurgical operations.

Allied to the fireclays, though not really a clay, but a siliceous rock with a low clay content, is the material known as ganister, which usually occurs in the coalfields below the coal seams: it is occasionally found nearer the surface, and in such cases the previously superincumbent coal has probably been removed by denudation.

The subject of fireclays is a very large one, and the reader desiring more information should therefore consult the author's "British Clays, Shales and Sands."

Fusible clays may be regarded as the opposite of fireclays, as they undergo partial fusion, and form a hard, vitrified mass when heated. If such clays retain their shape at a temperature approaching the melting point of steel, they are exceedingly valuable, and under the term "stoneware" are employed on a very extensive scale (see "Vitrifiable Clays").

Engineering, clinker and paving bricks are made of somewhat fusible clays which are able to retain their shape at a high temperature, notwithstanding the larger amount of vitrification which takes place. They owe their strength to the tenacity with which the infusible particles in the clay are bound together by the more fusible constituents.

Gault is a stiff, dark-coloured clay which occurs in the Greensand formation in the south-eastern counties, and extends westward towards Midhurst and southward to Eastbourne. 
Owing to the calcium carbonate it contains, bricks made from it are white. Some gault bricks are reddish in colour, but white ones may be made by the addition of chalk. Wherever it crops out near the surface of the ground, gault clay is found suitable for brickmaking, the exceptions to this statement being few, and chiefly in some parts of Cambridgeshire where the clay is more unctuous (see p. 6).

Though largely used for brickmaking - especially after the addition of chalk - gault clay cannot be regarded as a high-class material, though for common bricks it is excellent.

Grog is simply clay which has been burned in a kiln and then reduced to powder. The clay may be calcined specially, or the grog may be made by crushing broken bricks. According to the nature of the original clay, so will the grog be refractory or fusible, soft or hard, buff-coloured or red. The chief uses of grog are to increase the heat-resistance of a fusible clay and to reduce the plasticity and shrinkage of a clay which would otherwise be difficult to work.

Kaolin or china clay (the latter being one kind of kaolin) is not used for brickmaking, though the sandy residues obtained by washing are made into bricks in some localities. The value of good kaolin to paper makers and others is so great and its plasticity is so low that it is not likely to meet with extended use in the manufacture of building bricks in this country.

Laminated clays are those composed of layers or flakes and are troublesome to use, as they tend to split along the lines of deposition. When hard, they form shales (p. 316) to which this objection is less applicable, as the harder material can be reduced to particles so small that their lamination becomes imperceptible.

Lean clays may be regarded as the opposite of "fat" ones (p. 312) and have only slight plasticity. Clays of moderate leanness are the most useful for brickmaking, as they do not shrink unduly in drying. Indeed, many plastic clays which, by themselves, would be useless, may be made valuable by the addition of sufficient sand or grog to convert them into moderately lean clays. Clays which are so lean that they do not readily retain the shape into which they have been formed 
are of little value unless some of the sand or other non-plastic material they contain can be removed cheaply.

London clay is one of the best known clays, and is at the same time one of the most risky for the manufacture of bricks. It occurs chiefly around London and occupies a very extensive area. Unfortunately, it is so sticky and contractile that alone it is practically useless for brickmaking, but in localities where it occurs in close association with sand, it is a valuable material for this purpose. It is to be regretted that in many localities where it would be most useful the absence of sand renders it of no value.

The portions of London clay which are worked are mixed with sifted cinder dust (technically termed soil) and chalk, whereby the contraction is reduced and bricks obtained which have been long famous for their ability to resist-as no other building material appears to do-the corrosive action of the atmosphere and climate of the Metropolis.

Marine deposited clays are those which were originally deposited on an ocean bed, but now form dry land. They occur in many parts of Great Britain, that known geologically as the Oxford clay being one of the most important, particularly near Peterborough and Fletton, where some of the largest brickworks in the country are situated.

The Midland marls are Triassic clays of a friable texture and moderate plasticity, and are not true marls (p. 9). They are well known as the raw material from which the excellent terra-cotta and red facing bricks in the Midlands are made. These clays cover a very extensive area, and are largely used in places so far apart as Nottingham, Leicester, Shropshire and Wrexham.

Reading clays form the western end of the London basin and are much esteemed for the manufacture of red tiles and bricks. They are of moderate plasticity and not particularly difficult to work, providing that they are carefully selected.

Refractory clays have been sufficiently described under "Fire clays" (p. 312).

Rock clays are indurated clay deposits which have attained a hardness and form corresponding to that of rocks, owing to the pressure of neighbouring strata and the interpenetration 
of cementitious solutions. Shales, slates and fireclays are typical rock clays.

Sandy clays are, as their name implies, mixtures of clay and sand which contain so large a proportion of the latter substance as to have a sandy nature. As "loams" they are valuable, but if too rich in sand (" clayey sands") they are useless for brickmaking, as they do not possess sufficient cohesion.

Shales are laminated, indurated clays which must be crushed to powder and kneaded with water before they become plastic. They occur in many localities-usually at some depth below the surface of the ground-and their composition varies greatly. Some shales form buff, and others red bricks, and a few shales contain so much fusible matter that blue engineering bricks can be made from them.

Most shales contain only a small percentage of carbonaceous matter, but others contain so much shale oil that they are very difficult to use for brickmaking, and a specially designed kiln is usually necessary for them.

The shales chiefly used for brickmaking occur in the Oxford clay, Lias, Wealden and Coal Measure formations. The location and extent of these can be seen in any good geological atlas (see also p. 8).

Silt is an extremely fine sand which usually contains sufficient clay to form a plastic mass. It is chiefly found on the sites of ancient rivers and in low-lying districts, and is found in large quantities in the eastern counties. The silt found near Hull (and termed warp) has been largely used for brickmaking with considerable success, but it needs special knowledge and skill to obtain good results, and would probably prove disastrous to anyone not acquainted with its peculiar characteristics.

Slates are very hard clays, which have undergone a partial recrystallisation. They are not extensively used for brickmaking, though the accumulation of rubbish in slate quarries has caused many attempts to be made to convert this material into bricks. The material is not well adapted to this purpose and could only be used commercially in localities where ordinary bricks were unobtainable.

Soil is the uppermost layer of earthly material, and is the " home" of plants. It does not consist entirely of mineral 
matter, but usually contains a considerable proportion of materials derived from the decay of plants as well as of animal excreta and artificial fertilisers. On this account it is not usually suitable for inclusion in the material employed for brickmaking, and should, in most cases, be kept separate. The soil overlying a useful deposit of clay is commonly termed the overburden or callow, and is generally removed before the underlying clay is dug.

Strong clays are highly plastic and shrink, crack and warp extensively when made into bricks and dried. They are objectionable to most brickmakers, who commonly term them foul clays. If mixed with sand or grog, they usually make good brick earths, but the difficulty and cost of obtaining a satisfactory mixture often prohibits their use.

Surface clays are, strictly, any clays which occur near the surface of the ground and immediately below the soil. The term is, however, used colloquially by many brickmakers to indicate a red-burning clay as distinct from a buff-burning material obtained from a greater depth. This use of the term has led to much confusion in the past and should be avoided.

Tender clays are those which erack or warp when made into bricks. They are usually characterised by a high shrinkage and great plasticity. The tenderness may be reduced by the addition of sand or chalk, but some tender clays are so peculiarly constituted that the addition of non-plastic materials makes them so weak and friable as to be useless. Tender clays are the ruin of brickmakers who do not know how to deal with them, as they require expert knowledge before their use can be satisfactory.

Till clay is the plastic clay forming the lower portion of the boulder clay (p. 294), and is valued for brickmaking on account of its freedom from stones and gravel. The term is, however, applied in a loose manner to boulder clay generally, in which case its special significance is lost.

Vitrifable clays are used in brickmaking for the production of bricks of great strength and imperviousness to water and other fluids. Vitrification is the state in which a portion of the clay fuses and binds the remaining particles firmly together, 
the fused portion filling some or all of the pores previously existing in the material. The extent to which vitrification occurs depends on the nature of the fusible material present and on the temperature and duration of the heating; it is said to be complete when the whole of the pores have been completely filled with fused material. Nearly all clays can be vitrified if a sufficiently high temperature is reached, but many of them lose their shape before vitrification is complete. The commercial value of vitrifiable clays, therefore, depends on a considerable time elapsing between the production of a sufficient amount of fused material to close a sufficient number of pores and the commencing of a noticeable loss of shape. Clays which begin to vitrify and then to lose shape almost instantaneously or without any appreciable rise in temperature are useless commercially as vitrifiable clays. The time of heating or the rising temperature required between these two changes is termed the "range of vitrification," and it is an important factor in deciding the value of a clay. Clays in which the more readily fusible portion is rich in potash, soda or lime, usually have a short range of vitrification, and are therefore less valuable than clays in which the chief flux is magnesia, and therefore possess a longer range of vitrification.

The vitrifiable clays chiefly used in brickmaking are found in the Midlands, where they form the buff paving bricks of the Little Bytham district and the famous blue bricks of Staffordshire, but equally good bricks can be obtained from selected seams in most of the coalfields. The purer stoneware clays of Dorset, Devon and Cheshire are too valuable for this purpose, except where bricks impervious to strong acids are required for use in chemical works and for other special purposes.

Yellow clays, i.e., those which are yellow when freshly dug, are usually strong clays (p. 317) and difficult to work without the addition of sand, but the yellow colour gives so little indication of their nature that further tests are necessary before their value can be ascertained. 


\section{CHAPTER XII}

\section{METHODS OF BRICKMAKING}

From what has been stated on the foregoing pages, the reader will easily perceive that the variety of clays available and their complex nature make the manufacture of bricks a work requiring more skill than is generally supposed.

Capital required.-Before commencing the manufacture of bricks, and allied articles, there are two essentials which must be considered, viz., capital and knowledge. Without sufficient capital the risks of failure are very great, because the manufacture of bricks is subject to many vicissitudes which cannot be overcome without ample financial backing.

The amount of capital needed depends greatly on the locality of the works ; in an undeveloped area, where common bricks will be all that is desired, the money needed will be small-a few hundred pounds-but for a plant with an annual output of a million or more bricks, the capital required will be much greater. In the case of an "average" works producing 20,000 bricks per day, it may easily reach to $£ 10,000$, and many works with this output have a capital more than four times this amount. It is only fair to add, however, that the capital invested in a large number of brickworks is to a considerable extent "lost," it having been spent in continuous attempts to improve the product by methods which a man with sufficient technical and scientific knowledge could have predicted would be futile.

The cases where men have made fortunes out of brickmaking become fewer each year, and an investigation of most of them will show that whilst these brick manufacturers may not have had much cash of their own, yet the credit they have been able to obtain and other facilities they have possessed have had the same effect as the possession of considerable capital.

A man who would start a brickworks in the United Kingdom. 
at the present time without ample capital in some form or other would be almost certain to fail. With sufficient capital, however, there. are excellent prospects in a number of localities, particularly in the Midlands.

Technical Knowledge Needed.-Most brickmakers who started in business forty years or more ago did so under conditions very different from those at the present time. The use of machinery for this purpose was practically unknown, and the profits obtained were much higher than at the present time. With little or no literature on the subject the brickmakers of half a century ago were only able to use a very limited number of clay deposits, and those of a peculiarly favourable character.

The introduction of machinery effected a complete revolution in the technical equipment required, it increased enormously the number of clays and earths which could be made into bricks, and created an impression-as false as it is widespread - that, so long as an earthy material feels plastic when mixed with a little water, good bricks can be made from it by any man possessing the necessary plant.

This belief has caused the loss of hundreds of thousands of pounds, for the manufacture of bricks is an industry requiring much technical knowledge, and it is quite a mistake to imagine - as many engineers do-that all that is requisite are a few moulds or a machine, a kiln, and a few labourers. With good fortune the clay available may happen to be one which is easily worked in the manner which appeals most to the prospective brickmaker, but the enormous number of derelict works and of machines which fail to find purchasers prove that those who regard brickmaking merely as an elementary branch of engineering run risks of the most serious financial character.

In the author's experience as an expert adviser for many years past, he has found numberless cases of firms who were entirely mistaken as to the correct methods of working the particular clay available to them, and who, in consequence, have lost enormous sums of money which might have been saved had they obtained reliable and independent expert advice before purchasing plant or ordering the erection of kilns. 
In order that a brickworks may be a commercial success, it is necessary that only a reasonable amount of skill shall be needed in the production of bricks, and it is precisely because of failure to realise this fact that so many brickworks prove to be failures. Given ample time and labour, a few good merchantable bricks can be made with almost any machinery on the market, but this is far different from the conditions which must prevail in a brickworks working commercially. The result is that many prospective brick manufacturers are entirely misled by the sample bricks made from their clay by enterprising firms of machinery makers and kiln builders, and find, when too late, that they have prosecuted their enquiries in the wrong direction.

Almost equally serious and erroneous are so-called "tests" made by "practical men" on small quantities of clay. These " match box tests" (so called because a match box is frequently used in place of a proper mould) may or may not yield results worth the labour expended on them, but in any case it is exceedingly foolish to erect a works on so slight a result. The production of even 1,000 bricks by a friendly brickmaker is by no means conclusive evidence of the nature of the clay, as there are many other matters to be considered in manufacturing, of which these tests give no indication.

Finally, it is almost useless to have an analysis made of the clay. Certain chemical and physical tests are essential, but a chemical analysis as conducted by a works chemist or a public analyst is of scarcely any value, as it does not give the information required.

The only satisfactory method of ascertaining whether a given clay is likely to be suitable for the manufacture of bricks is to have it examined by an expert in clay testing, who is financially independent of all machinery and kiln constructing firms, and who is known not to accept secret commissions, rebates or other inducements which will bias his recommendations. The fees charged by such a man will be saved in the avoidance of unnecessary machinery and in the absence of those annoying "extras" by which the original estimate of costs is usually increased so largely, but which are almost unavoidable in the absence of such skilled technical supervision.

c. 
The man who wishes to build a house employs, if he is wise, an architect to advise and assist him in its design and erection, and to check the tendency to extravagance on the part of both owner and builder. The man who is ill is most likely to recover if he seeks the aid of a medical man, for an able physician, who has made a special study of the subject, wastes no time in effecting a cure. "A man who is his own lawyer has a fool for a client" is a proverb famous alike for its general applicability and its truthfulness. Yet an error in the selection of brick machinery or kilns, or in the valuation of a clay property, may easily involve the loss of several thousands of pounds, which the employment of a reliable expert in clay working would have saved.

Many instances might be quoted to illustrate this, but the following recent one, from the author's personal experience, must suffice. A certain landowner found a shale on his land, which he believed to be valuable, especially as the neighbourhood was one in which there was an increasing demand for bricks. A company was formed, machinery purchased, kilns erected and work begun. But, alas! the output was less than half that anticipated, and the costs were slightly higher than the selling price of bricks in the neighbourhood! Many weary months of working failed to improve the conditions and eventually an expert was called in to report upon the whole works. He found, as was only to be expected, that the machinery installed had been seriously overrated for the particular material to be treated, though the output promised could readily have been obtained with a different clay. He learned that various firms had tendered for the supply of machinery, and that the accepted tender was for the machinery not best fitted for the work. The kilns had been purchased in an indirect manner, the ordinary price for eight kilns had been paid for the five kilns erected (the balance representing a commission to the firm introducing the kiln builders, and a "little extra" for the builders because there was no competition). Reconstruction of the works was imperative, but was rendered difficult because the shareholders, having been " once bitten" were "twice shy." Eventually, however, the rearrangement of the plant was completed, and it has been working satisfac- 
torily ever since. Had the present method of working been installed in the first instance-as would certainly have been the case had the expert been consulted at a sufficiently early stage-the total amount saved would have been $£ 9,000$ plus the losses due to working with unsuitable machinery.

This is not an isolated example, but is typical of many in various parts of the United Kingdom. It is not fair to blame the firm who supplied the machinery and kilns; their first business was to sell their own goods and to make out the best case for these. To have recommended the inclusion of plant they did not make was no part of their work, hence their advice was necessarily and unavoidably biassed, whereas an expertexpressly chosen because of his independence and freedom from bias of this kind-would have specified the plant and kilns most suitable for that particular material.

The following description of methods of manufacturing bricks is only intended to outline the most important processes, and the reader who wishes for further information and for more illustrations of the machinery, etc. employed, should consult the author's "Modern Brickmaking" (Scott, Greenwood \& Son), the author's " Clayworkers' Handbook" (Griffin \& Co.) or "Bricks and Tiles," by Dobson and Searle (Crosby, Lockwood \& Co.).

Mining and Quarrying.- The first operation in the manufac. ture of bricks is the mining or quarrying of the clay or brick earth and its delivery to the machinery which prepares it for use. A description of the various methods of working in clay pits and mines would require a volume to itself, and it must here suffice to state that in mining the ordinary colliery methods are employed, and that in quarrying the clay is usually obtained by means of picks and shovels, the excavation being carried out in a series of shelves or ledges. Very hard materials are loosened by blasting with gelignite or other "safety" explosives.

Steam navvies and ditch cutters are used where the material is sufficiently soft and uniform, but their use is impracticable in many brickyards on account of the need for selecting certain portions and discarding others from the quarry face.

Selection of suitable materials and rejection of unsuitable 
ones will make all the difference between good and bad bricks, and in most quarries too much care cannot be taken to keep detrimental material away from the useful clay. It is, generally speaking, foolish to mix the materials indiscriminately together and expect good bricks to be made, though this is done successfully in some yards where the conditions of deposition of the various materials has been peculiar. The wise plan is to keep various materials separate, loading them into separate waggons and then mixing them in the desired proportions in the machines. Such treatment secures a more uniform product than is possible when they are mixed in the pit.

At one time, wheelbarrows were used to convey the clay to the machines; these are now used in some small works, but in the larger ones waggons are preferred. These waggons have a capacity of 5 to 15 cwts. of clay, the smaller ones being used on steep inclines and the larger ones for general work. The waggons travel on rails, turntables or " points " being used at junctions, so as to provide a good surface on which the wheels may rotate. These rails are of narrow gauge and are usually of a semi-portable character, so that they may be extended rapidly to convenient parts of the clay pit.

The loaded waggons are pushed by one or more men from the working face in the pit until they reach the hauling mechanism, or ponies may be employed to do the whole of the haulage if the clay hole is not very deep. Usually, the best method of haulage consists in the use of an endless rope or chain to which the waggons are attached by some simple form of clip. In some works the use of a simple haulage rope or a main and tail system, such as is used in collieries, is preferred, the arrangement most suitable in any particular case depending on the length of haulage, the inclines to be negotiated, the changes in direction of travel, and other purely local conditions.

Overhead ropeways are by far the most economical method of conveying clay to the works where the distance and quantity are large, but most brickworks are too small for an overhead ropeway to be used.

Many brick manufacturers spend far more in haulage costs than is really necessary, because of the directions in which 
the rails have been laid, but the reduction of these costs is too complex a problem for a solution to be attempted here. Suffice it to say that the shorter and more direct the course along which the waggons travel-providing the inclination is not too steep - and the nearer the further end of the hauling plant is to the working face, the cheaper will be the cost of transportation.

As soon as the waggons with their load of clay, sand or other material reach the near or machine end of their journey, the second stage of the manufacture is reached.

Clay Preparation.-The conversion of the freshly-mined or quarried material into one which is suitable for the direct production of bricks is by no means a simple task. Clays and brick-earths vary so much in composition and physical nature that a treatment which is ample for one may be quite insufficient or even unsuitable in character for another, and any short description of the processes of preparation must necessarily be merely indicative and incomplete.

The object of all preparation processes is the production of a plastic paste of such a consistency that it may readily be formed into bricks or other articles of any desired size and shape. ${ }^{1}$ In order that this object may be attained, the material may require to be crushed to powder and then kneaded or mixed with a suitable quantity of water, the latter treatment being carried out in such a manner as will secure a paste of as uniform a composition and texture as possible. Insufficient or careless treatment in the preparation of the paste is one of the most frequent causes of defective goods.

Some clays occur naturally as a paste, which only requires to be kneaded to make it uniform and of the desired consistency; these are the easiest clays to manipulate, but the quantity available is limited. Other clays require the addition of water and possibly of sand, chalk, cinder dust or other non-plastic materials, and some of them require to be crushed or pressed into thin sheets before being kneaded; unless this is done the water added will not mix properly, and they cannot be made into a suitable paste.

1 The only exception to this is in what is known as the "dry dust," or "semidry " process, in which the finely powdered material is compressed in powerful presses to the desired shape. This method of manufacture is described later. 
Marls, loams and friable brick-earths require a much larger proportion of water and a more thorough kneading before a uniform paste is produced. Some of these materials also require to be crushed or ground to powder and sifted before being mixed with water. If this grinding is omitted the "paste" will be so irregular in texture as to be quite useless for brickmaking.

Shales, also clays containing stones or pieces of hard material, must always be ground to powder and sifted-the coarse particles being returned to the mill and reground-before they can be kneaded with water to form a suitable paste. If the clay is naturally of a pasty nature, with small stones or gravel embedded in it, the preliminary crushing is sometimes extremely difficult, the unctuous nature of the clay making it almost impossible to crush the other ingredients sufficiently small.

During the past few years many clays of this character have been made available by means of a clay cleaner, which consists of a cylinder with a series of small apertures through which the soft, plastic material and the finer grains of gravel, sand, etc., are forced, whilst the coarser particles are retained because they are too large to pass through the apertures. Clay-cleaning machines are of several types, but the separating principle just mentioned is their chief feature.

Clays which contain sand as well as stones or gravel cannot be sufficiently purified in this manner, but must be washed by stirring the material with water in a large trough or shallow well, the solid portion being broken up by means of rotary beaters or "hurdles" until a cream or slurry is formed. This slurry is allowed to remain stationary for a few moments, during which much of the sand settles out, and the fluid is then run off to settling pits, where, after some time, the clear supernatant water is cautiously run off, and the clay paste remaining in the pits is allowed to stiffen. When sufficiently dry it is then taken to the mixing machines in order to render its texture as uniform as possible. No washing, however perfect, can completely remove the impurities from clay, but the treatment just described is extensively used by brickmakers in the southern counties, particularly in those districts where 
chalk is mixed with the clay. In such a case the chalk is made into a slurry in a separate wash-mill, and this slurry is then run into the clay-mill and afterwards to the settling pits.

Before any clay or brick-earth is crushed, however, it should be examined in order to ascertain whether the same effect and other improvements in its nature cannot be obtained by exposure to the weather. Many hard clays and earths are reduced to a comparatively soft material when exposed to frost, and not a few of them fall almost to powder if merely exposed for a few days to the action of the atmosphere. This exposure (or weathering) not only facilitates the crushing and mixing of the clay, but it frequently brings about chemical and physical changes of the greatest importance to the brick manufacturer. The precise nature of some of these changes is obscure, but it appears to be a kind of oxidation combined with the production of internal stresses and strains which cause the particles of clay to separate from each other and to form a loosely coherent mass. Weathering also effects the purification of some clays by causing the solution of some of the impurities, and, as the water evaporates, some of these are carried to the surface and form concretions or a scum which can be picked or scraped from the surface.

The crushing machinery used in brickmaking is of three chief types, consisting of :-

(a) One or more pairs of horizontal rolls, each about 18 inches diameter and 24 inches wide, placed side by side in such a manner that the raw material falls on them and is crushed to the desired fineness by passing between them. Ordinarily these rolls should not be further apart than the thickness of a penny, but some clays require them to be set almost in contact. The rolls tend to spring apart slightly in use, and as they become worn they permit larger pieces to pass between them, so that they cannot be relied upon to reduce the material to particles much less than $\frac{1}{8}$ inch in thickness, though the greater part will be much smaller. Where the clay contains stones or hard lumps the output of the machine can be increased by the use of two, three or even four pairs of rolls, placed one above the other, the rolls in each pair being set rather further apart than in the pair below. Thus, the lowest rolls 
may be $\frac{1}{16}$ inch apart, the middle pair $\frac{1}{4}$ ineh apart, and the ones in the upper pair may be an inch or more from each other. If the elay is exceptionally tenacious an additional pair of spiked, grooved : or studded rolls may be necessary, as lumps of such material would slip on smooth rolls and would not be erushed. Such rolls are termed kibblers or wolves.

(b) The seeond type of erushing machine consists of a pair of rollers each about 5 feet in diameter and 9 inches wide,

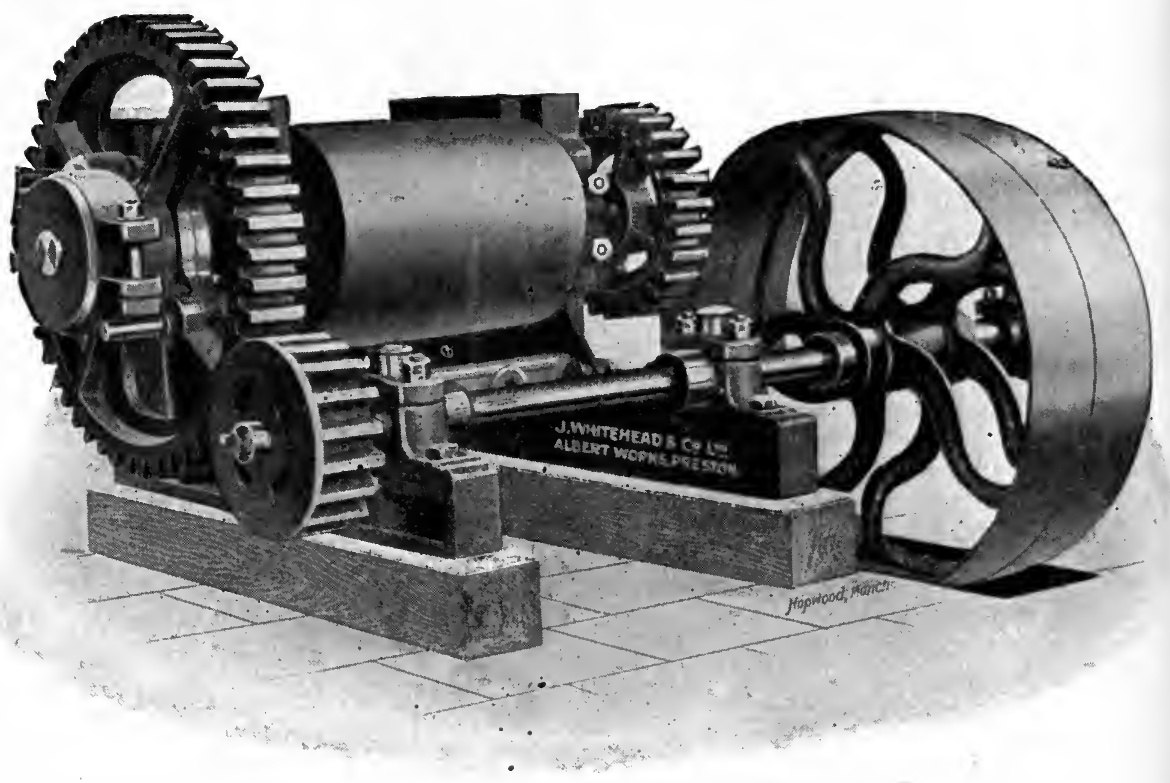

FIG. 96.-Crushing Rolls.

fixed at opposite ends of a single horizontal shaft and rotating on a pan or bed in such a manner that any material on the latter is erushed as the rollers pass over it. Such an arrangement is termed an edge-runner grinding mill, and it is speeially adapted for crushing dry or slightly moist rocks, hard elays and shales. Two patterns of edge-runner mills are in use ; in one, the bed is fixed and the rollers run over it, dragging behind them scrapers which 'remove the crushed material and conduct it to an elevator, whilst in the second form of 
mill the rollers are carried loosely in a framework and merely rotate by friction, whilst the pan or bed is rotated rapidly by mechanical power. This pan is perforated or provided with slots over a considerable part of its base, and as the material is crushed between the rolls and the pan, it passes through these perforations and falls into a well, fitted with an elevator.

The size and weight of the rollers, the speed at which the rollers or pan is driven, together with the size of the apertures in the base, determine the output of such mills, the nature of the material to be crushed being also an important factor.

Edge-runner mills of these patterns are not suitable for very pasty materials, though if the slots are sufficiently large (each about 3 inches by $\frac{1}{2}$ inch) they form admirable preliminary crushers where very adhesive clays are worked. The most suitable clay for crushing in an edge-runner mill is a friable marl, loam or soft shale which is not moist enough to adhere too closely to the pan or rolls. Some shales and fireclays are so dry that a considerable amount of water may be added to them during grinding without their becoming perceptibly

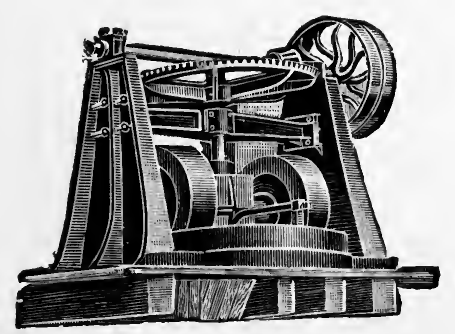

FIG. 97.-Edge-runner Grinding Mill. plastic or adhesive. The use of this water prevents the loss of the finest particles of clay which would otherwise escape in the form of fine dust.

It is seldom possible to have the perforations in the pan of an edge-runner mill less than $\frac{1}{8}$ inch diameter, and smaller ones so rapidly become larger with wear and tear that $\frac{1}{8}$-inch holes are rightly regarded as the least size practicable. Much of the crushed material is far finer than this, and some users of bricks demand such a texture that the whole of the material must be passed through a sieve with ten, twelve, fourteen or even eighteen holes per linear inch. It is therefore customary to lift the powder which issues from the edge-runner mill to a screen or riddle or suitable mesh, which is fixed on an upper floor well above the grinding plant. The fine material which 
has passed through the screen falls on to a floor or into a receiving hopper and the coarse material or tailings is returned to the mill for further treatment.

In order to obtain a uniform paste it is necessary to mix the clay or brickmaking material with water in a very thorough manner. Hence, the general necessity for first crushing the clay into thin sheets or of grinding it to powder as described. The water and material so prepared (if necessary) may then be kneaded together with a spade, but the process is slow

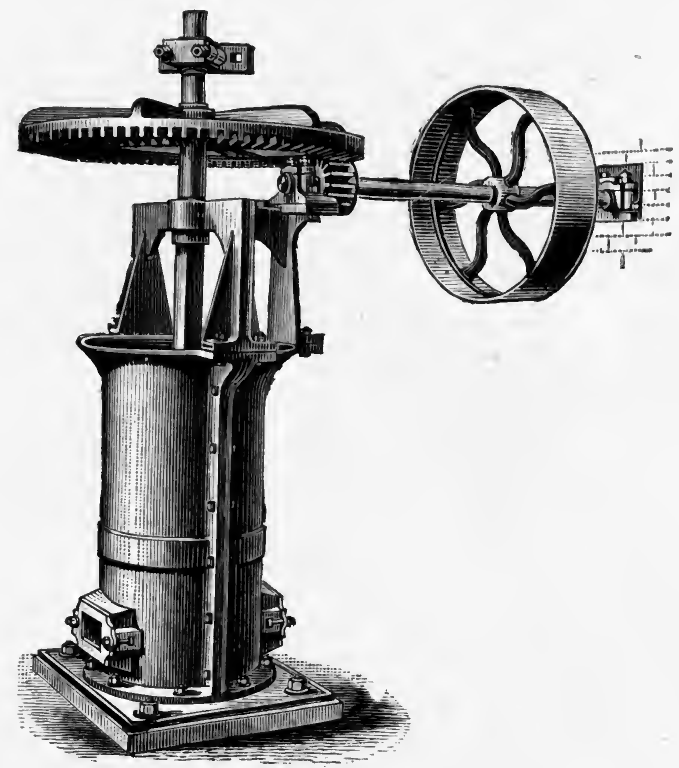

FIG. 98.-Vertical Pug-mill.

and imperfect. A better result is obtained by treading it with bare feet or by turning a number of horses on to it and keeping them moving about until the mass is sufficiently uniform; this method is also too imperfect in highly civilised lands.

It is usual, in this country, to employ a pug-mill or mixing machine driven by horse-power or mechanically according to the output required. Such a pug-mill consists of a closed cylinder with an inlet at one end and an outlet at the other, 
and provided with a shaft which runs right through the centre and is fitted with blades or mixing knives. These knives are specially designed to eut the clay contained in the cylinder and to mix it as it travels from one end of the machine to the other. Pug-mills were formerly of the vertical type, the clay, etc., being fed in at the top of the cylinder and passing out near the bottom, but at the present time a very large number of horizontal pug-mills are in use and have several advantages when employed in connection with other machinery. Moreover, by making the pug-mill horizontal a portion of the cylindrical casing may be omitted and an open or trough-mixer produced, with the advantage that the whole of the mixing operations may be observed and any defective blades replaced. It is also much easier to regulate the addition of
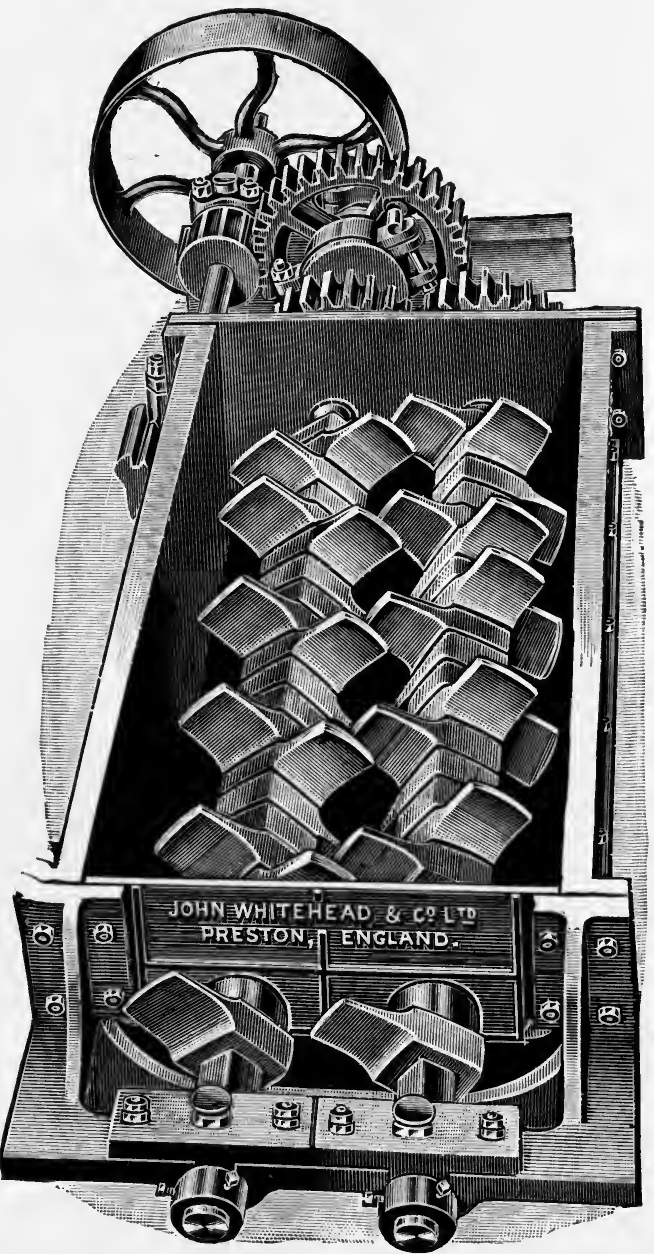

FIG. 99.-Open or Trough-mixer. water and, therefore, the consistency of the paste, when an open mixer is employed.

The speed of rotation of the shaft, the shape and number of the blades, and the length of the pug-mill will determine 
the extent of the kneading and the resultant texture of the pasty mass. Clays and mixtures which are difficult to work may require to be passed several times through the pug-mill, or through two or even three pug-mills in succession. With most brickmaking clays which have been adequately crushed or ground, a well designed pug-mill six feet in length will be found ample, but the variation in character of clays in different localities is so great that no definite limit of length can be laid down.

If an exceptionally thorough kneading of a somewhat lean clay is necessary in order to produce a clay of the desired plasticity - as is the case with some mixtures of grog and fireclay - an ordinary pug-mill is not always efficient, and it is then better to employ a pan mill or tempering mill. This machine consists of an edge-runner mill with a revolving pan similar to that used for grinding, but of lighter construction and with no perforations in the pan. Machines of this type are well known under the term mortar mills, as they are largely used for mixing mortar. The clay together with such other materials as are to be mixed with it, and the necessary quantity of water, are placed in the pan and the mill is set in action for twenty minutes or more, according to the amount of tempering required. At the end of a suitable time a peculiarly shaped shovel mounted on a swivel is employed to empty the mill, after which a fresh charge is added. The machine works intermittently, and the quality of the product will depend chiefly on the manner in which the materials constituting the charge are added. With a little care the paste obtained is remarkably uniform, and is somewhat more plastic than when the same materials have been treated in a pug-mill. The use of a tempering mill is, however, considerably more expensive, so that pug-mills are preferred wherever practicable.

Consistency.-The production of a paste of the required consistency completes the second stage of brickmaking. The consistency of this paste varies greatly with different clayssome needing to be made into a sloppy material scarcely stiffer than freshly-made mortar, whilst others are so stiff that considerable pressure has to be exercised in order to make any impression upon them. 
The softer the paste the easier it is to produce, so that in districts where little or no machinery is available, and the bricks are simply moulded by hand, the paste will be extremely soft. Where powerful mechanical mixers are available, however, it is more economical to employ a stiffer paste.

Methods of Shaping the Clay.-As already stated, there are a number of different methods in use for converting the prepared clay or mixed material into bricks, and these may now be considered in order.

In consequence of these differences in consistency, various methods of converting the paste into bricks and other articles are frequently distinguished by the kind of clay paste used. Thus-

(a) The plastic methods of brickmaking employ a plastic paste, as in the manufacture of hand-made and wire-cut bricks.

(b) The semi-plastic methods of brickmaking employ a stiff paste, and are sometimes termed "stiff plastic" processes.

(c) The semi-dry process of brickmaking consists in the use of a moistened powder which is almost devoid of plasticity.

(d) In the dry or dust process an almost diry powder is used.

For hand-made bricks the paste is made into the shape of bricks by means of wooden or metal moulds, consisting of a stout box, without lid or bottom, which rests on a piece of hardwood fastened to a rough table. The base piece is sometimes covered with a special kind of cloth, to which the paste adheres so slightly that the mould with its contents can be readily lifted off. Without the use of such a cloth or of sand sprinkled on the table the clay paste would adhere tenaciously to the table. If the bricks are to have a frog or cavity on one side, a piece of wood or brass is fixed to the table or base piece, and guides or pegs must then be used to secure the mould always being correctly placed on the bench. It is less easy to produce a frog on a slop-moulded than on a sand-moulded brick.

The moulder prepares the mould, places it in a convenient position on the table, and then takes up a convenient quantity of the soft paste in both hands, raises it above his head and throws it down with great force into an empty mould placed on a bench or table in front of him. He then presses the paste 
well into the corners of the mould, scrapes off any superfluous paste with a wooden blade or "strike," and with a dextrous turn of the wrist he empties the contents of the mould on to a small board or pallet placed convenient for its reception by the moulder's assistant. The brick thus produced is carried away to be dried, either by hand or on a barrow of special construction, so as to avoid undue vibration of the bricks. Meanwhile, the moulder dips his mould in water so as to wet it thoroughly (slop moulding), or first in water and then in sand (sand moulding). If sand is used it will cling to the surfaces of the clay in contact with the mould and will produce a rough-faced brick, the colour of which will depend upon that of the sand when burned. As red-burning sand is generally employed for this purpose, sand-faced or sand-moulded bricks are usually of a good red colour when sold, whilst slop-moulded bricks are the same colour as the burned clay of which they are made.

Although the difference between sand- and slop-moulding appears to be slight, in practice they necessitate an entirely different arrangement of the works. Slop-moulded bricks are so soft that they must usually be carried one at a time and placed about an inch apart on a level floor until they have hardened slightly and can then be taken to the hacks. Sandmoulded bricks, on the contrary, are stiffer and stronger, and can be taken in quantities on barrows and stacked directly on the hacks-one sand-moulder keeping two men and three barrows constantly employed in the transport of the bricks.

When slop-moulded bricks are made, the drying floor must be close to the moulding bench-it is, indeed, customary for the bench to be moved to different parts of the floor two or three times each day-but sand-moulded bricks can be taken on a barrow for any reasonable distance. In works provided with a steam-heated drying floor, slop-moulding is generally used, particularly if, as in the case of bricks for inside work, the colour of the finished bricks is of little importance.

The rate at which hand-made bricks can be moulded is very great, a fair average being 36,000 or more sand-moulded, or 9,000 to 10,000 slop-moulded, bricks per week.

Each brick when freshly moulded contains about 1 lb. of 
water, and this must be removed by drying in such a manner that the brick is not damaged. Slop-moulded bricks are usually allowed to remain on the flat or floor for about six days, after which they may be stacked in an open fashion in long rows about six bricks high, so as to make more room for fresh bricks. They remain stacked for several weeks until dry enough to be burned. Sand-moulded bricks are stiffer and are arranged in hacks (Fig. 110) immediately after they have left the mould, and take much longer to dry. These hacks consist of long rows of bricks set openly one above the other to a height of about two feet, and are covered with gableshaped boards to keep off the rain. The sides of the hacks are also protected, when necessary, with loo-boards, matting or straw in order that the bricks may not be damaged by frost, draughts or water. The bricks must usually be taken down and rearranged at least once during the drying, and if pressed bricks are desired a portable press is taken to the hacks and the bricks pressed and replaced.

The drying of bricks always requires care and attention; apparently insignificant draughts will crack many bricks, and even if the sun shines on some bricks during drying the damage will be serious. Hence, a considerable proportion of the anxiety experienced by the owner of a yard where hand-made bricks are produced is due to the difficulty of avoiding loss during the drying, especially if the clay is a tender one.

The thoroughly dry bricks are next taken to a clamp or kiln to be burned as described later.

The difficulties experienced in obtaining skilled brick-moulders has led to the introduction of machines in which the handmoulding process is closely imitated. These machines are described in the author's "Modern Brickmaking" (Scott Greenwood \& Son), but they have not been used extensively, as others working on entirely different principles have a much larger output.

Wire-cut bricks are produced by machinery; they are not moulded, but are shaped by expression through a suitable die in a manner greatly resembling the production of sausages. The plastic paste (prepared in one of the ways previously 
described) is passed from the mixing machine into a pug-mill, the die being attached to the exit end of the latter, and thus forming a mouthpiece, through which the clay exudes in the shape of a band or column $9 \frac{3}{4}$ inches by $4 \frac{3}{4}$ inches, i.e., whose width is the length of a brick, and whose thickness is the width of a brick. This band is cut into convenient lengths by means of a wire stretched tightly in a frame, and each section is again cut into pieces about $2 \frac{1}{2}$ inches or 3 inches wide by a series of other stretched wires. In this manner the bricks are produced six or more at a time, and are taken away on long boards or pallets to be dried.

This process of brickmaking is exceedingly simple in theory, but there are numerous matters in connection with it which require skill and care if good bricks are to be produced. Thus, the construction and maintenance of the mouthpiece need constant attention, or the elay band will be irregular in shape and having serrated edges. Some clays are extremely troublesome in this respect and have to be passed between a pair of expression rolls, placed between the pug-mill and the die, before good bricks can be obtained.

The arrangement of the wires on the cutting table also admits of numerous modifications, some of which are far better than others. The usual plan in this country is to keep the wires fixed and to push the clay column sideways through them by means of a push plate, but much neater bricks can be obtained by moving the frame carrying the wires in a diagonal direction towards the table, as in most of the Continental machines.

Any stones present in the clay band may catch the wires and tear the bricks, so that the wire-cut process is not well adapted for very rough clays, though excellent for most others.

Owing to the manner of their production, wire-cut bricks cannot be provided with frogs or depressions unless the bricks are passed through a re-press.

In order to reduce the space occupied by the plant, some of the makers of brick machinery combine the crushing rolls, mixer, pug-mill, mouthpiece, and expression rolls on a single framework so that the whole plant has the appearance of a single machine.

Bricks made by the wire-cut process are very soft, and must 
usually be laid out on a drying floor or kept separate on the racks of a drying tunnel or "stove" in order that they may

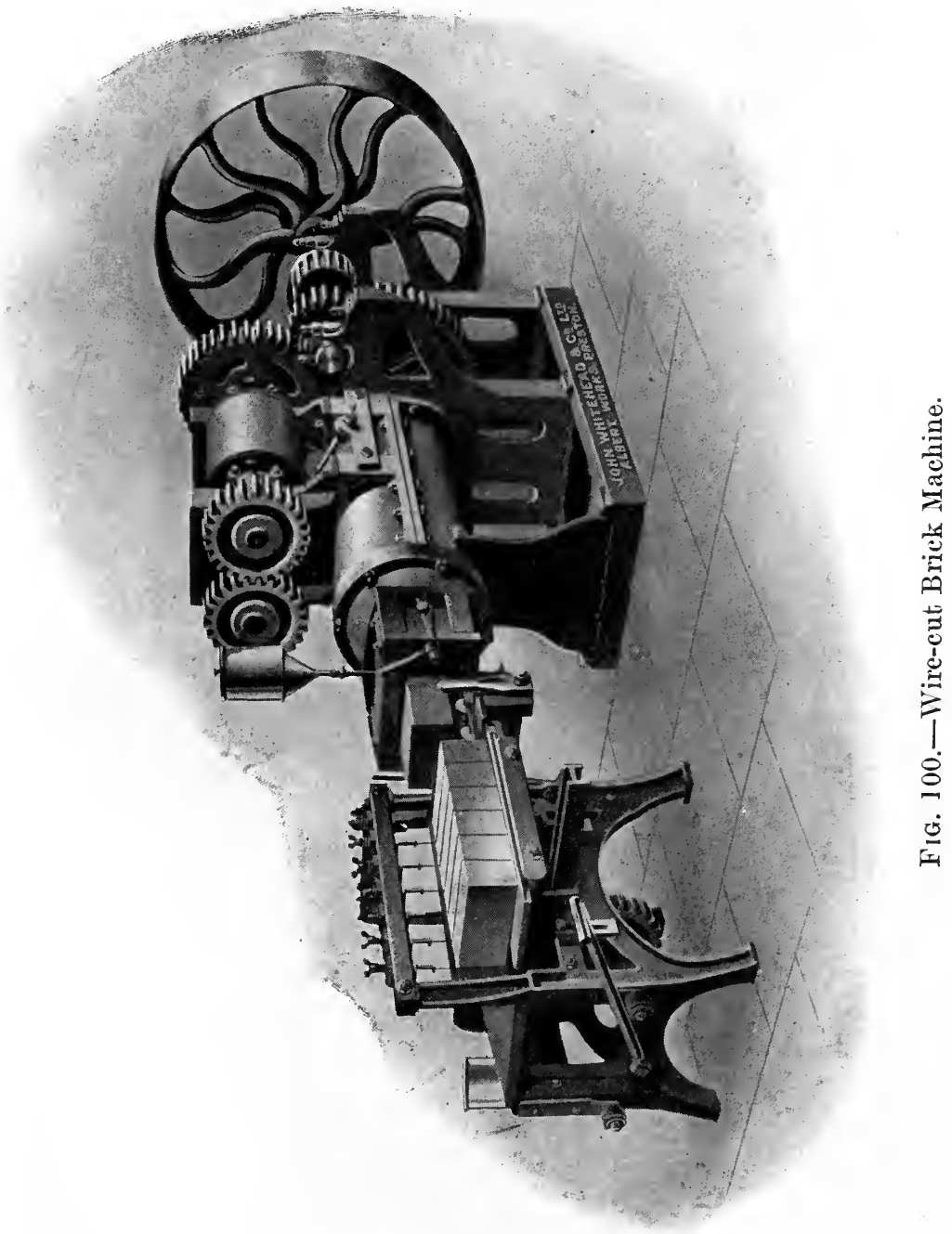

become dry and hard. The most generally employed arrangement for drying consists of a large concreted floor in a correc. 
spondingly large and well-ventilated shed. Beneath the floor is a series of flues heated by, steam or fires in such a manner that the temperature of the floor is as uniform as possible. Steam has several advantages over fires, particularly in the regulation of the temperature of various parts of the floor. Whichever source of heat is employed, the bricks are placed singly on the floor about $\frac{3}{4}$ inch apart and care is taken to avoid draughts and to raise the temperature very steadily. In three to five days the bricks are usually sufficiently dry to be taken to the kiln.

Where the output of bricks is sufficiently large a tunnel dryer may be employed and, if rightly constructed, will be more efficient than a drying floor. Unfortunately, however, many of the tunnel dryers now in use are far from satisfactory owing to the lack of knowledge, on the part of both designers and users, of the principles underlying the construction. In a tunnel dryer the bricks are placed on cars and enter one end of a tunnel, travel along it to the other end and finally emerge, after twenty-four to seventy hours, in a dry state. The simplicity of the operation, the reduction in theamount of handling, and the lower cost of heating are all in favour of the use of tunnel dryers, but at this and in all stages of brickmaking, the manufacture is not as simple as it appears to be, and both eare and skill are needed in the management of the temperature and ventilation of the tunnels.

The use of some means of drying plastic clays before they enter the kiln is imperative, as otherwise the bricks would erack and fall to pieces in the kiln. The details of design in a drying plant suited to a particular clay must be adapted to the special needs of that clay; it is no more reasonable to expect to dry a clay efficiently in a dryer which has not been made to suit it than it is for a man to expect to be well dressed in a ready-made suit of clothes, or for him to be suited with the first hat he tries on.

If, in spite of all care in drying and in the use of a dryer of suitable design, the proportion of bricks which crack continues to be large, there is a probability that the clay is too plastic and that it requires to be diluted with sand or some other non-plastic material. The impossibility of obtaining 
sand at a sufficiently cheap rate is one of the chief reasons why numerous clays-otherwise suitable-cannot be used for brickmaking.

If the cracks appear to emanate from the edges of any brand or other distinguishing mark stamped on the bricks or formed on them during the moulding, the texture of the material requires adjustment. If a coarse material is used, cracks are almost certain to be formed wherever there is an indentation in the bricks. The coarser particles act as centres of radiation for the cracks.

After being dried, the bricks are taken to a kiln and burned in a manner to be described later. There is often much unrecognised carelessness in drying which results in the production of numerous hair-like cracks in the bricks. These cracks are almost invisible in the unfired bricks, and their occurrence in the finished bricks is, for this reason, often wrongly attributed to the action of the kiln. Further details of the manufacture of bricks from a plastic paste will be found in the author's "Modern Brickmaking" (Scott, Greenwood \& Son).

In the semi-plastic or stiff-plastic methods of brickmaking a paste of such stiffness is employed that very considerable pressure has to be used in order to obtain the imprint of a thumb or finger. This very stiff paste is usually prepared from a powdered shale or other indurated clay, as the variations in stiffness of clays quarried in a stiff plastic condition make their use inconvenient.

The crushed, screened and powdered clay (p. 329) is received in an open mixer, and is there kneaded with the requisite quantity of water and passed into a small but powerful pugmill which compresses it into metal moulds. These moulds may be arranged on the top of a rotating table or on the circumference of a drum, both these constructions having proved satisfactory. The rough-shaped bricks or clots are then removed from the moulds, one at a time, and are pressed accurately to shape in a plunger-press, which is attached to the same framework. The shape of the moulds and the arrangements provided for removing the clots from them has a great influence on the power required by the machine, it 
being generally found that the simpler the clot mould the better. Thus, in the Bradley and Craven stiff-plastic brick machine the moulds are rectangular depressions in a horizontal steel dise; in the Scholefield machine they form similar depressions in the circumference of a drum, and in the Fawcett machine they form the "spaces" between the "cogs" in a peculiarly shaped " cogged wheel." In the two first-

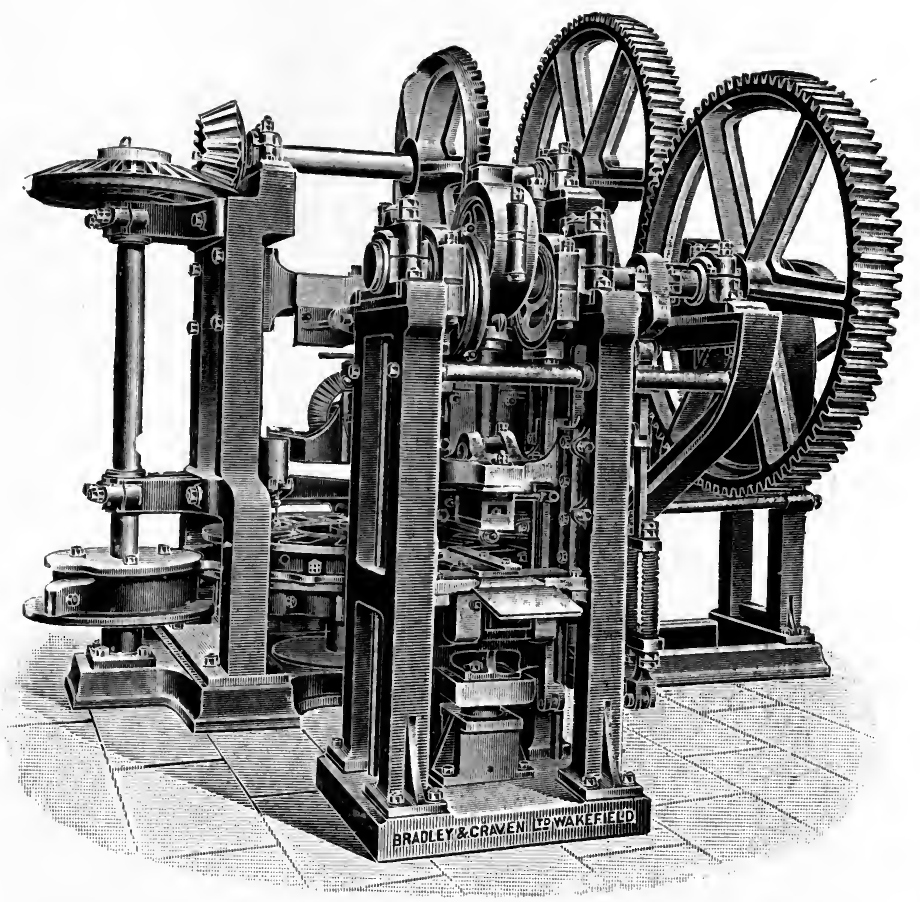

F1G. 101.-Bradley and Craven Stiff-plastic Brick-machine.

mentioned machines the clay is pressed upwards or outwards, but in the last-named one it is pressed longitudinally.

Each machine is rated at about 12,000 bricks per day, but the actual output depends on the nature of the clay.

The advantages of using so stiff a paste are twofold; the clay is obtained in a condition suitable for immediate pressing into shape, and the bricks may usually be sent direct to the 
kiln without the need of drying. A considerable saving is thereby effected, as it is difficult to watch the drying of plastic bricks so closely as to be able to re-press them when all are in the best condition for this operation, and, further, the cost of a dryer is completely avoided, though against this there is the cost of additional fuel required in the kiln. Where a continuous kiln is not available these bricks must, in some instances, be dried before being placed in intermittent kilns. The burning is carried out as described later.

Further details of the machines used for making stiff-plastic

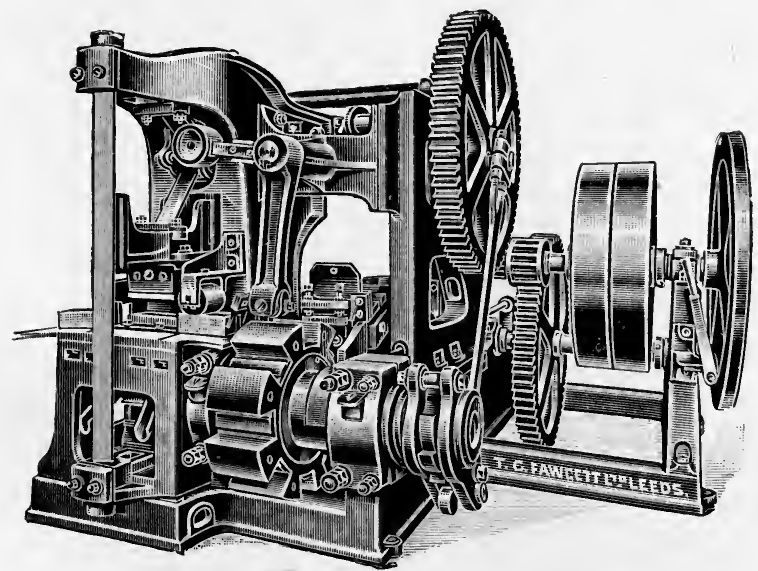

FIG. 102.-Fawcett S̊tiff-plastic Brick Machine.

bricks will be found in the author's "Modern Brickmaking" (Scott, Greenwood \& Son).

In the semi-dry process the material is used in the form of a powder which contains just sufficient moisture to make it " cake." It can only be used with shales and dry clay which are almost devoid of plasticity. The powder is obtained by crushing the material with edge runners, as already described (p. 329), and is fed into the boxes of plunger presses of a particularly powerful type, in which it is compressed into bricks. Several types of press are in use ; in each case they must be capable of exerting an enormous pressure and of giving several compressions in succession, as a single pressure, 
however great, will not produce a sound brick. It appears to be necessary to press once, release the pressure and allow air to escape, re-press, remove from the mould, and again re-press either once or twice before a reliable brick can be made from some matcrials.

The semi-dry process has gained its chief reputation in the neighbourhood of Accrington (where it is now being replaced

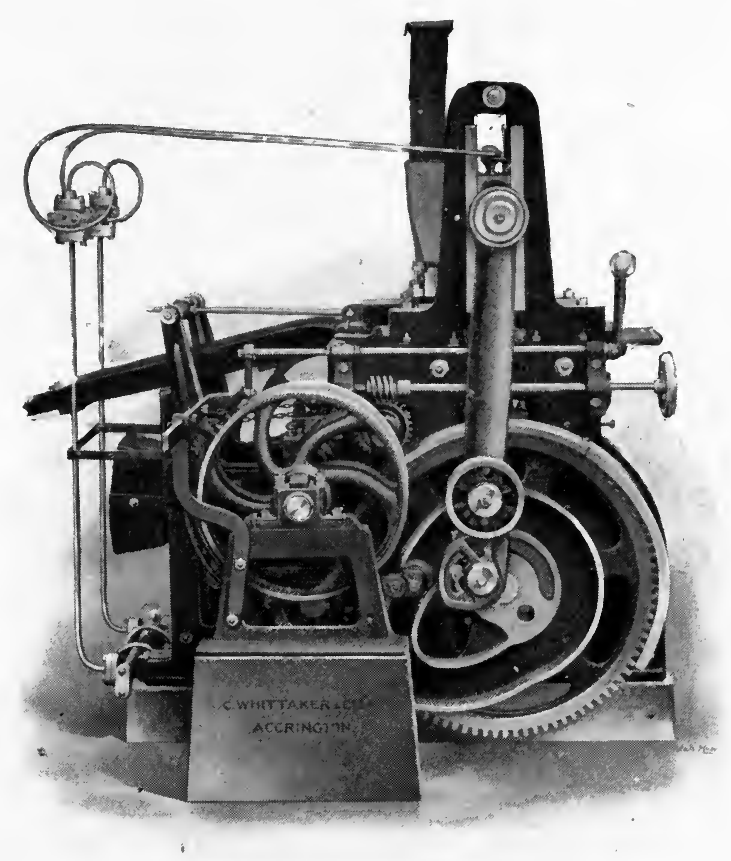

FIg. 103.-Whittaker Plunger Press.

by stiff-plastic machines) and Peterborough, where enormous quantities are made annually. It is claimed that, where it is applicable, this is the cheapest of all brickmaking processes when large quantities are required, though the bricks produced are less readily purchased by builders on account of their low porosity and their consequent tendency to "float" on mortar.

This process ought never to be installed except under expert advice which is quite independent of that of the various 
makers of machinery, or serious disappointment may result. It is therefore unnecessary to describe it in greater detail here, but a fuller description of it will be found in the author's "Modern Brickmaking" (Scott, Greenwood \& Son). As suggested, bricks made by the semi-dry process contain so little moisture that they are sent direct to the kiln and do not need to be dried.

The dry dust process is seldom used for bricks, as the difficultics experienced in obtaining sound bricks are very great. For tiles and other thin articles it is largely used. As the name implies, the clay or shale is ground to the form of a dust and this is placed in the box of the press and is duly compressed into the desired shape in a manner similar to bricks made by the semi-dry process. The difficulty of removing all air from between the particles and of exercising a perfectly uniform pressure over every part of the brick is so great as to make the use of a semi-dry material necessary for brickmaking. Indeed, the machines which are supposed to be making bricks from dry dust are, in almost every case, working with a slightly moistened material by means of the semi-dry process.

Re-pressing Bricks.-Facing bricks, or those in which great exactitude of shape and size is essential, are not infrequently placed in a re-press, and any irregularities in form are thereby corrected. Re-pressing is costly, as even with a power-driven press two strong youths cannot deal with more than 2,000 bricks a day, and even at this rate a considerable number of bricks will be defective. Unless the clay is in exactly the right condition the number of bricks which can be satisfactorily re-pressed will be very small. Too moist a paste will adhere too closely to the press box and plunger, no matter how well they are oiled, and too dry a clay will break and crack, thereby producing bricks of an unsightly appearance when burned. For this reason, where re-pressing is practised, both youths and foremen must be very alert as to the condition of the clay, and must be regardless of overtime if a large number of bricks is in the desired condition.

Much difference of opinion exists as to the real value of re-pressing. If the alteration in the shape of the brick or clot is appreciable, the structure of the brick will be damaged 
and the crushing strength seriously reduced. Where appearance and accuracy of shape are of such importance that a slight loss of strength need not be considered, re-pressing may be desirable. It is, however, quite a mistake to suppose that re-pressing really improves bricks; it may give them a better appearance, but it can only reduce their strength. Hence, the able brick manufacturer endeavours to make his bricks right at first and so to avoid the necessity of re-pressing. Burning Bricks.-In some countries, where the climatic conditions are favourable, bricks are simply placed in the sun, the rays from which are sufficiently intense to effect a sufficient hardening of the mass. Sun-baked bricks have so low a resistance that they are far from durable, so that one of the early results of civilisation is the substitution of bricks baked by means of fuel. In cooler climates the use of fuel is a necessity in the production of sound bricks.

Pieces of clay in the shape of bricks, but which have not been heated are termed green bricks, this term being analogous to that applied to freshly cut wood. "They cannot be used for building in moist climates, as they would be washed to pieces by a heavy shower of rain beating upon them. To render them permanent they must be heated to a temperature sufficiently high to make them durable.

When a piece of plastic clay is first allowed to dry thoroughly and is then heated slowly and steadily to a bright red heat, a number of remarkably interesting changes take place in both its chemical and physical properties. These are described more fully in a separate chapter, but the appliances used for effecting these changes may be briefly described here.

Two chief groups of appliances are used for heating bricks :

(a) Clamps, which consist of a peculiar stacking of the bricks and fuel, covering the outside of the stack, or clamp, with clay paste and then lighting the fuel. Under favourable conditions the heat produced will burn the raw clay into good and serviceable bricks.

Clamps are particularly suitable for small outputs, as there is no outlay for the construction of a kiln, but the bricks produced-whilst strong and durable-have not the pleasant appearance of kiln-burned bricks. 
The construction of a clamp requires too much skill for a detailed description to be given here. It consists essentially in building a series of flues, and above these the bricks are stacked close together, the direction of the courses changing frequently. Coke breeze is laid in the flues and fine coke or cinders is sprinkled over each course of bricks ; moreover, the bricks to be burned in clamps usually have a considerable percentage of coke or cinder dust mixed with the clay before it is used; this forms a further supply of fuel, with the result that when a clamp is burning briskly each brick becomes a sort of fireball, and the heating is so effective that only a very small proportion of fuel is needed. "London stocks" are typical clamp-burned bricks.

(b) Kilns or ovens, which consist of brickwork chambers into which the bricks are placed, the fuel being usually kept separate and burned in specially designed fireplaces or furnaces. Bricks burned in kilns have a more uniform and pleasing colour than those heated in clamps, and are of more uniform strength, but the cost of the kiln itself and of the additional fuel required enables clamp-burned bricks still to hold their own in districts where the clay or brick-earth is favourable. The number of different patterns of kilns is incalculable, but they can all be grouped under four heads, the kilns in each group differing from each other in details which, however, important in practice, cannot be adequately described here.

(1) Single up-draught kilns of rectangular shape, commonly termed Scotch kilns, are formed by building four walls around a suitably sized space, and providing a narrow doorway at each end and fireplaces along each of the longer sides. The top of the kiln is quite open and usually there is no chimney; though a series of small stacks-one to each fire-may be constructed if necessary. These kilns are filled with bricks carried through the doors or (in America) by means of a crane through the open top of the kiln. The bricks are stacked in a special manner about one finger's width apart, the courses being crossed so as to obtain the most uniform distribution of the heat. The top of the kiln is covered with old bricks and earth or ashes. Kilns of this type have long been in regular use in almost every county north of the Trent, but they are 
fuel wasters and are being replaced by continuous kilns wherever the output justifies the erection of the latter.

(2) Single down-draught kilns are either circular or rectangular in plan, and are covered with an arched roof or dome. The

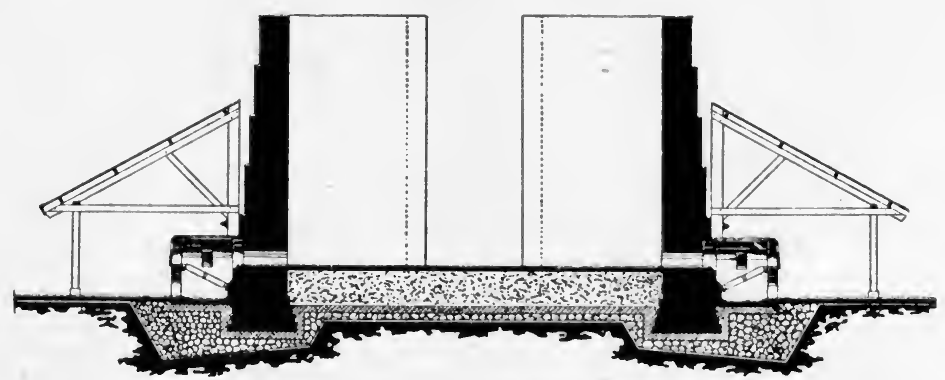

FIG. 104.—Single Up-draught Kiln.

fires are placed at regular intervals in the walls and the fire gases first rise up to the roof of the kiln and are then deflected downwards and distributed among the goods until they eventually pass out through flues in the floor of the kiln to the chimney

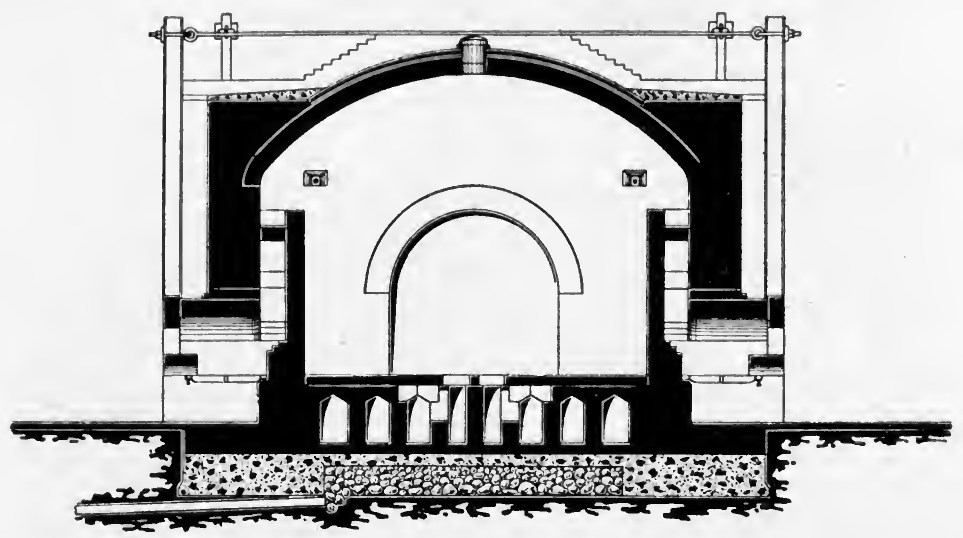

FIG. 105.--Single Down-draught Kiln.

stack. The great advantage of a well-built down-draught kiln is that facing bricks of best quality can be burned in it, the colour of the bricks not being damaged by the flame as in kilns with up-draught or horizontal draught. Consequently, 
for small yards where facing bricks, tiles and terra-cotta are made, single down-draught kilns are essential for these goods. In larger works, continuous kilns of a corresponding type are preferable.

(3) Single horizontal draught kilns are usually known as "Newcastle kilns" and are rectangular in plan. In outward appearance they resemble a rectangular down-draught kiln or a Scoteh kiln, to which a roof has been attached, but the fireplaces are arranged differently. In a Newcastle kiln the fires are all at one end, and the flames and hot gases travel horizontally through the goods to the opposite end, where they pass into a flue leading to the chimney. It is customary to

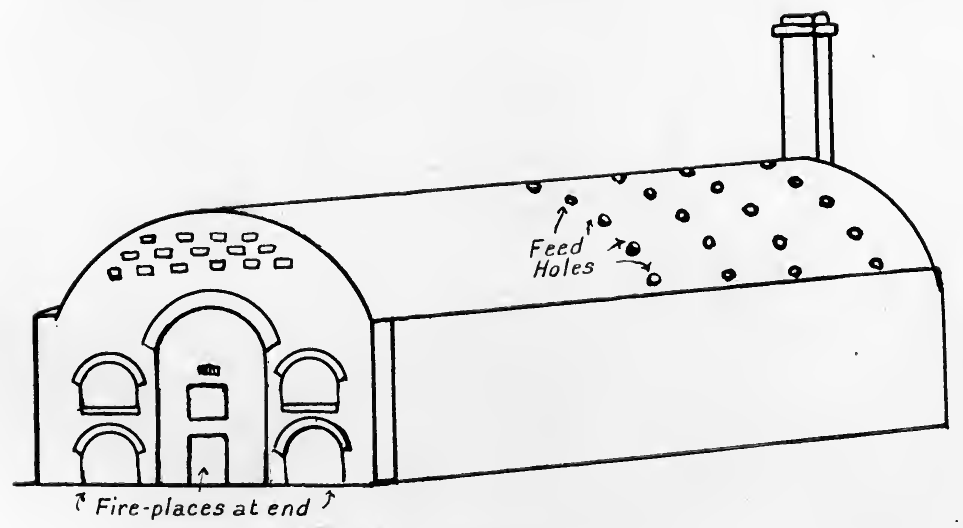

FIG. 106.-Newcastle Kiln.

arrange Newcastle kilns in series back to back, and when very large ones are used fires are built at both ends whilst the waste gases pass away at the centre. A separate ehimney may be built for each kiln, but where several kilns are in use it is better to employ a single chimney stack for all the kilns. Neweastle kilns are largely used for burning firebricks, though circular down-draught kilns are sometimes preferred for this purpose.

(4) Continuous kilns are really down-draught and horizontaldraught kilns, in which the waste gases from one kiln are not sent direct to the chimney, but are passed through a number of other kilns or " chambers" until the temperature of the gases is too low to be of further use. In these kilns the gases passing 
up the chimney should never have a temperature exceeding $130^{\circ} \mathrm{C}$., whereas those from single kilns frequently have a temperature of $800^{\circ} \mathrm{C}$. or even higher, thus wasting about half the fuel used. In a continuous kiln, on the contrary, this loss of fuel is prevented, as the heat which is not required to burn the goods to which it is first applied is utilised to warm up goods in other parts of the structure.

This method of heating is primarily due to Siemens, who adopted it in connection with the steel-melting furnace which bears his name. He observed that a large amount of heat was passing away from the furnace unused, and sought to utilise this by passing the waste gases through masses of checkered brickwork. When one such mass of brickwork was sufficiently heated the waste gases were diverted to another " regenerator" and air was drawn in the opposite direction through the hot brickwork. In this way hot air was supplied for the combustion of the fuel, and a great saving in heat was effected.

Hoffmann, who modified Siemens' furnace and applied it to brick-burning, soon saw that, instead of heating up permanent structures with the waste gases, the best result could be secured by using the bricks to be burned as regenerators, and accordingly devised the continuous kiln which bears his name. Many modifications of Hoffmann's original kiln have been made, and some of them are great improvements on it where the colour of the finished bricks is of importance, but in none of these improvements is the departure from the SiemensHoffmann regenerative principle very great, and most of the newer kilns may justly be regarded as adaptations of this principle to suit the special circumstances either as to the product or the fuel.

Wherever the output of a brickyard exceeds 15,000 bricks per day or 450,000 per year-and in some cases for even smaller outputs - a properly designed continuous kiln will be found to require only one-third to one-half the fuel needed by the corresponding number of single kilns, whilst the product is of equal value in every respect. There is a general impression that continuous kilns can only be used for common bricks; this is quite erroneous, as the best terra-cotta and facing bricks may be advantageously burned in continuous kilns. The 
nature of the product depends entirely on the suitability of the kiln for the purpose, and not on the "continuous" as distinct from "single" kilns. The selection of a kiln is, of course, a matter requiring expert knowledge, and even kiln builders themselves cannot be relied upon too implicitly in this direction, as they are naturally biassed in favour of the particular designs used by their firms and cannot be expected to admit that the kilns built by any other firm are more suitable for a particular case.

The following pages do not aim at presenting more than a mere outline of typical continuous kilns for various classes of bricks. They merely show the general principles of construction, and will require modification to local circumstances and requirements.

The original Hoffmann kilns were circular in plan, but it is found more convenient to adopt the shape shown in Fig. 3. The Hoffmann kiln, ${ }^{1}$ as now used, consists of a long brickwork structure containing a kind of endless tunnel from which a number of flues lead to a long central " main flue," the latter being connected directly to the chimney. Each of these flues is controlled by a separate damper.

In the "roof" of the "tunnel" is a series of rows of 5-inch openings, each row being about three feet apart and consisting of three, four or five holes. These openings are covered with air-tight metal caps, and are known as feed holes; through them the fuel is introduced into those portions of the kiln, whilst cold air is admitted through those parts which require cooling. Larger openings-termed "wickets" or "door gaps "- are made in the outer walls of the kiln and serve for the admission and removal of the bricks to be burned. The number of these wickets depends on the size of the kiln : usually there is one to each fourteen feet of linear kiln wall. A Hoffmann kiln of convenient size will have sixteen wickets and an equal number of dampers leading to the main flue.

As a matter of convenience, it is desirable to regard such a kiln as composed of a certain number of units or chambers, each of which corresponds to one wicket and one flue damper.

1 Hoffmann's patents have long since expired, and most firms of kiln builders are prepared to build "Hoffmann kilns." 
Thus, a kiln with sixteen wickets is termed a sixteen-chamber kiln, and is treated as though it were actually partitioned off into sixteen separate compartments, though, in reality, no such partitions exist in a true Hoffmann kiln. ${ }^{1}$ A smaller number than sixteen wickets is seldom desirable, though many kilns have only twelve or fourteen. They are, however, less economical in fuel than sixteen-chamber kilns, as the larger number of chambers permits a greater utilisation of the heat. It is, indeed, a very false idea of economy to erect a continuous kiln with a small number of chambers. If the output is to be small, the kiln should be made narrower than otherwise, i.e., the distance from the wickets to the centre of the kiln should be made less, but the effective perimeter of the kiln should never be less than 224 feet. In other words, the output of a continuous kiln should not be made to depend on the number of the chambers, but on their width. Failure to recognise this simple fact is the cause of much of the waste of fuel, and most of the disappointment which has attended the erection of continuous kilns in some localities.

The bricks are placed in the "tunnel" of a kiln, such as the one described, with their longer sides parallel to the length of the kiln, but a few courses of bricks at right angles to the others are valuable as "ties." The bricks are placed about $\frac{1}{2}$ inch or $\frac{5}{8}$ inch apart, so that the gases may travel between them and heat them uniformly. For the same reason a space of one or more inches is left between each blade or row of bricks. Immediately under each feed hole the bricks are arranged to form "fireplaces" in which the fuel can burn; these fireplaces may take the form of hollow shafts built of bricks, with oceasional projecting bricks to prevent all the fuel from falling directly to the bottom, or a trench or space the full width of the chamber may be left for the same purpose. The former method is usually regarded as being the more economical, as it wastes less space, but as one properly constructed trench to each fourteen feet of tunnel length is usually sufficient, there is very little difference in fuel consumption between the two eonstructions. By thus keeping the fuel entirely out of

1 For a description of continuous kilns in which permanent partitions are used, see later under the caption Chamber Kilns. 
contact with the bricks to be burned, the colour of the latter is greatly improved, and whereas only common bricks can be burned in the original Hoffmann kilns, facing bricks ean be burned in those provided with troughs and grates. The use of grates also enable the kilns to be fired from the front, i.e., from the ground level if this is preferred. As already remarked, there are many modifications of the Hoffmann kiln, in all the more important of which trenches, troughs or grates for the fuel are employed as in the Guthrie and Belgian kilns.

Assuming that the kiln is in full work, what takes place is, approximately, as follows: the fuel is fed into the feed holes covering three chambers (Nos. 1, 2 and 3) or about forty feet

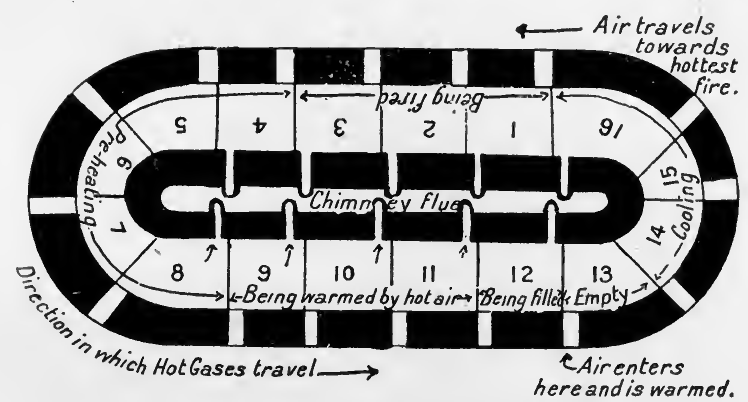

FIG. 107.-The Round of the Kiln.

of tunnel length, a light charge of fuel being placed in each hole every quarter of an hour. It is essential that the amount of fuel used should not be too large ; sufficient to fill an ordinary quart jug is ample, though in practice a very small shovel is the most convenient instrument for introducing the fuel. In a properly managed kiln the three chambers to which fuel is added will all be at a red-heat, and No. 1 will be nearly finished. The hot gases from the burning fuel will be carried by the draught through the five succeeding chambers (Nos. 4, $5,6,7$ and 8) and will gradually heat (i.e., pre-heat) them without their requiring any attention. After this, the gases will be of so low a temperature that they are no longer useful and are taken through the flue in chamber No. 8 into the main flue and so to the chimney. All the dampers in chambers 
1 to 7 are meanwhile kept closed, so that all the available heat is used in warming the bricks to be burned.

Chambers Nos. 9, 10 and 11 contain freshly-set bricks and these must be separated from the remainder of the kiln by partitions of paper or metal running across the whole of each side of the chamber, and their temperature must usually be raised to at least $120^{\circ} \mathrm{C}$. by a separate supply of heat; to heat them by waste gases would usually cause them to be badly scummed and so spoiled, though for some purposes this would not matter, and they may then be taken at once into what is termed the "round of the kiln" without any preliminary heating. Ordinarily, however, the bricks must be heated by as pure air as possible, until their temperature is such that no condensation products can form upon them ; $120^{\circ} \mathrm{C}$. being generally a suitable temperature for this purpose. The purest warm air obtainable is that which is drawn through the chambers containing cooling bricks, and many kilns have specially arranged flues for the supply of warm air for this purpose. Another, but less satisfactory method of warming the bricks to $120^{\circ} \mathrm{C}$. consists in lighting a small fire in the wicket and allowing air to pass over this into the chamber to be warmed. During this warming of the bricks the moisture present in them is driven off, and on cool days it forms a white smoke, whence this first stage of the burning is frequently termed uater-smoking or shortly, smoking.

As soon as the bricks have reached a temperature of about $120^{\circ} \mathrm{C}$. the partition between No. 8 and 9 is removed (or, if of paper, is torn) so as to admit the hot gases. The damper in No. 8 is closed, the supply of warm air to No. 9 is shut off and any opening made in connection with the wicket fire is closed. The hot gases from the fuel then pass into No. 9 chamber and the latter is then said to be "taken into the round of the kiln." Meanwhile, chamber No. 12 has been filled, and the "smoking" of this chamber is, therefore, commenced at once. Chamber No. 13 is, meanwhile, empty or being emptied, Chambers 14, 15 and 16, contain finished bricks which are cooling, this being accomplished automatically by the draught of the kiln which draws air through the open doorway of No. 13 through the bricks. The air thus admitted 
first comes into contact with almost cool bricks, and becomes gradually hotter in its journey until, when it reaches the burning fuel, it is of the same temperature as the hottest bricks in the kiln and ensures, with careful management, a very complete combustion of the fuel with scarcely any avoidable waste of heat.

Any description of the working of a continuous kiln must, necessarily, appear complicated, in reality these kilns are quite simple. As soon as a chamber is filled, its contents are first warmed by hot air or a wicket fire, and then it is taken into the round of the kiln as described. It then needs no further attention until it has become so hot that a little fuel must be fed into it in order to complete the burning. As soon as the contents of this chamber have been heated sufficiently, the addition of coal to it is stopped, another chamber is taken into the round of the kiln, and so on ; one chamber being emptied and another being filled continuously, and the fire travelling round and round the kiln in a perfectly regular and continuous manner. The work of the firemen is much lighter than for single kilns of equal output, and so long as the draught created by the chimney remains steady and the chambers are filled, emptied and fired regularly, there is little or no trouble.

Unfortunately, climatic changes greatly affect the draught and render constant watchfulness on the burner essential, and even with all the care possible, irregular heating will occur in stormy weather so long as a chimney is used to create the draught. For this reason, a number of firms have installed large fans-usually over six feet diameter-and in this way obtain a more powerful and perfectly steady draught. When carefully managed, their use for this purpose is highly advantageous, but like all other machinery, a fan requires to be understood, and well cared for, or it may cause trouble. The few failures which have arisen from the use of fans have, so far as the author has been able to investigate them, been due to three causes, none of which are the fault of the fan itself : (1) the use of too small a fan, (2) careless or improper management, and (3) failure to use and follow the indications of a recording draught gauge. A fan, being a far more powerful

c. 
draught producer than a chimney, requires to be kept under proper control ; it then works in the most satisfactory manner possible.

When it is desired to make bricks in large numbers over a period not exceeding five or six years-the colour of the bricks being unimportant so long as they are strong and well shaped - a much cheaper kiln may be constructed by omitting the arched roof and replacing it by a platting or cover of bricks laid flat and close together, and covering them with a 3-inch or 4-inch layer of cinder dust, sand or ballast. Holes are, of course, left in the platting for the insertion of feed-caps, it being usually convenient to employ square caps in this case. In a temporary kiln of this character the simplest possible form of construction should be used, the most convenient plan being a large rectangle 112 feet $\times 18$ feet internally, with stout walls well buttressed outside. Eight openings, each wide enough to admit a cart, are left in each side in order that the kiln may be filled and emptied expeditiously; these openings are closed by temporary brickwork, well coated with clay paste when the " chamber" to which they correspond is filled with fresh bricks.

Instead of the massive centre usual to permanent kilns, a single brickwork partition may be built longitudinally down the centre of the kiln, and a flue carried down each side of the kiln about one foot below the ground level may be connected to suitable openings (controlled by dampers) in the outer walls of the kiln and to the fan used to create the draught.

Kilns of this archless type have been used (with greater or less modification) with great success in the colonies and in the tropics, the saving in fuel as compared with ordinary kilns being fully 50 per cent. and sometimes 75 per cent. Two such kilns are in use in Great Britain at the present time under licence from the patentee, $\mathrm{H}$. Harrison.

Well-built Hoffmann kilns will usually require $2 \frac{1}{2}$ to $3 \mathrm{cwt}$. of coal per thousand bricks burned, but much depends on the quality of the coal used, on the nature of the clay and on the amount of vitrification needed in the goods. If grates or troughs and hot-air flues are used, the quantity of fuel will rise to 3 to 4 cwt. per thousand bricks, but should seldom 
exceed the higher figure. The fuel consumption of most Hoffmann kilns is, therefore, about half that of single kilns when a normal brick clay is being burned.

It may here be noted that the number of patents which have been taken out for some small modification of the Hoffmann kiln is very large. Consequently, there are many kilns advertised under various distinctive names which are, in reality, nothing but Hoffmann kilns with a flue for supplying hot air to the chambers to be "smoked," and grates or troughs for the fuel instead of the original shafts. The distinctive features of all these separate modifications of Hoffmann's original kiln would occupy more space than can be devoted to them in the present volume. Readers who wish to study the details more freely will find them set out very fully in the author's "Kilns and Kiln Burning." Two modifications may, however, be mentioned here on account of their different construction in several important particulars, and particularly because they are really composed of a series of chambers connected in such a manner as to work continuously. For this reason they are conveniently considered as a different type of kiln, and are suitably termed chamber kilns.

The "Staffordshire" kiln, in general shape, resembles the modern Hoffmann kiln, but internally it is divided into a number of chambers by permanent partitions. These partitions have vertical slits in them which can be closed by means of vertical dampers when it is required to shut off a chamber for water-smoking, annealing or other purposes. A number of special flues are also constructed in the roof and floor of the kiln so as to provide an ample supply of hot air for smoking, aiding combustion or for prolonged heating in a current of hot air, such as is needed with certain brick clays which, otherwise, form black cores or " hearts." As the amount of air which can be heated by drawing it through the chambers containing cooling bricks is not sufficient for all these purposes, the Staffordshire kiln is provided with additional flues in the arched roof of the kiln through which an additional supply of air can be drawn and heated. It should, however, be pointed out that the use of these flues involves the consumption of an additional amount of fuel in order to replace the heat 
supplied to the air by them. The convenience of this method of heating the air is, however, so great that it is, in the end, one of the most satisfactory ways of obtaining a sufficiently large supply of hot air. A number of other kilns have accessory flues of this character, thus, in Brown's kiln the flues are placed beneath the floor instead of in the roof.

With some clays it is necessary to provide for the rapid removal of large volumes of steam produced during the "smoking," and here again the "Staffordshire" kiln is well prepared. As in some cases the steam is best removed from the upper part of the kiln, and in others from near the floor level, arrangements for both are provided, and the steam evolved by the goods is therefore removed in any direction desired and at any speed which may be considered suitable. This kiln has, in fact, long been regarded as the most completely fitted continuous kiln at present in use, and in it large numbers of best facing bricks, terra-cotta and other valuable clay products are burned with complete success, the results being in every way equal to those obtained by the best single downdraught kilns and this, notwithstanding the fact that the draught in the Staffordshire kiln is horizontal rather than "down-draught" in direction, though it can be made completely down-draught if required. The fuel consumption of a Staffordshire kiln is about $\frac{1}{2}$ to 1 cwt. more than that of a plain Hoffmann kiln, but as the latter cannot be used for facing bricks and terra-cotta, the additional fuel consumption may be regarded as necessary.

Where a completely down-draught kiln is required without the additional flues provided in the kiln just mentioned and yet with the low fuel consumption of a continuous kiln, the "Ruabon" kiln will prove very suitable. This consists of a number of down-draught kilns arranged consecutively, the waste gases from one kiln passing directly into the next and through as many subsequent ones as may be considered desirable. By arranging the kilns in this manner most of the advantages of a continuous kiln are obtained in combination with the excellent colour and strength of goods burned in single down-draught kilns. The Ruabon kiln requires about $1 \frac{1}{2}$ to 2 cwt. per thousand bricks more than the plain Hoffmann 
kiln, or about $\frac{5}{8}$ ths of that of separate down-draught kilns of equal capacity.

From what has been stated about continuous and chamber kilns, the reader will understand that the greatest advantages are derived from those kilns in which the gases from the kiln travel the longest distance over and among bricks before they enter the exit flue, and those in which the distance the incoming air-has to travel among cooling bricks before it reaches the burning fuel. There is a great tendency in most British works to use kilns in which these distances are far too short, and consequently the amount of fuel burned is greater than would be the case if the kilns had been more advantageously designed. For instance, in twelve-chamber and fourteen-chamber kilns a wastage of $\frac{1}{2}$ to 1 cwt. of coal per thousand bricks is common, and would have been avoided had the kiln been built with sixteen or eighteen chambers.

Most continuous kilns in the United Kingdom are too wide, and therefore too short, this defect having originated from the fact that it is easier to get a good draught with a short, wide kiln than with a long, narrow one. Since the substitution of fans for chimneys in creating the draught, the use of such wide kilns is no longer neressary for bricks, especially as narrower kilns have several advantages. Hence, about thirty years ago, Jacob Bührer effected a great saving in fuel and a large increase in output by the use of a continuous kiln with a tunnel about twice as long and half as wide as those commonly in use. In order to overcome the difficulties of construction and loss of heat incidental to an extremely long and narrow kiln, Bührer arranged his tunnel in a zigzag manner (Fig. 108) so that whilst externally his kiln is square in plan, its effective tunnel length is almost double that of a Hoffmann kiln covering the same area. In this manner a continuous kiln can be built for common bricks with a fuel consumption of about 2 to $2 \frac{1}{2} \mathrm{cwt}$. per thousand, and as the fire travels very rapidly forward in so narrow a kiln, the conveniences and advantages which accrue from this are readily obtained. For various reasons Bührer's kilns have made no headway in the United Kingdom, there being only one-and that a new one-in use at the present time, whereas 
in Europe and abroad generally, they have been built in large numbers.

The use of a tunnel kiln in which the bricks to be burned are

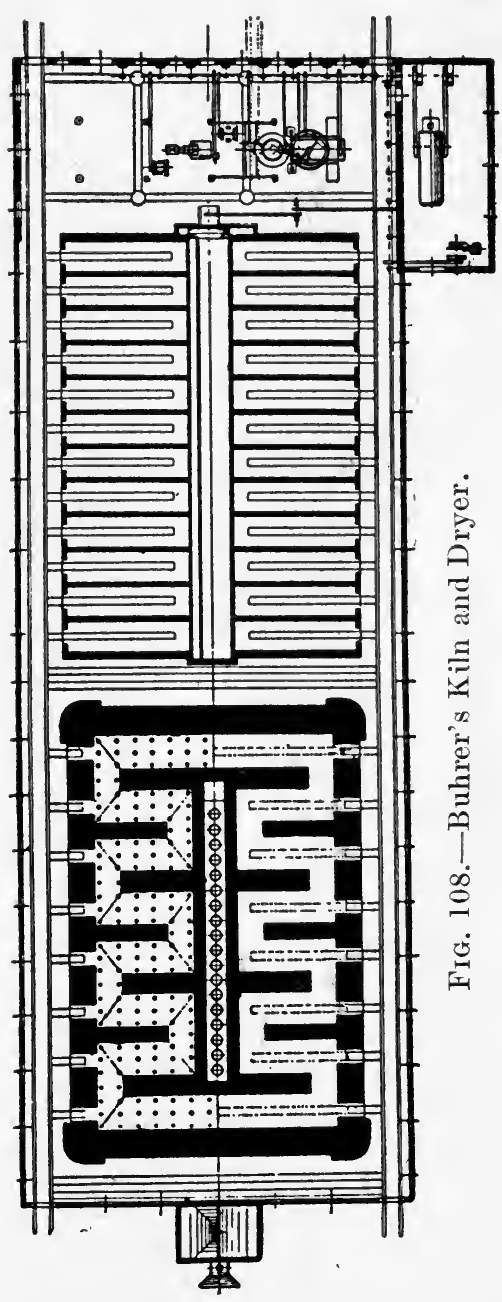
placed on small waggons and run slowly through a tunnel, the centre of which is heated to the finishing temperature of the bricks, has met with considerable success abroad, but has not been used in the United Kingdom except for pottery and other wares which are more expensive than bricks. The cost of repairs of the central portion of the tunnel when such solid materials as bricks are being burned, is greater than the cost of repairs of other types of continuous kilns.

Kilns in which gas is used instead of solid fuel are slowly increasing in popularity. They are no more economical than continuous kilns in which coal is used, so far as fuel consumption is concerned, but they are easier to regulate and to maintain at a constant temperature, and with some clays this is very important.

The changes which occur to bricks and other articles whilst they are in the kilns, form the subject of the following chapter. It is here sufficient to remark that the heating must be slow and steady from start to finish, as too rapid a rise in temperature or sudden changes in the temperature will result in cracked, 
warped or twisted goods. Similarly, the cooling must also be slow and uniform, great care being taken to avoid cold air impinging directly on to very hot goods. It is also obvious that the effect of the heat must be watched very carefully; if insufficiently heated, the goods will be weak and porous, whilst if over burned they will be misshapen. The man in charge of the kiln ascertains the completion of the burning by means of trials, shrinkage measurements or Seger cones. Pyrometers are sometimes used to determine the temperature actually reached, but what is required is the effect of the heatwhich is a function of the time of heating as well as of the temperature-and this cannot be ascertained by a pyrometer such as is used in other industries.

Trials consist of bricks or other pieces of clay which are placed in such parts of the kiln as to be easily removable whilst the kiln is being fired. One or more of these trials is withdrawn at intervals and is carefully examined. If it possesses all the desired characteristics of the finished brick the burning is considered to be finished; otherwise, it is continued until a satisfactorily fired trial is obtained. In most cases, the properties of trial bricks are not sufficiently distinctive to be clearly discernible, but with some clays, trials are invaluable. For instance, some bricks, when broken, show a black core or " heart," due to too rapid or incomplete burning. Such cores are objectionable in several ways, and they can be removed or prevented by careful heating with an ample supply of air at a temperature corresponding to a dullred heat. When a clay has a tendency to produce bricks with this defect, the withdrawal of trials at intervals is one of the simplest and most efficacious methods of ascertaining whether the formation of dark cores is being prevented or whether the cores are being properly burned out.

Trials are also useful, though to a much smaller extent, when bricks of a certain colour are required. Unfortunately, the rapid cooling of the trials - which is unavoidable-has a marked influence on the colour and renders accurate comparison impossible with some clays.

Glazed bricks are almost invariably burned with the aid of trials, as the appearance of the glaze can be readily judged in 
this manner and the firing regulated accordingly. Pieces of clay of convenient shape are covered with glaze in the same manner as the bricks-usually by dipping them into a cream or slurry made by mixing the glaze materials with water. Several of these trial pieces are placed in various parts of the kiln and are withdrawn and examined at intervals. A trial which has once been withdrawn should never be replaced; hence the need of a number of trials in each kiln or chamber.

Shrinkage measurements form an admirable method of determining the effect of the firing. All clays shrink when heated, and if the conditions of manufacture are kept reasonably constant, the amount of shrinkage will be uniform. The total shrinkage which occurs in the kiln is not great, averaging about $\frac{1}{2}$ inch per linear foot of material, so that a large amount of material is needed for an accurate measurement. The method usually adopted is very ingenious and consists in inserting an iron through the roof of the kiln until it touches the top of the bricks being burned. As the height to which the bricks are stacked in the kiln is known, their height during and after burning can readily be ascertained by noting how far the iron rod must be inserted. The pressure of the bricks in the upper part of the kiln affects the contraction of the lower ones to a slight extent, so that the shrinkage measured in this manner is somewhat greater than the average shrinkage of each brick. It will usually be found that the iron "shrinkage rod " can be inserted about three to five inches further into the kiln after the burning is complete, than it can at the start; the " settlement" of bricks in different districts varies, however, and in some localities a shrinkage of nine or even ten inches is not unusual. Bricks fired in clamps with a layer of fuel between the courses appear to shrink much more than those burned in kilns, because, as the fuel burns away, the bricks sink and take its place.

Measurements of the shrinkage of trial pieces are less satisfactory, as the roughness of the surface makes the errors of measurement on the smaller pieces very great.

Seger cones are small pyramids made of special materials. When placed in a kiln these pyramids bend over and form an arch, the heat-effect corresponding to a particular cone being 
quite constant. The cones are numbered and form a very extensive series, those most used for bricks being :-

No. $015 a$ to No. $2 a$ for building bricks.

No. $1 a$ to 14 for sintered bricks, paviours and clinkers.

No. $6 a$ to 9 for glazed bricks.

No. 6 to 20 for fire-bricks.

Strictly speaking, the Seger cones do not correspond to any definite temperatures, but to heat effects on the materials of which they are made. For this reason they are more valuable than simple temperature indicators, such as pyrometers. If, however, the heating is steady and the rise in temperature corresponds to that at which the cones have been tested by the manufacturers-about $\frac{1}{2}^{\circ} \mathrm{C}$. per minute-the cones correspond with sufficient accuracy to the tables of temperature supplied with them. For slower or more rapid heating, an error, depending on the time of heating, is introduced; this does not interfere with the use of cones in kilns, as in the latter the rate of heating should be as constant as possible each time the kiln is burned, and cones can, therefore, be relied upon to indicate whether the bricks and other goods have been sufficiently heated.

The use of these cones is quite simple : a trial is first made to ascertain which cone corresponds to the correct finishing point of the kiln, and afterwards the cones are arranged in groups of three in various parts of the kiln. In each group one cone bends at about $20^{\circ} \mathrm{C}$. below the correct finishing point of the kiln, the second cone indicates this finishing point, and the third, which should bend about $20^{\circ} \mathrm{C}$. above the second, is used as a precaution to show that the kiln has not been overheated. The cones are placed so that they can be viewed through spy-holes in the walls or top of the kiln, and by their use the progress of the burning can be watched with the greatest ease. If a clay is difficult to manage at a temperature much below the finishing point, the use of additional cones corresponding to the lower temperature enables the burner to know when any desired stage of the burning above the darkest visible red heat has been reached.

A wise burner will not rely solely on trials or shrinkage or cones, but will employ all three methods of controlling the 
kiln, and will, in addition, be able to tell by the colour of the inside of the kiln and by its general appearance whether the burning is or is not proceeding satisfactorily.

The manufacture of bricks by machinery is not difficult so far as the production of the undried and unburned bricks is concerned-though even here more technical skill and experience are necessary than is generally imagined. The chief difficulties of manufacture occur in the drying and in the burning, and so complex are the changes which occur in these two stages of manufacture that even when the greatest care is taken by the most skilful expert an occasional batch of defective bricks is produced.

If a firm manufacturing facing bricks can continue week in week out for several years without producing more than 4 per cent. of their output which is unsaleable as facing bricks, such a firm may be considered very fortunate. It is difficult to state the average ratio of facing bricks actually obtained to those made, but it will seldom exceed 90 per cent., most of the remainder being sold as common bricks, and a few being quite unsaleable except as brickbats. In the manufacture of common building bricks the ratio of saleable bricks to bricks made is about 97 per cent. in well-managed works, but with inferior management or unskilful burners it may drop, at times, to as low as 50 per cent.

In the manufacture of firebricks, which are usually moulded by hand, dried on a steam-heated floor and burned at cones 6 to 20 , according to the quality of the material used, the proportion of first-class bricks to the total output is about the same as that for facing bricks. Some firms are, however, more careful in sorting, and in this way they are able to supply bricks for various purposes at prices which represent a loss of not more than $1 \frac{1}{2}$ to 2 per cent. of the total number of bricks made. 


\section{CHAPTER XIII}

THE CHEMICAL AND OTHER CHANGES IN DRYING AND BURNING BRICKS

IT has been explained in a previous chapter that the " clays" used for the manufacture of building bricks are far from pure. They may, indeed, be regarded as mixtures of $(a)$ true clay, (b) sand, and $(c)$ fusible minerals.

In the green or unburned bricks these materials are in the form of a compressed powder containing grains of widely different sizes, from the coarse pieces of stone or gravel of $\frac{1}{4}$ inch diameter to the particles of clay which are so fine that their shape cannot be clearly distinguished under the most powerful microscope. In addition to these materials, most raw bricks contain a certain amount of water which has been added to secure the proper cohesion of the solid particles. This water, which in plastic bricks may easily amount to $1 \mathrm{lb}$. in each brick made, must be completely removed during the drying.

In the freshly-made brick, each solid particle may be regarded as surrounded more or less perfectly by a film of water which keeps each of the solid particles slightly separated from each other. When a brick is dried, however, this water is removed, and consequently the solid particles move nearer together. This is shown diagrammatically in Fig. 109, in which the solid particles are represented by black discs, the space between them in the left side (A) of the illustration indicating the water which separates them. When this water has been removed by drying, the particles take up the position shown in the right side $(\mathrm{B})$ of the diagram, and it will at once be observed that the total volume of the material has been reduced by the removal of the water. In other words the brick has shrunk on drying. 


\section{CHANGES IN DRYING AND BURNING BRICKS}

Whether the water in the freshly-made bricks is really in the form of a film, as suggested above, or whether it is in a state similar to that contained in glue which has been soaked for several hours, is a matter concerning which there is a divergence of opinion. Those who regard clays as colloidal substances naturally maintain that the bulk of the water is retained within the "meshes" of the colloidal aggregate, whilst others hold that the water which causes the shrinkage is almost, if not entirely, superficial, and acts as a film surrounding each particle.

In all probability the water occurs both as a film surrounding some of the particles and also in an adsorbed or enmeshed condition. Such water is conveniently termed shrinkage water.

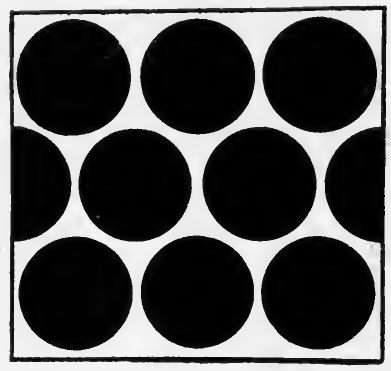

A

FIG. 109.

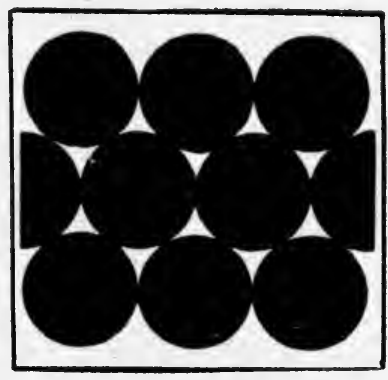

B

There is, however, a small proportion of water which occupies the pores or spaces between the particles, even when the latter are packed as closely as possible; this is conveniently termed the pore water.

If the diagram $\mathrm{B}$ is observed closely it will be noticed that there are a number of white spaces still left between the black discs. These contain the "pore water" just mentioned, and correspond to a stage in the drying at which the particles cannot move closer together, and yet-some water is still present in the brick; that is to say, the shrinkage ceases before all the water has been evaporated. This stage is very important to brick and terra-cotta manufacturers, though less attention is paid to it than its importance deserves. During the first stage of drying, when the particles are in motion, on 
account of the evaporation of the water which separates them from each other, there is a great danger of cracking and twisting. Some bricks are, indeed, so sensitive that they present great difficulties, and the clays from which they are made are practically worthless, because of the large proportion of cracked and warped bricks produced. As soon as the shrinkage ceases, however, the remainder of the water present may be readily evaporated, the sensitiveness of the material having almost entirely disappeared. Thus, bricks which have to be kept covered and fully protected from heat and draughts during the first stage of drying may be placed on a hot floor or even on an iron plate heated by a gas burner without damage during the removal of the remainder of the water. The wise manufacturer, therefore, ascertains as accurately as possible when the shrinkage during drying has ceased, and he then completes the removal of the water at a more rapid rate, usually by sending the bricks to. the kiln.

To remove the whole of the water from the bricks in a dryer is to work more slowly and less economically than when all the shrinkage water is taken out in a dryer and the remainder of the water is removed in the kiln.

Previous to the bricks entering the kiln, the only changes which occur in them are the removal of the water used to facilitate the shaping of the clay and the reduction in the size of the bricks due to the particles drawing closer to each other. Bricks made by the semi-dry process contain so little water that they are sent direct to the kilns, as the drying shrinkage they undergo is practically negligible. Bricks made of softer and more plastic clay require to be dried in hacks (p. 335), on a steam-heated floor or in a special dryer before they can be sent to the kilns. In short, the changes in drying are purely of a physical character, unless it may be assumed that the clay is a swollen colloid, the water enmeshed in it being in the form of a loosely combined compound and not simply in an adsorbed form. This loose combination is quite possible and has some evidence in its favour, but the view that the clay simply changes physically during drying is more readily understood, and as it explains most, if not all, the phenomena observed during drying, it is generally 


\section{CHANGES IN DRYING AND BURNING BRICKS}

accepted, notwithstanding the evidence in favour of the other theory.

It is after the bricks have entered the kilns that the greatest and most important changes occur. Before doing so, the bricks are soft, friable, grey masses, which must be handled with great care or corners and arrises will be broken off. If placed in a bowl of water such bricks would soften and, in time, would fall to powder or to a sticky shapeless mass of loosely coherent mud. When removed from the kiln, the bricks have increased enormously in hardness; instead of being weak and friable their resistance to crushing is exceptionally great, and is equal

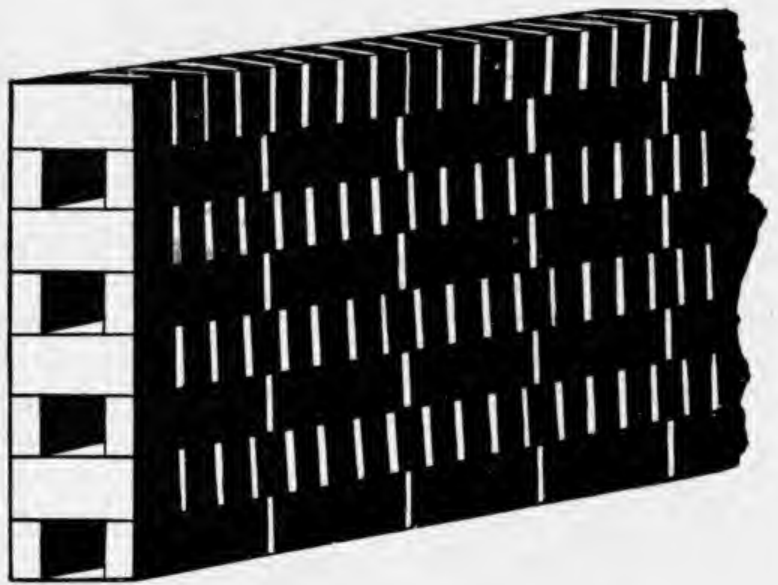

FIG. 110.-Bricks arranged in Hack.

or even superior to that of stone ; they are unaffected by water and atmospheric conditions, and form one of the most durable materials known. What, then, are the causes which have brought about so remarkable a change in the nature of the materials? How is it that such changes can occur as the result of heating the bricks?

In the first place, these great changes in the physical properties of the bricks are the result of a series of chemical changes of considerable complexity. As soon as the bricks are warmed to a slightly higher temperature to that to which they have previously been exposed, the remainder of the 
moisture or pore water in them is evaporated. This may be completely removed at or below a temperature of $120^{\circ} \mathrm{C}$., i.e., during the "smoking" period.

As the temperature rises above $120^{\circ} \mathrm{C}$. the clay and some of the fusible minerals begin to decompose, and at $500^{\circ} \mathrm{C}$. the decomposition is sufficiently rapid for the steam produced to become noticeable. No matter how carefully a clay is dried, it will be found on heating it to a temperature of 500 to $600^{\circ} \mathrm{C}$. to evolve a considerable amount of water. This water is not added to the clay, for it is an essential part of its constitution ; indeed, it does not exist as water in the clay, but the elements of which the clay molecule are composed are so arranged that on reaching the temperature mentioned the clay is decomposed, and one of the products of its decomposition is water. The amount of this combined water in a brick depends on the amount of true clay present ; ordinarily it is not more than 5 or 6 per cent. of the dried brick, but in a pure clay, such as the finest grades of china clay, it reaches 13 per cent.

With a steadily increasing temperature the decomposition of the clay and other hydrous minerals continues, water being evolved in the form of steam, rapidly at 500 to $600^{\circ} \mathrm{C}$., and more slowly at higher temperatures as the amount of undecomposed clay diminishes.

As soon as the whole of the clay has been decomposed, the brick consists of a light porous mixture of aluminosilicic anhydride (i.e., the calcined or dehydrated clay), ${ }^{1}$ sand and dehydrated fusible minerals, with negligible proportions of hydrous minerals which have not yet been affected by the heat. If removed from the kiln at this stage the bricks would be weaker and more friable than at first, but a little harder so far as the average particles are concerned. The colour would be a dirty grey, with irregular patches of black sooty matter derived from the vegetable matter contained in all clays.

As the temperature increases still more and reaches a red heat, the vegetable and other organic matter present begins to burn, and in some cases its combustion may require special

1 The precise constitution of this material is so complex that it cannot be described fully here. Some indications of its nature have becn given on pp. 40-43. 
attention. For instance, some of the shales used for brickmaking contain considerable quantities of paraffin and allied substances which, on heating, form readily combustible shale oil, and if carelessly managed this may burn too rapidly and result in the bricks being seriously overheated and so spoiled. In most brick clays, however, the proportion of combustible matter is too small to be serious in its consequences, though it is a prolific source of blue-black cores and hearts. In any case the kiln must be kept at a dull red heat until the whole of this combustible matter has been burned away, the supply of fuel being restricted and that of the air being controlled so as to secure complete combustion without an undue rise in temperature. If at this stage of the burning the temperature rises too high, vitrification will set in and it will be impossible to burn out the combustible matter.

Between the end of the removal of the shrinkage water in drying and the complete decomposition of the clay and the combustion of the organic matter present, the bricks undergo a second contraction or kiln shrinkage which is usually about equal in amount to (though frequently less than) that of the shrinkage in drying. This kiln shrinkage is partly due to the decomposition of the clay and other hydrous minerals present, whereby the particles become still smaller, and therefore occupy still less space than before. The kiln shrinkage is also due, in part, to fusion of some of the particles, as described later. Both these forms of kiln shrinkage are shown diagrammatically in Fig. 111, in which B is reproduced from Fig. 109 and indicates the particles which have shrunk in drying, whilst $\mathrm{C}$ shows further contraction which occurs in the kiln, due to decomposition of the clay, and D the material after partial fusion, the fused portion having filled some of the pore spaces, as shown.

The kiln shrinkage, which commences in the manner described, continues until the heating is finished, because as the temperature increases still further the more fusible materials begin to melt and then flow into the pores or interstices between the particles. This fusion increases as the temperature rises or the heating is prolonged.

Grains of sand, and particles of stone, gravel and various minerals other than clay, do not show the same kind of shrink- 
age as the clay grains. Many minerals only shrink when they reach a temperature near to the finishing point of the firing, and a few retain their volume throughout. The chief shrinkage occurs in the case of limestone which, on heating, is decomposed into carbonic acid gas, which escapes, and quicklime which remains in the bricks. All forms of limestone are objectionable as a constituent of bricks, but their presence is particularly detrimental when they occur in the form of race or septaria nodules. The quicklime formed in the kiln slakes slowly when the bricks are exposed to the air, and swells as it absorbs atmospheric moisture and acids. The white patches of lime near the surface of the bricks are soon washed out and leave unpleasant cavities; those somewhat below the surface will create strains in the bricks, which may cause parts of the latter to crack or spall off, and in very bad cases the whole of the bricks may be reduced to a mass of useless material. These D phenomena are known technically as blowing, and are, as already stated, due to the lime present in the clay. If the lime compound is in a very finely divided state, as in washed chalk, the bricks
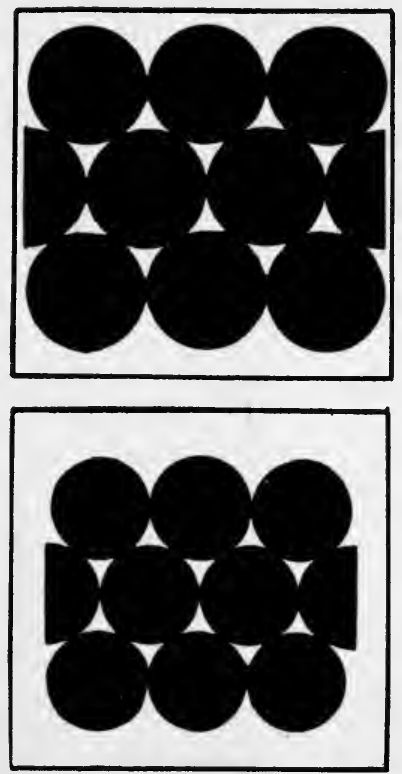

will not blow ; indeed, this defect may sometimes be prevented by grinding the clay (and consequently the lime compound) to an exceedingly fine powder.

Very small grains of lime, soda or potash combine with the clay at high temperatures and form a fused, glassy material. If the proportion of this is sufficiently large the bricks c. B B 
will lose their shape and may even fuse to a shapeless slag.

Iron compounds, when heated to a temperature at which all shrinkage in the bricks ceases, will produce the red compound which is the characteristic colouring material of red bricks, unless the presence of lime or reducing gases prevents the formation of this compound.

Pyrites, or iron disulphide, on the contrary, produces black slag-like spots of a ferrous silicate or ferrous alumino-silicate, and only under abnormal conditions does it form a red compound.

Soluble salts in the clay will be brought to the surface by the moisture, as it evaporates during the drying and early stage of burning and will form an efflorescence or scum on the bricks. If the temperature is sufficiently high these salts will combine with the clay and will then form a slight coating of glaze, the scum simultaneously disappearing. The production of this scum may be prevented, in many instances, by rendering the salts insoluble, as by the addition of barium carbonate to the raw clay.

Minerals of the felspar type fuse independently of the clay if the temperature reached in the kiln is sufficiently high, but in the manufacture of most building bricks it is seldom more than a very slight fusion of these minerals occurs except in the presence of some other more fusible minerals which, by their chemical action, lower the temperature required for the fusion of the felspar, etc.

If the bricks were to be removed from the kiln very soon after the first signs of fusion of some of the particles had commenced, they would be of moderate strength and only useful for inside work ; their colour would be pale or irregular, and they would be typical baked bricks.

Such bricks are used in large quantities for the interiors of buildings or where they can be covered with stucco or other waterproof material. The white bricks of Suffolk, the primrosecoloured bricks of other localities, "rubbers," "cutters," bath-bricks and all firebricks are of this type, as are many red building bricks. They are readily distinguished from more fully-burned bricks by the dull sound produced when two baked 
bricks are struck together-a sound very different from the clear, metallic note of a fully vitrified brick.

Another characteristic of baked bricks is their high porosity, whereby they can absorb upwards of 15 per cent. of water and yet appear to be perfectly dry. Bricklayers prefer such bricks, as the mortar adheres to them more rapidly, with little or no liability to "float."

In the manufacture of red facing bricks, for building purposes, and terra-cotta, the colour of the burned material is of great importance, and as soon as the articles have attained sufficient strength, the manufacturer concentrates all his attention in obtaining a pleasant colour. For this purpose he may prolong the heating indefinitely after vitrification or the melting of the more readily fusible particles has commenced, and will stop the heating as soon as a satisfactory colour has been obtained.

The red colour of bricks and terra-cotta is primarily due to iron compounds in the clay, these forming iron oxide or other polymerised compounds of a red colour when the clay is heated. As the temperature in the kiln rises, or the heating is prolonged, the colour increases in intensity until a maximum is reached, after which the fused material present affects the colour, converting it into a dark and unpleasant brown shade if the atmosphere inside the kiln is oxidising, or into a bluish grey or black if reducing gases are present in the kiln. Eventually, if the temperature rises still further, or the heating is excessively prolonged, the amount of fused matter produced destroys the strength of the remainder and the brick becomes a shapeless mass of slag. The burner must, therefore, stop the heating of the kiln as soon as the contents have reached the desired colour, or even slightly before this, because of the effect of the heat in the kiln whilst the fires are dying down.

When dark-coloured bricks are required, the addition of 2 to 4 per cent. of manganese dioxide will often be found to produce the desired tint. When purple and irregular tones are desired the clay must be specially selected and must bo fired with too little and too much air alternately, i.e., the atmosphere inside the kilns must be alternately oxidising and reducing. The tints produced on burning some clays are a 
special characteristic of the materials from certain loaclities and cannot be obtained artificially with other clays.

Insufficient heating will produce bricks of too pale a colour ; excessive heating, on the contrary, will result in bricks of an unpleasant tint. Where a clay can be found which can be made into bricks possessing all the desired mechanical properties, such as strength, lightness, porosity, in addition to an excellent colour, it may be said to form the ideal brick earth. Usually, however, some property must, in part, be sacrificed in favour of the others. Thus, many bricks in the Midlands and North of England are heated to a temperature which is rather too high for the production of the most pleasing colour, but the added strength gained by such treatment is considered to more than compensate this. It is always a temptation to the manufacturer of red bricks to pay the first attention to colour, as it is this property which attracts the attention of architects, though the strength of the bricks is, in most cases, of much greater importance.

Some very pretty colour effects are obtained by the use of reducing gases ; many of them being largely of the nature of " accidents." Thus, the admixture of a little coal or coke dust with the clay before it is made into bricks will often produce pleasing purple tones in the bricks. Sometimes organic matter and pyrites are present in sufficient quantities to produce these plays of colour without any effort on the part of the burner, but more frequently they are produced, as suggested, by the deliberate addition of organic matter or by purposely working with a very smoky fire towards the end of the "baking" stage.

In the manufacture of "blue bricks" in Staffordshire and elsewhere, the material used is so rich in iron oxide and in fusible matter that when smoky or reducing fires are used the iron becomes reduced and forms a ferrous silicate or ferrous alumino-silicate of the desired "blue" colour. The nature of the material is such that when this colouring substance has once been formed it is "fixed" by the fusible matter present, and so is not re-oxidised during the remainder of the heating. In clays which are not suitable for the manufacture of blue bricks, on the contrary, there is a great tendency for the 
bluish silicate to be re-oxidised into the red compound to which red bricks owe their colour. Indeed, if a clay which is ordinarily used for blue bricks is fired under purely oxidising conditions, excellent red bricks may be produced.

Another curious fact about the colour of bricks is that if 15 per cent. of chalk is mixed with a red-burning clay, the bricks withdrawn from the kiln at a temperature below about $750^{\circ} \mathrm{C}$. will be red, but those heated to a higher temperature will be white. A similar result will be obtained if a clay naturally containing both chalk and iron oxide is used, the chalk, iron and clay uniting to form a white alumino-silicate.

Engineering bricks and-others, in which the greatest possible strength is required, must be heated to such an extent that the fused material in them fills all the pores and unites the remaining particles into a very strong whole. Such bricks can only be produced by prolonged heating at sufficiently high temperatures, but care is required not to let the partial fusion, or vitrification, proceed too rapidly lest the bricks should lose their shape. The metallic oxides present in the clay are of great importance in this respect, as a clay containing magnesia will lose its shape far less readily with an equal amount of vitrification than will one containing an equivalent proportion of lime or alkalies.

The final stage of burning consists, therefore, in raising the temperature slowly and steadily until a sufficient amount of fused matter has been produced to give the bricks the necessary strength when cold. The amount of this fusion or vitrification is usually ascertained by drawing trials, breaking them and examining the texture of the fractured surface. Two pieces of clay which have been fired until vitrified will also ring with a metallic note when struck together, the dullness of the tone being some guide to the insufficiency of the heating.

Where the heating is pushed to the fullest extent possible without loss of shape, the material will be found to resemble an opaque glass or slag in character. It will be excessively hard, entirely impervious to water and highly resistant to corrosive acids. Its colour will be dark, approaching a brownish black, a slag grey, or what is known technically as a clinker or Staffordshire blue, and its density will be appreciably increased. 
In size, articles which have been burned to complete vitrification will be somewhat less than those which have been merely baked, but the difference is not very great. The formation of gases in the interior of the material tends to cause swelling; this, which may prove a serious defect, may be recognised by the shape of the pores observable on the fractured surface of the article when broken.

The most perfect vitrified texture is that obtained in hardfired porcelains, the raw materials for which are more carefully prepared than would be remunerative for bricks.

It is frequently stated in books and lectures on building materials (obviously by those who have little or no real knowledge of brickburning) that heating to one temperature will produce red bricks and to another temperature will produce blue ones. This is quite erroneous, as the difference in colour does not depend on temperature, but on the nature of the atmosphere inside the kiln. Moreover, clays which contain a considerable proportion of fluxing materials, such as chalk, limestone, magnesia, soda and potash compounds, will fuse and form a shapeless mass at temperatures far below those used for burning other brick clays.

The temperature at which a sufficiently intense colour is developed varies greatly with different materials; in some bricks it is reached at a temperature of about $800^{\circ} \mathrm{C}$. whilst for other bricks a temperature of over $1,000^{\circ} \mathrm{C}$. is needed, and a certain amount of fusion occurs before the full red colour is produced. As the colour of burned bricks is due to the chemical decomposition of the clay, it cannot be predicted from the appearance of the raw clay. Thus, a yellow clay will be red when burned, a grey clay may burn to a yellow, red or blue colour, and so on, and white bricks may be made from clays of almost any colour except a bright red one. The spotty appearance of some firebricks is due to the grains of pyrites in the clay, and instead of being regarded as a sign of inferiority it is rather an indication that the bricks have proved their refractoriness by the temperature to which they have been heated during the course of their manufacture.

The best qualities of firebricks are heated to temperatures higher than those used in burning any other kind of clay 
goods, but they are so resistant to heat that complete vitrification is never reached. It is essential that firebricks should not shrink appreciably when in use, particularly when they are employed in furnace linings; hence, they should be heated in the kiln to a higher temperature than they are ever likely to reach afterwards. Many manufacturers do not heat their firebricks to temperatures above $1310^{\circ} \mathrm{C}$., and many users consider that the spaces left by the shrinkage of the bricks in use are unavoidable. This is not the case, as if the bricks are burned at a sufficiently high temperature-which obviously must depend on that of the furnace in which they will be usedthe shrinkage is so small as to be immeasurable. For annealing, brass melting and much other work, the temperature reached in the kilns will be sufficient to prevent the bricks shrinking still further in use, but for steel manufacture, regenerators, coke ovens, etc., harder-fired bricks must be employed. In no case, however, can firebricks be said to be "fully burned" in the same sense in which this phrase is applied to engineering and other well-vitrified bricks. The resistance to heat of most firebricks is so great that the amount of vitrification produced is, necessarily, very small. Where bricks of only a moderate refractoriness are required in combination with a high degree of resistance to abrasion or to crushing, it is often possible to use vitrified bricks made of the lower-grade fireclays or of clays which vitrify readily, but still retain their shape at high temperatures.

Firebricks made of silica instead of clay are described in a later chapter. They are characterised by their expanding when heated instead of contracting like bricks made of clay. 


\section{CHAPTER XIV.}

THE PROPERTIES OF BRICKS

THE properties of bricks are chiefly of a physical character, their chemical characteristics being confined to their resistance to acids and to the action of water and other atmospheric conditions.

The chemical composition of bricks is seldom of any significance, though some architects and engineers attach to it a wholly unwarranted importance. As previously stated, the analysis of a clay is only of value for investigational purposes, and even then it is of much less importance than other tests. The same remark is equally applicable to bricks.

The one possible exception where an analysis may prove useful is in the case of firebricks, as a clay with more than 2 per cent. of lime, magnesia and alkalies can scarcely be expected to be highly refractory. Even in this case, however, a direct determination of the refractoriness is of greater value than an analysis.

Bricks are commonly classified according to their texture and colour, though the mode of manufacture, hardness and some other properties must also be taken into consideration, as will be observed in the following definitions.

Cutters and rubbers are the softest bricks used for building purposes. They have a uniform, sandy texture, and are easily cut or rubbed to any desired shape. Their chief use is for arches and other gauged work. The best bricks of this class are made of sandy clay, lightly burned in clamps.

Malms are yellow bricks, and are regarded in the neighbourhood of London as one of the best kinds of building bricks. They are composed of clay and chalk to which cinder dust has been added and are burned in clamps, with the result that they have an irregular colour and texture, with a considerable amount of vitrified matter. 
Stocks are common building bricks, and vary greatly in texture and other properties, according to the materials used and the method of manufacture. They are bricks left when the most regularly coloured ones have been sorted out, and are used for inside work, cellars, etc., but not for facing work. In some localities, however, the whole of the contents of a kiln are sold as "stocks," the builders selecting such facing bricks as they require after the bricks have been delivered to the site. Rough stocks, as their name implies, are somewhat irregular in colour, surface and shape, and are an inferior kind of stock brick used (on account of cheapness) for foundations and other work where appearance is of small importance. Grey stocks are so termed because of their colour ; apart from this, they are good bricks. Grizzles are underburned bricks; they have a loose, porous texture, and are soft and not very durable when exposed to the weather. Crozzles, burrs and clinkers are bricks which have partly lost their shape through overheating. They have a vitrified texture and are heavy, dense, and " ring" when struck. The term clinker is also used for well-vitrified paving bricks of a good quality. This double use of the term is liable to prove confusing. Bats or brickbats are broken bricks or those which are so misshapen as to be quite useless. They are the "unsaleable residue " of the brickyard. Shuffs, shivers and shakes are bricks which, in course of manufacture, have become cracked either internally or externally, and are consequently unsound. No matter how uniform their texture apart from the cracks, or how good their colour, they are practically useless except for low walls and other work where little or no strength is needed.

Engineering bricks and paving bricks have a close, wellvitrified texture, and are noted for their durability, imperviousness and strength. On account of their clinking or ringing note when struck, these bricks are sometimes termed clinkers.

In some localities the bricks which have been laid flat in a clamp-forming the "paving"-are termed paviours. They are not appreciably different from the stocks with which they are associated, and must not be confused with pavers, which are bricks used in the construction of floors and pavements. 
The shapes and sizes of bricks are exceedingly varied, according to the custom of the locality and the purposes for which they are.used. Thus, the standard brick, as defined by the Royal Institute of British Architects in 1904, measures -length between $8 \frac{7}{8}$ and 9 inches; breadth, between $4 \frac{5}{16}$ and $4 \frac{3}{8}$ inches; thickness, between $2 \frac{5}{8}$ and $2 \frac{11}{16}$ inches, but bricks of larger and smaller sizes are made in many works. Thinner bricks (some of them only one inch in thickness) are also used in large quantities, as are bricks with one corner cut off or ornamented (squints), bricks with one rounded corner (bullnoses), bricks with an ornamental end (jambs), or with an ornamental face (diamond stretcher, dog-tooth stretcher, halfmoon stretcher, string course bricks, etc.). Some bricks are also made of special shapes for arches, channels, copings, etc.; others are perforated to make them lighter or in order that they may serve as ventilators, etc. The surface is sometimes scored to prevent slipping, as in paving and stable bricks, or a depression, or frog, is made in one or both sides of the brick, partly in order that the mortar may grip more firmly and partly to reduce the weight of the brick without affecting its size.

Ornamental bricks are made in an endless variety of shapes and sizes, the modelled work on some being exceedingly elaborate. It is usually better, however, to have the more highly decorative work on larger pieces (terra-cotta), as the joints of ordinary brickwork are a disfigurement to modelled or carved work. The modelling should be completed before the material is burned, as if sculptured afterwards the outer "skin " which forms the most durable surface of the material is destroyed by the carving.

Irregularity in the size of bricks is a source of great annoyance to bricklayers, and causes unsightly work. It is sometimes due to the use of inaccurate moulds or to allowing one or more moulds or presses to become unduly worn, whilst others in use at the same time are of the correct size. It is occasionally due to the different temperatures reached in different parts of a kiln or to variations in the temperature of the same kiln on different occasions. Some irregular bricks are produced in almost every kiln, but if the proportion is large it indicates carelessness or ignorance in manufacture; they are removed 
from the better qualities by sorting the bricks as they come from the kiln.

The surface of bricks is of moderate smoothness ; that of terra-cotta is smoother, and glazed bricks have a surface resembling that of glass. Too smooth a surface is considered undesirable for building bricks, as a moderate degree of roughness increases the adhesion of the mortar and enables the bricks to present a more pleasing appearance than would otherwise be the case. For the last-named reason, some brickmakers have for many years past covered their bricks with redburning sand (sand-faced bricks, p. 334), whilst others use some form of vibrating wire to produce a special form of roughness of face.

In glazed bricks, the surface should be as glossy as possible, free from pinholes and cracks, and, if the bricks are to be exposed to trying conditions, the glaze should be impermeable to red ink.

The colour of bricks varies with the purposes for which they are required. As stated on a previous page, the majority of brick manufacturers endeavour to obtain bricks of as uniform a colour as possible, though some architects prefer a play of colours produced by irregularities in the composition of the material and in the stoking of the fires. A perfectly uniform colour can only be obtained with materials of great fineness which are extremely well mixed. Coarse particles, imperfect mixing and materials of a different composition to the main mass tend to produce irregular colouring.

A whitish scum, or efflorescence, on the surface of bricks may be produced by soluble salts in the clay or by condensation products which are deposited whilst the bricks are in the kiln. These salts dissolve in the water used to make the clay plastic, the solution is gradually drawn to the surface as the bricks dry, and as the water evaporates the salts are deposited on the surface of the bricks.

Some bricks have a white, or grey face or exterior, but are red internally. The white, or grey, coating is due to the kiln gases condensing on the bricks. The moisture in these gases is condensed into minute drops of water, and any sulphuric or other acids present are dissolved by these drops. The 
dilute acid solution, so formed, dissolves some of the bases in the clay and forms a scum similar to that described in the foregoing paragraph, but usually distributed more uniformly over the surface of the bricks. Bricks of this character do not receive any more heating than red bricks, as the grey or white coating is produced at temperatures far below red heat. Notwithstanding this fact, many architects consider these bricks to be better and stronger than if the same material was burned so as to produce bricks of a uniform red colour. The origin of this erroneous opinion is obscure, but is apparently due to confusion of scummed red bricks with grey engineering bricks of an entirely different character.

When the natural colour of bricks is too irregular and displeasing for facing purposes, the bricks are sometimes coated with a special engobe made of a red-burning clay of superior colour. These coated bricks are naturally regarded as inferior, as the coating tends to wear and chip off leaving the discoloured interior visible. In a few cases, bricks are dipped in a special slurry after they have been withdrawn from the kiln, in order to give them a red surface. Such bricks may be compared to bricks which are merely painted to hide their defects.

The hardness of bricks varies greatly. Most building bricks are rather harder than sandstone, and the best vitrified paving and engineering bricks are too hard to be scratched by an ordinary steel knife.

Soft bricks are regarded as having been insufficiently heated, and are termed "underburned." They occur in those parts of the kiln where the average temperature is not reached, and are particularly numerous in kilns which are badly designed or which have been improperly fired. Sometimes bricks which are seriously underfired may be returned to the kiln and burned a second time, but this obviously causes a serious increase in the cost of manufacture.

Soft, friable bricks are weak and therefore of more limited use than stronger bricks in which the particles are more firmly cemented together by the fused material present.

The resistance to abrasion shown by the more vitrified bricks is very considerable, and is an important property where bricks are used for pavements, roadways, etc. In the United 
States, paving bricks are tested by placing them in a barrel or tumbler with heavy pieces of iron and rotating for a definite time, usually 1,000 revolutions at the rate of thirty per minute. The loss in weight undergone by the bricks is regarded as indicating their lack of durability. In Germany the brick is held by a weight on to the surface of a grinding table and the amount worn away is ascertained. Neither of these tests is really accurate, though useful as a rough method of sorting out the worthless bricks. Resistance to wear and tear is, largely, dependent on the toughness of the bricks, and no means have yet been devised for accurately measuring this property. It appears, however, that the more fused material a brick contains, i.e., the more completely it is vitrified the greater will be its toughness, though some very completely vitrified bricks are too brittle to be of value. Bricks made of glass are quite useless for paving roads because of their brittleness.

Brittleness is an undesirable property in bricks, and is most noticeable in those which have been heated excessively, though in some of the softest and underburned bricks the particles have so little power of cohesion that the bricks appear to be brittle. Bricks which have been properly burned, but cooled too rapidly, are usually brittle because of the strains set up by the rapid cooling.

The density of bricks is the ratio of their weight to that of an equal volume of water, but the term is sometimes used in a different sense with reference to their texture. The porous nature of most bricks makes it difficult to ascertain their density with accuracy, and it is better to use the term specific gravity in reference to the true density of the material itself, apart from the pores it may contain. The apparent density may then be understood to relate to the weight of a brick including its pores, relative to that of an equal volume of water. The practical value of a study of changes in the specific gravity and apparent density of bricks during various stages of burning is important, as it enables the degree of vitrification at different temperatures to be compared, and, apart from any consideration of the colour of the finished brick, shows the temperature at which the heating of the kiln 
should stop and the nature of the heating which is most suitable for any particular material. These tests are, however, best relegated to an expert in clay testing, or erroneous conclusions may be reached. Apart from this and from speculations on the precise chemical constitution of the substances which exist in burned clays, the determination of specific gravity and apparent density are of minor importance.

Heavy bricks are usually, but not necessarily, strong ones, and are of a more vitrified nature than the lighter porous bricks.

Light bricks are valuable in some localities because of the lower cost of carriage per thousand bricks. The cause of their low apparent density is their great porosity; this may be a natural property of the clay, but it is usually due to the addition of sawdust or some other combustible material of the clay. This combustible matter burns away in the kiln and leaves a brick of normal volume, but highly porous, and so of very small weight. The properties of these bricks are such that they can only be used for inside work where great strength is not required.

The texture of bricks is best observed by breaking them and studying the fractured surface. It will then be seen that the texture is that of an amorphous material of a somewhat spongy or porous character, the particles being held firmly together by a glassy substance which is formed by the action of heat on the more fusible portion of the material. Hence, the texture of bricks in some ways resembles that of building stones, but is more homogeneous and the particles of material are usually smaller.

Bricks of perfectly uniform texture are costly to produce from some materials, and when shales and other indurated clays or boulder clays are used, the bricks frequently contain pieces as large as peas, which produce an irregular texture; this is often an indication of weakness.

A well-made brick should present as uniform an appearance as possible when it is broken, and the fractured faces are examined with the unaided eye. If a good magnifying lens of the Coddington type, or a microscope, is used, the irregularities in the material will be made more apparent, localised patches 
of fused material being found irregularly distributed throughout the brick. In a low grade of brick the presence of various materials other than clay may usually be recognised without much difficulty, though the definite identification of them with certain minerals is not always possible.

Though not often found, the best texture of a brick is that which consists of a complex, felted mass of minute crystals, due to maintaining the bricks for a considerable time at a temperature somewhat above that at which vitrification is first noticeable. The risk of spoiling the bricks completely makes the majority of manufacturers unwilling to prolong the heating, and consequently, in most bricks, this crystalline, felted texture is replaced by a main mass of amorphous particles cemented together by a kind of glass.

Apart from showing any great irregularities in the texture, a microscopic examination is of little value to the engineer and builder, as the porosity and crushing strength yield similar information in a simple form.

The porosity of bricks is an important characteristic in two respects : the more porous a brick the less will be the cost of transport, and the better will be its ventilating power; on the other hand, the more vitrified and dense a brick the better will it be able to resist the action of frost and rain. It is therefore necessary for the manufacturer to produce bricks which shall not be so porous that walls made of them remain damp, or bricks which are, so impervious that no air can pass through them. For ordinary building bricks a porosity corresponding to the absorption of water equal to 6 to 15 per cent. of the weight of the bricks is found to be generally satisfactory, but for bridges, sewers and other engineering work bricks which are completely impervious are preferable.

The porosity is usually determined by weighing three bricks, separately immersing each in water in such a manner that a piece of the brick, about $9 \times 4 \frac{1}{2} \times \frac{1}{2} \mathrm{inch}$, is above the water level. After half an hour the brick is immersed completely and is left for twenty-four hours. At the end of this time each brick is taken out, rapidly wiped dry with a smooth cloth, so as to remove the water adherent to the surface, and is reweighed. The increase in weight is due to the water absorbed 
by the pores in the brick, and is calculated to a percentage on the weight of the original brick. Thus, if a brick weighs $9 \frac{1}{4} \mathrm{lbs} .=148$ ounces before immersion, and $163 \frac{1}{2}$ ounces afterwards, its porosity will be $163 \frac{1}{2}-148=15 \frac{1}{2}$ ounces in 148 ounces, or $10 \frac{1}{2}$ per cent. The object of a partial immersion at first is to permit the air to be displaced from the pores by the water. A more accurate method consists in breaking the brick, immersing it in water and extracting the air with a vacuum pump, but this does not so nearly represent the porosity under the normal conditions of use as the form of test first described, as the protective action of the dense "skin" on the surface of the brick is nullified by breaking the brick.

The porosity of samples cut from the interior of bricks is often useful for studying the extent to which the burning has been carried. If sufficient care be taken in the determination, the amount of porosity will indicate the amount of fused matter which has been formed in the brick, and will, therefore, show the conditions under which bricks of the greatest strength can be made from the material under examination. So many considerations enter into this question, however, that it is best left in the hands of a competent expert, as, otherwise, very erroneous conclusions may be drawn.

The permeability to water shown by some bricks is important on some occasions. For ordinary buildings, bricks should be permeable to air, but less so to water, in order that the buildings may "breathe" through the brickwork and yet not have damp walls. The best bricks for this purpose are those which have a sufficient porosity to retain more water than will impinge on them by the heaviest rainfall to which they are subject, without the pores being so large that the inside of the wall becomes damp. Walls built of such bricks will dry between the showers and will preserve a dry and warm interior to the building of which they form a part.

The strength of bricks is invariably expressed in terms of the weight required to crush them. Bricks vary greatly in this respect, those which are the most vitrified (i.e., the ones which have been the most intensely heated) being the strongest. In this connection it is important to remember that the strength 
of even a poor brick is much greater than that of a well-built wall made of good bricks, as the mortar used in jointing is not as strong as the bricks. The demands of architects that bricks shall show a minimum crushing strength are, therefore, somewhat beside the mark, and are chiefly of value in checking the general nature of the bricks specified rather than in showing their actual strength when in use.

The strength of bricks is affected by the precise chemical and physical nature of the raw materials, the amount of water added, the general treatment in mixing, shaping, and burning, as well as by the manner of cooling. Hence, no two bricks have precisely the same crushing strength. Figures which state that "Staffordshire blue bricks" have a crushing strength of 800 tons per square foot are, therefore, misleading to the extent that some blue bricks made in Staffordshire are much weaker (300 tons per square foot) and others are much stronger than the figure mentioned. Even in the same works the strength of the bricks varies greatly at different times, and to assume that because certain bricks made at one time have a satisfactory crushing strength, therefore all the bricks made by the firm will be equally strong, is entirely to misunderstand the facts.

Comparison of the crushing strengths of bricks of different characters and from different parts of the country is, therefore, of little value. The following figures, obtained from a very large number of samples by the author, in the course of his practice as a consulting expert in brick manufacture, etc., represent about as fair an average as the widely divergent results obtained from different bricks of the same class permits :-

Crushing strength.

Tons per square foot.

London grey stock bricks

Suffolk white bricks (Gault)

139

Essex red sand stocks

Leicester red bricks (wire-cut)

273

South Yorkshire bricks (stiff-plastic)

543

Fletton bricks (semi-dry process)

253

Staffordshire blue bricks

790

Rubbers and cutters (very variable)

70 C. 
In Germany no building bricks may be used which have a crushing strength below 136 tons per square foot.

The principal assurance required by the architect and engineer is not the total strength of the bricks when new, but their strength after they have been in use for some time.

The durability of bricks is of greater importance than their strength, for if a brick decays rapidly, its primary strength is of no importance. Broadly speaking, the durability of a brick will be greatest when the porosity is least, but as completely impervious bricks are undesirable for many structures, too much stress must not be laid on a low percentage of porosity. Again, some bricks, notwithstanding their impermeability, are so weak as to be far from durable under a heavy load, and others are so affected by vibrations as to be useless where heavy machinery is employed. The durability of bricks depends primarily on the closeness of their texture and on their resistance to the action of very dilute acids.

Air itself has no power to destroy bricks, but the gases, water and salts it contains can do so. Thus, the small proportion of carbonic acid present in the air is sufficient to attack any free lime in the bricks and, eventually, to cause it to "blow," forming unsightly white patches and cavities on the surface, or actually cracking the bricks. No matter how fine may be the particles of lime in the brick, if the latter is porous they will become carbonated in the course of time.

The action of rain is also much greater on a porous brick than on an impervious one. The water has a solvent action on some of the materials, including the lime, and so washes them away; at the same time it has a softening action on imperfectly burned clay, rendering it easier for subsequent rains to remove such material. If a brick absorbs a certain amount of rain and is then exposed to frost, the water will expand and so set up strains which, in time, will cause the brick to crumble away. Vegetable matter, such as lichens, mosses and algæ, also effect the destruction of bricks on to which they settle from the air, the rain keeping them moist and permitting them to thrive if the bricks are sufficiently porous and rough of surface. Some bricks have such small pores and so smooth a surface that the lichens, etc., cannot 
adhere to them ; such bricks do not vegetate. The "scum". formed by vegetation can readily be recognised under the microscope.

Bricks behave very erratically so far as durability is concerned, and cases are known where the same manufacturer has supplied bricks for two houses in the same town and one house has suffered far more than the other from the weather.

The sheltered or exposed nature of the site and the direction and intensity of the prevailing winds are often important factors in such a case. Slight, but oft-repeated changes in temperature are another cause of the destruction of some bricks, the more compact and vitrified kinds suffering the most damage. In very porous bricks there is sufficient space between the particles to absorb the expansion due to heat or to allow for the contraction on cooling, but impervious bricks cannot do this. The damage caused by changes in temperature is most serious in the case of bricks and terra-cotta which have a thin dense "skin" on the surface; this "skin" does not expand and contract at the same rate as the body behind it and so tends to peel or "shell" off, leaving a rough under-surface which rapidly becomes dirty and unsightly. This expansion, which is not infrequently permanent, is most noticeable in copings.

A cause of decay which is not usually important as regards the durability of the bricks, but is very detrimental to their appearance, is the formation of scum or efflorescence. If this does not occur on the bricks when first laid, it will usually be derived from the mortar or from the foundation on which the bricks are laid. In any case this scum or efflorescence (providing that it is not of a vegetable nature) is due to soluble salts which have gained access to the bricks. Usually they have been dissolved in the water mixed with the mortar and have dried out on the surface of the bricks ais the mortar dried, or the rain falling on the wall has dissolved the salts out of the water and has brought them to the surface of the bricks by capillary attraction, as the rain-water evaporated. An alternative and by no means infrequent cause of scum is the presence, in the foundations, of soluble salts. If the brickwork is not provided with an adequate damp-proof course, the 
ground water will dissolve these salts and will rise up in the brickwork, and later, as it dries away, it will leave them as a scum on the surface. The irregularity of the patches of scum on bricks is often a clear sign of variations in their porosity.

Notwithstanding all that has been stated above with regard to causes which lessen the durability of bricks, the fact still remains that well-made bricks are the most durable building material known. Granite and all other stones are by their very nature subject to decay by the agency of the weather, but bricks which have been properly made and burned have been found to outlast the hardest stones. The remarkable state of preservation of many ancient Chaldean, Assyrian, Egyptian, Indian and other buildings is due, in large measure, to the fact that they were built of burned clay. The climatic conditions of modern industrial towns are much more severe than those of ancient days, owing to the peculiarly corrosive action of the acids contained in smoke and in furnace gases, yet even at the present day the evidence is all in favour of good bricks as by far the most durable building material, and, in many localities, one of the cheapest.

Resistance to strong acids is a property possessed in a marked degree by many vitreous bricks and by all those which have been glazed by the aid of salt. Porous bricks, if free from lime, will resist the action of strong acids for a time, but not for long. The more free the clay is from iron, lime and magnesia compounds and alkalies, and the more completely it is vitrified, the greater will be its resistance to acids.

Bricks which are rendered impervious by a coating of glaze will only resist the action of acids so long as the glaze is undamaged. If it cracks, spalls or is broken, the resistance of the brick will be very small. Hence, the use of glazed bricks is limited to those cases where there is little likelihood of the surface being damaged.

The refractoriness or resistance to very high temperatures possessed by firebricks deserves brief mention here. Strictly speaking, the refractoriness of a clay is its power of resisting the action of heat alone, quite apart from any accessory conditions, but the term is generally used to imply resistance to heat when used in furnaces, boilers, fireplaces, etc., in which 
the bricks come in contact with coal and coke ashes, dust of various kinds, slags or metal drosses, and with other substances, all of which tend to reduce their resistance to heat. The coal in contact with the bricks brings about reducing conditions, and effects an undue slagging of the iron compounds ; the ashes, slags, dross, dust, etc., combine with the clay and form a more fusible material, thereby spoiling the bricks and rendering them useless.

Some firebricks are very sensitive to sudden changes in temperature, and crack and spall (i.e., throw off portions of material from the surface) if cooled suddenly, as when a furnace is emptied, or the fires in the boiler are withdrawn. This sensitiveness is not due to lack of true refractoriness, but to the texture of the material. It is generally found that highly porous firebricks are capable of withstanding the most rapid changes in temperature, whilst the same bricks, when heated more strongly, and thereby rendered more dense, are found to spall when cooled suddenly.

For lining furnaces used in metallurgical operations, firebricks must be highly resistant to the metal and the corrosive slags and dross, and at the same time the bricks must not spall or crack with the sudden drop in temperature when the furnace is emptied. Such firebricks are, therefore, required to possess two diametrically opposite characteristics-for resistance to corrosion they must be dense, and for resistance to sudden changes in temperature they must be as porous as possible. A compromise is usually effected by making the bricks porous with a dense face or surface.

As shrinkage during use would be serious, many furnace builders use firebricks made of silica instead of clay, as silica bricks expand on heating instead of shrinking. They are, however, less refractory than the best fireclay bricks. Their manufacture is described on p. 399.

The selection of firebricks for various purposes would be greatly facilitated if their properties were better known to the users. At present, the only basis of specification, and that of only a semi-official character and by no means widely adopted, is the one published by the Institution of Gas Engineers. 
This provides that a material made from fireclay shall contain approximately not more than 75 per cent. of silica. It is known, however, that there are, in cortain areas, fireclays containing as much as 80 per cent. silica, and material made from such clays shall be considered to conform to this specification if it passes the tests herein specified.

Clause 1. Refractoriness.-Two grades of material are covered by the specification :

(1) Material which shows no sign of fusion when heated to a temperature of not less than Seger cone 30 (about $1,670^{\circ}$ C.).

(2) Material which shows no sign of fusion when heated to a temperature of not less than Seger cone 26 (about $1,580^{\circ} \mathrm{C}$.).

The test shall be carried out in an oxidising atmosphere, the temperature of the furnace being increased at the rate of about $50^{\circ} \mathrm{C}$. per five minutes.

The "new scale" of Seger cones is to be used.

The material is to be chipped to the form and size of a Seger cone and tested against standard Seger cones (small size).

A preliminary trial is first made with a piece of the material chipped into the approximate form of a cone. This should be cemented on to a refractory disc or slab with a mixture of alumina and best china clay, together with Seger cones 28, 30 and 32 (small size). It is essential, however, that the temperature should be maintained constant; and if it is necessary to remove plugs, etc., for the purpose of obtaining the temperature, great care should be taken to avoid cooling the furnace by such means. The cones should, in all cases, be placed relative to the sample so that both are subjected to the same temperature. These cones are selected because they cover the range of first-class clays. Best china clay fuses between cones 35 and 36 ; and all British fireclays fall below this point. If cones 28 and 30 fall, the furnace should be cooled, and the material under investigation examined. If it exhibits no sign of fusion, the trial should be repeated with cones 31,32 and 33 . When cone 32 squats, the piece should be again examined, and if it shows signs of fusion, the trial should be repeated with cones 30,31 and 32. By this method of approximation, it is possible to decide whether the piece vitrified between cones 30 and 31 or betweenlcones 31 and 32 . A similar method should be adopted when testing secondgrade material.

It may be noted that clays and related materials have no sharply defined melting point, and the definition of refractoriness here adopted refers to the temperature at which the angular edges of the material under investigation begin to lose their angularity when heated.

Clause 2. Chemical Analysis.-A complete chemical analysis of the materials is to be provided when required by the engineer (or purchaser), for his personal information only.

The silica should be determined by two evaporations with an intervening filtration; and the alumina, lime and magnesia by two precipitations. The amount of titanic oxide should be indicated, and not included with alumina and iron. The potash and soda should be separately determined.

Clause 3. Surfaces and Texture.-The material shall be evenly burnt throughout, and the texture regular, containing no holes or flaws. All surfaces shall be reasonably true and free from flaws or winding.

Clause 4. Contraction or Expansion.-A test piece, when heated to 
a temperature of Seger cone 14 for two hours, shall not show more than the following linear contraction or expansion :-

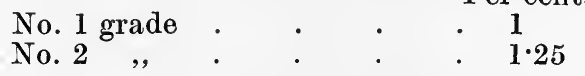

After the test temperature has been reached, the furnace shall be maintained constant at that temperature throughout the testing period.

The test piece shall be $4 \frac{1}{2}$ inches long and $4 \frac{1}{2}$ inches wide, the ends being ground flat, and the contraction measured by means of Vernier calipers reading to $0.1 \mathrm{~mm}$.- - a suitable mark being made on the test piece, so that the calipers may be placed in the same position before and after firing.

The contraction referred to is linear, and is equal to-

$$
\frac{\text { change in length } \times 100}{\text { original length of test piece }} \text {. }
$$

A pyrometer is required to ensure the temperature being maintained within the proper limits.

Clause 5. Variations from Specified Measurements. - In the case of ordinary bricks, 9 inches by $4 \frac{1}{2}$ inches, by 3 inches or $2 \frac{1}{2}$ inches thick, there shall not be more than $\pm 1 \frac{1}{2}$ per cent. variation in length, nor more than \pm per cent. variation in width or thickness, and in all cases the bricks shall work out their own bond, with not more than $\frac{1}{8}$-inch allowance for joint. In the case of special bricks, blocks, or tiles, there shall not be niore than \pm 2 per cent. variation from any of the specified dimensions.

Clause 6. Crushing Strength.-The material shall be capable of withstanding a crushing strain of not less than 1,800 lbs. per square inch, ${ }^{1}$ when applied to whole bricks placed with their long side vertical between the jaws of the machine, giving a vertical thrust. The most important factors requiring attention are :-

(1) The two ends of the brick which come in contact with the jaws of the machine must be either ground or sawn flat and parallel, so as to receive a vertical thrust.

(2) An average of not less than three bricks must be used, because flaws, etc., may give an abnormal result, which might not be detected if only one brick be used.

Clause 7. Cementing Clay or "Fireclay Mortar."-This shall be machine ground, and, at the discretion of the manufacturer, may contain a suitable percentage of fine grog; but in all cases the cement clay shall be quite suitable for the purpose of binding together the bricks, blocks, or tiles for which it is supplied, and shall be capable of withstanding the same test for refractoriness.

Clause 8. Marking of Material.-All bricks, blocks, or tiles shall be distinctly marked by means of a figure 1 or 2 (not less than one inch long) stamped on them to indicate the grade to which they belong, and it shall be understood that any material not so marked shall be ungraded, and is not purchased in accordance with the terms of this specification.

Clause 9. Inspection and Testing.-The engineer (or purchaser), or his agreed representative, shall have access to the works of the maker at any reasonable time, and shall be at liberty to inspect the manufacture at any stage, and to reject any material which does not conform

${ }^{1}$ This figure is exceedingly low, and is only 85 per cent. of the minimum crushing strength permitted for common building bricks in Germany. A. B. S. 
to the terms of this specification. Pieces may be selected for the purposes of testing, either before or after delivery, but, in either case, a representative of the maker shall, if he choose, be present when such selection is made, and shall be supplied with a similar piece of the retort material to that taken for the purpose of testing.

If the engineer (or purchaser) and the maker are not prepared to accept each other's tests, they shall agree to submit the samples for testing to an independent authority to be mutually agreed upon, and the engineer (or purehaser) reserves to himself the right, if the material does not conform to the tests laid down in the specification, to reject any or all the material in the consignment from which the test pieces were taken.

The cost of these independent tests and of any retort lengtls or tiles damaged before delivery for obtaining test pieces, shall be equally divided between the purchaser and the maker if the test proves satisfactory, and if unsatisfactory such cost, and that for all other subsequent tests required on this account from the same consignment, shall be borne by the makers.

The cost of any tests or of any material damaged for the purpose of obtaining test pieces after delivery shall be borne by the purchaser in the event of the test being satisfactory, and, if unsatisfactory, by the manufacturers, in a similar manner to that speeified for the tests prior to delivery.

It is suggested that, until all the manufacturers have suitable arrangements and appliances for eonstantly testing their goods, it may be possible to render them some assistance by allowing a fairly large sample of their material to be sent in for testing and general approval before extersive deliveries are made. This is in no way, however, to be construed as removing the right of the purchaser to test material in any subsequent consignment.

Such a specification cannot, by its very nature, meet the needs of more than a few users of firebricks, for the following reasons :-

(a) The specification is so lenient that many unsatisfactory firebricks conform to it.

(b) It does not recognise the relative importance of various properties under given conditions of use.

(c) It has been based upon a too limited knowledge and experience of the purposes for which firebricks are used and the conditions under which they are employed.

In selecting firebricks for a particular purpose it is important to remember that the actual resistance to heat alone may not be the most important factor. It has already been stated that the strength of a building brick depends very largely on the amount of vitrification which has taken place in it-i.e., on the extent to which the fused matter has bound the less fusible particles together. The same is equally true of firebricks so 
far as the load-carrying power of the cold bricks is concerned. When they are heated, however, the glassy material in them softens and is a source of weakness. If, therefore, the temperature to which the firebricks will be exposed in use is not very high-say not exceeding $1,100^{\circ} \mathrm{C}$.-it is preferable to use a firebrick which shows a low refractoriness, corresponding to cone 26 to 29 , in preference to a highly refractory one (cone 34 or above). Such a second-grade or third-grade brick will, if it has been properly burned, contain more fused matter than a better grade of brick, and will be better able to resist the action of various abrasives and reducers with which it may come into contact, and will be better able to withstand rough usage. If, on the contrary, the temperatures in the furnace reach $1,400^{\circ} \mathrm{C}$. or above, the choice of a firebrick is much more difficult. It is then necessary to ascertain by experiment what importance should be attached to strength and heat resistance respectively, it being always borne in mind that as the resistence to heat is increased the strength is diminished, and vice versî.

For this reason, it is usually wise to build different portions of the furnace with different kinds of firebricks. Thus, the dome or arch will require to be built of bricks whose chief characteristic is strength to resist the crushing tendency due to expansion and contraction, combined with ability to withstand sudden changes of temperature ; in these bricks resistance to heat per se is of secondary importance. The walls of the furnace will require to be more heat-resisting, whilst still retaining as much mechanical strength as possible. In the hearth or hottest part of the furnace, where the greatest possible resistance to heat is required, some strength must be sacrificed to secure refractoriness.

It is futile, if the best results are desired at very high temperatures, to expect to have the furnace built throughout of the same materials, and for the same reason it is equally futile to expect any official or semi-official specification to be of value except in excluding materials which have so low a resistance to heat as to be unworthy of the adjective "refractory." To secure the maximum of durability each portion of a furnace requires a different specification, and even then, unless the 
type of furnace and its uses are fully recognised, the specification will be of small value.

It is the absence of any proper basis of specification which is the cause of so much contention and dissatisfaction between the manufacturers and certain users of firebricks. In many instances neither the user nor the manufacturer knows what properties the bricks are required to possess, or, if a selection of properties must be made, which are the most important ones. In other cases, the manufacturer could be of great assistance if only the user would describe more fully the precise purpose for which the bricks are required and for which part of the furnace. In the most difficult cases, the best results are obtained by consulting an expert who is independent alike of the manufacturer and the user, and whose training and experience are such that he knows what neither of the other parties concerned can ascertain. The rapidly increasing demand for furnaces to work commercially at temperatures unattainable ten years ago has made the consultation of such independent experts an absolute necessity in many cases and desirable in many more.

Other properties of bricks and clays which have been burned in kilns will be found described in the author's "Modern Brickmaking," in his "British Clays, Shales and Sands," and in "Bricks and Tiles," by Dobson and Searle. 


\section{CHAPTER XV}

S I L I C E U S B R I C K S

BRICKs made of clay, or of earths containing a large proportion of clay, are by far the strongest and most durable as a building material, but in localities where clay is scarce and sand is plentiful, the latter may be used. Sand possesses so little cohesion that the grains must be cemented together by the aid of some added material. The nature of this added material determines the properties of the bricks made.

Siliceous bricks are of three main kinds, termed respectively (a) lime-sand bricks, $(b)$ cement-sand bricks, and $(c)$ silica firebricks.

Lime-sand bricks are made by mixing sand or crushed sandstone with a "milk of lime." This material, which consists of quicklime suspended in water, all lumps being removed by passing it through a fine sieve (No. 50), is mixed directly with the sand so as to form a very stiff coherent mass. Much better results may be obtained by grinding the quicklime with rather more than an equal weight of sand in a ball mill until the mixture is fine enough to pass completely through a No. 50 sieve. It is then mixed with the remainder of the (unground) sand, water is added and the mixture heated so that it "boils" whilst passing through a further mixing machine. The proportion of lime required in either case is between 6 and 10 per cent. of the weight of the sand, but the proportion which gives the best result must be determined by experiment and rigidly maintained. It is essential that no unslaked lime shall be present in the mixture, as this would make the bricks unsound and weak. Hence, it is a wise precaution to store the mixture of lime, sand and water in large bins or silos for twenty-four to seventy-two hours, in order that the water may be uniformly distributed and the 


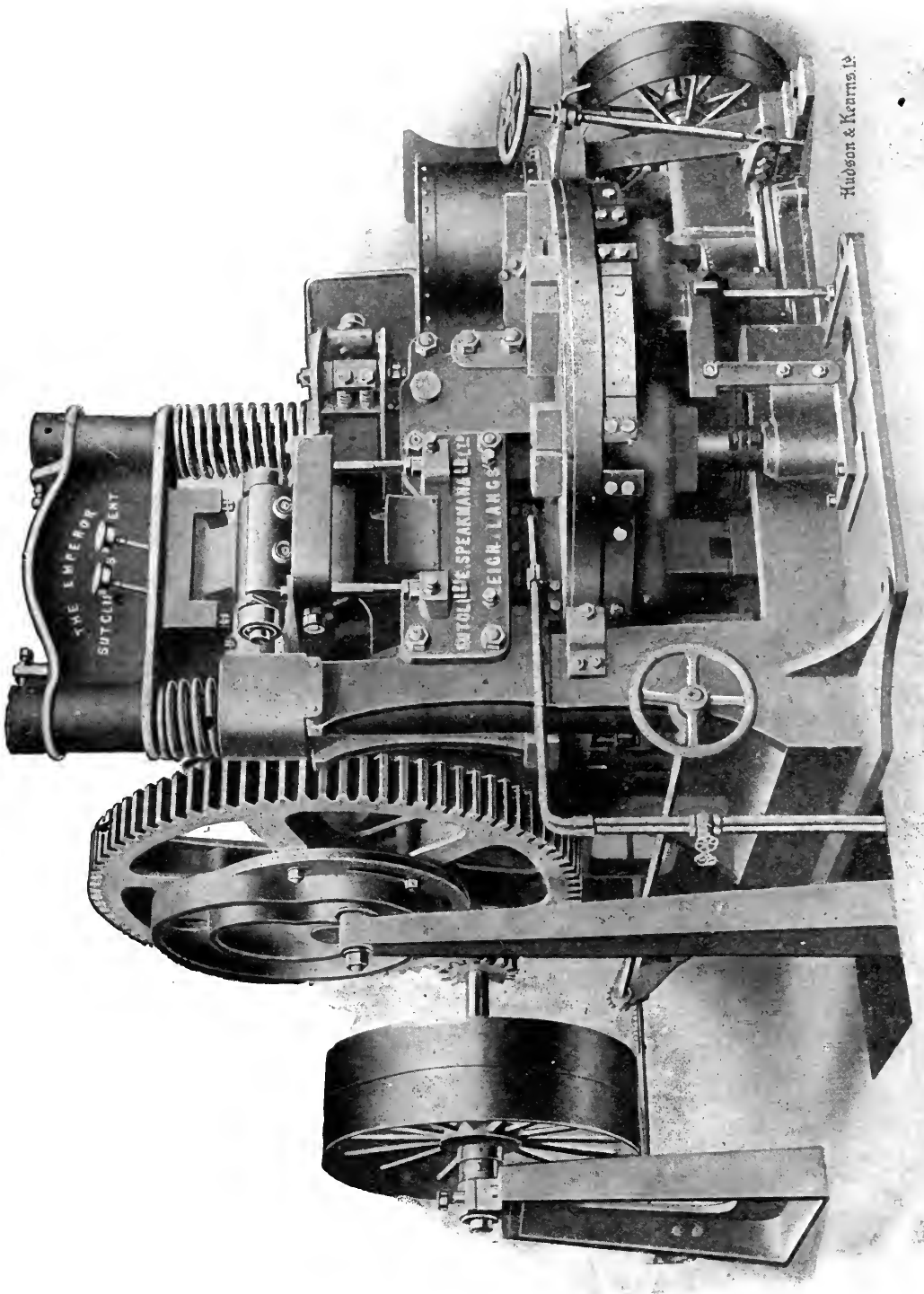


lime completely slaked. The stored mixture is formed into bricks in machines capable of exerting a pressure of 100 to 150 tons, and similar to those used for making "dry" or "dust" bricks (p. 343). The bricks so produced are then placed on waggons and heated with steam at about 125 lbs. per square inch pressure for eight to ten hours in an autoclave or hardening chamber. On removal from this chamber they are ready for use, but their strength is increased and their quality is improved by storing them in open sheds for several weeks, or even months, before they are used.

There are many details which require skilled attention in the manufacture of these bricks, and it is by no means so easy to make them remuneratively as may appear to be the case from this description. With suitable sand and strict and skilful management, however, the production of lime-sand bricks is by no means so difficult as that of bricks made of clay, as the very difficult process of burning is entirely avoided.

Lime-sand bricks are usually white, or as nearly so as the natural colour of the sand used in their manufacture permits them to be. They should have a crushing strength of at least 128 tons per square foot, and are, therefore, quite as strong as the average building bricks used in the south of England. They are seldom so strong as the best bricks made by the stiff-plastic process in the Northern Midlands.

As "sand" is a term used to indicate the physical nature and not the composition of materials to which it is applied, the term "lime-sand bricks" is frequently used for bricks made from ground slag, boiler and destructor refuse or similar siliceous materials. These clinker bricks are made in the same manner as bricks made from sand and lime, but the chemical reaction which occurs when the crushed slag or ashes are mixed with water renders a thorough heating, mixing and slaking even more essential than when a purely siliceous sand is used. Clinker bricks and slabs form a useful means of converting an inconvenient waste product into a commercially valuable one, and they are, therefore, being made in increasingly large quantities by corporations and firms with sufficiently large supplies of clinker to make their utilisation possible as a commercially profitable process. 
Cement-sand bricks are those in which the particles of sand or other crushed siliceous material are bound together with

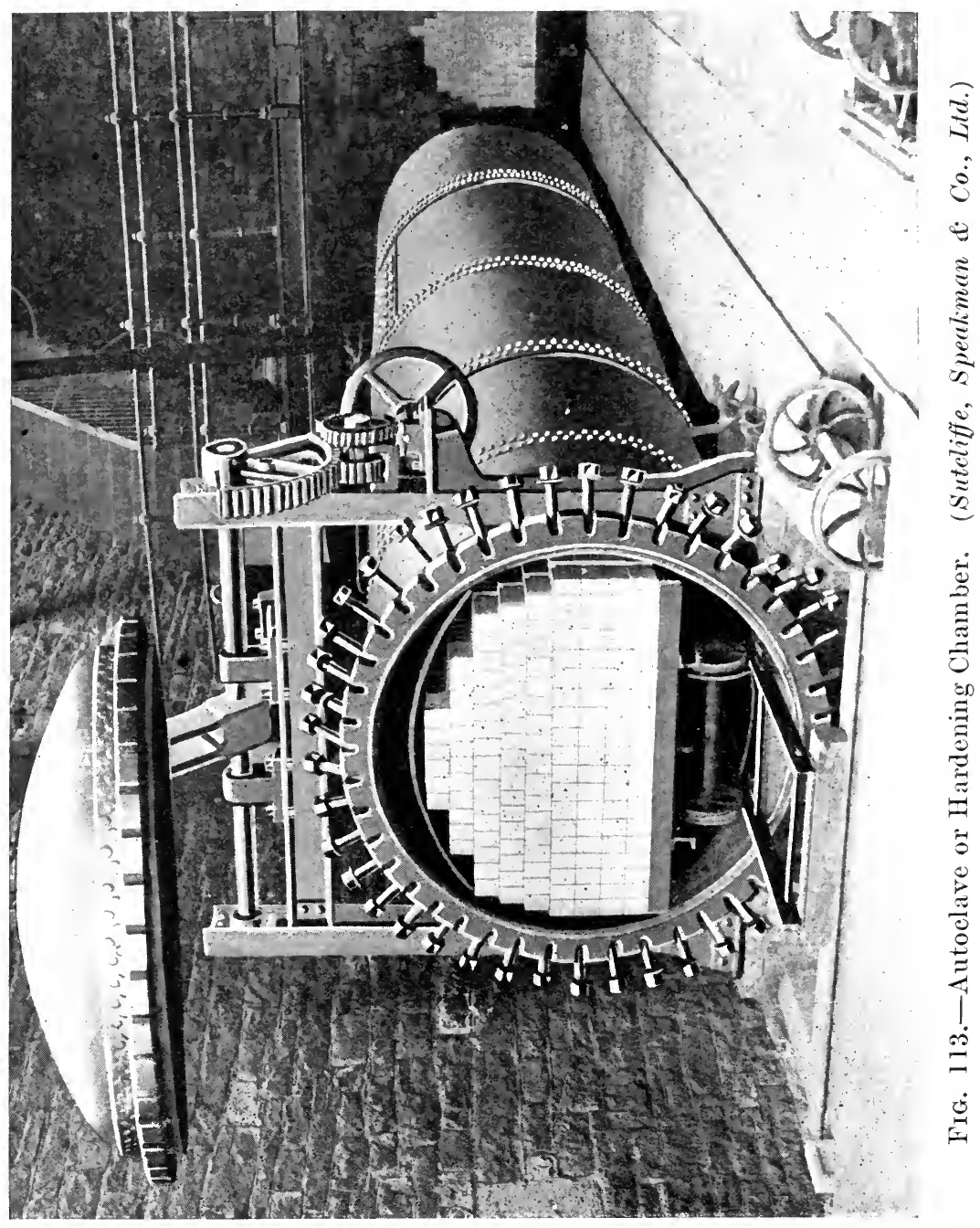

Portland and other suitable cement. The sand is screened or washed so as to remove gravel and other coarse particles, and is then mixed with about one-third of its weight of Portland 
cement and with sufficient water to produce a suitable paste. The mixture-which is really a concrete (see p. 250) - is then mixed by hand or in a mixing machine, and is filled into moulds and tamped until a film of water rises to and covers the surface. The mould is then removed and the brick allowed to stand for a few weeks until it is fully matured. Cement-sand bricks are sometimes made in power-presses (Fig. 112), but they are seldom so satisfactory as those made in hand presses (Fig. 88); excessive pressure appears to disturb the arrangement of the particles during hardening. As the process of moulding is somewhat slow, it is customary either to mould six or more bricks at a time or to form larger blocks, about $1 \frac{1}{2}$ cubic feet each (Fig. 86). These may be made with a face cut to imitate worked stone, by the insertion of a suitable die in the mould.

The "sand" used in cement-sand bricks need not consist of a siliceous sand; boiler and destructor refuse, ground furnace slag and various other waste products may be used, providing that they do not contain raw clay. If more than about 3 per cent. of raw clay is present the bricks or blocks will be too weak.

For a full description of the processes and reactions which occur in the manufacture of cement-sand bricks, the reader should consult the section on concrete, pp. 248, et seq. The use of these bricks is distinctly limited in scope, as the erection of a monolithic concrete structure is cheaper-except in the case of small repairs-because in addition to the cost of making the bricks or blocks there is the expense of laying them. The chief use of such bricks or blocks is thus confined to localities or circumstances where concrete monolithic work is undesirable or impracticable.

Silica firebricks-sometimes termed "Silica bricks," Dinas bricks or Ganister bricks - are chiefly used in metallurgical furnaces, for which purpose some firms prefer them to bricks made of fireclay. In general composition they resemble lime-sand bricks (p. 395), but contain less lime, and, in order to prevent them from shrinking when in use in the hottest parts of the furnace, they are fired in kilns previous to being sent out by the manufacturer.

They are chiefly made from a pure siliceous rock or from a 
similar rock, known as ganister, which contains about 10 per cent. of clay, and occurs in the Coal Measures. The clay in the ganister bricks is often sufficient to provide all the binding material necessary to cement the particles together, but the purer siliceous rocks require the addition of about 2 per cent. of their weight of quicklime. The proportion of lime should be kept as low as is possibly consistent with the strength of the bricks, as it reduces their refractoriness (pp. 307, 388).

The crushed rock is mixed with milk of lime (p. 395) and water so as to form a stiff coherent mass similar to that used in the manufacture of lime-sand bricks. The paste is then taken direct from the mixer to hand moulds, where it is formed into bricks under a slight pressure. The bricks are then dried in a warm room and are afterwards taken to the kiln, where they are burned under such conditions that cone 18 is bent after about three days. Some firms are content to bend cone 14, but the additional heating secures several advantages and greatly increases the durability of the bricks.

Such bricks, when broken, have a texture resembling sandstone, the lime having combined with some of the silica to form a fusible compound, which, on cooling, cements the grains of silica together. Though not so refractory as the best fireclay bricks, silica bricks are superior to low-grade firebricks so far as mere resistance to heat is concerned. They are, however, extremely sensitive to sudden changes in temperature, and crack, spall and peel badly when cooled suddenly. Unlike fireclay bricks, they expand instead of shrinking when heated. 


\section{CHAPTER XVI}

\section{BASIC AND NEUTRAL BRICKS}

For some purposes it is important that the bricks used should have a definitely basic or neutral character. This is particularly the case in the manufacture of certain chemicals and of certain metals and alloys.

Basic bricks are specially useful for furnaces in which slags rich in lime are produced, as they are unattacked by such slags, whereas acid bricks (made of fireclay or silica) would rapidly be corroded, owing to the combination of the acid and the base. Basic bricks are made of magnesia or lime, but the latter are so weak as to be seldom employed.

Magnesite bricks, which are the most extensively used basic bricks, are made by cautiously burning magnesite in a shaft kiln similar to those used for burning lime. The magnesite is thus decomposed, evolving carbonic acid gas, and forming magnesia. Some of the material is drawn from the kiln after a short exposure at a red heat, but for the remainder the heating is continued until the magnesia sinters and forms a slaggy mass. The caustic magnesia and the sintered magnesia are then mixed in suitable proportions and ground to a fine powder; a little water is added and mixed thoroughly with the materials so as to form a stiff paste. The paste-is then compressed in powerful hydraulic presses and the bricks so produced are dried and then burned in suitable kilns. The temperature required for burning magnesia bricks is so high (cone 18 to 23) that gas-fired kilns fitted with regenerators are the most economical, though round down-draught kilns are also extensively used for this purpose.

The manufacture of magnesite bricks is one of peculiar difficulty, as the sintered magnesia is difficult to grind, the bricks as they come from the drying chamber are exceedingly tender and must be handled with great care, and the high temperatures in the kilns are by no means easy to maintain.

c.

D D 
The production of these bricks is, therefore, confined to a limited number of firms.

Magnesite bricks are particularly sensitive to silica and clay, and with these materials form a glassy slag at high temperatures. It is, for this reason, very difficult to use both magnesite and clay- or-silica-bricks in the same structure.

Bauxite bricks are commonly regarded as basic, though in many ways they partake of a neutral character. Bauxite is the mineral name for a variety of impure alumina, which usually contains considerable proportions of iron oxide and combined water. The bauxite is ground to powder, mixed with a little clay and water to form a stiff paste, and $s$ then moulded in a manner similar to hand-made bricks (p. 333). The burning may be effected in any kiln suitable for firebricks, but the greatest possible care must be taken to avoid a shortage of air. If there is a reducing atmosphere in the kiln the iron compounds in the bauxite will be reduced, and bricks of very low heat resistance will be produced. Bauxite shrinks greatly during the burning, and if this is carried out at too low a temperature the bricks may shrink badly when in use. The great shrinkage makes it very difficult to produce bauxite bricks of a uniform size, and the men engaged in emptying the kilns must be instructed to sort them carefully with the aid of gauges. Unless this is done it will be impossible to keep the joints in the brickwork uniform.

Neutral bricks are those which are not affected by either basic substances, such as lime or magnesia, or by acid substances, such as clay or silica. They are more costly than other bricks, and are only used for purposes for which the others are unsuitable.

The majority of neutral bricks are made of chromite, and are composed of chromium oxide with some iron oxide. As this material has no inherent binding power, it is usually mixed with twice its weight of fireclay. Chromic bricks are made in the same manner as ordinary firebricks, though some makers prefer to compress them in powerful presses instead of moulding them by hand.

Several other materials are made into bricks for special purposes, but their use is too limited to warrant their description in the present volume. 


\section{INDEX}

a-ORTHO-SILICATE, 51

Abrasion, resistance to (bricks), 380

Accelerated tests, 121

Accrington, 342

Adhesion, 1, 229

between concrete and steel, 255

of cement to metal, 144

of concrete to metal, 217,218

Adie's machinc, 135

Adulterants in cement, 38, 102

Aeration, 74

Agglomerate clay, 311

Aggregate, 146

grading, 156

measuring, 168

washing, 154

Aggregates for concrete, 147

for reinforced concrete, 209 testing, 277

Air, exposure of cement to, 92

Air separator, 105

Alite, 50, 52

Alkali-wastc, 18

Alkalics, 73 in clays, 308

Alligating, 195

Alluvial clay, $6,7,311$

Alum, 92

Alumina, 75

and lime, reactions between, 69

effect of heat on, 43

free, 307

free, in cement, 43,90

in cements, 69,70

lime and silica, reactions between, 71

-silica ratio, 65

Aluminatc theory, 71

Aluminates, 54, 69, 90

Aluminium chloride, 92

sulphate, 92

Aluminosilicates, $47,48,55,74,78,83$, $85,87,89,90,93$

Aluminosilicic acid, 5, 39, 55

American Standard Specification, 121

Analysis of clay, 321

Anchored spirals, 223

Apparent density, 99, 381

Aqueducts, 242
Arches, 241

Architects' Institute recommendations, 211

Archless kiln, 354

Argillaceous limestone, 5

Artificial aggregates, 149

Asch, W. \& D., 87, 93, 112, 266

Asch's theory, 40, 55, 61, 65, 267

Ash, proportion of, 110

Ashes as aggregate, 151

Associated Portland Cement Manufacturers, Jimited, 154, 155, 157, 169

$\beta$-ORTHO-SILICATE, 51

Bach, von, 283

Baked bricks, 370

Ball clays, 311 mills, 105

Ballast, 148, 149, 193, 258

Barker and Hunter, 183

Bars for reinforcement, 219 smooth, 217

with wings, 222

Basic bricks, 401

Batch mixers, 176

Bauschinger's method, 124

Bauxite bricks, 402

Beam, continuous, 216 loaded, 215

Beams, 216, 218, 224, 225, 233, 248 .

Belgian cement, 13, 31

Belite, 50, 51 kilns, 351

Bending moments, 216, 218 strength, 142

Berry, H. C., 284

Binary silicates, 69

Bınne, C. F., 288

Binns and Makeley, 290

Bins, 25

Bitumens, 200

Blaese, C. von, 265

Blast furnace slag, 17

Block-making machine, 251

Blocks, 248

Blount, B., 101

Blowing in bricks, 295, 369

of cement, 94, 104, 116, 119

D D 2 
Blowing of concrete, 150

Blue bricks, 289, 372

Boats, 252

Bonna system, 242

Boracic acid, 92

Borax, 92

Boudouard, 67

Boulder clays, 294

Bradley and Craven stiff-plastic brick machine, 340

Breaking strength of briquettes, 137

Brickbats, 377

Brick clays, 286 earth, 311, 326

Brickmaking, methods of, 319

Bricks, 286 basic, 401

bauxite, 402

chromic, 402

Fletton, 150, 210

for aggregate, 149

glazed, 359

magnesite, 401

neutral, 401, 402

properties of, 376

siliceous, 395

Bridges, 240

British Concrete-Steel Co., 212

British Fire Prevention Committee, 259

British Reinforced Concrete Engineering Co., Ltd., 212

British Standard Specification, 97, 98, $103,107,109,111,118,125,127,129$, $131,132,133,135,137,139,140,147$, 212

Brittleness of bricks, 381

Brown, H. P., 270

Buff bricks, 290

Bührer's kiln, 357

Builders' and Contractors' Plant, Ltd., 176

Building blocks, 248

Bulging, 221

Bullnoses, 378

Burning, 33

bricks, 344

changes in, 363

cement, 23, 68

Burrs, 305, 377

Butler, D. B., 104, 108, 116, 122, 137

Calcareous sands, 159

Calcined clay, $43,46,47,48,88,367$

Calcium aluminates, $47,52,54,69,70$, 71

aluminosilicates, 47,55

carbonate. See Chalk, Limestone and Lime.

chloride, 92, 93
Calcium ferrite, 262

meta-silicate, 67

mono-silicate, 67

ortho-silicate, 51, 89

phosphate, 6

silicates, 47, 52, 91

sulphate, $67,75,76,92,93,94$

sulphate, action of, on cement, 92

Callow, 317 sulphide, $7 \mathrm{v}$

$\mathrm{CaO}: \mathrm{SiO}$ ratio, 53

Candlot, E., 92, 266

Cantilever wall, 220

Capital required for bricks, 319

Carbon dioxide, action of, 91, 94

Carbonaceous matter in clays, 310

Cart for concrete, 188

Celite, 50, 51

Cement, 1 clinker. See Clinker. coatings, 199

for concrete, 147

for reinforced concrete, 210

hardened, constituents of, 90

in concrete, 165

manufacture, 20

mixture, effect of heat on, 45

sand bricks, 395,398

sand tests, 138

testing, 96

Cements, organic, 1

Centering, 184 striking, 193

Chalcopyrite, 310

Chalk, 1-3

and clay, reactions between, 46

effect of heat on, 44

in bricks, 291, 373

Chamber kilns, 355

Changes to bricks in burning, 358

Chapman, C. M., 205

Checking mixture of concrete, 169

Chemical changes in cements, 39

Chemical composition, 98

Chicago cube mixer, 177

Chimneys of concrete, 246

China clay, 5, 314

Chromic bricks, 402

Cinders for reinforced concrete, 209

Clamps, 344.

Clark, R. G., 262

Clay and lime, reactions between, 46,57 effect of heat on, 40, 366 preparation of, 325

Clays, 1, 2, 5, 39, 55, 286

action of heat on, 304

occurrence of, 12

plastic, 296

various, 315 
Cleaning the surface of concrete, 195

Climates, effect of, on setting, 81

Clinker, 26, 30, 50, 80, 118

as aggregate, 151

bricks, 305, 377, 397

physical properties of, 80

Clots, 339

Clunches, 312

Coal bunkers, 243

Cobb, J. W., 66, 67, 69, 72, 76, 77

Coefficient of elasticity, 216

Coffer-dams, 192

Coignet, Edmond, Limited, 213, 231

pile, 245

pipe, 242

reinforcement, 230

Coke-breeze aggregate, 150, 258 in clays, 299

for reinforced concrete, 209

Colloidal material in clay, 301

silica, 84

Colloids, 83 substance, 82

Colour of brick clays, 287

of bricks, 371,379

of terra-cotta, 371

Colouring concrete, 196

Column base, 224

Columns, 215, 221

testing, 279

Combined water in clay, 367

Commercial specifications, 213

Compactness, 145

Components of concrete, 146

Composition of bricks, 376

of cements, limits of, 61,62

of concrete mixtures, checking, 169 .

Compression bar, 228

of Portland cement, 98

Compressive strength, 126, 224

Concrete, 146

blocks, 249

Institute, recommendations, 211

placing, 187

preparation of, 162

reinforced, 206

spading, 189

testing, 277

Conduits, 242

Cones, Seger, 360

Conglomerate clays, 312

Considère Construction Co., Ltd., 212 pile, 247

system, 222

Consistency of concrete, 170 of paste for bricks, 332

Continuous kilns, 347

Contraction of cement, 120

Cooling clinker, 26
Core, metallic, 223

Cores, 368

Corrosion, electrolytic, 270

of reinforced concrete, 269

resistance to, 262

Costs, 217, 324

Cracking (bricks), 369 of cement, 116

Cracks, 236, 272 of concrete, 150, 195, 273

Crocodile surfaces of concrete, 195

Crozzles, 305, 377

Crushing, 25

machinery, 327

strength, 214, 278

strength of bricks, 385

strength of concrete, 254 tests, 278

Crystallisation, 82

Crystals, 54

formation of, 49

in cement, 50

Cushmann, 107

Cutters, 370, 376

DAMP-PRoOfing CONCRETE, 197

"Darrprobe," 123

Day, 67

Day and Shepherd, 51

Day, Shepherd and Wright, 53

Dead-burnt lime, 33

loads, 213

loads, equivalent, 214

Deflection under load, 284

Dense surfaces of concrete, 195

Density, apparent, 99, 145 of bricks, 381

Desch, C. H., 50

Deval's test, 123

"Diamond" stretcher, 378

Di-calcium aluminate, 52, 70, 90 silicate, 52

Dinas bricks, 399

Discoloration of concrete, 194, 273

Ditch cutters, 323

Dittler, E., 60, 79

Docks, 242

Doetler, C., 68, 79

"Dog-tooth" stretcher, 378

Dolomitic limestone, 5

Dormann, O., 65, 68

Down-draught kilns, 346

Drift clays, 312

Dry concrete mixture, 170 dust process, 343 process, 24, 27

Drying, 24 bricks, 304, 335, 362 changes in, 363 
Drying clays, 338

Durability of bricks, 386 of concrete, 271

Dye-test, 84

Dyes absorbed by clays, 301

Dynamo beds, 248

EARTHQdake tremors, resistance to, 260

Edge-runner grinding mill, 328

Efflorescence, 195, 273, 379, 387

Elasticity coefficient. 216

Electrical conductivity of cement mixes, 60

Electrolytic corrosion, 270

Emperger, F. von, 279

Encastré, 216

Engine beds, 248

Engineering bricks, 373, 377

Expanded metal, 248

Metal Company, Limited, 213 metal system, 236

Expansion of cement, 94, 116, 125 of coke-conerete, 150

FACING BRICKS, 343,362 concrete, 197 with terra-cotta, 258

Factors of safety, 214

Faija, H., 112, 122, 131

Faija's mechanical gauger, 131

Failure, causes of, 253, 274, 275

Fat clays, 312

lime, 33

Fawcett stiff-plastic brick machine, 341

Feichtinger, 87

Felite, 50, 52

Felspar, 370

Felspathic matter, effect of, 72

Feret, M., 226

Ferrates, 90

Ferric oxide, 75

Ferrocrete, 206

Ferro-silicates, 74, 90

Ferrous carbonate, 289 compounds, 74 sulphide, 75

Filling in the surface of concrete, 196

Final set, 90, 110

Fineness, 68, 103

Fire Prevention Committee tests, 150 resistance of concrete, 256

resistance; standard classification for floors, 259

Firebricks, 305, 362, 375, 395

durability of, 393

selection of, 389

silica, 395,399
Fireclays, 312, 313

Fish glue, 1

Fletton bricks, 150,210

Flints, 3 for aggregate, 149

Floor slabs, 248

Floors, 214, 215, 216, 225, 231, 248 concrete, 210 testing, 279

“Flour," 103, 106

Flourometer, 108

Fluates, 199

"Flying" of aggregates, 209

Forms, 184, 185, 186, 191

Formulæ of cement, 88 of Portland cements, 57

Foul clays, 297, 317

Foundations for machinery, 248

Free lime in Portland cement, 45

Fremy, 89

French standard for tensile strength, 141

Frey, O., 143

Frog in bricks, 333, 336, 378

Frost, effect of, 190, 271

Fuel consumption in brick kilns, 354

Furnace slag as aggregate, 151

Furnaces, lining, 389

Fusible clays, 313

Fusion, 46, 47, 54, 68, 69, 70, 80

$\gamma$-ORTHO-SILICATE, 51

Ganister, 313

bricks, 399

Garden ornaments, 252

Gary, 107, 112

Gas Engineers, Institution of, 389

Gas-fired kilns, 358

Gate posts, 252

Gauging, 81, 113, 115, 131

Gault clay, 6, 313

Gee, W. J., 108

Gel, 82, 83

German standard for tensile strength, 141

Standard Rules, 121

Girders, 224

Glassy matter, $72,74,80$

Glazed bricks, 359, 379

Gliding, resistance to, 145

Goldbeck, A. T., 284

Goreham, process of, 22

Graded sands, 160

Grading, 261 aggregates̀, 153, 253

Grains, size of, 68

Granite, 148

Granolithic facings, 197

Granulation of slag, 37 
Grappier cement, 34, 266

Grappiers, 34, 52

Green bricks, 344 concrete, 196

Grey bricks, 291 stocks, 377

Grinding, 23, 118 object of, 47

Grizzles, 377

Grog, 314

Grout, 170

Guthrie's kiln, 351

Gypsum, 76, 93, 94

\section{HaCks, 335}

Hair-lines in concrete, 195

"Half-moon" stretcher, 378

Hand-made bricks, 333

Hard materials, treating, 23

Hardening, 109

chambers for bricks, 398

changes in, 81

of concrete, 192

Hardness of bricks, 380

Haulage, 324

Hearts in bricks, 368

Heat, action of, on clays, 40, 304 on limestone, 44

conductivity, 258 on silica, 43

development of, in setting, 86

effect of, on alumina, 43

on bricks, 366

on cement mix, 59, 79

on lime and silica, 66

resistance to, by bricks, 388

Heating, insufficient, 372

Heavy bricks, 382

concrete work, 210

Hennebique column, 222

base, 224

F., 221, 227

piles, 246

stirrups, 227, 228

system, $212,226,229,230$,

Herold, K., 60 234,245

Hillebrand, 73

Hoffmann kiln, 24, 46, 348

Horizontal draught kilns, 347

Hot water tests, 120

Hubbard, 107

Humphrey, R. L., 268

Hydraulic cements, 1, 2

lime, $1,2,12,13,77,86,266$ burning, 33

concrete, 147

manufacture of, 32
Hydraulic lime, tensile strength of, 142 modulus, 64

Hydraulite, 2

Hydro-silicates, 85

\section{IMPURITIES, 3, 84}

effect of, 72

in cement, 52

in chalk, 21,46

in clays, 305,307

Inclined members, 222

Indented bars, 219, 235

Inert material in concrete, 146

Initial set, $81,88,90$

Insoluble residue, 99

Integral waterproofing, 200

Inter-reactions in cements, 72

Iron compounds, 74 in clays, 309

in cement, 74

ore, 18

ore waste, 18

Portland cement, 36

Irregularity in bricks, 378

Jesser, I., 60

Johnson, R., Clapham and Morris, Ltd., 239,240

Johnson's kiln, 22

Jones, H. R., 255

KAHN SYSTEM, 212 trussed bar, 217, 231, 232

Kallauner, 265

Kaolin, 314

Kaolinite, 306

Keedon bar, 229, 234

Keene's cement, 1

Kentish rag, 139 specific gravity of, 102

Kibblers, 328

Kiefer, H. E., 119

Kiln, Hoffmann, 24

Johnson's, 22

rotary, 25

shaft, 23

Kilns, 23, 33, 46, 72, 76, 79, 110, 345 changes occurring in, 366

Kloes, J. A. van der, 267

Kühl, H., 117

LAMINATED clays, 314

Lateral ties, 221

Lavas, 2, 14

Lean clays, 297, 314

Lean mixture concrete, 167 
Le Chatelier, 50, 52, 55, 101, 120, 121, 285

Le Chatelier's test, 124

Leicester red brịcks, 293

Lias limestone, 4, 14

Liassic marls, 11

Light bricks, 382

Lime, 1, 2 action of heat on, 45

alumina and silica, reactions between, 71

-alumina ratio, 53

and clay, reactions between, 46,57

and silica, effect of heat on, 66

carbonated, 91 reactions between, 66

carbonation of, 94

compounds, 3

in clay, 307

concrete, 147, 167, 214

effect of, on setting, 83

(free) in cement, 45, 117, 118, 119

hydraulic. See Hydraulic lime.

minimum proportion of, 65

sand bricks, 395

Limestone, 1, 2, 4, 165

action of heat on, 44

in bricks clays, 295,369

Limestones for aggregate, 149

Lindner, 107

Lines of stress in beam, 233

Lintels, 250

Litre weight, 99

Live loads, 213

Loads, calculating, 213, 215

heavy, 228

in buildings, 213

varying, 215

Loading tests, 279

Loams, 8, 293, 326

London clay, 315

L.C.C. rules, 219

London stocks, 345

Loss in manufacture of bricks, 362 of shape (bricks), 370 on ignition, 99

Magazines, 243

Magnesia, 5, 46, 57, 73, 99, 117, 265 compounds, reactions of, 266 effects of, 73

Magnesite bricks, 401

Magnesium chloride, 93 compounds in clays, 308

Malm bricks, 290

Malms, 292, 376

Manufacture, changes in, 39

Marcasite, 310

Marine deposited clays, 315
Maritime work, 267

Marls, 5, 9, 292, 326

for brickmaking, 10

for cement manufacture, 10

of Staffordshire, 289

red, 293

Materials for cements, 1

Meal, 25 selection of, 323

Mechanical bond, 228 mixers, 176

Medium mixture concrete, 169 setting, 110

Melting point and electrical conductivity, 61

Membrane wateiproofing, 200, 203

Meta-silicates, 67, 82

Methods of cement manufacture, 20

Michaelis, W., 104, 106

Microscopical examination, 49

Midland marls, 315 study of cement, 84

Mild clays, 297

Mills, 25

Millstones, 105

Mineral matter, effect of, 72$\rfloor$

Minerals in clay, 44

Mining, 323

Mixer for clay, 331

Mixers, 25, 176-183

Mixing clay for bricks, 331 concrete, 173

Mixture theory, 48

Moisture, exposure to, 92

Mono-silicate, 67

Mörsch, 283

Mortar, 5 mill, 332

tensilc strength of, 142

Moss bar, 234, 235

Mouchel, L. G., and Partners, 212 hollow pile, 245

Moulding bricks, 333

Moulds, 184

Muds, 2, 7, 9

Mundic, 310

NATURAL cement, 2, 12, 77

manufacture of, 29

Neat cement, 129

Neat tensile test, 138

Netting, 239

Network for reinforcing, 22

Neutral bricks, 401, 402

Newberry Bros., 53, 73, 74

Newcastle kilns, 347

Nodules, 6, 13

Nontronite, 288

Norton, C. L., 258, 260 
OILs in concrete, 204

Ordinary concrete mixture, 170

Ore, 18

Ornamental bricks, 378

Ornum, Van, 284

Ortho-silicates, 51, 89

Ostwald, W., 112

Overburden, 317

Over-heating, 33

Overlimed cement, 104

Overloaded columns, 221

Oxy-chloride cements, 1

Oxy-phosphate cements, 1

Paint applied to concrete, 199

Pan mill, 332

Paving blocks, 248 bricks, 377

Paviours, 377

Parian cement, 1

Pebbles, 148

Peeling, 195, 196 of bricks, 387

Pelinite, 306

Permeability of bricks, 384 of concrete, 261,265 tests of, 284

Permean marls, 11

Peterborough, $\mathbf{3 4 2}$

Physical changes in cements, 39

Piers, 215, 221

Piles, concrete, 243

Pipes, concrete, 242

Pit props, 252

Placing concrete, 187

in water, 191

Plaster of Paris, 76, 94 slag cements, 36

Plastic clays, 296

" Plums," 154 methods of brickmaking, 333

Plunge test, 122

Polished concrete, 196

Pontoons, 252

Popplewell, 255

Pore water, 364

Porosity, 145 of aggregates, 158 of bricks, 383

Porous surfaces of concrete, 195

Portland cement, 1 action of sea water on, 266 adulterants of, 38 manufacture of, 20

Potash, 73

Potassium carbonate, 92 compounds in clay, 308 di-chromate, 92 sulphate, 92
Potassium sulphide, 92

Pozzolana, 1, 2, 15, 35, 42, 77, 78, 88, 146,205

tensile strength of, 142

Pozzolanic sands, 159

slag, 17 cements, 36

Practical test, 96

Preheating bricks, 351

Preparation of concrete, 162

Properties of concrete, 254

Proportions, 30, 62, 68, 71

for beams, etc., 224

for reinforced concrete, 210

in concrete work, 252

of clay and lime, 12

of components of concrete, 163

Pugmill, 330

"Pure clay," 306

Purple bricks, 289, 371

Pyrites, 6, 290, 309, 370

QUARRYiNG, 323

Quartz, 66, 68

Quicklime, 5, 33

manufacture of, 32

Quick setting, 110

$$
\text { cement, 81, 90, 94, } 109
$$

RACE in bricks, 369

Rafts, 248

Railway sleepers, 252

Ramming, 189 mechanical, 142

Rankine, 67

Ransome ver Mehr Machinery Company, $176,179,181,182,187$

Rasenow, 299

Rate of setting, 82, 92, 95, 109

Rational analysis, 306

Raw materials for bricks, 286

Raw meal, 25

Reading clays, 315

Red-burning clays, 288

Reducing atmosphere, 76,372

Refractoriness of bricks, 388

Refractory clays, 315

Re-heating, 103

Reinforced concrete, 206

Metal, Limited, 223

Re-pressing bricks, 343

Reservoirs, 242

Resistance to abrasion of bricks, 380 to corrosion, 262 to shocks, 260 to strong acids of bricks, 388

Retaining walls, 220

Retardation of setting, 92 
Rib mesh reinforcement, 237

Rich mixture concrete, 167

Richardson, 51

Roads, conerete, 250

Rock cement, 13 manufacture of, 29 tensile strength of, 142

Rock clays, 315

Rohland, P., 92

Roman cement, 1, 13, 31, 77, 90 tensile strength of, 142

Roof, 216

Ropeways, 324

Ross, 190

Rotary kiln, 25, 46, 72

Rough stocks, 377

Roughness, 195

R.I.B.A. Committee, 211, 218, 257, 279, 283

standard for bricks, 378

"Ruabon" kiln, 356

Ruabon terra-cotta clay, 293

"Rubbers," 370, 376

SAFE load for concrete, 214

for lime-concrete, 214

Safety factors, 214

Salter tensile test machine, 136

Salts, effect of, 113 soluble, 370

Sampling, 98

Sand, 146, 150, 159 cement, 29 cementitious, 193

- for reinforced concrete, 209 measuring, 168 moulding, 334 standard, 139 testing, 277

Sandstones for aggregate, 149

Sandy clays, $294,316,326$

Santorin earth, 15

Schmidt and Unger, 54

Schüle's machine, 143

Schuljatschenko, 267

Scotch kilns, 345

Scott's cement, 34

Scum, 195, 293, 309, 379, 387

Scummed bricks, 291

Sea sand, 209

water, 93 action of, 264

Seasoning, 119

Seccotine, 1

Seger cones, 360

Selenitic cement, 34

Semi-dry process of brickmaking, 333, 341
Semi-plastic methods of brickmaking, 333,339

Septaria, 12

in bricks, 369

Setting of cement, 76

of conerete, 192

rate of, $81,82,109$

retardation of, 92

Sewage, action of, on concrete, 263

Sewell, J. S., 270

Sewers, 242

Shaft kiln, 23

Shakes, 377

Shales, 5, 8, 55, 286, 292, 314, 316, 326

for aggregate, 149

occurrence of, 12

Shapes of bricks, 378

Shaping the clay, 333

Shear bar, 218

$$
\begin{aligned}
& \text { diagram, } 215 \\
& \text { members, } 219,233 \\
& \text { reinforcement, 225 } \\
& \text { resistance to, 145, 235 } \\
& \text { tests, } 254
\end{aligned}
$$

Shearing strength, 144, 254, 255

stress of concrete, 226

Shelling of bricks, 387

Shepherd, 67, 69

Shivers, 377

Shocks, resistance to, 260

Shrinkage measurements, 360 of clay, $301,302,363,389$

of concrete, 195

Shuffs, 377 water, 364

Shuttering, 184

Shutters, 184

Siderite, 289

Sifting, 105

Silica, action of heat on, 43

alumina and lime, reactions between, 71

and lime, reactions between, 66

bricks, 399

colloidal, 84

firebricks, 395, 399

free, 90,306

in Portland cement, 67

Silicates, 51, 52, 67, 69, 72

containing iron, 309

Siliceous bricks, 395

Sillimanite, 42

Silos, 25, 243

Silt, 316

Size of sand particles, 160

Sizes of bricks, 378

of particles in aggregate, 151, 153

Slabs, 216, 248

testing, 279 
Slag cements, 78

manufacture of, 35

tensile strength of, 142

Slag, specific gravity of, 102

Slags, 2, 16, 51, 67, 76, 78, 258

Slate waste, 8

Slates, 316

Sleepers, 252

Sliding of reinforcement, 144

Slipping of stirrups or bars, 233

Slop moulding, 334

Slow setting, 110

Slurry, 21

cements, 86, 92, 109, 269

Smith, 'T. L., Co., Ltd., 176, 178, 179

"Smoking" bricks, 352

Soaps in concrete, 204

Soda, 73

Sodium carbonate, 92 compounds in clay, 308

Soil, 316 sulphate, 92

Sol, 83

Solid solution, 70, 86

Soluble salts, 370

$$
\text { theory, } 48
$$

silica, 43

Soundness of ccments, 116, 117 tests, 119

Spade for concrete, 190

Spading, 195

Spalling (concrete), 195

Spans, 216

$$
\text { (bricks), } 369
$$

Specific gravity, 100

$$
\text { of bricks, } 381
$$

Specification for firebricks, 391

Specifications, commercial, 213

Spiral bars, 236 reinforcement, 242

Spissograph, 114

Splintering, 209

Spofforth, 226

Spots on bricks, 370

Squints, 378

Staffordshire bricks, 372

Stairways, 251

$$
\text { kiln, } 355
$$

Stanchions, 221, 224

Standard mixture concrete, 167 sand, 139 specifications for cements, 97

Stanger, W. H., 101

Stationary kilns, 72

Steam, effect of, 92 navvies, 323

Steel for reinforcement, 211

$$
\text { in concrete, } 206
$$

testing, 277

Steelcrete, 206
Steinbrück, 131

-Schmelzer machine, 133

Steps, 251

Stiff-plastic process, 333, 339

Stirrups, 218

Stocks, 377

Hennebique, 227, 228

Stones, 148

Stony clay, 294

Storage, 25

Straight line formula, 217

Strength of bricks, 384 of cement, 90 of concrete, 254, 271

of mixtures, 104

to age, ratio of, 227

Stress, distribution of, 239

lines of, 215

shearing, 255

Stresses, internal, 216 working, 213, 216

Striking centering, 193

String course bricks, 378

Strong clays, 297, 317

Submarine work, 265

Suffolk bricks, 370

Sulphates, 67, 75, 117, 211, 265

effect of, 93

in clay, 307

Sulphide of iron, 309

Sulphides, 75

Sulphur, 258

compounds in concrete, 151

in concrete, 150

tri-oxide, 76, 99

Surface clays, 6,317

fillings, 196

treatment of concrete, 194

Swelling, 221

Sylvester process of damp-proofing, 198

Systems of reinforcement, 217

TALBot, 226

Tamping, 189

tool, 189

Tanks, concrete, 210, 242

Tar, 199

Technical knowledge needed by brickmakers, 320

Teil lime, 34

Telegraph poles, 252

Temperature, effect of, 115

required in burning

Tempering mill, 332 bricks, 374

Tender clays, 317

Tensile strength, 128, 161

of concrete, 254

of mixtures, 139 
Tensile strength of slag cements, 142

Tension bars, 225

$$
\text { diagonal, } 226
$$

Terra-cotta, architectural, 303 facing with, 258 for aggregate, 149

Testing aggregates, 154, 277 cements, 96 clay for bricks, 321 concrete, 277

Tests, loading, 279 of concrete columns, 222

Tetmajor, 128

Texture of bricks, 382 of clay, 292

Thermal method, 113

Tiles, cement, 251

Till clay, 317

Time of setting, 81, 88, 112

Törnebohm, 50

Tosca, 15

Tough clays, 297

Toughness of bricks, 381

Tournai cement, 31

Tramway standards, 252

Transverse bending strength, 143 bonds, 221 strength of concrete, 254, 255

Trass, 1, 14, 15, 42, 88, 205, 269, 271 tensile strength of, 142

Tremie, use of, 192

Trials, 359

Triangle mesh reinforcement, 240

Triassic clays, 315 marls, 11

Tri-calcium aluminate, 69,90

Tridymite, 68 silicate, $52,67,69,90$

Truss girder, 225

Trussed bar, 231

Trussed Concrete Steel Co., Ltd., 212

Tube-mills, 105

Tuffs, 2, 14

Tunnel dryer, 338

Turneaure, 228

UNDER-BURNING, 119

Unsoundness, 116

Unwin, 128

Updraught kilns, 345

VibRation of concrete, 256
Vibrators, 189

Vibrocel Co., Ltd., 189, 192

Vicat needle, 110, 111

Vitrifiable clays, 317

Voids, 152, 157, 163

in sand, 161

Volcanic lavas, 2, 14 tuffs, 2

WaLLS, concrete, 210

Water absorption, 145 action of, on cement, 85 combined, in brick, 367 fer concrete, 147 fresh, action of, on concrete, 263 in bricks, 363 -mains, 242 -proofing concrete, 197 proportion of, in concrete, 172 repellents, 204 -smoking bricks, 352 tanks, 242

Weak clays, 297

Weathering, 327

Web-connection, 228

Web members, 233 rèinforcement, 225

Weight per bushel, 99 per cubic foot, 215

Wet concrete mixture, 170 process, $21,27,118$

White bricks, 290 burning clays, 290

Whittaker plunger press, 342

Wilson and Gaylord, 168

Wine musts, action of, on concrete, 263

"Winget" concrete blocks, 250

Winget Concrete Machine Company, $176,180,251$

Wire-cut bricks, 335

Wire netting, 239 process, 337

"Wolves," 328

Woolson, 258

Wright, 68

YELLOW bricks, 290 clays, 318

ZschoKkE, 299

Zulkowski, 88, 89 


\section{VAN NOSTRAND'S \\ "WESTMINSTER" SERIES}

Bound in Uniform Style.

\section{Fully Illustrated. Price $\$ 2.00$ net each.}

Gas Engines. By W. J. Marshall, Assoc. M.I.Mech.E., and CAPT. H. Riall Sankey, R.E. (Ret.). M.Inst.C.E., M.I.Mech.E. 300 Pages, 127 Illustrations.

List of Contents : Theory of the Gas Engine. The Otto Cycle. The Two Stroke Cycle. Water Cooling of Gas Engine Parts. Ignition. Operating Gas Engines. The Arrangement of a Gas Engine Installation. The Testing of Gas Engines. Governing. Gas and Gas Producers. Index.

Textiles. By A. F. BARKer, M.Sc., with Chapters on the Mercerized and Artificial Fibres, and the Dyeing of Textile Materials by W. M. GARDNER, M.Sc., F.C.S.; Silk Throwing and Spinning, by R. SNow; the Cotton Industry, by W. H. Cook; the Linen Industry, by F. BRAdBURY. 370 Pages. 86 Illustrations.

Contents: The History of the Textile Industries; also of Textile Inventions and Inventors. The Wool, Silk, Cotton, Flax, etc., Growing Industries. The Mercerized and Artificial Fibres employed in the Textile Industries. The Dyeing of Textile Materials. The Principles of Spinning. Processes preparatory to Spinning. The Principles of Weaving. The Principles of Designing and Colouring. The Principles of Finishing. Textile Calculations. The Woollen Industry. The Worsted Industry. The Dress Goods, Stuff, and Linings Industry. The Tapestry and Carpet Industry. Silk Throwing and Spinning. The Cotton Industry. The Linen Industry historically and commercially considered. Recent Developments and the Future of the Textile Industries. Index.

Soils and Manures. By J. Alan Murray, B.Sc. 367 Pages. 33 Illustrations.

Contents : Introductory. The Origin of Soils. Physical Properties of Solls. Chemistry of Soils. Biology of Soils. Fertility. Principles of Manuring. Phosphatic Manures. Phosphonitrogenous Manures. Nitrogenous Manures. Potash Manures. Compound and Miscellaneous Manures. General Manures. Farmyard Manure. Valuation of Manures. Composition and Manural Value of Various Farm Foods. 
Coal. By James Tonge, M.I.M.E., F.G.S., etc. (Lecturer on Mining at Victoria University, Manchester). 283 Pages. With 46 Illustrations, many of them showing the Fossils found in the Coal Measures.

LisT of Contents : History. Occurrence. Mode of Formation of Coal Seams. Fossils of the Coal Measures. Botany of the Coal-Measure Plants. Coalfields of the British Isles. Foreign Coalfields. The Classification of Coals. The Valuation of Coal. Foreign Coals and their Values. Uses of Coal. The Production of Heat from Coal. Waste of Coal. The Preparation of Coal for the Market. Coaling Stations of the World. Index.

Iron and Steel. By J. H. Stansbie, B.Sc. (Lond.), F.I.C. 385 Pages. With 86 Illustrations.

List of Contents : Introductory. Iron Ores. Combustible and other materials used in Iron and Steel Manufacture. Primitive Methods of Iron and Steel Production. Pig Iron and its Manufacture. The Refining of Pig Iron in Small Charges. Crucible and Weld Steel. The Bessemer Process. The Open Hearth Process. Mechanical Treatment of Iron and Steel. Physical and Mechanical Properties of Iron and Steel. Iron and Steel under the Microscope. Heat Treatment of Iron and Steel. Electric Smelting. Special Steels. Index.

Timber. By J. R. Baterden, Assoc.M.Inst.C.E. 334 Pages. 54 Illustrations.

Contents : Timber. The World's Forest Supply. Quantities of Timber used. Timber imports into Great Britain. European Timber. Timber of the United States and Canada. Timbers of South America, Central America, and West India Islands. Timbers of India, Burma, and Andaman Islands. Timber of the Straits Settlements, Malay Peninsula, Japan and South and West Africa. Australian Timbers. Timbers of New Zealand and Tasmania. Causes of Decay and Destruction of Timber. Seasoning and Impregnation of Timber. Defects in Timber and General Notes. Strength and Testing of Timber. "Figure" in Timber. Appendix. Bibliography.

Natural Sources of Power. By Robert S. Ball, B.Sc., A.M.Inst.C.E. 362 Pages. With I04 Diagrams and Illustrations.

Contents : Preface. Units with Metric Equivalents and Abbreviations. Length and Distance. Surface and Area. Volumes. Weights or Measures. Pressures. Linear Velocities, Angular Velocities. Acceleration. Energy. Power. Introductory Water Power and Methods of Measuring. Application of Water Power to the Propulsion of Machinery. The Hydraulic Turbine. 


\section{THE “WESTMINSTER" SERIES}

Various Types of Turbine. Construction of Water Power Plants. Water Power Installations. The Regulation of Turbines. Wind Pressure, Velocity, and Methods of Measuring. The Application of Wind Power to Industry. The Modern Windmill. Constructional Details. Power of Modern Windmills. Appendices. A, B, C Index.

\section{Electric Lamps. By Maurice Solomon, A.C.G.I.,} A.M.I.E.E. 339 Pages. II2 Illustrations.

Contents : The Principles of Artificial Illumination. The Production of Artificial Illumination. Photometry. Methods of Testing. Carbon Filament Lamps. The Nernst Lamp. Metallic Filament Lamps. The Electric Arc. The Manufacture and Testing of Arc Lamp Carbons. Arc Lamps. Miscellaneous Lamps. Comparison of Lamps of Different Types.

Liquid and Gaseous Fuels, and the Part they play in Modern Power Production. By Professor Vivian B. Lewes, F.I.C., F.C.S., Prof. of Chemistry, Royal Naval College, Greenwich. 350 Pages. With 54 Illustrations.

List of Contents : Lavoisier's Discovery of the Nature of Combustion, etc. The Cycle of Animal and Vegetable Life. Method of determining Calorific Value. The Discovery of Petroleum in America. Oil Lamps, etc. The History of Coal Gas. Calorific Value of Coal Gas and its Constituents. The History of Water Gas. Incomplete Combustion. Comparison of the Thermal Values of our Fuels, etc. Appendix. Bibliography. Index.

Electric Power and Traction. By F. H. DAvies, A.M.I.E.E. 299 Pages. With 66 Illustrations.

List of Contents: Introduction. The Generation and Distribution of Power. The Electric Motor. The Application of Electric Power. Electric Power in Collieries. Electric Power in Engineering Workshops. Electric Power in Textile Factories. Electric Power in the Printing Trade. Electric Power at Sea. Electric Power on Canals. Electric Traction. The Overhead System and Track Work. The Conduit System. The Surface Contact System. Car Building and Equipment. Electric Railways. Glossary. Index.

\section{Decorative Glass Processes. By ArThur Louis} Duthie. 279 Pages. 38 Illustrations.

ConTEnTs: Introduction. Various Kinds of Glass in Use : Their Characteristics, Comparative Price, etc. Leaded Lights. Stained Glass. Embossed Glass. Brilliant Cutting and Bevelling. SandBlast and Crystalline Giass. Gilding. Silvering and Mosaic. Proprietary Processes. Patents. Glossary. 


\section{THE “WESTMINSTER" SERIES}

\section{Town Gas and its Uses for the Production of Light, Heat, and Motive Power. By W. H. Y. WEBBER; C.E. 282 Pages. With 7I Illustrations.}

List of Contents : The Nature and Properties of Town Gas. The History and Manufacture of Town Gas. The Bye-Products of Coal Gas Manufacture. Gas Lights and Lighting. Practical Gas Lighting. The Cost of Gas Lighting. Heating and Warming by Gas. Cooking by Gas. The Healthfulness and Safety of $\mathrm{Gas}$ in all its uses. Town Gas for Power Generation, including Private Electricity Supply. The Legal Relations of Gas Suppliers, Consumers, and the Public. Index.

\section{Electro-Metallurgy. By J. B. C. Kershaw, F.I.C.} 318 Pages. With 6I Illustrations.

Contents: Introduction and Historical Survey. Aluminium. Production. Details of Processes and Works. Costs. Utilization. Future of the Metal. Bullion and Gold. Silver Refining Process. Gold Refining Processes. Gold Extraction Processes. Calcium Carbide and Acetylene Gas. The Carbide Furnace and Process. Production. Utilization. Carborundum. Details of Manufacture. Properties and Uses. Copper. Copper Refining. Descriptions of Refineries. Costs. Properties and Utilization. The Elmore and similar Processes. Electrolytic Extraction Processes. Electro-Metallurgical Concentration Processes. Ferro-alloys. Descriptions of Works. Utilization. Glass and Quartz Glass. Graphite. Details of Process. Utilization. Iron and Steel. Descriptions of Furnaces and Processes. Yields and Costs. Comparative Costs. Lead. The Salom Process. The Betts Refining Process. The Betts Reduction Process. IVhite L.ead Processes. Miscellaneous Products. Calcium. Carbon Bi iulphide. Carbon Tetra-Chloride. Diamantine. Magnesium. I'hosphorus. Silicon and its Compounds. Nickel. IVet Proceses. Dry Processes. Sodium. Descriptions of Cells and Procese: T'iir. Alkaline Processes for Tin Stripping. Acid Processes for Tin Stripping. Salt Processes for Tin Stripping. Zinc. Wet Pro cesses. Dry Processes. Electro-Thermal Processes. Electro, Galvanizing. Glossary. Name Index.

Radio-Telegraphy. By C. C. F. Monckton, M.I.E.E. 389 Pages. With I73 Diagrams and Illustrations.

Contents: Preface. Electric Phenomena. Electric Vibrations. Electro-Magnetic Waves. Modified Hertz Waves used in RadioTelegraphy. Apparatus used for Charging the Oscillator. The Electric Oscillator: Methods of Arrangement, Practical Details. The Receiver: Methods of Arrangement, The Detecting Apparatus, and other details. Measurements in Radio-Telegraphy. The Experimental Station at Elmers End: Lodge-Muirhead System. Radio - Telegraph Station at Nauen : Telefunken System. Station at Lyngby: Poulsen System. The Lodge- 


\section{THE “WESTMINSTER" SERIES}

Muirhead System, the Marconi System, Telefunken System, and Poulsen System. Portable Stations. Radio-Telephony. Appendices: The Morse Alphabet. Electrical Units used in this Book. International Control of Radio-Telegraphy. Index.

India-Rubber and its Manufacture, with Chapters on Gutta-Percha and Balata. By H. L. TERRY, F.I.C., Assoc.Inst.M.M. 303 Pages. With Illustrations.

List of Contents: Preface. Introduction: Historical and General. Raw Rubber. Botanical Origin. Tapping the Trees. Coagulation. Principal Raw Rubbers of Commerce. PseudoRubbers. Congo Rubber. General Considerations. Chemical and Physical Properties. Vulcanization. India-rubber Plantations. India-rubber Substitutes. Reclaimed Rubber. Washing and Drying of Raw Rubber. Compounding of Rubber. Rubber Solvents and their Recovery. Rubber Solution. Fine Cut Sheet and Articles made therefrom. Elastic Thread. Mechanical Rubber Goods. Sundry Rubber Articles. India-rubber Proofed Textures. Tyres. India-rubber Boots and Shoes. Rubber for Insulated Wires. Vulcanite Contracts for India-rubber Goods. The Testing of Rubber Goods. Gutta-Percha. Balata. Bibliography. Index.

The Railway Locomotive. What It Is, and Why It is What It Is. By Vaughan PENDred, M.Inst.M.E., Mem.Inst.M.I. 32I Pages. 94 Illustrations.

Contents: The Locomotive Engine as a Vehicle-Frames. Bogies. The Action of the Bogie. Centre of Gravity. Wheels. Wheel and Rail. Adhesion. Propulsion. Counter-Balancing. The Locomotive as a Steam Generator-The Boiler. The Construction of the Boiler. Stay Bolts. The Fire-Box. The Design of Boilers. Combustion. Fuel. The Front End. The Blast Pipe. Steam Water. Priming. The Quality of Steam. Superheating. Boiler Fittings. The Injector. The Locomotive as a Steam EngineCylinders and Valves. Friction. Valve Gear. Expansion. The Stephenson Link Motion. Walschaert's and Joy's Gears. Slide Valves. Compounding. Piston Valves. The Indicator. Tenders. Tank Engines. Lubrication. Brakes. The Running Shed. The Work of the Locomotive.

Glass Manufacture. By Walter Rosenhain, Superintendent of the Department of Metallurgy in the National Physical Laboratory, late Scientific Adviser in the Glass Works of Messrs. Chance Bros. \& Co. 28o Pages. With Illustrations.

Contents : Preface. Definitions. Physical and Chemical Qualities, Mechanical, Thermal, and Electrical Properties. Transparency 


\section{THE "WESTMINSTER" SERIES}

and Colour. Raw materials of manufacture. Crucibles and Furnaces for Fusion. Process of Fusion. Processes used in Working. of Glass. Bottle. Blown and Pressed. Rolled or Plate. Sheet and Crown. Coloured. Optical Glass: Nature and Properties, Manufacture. Miscellaneous Products. Appendix. Bibliography of Glass Manufacture. Index

Precious Stones. By W. GoodchILD, M.B., B.Ch. 3I9 Pages. With 42 Illustrations. With a Chapter on Artificial Stones. By Robert Dykes.

List of Contents: Introductory and Historical. Genesis of Precious Stones. Physical Properties. The Cutting and Polishing of Gems. Imitation Gems and the Artificial Production of Precious Stones. The Diamond. Fluor Spar and the Forms of Silica. Corundum, including Ruby and Sapphire. Spinel and Chrysoberyl. The Carbonates and the Felspars. The Pyroxene and Amphibole Groups. Beryl, Cordierite, Lapis Lazuli and the Garnets. Olivine, Topaz, Tourmaline and other Silicates. Phosphates, Sulphates, and Carbon Compounds.

\section{INTRODUCTION TO THE}

\section{Chemistry and Physics of Building Materials.} By Alan E. Munby, M.A. 365 Pages. Illustrated.

Conrents: Elementary Science : Natural Laws and Scientific Investigations. Measurement and the Properties of Matter. Air and Combustion. Nature and Measurement of Heat and Its Effects on Materials. Chemical Signs and Calculations. Water and Its Impurities. Sulphur and the Nature of Acids and Bases. Coal and Its Products. Outlines of Geology. Building Materials: The Constituents of Stones, Clays and Cementing Materials. Classification, Examination and Testing of Stones, Brick and Other Clays. Kiln Reactions and the Properties of Burnt Clays. Plasters and Limes. Cements. Theories upon the Setting of Plasters and Hydraulic Materials. Artificial Stone. Oxychloride Cement. Asphaite. General Properties of Metals. Iron and Steel. Other Metals and Alloys. Timber. Paints: Oils, Thinners and Varnishes; Bases, Pigments and Driers.

\section{Patents, Designs and Trade Marks: The Law} and Commercial Usage. By Kenneth R. Swan, B.A. (Oxon.), of the Inner Temple, Barrister-at-Law. 402 Pages.

Contents: Table of Cases Cited-Part I.-Letters Patent. Introduction. General. Historical. I., II., III. Invention, Novelty, 
Subject Matter, and Utility the Essentials of Patentable Invention. IV. Specification. V. Construction of Specification. VI. Who May Apply for a Patent. VII. Application and Grant. VIII. Opposition. IX. Patent Rights. Legal Value. Commercial Value. X. Amendment. XI. Infringement of Patent. XII. Action for Infringement. XIII. Action to Restrain Threats. XIV. Negotiation of Patents by Sale and Licence. XV. Limitations on Patent Right. XVI. Revocation. XVII. Prolongation. XVIII. Miscellaneous. XIX. Foreign Patents. XX. Foreign Patent Laws: United States of America. Germany. France. Table of Cost, etc., of Foreign Patents. APPENDIx A.1. Table of Forms and Fees. 2. Cost of Obtaining a British Patent. 3. Convention Countries. Part II.-Copyright in Design. Introduction. I. Registrable Designs. II. Registration. III. Marking. IV. Infringement. APPENDIX B.-I. Table of Forms and Fees. 2. Classification of Goods. Part III.-Trade Marks. Introduction. I. Meaning of Trade Mark. II. Qualification for Registration. III. Restrictions on Registration. IV. Registration. V. Effect of Registration. VI. Miscellaneous. APPENDIX C.-Table of Forms and Fees. INDICES. I. Patents. 2. Designs. 3. Trade Marks.

\section{The Book: Its History and Development. By} Cyril Davenport, V.D., F.S.A. 266 Pages. With 7 Plates and 126 Figures in the text.

List of Contents: Early Records. Rolls, Books and Book bindings. Paper. Printing. Illustrations. Miscellanea. Leathers. The Ornamentation of Leather Bookbindings without Gold. The Ornamentation of Leather Bookbindings with Gold. Bibliography. Index.

The Manufacture of Paper. By R. W. Sindall, F.C.S., Consulting Chemist to the Wood Pulp and Paper Trades; Lecturer on Paper-making for the Hertfordshire County Council, the Bucks County Council, the Printing and Stationery Trades at Exeter Hall (I903-4), the Institute of Printers; Technical Adviser to the Government of India, I905. 275 Pages. 58 Illustrations.

Contents : Preface. List of Illustrations. Historical Notice. Cellulose and Paper-making Fibres. The Manufacture of Paper from Rags, Esparto and Straw. Wood Pulp and Wood Pulp Papers. Brown Papers and Boards. Special kinds of Paper. Chemicals used in Paper-making. The Process of "Beating." The Dyeing and Colouring of Paper Pulp. Paper Mill Machinery. The Deterioration of Paper. Bibliography. Index. 


\section{THE “WESTMINSTER” SERIES}

Wood Pulp and its Applications. By C.F. Cross, B.Sc., F.I.C., E. J. Bevan, F.I.C., and R. W. Sindall, F.C.S. 266 pages. 36 Illustrations.

Contents: The Structural Elements of Wood. Cellulose as a Chemical. Sources of Supply. Mechanical Wood Pulp. Chemical Wood Pulp. The Bleaching of Wood Pulp. News and Printings. Wood Pulp Boards. Utilisation of Wood Waste. Testing of Wood Pulp for Moisture. Wood Pulp and the Textile Industries. Bibliography. Index.

Photography: its Principles and Applications. By Alfred Watkins, F.R.P.S. 342 pages. 98 Illustrations.

Contents: First Principles. Lenses. Exposure Influences. Practical Exposure. Development Influences. Practical Development. Cameras and Dark Room. Orthochromatic Photography. Printing Processes. Hand Camera Work. Enlarging and Slide Making. Colour Photography. General Applications. Record Applications, Science Applications. Plate Speed Testing. Process Work. Addenda. Index.

\section{IN PREPARATION.}

Commercial Paints and Painting. By A. S. JennINGS, Hon. Consulting Examiner, City and Guilds of London Institute.

Brewing and Distilling. By James Grant, F.S.C. 

THIS BOOK IS DUE ON THE IAST DATE STAMPED BELOW

AN INITIAL FINE OF 25 CENTS WILL BE ASSESSED FOR FAILURE TO RETURN THIS BOOK ON THE DATE DUE. THE PENALTY WILL INCREASE TO 50 CENTS ON THE FOURTH DAY AND TO \$1.00 ON THE SEVENTH DAY OVERDUE.

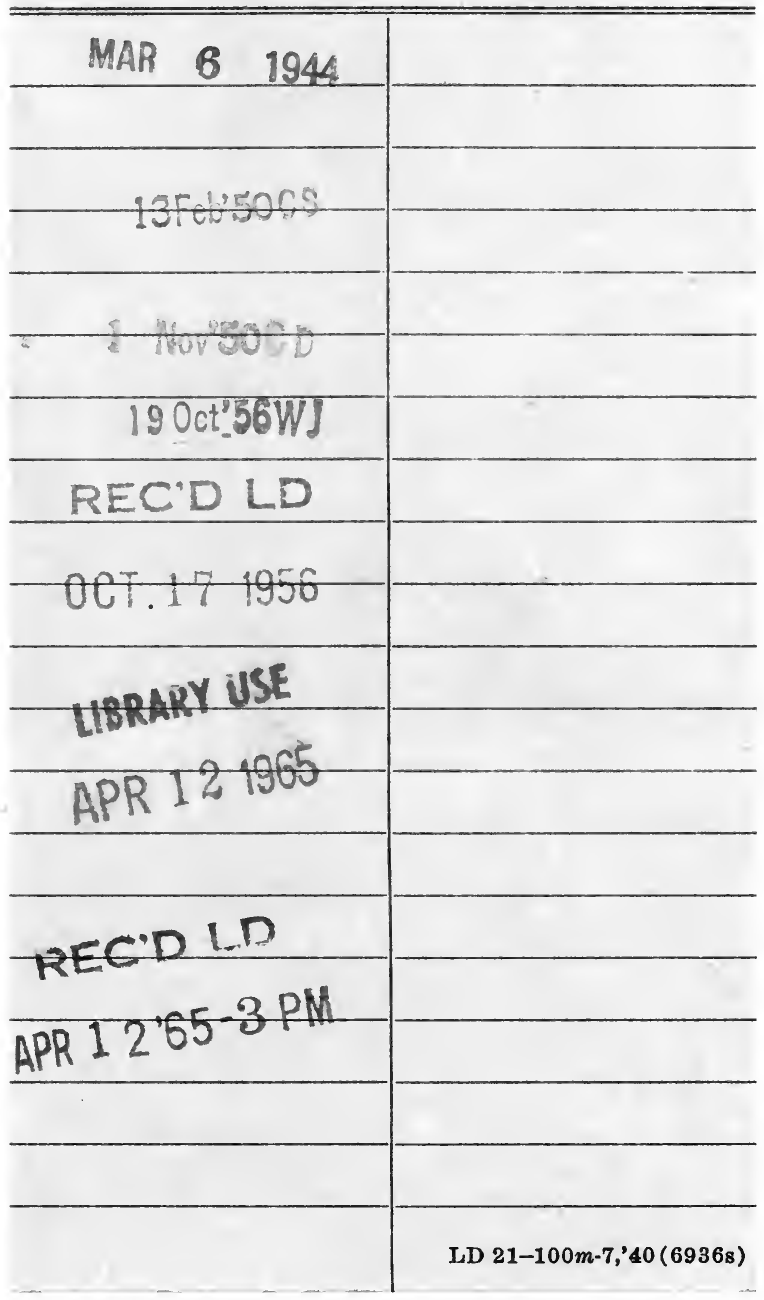


$\operatorname{loc}_{\text {wet }}$ YO 13708

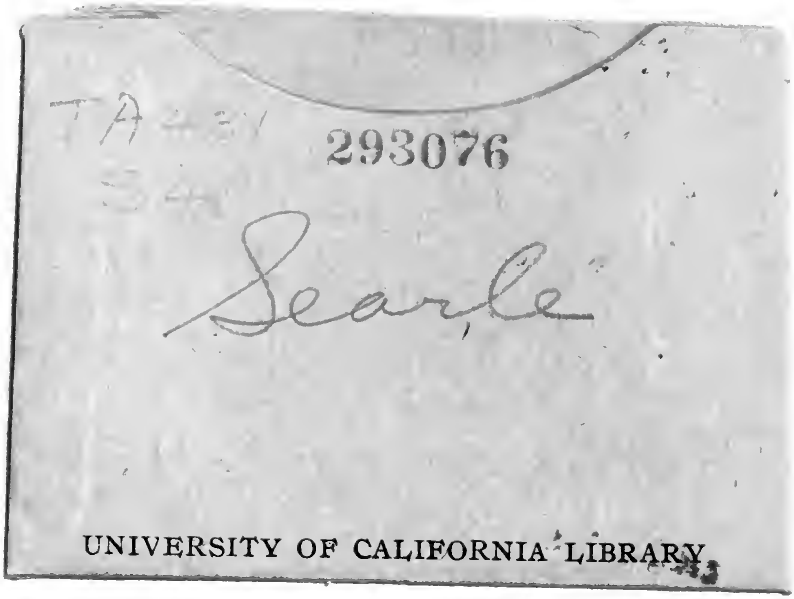


